Dissertation Utrecht University, Faculty of Veterinary Medicine.

ISBN: 978-94-93184-37-4

(c) Filipe Manuel Serra Bragança, 2020

Cover design: Adapted from Animal Locomotion, Plate 626 by Eadweard Muybridge (1887).

Layout and printing: Proefschrift-aio.nl

All right reserved. No part of this thesis may be reproduced in any form without prior permission of the author. 


\title{
Where art and science meet
}

\section{Empowering the equine clinician's eye by advanced quantitative gait analysis}

\author{
Op het snijvlak van ambacht en academie: \\ hoe geavanceerde kwantitatieve bewegingsanalyse de klinische blik \\ scherper maakt \\ (met een samenvatting in het Nederlands)
}

Proefschrift

ter verkrijging van de graad van doctor aan de

Universiteit Utrecht

op gezag van de

rector magnificus, prof.dr. H.R.B.M. Kummeling,

ingevolge het besluit van het college voor promoties

in het openbaar te verdedigen op

donderdag 1 october 2020 des middags te 12.45 uur

door

Filipe Manuel Serra Bragança

geboren op 3 februari 1988

te Faro, Portugal 


\section{Promotoren:}

Prof. dr. P.R. van Weeren

Prof. dr. L. Roepstorff

\section{Copromotoren:}

Dr. M. Rhodin

Dr. M. Weishaupt 



\section{Table of content}

\section{Chapter 1}

General introduction

\section{Literature review}

\section{Chapter 2}

On the brink of daily clinical application of objective gait analysis: What evidence do we have so far from studies using an induced lameness model?

Technical developments and validation studies for the daily application of gait analysis

\section{Chapter 3}

Quantification of the effect of instrumentation error in objective gait assessment in the horse on hindlimb symmetry parameters

\section{Chapter 4}

Quantitative lameness assessment in the horse based on upper body movement symmetry: The effect of different filtering techniques on the quantification of motion symmetry

\section{Chapter 5}

Validation of distal limb mounted inertial measurement unit sensors for stride detection in Warmblood horses at walk and trot

\section{Clinical application of gait analysis for studies on} lameness and general locomotion

\section{Chapter 6}

EquiMoves: A Wireless Networked Inertial Measurement System for Objective Examination of Horse Gait

\section{Chapter 7}

Variation in gait parameters used for objective lameness assessment in sound horses at the trot on the straight line and the lunge 


\section{Chapter 8}

Adaptation strategies of horses with induced forelimb lameness walking on a treadmill

\section{Chapter 9}

The development of hoof balance and landing preference in the postnatal period

\section{Chapter 10}

Mouldable, thermoplastic, glue-on frog-supportive shoes change hoof kinetics in normal and obese Shetland ponies

\section{Chapter 11}

Subjective and objective evaluations of horses for fit-to-compete or unfit-to-compete judgement

\section{Chapter 12}

Pain-related facial expressions and movement asymmetry in horses with induced low-degree orthopaedic pain

\section{Chapter 13}

Improving gait classification in horses by using inertial measurement unit (IMU) generated data and machine-learning

\section{Chapter 14}

General discussion

\section{Addendum}

Dankwoord

Nederlandse samenvatting 



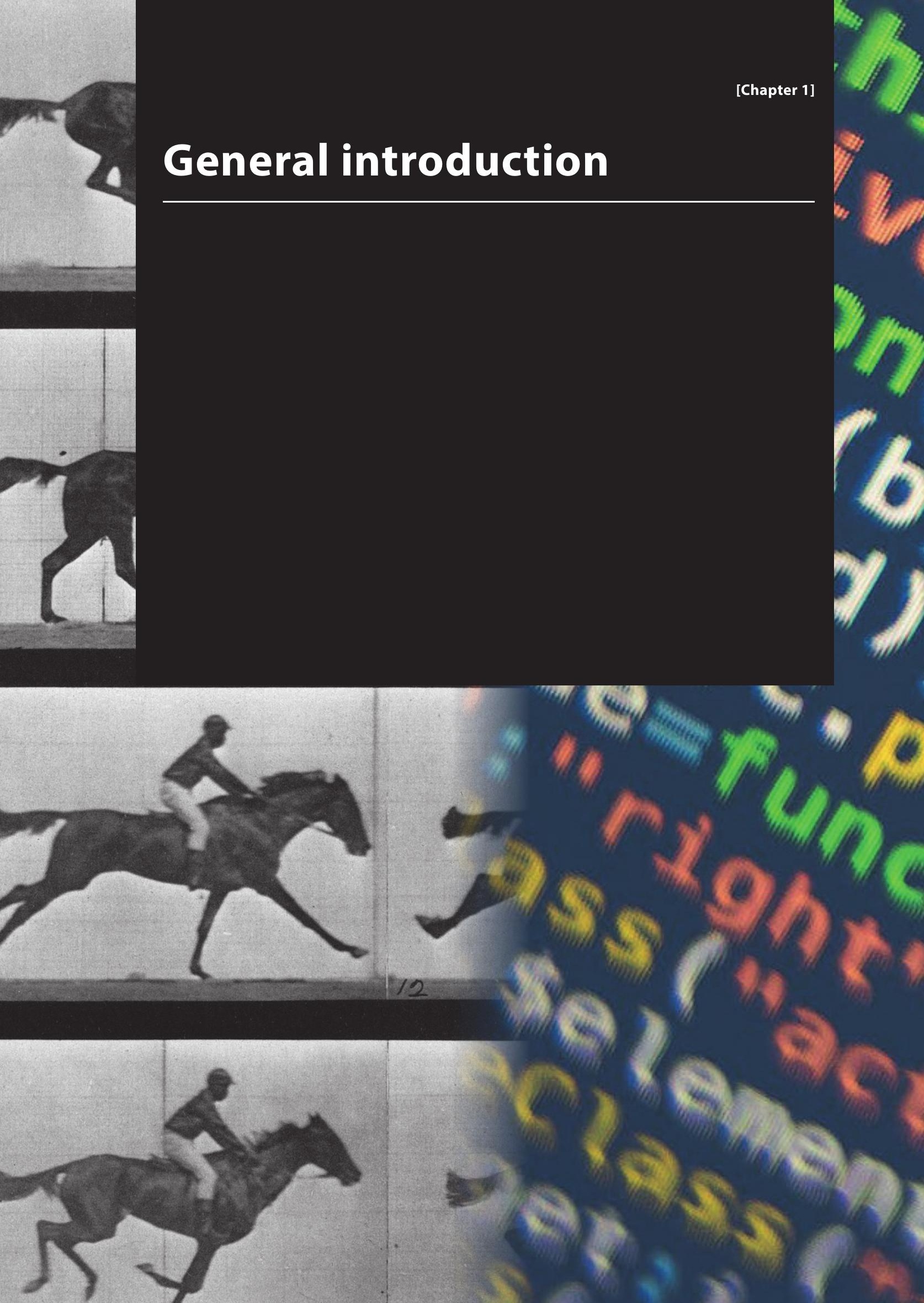




\section{Technology won't replace}

vets. . .but vets who use technology logically and carefully will replace those who don't a 


\section{Introduction}

The horse has been domesticated by humans for the amazing capacities of its locomotor system and ever since virtually all purposes for which horses have been kept were related to this athletic potential. The animal's main usages until very recently were in agriculture, transport, and warfare, all requiring a properly functioning locomotor system. It is no surprise, therefore, that lameness has always been described as one of the most important problems affecting the function of the horse. For farriers and horse doctors, understanding lameness has been a significant challenge over the ages up to and including the present times in which high-level sport performance places even higher demands on the quality of the locomotor system.

During the modern era, researchers started to use modern technology to study locomotion of horses. Using the newly developed technique of photography Muybridge [1] was able in the 1870s to accurately visualize the various phases of the principal equine gaits. Around the same time, in 1873, Marey [2] developed a pneumatic accelerometric device which was able to record movement of the saddle, sacrum and all four limbs, enabling him to describe the footfall pattern of horses for the first time in great detail. These two men can be seen as the ground-breaking pioneers of in-depth on equine gait analysis.

After World War II, research in equine gait analysis slowed down, reflecting the decline of societal relevance of the horse after being made redundant in all its former jobs by the rapid mechanization. Nevertheless, some very important studies were published in this period, for example the one by Hildebrand [3], which focused on the different gaits of the horse, and their classification.

The glorious comeback of the horse on the societal stage as a beloved sports and leisure animal from the 1960s onwards sparked new interest in the study of equine gait. This coincided with the development of higher spatial and temporal resolution in cinematography technology and of more powerful computers. It were researchers in Sweden such as Fredricson [4-6] , Drevemo [4-6] and Dalín [5,6], who were the first to use novel technology to describe in more detail the kinematics of horses in motion. Fredricson and Drevemo were focusing on the use of 2D high-speed cinematography, which is very labor intensive to work with, due to the requirement of manual tracking of the markers placed on the horse in every frame of the film. To overcome this limitation Kübber, Kastner and colleagues from Vienna [7,8], started working on computer-assisted 3D optical motion capture, which dramatically increased the 
accuracy of this method and allowed for the quantitative study of kinematic changes of the motion of the head withers and pelvis in cases of lameness.

A few years earlier, the force plate had been introduced for the study of equine locomotion [9], which proved to be a highly valuable asset in lameness research $[10,11]$. In Utrecht, the tremendous work of Buchner and colleagues [12-14] paved the way to what we now know as objective gait analysis of the horse using motion capture. These publications can be seen as the first steps towards the full-scale clinical application of quantitative lameness assessment in the horse.

More recently, sensor technology started gaining interest among researchers to study locomotion and lameness in horses [15-17]. Sensors are portable devices that can easily be used in field situations and these devices were crucial in taking the big step from the lab to more clinical and field applications, as they overcame the main limitations of optical motion capture: lack of portability and easiness of use.

There are two main areas in which gait analysis in the horse has been studied in the last century [18]: general biomechanics related to sports/performance [19] and locomotion changes due to lameness [20]. Both areas have tremendous potential but, until recently, the technology did not permit practical daily application of any of the gait analysis methods. However, in the last decade this situation has changed and there is increasing interest in the quantification of lameness in a clinical setting. There are 2 major factors that are at the basis of this change and of the implementation of the first systems in a clinical setting: 

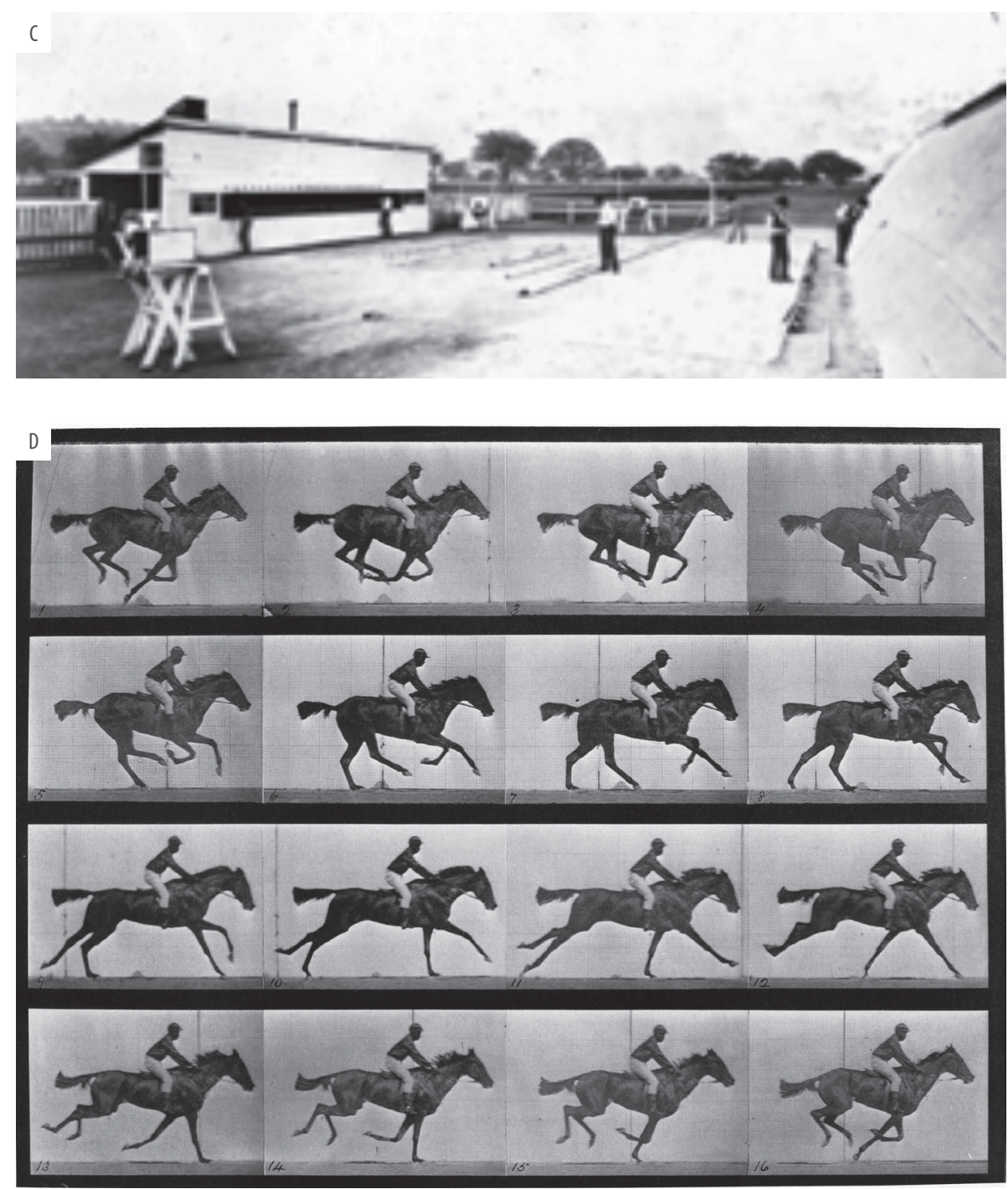

1) The introduction of reliable and portable gait analysis systems based on microelectromechanical systems (MEMS) technology, which, thanks to the quick technological developments tend to become cheaper [21].

2) The realization of the low interobserver agreement [22] and existence of often substantial bias [23], which strongly question the scientific validity of the "classic" subjective lameness perception by the clinician.

This thesis can to a certain extent be seen as emblematic for the current transitional period in which equine gait analysis progresses from being a scientifically interesting topic within the realm of academic research to a massively used tool in daily clinical 
practice of which it will be as unthinkable not to use it as it is currently for diagnostic imaging. The work explores the great potential of quantitative gait analysis, contributes to the further technical development of the tool, researches added value, implications but also limitations of the method, and develops a vision on how to go forward.

\section{Aim and scope of the thesis}

The part of this thesis reporting original scientific work is divided in three main sections:

1. A literature review on the clinical applications of gait analysis related to the quantification of lameness.

CHAPTER 2: 'On the brink of daily clinical application of objective gait analysis: What evidence do we have so far from studies using an induced lameness model?'. The chapter presents a literature review of the current evidence related to the use of gait quantitative analysis as a tool for lameness assessment. Here we identify the most recent developments and identify the areas where further research is needed.

2. Technical developments and validation studies for the daily application of gait analysis.

CHAPTER 3: 'Quantification of the effect of instrumentation error in objective gait assessment in the horse on hindlimb symmetry parameters.' In this study we have investigated the expected measurement inaccuracy due to instrumentation error in parameters used for quantitative lameness assessment.

CHAPTER 4: 'Quantitative lameness assessment in the horse based on upper body movement symmetry: The effect of different filtering techniques on the quantification of motion symmetry'. In this technical paper we have evaluated the effect on outcome of various filter techniques when processing kinematic signals used for quantitative lameness assessment of horses.

CHAPTER 5: 'Validation of distal limb mounted inertial measurement unit sensors for stride detection in Warmblood horses at walk and trot.' In this study we describe a method to estimate the kinematic events of hoof-on/off based on limb-mounted inertial measurement units (IMUs).

CHAPTER 6: 'EquiMoves: A Wireless Networked Inertial Measurement System for Objective Examination of Horse Gait.' Here we describe the technical validation of a sensor-based system for full body kinematic analysis of equine locomotion. This 
includes the description of system functionality and validation of some kinematic parameters, compared to a 'gold standard' system, in this case optical motion capture.

3. Clinical application of gait analysis for studies on lameness and general locomotion.

CHAPTER 7: 'Variation in gait parameters used for objective lameness assessment in sound horses at the trot on the straight line and the lunge.' In this study we have evaluated the expected variation in kinematic parameters used for objective lameness assessment between repeated measurements in a group of healthy horses.

CHAPTER 8: 'Adaptation strategies of horses with induced forelimb lameness walking on a treadmill.' This study focuses on the effect of supporting limb lameness (impact lameness) on several kinematic and kinetic parameters in horses trotting and walking on an instrumented treadmill.

CHAPTER 9: 'The development of hoof balance and landing preference in the postnatal period.' The changes in limb kinetics and landing preference in warmblood foals, from birth to 6 months of age are studied in this chapter.

CHAPTER 10: 'Mouldable, thermoplastic, glue-on frog-supportive shoes change hoof kinetics in normal and obese Shetland ponies.' In this study we have described the effect of plastic glue-on shoes on limb kinetics in two groups of Shetland ponies: animals with normal body weight and being overweight.

CHAPTER 11: 'Subjective and objective evaluations of horses for fit-to-compete or unfit-to-compete judgement.' In this study we have evaluated the inter and intraobserver agreement in judging horses as fit or unfit to compete under FEI rules and compared the subjective assessments with objective gait analysis.

CHAPTER 12: 'Pain-related facial expressions and movement asymmetry in horses with induced low-degree orthopaedic pain.' This chapter compares the parameters used for objective gait analysis to the outcome of pain scoring systems in horses with induced weight-bearing lameness.

CHAPTER 13: 'Improving gait classification in horses by using inertial measurement unit (IMU) generated data and machine-learning.' This study is the first to pioneer the use of different machine learning techniques in processing IMU data for achieving accurate gait classification in horses, finally experimentally conforming or refuting the classification of equine gait as proposed by Hildebrand in his 1965 landmark paper [3]. 
The last chapter of this thesis CHAPTER 14 discusses the contents of the preceding chapters and puts these in perspective against the background of the ongoing change in equine clinical practice in which indeed, perhaps slowly but certainly irrevocably, "vets who use technology logically and carefully will replace those who don't". It ends with an outlook in which both possibilities and needs for further developments in the field are identified alongside the challenges researchers in this field will face in the upcoming years. It further presents a vision on how quantitative gait analysis and its matrimony with modern developments in computer sciences, will be not only able to improve the quality and impact of lameness diagnosis and therapy in horses, but also to foster the quality of the general management and the welfare of the horse and eventually many other species in a much wider sense. 


\section{References}

1. Muybridge, E. (1899) Animals in motion, Republished (1957), L.S. Brown

2. Marey, E.-J. (1873) La machine animale. Locomotion terrestre et aérienne., Paris, G. Baillie.

3. Hildebrand, M. (1965) Symmetrical gaits of horses. Science (80-.). 150, 701-708.

4. Fredricson, I. and Drevemo, S. (1971) A New Method of Investigating Equine Locomotion. Equine Vet. J. 3, 137-140.

5. Fredrickson, I., Drevemo, S., Dalin, G., Hjerten, G. and Björne, K. (1980) The application of highspeed cinematography for the quantitative analysis of equine locomotion. Equine Vet. J. .

6. Drevemo, S., Dalin, G., Fredrickson, I. and Björne, K. (1980) The reproducibility of gait in Standardbred trotters. Equine Vet. J. 12, 71-73.

7. Kastner, J., Knezevic, P.F., Girtler, D. and Toeltsch, M. (1990) Die 3-Dimensionale Bewegungsanalyse als Klinische Methode zur Objektivierung von Lahmheiten Beim Pferd. Biomed. Tech. 35, 171-172.

8. Kübber, P., Kastner, J., Girtler, D. and Knezevic, P.F. (1994) Erkenntnisse über den Einfluß der tiefen Palmarnervanästhesie auf das Gangbild des lahmheitsfreien Pferdes mit Hilfe einer kinematischen Meßmethode. Pferdeheilkunde 10, 11-21.

9. Morris, E. and Seeherman, H. (1987) Redistribution of ground reaction forces in experimentally induced equine carpal lameness. Equine Exerc Physiol 2, 553-563.

10. Aviad, A.D. (1988) The use of the standing force plate as a quantitative measure of equine lameness. J. Equine Vet. Sci. 8, 460-462.

11. Merkens, H.W. and Schamhardt, H.C. (1988) Evaluation of equine locomotion during different degrees of experimentally induced lameness. I: Lameness model and quantification of ground reaction force patterns of the limbs. Equine Vet. J. Suppl. 20, 99-106.

12. Buchner, H.H., Savelberg, H.H., Schamhardt, H.C. and Barneveld, A. (1996) Limb movement adaptations in horses with experimentally induced fore- or hindlimb lameness. Equine Vet. J. 28, 63-70.

13. Buchner, H.H.F., Savelberg, H.H.C.M., Schamhardt, H.C. and Barneveld, A. (1995) Temporal stride patterns in horses with experimentally induced fore- or hindlimb lameness. Equine Vet. J. 27, 161-165.

14. Buchner, H.H.F., Savelberg, H.H., Schamhardt, H.C. and Barneveld, A. (1996) Head and trunk movement adaptations in horses with experimentally induced fore- or hindlimb lameness. Equine Vet. J. 28, 71-76.

15. Barrey, E. and Descbrosse, F. (1996) Lameness detection using an aaccelerometric device. Pferdeheikunde 12,617-622.

16. Audigié, F., Pourcelot, P., Degueurce, C., Geiger, D. and Denoix, J.M. (2002) Fourier analysis of trunk displacements: A method to identify the lame limb in trotting horses. J. Biomech. 35, 1173-1182.

17. Barrey, E., Hermelin, M., Vaudelin, J.L., Poirel, D. and Valette, J.P. (1994) Utilisation of an accelerometric device in equine gait analysis. Equine Vet. Journal.Supplement 17, 7-12.

18. Egan, S., Brama, P. and McGrath, D. (2019) Research trends in equine movement analysis, future opportunities and potential barriers in the digital age: A scoping review from 1978 to 2018. Equine Vet. J. .

19. Clayton, H. and Hobbs, S. (2017) The role of biomechanical analysis of horse and rider in equitation science. Appl. Anim. Behav. Sci. .

20. Keegan, K.G. (2007) Evidence-Based Lameness Detection and Quantification. Vet. Clin. North Am. Equine Pract. 23, 403-423.

21. Keegan, K.G., Kramer, J., Yonezawa, Y., Maki, H., Pai, P.F., Dent, E. V, Kellerman, T.E., Wilson, D.A. and Reed, S.K. (2011) Assessment of repeatability of a wireless, inertial sensor-based lameness evaluation system for horses. Am. J. Vet. Res. 72, 1156-63. 
22. Schmidt, P.L. (2007) Evidence-Based Veterinary Medicine: Evolution, Revolution, or Repackaging of Veterinary Practice? Vet. Clin. North Am. Small Anim. Pract. 37, 409-417.

23. Arkell, M., Archer, R.M., Guitian, F.J. and May, S. a (2006) Evidence of bias affecting the interpretation of the results of local anaesthetic nerve blocks when assessing lameness in horses. Vet. Rec. 159, 346-349. 



\section{Literature review}
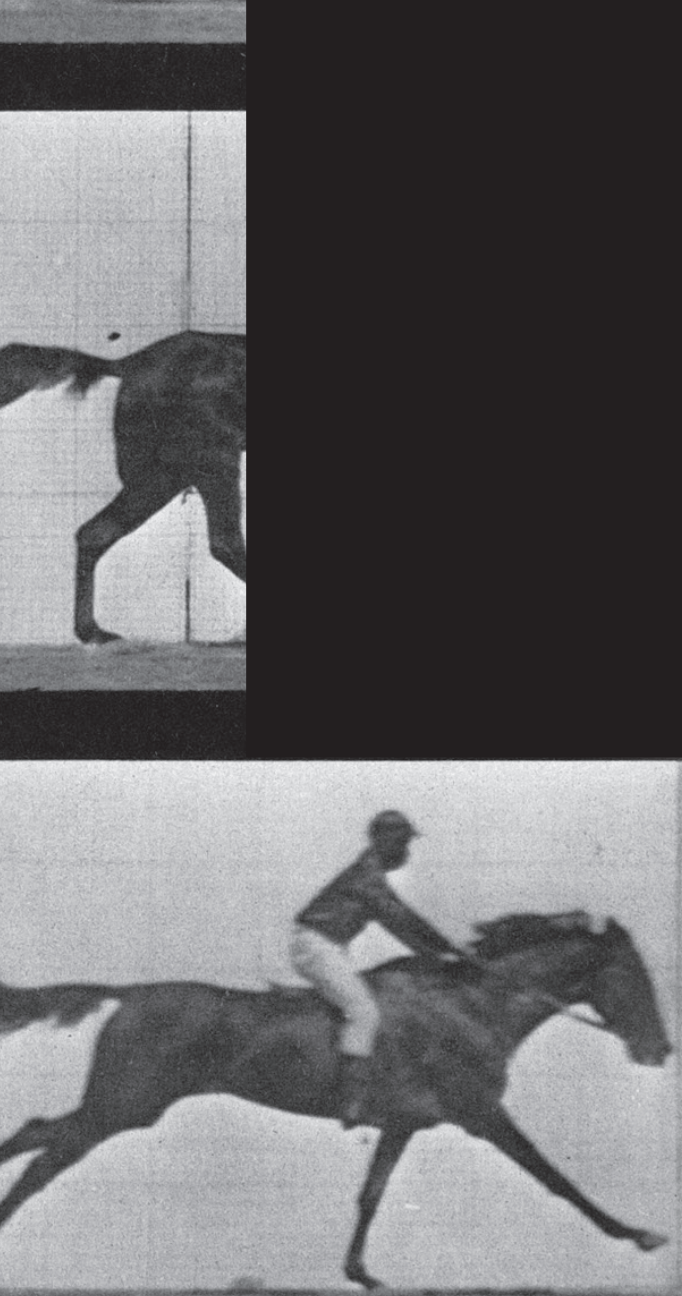


\section{On the brink of daily clinical application of objective gait analysis: What evidence do we}

\section{have so far from studies using an induced lameness model?}

F.M. Serra Bragança ${ }^{\mathrm{a},{ }^{*},}$, M. Rhodin ${ }^{\mathrm{b}}$, P.R. van Weeren ${ }^{\mathrm{a}}$

\footnotetext{
a Department of Equine Sciences, Faculty of Veterinary Medicine, Utrecht University, Yalelaan 112 114, NL-3584 CM Utrecht, The Netherlands

${ }^{b}$ Department of Clinical Sciences, Swedish University of Agricultural Sciences, SE-750 07 Uppsala, Sweden
}

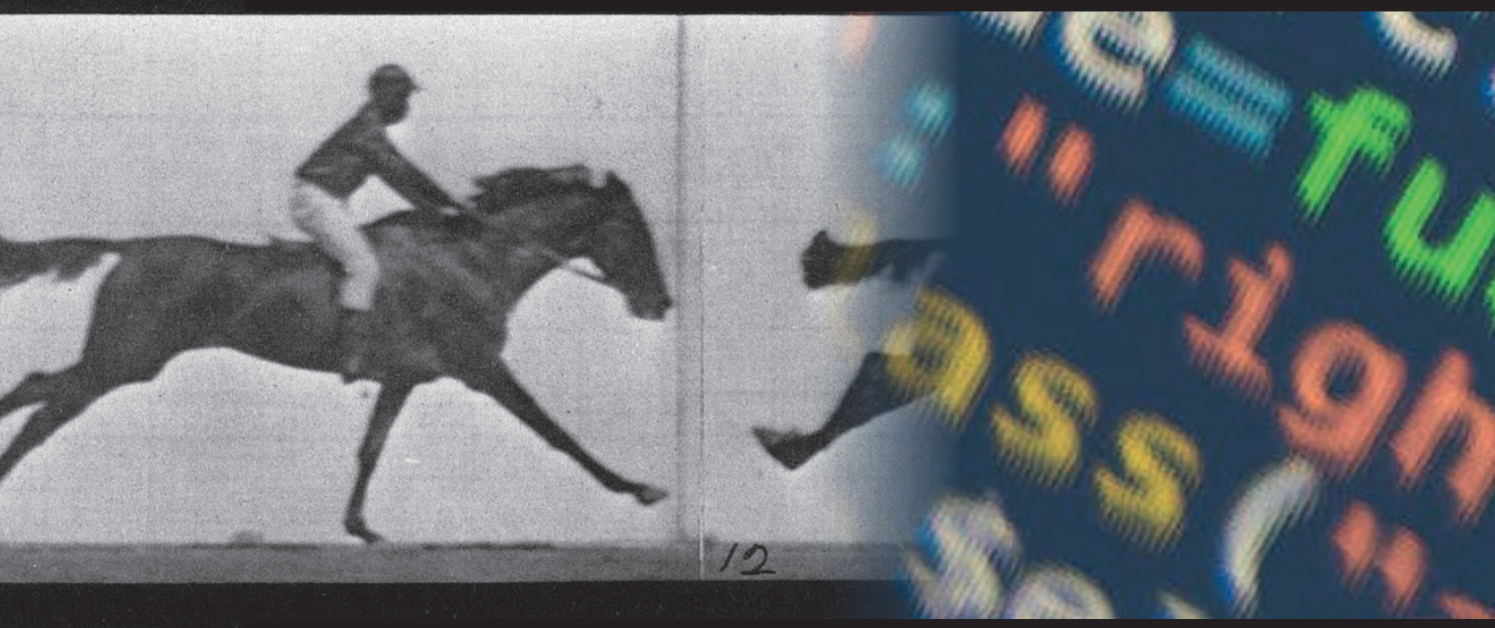




\section{Abstract}

Quantitative gait analysis has the potential to offer objective and unbiased gait information that can assist clinical decision-making. In recent years, a growing number of gait analysis systems have come onto the market, highlighting the demand for such technology in equine orthopaedics. However, it is imperative that the measured variables which are used as outcome parameters are supported by scientific evidence and that the interpretation of such measurements is backed by a proper understanding of the biomechanical principles of equine locomotion. This review, which is based on studies on experimentally induced lameness, summarises the currently most widely used methods for gait analysis and the available evidence concerning gait parameters that can be used to quantify gait changes due to lameness. These are discussed regarding their current and future potential for routine clinical application. 


\section{Introduction}

The primary uses of the horse as sport and leisure animal are based on the capacity of its locomotor system. Disorders of that system, which become almost invariably clinically manifest as lameness, are one of the main reasons for equine veterinary consultation (Nielsen et al., 2014). It has also been reported that equine practitioners spend most of their working time on lameness examination (Loomans et al., 2007). Lameness can affect horses from all equestrian disciplines, leading to a financial loss for horse owners, days lost in training and/or competition (Jeffcott et al., 1982; Murray et al., 2006; Dyson et al., 2008; Egenvall et al., 2008, 2013).

In the context of this review, it is essential to define the term 'lameness' as a clinical interpretation of one or more signs indicating a pathological condition of the locomotor system (van Weeren et al., 2017). It is hence an alteration of the normal gait due to a functional or structural disorder in this system (Buchner, 2013), making it a clinical entity that is more than just a deviation of what can be seen as optimal gait. This definition of lameness challenges the veterinarian to discriminate between normal and abnormal (i.e. pathological) gait for a specific subject presented with a complaint of lameness. When confronted with animals without complaints, the challenge may be two-fold. First, to decide whether some gait irregularity and/or asymmetry is present. Second, to judge whether there is an underlying pathological condition or not, hence whether or not the irregularity/asymmetry should be considered a subclinical sign of lameness. In the majority of cases, standard practice has been and still is to accomplish this by subjective assessment of gait.

Although it is widely recognised that most gait events can be assessed efficiently by experienced clinicians through subjective visual examination (Dyson, 2014), any observer is hampered by limitations of the maximal temporal resolution of the human eye, limits to the perception of asymmetry (Parkes et al., 2009) and memorisation. Partially related to these limitations, a subjective visual evaluation suffers from some substantial drawbacks which are reflected in the low inter-observer agreement (Fuller et al., 2006; Hewetson et al., 2006; Keegan et al., 2010; Thomsen et al., 2010; McCracken et al., 2012; Keegan et al., 2013; Hammarberg et al., 2016) and the difficulty of consistent and interchangeable documentation of gait alterations. The latter is mainly due to the lack of uniformity in lameness rating scales (Wyn-Jones, 1988; AAEP, 1999; Dyson, 2011; Ross, 2013). A detailed overview of the limitations of subjective lameness assessment can be found in the review of Keegan (2007). 
There is also a potential bias in the interpretation of nerve/joint blocks (Arkell et al., 2006), which can be aggravated by false positive and false negative results (Schumacher et al., 2014). An additional confounding issue may be the effect of nerve blocks in sound horses, although the few studies available (Kübber et al., 1994; Keegan et al., 1997; Drevemo et al., 1999; Liedtke et al., 2012) have reported somewhat contradictory results (Van de Water et al., 2016), and further investigation of the effect of diagnostic analgesia in sound horses is warranted.

These issues complicate lameness examinations and form confounding factors affecting clinical decision-making and ham- pering clinical orthopaedic research on the evaluation of diagnos- tic procedures, treatments and rehabilitation protocols.

Long restricted to sophisticated gait labs due to financial and practical constraints, measurement systems for equine gait are becoming more affordable and practically applicable, paving the way for routine application in daily clinical practice. This development raises new issues about the reliability of available systems and the validity and usefulness of the output of such systems. This review aims to summarise and critically evaluate current evidence related to methods of objective gait analysis in horses. This review is limited to techniques of gait analysis with potential for practical daily use in a clinical setting, of which evidence regarding the relevant outcome parameters and the applications and limitations are discussed. The emphasis is on data regarding objective gait parameters associated with lameness based on induced lameness models and the interpretation of objective gait assessment measurements. Essential areas for future development are also identified.

\section{Searches}

PubMed and Google Scholar were used as search engines to find suitable references for this review. The terms 'horse' and 'equine' were used in combination with the keywords 'kinematics'; 'kinetics'; 'gait analysis'; 'motion capture'; 'objective lameness'; 'lameness'; 'force plate'; 'pressure plate'; 'treadmill'; 'sensor'; 'IMU'; 'inertial measurement unit'; 'agreement'; 'assessment'; 'observer'. Articles were first selected based on their relevance to the topic of this review. Only manuscripts in the field of equine gait analysis were selected; studies using quantitative gait analysis tools for purposes other than lameness evaluation were excluded; as well as studies using theoretical models of lameness. Subsequently; the references in all selected articles were screened for further possibly relevant articles. As our purpose was the identification of the best parameters to give information about lameness; the majority of studies concerned experimental studies in which lameness was induced. This eliminated bias from possible multi-limb lameness; any disagreement regarding 
the exact location of pain; or inconsistencies of diagnostic methods to correctly identify the lame limb(s); as often encountered in clinical studies. No meta-analysis or statistical analysis was performed; this article constitutes a descriptive review. Measuring techniques for objective gait assessment based on quantification of either forces (kinetics) or motion (kinematics)

\section{Kinetics}

In kinetic studies, the internal and external forces resulting from musculoskeletal work are analysed. The stationary force measuring platforms were among the first instruments used for objective lameness assessment (Morris and Seeherman, 1987; Aviad, 1988; Merkens and Schamhardt, 1988a) and are still considered as the 'gold standard' for kinetic gait analysis and the detection of (weight-bearing) lameness. They measure the three components in which the ground reaction force (GRF) can be decomposed in a Cartesian coordinate system. Force plates are precise and accurate instruments, but the data collection process is laborious and time-consuming.

Pressure measuring plates (van Heel et al., 2004) overcome some of these limitations by allowing collection of consecutive strides (if plate size is appropriate) and detailed mapping of the force distribution underneath the hoof. However, the sensors of a pressure plate cannot decompose the GRF in the three constituting elements and outcome will to a certain extent be influenced by shear forces as well. Furthermore, pressure plates are not as accurate and precise as force plates that use piezoelectric sensors (Oosterlinck et al., 2010) and this might be due to the lower sampling frequencies when compared to force plates and in some extent, to sensor activation thresholds (Oosterlinck et al., 2012). An alternative to force or pressure plates is the force measuring horseshoe. This idea dates from the late 50s (Björck, 1958), but was only further developed in the 90s (Roepstorff and Drevemo, 1993). Several types of force shoes have been developed and have been used successfully for measuring ground reaction forces (Kai et al., 2000), however, in most cases, size and weight of the shoe were critical limiting factors for their clinical applicability. More recently, a more advanced, lighter version has been used successfully during athletic activity (Munoz-Nates et al., 2015), but the technology is not yet widely available.

An attempt to overcome most of the limitations associated with stationary force plates was the development of a force measuring treadmill (Weishaupt et al., 2002), which allows measurements of consecutive strides of all four limbs simultaneously. The method enables accurate, quick and practical determination of GRF, but is only available in one specialised lab (University of Zurich, Switzerland), solely measures the vertical GRF and requires horses being accustomed to locomotion on a treadmill. 
Overall, the currently available kinetic methods for the assessment of lameness are not ready for widespread clinical application, due to complexities in data collection and analysis. Hence, there is a need to develop measuring systems for quantifying kinetics in a clinical setting. In the meantime, the existing methods remain highly valued tools for researchers in the field of equine gait analysis.

\section{Kinematics}

Kinematics is the study of the movement of body segments during locomotion. The movement can be described as the displacement/velocity/acceleration as a function of time, of a body segment relative to a reference coordinate system, or it can represent the relation (i.e. angle) between body segments. Since their development, serial photography and cine film were almost immediately used for equine gait analysis (van Weeren, 2013) and in the so-called modern era of equine gait analysis, high speed film was the first technique used for recording equine locomotion using reflective skin markers, initially based on two-dimensional (2D) analysis (Fredricson and Drevemo, 1971). Further technological developments led to the introduction of more sophisticated methods of gait analysis (Kastner et al., 1990; van Weeren et al., 1990b) that allowed for higher recording speeds (up to $300 \mathrm{~Hz}$ ) in three dimensions (3D). Nowadays, the most widely used systems are the Oqus/ Qhorse (Qualisys AB) system, the Vantage (Vicon) system and the Motion Analysis (Motion Analysis Systems) system. Three-dimensional optical motion capture (OMC) uses several (mostly infrared) cameras positioned around a calibrated measur- ing volume and records and automatically tracks the position of several reflective markers simultaneously, correcting for perspec- tive and distortion errors and other artefacts that might influence single-camera 2D systems. The 3D systems are highly accurate and precise and are therefore considered the 'gold standard' for kinematic analysis.

Studies on equine kinematics using OMC have initially often been carried out on a treadmill due to the limited field of view of the cameras, but nowadays there are several locations where camera systems are used for the capture of overground locomo- tion. OMC using skin markers is affected by skin displacement artefacts due to the displacement of the skin over the skeletal structures that are in most cases the real objects of the measure- ments. This artefact depends mainly on the location on the body, being almost negligible in the distal limb but being large in the proximal parts of the limb where for example the greater trochanter of the femur may move over a range of up to $15 \mathrm{~cm}$ under the skin (van Weeren et al., 1988, 1990a). However, this is less important in comparative studies, as it affects horses of similar size and conformation to the same extent. For studies in which absolute values are essential, skin displacement correction algorithms have been developed (van den Bogert et 
al., 1990). More recently, low pass Butterworth filters (Sinclair et al., 2013) have been used to remove soft tissue artefacts since correction algorithms are subject- and taskspecific and therefore not universally applicable.

Around the same time the use of OMC became more common in equine gait analysis, another method of kinematic analysis based on body mounted accelerometers was reported (Kastner, 1989). The technology relies on sensors attached to body segments and recording data on acceleration during locomotion. This technique allows gait analysis during overground locomotion without the need for costly infrastructure, making these systems very versatile. The development of this technology has been boosted by the introduction of microelectromechanical systems (MEMS) and the introduction of miniature wireless accelerometers (Keegan et al., 2011), permitting the fabrication of more complex inertial measurement units (IMUs) (Pfau et al., 2005). These instruments provide objective gait information calculated from acceleration data (Barrey et al., 1994), or acceleration data can be double integrated to estimate displacement. However, IMU sensors are prone to integration errors that may accumulate (i.e. drift), making these instruments less and less accurate as the measurement progresses. This can be accounted for by attitude and heading reference systems (AHRS), periodically re-setting the gyroscope during cyclical movements, by advanced filters (e.g. a Kalman filter Kalman, 1960) and, if measuring outdoors, by global positioning system (GPS) data. Nevertheless, these systems are less accurate and precise compared with OMC measuring displacement, although they are more accurate and reliable than OMC when measuring acceleration (Clayton and Schamhardt, 2013; Peham, 2013). Despite these well-known limitations, they may be a practical, mobile and user-friendly solution with suitable potential for practical daily clinical use.

In conclusion, OMC and IMU technology can successfully measure overground locomotion. However, OMC needs several cameras to cover several strides during one run. IMU systems are attached to the horse and can hence record many continuous strides, but they are less accurate than OMC for determining an absolute position.

\section{Kinetic and kinematic parameters associated with lameness}

There is extensive evidence regarding the association between individual gait parameters and lameness (Tables 1-3), but there are some inconsistencies between publications, leading to divergence concerning the assessment of the significance of some of these gait changes for lameness evaluation. Several factors may contribute to this, such as difficulty in assessing the level of pain experienced by the horse, different methodologies to measure specific parameters, differences in study design, 
Table 1. Summary of publications describing kinetic changes due to lameness.

\begin{tabular}{|c|c|c|c|c|c|}
\hline Parameter & $\begin{array}{l}\text { Measuring } \\
\text { tool }\end{array}$ & $\begin{array}{l}\text { Treadmill/ } \\
\text { overground }\end{array}$ & Model & $\begin{array}{l}\text { Response } \\
\text { measured on } \\
\text { the lame limb }\end{array}$ & Reference \\
\hline \multirow[t]{5}{*}{ Peak vertical force } & Force plate & Overground & $\begin{array}{l}\text { Induced lameness, modified } \\
\text { shoe }\end{array}$ & Decreases & $\begin{array}{l}\text { (Merkens and Schamhardt, } \\
\text { 1988a; Ishihara et al., 2005) }\end{array}$ \\
\hline & & & $\begin{array}{l}\text { Induced lameness, carpal } \\
\text { joint defect }\end{array}$ & Decreases & $\begin{array}{l}\text { (Morris and Seeherman, } \\
\text { 1987) }\end{array}$ \\
\hline & & & $\begin{array}{l}\text { Induced lameness, flexor } \\
\text { tendon lesion }\end{array}$ & Decreases & $\begin{array}{l}\text { (Keg et al., 1994) (Clayton } \\
\text { et al., 2000) }\end{array}$ \\
\hline & & & $\begin{array}{l}\text { Induced lameness, LPS } \\
\text { injection (distal intertarsal } \\
\text { and tarsometatarsal joints) }\end{array}$ & Decreases & (Khumsap et al., 2003) \\
\hline & & Treadmill & $\begin{array}{l}\text { Induced lameness modified } \\
\text { shoe }\end{array}$ & Decreases & $\begin{array}{l}\text { (Weishaupt et al., 2006, } \\
\text { 2010b) }\end{array}$ \\
\hline \multirow[t]{4}{*}{ Vertical impulse } & Force plate & Overground & $\begin{array}{l}\text { Induced lameness modified } \\
\text { shoe }\end{array}$ & Decreases & $\begin{array}{l}\text { (Merkens and Schamhardt, } \\
\text { 1988a; Ishihara et al., 2005) }\end{array}$ \\
\hline & & & $\begin{array}{l}\text { Induced lameness, carpal } \\
\text { joint defect }\end{array}$ & Decreases & $\begin{array}{l}\text { (Morris and Seeherman, } \\
\text { 1987) }\end{array}$ \\
\hline & & & $\begin{array}{l}\text { Induced lameness, flexor } \\
\text { tendon lesion }\end{array}$ & Decreases & (Keg et al., 1994) \\
\hline & & Treadmill & $\begin{array}{l}\text { Induced lameness modified } \\
\text { shoe }\end{array}$ & Decreases & $\begin{array}{l}\text { (Weishaupt et al., 2006, } \\
\text { 2010b) }\end{array}$ \\
\hline \multirow[t]{2}{*}{$\begin{array}{l}\text { Breaking force } \\
\text { impulse }\end{array}$} & Force plate & Overground & $\begin{array}{l}\text { Induced lameness, LPS } \\
\text { injection }\end{array}$ & $\begin{array}{l}\text { Decreases (in the } \\
\text { highest degrees of } \\
\text { lameness) }\end{array}$ & (Ishihara et al., 2005) \\
\hline & & & $\begin{array}{l}\text { Induced lameness, flexor } \\
\text { tendon lesion }\end{array}$ & Decreases & $\begin{array}{l}\text { (Morris and Seeherman, } \\
\text { 1987) }\end{array}$ \\
\hline \multirow[t]{3}{*}{ Breaking force peak } & Force plate & Overground & $\begin{array}{l}\text { Induced lameness, LPS } \\
\text { injection }\end{array}$ & Decreases & (Ishihara et al., 2005) \\
\hline & & & $\begin{array}{l}\text { Induced lameness, carpal } \\
\text { joint defect }\end{array}$ & Decreases & $\begin{array}{l}\text { (Morris and Seeherman, } \\
\text { 1987) }\end{array}$ \\
\hline & & & $\begin{array}{l}\text { Induced lameness, flexor } \\
\text { tendon lesion }\end{array}$ & Decreases & (Clayton et al., 2000) \\
\hline \multirow[t]{4}{*}{$\begin{array}{l}\text { Propulsive force } \\
\text { peak }\end{array}$} & Force plate & Overground & $\begin{array}{l}\text { Induced lameness, LPS } \\
\text { injection }\end{array}$ & Decreases $t$ & (Ishihara et al., 2005) \\
\hline & & & $\begin{array}{l}\text { Induced lameness, flexor } \\
\text { tendon lesion }\end{array}$ & Decreases & (Keg et al., 1994) \\
\hline & & & $\begin{array}{l}\text { Induced lameness, carpal } \\
\text { joint defect }\end{array}$ & $\begin{array}{l}\text { Not significantly } \\
\text { affected }\end{array}$ & $\begin{array}{l}\text { (Morris and Seeherman, } \\
\text { 1987) }\end{array}$ \\
\hline & & & $\begin{array}{l}\text { Induced lameness, flexor } \\
\text { tendon lesion }\end{array}$ & $\begin{array}{l}\text { Not significantly } \\
\text { affected }\end{array}$ & (Clayton et al., 2000) \\
\hline \multirow[t]{3}{*}{$\begin{array}{l}\text { Propulsive force } \\
\text { impulse }\end{array}$} & Force plate & Overground & $\begin{array}{l}\text { Induced lameness, LPS } \\
\text { injection }\end{array}$ & $\begin{array}{l}\text { Decreases (in the } \\
\text { highest degrees of } \\
\text { lameness) }\end{array}$ & (Ishihara et al., 2005) \\
\hline & & & $\begin{array}{l}\text { Induced lameness, flexor } \\
\text { tendon lesion }\end{array}$ & $\begin{array}{l}\text { Not significantly } \\
\text { affected }\end{array}$ & $\begin{array}{l}\text { (Keg et al., 1994; Clayton et } \\
\text { al., 2000) }\end{array}$ \\
\hline & & & $\begin{array}{l}\text { Induced lameness, carpal } \\
\text { joint defect }\end{array}$ & $\begin{array}{l}\text { Not significantly } \\
\text { affected }\end{array}$ & $\begin{array}{l}\text { (Morris and Seeherman, } \\
\text { 1987) }\end{array}$ \\
\hline
\end{tabular}




\begin{tabular}{|c|c|c|c|c|c|}
\hline $\begin{array}{l}\text { Time of zero- } \\
\text { crossing of } \\
\text { horizontal ground } \\
\text { reaction force as } \\
\text { a percentage of } \\
\text { stance time }\end{array}$ & Force plate & Overground & $\begin{array}{l}\text { Induced lameness, LPS } \\
\text { injection }\end{array}$ & $\begin{array}{l}\text { Decreases (in the } \\
\text { highest degrees of } \\
\text { lameness) }\end{array}$ & (Ishihara et al., 2005) \\
\hline \multirow[t]{4}{*}{ Stance duration } & Force plate & Overground & $\begin{array}{l}\text { Induced lameness, LPS } \\
\text { injection }\end{array}$ & Increases & (Ishihara et al., 2005) \\
\hline & & & $\begin{array}{l}\text { Induced lameness, carpal } \\
\text { joint defect }\end{array}$ & $\begin{array}{l}\text { Not significantly } \\
\text { affected }\end{array}$ & $\begin{array}{l}\text { (Morris and Seeherman, } \\
\text { 1987) }\end{array}$ \\
\hline & & & $\begin{array}{l}\text { Induced lameness, flexor } \\
\text { tendon lesion }\end{array}$ & $\begin{array}{l}\text { Not significantly } \\
\text { affected }\end{array}$ & (Clayton et al., 2000) \\
\hline & & Treadmill & $\begin{array}{l}\text { Induced lameness, modified } \\
\text { shoe }\end{array}$ & Increases & $\begin{array}{l}\text { (Weishaupt et al., 2006, } \\
\text { 2010b) }\end{array}$ \\
\hline Swing duration & Force plate & Treadmill & $\begin{array}{l}\text { Induced lameness modified } \\
\text { shoe }\end{array}$ & Decreases & $\begin{array}{l}\text { (Weishaupt et al., 2006, } \\
\text { 2010b) }\end{array}$ \\
\hline Stride frequency & Force plate & Treadmill & $\begin{array}{l}\text { Induced lameness modified } \\
\text { shoe }\end{array}$ & Increases & $\begin{array}{l}\text { (Weishaupt et al., 2006, } \\
\text { 2010b) }\end{array}$ \\
\hline
\end{tabular}

LPS: lipopolysaccharide.

in lameness model and differences between treadmill and overground locomotion (Barrey et al., 1993; Buchner et al., 1994; Gómez Álvarez et al., 2009). However, in general, the evidence is robust with a clear association between lameness and changes for several gait parameters at the trot.

\section{Kinetics and temporal stride parameters}

In unilateral lameness at the trot, the most commonly reported changes measured in the lame limb are a reduction of peak vertical force, vertical impulse (Fig. 1) and decreased swing duration (Table 1), although swing duration is reduced in all limbs. The horizontal forces during the stance phase, described as breaking and propulsion forces, are also affected by lameness, with the reduction of peak breaking force reported as the most consistently altered parameter due to lameness (Morris and Seeherman, 1987; Keg et al., 1994; Clayton et al., 2000; Ishihara et al., 2005).

Stance duration has been reported to decrease, but this was only observed in studies using the shoe pressure model for transient lameness induction (Merkens and Schamhardt, 1988b), suggesting that the location of pain might influence the observed gait adaptation mechanisms. 
Some kinetic variables of the non-lame limbs are also affected to a certain extent, as a consequence of compensatory mechanisms in gait adaptation to lameness (Weishaupt, 2008).

\section{Kinematics}

Most research has focused on the kinematic analysis of head and pelvis movement, back motion and temporal and angular changes in limb motion. Although the first reports on symmetry parameters to quantify lameness were based on acceleration measurements (Kastner, 1989; Kastner et al., 1990), research in the last two decades has focussed more on measurements of vertical displacement, probably since interpretation of displacement data is more intuitive and closer to the commonly observed parameters during visual lameness assessment than acceleration or speed (Fig. 1).

At the trot in a straight line, the head, withers and pelvis of non- lame horses move upwards and downwards twice during the stride cycle, generating a typical sinusoidal pattern. In the presence of lameness, this sinusoidal pattern becomes asymmetrical and, by measuring the specific changes in the vertical displacement curves, lameness can be quantified objectively (Buchner et al., 1996a) (Fig. 1).

With increasing lameness, the amplitude of the vertical displacement during the stance phase of the lame limb decreases, while the amplitude of the contralateral limb increases (Buchner et al., 1996a). This can be measured as the difference of the amplitude of the vertical displacement, or as a symmetry index between contralateral steps (Fig. 1; Table 2).

Due to this change in the amplitude of the vertical displacement during the stance phase of a lame limb, the head/withers and pelvis reach a minimum position that is higher when compared with the contralateral non-lame limb, resulting in a difference between minimum positions (MinDiff) (Table 2) of either the head/withers or the pelvis in case of fore or hindlimb lameness, respectively (Fig. 1). The head/withers or pelvis also reaches a maximum position at the end of the swing phase just before hoof contact with the ground and again at the end of the stance phase (Buchner et al., 1996a; Starke et al., 2012b). During lameness, the maximum positions of the head and pelvis at the end of the stance phase of the lame limb are also lower when compared to the non-lame limb, resulting in a difference between maximum positions (MaxDiff) (Table 2) of the head/withers or pelvis in case of fore or hindlimb lameness, respectively (Buchner et al., 1996a; Keegan et al., 2004). The relation between MinDiff, MaxDiff and ground reaction forces has also been investigated for 


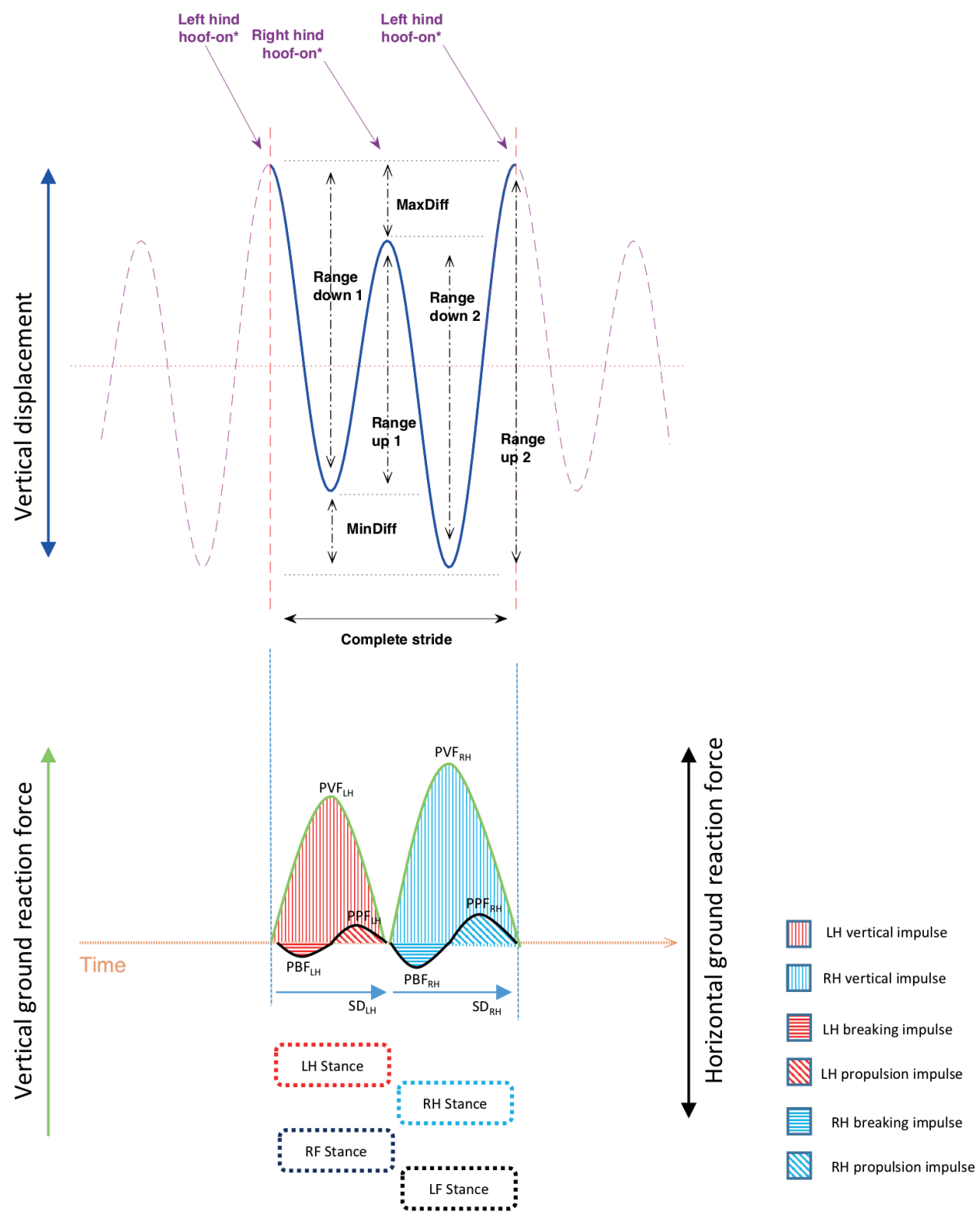

Fig. 1. Graphical presentation of the vertical displacement of the pelvis during a complete stride at the trot (top) and vertical/horizontal ground reaction forces (bottom). The stance phase of each limb is represented by the horizontal bars below. The graph illustrates a left hind lameness. The vertical displacement of the pelvis, the vertical ground reaction force and the horizontal ground reaction force are presented in blue, green and black, respectively. Symmetry of the upward vertical displacement (Slup) is calculated as the difference between Range up 1 and Range up 2, and the symmetry of the downward vertical displacement (SIdown) is calculated as the difference between Range down 1 and Range down 2 (LH: left hind, RH: right hind, LF: left front, RF: right front, PVF: peak vertical force, PBF: peak breaking force, PPF: peak propulsive force, SD: stance duration, asterisk: approximate timing of hoof-on). 
Table 2. Summary of publications describing kinematic changes due to lameness.

\begin{tabular}{|c|c|c|c|c|c|c|}
\hline Parameter & $\begin{array}{l}\text { Detailed } \\
\text { parameter }\end{array}$ & Measured & $\begin{array}{l}\text { Treadmill/ } \\
\text { overground }\end{array}$ & Model & $\begin{array}{l}\text { Response } \\
\text { measured on the } \\
\text { specific kinematic } \\
\text { parameter }\end{array}$ & Reference \\
\hline \multirow[t]{8}{*}{$\begin{array}{l}\text { Head vertical } \\
\text { displacement }\end{array}$} & MinDiff & OMC & Treadmill & $\begin{array}{l}\text { Induced FL lameness - } \\
\text { modified shoe }\end{array}$ & $\begin{array}{l}\text { Increases. Values will } \\
\text { be }<\text { or }>\text { than zero } \\
\text { depending on the } \\
\text { side of lameness }\end{array}$ & $\begin{array}{l}\text { (Keegan et al., } \\
\text { 2001, 2000; } \\
\text { Kelmer et al., } \\
\text { 2005) }\end{array}$ \\
\hline & & IMU & Overground & $\begin{array}{l}\text { Induced FL/HL } \\
\text { lameness - modified } \\
\text { shoe }\end{array}$ & $\begin{array}{l}\text { Increases. Values will } \\
\text { be }<\text { or }>\text { than zero } \\
\text { depending on the } \\
\text { side of lameness }\end{array}$ & $\begin{array}{l}\text { (Rhodin et al., } \\
\text { 2013) }\end{array}$ \\
\hline & MaxDiff & OMC & Treadmill & $\begin{array}{l}\text { Induced FL lameness - } \\
\text { modified shoe }\end{array}$ & $\begin{array}{l}\text { Increases. Values will } \\
\text { be }<\text { or }>\text { than zero } \\
\text { depending on the } \\
\text { side of lameness }\end{array}$ & $\begin{array}{l}\text { (Kelmer et al., } \\
\text { 2005) }\end{array}$ \\
\hline & & IMU & Overground & $\begin{array}{l}\text { Induced FL/HL } \\
\text { lameness - modified } \\
\text { shoe }\end{array}$ & $\begin{array}{l}\text { Increases. Values will } \\
\text { be }<\text { or }>\text { than zero } \\
\text { depending on the } \\
\text { side of lameness }\end{array}$ & $\begin{array}{l}\text { (Rhodin et al., } \\
\text { 2013) }\end{array}$ \\
\hline & Range up & OMC & Treadmill & $\begin{array}{l}\text { Induced FL lameness - } \\
\text { modified shoe }\end{array}$ & $\begin{array}{l}\text { Increases. Values will } \\
\text { be }<\text { or }>\text { than zero } \\
\text { depending on the } \\
\text { side of lameness }\end{array}$ & $\begin{array}{l}\text { (Peloso et al., } \\
\text { 1993; Buchner } \\
\text { et al., 1996a) }\end{array}$ \\
\hline & $\mathrm{SI}_{\text {up }}$ & $O M C$ & Treadmill & $\begin{array}{l}\text { Induced FL lameness - } \\
\text { modified shoe }\end{array}$ & Decreases & $\begin{array}{l}\text { (Buchner et al., } \\
\text { 1996a) }\end{array}$ \\
\hline & & & & $\begin{array}{l}\text { Induced HL lameness } \\
\text { - modified shoe }\end{array}$ & $\begin{array}{l}\text { Decreases - only } \\
\text { in higher degree of } \\
\text { lameness }\end{array}$ & $\begin{array}{l}\text { (Buchner et al., } \\
\text { 1996a) }\end{array}$ \\
\hline & $\begin{array}{l}\text { Head signal } \\
\text { transformation } \\
\text { (FFT) }\end{array}$ & $O M C$ & Treadmill & $\begin{array}{l}\text { Induced FL lameness - } \\
\text { modified shoe }\end{array}$ & $\begin{array}{l}\text { Increased signal } \\
\text { amplitude of } \\
\text { fundamental } \\
\text { wave after FFT } \\
\text { transformation }\end{array}$ & $\begin{array}{l}\text { (Peham et al., } \\
\text { 1996) }\end{array}$ \\
\hline \multirow[t]{2}{*}{$\begin{array}{l}\text { Head } \\
\text { acceleration }\end{array}$} & $\begin{array}{l}\text { Maximum head } \\
\text { acceleration }\end{array}$ & OMC & Treadmill & $\begin{array}{l}\text { Induced FL lameness - } \\
\text { modified shoe }\end{array}$ & $\begin{array}{l}\text { Decreases during the } \\
\text { lame stance and } \\
\text { increases during the } \\
\text { contralateral stance }\end{array}$ & $\begin{array}{l}\text { (Buchner et al., } \\
\text { 1996a) }\end{array}$ \\
\hline & $\begin{array}{l}\text { Head acceleration } \\
\text { amplitude }\end{array}$ & OMC & Treadmill & $\begin{array}{l}\text { Induced FL lameness - } \\
\text { modified shoe }\end{array}$ & $\begin{array}{l}\text { Decreases during } \\
\text { the lame stance and } \\
\text { increases during the } \\
\text { contralateral stance }\end{array}$ & $\begin{array}{l}\text { (Buchner et al., } \\
\text { 1996a) }\end{array}$ \\
\hline \multirow[t]{3}{*}{$\begin{array}{l}\text { Withers vertical } \\
\text { displacement }\end{array}$} & Range up & OMC & Treadmill & $\begin{array}{l}\text { Induced FL lameness - } \\
\text { modified shoe }\end{array}$ & Decreases & $\begin{array}{l}\text { (Peloso et al., } \\
\text { 1993; Buchner } \\
\text { et al., 1996a) }\end{array}$ \\
\hline & $\mathrm{SI}_{\mathrm{up}}$ & OMC & Treadmill & $\begin{array}{l}\text { Induced FL lameness - } \\
\text { modified shoe }\end{array}$ & $\begin{array}{l}\text { Decreases - only } \\
\text { in higher degree of } \\
\text { lameness }\end{array}$ & $\begin{array}{l}\text { (Buchner et al., } \\
\text { 1996a) }\end{array}$ \\
\hline & MinDiff & $O M C$ & Overground & $\begin{array}{l}\text { Induced FL/HL } \\
\text { lameness - modified } \\
\text { shoe }\end{array}$ & $\begin{array}{l}\text { Increases. Values will } \\
\text { be }<\text { or }>\text { than zero } \\
\text { depending on the } \\
\text { side of lameness }\end{array}$ & $\begin{array}{l}\text { (Persson Sjödin } \\
\text { et al., 2016) }\end{array}$ \\
\hline
\end{tabular}




\begin{tabular}{|c|c|c|c|c|c|c|}
\hline $\begin{array}{l}\text { Withers } \\
\text { acceleration } \\
\text { acceleration }\end{array}$ & $\begin{array}{l}\text { Withers } \\
\text { maximum }\end{array}$ & OMC & Treadmill & $\begin{array}{l}\text { Induced FL lameness - } \\
\text { modified shoe }\end{array}$ & $\begin{array}{l}\text { Decreases during the } \\
\text { lame stance }\end{array}$ & $\begin{array}{l}\text { (Buchner et al., } \\
\text { 1996a) }\end{array}$ \\
\hline \multirow[t]{11}{*}{$\begin{array}{l}\text { Pelvis vertical } \\
\text { displacement }\end{array}$} & MinDiff & $\begin{array}{l}\text { Tri-axis } \\
\text { accelerometer }\end{array}$ & Overground & $\begin{array}{l}\text { Induced stifle synovitis } \\
\text { (intra articular } \\
\text { injection of IL-1b) }\end{array}$ & $\begin{array}{l}\text { Increases. Values will } \\
\text { be }<\text { or }>\text { than zero } \\
\text { depending on the } \\
\text { side of lameness }\end{array}$ & $\begin{array}{l}\text { (Tóth et al., } \\
\text { 2014) }\end{array}$ \\
\hline & & OMC & Treadmill & $\begin{array}{l}\text { Induced FL/HL } \\
\text { lameness - } \\
\text { modified shoe }\end{array}$ & $\begin{array}{l}\text { Increases. Values will } \\
\text { be }<\text { or }>\text { than zero } \\
\text { depending on the } \\
\text { side of lameness }\end{array}$ & $\begin{array}{l}\text { (Kramer et al., } \\
\text { 2004; Kelmer } \\
\text { et al., 2005) }\end{array}$ \\
\hline & & OMC & Treadmill & $\begin{array}{l}\text { Induced HL lameness } \\
\text { - LPS injection hock }\end{array}$ & $\begin{array}{l}\text { Not significantly } \\
\text { affected }\end{array}$ & $\begin{array}{l}\text { (Kramer et al., } \\
\text { 2000) }\end{array}$ \\
\hline & & IMU & Overground & $\begin{array}{l}\text { Induced FL/HL } \\
\text { lameness - modified } \\
\text { shoe }\end{array}$ & $\begin{array}{l}\text { Increases. Values will } \\
\text { be }<\text { or }>\text { than zero } \\
\text { depending on the } \\
\text { side of lameness }\end{array}$ & $\begin{array}{l}\text { (Rhodin et al., } \\
\text { 2013) }\end{array}$ \\
\hline & MaxDiff & Tri-axis & Overground & $\begin{array}{l}\text { Induced stifle synovitis } \\
\text { (intra-articular } \\
\text { injection of IL-1b) }\end{array}$ & $\begin{array}{l}\text { Increases. Values will } \\
\text { be }<\text { or }>\text { than zero } \\
\text { depending on the } \\
\text { side of lameness }\end{array}$ & $\begin{array}{l}\text { (Tóth et al., } \\
\text { 2014) }\end{array}$ \\
\hline & & OMC & Treadmill & $\begin{array}{l}\text { Induced FL/HL } \\
\text { lameness - modified } \\
\text { shoe }\end{array}$ & $\begin{array}{l}\text { Increases. Values will } \\
\text { be }<\text { or }>\text { than zero } \\
\text { depending on the } \\
\text { side of lameness }\end{array}$ & $\begin{array}{l}\text { (Kramer et al., } \\
\text { 2004; Kelmer } \\
\text { et al., 2005) }\end{array}$ \\
\hline & & IMU & Overground & $\begin{array}{l}\text { Induced FL/HL } \\
\text { lameness - modified } \\
\text { shoe }\end{array}$ & $\begin{array}{l}\text { Increases. Values will } \\
\text { be }<\text { or }>\text { than zero } \\
\text { depending on the } \\
\text { side of lameness }\end{array}$ & $\begin{array}{l}\text { (Rhodin et al., } \\
\text { 2013) }\end{array}$ \\
\hline & $\begin{array}{l}\text { Pelvis vertical } \\
\text { displacement FFT, } \\
\text { signal to noise } \\
\text { ratio }\end{array}$ & OMC & Treadmill & $\begin{array}{l}\text { Induced HL lameness } \\
\text { - modified shoe }\end{array}$ & $\begin{array}{l}\text { Increased signal to } \\
\text { noise FFT ratio }\end{array}$ & $\begin{array}{l}\text { (Kramer et al., } \\
\text { 2004) }\end{array}$ \\
\hline & Range up & OMC & Treadmill & $\begin{array}{l}\text { Induced HL lameness } \\
\text { - modified shoe }\end{array}$ & Decreases & $\begin{array}{l}\text { (Buchner et al., } \\
\text { 1996a) }\end{array}$ \\
\hline & $\begin{array}{l}\text { Tuber coxae } \\
\text { upward } \\
\text { movement } \\
\text { amplitude during } \\
\text { stance of the lame } \\
\text { limb }\end{array}$ & OMC & Treadmill & $\begin{array}{l}\text { Induced HL lameness } \\
\text { - } \\
\text { modified shoe }\end{array}$ & Decreases & $\begin{array}{l}\text { (Buchner et al., } \\
\text { 1996a) }\end{array}$ \\
\hline & $\mathrm{SI}_{\text {up }}$ & OMC & Treadmil & $\begin{array}{l}\text { Induced FL lameness - } \\
\text { modified shoe } \\
\text { Induced HL lameness } \\
\text { - } \\
\text { modified shoe }\end{array}$ & $\begin{array}{l}\text { Decreases } \\
\text { Decreases }\end{array}$ & $\begin{array}{l}\text { (Buchner et al., } \\
\text { 1996a) } \\
\text { (Buchner et al., } \\
\text { 1996a) }\end{array}$ \\
\hline $\begin{array}{l}\text { Pelvis } \\
\text { acceleration } \\
\text { amplitude }\end{array}$ & $\begin{array}{l}\text { Sacrum } \\
\text { acceleration }\end{array}$ & OMC & Treadmill & $\begin{array}{l}\text { Induced HL lameness } \\
\text { - modified shoe }\end{array}$ & $\begin{array}{l}\text { Decreased maximum } \\
\text { acceleration and } \\
\text { acceleration } \\
\text { amplitude during } \\
\text { lame stance }\end{array}$ & $\begin{array}{l}\text { (Buchner et al., } \\
\text { 1996a) }\end{array}$ \\
\hline
\end{tabular}




\begin{tabular}{|c|c|c|c|c|c|c|}
\hline \multirow[t]{2}{*}{ Trunk } & \multirow[t]{2}{*}{$\begin{array}{l}\text { Acceleration } \\
\text { symmetry }\end{array}$} & $\begin{array}{l}\text { Tri-axis } \\
\text { accelerometer }\end{array}$ & $\begin{array}{l}\text { Treadmill and } \\
\text { overground }\end{array}$ & $\begin{array}{l}\text { Induced FL lameness - } \\
\text { modified shoe }\end{array}$ & $\begin{array}{l}\text { Decreased coefficient } \\
\text { of correlation of } \\
\text { the dorsoventral } \\
\text { acceleration signal } \\
\text { autocorrelation }\end{array}$ & $\begin{array}{l}\text { (Barrey et al., } \\
\text { 1994) }\end{array}$ \\
\hline & & $\begin{array}{l}\text { Tri-axis } \\
\text { accelerometer }\end{array}$ & Overground & $\begin{array}{l}\text { Induced FL lameness - } \\
\text { saline injection in to } \\
\text { metacarpophalangeal } \\
\text { joint }\end{array}$ & $\begin{array}{l}\text { A-scorea increases. } \\
\text { Values will be }<\text { or }> \\
\text { than zero depending } \\
\text { on the side of } \\
\text { lameness; S-scoreb } \\
\text { increases }\end{array}$ & $\begin{array}{l}\text { (Thomsen et } \\
\text { al., 2010) }\end{array}$ \\
\hline \multirow[t]{4}{*}{ Back } & \multirow[t]{2}{*}{$\begin{array}{l}\text { Back range of } \\
\text { motion }\end{array}$} & \multirow[t]{2}{*}{ OMC } & \multirow[t]{2}{*}{ Treadmill } & $\begin{array}{l}\text { Induced lameness - } \\
\text { modified shoe }\end{array}$ & $\begin{array}{l}\text { Flexion-extension } \\
\text { and lateral bending } \\
\text { of back segments } \\
\text { change significantly } \\
\text { both in walk and trot }\end{array}$ & $\begin{array}{l}\text { (Gómez } \\
\text { Álvarez et al., } \\
2007,2008 \text { ) }\end{array}$ \\
\hline & & & & $\begin{array}{l}\text { Induced back pain - } \\
\text { Lactic acid injection }\end{array}$ & $\begin{array}{l}\text { Flexion-extension } \\
\text { and lateral bending } \\
\text { of back segments } \\
\text { change significantly } \\
\text { both in walk and trot }\end{array}$ & $\begin{array}{l}\text { (Wennerstrand } \\
\text { et al., 2009) }\end{array}$ \\
\hline & \multirow[t]{2}{*}{$\begin{array}{l}\text { Pelvic axial } \\
\text { rotation }\end{array}$} & \multirow[t]{2}{*}{ OMC } & \multirow[t]{2}{*}{ Treadmill } & $\begin{array}{l}\text { Induced lameness - } \\
\text { modified shoe }\end{array}$ & $\begin{array}{l}\text { Walk - increased; } \\
\text { Trot - decreased }\end{array}$ & $\begin{array}{l}\text { (Gómez } \\
\text { Álvarez et al., } \\
2007,2008 \text { ) }\end{array}$ \\
\hline & & & & Induced back pain & $\begin{array}{l}\text { Not significantly } \\
\text { affected }\end{array}$ & $\begin{array}{l}\text { (Wennerstrand } \\
\text { et al., 2009) }\end{array}$ \\
\hline
\end{tabular}

OMC: optical motion capture; IMU: inertial measurement unit; LPS: lipopolysaccharide; FL: forelimb; $\mathrm{HL}$ : hindlimb; MinDiff: difference in minimum position between two consecutive steps; MaxDiff: difference in maximum position between two consecutive steps; range up/down: difference in range of motion in the upwards/downwards direction between two consecutive steps; $\mathrm{SI}_{\mathrm{Up}}{ }^{\prime}$ Down $:$ symmetry index (between -1 and 1) in range of motion in the upwards/downwards direction between two consecutive steps. FFT: fast Fourier transform.

a The natural logarithmic quotient of the total upwards accelerations during stance of the right and the left diagonals.

b The natural logarithmic quotient of the squared odd-numbered and even-numbered Fourier coefficients from the dorsoventral acceleration signal.

horses with hindlimb lameness. It has become clear from force plate measurements in lame horses that MinDiff reflects the difference in vertical ground reaction forces and MaxDiff the differences in horizontal forces between limbs (Bell et al., 2016). However, kinetic analysis remains most discriminative for supporting limb lameness and, the authors stated that the kinematic parameters MaxDiff and MinDiff cannot be used to replace measurements of vertical and horizontal forces (Bell et al., 2016).

Compensatory movements of adaptation to lameness have also been reported for kinematic parameters (Kelmer et al., 2005; Rhodin et al., 2013) (Fig. 2), wherein primary (induced) hindlimb lameness, a compensatory head nod resembling a 
forelimb lameness in the ipsilateral forelimb has been described (Buchner et al., 1996a; Kelmer et al., 2005). On the other hand, in case of a primary (induced) forelimb lameness, compensatory movements have been described in both the ipsilateral and contralateral hindlimbs (Buchner et al., 1996a; Kelmer et al., 2005). The compensatory head movement due to a primary hindlimb lameness is more pronounced than the compensatory movement in the pelvis caused by a primary forelimb lameness (Rhodin et al., 2013).

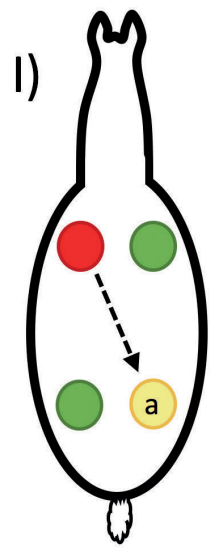

Subjective gait analysis
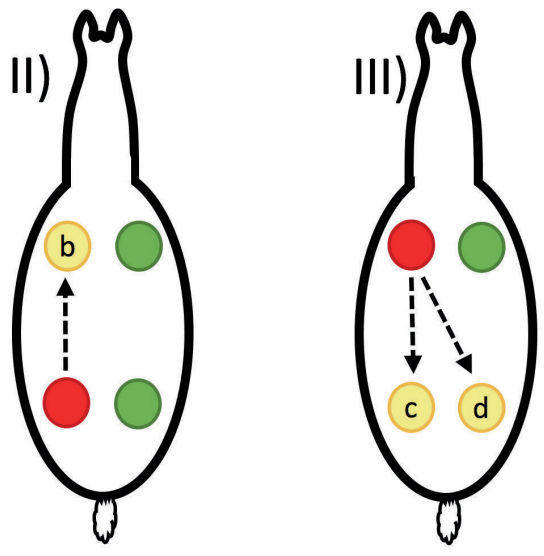

Objective gait analysis

Fig. 2. Schematic representation of the compensatory movements (yellow) of the head and pelvis, as traditionally observed during subjective lameness assessment (I, II) in case of a primary (red) forelimb limb lameness (I: with a compensatory contralateral (diagonal) vertical displacement asymmetry of the pelvis, indicated as a) and in case of a primary hindlimb lameness (II: with an ipsilateral compensatory vertical displacement asymmetry of the head, indicated as b). In objective gait assessment (III, IV), a primary forelimb lameness (III) is commonly seen accompanied by a compensatory effect on the contralateral pelvis MaxDiff (d) and the ipsilateral pelvis MinDiff (c). For a primary hindlimb lameness (IV), effects on sagittal head MinDiff and MaxDiff (e) have been described. See Table 1 and Fig. 1 for a description of these parameters.

In forelimb lameness, the parameters associated with vertical head displacement have been reported to be affected more importantly than those associated with the vertical displacement of the withers (Buchner et al., 1996a). This may be true with respect to the magnitude of the effect, but there is indeed an effect on wither motion (Uhlir et al., 1997; Kelmer et al., 2005), and recent work (Persson Sjödin et al., 2016) showed that withers' movement might be used to differentiate between head movement asymme- tries resulting from a primary forelimb or a primary 
Table 3. Summary of publications describing limb kinematic changes due to lameness

\begin{tabular}{|c|c|c|c|c|c|c|}
\hline $\begin{array}{l}\text { Parameter } \\
\text { studied }\end{array}$ & Detailed parameter & Measured & $\begin{array}{l}\text { Treadmill/ } \\
\text { overground }\end{array}$ & Model & $\begin{array}{l}\text { Response } \\
\text { measured on the } \\
\text { specific kinematic } \\
\text { parameter }\end{array}$ & Reference \\
\hline \multirow[t]{16}{*}{ Limbs } & Stance duration & OMC & Treadmill & $\begin{array}{l}\text { Induced FL lameness - } \\
\text { modified shoe }\end{array}$ & $\begin{array}{l}\text { Increased on the } \\
\text { sound forelimb and } \\
\text { decreased on the } \\
\text { diagonal hindlimb }\end{array}$ & $\begin{array}{l}\text { (Buchner et al., } \\
\text { 2010) }\end{array}$ \\
\hline & & & & $\begin{array}{l}\text { Induced HL lameness - } \\
\text { modified shoe }\end{array}$ & $\begin{array}{l}\text { Decreased only on } \\
\text { the ipsilateral and } \\
\text { diagonal forelimb }\end{array}$ & $\begin{array}{l}\text { (Buchner et al., } \\
\text { 2010) }\end{array}$ \\
\hline & Stride duration & OMC & Treadmill & $\begin{array}{l}\text { Induced FL lameness - } \\
\text { modified shoe }\end{array}$ & Decreases & $\begin{array}{l}\text { (Keegan et al., } \\
\text { 2000; Buchner et } \\
\text { al., 2010) }\end{array}$ \\
\hline & & & & $\begin{array}{l}\text { Induced HL lameness - } \\
\text { modified shoe }\end{array}$ & Decreases & $\begin{array}{l}\text { (Buchner et al., } \\
\text { 2010) }\end{array}$ \\
\hline & & Force plate & Treadmill & $\begin{array}{l}\text { Induced FL lameness - } \\
\text { modified shoe }\end{array}$ & Decreases & $\begin{array}{l}\text { (Weishaupt et al., } \\
\text { 2006) }\end{array}$ \\
\hline & $\begin{array}{l}\text { Relative stance duration } \\
\text { as a percentage of the } \\
\text { stride duration }\end{array}$ & OMC & Treadmill & $\begin{array}{l}\text { Induced FL lameness - } \\
\text { modified shoe }\end{array}$ & Increases & $\begin{array}{l}\text { (Keegan et al., } \\
\text { 2000; Buchner et } \\
\text { al., 2010) }\end{array}$ \\
\hline & & & & $\begin{array}{l}\text { Induced HL lameness - } \\
\text { modified shoe }\end{array}$ & $\begin{array}{l}\text { Not significantly } \\
\text { affected }\end{array}$ & $\begin{array}{l}\text { (Buchner et al., } \\
\text { 2010) }\end{array}$ \\
\hline & & Force plate & Treadmill & $\begin{array}{l}\text { Induced FL lameness - } \\
\text { modified shoe }\end{array}$ & Increases & $\begin{array}{l}\text { (Weishaupt et al., } \\
\text { 2006) }\end{array}$ \\
\hline & & & & $\begin{array}{l}\text { Induced HL lameness - } \\
\text { modified shoe }\end{array}$ & Increases & $\begin{array}{l}\text { (Weishaupt et al., } \\
\text { 2006) }\end{array}$ \\
\hline & $\begin{array}{l}\text { Diagonal advanced } \\
\text { placement }\end{array}$ & OMC & Treadmill & $\begin{array}{l}\text { Induced FL lameness - } \\
\text { modified shoe }\end{array}$ & $\begin{array}{l}\text { Decreases - lame } \\
\text { diagonal }\end{array}$ & $\begin{array}{l}\text { (Buchner et al., } \\
\text { 2010) }\end{array}$ \\
\hline & & & & $\begin{array}{l}\text { Induced HL lameness - } \\
\text { modified shoe }\end{array}$ & $\begin{array}{l}\text { Not significantly } \\
\text { affected }\end{array}$ & $\begin{array}{l}\text { (Buchner et al., } \\
\text { 2010) }\end{array}$ \\
\hline & Limb joint angles & OMC & Treadmill & $\begin{array}{l}\text { Induced lameness - } \\
\text { modified shoe }\end{array}$ & $\begin{array}{l}\text { Various significant } \\
\text { responses depending } \\
\text { on the measured joint } \\
\text { ROM }\end{array}$ & $\begin{array}{l}\text { (Buchner et al., } \\
\text { 1996b; Keegan et } \\
\text { al., 2000) }\end{array}$ \\
\hline & & & & $\begin{array}{l}\text { Induced lameness - } \\
\text { intra- articular LPS } \\
\text { injection }\end{array}$ & $\begin{array}{l}\text { Various significant } \\
\text { responses depending } \\
\text { on the measured joint } \\
\text { ROM }\end{array}$ & $\begin{array}{l}\text { (Kramer et al., } \\
\text { 2000; van Loon et } \\
\text { al., 2010) }\end{array}$ \\
\hline & & & Overground & $\begin{array}{l}\text { Induced lameness, flexor } \\
\text { tendon lesion }\end{array}$ & $\begin{array}{l}\text { Various significant } \\
\text { responses depending } \\
\text { on the measured joint } \\
\text { ROM }\end{array}$ & $\begin{array}{l}\text { (Clayton et al., } \\
2000)\end{array}$ \\
\hline & & & Overground & $\begin{array}{l}\text { Induced lameness, LPS } \\
\text { injection } \\
\text { (distal intertarsal and } \\
\text { tarsometatarsal joints) }\end{array}$ & $\begin{array}{l}\text { Reduction of ROM of } \\
\text { the tarsal joint }\end{array}$ & $\begin{array}{l}\text { (Khumsap et al., } \\
\text { 2003) }\end{array}$ \\
\hline & & Goniometry & Overground & Clinical lameness (carpal) & $\begin{array}{l}\text { Reduced ROM of the } \\
\text { affected } \\
\text { joint, in unilateral } \\
\text { carpal lameness }\end{array}$ & $\begin{array}{l}\text { (Ratzlaff et al., } \\
\text { 1982) }\end{array}$ \\
\hline
\end{tabular}




\begin{tabular}{|c|c|c|c|c|c|}
\hline Protraction (max) & OMC & Treadmill & $\begin{array}{l}\text { Induced lameness - } \\
\text { modified shoe }\end{array}$ & $\begin{array}{l}\text { No effect in bilateral } \\
\text { lameness Decreases } \\
\text { (only for the forelimbs, } \\
\text { walk and trot) } \\
\text { Not significantly } \\
\text { affected }\end{array}$ & $\begin{array}{l}\text { (Gómez Álvarez } \\
\text { et al., } \\
\text { 2007,2008) }\end{array}$ \\
\hline & & & & $\begin{array}{l}\text { Increased - } \\
\text { protraction distance }\end{array}$ & $\begin{array}{l}\text { (Keegan et al., } \\
2000 \text { ) }\end{array}$ \\
\hline & & & $\begin{array}{l}\text { Induced HL lameness - } \\
\text { tarsal joint LPS injection }\end{array}$ & $\begin{array}{l}\text { Increased protraction } \\
\text { length }\end{array}$ & $\begin{array}{l}\text { (Kramer et al., } \\
\text { 2000) }\end{array}$ \\
\hline & & Overground & $\begin{array}{l}\text { Induced lameness, flexor } \\
\text { tendon lesion }\end{array}$ & $\begin{array}{l}\text { Reduced, compared to } \\
\text { the contralateral limb }\end{array}$ & $\begin{array}{l}\text { (Clayton et al., } \\
2000)\end{array}$ \\
\hline & OMC & Treadmill & $\begin{array}{l}\text { Induced lameness - } \\
\text { modified shoe }\end{array}$ & $\begin{array}{l}\text { Decreases (only for } \\
\text { the hindlimbs, walk } \\
\text { and trot) } \\
\text { Not significantly } \\
\text { affected }\end{array}$ & $\begin{array}{l}\text { (Clayton et al., } \\
\text { 2000) (Buchner et } \\
\text { al., 1996b } \\
\text { (Gómez Álvarez } \\
\text { et al., } \\
\text { 2007,2008) }\end{array}$ \\
\hline & & & $\begin{array}{l}\text { Induced HL lameness - } \\
\text { tarsal joint LPS injection }\end{array}$ & $\begin{array}{l}\text { Not significantly } \\
\text { affected }\end{array}$ & $\begin{array}{l}\text { (Kramer et al., } \\
2000)\end{array}$ \\
\hline & & Overground & $\begin{array}{l}\text { Induced lameness, flexor } \\
\text { tendon lesion }\end{array}$ & $\begin{array}{l}\text { Increased compared to } \\
\text { the contralateral limb }\end{array}$ & $\begin{array}{l}\text { (Clayton et al., } \\
2000)\end{array}$ \\
\hline Step length & OMC & Treadmill & $\begin{array}{l}\text { Induced lameness - } \\
\text { modified shoe }\end{array}$ & $\begin{array}{l}\text { Decreases (only for the } \\
\text { hindlimbs at trot) }\end{array}$ & $\begin{array}{l}\text { (Buchner et al., } \\
\text { 1996b) }\end{array}$ \\
\hline Hoof orientation angles & $\begin{array}{l}\text { Hoof } \\
\text { mounted IMU } \\
\text { sensors }\end{array}$ & Overground & Induced lameness & $\begin{array}{l}\text { Various significant } \\
\text { responses based } \\
\text { on measured angle } \\
\text { orientation }\end{array}$ & $\begin{array}{l}\text { (Moorman et al., } \\
\text { 2014) }\end{array}$ \\
\hline Max hoof height & OMC & Treadmill & $\begin{array}{l}\text { Induced lameness - } \\
\text { modified shoe }\end{array}$ & $\begin{array}{l}\text { Decreases (only for } \\
\text { hindlimbs at trot) }\end{array}$ & $\begin{array}{l}\text { (Buchner et al., } \\
\text { 1996b) }\end{array}$ \\
\hline Fetlock extension & OMC & Treadmill & $\begin{array}{l}\text { Induced lameness - } \\
\text { modified shoe }\end{array}$ & Decreases & $\begin{array}{l}\text { (Buchner et al., } \\
\text { 1996b; Clayton et } \\
\text { al., 2000; Keegan } \\
\text { et al., 2000) }\end{array}$ \\
\hline
\end{tabular}

OMC: optical motion capture; IMU: inertial measurement unit; LPS: lipopolysaccharide; FL: forelimb; HL: hindlimb; FFT: fast Fourier transform; ROM: range of motion.

hindlimb lameness. Horses with primary forelimb lameness show ipsilateral head and withers asymmetry (so pointing towards the same side as being lame), while in horses with primary hindlimb lameness, the compensatory asymmetry of head is contralateral to the asymme- try of the withers (so both pointing towards a different side as being lame), with the withers asymmetry indicating the lame diagonal and the head asymmetry suggesting the non-lame diagonal (Persson Sjödin et al., 2016). Nevertheless, in case of subtle lameness, the symmetry of withers' movement might not be affected (Buchner et al., 1996a). 
Regarding thoracolumbar movement, a change in the range of motion (ROM) of back segments in horses with induced back pain at trot has been reported (Table 2). In one study, it was observed that unilateral pain in the longissimus dorsi muscle provoked increased flexion-extension and lateral bending of the back at the trot (Wennerstrand et al., 2009). However, the reported changes in back motion are not very prominent, and further studies are needed to fully understand how back pain may affect back kinematics. In case of primary forelimb lameness at the trot, an increase of back ROM for flexion-extension and a reduction of lateral bending has been reported (Gómez Álvarez et al., 2007). In horses with primary hindlimb lameness at the trot, only a reduction of ROM for flexion-extension was reported (Gómez Álvarez et al., 2008). Nevertheless, the currently commercially available clinical gait analysis systems do not generate data on back-specific parameters, and further development of the meth- odology for the specific assessment of back function is urgently needed.

Apart from asymmetries, changes in the motion pattern of the individual limb due to lameness have also been reported (Table 3 ). The most consistently described changes in case of lameness induced in joints are reductions in stride duration, fetlock extension and in joint ROM (Table 3). Moreover, there is also an increase of relative stance duration, as a percentage of stride duration (Keegan et al., 2000; Weishaupt et al., 2006; Buchner et al., 2010).

The available evidence on objective kinematic parameters during lunging is scarce, with one study on induced lameness reporting an increase in the minimum pelvic height difference (PDmin) when the lame hindlimb was on the inside of the circle, compared with the measurements on a straight line (Rhodin et al., 2013). More studies are needed to better understand the circle- dependent changes in the measured kinematic parameters of horses with different causes of lameness. The situation is more complicated than on the straight line, as circular movements such as lunging induce asymmetrical kinematic patterns by itself (Starke et al., 2012a; Pfau et al., 2014; Rhodin et al., 2015; Greve and Dyson, 2016; Greve et al., 2017) and because the magnitude of these effects depends on the speed and diameter of the circle (Pfau et al., 2012).

\section{The interpretation of asymmetries detected by quantitative gait analysis}

Most of currently used objective gait analysis methods rely on gait symmetry measurements. In this respect, it is important to question whether or not asymmetry is invariably a sign of lameness. Whereas the relationship between unilateral pain induction and the consequential occurrence of kinematic asym- metry has been demonstrated multiple times (Peloso et al., 1993; Barrey et al., 1994; Buchner et 
al., 1996a, 1996b; Peham et al., 1996; Keegan et al., 2000, 2001; Kramer et al., 2004; Kelmer et al., 2005; Rhodin et al., 2013; Tóth et al., 2014; Persson Sjödin et al., 2016), the inverse relationship has not yet been investigated and the question if and to what extent small measurable asymmetries can be directly attributed to pain has not been answered so far. Furthermore, movement asymmetries may not be evident in horses with bilateral lameness and lameness may only become apparent after unilateral diagnostic analgesia.

The issue is not limited to the outcome of objective gait analysis since some reports suggest that up to $75 \%$ of horses in regular work are lame when subjected to a rigorous subjective lameness exam (Dyson and Greve, 2016). Using an objective gait analysis system, Rhodin et al. (2017) found that a large proportion (72.5\%) of 222 horses presented significant movement asymmetries. In another study, 47\% of 201 riding horses in training, which were all perceived as free from lameness by their owner, showed movement asymmetries at the trot in a straight line, above previously reported asymmetry thresholds (Rhodin et al., 2015). If all these horses would have underlying pathology indeed, this may be considered a severe welfare problem, but, as said, it remains to be established if all visible or measurable asymmetries are indeed caused by orthopaedic pain. Nevertheless, it has been demon- strated clinically (Maliye et al., 2013, 2015; Maliye and Marshall, 2016) and experimentally (Tóth et al., 2014; Hoerdemann et al., 2017) that measurable movement asymmetries can successfully respond to diagnostic anaesthesia.

It is therefore of utmost importance to investigate the relation between (mild) gait asymmetries and pain using objective parameters for both conditions. It should be stressed that at this moment, objective gait analysis systems only measure gait asymmetry and do not establish whether this asymmetry is due to an underlying pathological process. Moreover, it should be emphasised that objective gait analysis gives valuable additional information to the clinician that can help in decisionmaking, but does not and cannot replace the expertise of a veterinarian, who will make a final evaluation and decide whether the asymmetry that was detected should be labelled 'lameness' or not (Fig. 3) (van Weeren et al., 2017).

\section{Practical handling of information from objective gait analysis in a research or clinical setting}

When performing objective gait analysis, the results can be interpreted and analysed in a variety of ways. First, the gait parameters can be compared with a'standard horse', i.e. an average of a sample being as representative as possible for the population. Although this approach is simple and commonly used for example in clinical 


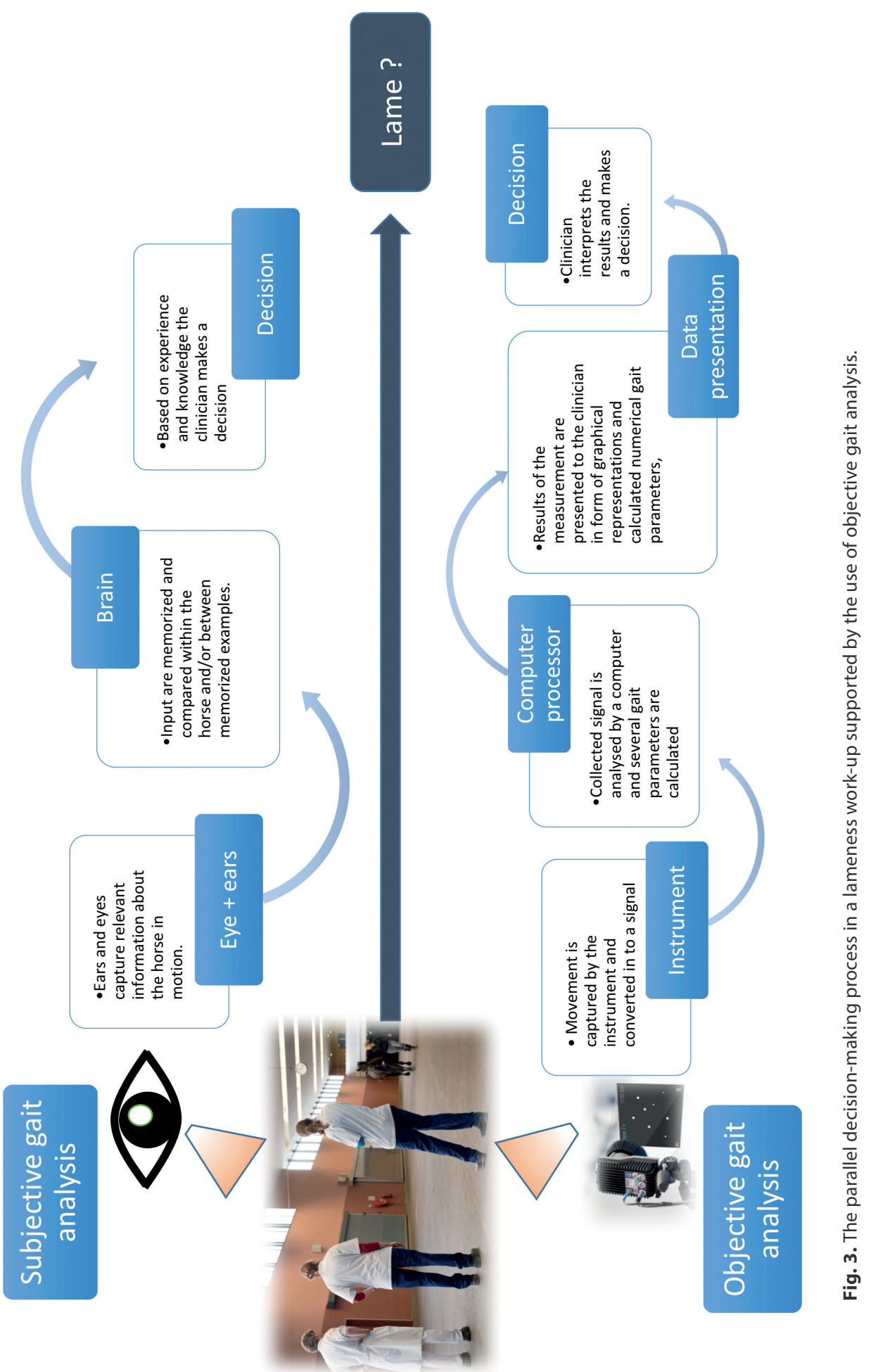


chemistry, it might be less suitable for the interpretation of gait analysis information due to the considerable individual variation in most kinematic parameters. When the inter-individual biological variation is more prominent than the variation induced by lameness in an individual horse, this approach will not work. Also, this method is affected by differences in kinematic and kinetic parameters due to individual differences in preferred speed (Khumsap et al., 2001; Weishaupt et al., 2010a; Pfau et al., 2012; Starke et al., 2013) and in conformation.

Second, gait parameters can be compared using repeated measurements of absolute kinetic/kinematic parameters of the same subject over time, or after interventions (e.g. diagnostic anaesthesia). Whereas this approach assumes the availability of baseline data, which is not always the case in horses presented for lameness, unless the situation after application of diagnostic anaesthesia is used as such, it does not suffer from the problems mentioned above. The approach could be very time consuming for some methods of gait analysis (e.g. force plate analysis), but this is not an issue for more recent automated techniques that are becoming increasingly available (e.g. IMU and OMC). This approach can also be affected by inter-trial differences in speed which may influence several gait parameters (Weishaupt et al., 2010a).

Third, an alternative method that tries to overcome most of the problems mentioned above is the comparison between left and right steps and the calculation of asymmetry between both sides (i.e. left vs. right), since all quadrupedal vertebrates are expected to exhibit bilateral movement symmetry within limb pairs (i.e. forelimb pair and hindlimb pair) (Abourachid, 2003). This approach is less affected by inter-trial variation, since both sides are compared on a stride-to-stride basis, and is not affected by the within-horse variation since the measured horse is always its own control. Although this method eliminates the between-horse variation and minimises some of the inter-trial variation, it might fail to detect gait changes in cases of bilateral or even more complex multilimb lameness (Ratzlaff et al., 1982; Buchner et al., 1995; Pourcelot et al., 1997; Serra Bragança et al., 2016), depending on the bi-or unilateral expression of compensatory mechanisms. Moreover, this method may not be suitable for assessment on a circle, by differences in circle diameter and speed (Pfau et al., 2012).

Further, the approach is only valid for naturally symmetrical gaits (walk, trot, pace) and has thus far only been used for lameness assessment at unridden trot, on a straight line or during lunging (Peloso et al., 1993; Barrey et al., 1994; Buchner et al., 1996a, 1996b; Peham et al., 1996; Keegan et al., 2000, 2001; Kramer et al., 2004; Kelmer et al., 2005; Rhodin et al., 2013; Tóth et al., 2014; Persson Sjödin et al., 2016). 
As mentioned earlier, the challenge of using asymmetry measurements is to determine whether the measured asymmetry is caused by any underlying pathology or should be seen as the trait of a particular individual. Previous studies have used thresholds to determine whether horses should be deemed lame or not based on the measured asymmetry (Keegan et al., 2012, 2013). However, thresholds are based on limited reference populations and depend on the bandwidth chosen. Therefore, they may well represent the population as a whole but may present limitations for the evaluation of an individual case. This warning against the indiscriminate application of such thresholds to judge a horse sound or lame has been recently raised (van Weeren et al., 2017). A combination of repeated measurements of asymmetry (e.g. before and after a diagnostic anaesthesia/intervention) might provide the best information for research and clinical use. Another example is the use of repeated measurements before and after flexion tests to objectify the response to such provocations (Marshall et al., 2012; Starke et al., 2012c).

Another critical factor that poses a challenge when interpreting repeated measurements from the same horse is the effect of inter- trial variation due to differences in subject demeanour and speed. However, although speed is known to influence many of the measured kinetic and kinematic parameters (Khumsap et al., 2001; Weishaupt et al., 2010a; Pfau et al., 2012; Starke et al., 2013), the effect of increased speed appears to only slightly affect the measured movement asymmetry during trot at a straight line, whilst during the subjective lameness assessment, increased speed can lead to the erroneous classification of lame horses as sound (Starke et al., 2013).

In summary, although with some constraints, there is sufficient evidence to support the use of objective gait analysis during lameness assessment in research and in a clinical setting. It is important to stress that the technology should be used as a tool supporting the clinician formulating an evidence-based diagnosis, prognosis and/or therapeutic plan, and not as an infallible guideline that should be obeyed. The incorporation of this technology is not much different from the establishment of advanced imaging technology in the orthopaedic workup of horses. However, clinical expertise will remain paramount and decisive in the final decision making in equine orthopaedics. 


\section{Conclusions}

We have reached the stage that kinematic analysis techniques have developed far enough regarding reliability and practicality to warrant regular clinical application. It is hence justified to incorporate objective gait analysis in the daily clinical assessment of lameness using state-of-the-art sensor or OMC-based gait analysis systems. The approach offers veterinarians an objective method to quantify gait and can be extremely relevant, especially in cases of mild lameness and as an invaluable aid in the comparison/interpretation of repeated measurements between interventions (e.g. diagnostic anaesthesia and flexion tests). It can be anticipated that objective gait quantification techniques will become standard procedures for the longitudinal monitoring of sound and lame horses, and for accurate and unambiguous documentation of gait evaluation data.

\section{Conflict of interest statement}

None of the authors of this paper has a financial or personal relationship with other people or organisations that could inappropriately influence or bias the content of the paper. 


\section{References}

AAEP, 1999. Guide to Veterinary Services for Horse Shows, Seventh Ed. American Association of Equine Practitioners, Lexington, KY.

Abourachid, A., 2003. A new way of analysing symmetrical and asymmetrical gaits in quadrupeds. Comptes Rendus Biologies 326, 625-630.

Arkell, M., Archer, R.M., Guitian, F.J., May, S.A., 2006. Evidence of bias affecting the interpretation of the results of local anaesthetic nerve blocks when assessing lameness in horses. The Veterinary Record $159,346-349$.

Aviad, A.D., 1988. The use of the standing force plate as a quantitative measure of equine lameness. Journal of Equine Veterinary Science 8, 460-462.

Barrey, E., Galloux, P., Valette, J.P., Auvinet, B., Wolter, R., 1993. Stride characteristics of overground versus treadmill locomotion in the saddle horse. Acta Anatomica 146, 90-94.

Barrey, E., Hermelin, M., Vaudelin, J.L., Poirel, D., Valette, J.P., 1994. Utilisation of an accelerometric device in equine gait analysis. Equine Veterinary Journal 26 (Suppl. 17), 7-12.

Bell, R.P., Reed, S.K., Schoonover, M.J., Whitfield, C.T., Yonezawa, Y., Maki, H., Pai, P.F., Keegan, K.G., 2016. Associations of force plate and body-mounted inertial sensor measurements for identification of hindlimb lameness in horses.

American Journal of Veterinary Research 77, 337-345.

Björck, G., 1958. Studies on the draught force of horses. Development of a method using strain gauges for measuring forces between hoof and ground. Acta Agriculturö Scandinavica 8 (Suppl. 4), 1-109.

Buchner, H.H.F., Savelberg, H.H., Schamhardt, H.C., Merkens, H.W., Barneveld, A., 1994. Kinematics of treadmill versus overground locomotion in horses. The Veterinary Quarterly 16 (Suppl. 2), 87-90.

Buchner, H.H.F., Savelberg, H.H., Schamhardt, H.C., Barneveld, A., 1995. Bilateral lameness in horses-a kinematic study. The Veterinary Quarterly 17, 103-105.

Buchner, H.H.F., Savelberg, H.H., Schamhardt, H.C., Barneveld, A., 1996a. Head and trunk movement adaptations in horses with experimentally induced fore- or hindlimb lameness. Equine Veterinary Journal 28, 71-76.

Buchner, H.H.F., Savelberg, H.H., Schamhardt, H.C., Barneveld, A., 1996b. Limb movement adaptations in horses with experimentally induced fore- or hindlimb lameness. Equine Veterinary Journal 28, 63-70.

Buchner, H.H.F., Savelberg, H.H.C.M., Schamhardt, H.C., Barneveld, A., 2010. Temporal stride patterns in horses with experimentally induced fore- or hindlimb lameness. Equine Veterinary Journal 27, 161165.

Buchner, H.H.F., 2013. Gait adaptation in lameness, In: Clayton, H.M., Back, W. (Eds.), Equine Locomotion. Second Ed. Saunders Elsevier, St. Luis, MO, USA p. 175.

Clayton, H.M., Schamhardt, H.C., Willemen, M.A., Lanovaz, J.L., Colborne, G.R., 2000. Kinematics and ground reaction forces in horses with superficial digital flexor tendinitis. American Journal of Veterinary Research 61, 191-196.

Clayton, H.M., Schamhardt, H.C., 2013. Measurement techniques for gait analysis, In: Clayton, H.M., Back, W. (Eds.), Equine Locomotion. Second Ed. Saunders Elsevier, St. Luis, MO, USA, pp. 31-60.

Drevemo, S., Johnston, C., Roepstorff, L., Gustås, P., 1999. Nerve block and intra- articular anaesthesia of the forelimb in the sound horse. Equine Veterinary Journal 31 (Suppl. 30), 266-269.

Dyson, P.K., Jackson, B.F., Pfeiffer, D., Price, J.S., 2008. Days lost from training by two- and three-year-old Thoroughbred horses: a survey of seven UK training yards. Equine Veterinary Journal 40, 650-657.

Dyson, S., 2011. Can lameness be graded reliably? Equine Veterinary Journal 43, 379-382.

Dyson, S., 2014. Recognition of lameness: man versus machine. The Veterinary Journal 201, 245-248.

Dyson, S., Greve, L., 2016. Subjective gait assessment of 57 sports horses in normal work: a comparison of the response to flexion tests, movement in hand, on the lunge and ridden. Journal of Equine Veterinary Science 38, 1-7. 
Egenvall, A., Bonnett, B., Wattle, O., Emanuelson, U., 2008. Veterinary-care events and costs over a 5-year follow-up period for warmblooded riding horses with or without previously recorded locomotor problems in Sweden. Preventive Veterinary Medicine 83, 130-143.

Egenvall, A., Tranquille, C.A., Lönnell, A.C., Bitschnau, C., Oomen, A., Hernlund, E., Montavon, S., Franko, M.A., Murray, R.C., Weishaupt, M.A., et al., 2013. Days-lost to training and competition in relation to workload in 263 elite show-jumping horses in four European countries. Preventive Veterinary Medicine 112, 387- 400.

Fredricson, I., Drevemo, S., 1971. A new method of investigating equine locomotion.

Equine Veterinary Journal 3, 137-140.

Fuller, C.J., Bladon, B.M., Driver, A.J., Barr, A.R.S., 2006. The intra- and inter-assessor reliability of measurement of functional outcome by lameness scoring in horses. The Veterinary Journal 171, 281-286.

Gómez Álvarez, C.B., Wennerstrand, J., Bobbert, M.F., Lamers, L., Johnston, C., Back, W., van Weeren, P.R., 2007. The effect of induced forelimb lameness on thoracolumbar kinematics during treadmill locomotion. Equine Veterinary Journal 39, 197-201.

Gómez Álvarez, C.B., Bobbert, M.F., Lamers, L., Johnston, C., Back, W., van Weeren, P. R., 2008. The effect of induced hindlimb lameness on thoracolumbar kinematics during treadmill locomotion. Equine Veterinary Journal 40, 147-152.

Gómez Álvarez, C.B., Rhodin, M., Byström, A., Back, W., van Weeren, P.R., 2009. Back kinematics of healthy trotting horses during treadmill versus over ground locomotion. Equine Veterinary Journal 41, 297-300.

Greve, L., Dyson, S., 2016. Body lean angle in sound dressage horses in-hand, on the lunge and ridden. The Veterinary Journal 217, 52-57.

Greve, L., Pfau, T., Dyson, S., 2017. Thoracolumbar movement in sound horses trotting in straight lines in hand and on the lunge and the relationship with hindlimb symmetry or asymmetry. The Veterinary Journal 220, 95-104.

Hammarberg, M., Egenvall, A., Pfau, T., Rhodin, M., 2016. Rater agreement of visual lameness assessment in horses during lungeing. Equine Veterinary Journal 48, 78-82.

Hewetson, M., Christley, R.M., Hunt, I.D., Voute, L.C., 2006. Investigations of the reliability of observational gait analysis for the assessment of lameness in horses. Veterinary Record 158, 852-857.

Hoerdemann, M., Smith, R.L., Hosgood, G., 2017. Duration of action of mepivacaine and lidocaine in equine palmar digital perineural blocks in an experimental lameness model. Veterinary Surgery 46 , 986-993.

Ishihara, A., Bertone, A.L., Rajala-Schultz, P.J., 2005. Association between subjective lameness grade and kinetic gait parameters in horses with experimentally induced forelimb lameness. American Journal of Veterinary Research 66, 1805- 1815.

Jeffcott, L.B., Rossdale, P.D., Freestone, J., Frank, C.J., Towers-Clark, P.F., 1982. An assessment of wastage in thoroughbred racing from conception to 4 years of age. Equine Veterinary Journal 14, 185-198.

Kai, M., Aoki, O., Hiraga, A., Oki, H., Tokuriki, M., 2000. Use of an instrument sandwiched between the hoof and shoe to measure vertical ground reaction forces and three-dimensional acceleration at the walk, trot, and canter in horses. American Journal of Veterinary Research 61, 979-985.

Kalman, R.E., 1960. A new approach to linear filtering and prediction problems.

Journal of Basic Engineering 82, 35-45.

Kastner, J., 1989. Bewegungsmessung auf dem weg zur klinischen methode.

Osterreich Hochschulzeitung 9, 15-16.

Kastner, J., Knezevic, P.F., Girtler, D., Toeltsch, M., 1990. Die 3-dimensionale bewegungsanalyse als klinische methode zur objektivierung von lahmheiten beim pferd. Biomedizinische Technik/ Biomedical Engineering 35, 171-172. 
Keegan, K.G., Wilson, D.J., Wilson, D.A., Frankeny, R.L., Loch, W.E., Smith, B., 1997. Effects of anesthesia of the palmar digital nerves on kinematic gait analysis in horses with and without navicular disease. American Journal of Veterinary Research 58, 218-223.

Keegan, K.G., Wilson, D.A., Smith, B.K., Wilson, D.J., 2000. Changes in kinematic variables observed during pressure-induced forelimb lameness in adult horses trotting on a treadmill. American Journal of Veterinary Research 61, 612-619.

Keegan, K.G., Pai, P.F., Wilson, D.A., Smith, B.K., 2001. Signal decomposition method of evaluating head movement to measure induced forelimb lameness in horses trotting on a treadmill. Equine Veterinary Journal 33, 446-451.

Keegan, K.G., Yonezawa, Y., Pai, F., Wilson, D.A., Kramer, J., 2004. Evaluation of a sensor-based system of motion analysis for detection and quantification of forelimb and hindlimb lameness in horses. American Journal of Veterinary Research 65, 665-670.

Keegan, K.G., 2007. Evidence-based lameness detection and quantification.

Veterinary Clinics of North America: Equine Practice 23, 403-423.

Keegan, K.G., Dent, E.V., Wilson, D.A., Janicek, J., Kramer, J., Lacarrubba, A., Walsh, D. M., Cassells, M.W., Esther, T.M., Schiltz, P., et al., 2010. Repeatability of subjective evaluation of lameness in horses. Equine Veterinary Journal 42, 92-97.

Keegan, K.G., Kramer, J., Yonezawa, Y., Maki, H., Pai, P.F., Dent, E.V., Kellerman, T.E., Wilson, D.A., Reed, S.K., 2011. Assessment of repeatability of a wireless, inertial sensor-based lameness evaluation system for horses. American Journal of Veterinary Research 72, 1156-1163.

Keegan, K.G., MacAllister, C.G., Wilson, D.A., Gedon, C.A., Kramer, J., Yonezawa, Y., Maki, H., Pai, P.F., 2012. Comparison of an inertial sensor system with a stationary force plate for evaluation of horses with bilateral forelimb lameness. American Journal of Veterinary Research 73, 368-374.

Keegan, K.G., Wilson, D. a., Kramer, J., Reed, S.K., Yonezawa, Y., Maki, H., Pai, P.F., Lopes, M.A., 2013. Comparison of a body-mounted inertial sensor system-based method with subjective evaluation for detection of lameness in horses.

American Journal of Veterinary Research 74, 17-24.

Keg, P.R., Barneveld, A., Schamhardt, H.C., van den Belt, A.J.M., 1994. Clinical and force plate evaluation of the effect of a high plantar nerve block in lameness caused by induced mid-metatarsal tendinitis. The Veterinary Quarterly 16 (Suppl. 2), 70-75.

Kelmer, G., Keegen, K.G., Kramer, J., Wilson, D.A., Pai, F.P., Singh, P., 2005. Computer- assisted kinematic evaluation of induced compensatory movements resembling lameness in horses trotting on a treadmill. American Journal of Veterinary Research 66, 646-655.

Khumsap, S., Clayton, H.M., Lanovaz, J.L., 2001. Effect of walking velocity on ground reaction force variables in the hindlimb of clinically normal horses. American Journal of Veterinary Research 62, 901-906.

Khumsap, S., Lanovaz, J.L., Rosenstein, D.S., Byron, C., Clayton, H.M., 2003. Effect of induced unilateral synovitis of distal intertarsal and tarsometatarsal joints on sagittal plane kinematics and kinetics of trotting horses. American Journal of Veterinary Research 64, 1491-1495.

Kramer, J., Keegan, K.G., Wilson, D.A.J., Smith, B.K., Wilson, D.A.J., 2000. Kinematics of the hindlimb in trotting horses after induced lameness of the distal intertarsal and tarsometatarsal joints and intraarticular administration of anesthetic. American Journal of Veterinary Research 61, 1031-1036.

Kramer, J., Keegan, K.G., Kelmer, G., Wilson, D.A., 2004. Objective determination of pelvic movement during hindlimb lameness by use of a signal decomposition method and pelvic height differences. American Journal of Veterinary Research 65, 741-747.

Kübber, P., Kastner, J., Girtler, D., Knezevic, P.F., 1994. Erkenntnisse über den einfluß der tiefen palmarnervanästhesie auf das gangbild des lahmheitsfreien pferdes mit hilfe einer kinematischen meßmethode. Pferdeheilkunde 10, 11-21.

Liedtke, A., Moore, S., Witte, T., Spence, A., 2012. How does loss of digital sensory feed back affect locomotion in the horse? Equine Veterinary Journal 44 (42), 16. 
Loomans, J.B.A., Stolk, P.W.T., van Weeren, P.R., Vaarkamp, H., Barneveld, A., 2007. A survey of the workload and clinical skills in current equine practices in The Netherlands. Equine Veterinary Education 19, 162-168.

Maliye, S., Voute, L., Lund, D., Marshall, J.F., 2013. An inertial sensor-based system can objectively assess diagnostic anaesthesia of the equine foot. Equine Veterinary Journal 45, 26-30.

Maliye, S., Voute, L.C., Marshall, J.F., 2015. Naturally-occurring forelimb lameness in the horse results in significant compensatory load redistribution during trotting. The Veterinary Journal 204, 208-213.

Maliye, S., Marshall, J.F., 2016. Objective assessment of the compensatory effect of clinical hindlimb lameness in horses: 37 cases (2011-2014). Journal of the American Veterinary Medical Association 249, 940-944.

Marshall, J.F., Lund, D.G., Voute, L.C., 2012. Use of a wireless, inertial sensor-based system to objectively evaluate flexion tests in the horse. Equine Veterinary Journal 44, 8-11.

McCracken, M.J., Kramer, J., Keegan, K.G., Lopes, M., Wilson, D.A., Reed, S.K., LaCarrubba, A., Rasch, M., 2012. Comparison of an inertial sensor system of lameness quantification with subjective lameness evaluation. Equine Veterinary Journal 44, 652-656.

Merkens, H.W., Schamhardt, H.C., 1988a. Evaluation of equine locomotion during different degrees of experimentally induced lameness. II: distribution of ground reaction force patterns of the concurrently loaded limbs. Equine Veterinary Journal 20 (Suppl. 6), 107-112.

Merkens, H.W., Schamhardt, H.C., 1988b. Evaluation of equine locomotion during different degrees of experimentally induced lameness. I: lameness model and quantification of ground reaction force patterns of the limbs. Equine Veterinary Journal 20 (Suppl. 6), 99-106.

Moorman, V.J., Reiser, R.F., Mahaffey, C.A., Peterson, M.L., Mcllwraith, C.W., Kawcak, C.E., 2014. Use of an inertial measurement unit to assess the effect of forelimb lameness on three-dimensional hoof orientation in horses at a walk and trot. American Journal of Veterinary Research 75, 800-808.

Morris, E., Seeherman, H., 1987. Redistribution of ground reaction forces in experimentally induced equine carpal lameness. Equine Exercise Physiology 2, 553-563.

Munoz-Nates, F., Chateau, H., Van Hamme, A., Camus, M., Pauchard, M., Ravary- Plumioen, B., Denoix, J.M., Pourcelot, P., Crevier-Denoix, N., 2015.

Accelerometric and dynamometric measurements of the impact shock of the equine forelimb and hindlimb at high speed trot on six different tracks - preliminary study in one horse. Computer Methods in Biomechanics and Biomedical Engineering 18 (Suppl. 1), 2012-2013.

Murray, R.C., Dyson, S.J., Tranquille, C., Adams, V., 2006. Association of type of sport and performance level with anatomical site of orthopaedic injury diagnosis. Equine Veterinary Journal 38 (Suppl. 36), 411-416.

Nielsen, T.D., Dean, R.S., Robinson, N.J., Massey, A., Brennan, M.L., 2014. Survey of the UK veterinary profession: common species and conditions nominated by veterinarians in practice. Veterinary Record 174, 324.

Oosterlinck, M., Pille, F., Huppes, T., Gasthuys, F., Back, W., 2010. Comparison of pressure plate and force plate gait kinetics in sound Warmbloods at walk and trot. The Veterinary Journal 186, 347-351.

Oosterlinck, M., Pille, F., Sonneveld, D.C., Oomen, A.M., Gasthuys, F., Back, W., 2012. Contribution of dynamic calibration to the measurement accuracy of a pressure plate system throughout the stance phase in sound horses. The Veterinary Journal 193, 471-474.

Parkes, R.S.V., Weller, R., Groth, A.M., May, S., Pfau, T., 2009. Evidence of the development of domainrestricted expertise in the recognition of asymmetric motion characteristics of hindlimb lameness in the horse. Equine Veterinary Journal 41, 112-117.

Peham, C., Scheidl, M., Licka, T., 1996. A method of signal processing in motion analysis of the trotting horse. Journal of Biomechanics 29, 1111-1114.

Peham, C., 2013. Signals from materials, In: Back, W., Clayton, H.M. (Eds.), Equine Locomotion. Second Ed. Saunders Elsevier, St. Luis, MO, USA, pp. 61-71. 
Peloso, J.G., Stick, J.A., Soutas-Little, R.W., Caron, J.C., DeCamp, C.E., Leach, D.H., 1993. Computer-assisted three-dimensional gait analysis of amphotericin-induced carpal lameness in horses. American Journal of Veterinary Research 54, 1535- 1543.

Persson Sjödin, E., Serra Braganca, F.M., Pfau, T., Egenvall, A., Weishaupt, M.A., Rhodin, M., 2016. Movement symmetry of the withers can be used to discriminate primary forelimb lameness from compensatory forelimb asymmetry in horses with induced lameness. Equine Veterinary Journal 48, 32- 33.

Pfau, T., Witte, T.H., Wilson, A.M., 2005. A method for deriving displacement data during cyclical movement using an inertial sensor. The Journal of Experimental Biology 208, 2503-2514.

Pfau, T., Stubbs, N.C., Kaiser, L.J., Brown, L.E.A., Clayton, H.M., 2012. Effect of trotting speed and circle radius on movement symmetry in horses during lunging on a soft surface. American Journal of Veterinary Research 73, 1890-1899.

Pfau, T., Jennings, C., Mitchell, H., Olsen, E., Walker, A., Egenvall, A., Tröster, S., Weller, R., Rhodin, M., 2014. Lungeing on hard and soft surfaces: movement symmetry of trotting horses considered sound by their owners. Equine Veterinary Journal 48, 83-89.

Pourcelot, P., Audigié, F., Degueurce, C., Denoix, J.M., Geiger, D., 1997. Kinematic symmetry index: a method for quantifying the horse locomotion symmetry using kinematic data. Veterinary Research 28, 525-538.

Ratzlaff, M.H., Grant, B.D., Adrian, M., 1982. Quantitative evaluation of equine carpal lamenesses. Journal of Equine Veterinary Science 2, 78-88.

Rhodin, M., Pfau, T., Roepstorff, L., Egenvall, A., 2013. Effect of lungeing on head and pelvic movement asymmetry in horses with induced lameness. The Veterinary Journal 198, e39-e45.

Rhodin, M., Roepstorff, L., French, A., Keegan, K.G., Pfau, T., Egenvall, A., 2015. Head and pelvic movement asymmetry during lungeing in horses with symmetrical movement on the straight. Equine Veterinary Journal 48, 315-320.

Rhodin, M., Egenvall, A., Haubro Andersen, P., Pfau, T., Pfau, T., Weeren, P., 2017. Head and pelvic movement asymmetries at trot in riding horses in training and perceived as free from lameness by the owner. PLoS One 12, e0176253.

Roepstorff, L., Drevemo, S., 1993. Concept of a force-measuring horseshoe. Acta Anatomica 146, 114119.

Ross, M.W., 2013. Movement, In: Ross, M.W., Dyson, S. (Eds.), Diagnosis and Management of Lameness in the Horse. Second Ed. Saunders Elsevier, St. Louis, MO, USA, pp. 71-72.

Schumacher, J., Schramme, M.C., Moyer, W., 2014. Review of mistakes that can be made when interpreting the results of diagnostic analgesia during a lameness examination. Salt Lake City, Utah, 6-10 December 2014Proceedings of the AAEP Annual Convention, Vol. 60. , pp. 83-94.

Serra Bragança, F.M., Mancini, I., Brommer, H., Malda, J., Visser, J., van Weeren, P.R., 2016. Compensatory mechanism of gait adaptation to bilateral stifle joint injuries in shetland ponies at trot. Equine Veterinary Journal 48 17-17.

Sinclair, J., Taylor, P.J., Hobbs, S.J., 2013. Digital filtering of three-dimensional lower extremity kinematics: an assessment. Journal of Human Kinetics 39, 25-36.

Starke, S.D., Willems, E., May, S.A., Pfau, T., 2012a. Vertical head and trunk movement adaptations of sound horses trotting in a circle on a hard surface. The Veterinary Journal 193, 73-80.

Starke, S.D., Witte, T.H., May, S., a Pfau, T., 2012b. Accuracy and precision of hindlimb foot contact timings of horses determined using a pelvis-mounted inertial measurement unit. Journal of Biomechanics 45, 1522-1528.

Starke, S.D., Willems, E., Head, M., May, S.A., Pfau, T., 2012c. Proximal hindlimb flexion in the horse: effect on movement symmetry and implications for defining soundness. Equine Veterinary Journal 44, 657-663.

Starke, S.D., Raistrick, K.J., May, S.A., Pfau, T., 2013. The effect of trotting speed on the evaluation of subtle lameness in horses. The Veterinary Journal 197, 245-252. 
Thomsen, M.H., Persson, A.B., Jensen, A.T., Sørensen, H., Andersen, P.H., 2010. Agreement between accelerometric symmetry scores and clinical lameness scores during experimentally induced transient distension of the metacarpophalangeal joint in horses. Equine Veterinary Journal 42 (Suppl. 38), 510515.

Tóth, F., Schumacher, J., Schramme, M.C., Hecht, S., 2014. Effect of anesthetizing individual compartments of the stifle joint in horses with experimentally induced stifle joint lameness. American Journal of Veterinary Research 75, 19- 25.

Uhlir, C., Licka, T., Kübber, P., Peham, C., Scheidl, M., Girtler, D., 1997. Compensatory movements of horses with a stance phase lameness. Equine Veterinary Journal 29 (Suppl. 23), 102-105.

Van de Water, E., Oosterlinck, M., Pille, F., 2016. The effect of perineural anaesthesia and handler position on limb loading and hoof balance of the vertical ground reaction force in sound horses. Equine Veterinary Journal 48, 608-612.

van den Bogert, A.J., Weeren, P.R., van Schamhardt, H.C., 1990. Correction for skin displacement errors in movement analysis of the horse. Journal of Biomechanics 23, 97-101.

van Heel, M.C.V., Barneveld, A., van Weeren, P.R., Back, W., 2004. Dynamic pressure measurements for the detailed study of hoof balance: the effect of trimming. Equine Veterinary Journal 36, 778-782.

van Loon, J.P.A.M., de Grauw, J.C., van Dierendonck, M., L'ami, J.J., Back, W., van Weeren, P.R., 2010. Intraarticular opioid analgesia is effective in reducing pain and inflammation in an equine LPS induced synovitis model. Equine Veterinary Journal 42, 412-419.

van Weeren, P.R., van den Bogert, A.J., Barneveld, A., 1988. Quantification of skin displacement near the carpal, tarsal and fetlock joints of the walking horse. Equine Veterinary Journal 20, 203-208.

van Weeren, P.R., van den Bogert, A.J., Barneveld, A., 1990a. Quantification of skin displacement in the proximal parts of the limbs of the walking horse. Equine Veterinary Journal 22 (Suppl. 9), 110-118.

van Weeren, P.R., van den Bogert, A.J., Barneveld, A., Hartman, W., Kersjes, A.W., 1990b. The role of the reciprocal apparatus in the hindlimb of the horse investigated by a modified CODA-3 opto-electronic kinematic analysis system. Equine Veterinary Journal 22 (Suppl. 9), 95-100.

van Weeren, P.R., 2013. History, In: Clayton, H.M., Back, W. (Eds.), Equine Locomotion. Second Ed. Saunders Elsevier, St. Luis, MO, USA, pp. 1-30.

van Weeren, P.R., Pfau, T., Rhodin, M., Roepstorff, L., Serra Bragança, F.M., Weishaupt, M.A., 2017. Do we have to redefine lameness in the era of quantitative gait analysis? Equine Veterinary Journal 49, 567-569.

Weishaupt, M.A., Hogg, H.P., Wiestner, T., Denoth, J., Stüssi, E., Auer, J.A., 2002.

Instrumented treadmill for measuring vertical ground reaction forces in horses. American Journal of Veterinary Research 63, 520-527.

Weishaupt, M.A., Wiestner, T., Hogg, H.P., Jordan, P., Auer, J.A., 2006. Compensatory load redistribution of horses with induced weight-bearing forelimb lameness trotting on a treadmill. The Veterinary Journal 171, 135-146.

Weishaupt, M.A., 2008. Adaptation strategies of horses with lameness. Veterinary Clinics of North America: Equine Practice 24, 79-100.

Weishaupt, M.A., Hogg, H.P., Auer, J.A., Wiestner, T., 2010a. Velocity-dependent changes of time, force and spatial parameters in Warmblood horses walking and trotting on a treadmill. Equine Veterinary Journal 42, 530-537.

Weishaupt, M.A., Wiestner, T., Hogg, H.P., Jordan, P., Auer, J.A., 2010b. Compensatory load redistribution of horses with induced weightbearing hindlimb lameness trotting on a treadmill. Equine Veterinary Journal 36, 727-733.

Wennerstrand, J., Gómez Álvarez, C.B., Meulenbelt, R., Johnston, C., van Weeren, P.R., Roethlisberger-Holm, K., Drevemo, S., 2009. Spinal kinematics in horses with induced back pain. Veterinary and Comparative Orthopaedics and Traumatology 22, 448-454.

Wyn-Jones, G., 1988. The diagnosis of the causes of lameness. Equine Lameness. Blackwell Scientific Publications, Oxford p. 5. 
Technical developments and validation studies for the daily application of gait analysis 



\section{Quantification of the effect of instrumentation error in objective gait assessment in the horse on hindlimb symmetry parameters}

F. M. Serra Braganca ${ }^{A+*}$, M. Rhodin ${ }^{\ddagger}$, T. Wiestner ${ }^{\S}$, E. Hernlund ${ }^{\ddagger}$, T. Pfau", P.r. Van Weeren ${ }^{\dagger}$ and M. A. Weishaupt ${ }^{\S}$

† Department of Equine Sciences, Faculty of Veterinary Medicine, Utrecht University, Utrecht, The Netherlands

\# Department of Clinical Sciences, Swedish University of Agricultural Sciences, Uppsala, Sweden

§ Equine Department, Vetsuisse Faculty University of Zurich, Zurich, Switzerland १ Department of Clinical Science and Services, The Royal Veterinary College, Hatfield, Hertfordshire, UK.

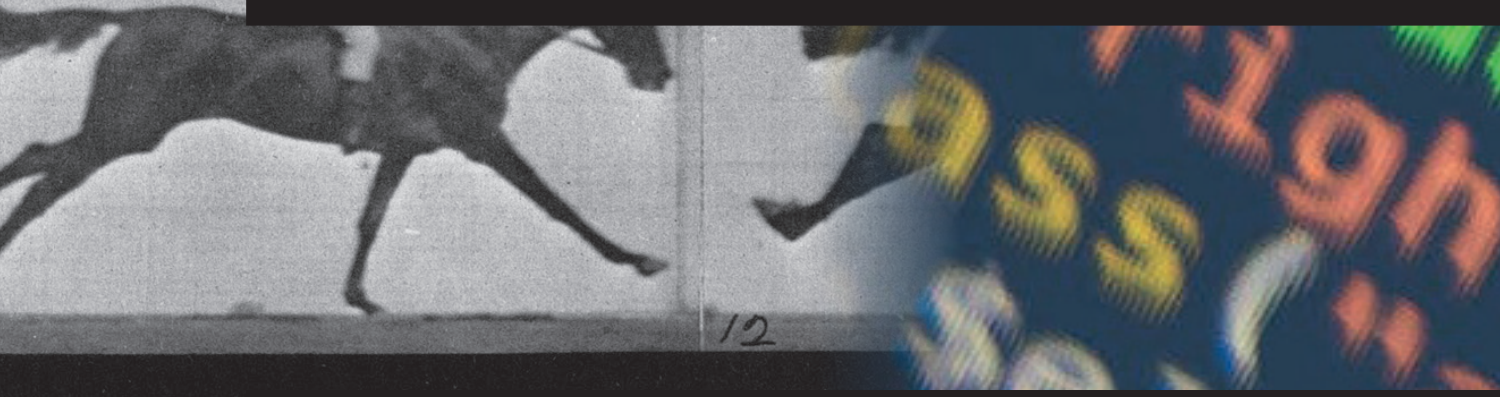




\section{Summary}

Background: Objective gait analysis is becoming more popular as a tool assisting veterinarians during the clinical lameness exam. At present, there is only limited information on the effect of misplacement of markers/motion-sensors.

Objectives: To investigate and describe the effect of marker misplacement on commonly calculated pelvic symmetry parameters.

Study design: Experimental study.

Methods: Each horse was equipped with custom-made devices consisting of several reflective markers arranged in a predefined manner with a reference marker correctly positioned regarding the anatomical landmark and several misplaced markers along the sagittal and transverse planes. Linear regression analysis was used to estimate the effect of marker misplacement.

Results: For the tubera sacrale, each $\mathrm{cm}$ of left/right misplacement led to a difference in minimum position of the pelvis (PDmin) of $\pm 1.67 \mathrm{~mm}(95 \% \mathrm{Cl} 1.54-1.8 \mathrm{~mm}$ ) $(P<0.001)$; maximum position of the pelvis (PDmax) was affected by $\pm 0.2 \mathrm{~mm}(95 \%$ $\mathrm{Cl} 0.071-0.33 \mathrm{~mm})(\mathrm{P}=0.003)$. With respect to cranial/caudal misplacement, each $\mathrm{cm}$ of misplacement resulted in a PDmin difference of $0.04 \mathrm{~mm}(95 \% \mathrm{Cl} 0.09$ to 0.16 $\mathrm{mm})(\mathrm{P}=0.56)$ and a PDmax difference of $\pm 0.008 \mathrm{~mm}(95 \% \mathrm{Cl} 0.13$ to $0.12 \mathrm{~mm})$ $(P=0.9)$. For the tubera coxae, each $\mathrm{cm}$ of vertical misplacement led to a difference in the displacement amplitude between left and right tubera coxae (Hip-Hike_Diff) of $1.56 \mathrm{~mm}(95 \% \mathrm{Cl} 1.35-1.77 \mathrm{~mm})(\mathrm{P}<0.001)$; for the cranial/caudal misplacement, this was $\pm 0.82 \mathrm{~mm}(95 \% \mathrm{Cl} 0.66-0.97 \mathrm{~mm})(\mathrm{P}<0.001)$.

Main limitations: Only three horses were used in this experiment and the study design did not permit to determine the influence of marker misplacement on the evaluation of different degrees of lameness.

Conclusions: Marker misplacement significantly affects calculated symmetry parameters of the pelvis. The observed errors are overall small but significant. In cases of mildly asymmetrical horses, this error might influence the decision-making process whereas in more severe asymmetries, the influence of the error effect may become less significant. 


\section{Introduction}

Kinematic gait analysis has the potential to provide clinicians with accurate and unbiased information that can be used during orthopaedic examinations of horses. This technique is also routinely used in equine research as a method of objective quantification of locomotion and to quantify gait changes due to orthopaedic pain. Its clinical application helps overcoming the inherent limitations of subjective lameness assessment, mainly the low inter-observer agreement [1-4] and human limitations of visual asymmetry perception $[5,6]$. In recent years, several clinically applicable methods have become available and these are in general based on the evaluation of asymmetries of the vertical displacement of head, withers and pelvis [7-12] during unridden trot.

Kinematic gait analysis relies on the placement of sensors or markers attached to the skin over predetermined anatomical landmarks. Although the repeatability of most symmetry parameters has been evaluated to a certain extent [7], there is only limited information $[13,14]$ about how misplacement of markers might affect the measured symmetry parameters and ultimately influence the decision-making process. Previous research demonstrated that marker placement is crucial when assessing locomotion asymmetries using limb mounted markers [15] and that small differences in marker placement can indeed create artificial asymmetries in the measured outcome. Skin displacement artefacts due to the displacement of the skin are also a known issue in equine gait analysis and can have a major effect on kinematic measurements of the limbs $[16,17]$ and to a certain extent also of the tubera coxae and sacrale [18].

The objectives of this study were to investigate to what extent misplacement of markers for kinematic gait analysis might influence the commonly calculated symmetry parameters used for hindlimb lameness quantification. Our hypotheses were that: 1) marker misplacement will have a significant effect on all measured symmetry parameters and 2) such effect will be more important when the misplacement is out of the sagittal plane.

\section{Materials and methods}

Animals: Three riding school horses (Horse ID: 1, 2 and 3) were used in this study (one German Warmblood, one German Riding pony and one Fjord horse) with a height at withers of $1.70 \mathrm{~m}, 1.48 \mathrm{~m}$ and $1.44 \mathrm{~m}$, respectively, a body mass of $640 \mathrm{~kg}$, $410 \mathrm{~kg}$ and $520 \mathrm{~kg}$, respectively and ages of 7, 11 and 15 years, respectively. Horses 
had been accustomed beforehand to treadmill locomotion as previously described [19]. Horses were in regular use and known to be mildly asymmetrical. Measurements for objective lameness assessment can be found in Table 1.

Marker placement: 121 spherical reflective markers were used, with a cluster of three markers placed on the head $(20 \mathrm{~mm} \varnothing)$, a cluster of four markers $(15 \mathrm{~mm} \varnothing)$ on the mid-lateral aspect of each metacarpal/metatarsal bone aligned with the bone longitudinal axis, and star clusters of 17 markers $(12 \mathrm{~mm} \varnothing)$ each on the left tubera coxae (LTC), right tubera coxae (RTC), sacrum, withers and left and right tubera of the spina scapulae, respectively (Fig 1). For this investigation, only the sacrum, LTC and RTC cluster markers were analysed. The central marker of each cluster was positioned over the correct anatomical landmark (sacrum, centrally between the cranial aspects of the tubera sacrale; LTC/RTC, dorso-cranial aspect of the tubera coxae) and one of the arms of the star-shaped figure was aligned with the transverse plane of the horse at that position. The label name of each marker can be found in Table 2.

scapulae, respectively (Fig 1). For this investigation, only the sacrum, LTC and RTC cluster markers were analysed. The central marker of each cluster was positioned over the correct anatomical landmark (sacrum, centrally between the cranial aspects of the tubera sacrale; LTC/RTC, dorso-cranial aspect of the tubera coxae) and one of the arms of the star-shaped figure was aligned with the transverse plane of the horse at that position. The label name of each marker can be found in Table 2.

\section{Data collection}

Kinematic data were collected at trot at $3.6 \mathrm{~m} / \mathrm{s}$ (treadmill belt speed) using 10 infra-

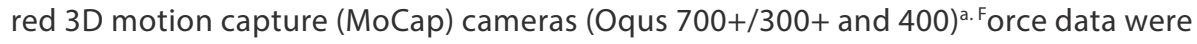
recorded with an instrumented treadmillb[20]. Sampling frequency was $400 \mathrm{~Hz}$ for force and $200 \mathrm{~Hz}$ for MoCap data. Both measurement systems were synchronised using hardware synchronisation. Each recording lasted $20 \mathrm{~s}$.

\section{Data processing}

During the measurements, the three-dimensional coordinates of each marker were

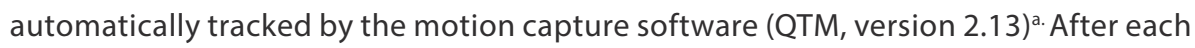
measurement, visual inspection of the 3D tracked data confirmed that all markers were properly tracked and data were suitable for analysis. Measurements with poor marker tracking or irregular gait patterns were discarded and repeated. All data were exported into a Matlabc file. Custom-made Matlab scriptsc were used to process all data and calculate symmetry parameters for each marker of each cluster. Stride split was performed using hoof contact timings based on the kinetic data. The vertical 
Table 1. Baseline symmetry parameters calculated for each of the study subjects for head and pelvis. HDmin/HDmax: Head minimum/ maximum position difference, PDmin/PDmax: Pelvis minimum/ maximum position difference, HD_SI_up/HD_SI_down: Head upwards/ downwards vertical displacement difference index. PD_SI_up/PD_SI_down: Pelvis upwards/downwards vertical displacement difference index. Values are mean and standard deviation in brackets

\begin{tabular}{lccc}
\hline Horse & Warmblood horse & Riding pony & Fjord horse \\
\hline HDmin & $-6.1(25.7) \mathrm{mm}$ & $-16.5(19.5) \mathrm{mm}$ & $1.6(10.9) \mathrm{mm}$ \\
HDmax & $12.7(15.4) \mathrm{mm}$ & $11.5(16.1) \mathrm{mm}$ & $9.9(7.9) \mathrm{mm}$ \\
HD_SI_up & $0.06(0.37)$ & $-0.1(0.5)$ & $0.1(0.2)$ \\
HD_SI_down & $-0.3(0.4)$ & $-0.5(0.3)$ & $-0.1(0.1)$ \\
PDmin & $13.3(6.0) \mathrm{mm}$ & $-5.2(5.7) \mathrm{mm}$ & $-6.2(5.4) \mathrm{mm}$ \\
PDmax & $0.1(3.9) \mathrm{mm}$ & $4.1(7.2) \mathrm{mm}$ & $-8.2(5.7) \mathrm{mm}$ \\
PD_SI & $0.2(0.1)$ & $-0.01(0.1)$ & $-0.2(0.1)$ \\
PD_SI & $0.2(0.1)$ & $-0.1(0.1)$ & $0.03(0.1)$ \\
Hip-Hike Diff & $21.4(8) \mathrm{mm}$ & $0.6(9.5) \mathrm{mm}$ & $-11.5(10.9) \mathrm{mm}$ \\
\hline
\end{tabular}

Table 2. Naming of the different markers for each cluster location in relation to the horse, relative to global-coordinate system (treadmill)

\begin{tabular}{lll}
\hline $\begin{array}{l}\text { Location/ } \\
\text { Naming }\end{array}$ & Sacrum & LTC/RTC \\
\hline 0 & Reference marker & Reference marker \\
a/a & $\pm 3 \mathrm{~cm}$ displacement. Left (+), Right (-) & $\pm 3 \mathrm{~cm}$ displacement. Proximal (+), Distal (-) \\
$\mathrm{b} / \mathrm{b}$ & $\pm 6 \mathrm{~cm}$ displacement. Left (+), Right (-) & $\pm 6 \mathrm{~cm}$ displacement. Proximal (+), Distal (-) \\
$1 / 1$ & $\pm 3 \mathrm{~cm}$ displacement. Cranial (+), Caudal (-) & $\pm 3 \mathrm{~cm}$ displacement. Cranial (+), Caudal (-) \\
$2 / 2$ & $\pm 6 \mathrm{~cm}$ displacement. Cranial (+), Caudal (-) & $\pm 6 \mathrm{~cm}$ displacement. Cranial (+), Caudal (-) \\
$\mathrm{l} / \mathrm{l}$ & $\pm 3 \mathrm{~cm}$ displacement. Left/Caudal (+), Right/Cranial (-) & $\pm 3 \mathrm{~cm}$ displacement. Cranial/Distal (+), Caudal/Proximal (-) \\
II/II & $\pm 6 \mathrm{~cm}$ displacement. Left/Caudal (+), Right/Cranial (-) & $\pm 6 \mathrm{~cm}$ displacement. Cranial/Distal (+), Caudal/Proximal (-) \\
a/a & $\pm 3 \mathrm{~cm}$ displacement. Left/Cranial (+), Right/Caudal (-) & $\pm 3 \mathrm{~cm}$ displacement. Cranial/Vertical (+), Caudal/Distal (-) \\
$\beta / \beta$ & $\pm 6 \mathrm{~cm}$ displacement. Left/Cranial (+), Right/Caudal (-) & $\pm 3 \mathrm{~cm}$ displacement. Cranial/Vertical (+), Caudal/Distal (-) \\
\hline
\end{tabular}

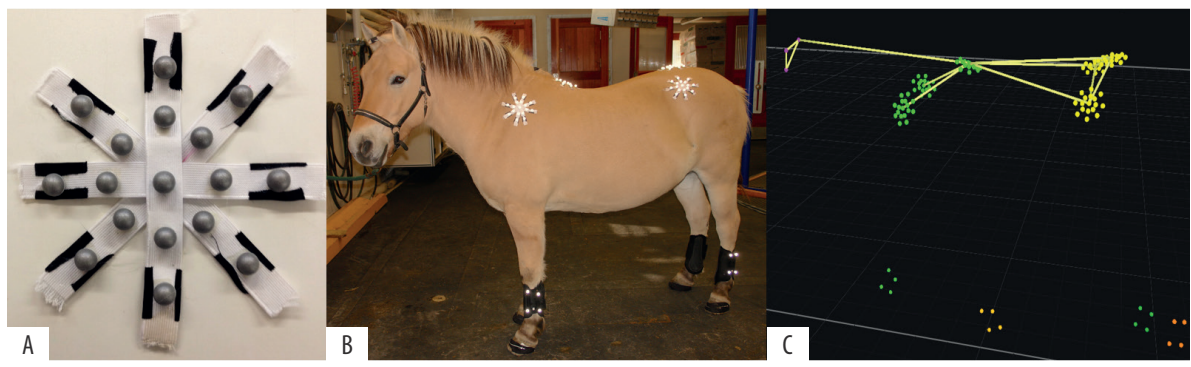

Figure 1. Marker experimental setup. a): Reflective marker cluster construction. b) Marker placement in one of the study subjects. c) Example of left lateral view of all 121 markers as depicted by the 3D tracking software. 
displacement of each marker was high-pass filtered using a 4th order zero-phase Butterworth filter with the cut-off frequency (frequencies used: 1.1, 1.0, $0.95 \mathrm{~Hz}$ ) adjusted to the stride frequency of each trial/horse (stride frequency: 1.6, 1.5, $1.4 \mathrm{~Hz}$, respectively). For each marker, the calculated symmetry parameters were the pelvis PDmin/PDmax, PD_SI ${ }_{\text {up }}$ / PD_SIdown and Hip-Hike difference as described in Table 3. All parameters were calculated for each stride as previously described [21].

\section{Data analysis}

Open software (R-Studio, version 3.3.1) ${ }^{\mathrm{d}}$ was used for statistical analysis of the calculated symmetry parameters. For the sacrum, LTC and RTC clusters, a generalised linear model (function: $\mathrm{glm}$ ) was used with the position of each cluster marker in the volume as an explanatory variable and the tested symmetry parameters (per stride) used as a response variable. To determine the position of each marker in relation to the treadmill coordinate system ( $x$ : left/right, $y$ : cranial/caudal, $z$ : vertical), the horizontal coordinates (i.e. $x, y$ ) were used to determine cranial/caudal and left/right misplacement. For LTC and RTC, the vertical plane (i.e. $y, z$ ) coordinates were used for determining cranial/caudal and proximal/distal misplacement. Since all horses had a baseline motion asymmetry measured at the reference marker, all the measured symmetry variables (response variable) were normalised to the baseline measured asymmetry, thus defining the reference symmetry for each parameter at the reference marker as zero. All models were also tested for a nonlinear relation between outcome and explanatory variables. The Akaike's information criterion was used to select the best model. Best fit of each model was evaluated by plotting the residuals vs. fitted values to ensure homoscedasticity. Normal distribution of the residuals was verified using Q-Q plots. Model plots were generated using the package ggplot2. Linear regression lines were also generated (function: geom_smooth) for model outcome visualisation.

Since the hip-hike difference needs both LTC and RTC markers for its calculation, the analysis was performed by testing misplacement on one side while on the opposite only the central reference marker was used.

\section{Results}

Per horse, a total of 30, 28 and 27 valid strides were analysed, respectively. None of the models improved significantly by using polynomial (i.e. nonlinear) relations and therefore all results are presented using linear models. 
Table 3. Detailed description of the calculated asymmetry parameters used in this study

\begin{tabular}{|c|c|}
\hline Parameter & Description \\
\hline PDmin & $\begin{array}{l}\text { Difference between left and right stride half-cycle in minimum vertical displacement/position } \\
\text { of the sacrum in mm.* }\end{array}$ \\
\hline PDmax & $\begin{array}{l}\text { Difference between left and right stride half-cycle in maximum vertical displacement/position } \\
\text { of the sacrum in } \mathrm{mm} .{ }^{*}\end{array}$ \\
\hline$P D \_S I_{\text {up }}$ & $\begin{array}{l}\text { Symmetry index of the upward pelvis vertical displacement as a proportion of the absolute } \\
\text { pelvis vertical range of motion of each stride. }{ }^{\dagger}\end{array}$ \\
\hline PD_SI down & $\begin{array}{l}\text { Symmetry index of the downwards pelvis vertical displacement as a proportion of the absolute } \\
\text { pelvis vertical range of motion of each stride. }{ }^{\dagger}\end{array}$ \\
\hline Hip-Hike difference & $\begin{array}{l}\text { The difference in the upwards amplitude of the vertical displacement between the left tubera } \\
\text { coxae and the right tubera coxae in mm.* }\end{array}$ \\
\hline
\end{tabular}

*A value of 0 indicates perfect symmetry; increasing values indicate an increased asymmetry. Positive values indicate an asymmetry towards the right limb lameness and a negative value indicates an asymmetry towards the left limb lameness.

${ }^{\dagger} A$ value of 0 indicates perfect symmetry, a value of 1 indicates maximum asymmetry towards the right limb and a value of 1 indicates maximum asymmetry towards the left limb.

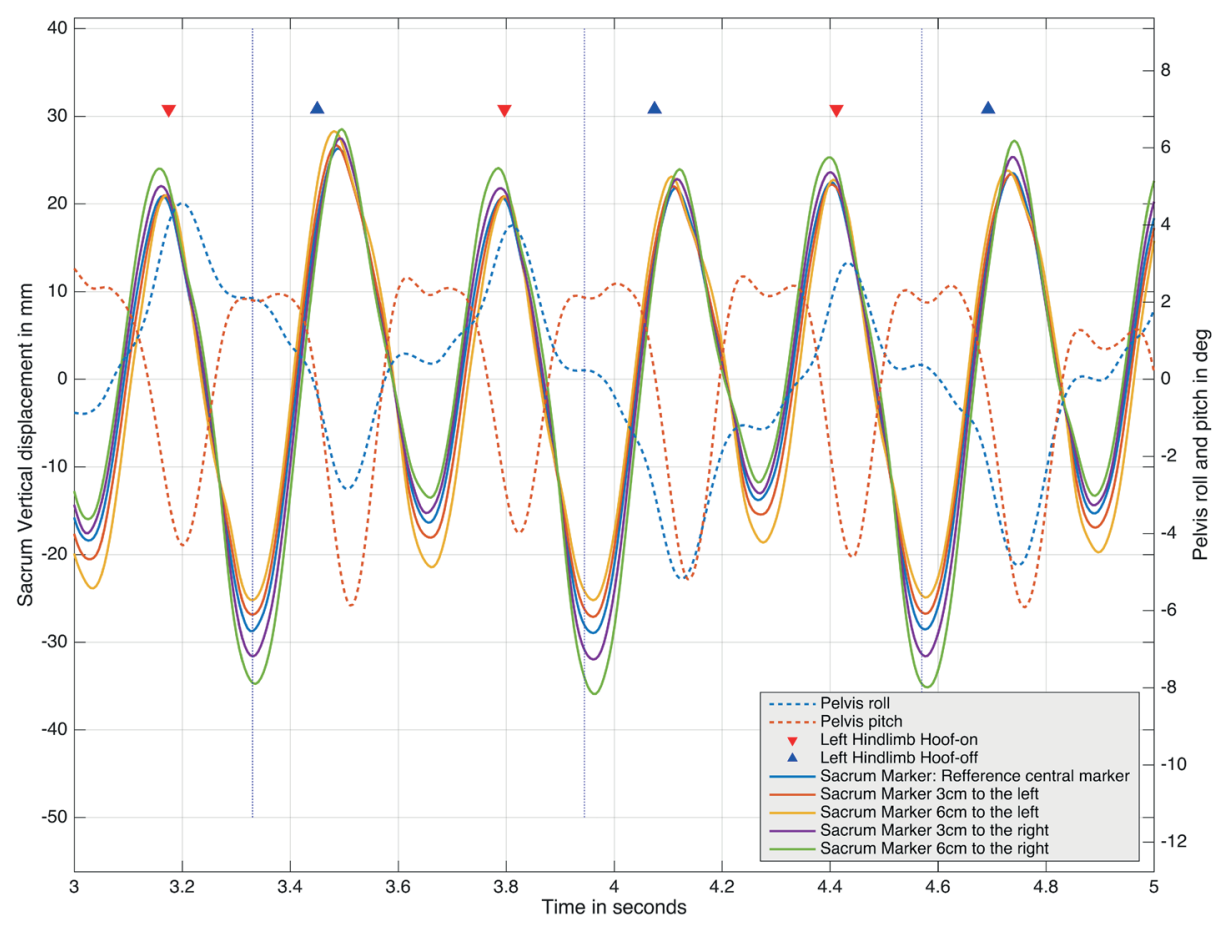

Figure 2. Tubera sacrale marker vertical displacement, pelvis roll and pitch angle related to left hindlimb midstance (vertical dotted blue line) for the Warmblood Horse. Midstance is defined as the moment of peak vertical ground reaction force. Pelvis roll (): Left tubera coxae is below horizontal. Pelvis roll (+): Right tubera coxae is below horizontal. Pelvis Pitch (+): Lumbosacral extension. Pelvis Pitch (): Lumbosacral flexion. 

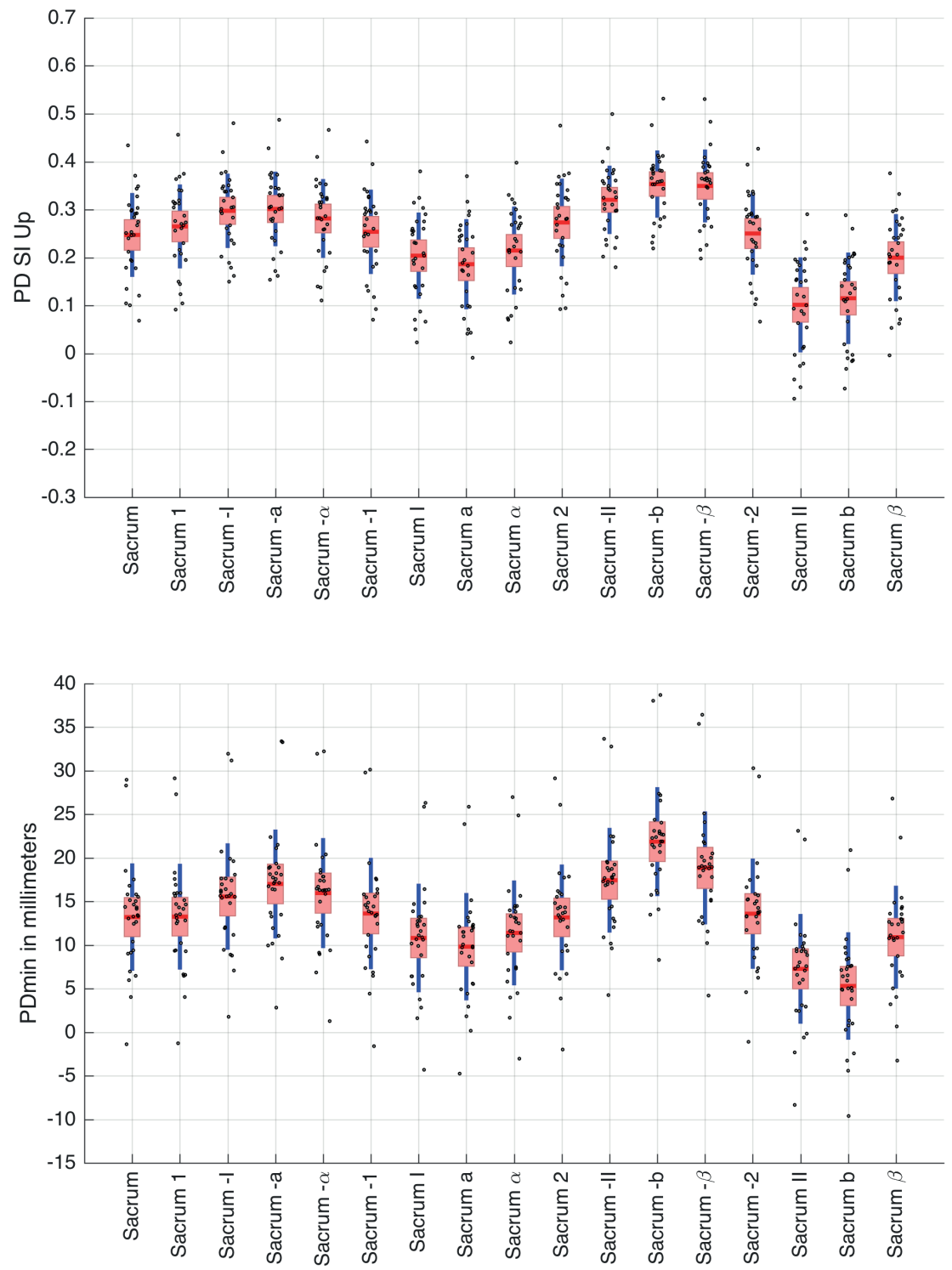

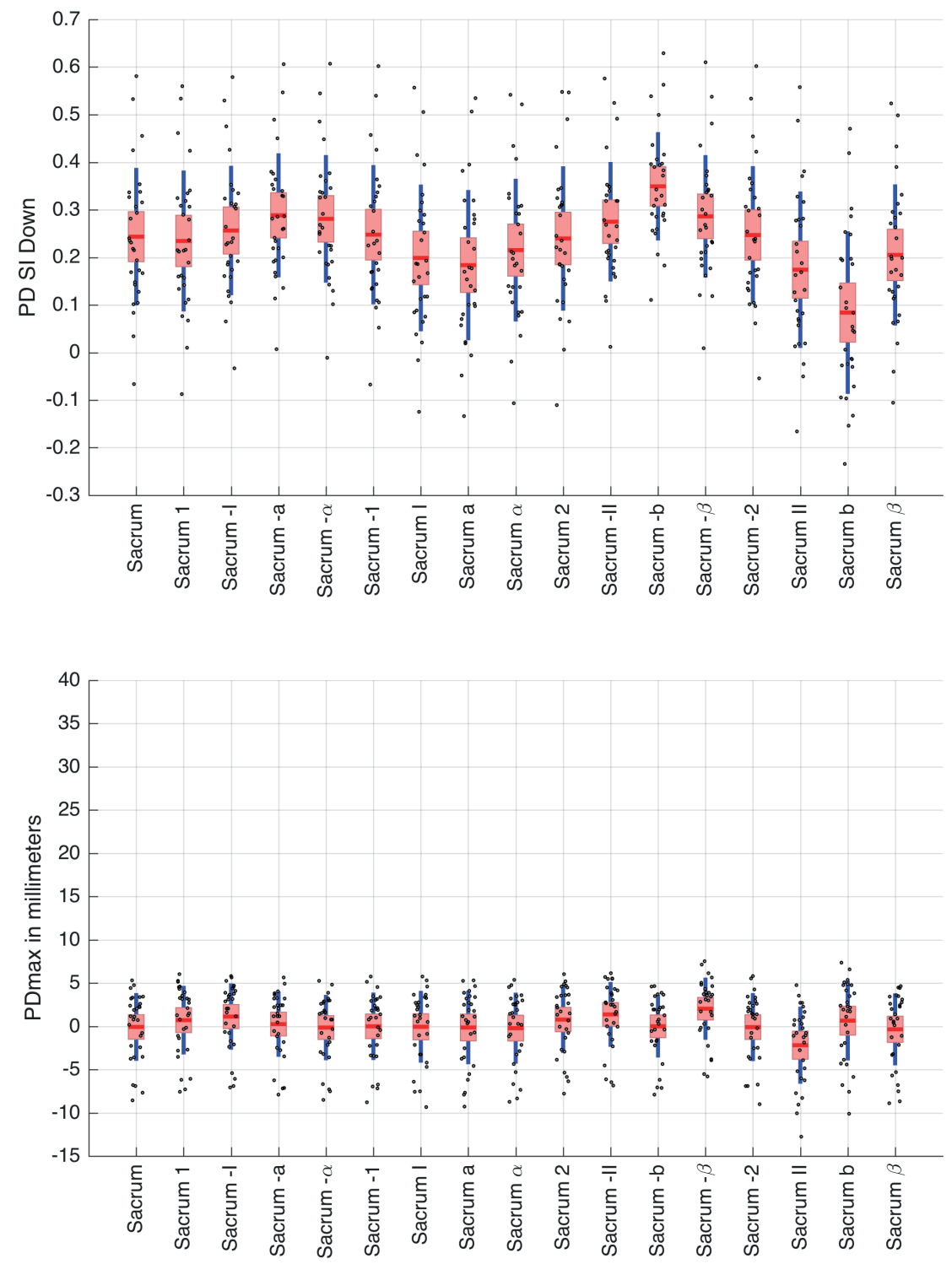

Figure 3. Plot of the symmetry parameters PDmin, PDmax, PD_SI_up and PD_SI_down for the Warmblood horse (30 strides). The red box indicates the standard deviation, the blue line the $95 \%$ SEM, the red line indicates the mean and all data points are scattered along each plot. Please refer to Table 2 and Fig 1 for marker names and corresponding orientation with respect to the central reference marker. 


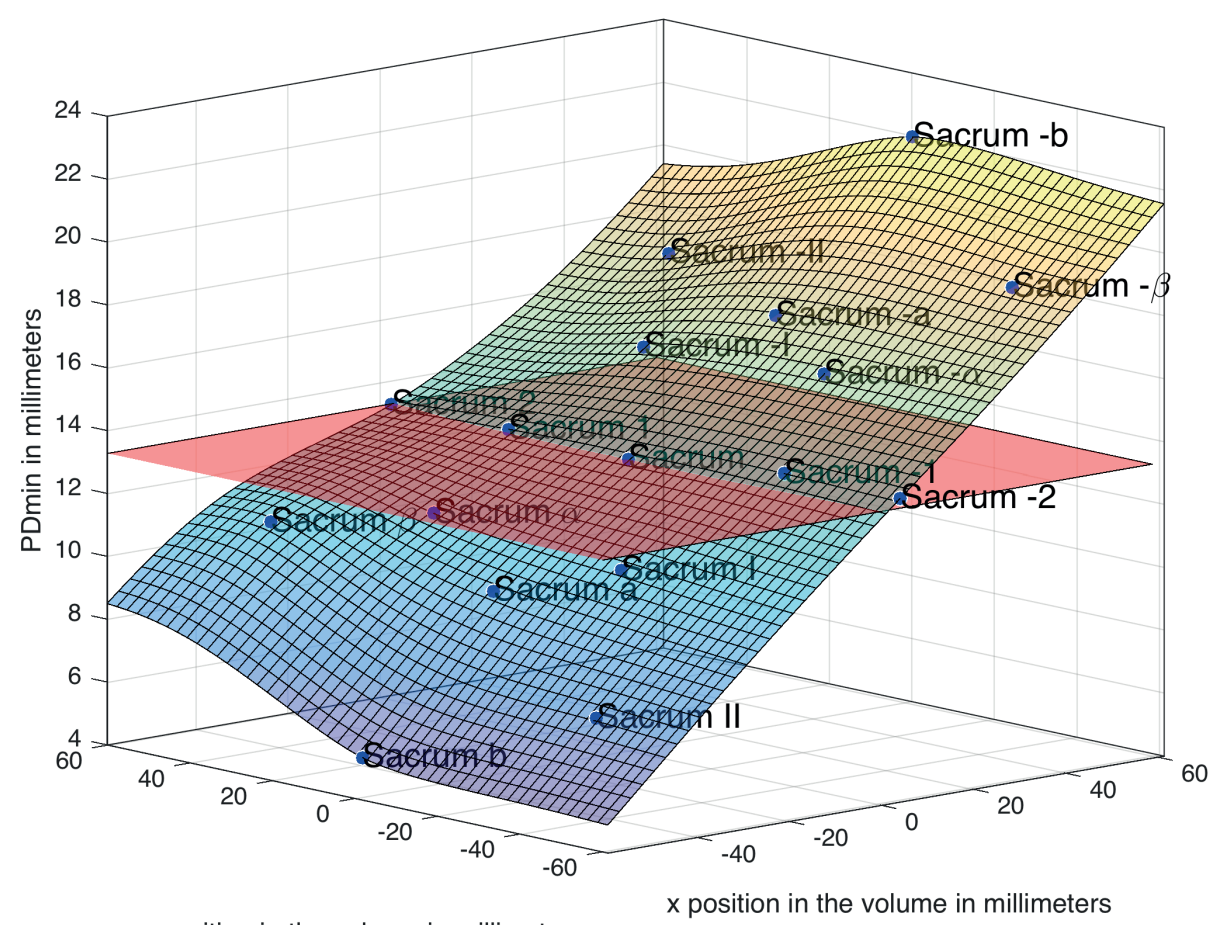

y position in the volume in millimeters

Figure 4. Change in PDmin ( $z$ axis) for the different marker placements for the tubera coxae. $x$ and $y$ axis represent the position of each marker in the globalcoordinate system (y positive to cranial and $x$ positive to right). Each blue point represents one marker of the cluster as the average of all collected strides for the Warmblood horse (30 strides). The horizontal red plane represents the PDmin value of the central reference marker. The plane fitted along the different markers was generated using a thinplate smoothing spline method. Please refer to Table 2 and Fig 1 for marker names and corresponding orientation with respect to the central reference marker.

\section{Sacrum}

Figure 2 represents the timing of events between left/right displacement of the sacrum markers, limb-midstance, pelvis roll and yaw, and hoof-on/off events for one horse.

The baseline asymmetry calculated for each subject can be found in Table 1 . Descriptive statistics of the symmetry parameters calculated for each marker are presented in Figures 3 and 4 for one horse (ID: 1). The model estimates including all horses indicated that for each $\mathrm{cm}$ the marker was misplaced to the left or right from the reference anatomical landmark, PDmin was affected by $1.67 \mathrm{~mm} \mathrm{(95 \%} \mathrm{Cl}$ 1.54-1.8 mm; P<0.001), PDmax by _0.2 mm (95\% Cl 0.071-0.33 mm; P = 0.003) (Fig 4), PD_SI by_0.019 (95\% Cl 0.017-0.022; P<0.001) and PD_SI down by _0.026 (95\% Cl 

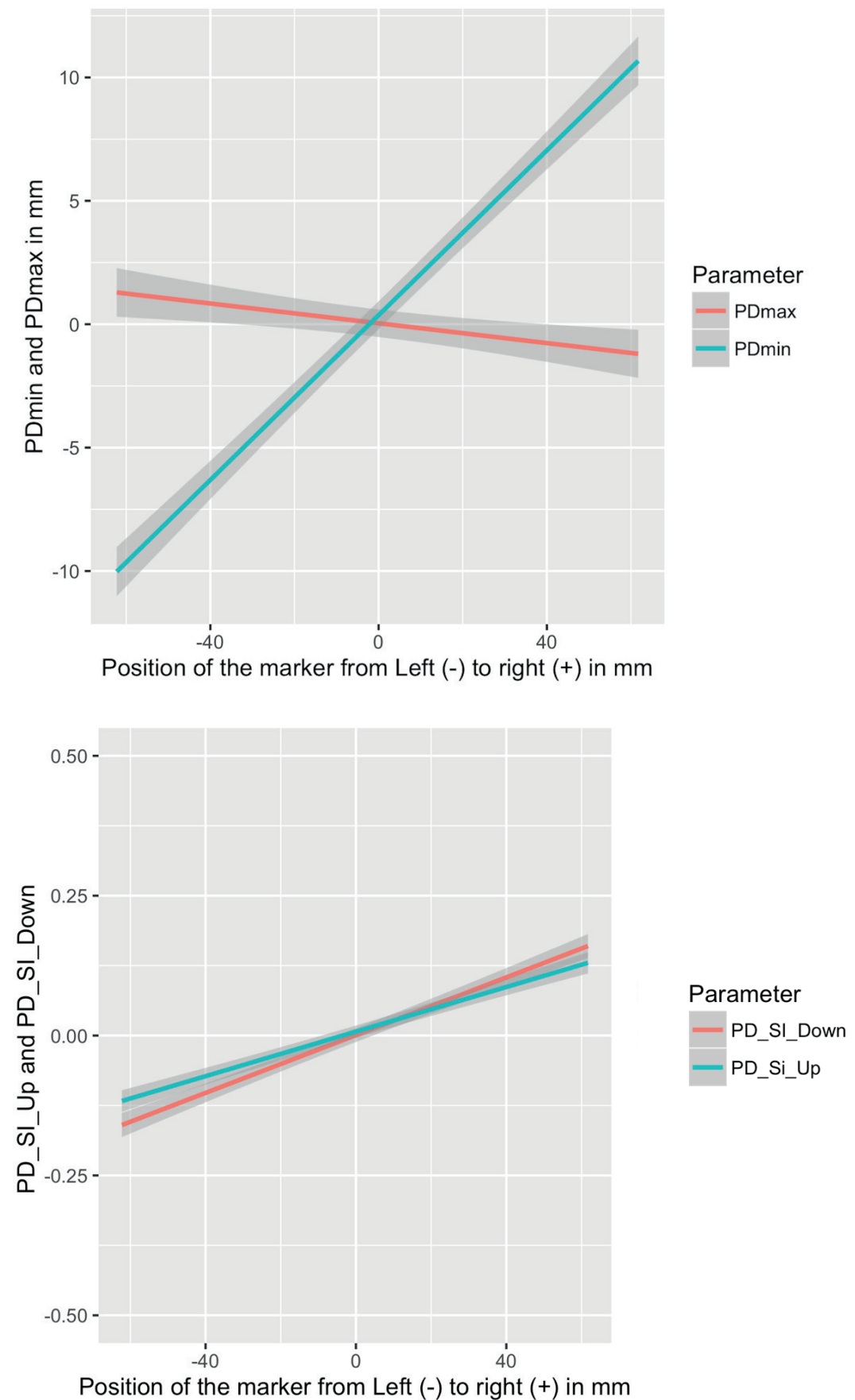

Figure 5. Left: Linear regression line with $95 \%$ confidence interval for PDmax and PDmin when markers are misplaced to the left or right. Right: Linear regression lines with $95 \%$ confidence interval for PD_SI ${ }_{- \text {up }}$ and PD_SI ${ }_{- \text {down }}$ when markers are misplaced to the left or right. 
0.023-0.029; $\mathrm{P}<0.001$ ) (Fig 5), depending on to which side the marker was misplaced (to the left or to the right).

\section{Hip-Hike}

For proximal-distal misplacement, each $\mathrm{cm}$ away from the reference anatomial landmark (LTC/RTC) Hip-Hike_Diff was affected by _1.56 mm (95\% Cl 1.35-1.77 mm; $\mathrm{P}<0.001$ ) (Fig 6). For cranial/caudal misplacement, each $\mathrm{cm}$ away from the reference anatomical landmark (LTC/RTC) Hip-Hike_Diff was affected by _ $0.82 \mathrm{~mm}(95 \% \mathrm{Cl}$ $0.66-0.97 \mathrm{~mm} ; \mathrm{P}<0.001)$

\section{Discussion}

The hypotheses that marker misplacement would affect symmetry parameters and this effect would be more pronounced when the misplacement is out of the sagittal plane are supported by the outcome of this study. We did not observe a considerable timing difference (on visual inspection of the signals) of peaks and valleys in the measured sacrum marker signals. We did observe a difference in amplitude of the signals and a difference in maximum and minimum vertical position when compared to the reference marker (Fig 5). This can be explained by the fact that the pelvis behaves like a rigid body [22]; therefore, when using markers attached to the same rigid structure, vertical displacement events happen synchronously through the whole structure. For the calculated symmetry parameters of the sacrum, left/right misplacement had a considerably greater effect when compared to cranial/caudal misplacement. This is in line with previous research using sensors mounted along the midline of the horse, (between T6 and S3) [23], where small differences between locations of the sensor along the sagittal midline were reported for the calculated asymmetry parameters in most of the tested horses. In our study, the left/right misplacement PDmin was substantially more affected by misplacement than PDmax, as observed by the different model estimates $\pm 1.67 \mathrm{~mm}$ for PDmin and $\pm 0.2 \mathrm{~mm}$ for PDmax and as described for misplacement when using a pelvis mounted uniaxial accelerometer [14].

We hypothesise that this difference between PDmin and PDmax is mainly due to the soft tissue artefacts underneath the markers combined with the effect of pelvis roll. Functional surface EMG studies indicate that the gluteus medius muscle, located underneath the left/right misplaced markers, is active during the stride cycle, between the end of the swing phase until midstance during trot [24,25]. PDmin occurs during midstance. At this moment, the pelvis is most often slightly tilted (rolls) 

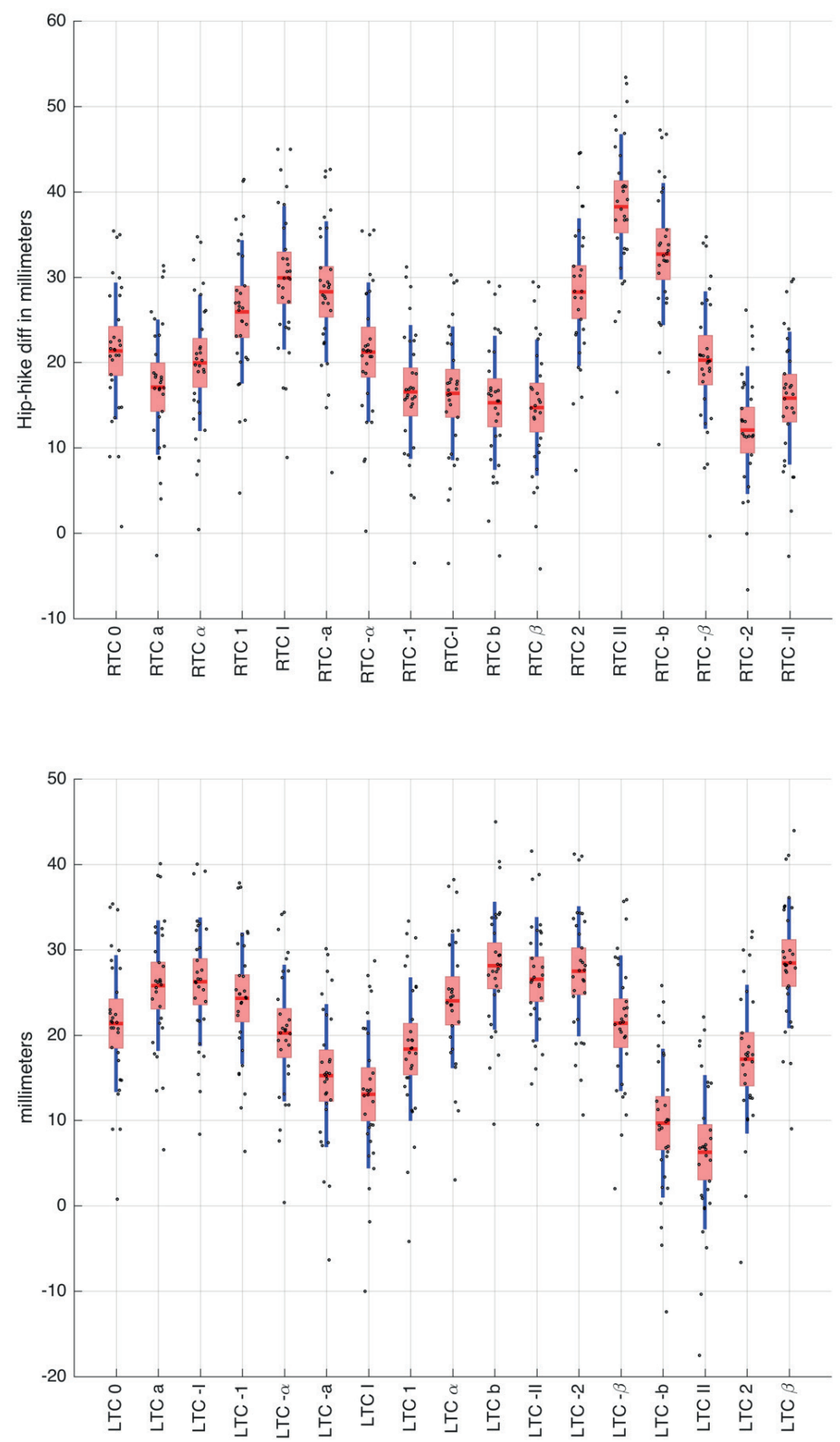

Figure 6. Plot of the symmetry parameter Hip-Hike Difference when markers are misplaced on the LTC or RTC. The red box indicates the s.d., the blue line the 95\% SEM, the red line indicates the mean and all data points are scattered along each plot. Please refer to Table 2 and Fig 1 for marker names and corresponding orientation with respect to the central reference of each marker. 
so that the tuber coxae of the stance limb is higher than that of the swinging limb (Fig 5). Hence, we argue that a sacral marker, misplaced to the right, would in right limb stance achieve its higher vertical position. This is possibly due to the combined effect of the roll of the pelvis and the upward push from the actively contracting gluteus medius of the stance limb.

PDmax is calculated at the pelvis' maximum vertical position, which is the moment when the hoof is just about to strike the ground at the end of the swing phase. At this moment, the pelvis vertical position and roll is at its maximum with a clearly higher position of the tubera coxae of the protracting hindlimb. One might expect that this tilt would result in differences in vertical position between the several left/ right misplaced markers, but in fact the difference between the markers is small (Fig 5). We hypothesise that during the maximum vertical position of the pelvis, even though electrical activity in the gluteal muscle is low, in the limb that has just pushed the body forward (i.e. the limb that is at the end of stance phase) $[24,25]$ there is a maximum extension of the hip joint [25] that passively compresses the gluteal muscle (and fat) on that side. This soft tissue movement will counteract the tilt created by the maximum pelvis roll and therefore result in only small vertical position differences across the markers observed (Fig 5).

Both PD_SI up $_{\text {and }}$ PD_SI ${ }_{\text {down }}$ were affected by left/right marker misplacement, but to a different extent. Since these parameters are calculated based on the vertical range of motion difference between sides [21], both the upwards and the downwards pelvis movement ranges depend on the minimum position of the pelvis and, therefore, are affected by left/right marker misplacement.

The magnitude of the observed error remained small for small misplacements. Nevertheless, if the misplacement was big enough, the calculated symmetry parameters exceeded previously reported threshold values for PDmin ( $\pm 3 \mathrm{~mm}$ [3]) and hence led to a classification as lame. From our model estimates (Fig 4), a left/right misplacement of $3 \mathrm{~cm}$ resulted indeed in a false PDmin of $\pm 5.01 \mathrm{~mm}$, hence resulting in a type 1 error false positive result.

Misplacement of tuber coxae markers affects Hip-Hike difference calculations and the effect is greater for the proximal-distal misplacement. The observed artefact for proximal-distal misplacement occurs on the tubera coxae peak just before hoof-on on the misplaced side, which corresponds to the maximum pelvis roll towards that side (max tuber coxae elevation on the misplaced side) Also, during midstance on the misplaced side, the marker will achieve a lower position when compared to the 
reference marker, resulting in a systematic error of the calculated parameter. As there are yet no reference threshold levels for the pelvis Hip-Hike difference, we cannot determine if the effect we measured might affect the clinical decision making. Nevertheless, attention should be given to properly place the markers in the correct anatomical location and in cases of horses with an asymmetrical pelvis conformation. In this situation, marker placement should be performed in a way that the distance to the tuber sacrale from each marker/sensor placed at the LTC and RTC is equal, avoiding any possible misplacement. This can be performed by measuring with a tape the distance between the sacrum marker/sensor and the LTC/ RTC marker/senor.

In the present study, we used a small but diverse population of horses to avoid bias by any specific breed-related morphological characteristics. It is unknown if different degrees of lameness that ultimately may alter the motion pattern of the pelvis $[22,26]$ could affect the model estimates we describe, but, as previously described, the horses included in this study were mildly asymmetrical (Table 1) and one of the horses even had a consistent pelvis movement asymmetry (PDmin $=13.3( \pm 6.0) \mathrm{mm}$ and Hip- Hike Diff $=21.4( \pm 8) \mathrm{mm}$ ). Further studies are needed to better understand the effect of marker misplacement on our investigated symmetry parameters in lame horses.

Although markers attached to the skin and moving relatively to the underlying bony structures do affect sensor orientation angle (Euler angles) [18], this effect was not yet tested for vertical displacement calculations. We believe that this orientation error effect would be more relevant for measurements using uniaxial accelerometer sensors $[8,14]$. Uniaxial accelerometers must be aligned with gravity to accurately measure displacement along the vertical axis. If incorrectly positioned, they will only measure a fraction of the total vertical acceleration, depending on their instantaneous orientation. This could in part explain the bigger effect of sensor misplacement described in another study using a uniaxial accelerometer [14]. However, in that study the researchers used lame horses and sensors were misplaced between consecutive trials. Therefore, one cannot establish whether some of the observed differences may be related to between-trial variation [8] or lameness-related asymmetry.

More advanced sensor units such as an inertial measurements unit (IMU) sensor might be less prone to the orientation error, since their vertical orientation is corrected using three gyroscope sensors and three accelerometers [27]. They therefore maintain the estimated vertical displacement in relation to the global-coordinate system, resulting in the same vertical displacement as when measured using a 3D motion capture system. Therefore, the results presented here are also valid for sensors measuring vertical displacement in a global-coordinate system [27], as long as the 
displacement estimated by the sensor is not under or over estimated. Thus, prior to the development of a sensor-based system for objective lameness assessment, a validation study including agreement analysis with a 3D motion capture-based system is imperative [27].

\section{Conclusion}

Marker placement is important and due attention should be given to the instrumentation before performing objective gait assessment ensuring no markers/ sensors are misplaced. For the sacrum and tubera coxae, left/right misplacement affected the measured symmetry parameters in a much greater magnitude in comparison to cranial/caudal misplacement. Overall, the observed error magnitude due to marker misplacement was small emphasising the repeatability of this technique. Nonetheless, if the left/right marker misplacement for the sacrum is for example greater than $3 \mathrm{~cm}$, the observed error might exceed the previously described thresholds for lame horses and therefore result in a false positive or negative result. Since this study was carried out in a small population and using mildly asymmetrical horses, we cannot conclude that our results will hold true in clinically lame horses where a greater or smaller effect of marker misplacement might exist. As shown by our results, this could be due to changes in the pelvis rotation pattern. Nevertheless, the effect of lameness in pelvis rotation is known to be small [22]. To study this, a kind of dose-effect study would have to be conducted in a larger population of horses. However, this was beyond the scope of our study and here we aim to create awareness of the importance of correct marker placement. 


\section{Authors' declaration of}

\section{interests}

No competing interests have been

declared.

\section{Ethical animal research}

The study was performed with the

approval of the Animal Health and

Welfare Commission of the Canton of

Zurich (permission No. 206/2010).

\section{Sources of funding}

None.

\section{Acknowledgements}

The authors wish to thank Katrin

Brunnschweiler, who kindly left her

horses at the study's disposal.

\section{Authorship}

F.M. Serra Braganc,a contributed to planning of the experiment, data processing, statistics and writing of manuscript. M. Weishaupt and T. Wiestner contributed to planning of the experiment, data collection and writing of manuscript. M. Rhodin, E. Hernlund, T. Pfau and R. van Weeren contributed to the writing of the manuscript and planning of the experiment. 


\section{References}

1. Fuller, C.J., Bladon, B.M., Driver, A.J. and Barr, A.R.S. (2006) The intra- and inter-assessor reliability of measurement of functional outcome by lameness scoring in horses. Vet. J. 171, 281-286.

2. Keegan, K.G., Dent, E.V., Wilson, D.A., Janicek, J., Kramer, J., Lacarrubba, A., Walsh, D.M., Cassells, M.W., Esther, T.M., Schiltz, P., Frees, K.E., Wilhite, C.L., Clark, J.M., Pollitt, C.C., Shaw, R. and Norris, T. (2010) Repeatability of subjective evaluation of lameness in horses. Equine Vet. J. 42, 92-97.

3. McCracken, M.J., Kramer, J., Keegan, K.G., Lopes, M., Wilson, D.A., Reed, S.K., LaCarrubba, A. and Rasch, M. (2012) Comparison of an inertial sensor system of lameness quantification with subjective lameness evaluation. Equine Vet. J. 44, 652-656.

4. Hammarberg, M., Egenvall, A., Pfau, T. and Rhodin, M. (2016) Rater agreement of visual lameness assessment in horses during lungeing. Equine Vet. J. 48, 78-82.

5. Parkes, R.S.V., Weller, R., Groth, A.M., May, S. and Pfau, T. (2009) Evidence of the development of "domain-restricted" expertise in the recognition of asymmetric motion characteristics of hindlimb lameness in the horse. Equine Vet. J. 41, 112-117.

6. Arkell, M., Archer, R.M., Guitian, F.J. and May, S.A. (2006) Evidence of bias affecting the interpretation of the results of local anaesthetic nerve blocks when assessing lameness in horses. Vet. Rec. 159, 346-349.

7. Kastner, J., Knezevic, P.F., Girtler, D. and Toeltsch, M. (1990) Die 3-dimensionale Bewegungsanalyse als klinische Methode zur Objektivierung von Lahmheiten beim Pferd. Biomed. Tech. Eng. 35, 171-172.

8. Keegan, K.G., Kramer, J., Yonezawa, Y., Maki, H., Pai, P.F., Dent, E.V., Kellerman, T.E., Wilson, D.A. and Reed, S.K. (2011) Assessment of repeatability of a wireless, inertial sensor-based lameness evaluation system for horses. Am. J. Vet. Res. 72, 1156-1163.

9. Persson Sjo€din, E., Serra Braganca, F., Pfau, T., Egenvall, A., Weishaupt,

10. M.A. and Rhodin, M. (2016) Movement symmetry of the withers can be used to discriminate primary forelimb lameness from compensatory forelimb asymmetry in horses with induced lameness. Equine Vet. J. 48, 32-33.

11. Peloso, J.G., Stick, J.A., Soutas-Little, R.W., Caron, J.C., DeCamp, C.E. and Leach, D.H. (1993) Computer-assisted three-dimensional gait analysis of amphotericin-induced carpal lameness in horses. Am. J. Vet. Res. 54, 1535-1543.

12. Buchner, H.H., Savelberg, H.H., Schamhardt, H.C. and Barneveld, A. (1996) Head and trunk movement adaptations in horses with experimentally induced fore- or hindlimb lameness. Equine Vet. J. 28, 71-76.

13. Rhodin, M., Egenvall, A., Andersen, P.H. and Pfau, T. (2017) Head and pelvic movement asymmetries at trot in riding horses in training and perceived as free from lameness by the owner. PLoS ONE 12, e0176253.

14. Starke, S.D., McDonald, J., May, S.A. and Pfau, T. (2012) Effect of inaccurate equipment placement on displacement trajectories and asymmetry features in horses at walk and trot. In: International Conference on Canine and Equine Locomotion. p 49.

15. Moorman, V.J., Frisbie, D.D., Kawcak, C.E. and Mcllwraith, C.W. (2017) Effects of sensor position on kinematic data obtained with an inertial sensor system during gait analysis of trotting horses. J. Am. Vet. Med. Ass. 250, 548-553.

16. Audigie,, F., Pourcelot, P., Degueurce, C., Denoix, J.M., Geiger, D. and Bortolussi, C. (1998) Asymmetry in placement of bilateral skin markers on horses and effects of asymmetric skin marker placement on kinematic variables. Am. J. Vet. Res. 59, 938-944.

17. van Weeren, P.R., van den Bogert, A.J. and Barneveld, A. (1990) Quantification of skin displacement in the proximal parts of the limbs of the walking horse. Equine Vet. J. 22, Suppl. 9, 110-118. 
18. van Weeren, P.R., van den Bogert, A.J. and Barneveld, A. (1988) Quantification of skin displacement near the carpal, tarsal and fetlock joints of the walking horse. Equine Vet. J. 20, 203-208.

19. Goff, L., van Weeren, P.R., Jeffcott, L., Condie, P. and Mcgowan, C. (2010) Quantification of equine sacral and iliac motion during gait: a comparison between motion capture with skin-mounted and bone-fixated sensors. Equine Vet. J. 42, 468-474.

20. Buchner, H.H.F., Savelberg, H.H.C.M., Schamhardt, H.C., Merkens, H.W. and Barneveld, A. (1994) Habituation of horses to treadmill locomotion. Equine Vet. J. 26, Suppl. 17, 13-15.

21. Weishaupt, M.A., Hogg, H.P., Wiestner, T., Denoth, J., Stu€ssi, E. and Auer,

22. J.A. (2002) Instrumented treadmill for measuring vertical ground reaction forces in horses. Am. J. Vet. Res. 63, 520-527.

23. Starke, S.D., Willems, E., May, S.A. and Pfau, T. (2012) Vertical head and trunk movement adaptations of sound horses trotting in a circle on a hard surface. Vet. J. 193, 73-80.

24. Starke, S.D., May, S.A. and Pfau, T. (2015) Understanding hind limb lameness signs in horses using simple rigid body mechanics. J. Biomech. 48, 3323-3331.

25. Warner, S.M., Koch, T.O. and Pfau, T. (2010) Inertial sensors for assessment of back movement in horses during locomotion over ground. Equine Vet. J. 42, 417-424.

26. Wentink, G.H. (1978) Biokinetical analysis of the movements of the pelvic limb of the horse and the role of the muscles in the walk and the trot. Anat. Embryol. (Berl) 152, 261-272.

27. Robert, C., Valette, J.P., Degueurce, C. and Denoix, J.M. (1999) Correlation between surface electromyography and kinematics of the hindlimb of horses at trot on a treadmill. Cells Tissues Organs 165, 113-122.

28. May, S.A. and Wyn-Jones, G. (1987) Identification of hindleg lameness.

29. Equine Vet. J. 19, 185-188.

30. Pfau, T., Witte, T.H. and Wilson, A.M. (2005) A method for deriving displacement data during cyclical movement using an inertial sensor. J. Exp. Biol. 208, 2503-2514. 


\section{Quantitative lameness}

\section{assessment in the horse based on upper body movement} symmetry: The effect of different filtering techniques on the quantification of motion symmetry

F.M. Serra Braganca ${ }^{a, *}$, C. Roepstorff ${ }^{b}$, M. Rhodinc, T. Pfaud, P.R. van Weeren ${ }^{a}$, L. Roepstorffc

a Department of Equine Sciences, Faculty of Veterinary Medicine, Utrecht University, Yalelaan 112 114, NL-3584 CM Utrecht, the Netherlands

b Equine Department, Vetsuisse Faculty, University of Zurich, Winterthurerstrasse 260, CH-8057 Zurich, Switzerland

c Department of Anatomy, Physiology and Biochemistry, Swedish University of Agricultural Sciences, Uppsala, Sweden

d Department of Clinical Science and Services, The Royal Veterinary College, Hawkshead Lane, North Mymms, Hatfield, AL9 7TA, UK

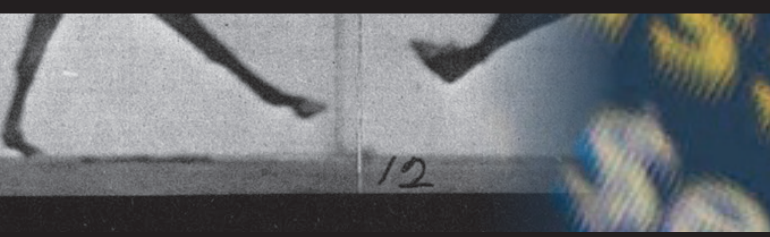




\section{Abstract}

Quantitative gait analysis in horses is rapidly gaining importance, both clinically and in research. The number of available systems is increasing, but the methods of signal analysis differ between systems and research groups. Our objectives are to describe and evaluate the effects of different methods of signal analysis for processing of data from equine kinematic gait analysis. To this end, we use theoretical signals based on previously published work, followed by the evaluation of the performance of each technique using real data from horses with induced lameness. Two infinite impulse response (IIR), high-pass filters (Butterworth and Chebyshev), a signal decomposition method and a moving average filtering technique were evaluated. First, we describe methods to fine-tune each filter to the optimal settings based on residual analysis. Second the performance of each filter is evaluated based on differences in calculated symmetry parameters from horses with induced lameness. We show that optimisation of filtering techniques is crucial when processing signals used for objective lameness quantification. Improper selection of the cut-off frequency for IIR filters can result in false negative results (average values above or below predefined reference values). The IIR Butterworth filter and the signal decomposition method achieved the best reduction of unwanted signal components. Knowledge of the available filtering techniques is a pre-requisite for adequate signal processing of gait data from quantitative analysis systems in horses. 


\section{Introduction}

Quantitative gait analysis in horses is a long-standing technique in research, but is now rapidly becoming very popular as an objective method to detect and quantify gait abnormalities in a clinical setting $[1,2]$. It provides the veterinarian profession with objective and unbiased gait information that can be used during the clinical examination of horses presented with problems of the locomotor system, aiding the veterinarian in the localization and diagnosis of orthopaedic problems and offering a unique opportunity for the objective monitoring of the effect of diagnostic or therapeutic interventions. Presently, objective lameness assessment in horses is generally based on the identification and quantification of movement asymmetries of the vertical displacement/acceleration of the head [3-6], withers [3,6-8] and pelvis [9-12] during straight line locomotion at the trot. This is further explained in the background section.

Errors related to kinematic measurements in equine gait analysis can result from a variety of factors including: (a): improper sensor or marker placement $[13,14]$ and Serra Braganca et al. 2017); (b): effect of skin displacement [15,16]; (c) improper recording settings (e.g. frame rate) [17] and, in case 3D motion capture is used as the technique, improper number of cameras, marker size and tracking algorithms [18]. These factors are well-known, and measures to minimise them form part of most kinematic measurement protocols. Nevertheless, all raw kinematic data collected in a biological setting using any instrument will, due to confounding factors, ultimately contain a certain number of unwanted components [4] that affect the signal, necessitating a treatment to allow for the accurate calculation of relevant kinematic parameters [18-20].

One important unwanted component in the vertical displacement signal (VDS) of the head, withers, or pelvis in horses is the displacement offset for the different strides caused by extraneous non-cyclical motion (for instance caused by the animal raising/ lowering its head) that is unrelated to the primary locomotion symmetry and which might obscure the original sinusoidal motion signal. Other unwanted components can be an offset in the displacement caused by a slope on the surface the horse is measured when measuring with optical motion capture. The presence of these unwanted components, renders the interpretation and quantification of motion symmetry problematic [4]. Data are therefore routinely processed using a variety of filter techniques. 
The effect of different filtering techniques, used for determination of the VDS has been hypothesised as a possible source of differences in between-stride variation (i.e., variation in motion symmetry between consecutive strides) among different publications [21]. However, to the authors' best knowledge, the topic has never been investigated to some depth.

The objectives of this manuscript are to describe and evaluate the performance of different commonly used signal analysis techniques/filter methods using theoretical and real signals of the VDS measured in clinically lame horses. We aimed to establish the optimal configuration for each filter and to assess to what extent the original signal can be distorted and how this might affect the clinically relevant gait parameters that are used for data interpretation. To this end, the manuscript is structured as follows:

1. Description, evaluation and comparison of different methods for filtering VDS data.

2. Proposition of optimal filter settings that should be used when processing VDS data.

3. Comparison of the effect of each filter on real data from horses with induced lameness.

\section{Background}

\section{A theoretical representation of the VDS of a trotting horse}

During trot, the upper body segments (head, withers, sacrum) describe a sinusoidal curve with twice the frequency of the stride cycle, i.e. the head, pelvis and withers move up and down twice during a full stride [3]. This movement can be thought of as a sum of 2 harmonics $(\mathrm{H} 1)$ and $(\mathrm{H} 2)$ (Fig. 1). $\mathrm{H} 1$ has the same frequency as the stride frequency of the horse $\left(w_{s}\right)$, and $\mathrm{H} 2$ has twice the stride frequency:

$$
y_{t}(t)=A_{1} \cos \left(w_{s} t+\theta_{2}\right)+A_{2} \cos \left(2 w_{s} t\right)
$$

Where $\mathrm{A} 1$ is the amplitude of the $\mathrm{H} 1$ and $\mathrm{A} 2$ is the amplitude of the $\mathrm{H} 2$ component of the signal, wsis the stride frequency and_2is thephase of $\mathrm{H} 1$ relative to $\mathrm{H} 2$. In a perfectly symmetrical movement $\mathrm{H} 2$ is the only component of the signal. A detailed description anddeduction of this equation can be found in Appendix A.When a horse is experiencing prominently unilateralorthopaedic pain, the motion cycle of vertical displacementbecomes asymmetrical $[3,22]$ and the first harmonic of the signal(H1) increases in amplitude. This results in a reduced amplitude ofthe VDS during the 
stance phase of the lame limb, and an increaseon the opposite diagonal [3]. As a consequence of this differencebetween diagonals, the VDS becomes asymmetrical and severalsymmetry parameters can be used to quantify this asymmetry[23].

\section{Methods}

\section{Initial investigation: filter evaluation and design methods}

Several methods to remove the unwanted components present in the VDS have been described in the literature for equine gait analysis including high-pass digital filters like the Butterworth and Chebyshev filters, analysis of the Fourier coefficients [24] and a signal decomposition method [4].

We have generated a theoretical asymmetrical VDS mimicking the motion observed in lame horses, having a frequency of $\mathrm{H} 1$ and $\mathrm{H} 2$ of $1.5 \mathrm{~Hz}$ and $3 \mathrm{~Hz}$ respectively, sampled at $200 \mathrm{~Hz}$, with a signal length of $12 \mathrm{~s}$. To this, with added unwanted lowfrequency components (noise), in order to mimic data described in the literature [4] (Fig. 1).

\section{Digital IIR filters}

Since the noise signal frequency is lower than the frequency of the first and second harmonic an high-pass filter could be applied. We started by comparing two infinite impulse response (IIR) filters that can be used to remove this low-frequency noise, the Butterworth filter and the Chebyshev type I filter (Supplement, Fig. 1). IIR filters have been extensively used to filter VDS from horses during trot [25-28]. Both filters were applied using a zero-phase filtering technique using the Matlab (MathWorks, Natick, Massachusetts, USA) function 'filtfilt'. To investigate the effect of the filter transients and to mitigate this problem, we have evaluated both IIR filters using a padding technique that fills both edges of the signal, with an artificial signal. This operation was performed by autoregressive modelling using the Matlab function 'fillgaps.' For this model, the padding length was defined as $25 \%$ of the original length of the signal on each edge.

\section{Design of the analysis of signal decomposition method filter (SDMF)}

SDMF is based on the principle described by [4]. This approach uses a curve fitting operation to estimate the three components of the VDS $(\mathrm{H} 1, \mathrm{H} 2$ and the unwanted component). The filter was designed according to the following algorithm. 

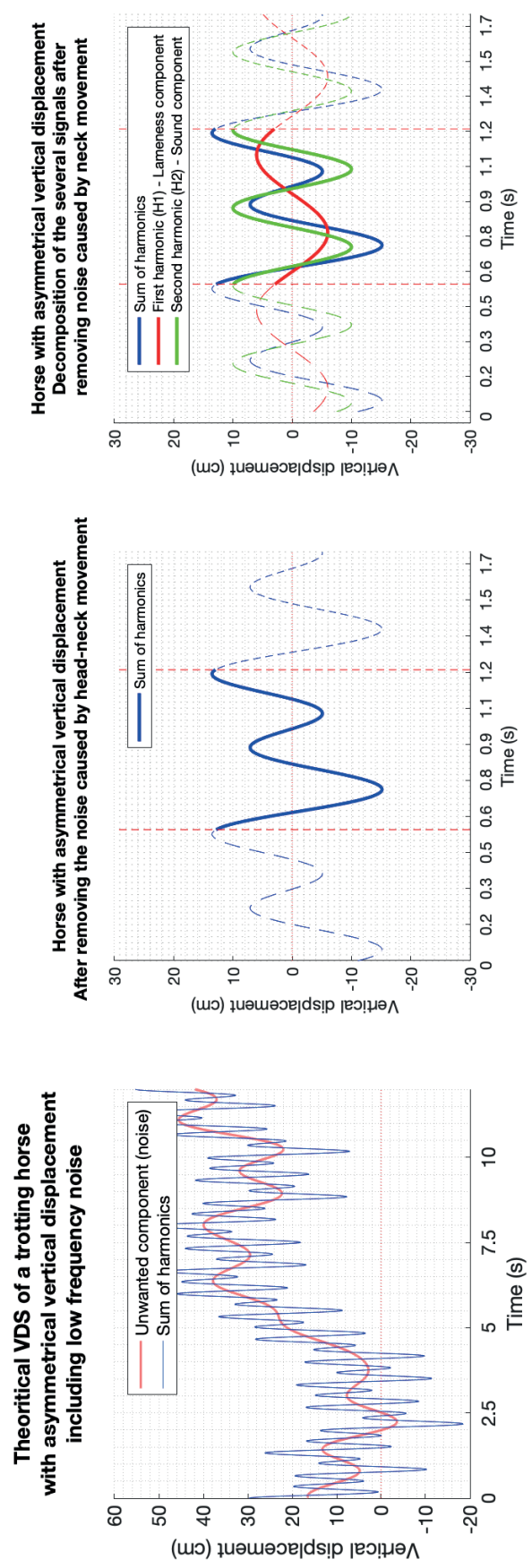

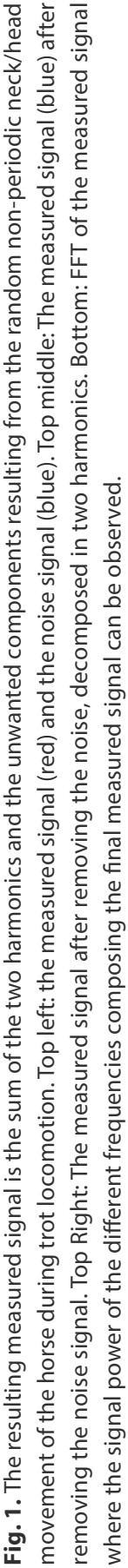


1. A window for the data analysis is initiated. The window length corresponds to two complete stride cycles, which allows for complete discrimination between the three components of the signal. The window length can be defined by stride events when available or using a fast Fourier transformation (FFT) on the VDS to find the frequency of the two harmonics, $\mathrm{H} 1\left[w_{s}\right]$ and $\mathrm{H} 2\left[2 w_{s}\right]$. Using the sampling frequency $\left(F_{s}\right)$ and the stride frequency $\left(w_{s}\right)$, the window length can, therefore, be defined as:

$$
\text { window }_{\text {length }}=\frac{2 \pi \cdot F s}{w_{s}}
$$

2. A fast Fourier transformation (FFT) is then performed on the VDSwithin the window to find the specific frequency of the two har-monics ( $\mathrm{H} 1$ [ws] and $\mathrm{H} 2[2$ ws]).

3. For each window, a curve fitting operation is performed on themeasured VDS using a non-linear least squares approach and theequation previously described (Appendix A):

$$
y_{t}(t)=A_{1} \cos \left(w_{s} t+\theta_{2}\right)+A_{2} \cos \left(2 w_{s} t\right)+A_{3}+A_{4} t+A_{5} t^{2}+A_{6} t^{3}
$$

Where wsis the frequency of the first harmonic $(\mathrm{H} 1)$, _2is the phaseshift of $\mathrm{H} 1$ relative to $\mathrm{H} 2, \mathrm{~A} 1$ and $\mathrm{A} 2$ are the amplitudes of $\mathrm{H} 1$ and $\mathrm{H} 2$ respectively, $A_{3}$ is a moving average and $A_{4-6}$ are the amplitudes of each element of a third order polynomial function.

4. The unknown coefficients are estimated using a trust-regionreflective least squares approach, using Matlab function 'Isqnonlin'. Using coefficients $A_{3-6}$ the unwanted components present in the signal can be predicted and using the remaining coefficients, the VDS signal can be estimated.

\section{Designing a moving average filter}

A moving average was calculated for each frame of the data using a sliding window. Varying window lengths were tested, ranging from 0.1-6 complete strides. This filter technique was also evaluated with and without the padding technique as described in section. 1.1. The filtered signal was calculated by subtracting the moving average from the raw signal. 


\section{Filter evaluation and optimisation}

To evaluate the performance of each filter technique, we calculated the residuals $(r)$ between the raw and filtered signal:

$$
r=p-(p \hat{+} n)
$$

Where $(p)$ represents the original clean VDS, $(n)$ represents the unwanted components on the signal and $(p \hat{+} n)$ represents the filter output of $(p+n)$. This operation was performed in signals with increasing degree of asymmetry (Supplement, Fig. 2). For the IIR filters and the moving average filter we calculated residuals for incremental degrees of asymmetry (See supplement Fig. 2) and filter cut-off frequency (from 0.1 $\mathrm{Hz}$ to $6 \mathrm{~Hz}$ ), thus covering the upper and lower ranges of previously described cut-off frequencies [25-28]. For the moving average filter, we have calculated residuals for incremental degrees of asymmetry and moving window length (defined as the number of strides, ranging from 0.1-6 strides). The increasing degrees of asymmetry was generated by increasing the amplitude of $\mathrm{H} 1$, as previously shown in horses with induced lameness [4].

\section{Evaluation of the different filter techniques in VDS symmetry in real data from horses, before and after lameness induction}

Based on the results of the initial investigation, we have createda procedure (Diagram 1) to evaluate the effect and performanceof the different filters using real data. We have used data from aprevious study [29] in which lameness had been induced in sevenhealthy horses (in 4 horses in a forelimb and in 3 in a hindlimb)using a modified horseshoe. This shoe consists of a heart-bar horse-shoe, where an M10 screw is fitted, so the end of the screw willcontact the tip of the frog (Supplement Fig. 3). Lameness is inducedwhen the screw is inserted and tightened, applying pressure tothe tip of the frog. Horses were measured in trot on a straightline, before and after lameness induction using 18 optical motioncapture cameras (Oqus 700+, $200 \mathrm{~Hz}$, Qualisys AB, Motion CaptureSystems, Gothenburg, Sweden). Data tracking was manually val-idated, and the 3D coordinates of reflective markers $(19 \mathrm{~mm} \varnothing)$ placed on the poll, withers and pelvis (Supplement, Fig. 4) wereexported into Matlab. Stride segmentation was performed usingthe time index of the maximum protraction of the left hind limb[8]. Data were processed in Matlab:2017b using custom-written scripts. Each filter was developed as described in Diagram 1 and symmetry parameters were calculated as previously described [23]. These parameters were RUD and RDD (difference in upward resp. downward movement of the head, withers and sacrum markers between the right and left halves of a stride), and MinDiff and MaxDiff (difference between right and left halves of a stride in minimum resp. maximum height of markers). 
The study was approved by the local ethics committee in compliance with the Dutch Act on Animal Experimentation.

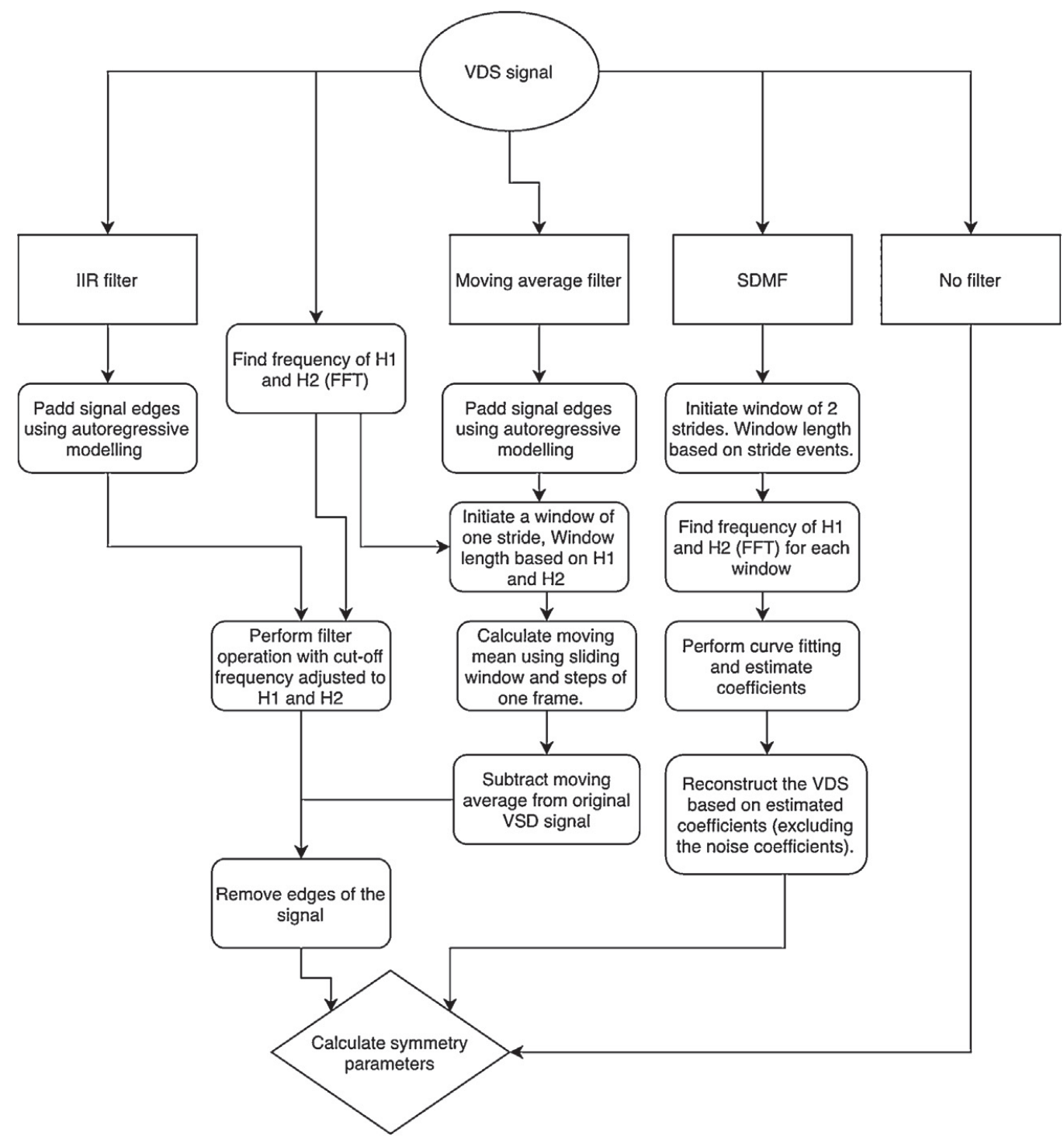

Diagram 1. Data processing and sequence of operations used to evaluate the effect and performance of each filter in the data from horses with induced lameness. VDS: Vertical displacement signal; IIR: Infinite impulse response; SDMF: Signal Decomposition method filter; FFT: Fast Fourier transformation. 


\section{Statistics}

Open software R (R-Studio, Boston, Massachusetts, USA) (version 3.3.1) was used for statistical analysis. To evaluate the effect of each filter, two linear mixed models were generated using the function Imer (Ime4, version 1.1-12). The first model aimed at evaluating the effect of each filter on the mean symmetry parameter calculated for each trial. The second model aimed at evaluating the effect of each filter on betweenstride variation, and its effect on the symmetry parameters calculated for each trial. Betweenstride variation was defined as the median absolute deviation on a trial level. For both models, horse ID and trial within horse ID were used as random effects and the interaction between the filter and the condition (sound and lame) as a fixed effect. The outcome variables were each calculated symmetry parameter. Model estimates (least square means), confidence intervals and $p$-values were calculated from the models using the package Ismeans (version 2.23-5). P-values for the model outcome were corrected for multiple comparison using the false discovery rate method of Benjamini \& Hochberg.

\section{Results and discussion}

\section{Effects of the different filtering techniques on the theoretical VDS}

All tested filters were able to remove the unwanted components of the signal to different extents (Table 1, Figs. 1 and 3). The described padding technique achieved an optimal reduction of the transient effect on the VDS edges (Table 1, Fig. 3). The degree of asymmetry did not affect the selection of the optimal cut-off frequency in our results. Choosing an appropriate value for the cut-off frequency of the IIR filters and the window size for the moving average filter, appear to be of great importance when optimising filtering techniques for the tested VDS (Fig. 1).

\section{Selection of the optimal cut-off frequency}

An initial investigation of the theoretical signal demonstrated that the selection of the cut-off frequency used for the IIR filter is crucial (Fig. 4). When the cut-off frequency of the filter is too low, almost no unwanted components are attenuated, as can be anticipated. On the other hand, if the cut-off frequency of the filter approaches the frequency of the first harmonic $(\mathrm{H} 1)$, the asymmetry of the signal is reduced, and any symmetry parameters calculated after that will be affected (Fig. 4). This is also demonstrated in Fig. 2. The residual analysis shows that a clear optimal cut-off frequency can be achieved (Table 1), and this frequency is below the frequency of $\mathrm{H} 1$ (stride frequency). 
Table 1. Descriptive statistics of the comparison of the four different filter techniques at their optimal setting RMSE: root mean square error. Mean residual as the mean of the absolute residuals (theoretical signal - filter output). *: This parameter was not tested as it is already described in the literature ([4]).

\begin{tabular}{|c|c|c|c|c|c|c|c|}
\hline & \multicolumn{2}{|c|}{ Butterworth } & \multicolumn{2}{|c|}{ Chebyshev type I } & \multicolumn{2}{|c|}{ Moving average } & \multirow[t]{2}{*}{ SDMF } \\
\hline & $\begin{array}{c}\text { with } \\
\text { padding }\end{array}$ & $\begin{array}{l}\text { without } \\
\text { padding }\end{array}$ & $\begin{array}{c}\text { with } \\
\text { padding }\end{array}$ & $\begin{array}{l}\text { without } \\
\text { padding }\end{array}$ & $\begin{array}{c}\text { with } \\
\text { padding }\end{array}$ & $\begin{array}{l}\text { without } \\
\text { padding }\end{array}$ & \\
\hline RMSE & 0.24 & 1.29 & 0.05 & 1.35 & 0.99 & 1.17 & 0.17 \\
\hline Mean residual (mm) & -0.07 & -1.21 & -0.03 & -1.08 & -0.5 & 0.81 & 0.17 \\
\hline s.d. residual (mm) & 2.4 & 77.45 & 0.59 & 13.51 & 9.98 & 11.69 & 1.78 \\
\hline Max residual (mm) & 5.48 & 130.18 & 1.12 & 27.43 & 19.92 & 35.63 & 5.8 \\
\hline Min residual (mm) & -4.2 & -147.09 & -2.3 & -112.21 & -20.07 & -20.07 & -3.08 \\
\hline $\begin{array}{l}\text { Optimal - cut-off frequency, as } \\
\text { a \% of the step frequency ( } \mathrm{H} 2)\end{array}$ & $36 \%$ & $36 \%$ & $48.7 \%$ & $48.7 \%$ & & & \\
\hline $\begin{array}{l}\text { Window length } \\
\text { (number of strides) }\end{array}$ & & & & & 0.95 & 0.95 & $2 *$ \\
\hline
\end{tabular}
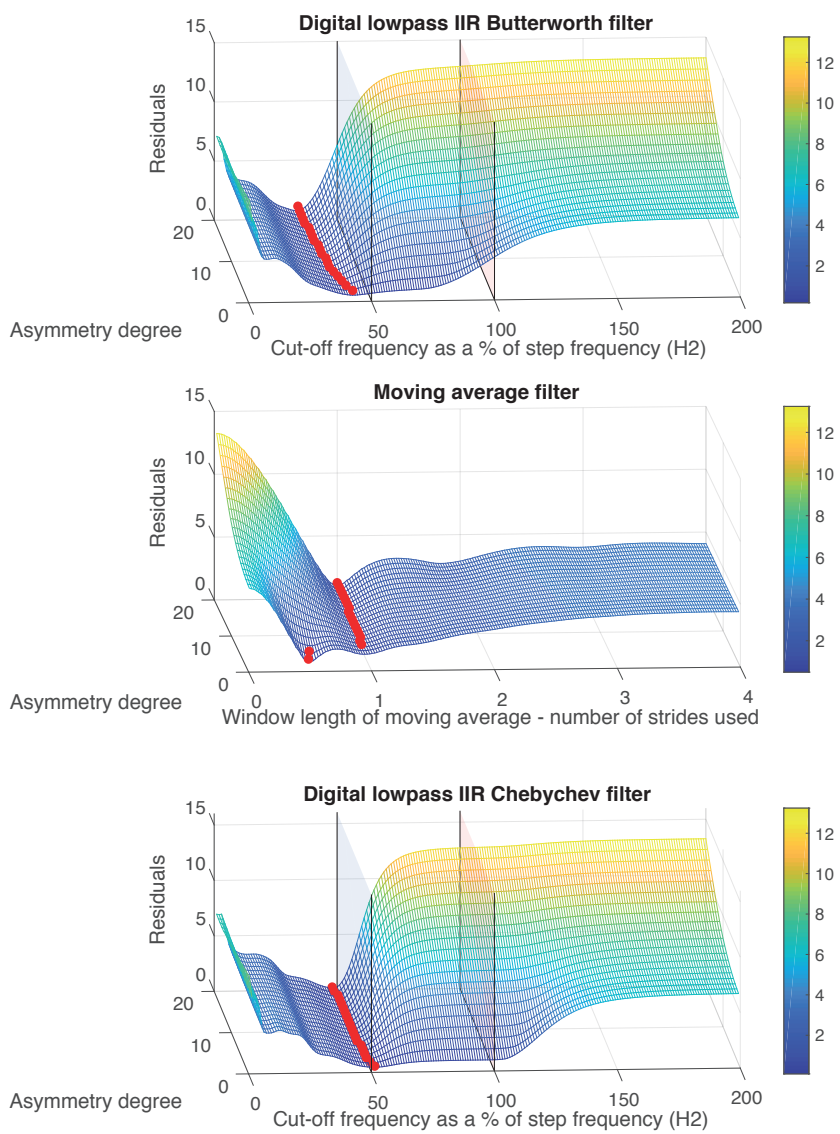

Fig. 2. 3D mesh plot of the filter residuals (z-axis) against increasing filter order (y-axis) and increasing cut-off frequency (x-axis) for both Butterworth and Chebyshev type I filters. The points with the lowest residuals are indicated in red. 


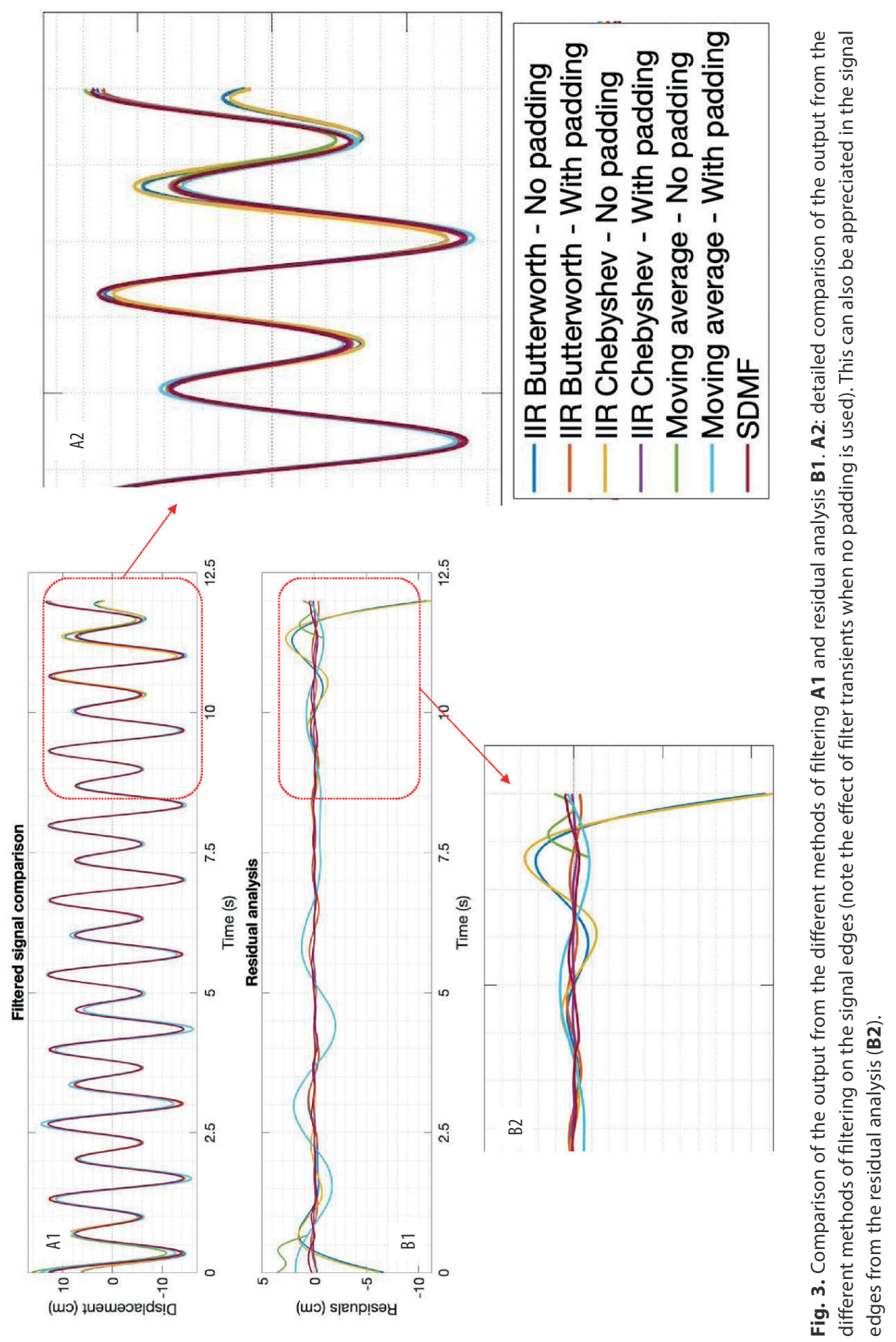



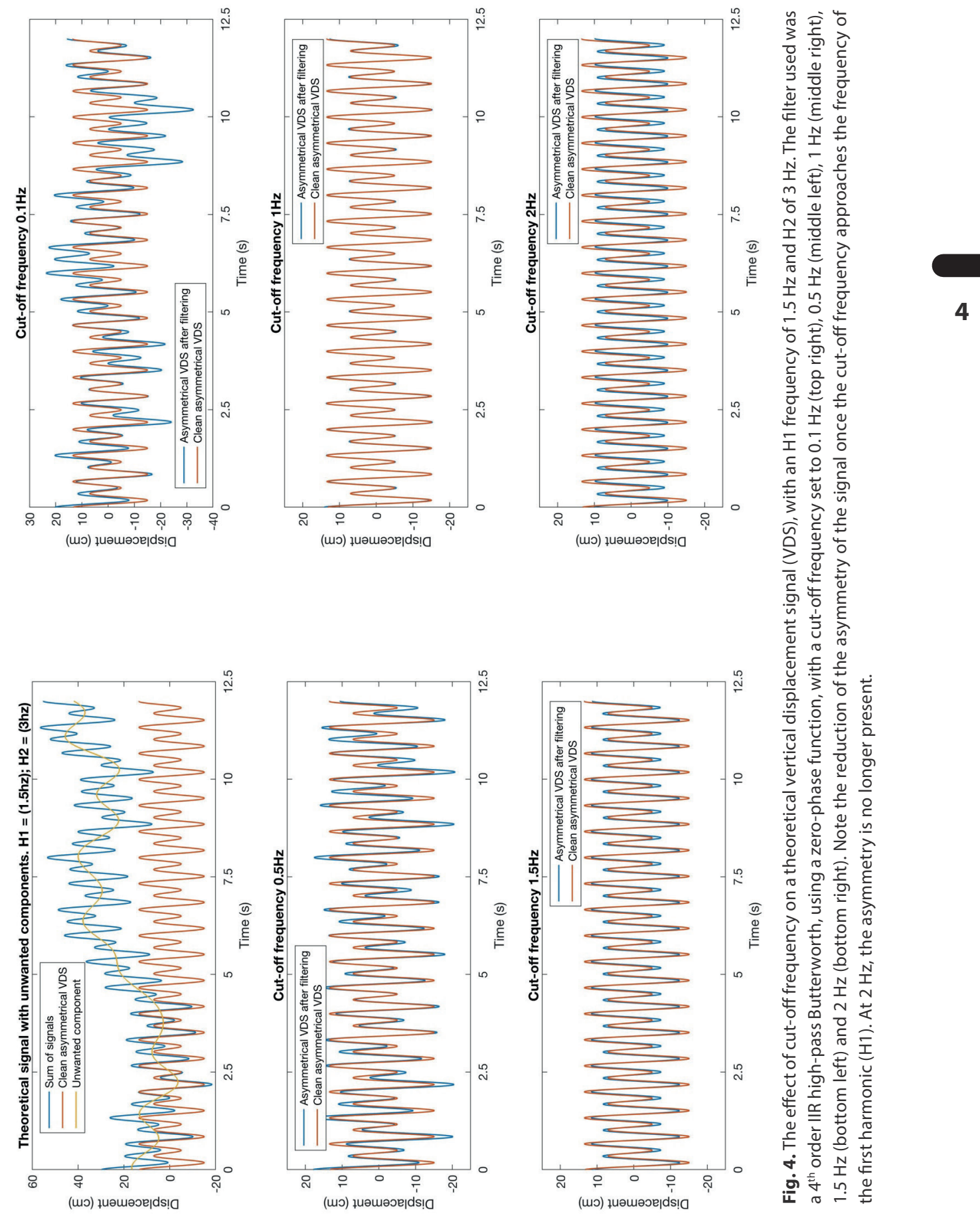
Suboptimal selection of the cut-off frequency, aproaching or even above the frequency of $\mathrm{H} 1$ can, in theory, result in false negative results when this technique is used to evaluate motion symmetry due to lameness. This has not always been acknowledged explicitly in earlier research where a set cut-off frequency was used for IIR filters [2528]. However, in these publications, the chosen cut-off frequencies were below the expected stride frequency $(\mathrm{H} 1)$ for trotting horses, so no considerable reduction of asymmetry can be expected to have occurred. Nevertheless, it is crucial to determine the optimal cut-off frequency for each signal, since the frequency of each harmonic is dependent on the speed of the horse [30] as well as individual horses can have rather different stride frequencies, within the same speed. Higher speeds are related to higher stride frequencies $(\mathrm{H} 1)$, and if the preset cutoff frequency is too low in relation to the frequency of $\mathrm{H} 1$, this might result in a suboptimal noise reduction and higher values of between-stride variation.

Another crucial factor is that, when the cut-off frequency is selected for a specific signal, it is assumed that the frequency of the signal does not change over time. For measurements performed on a treadmill this is generally the case, as belt speed can be adjusted and maintained. However, measurements overground are subject to variations in speed over time (Fig. 5), which will affect the frequency of the signal components $\mathrm{H} 1$ and $\mathrm{H} 2$. When a high variation in speed is present within a measurement, IIR filters might not be the optimal solution since they work on a frequency domain.

It should be noted that the approach for filter optimisation described above was applied to theoretical signals. In this context, it is important to state that the optimal cut-off frequency is most likely dependent on the different unwanted components present in the VDS and thus can be different under other conditions. Therefore, the results here described should be used as guidelines and not seen as a strict rule. We advise readers to study their signals and adjust their filter settings accordingly. Nevertheless, the use of standardised methods for signal analysis allows for the better comparison of measurements from different studies and will increase reproducibility.

\section{Effect of filter transients when using IIR filters}

The effect of filter transients when using IIR filters is well described. As seen in Fig. 3, the edges of the filtered signal can be severely affected, which may ultimately result in erroneous symmetry calculations. To overcome this problem, our proposed method of autoregressive modelling of the edges of the signal successfully resulted in removing the effect of filter transients, while preserving all available strides from a measurement and not affecting the optimal cut-off frequency (Table 1). 


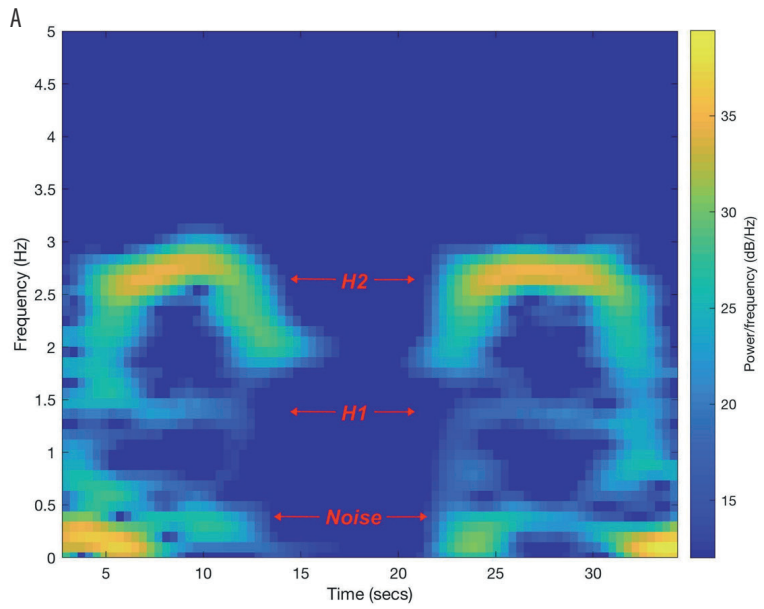

B

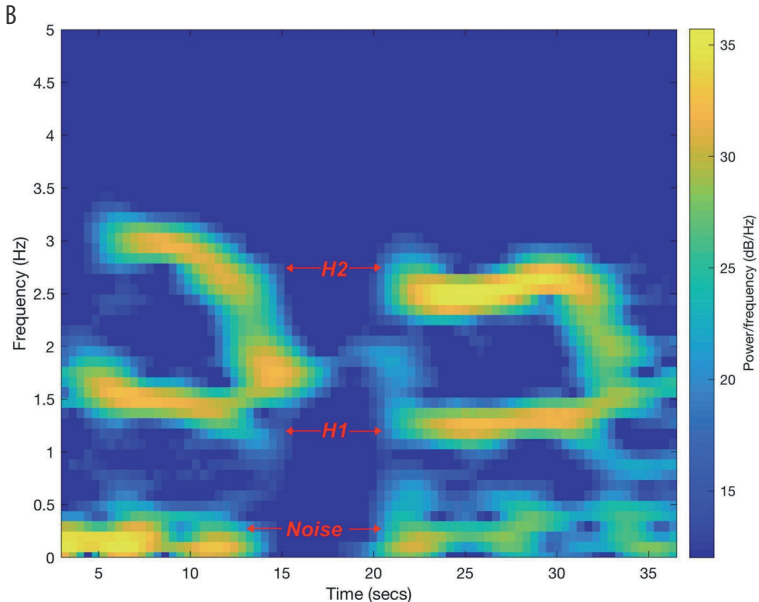

Fig. 5. Spectrogram of the vertical displacement signal from a horse trotting overground, before (A) and after (B) lameness induction. Each plot consists of two runs, with a period where the horse stopped between the runs. Note that the frequencies of $\mathrm{H} 1$ and $\mathrm{H} 2$ are not constant throughout the measurement due to variations in speed. Also, note the increased amplitude (Power) of $\mathrm{H} 1$ after lameness induction.

An additional approach to mitigate this can be excluding the first and last stride(s) of a measurement. Removing the first and last stride(s) might also be useful in measurements where there are large variations in speed, which ultimately might cause an increase in between-stride variation. However, if the number of available strides for a specific measurement is small, which is often the case for gait analysis using optical motion capture (due to the number of cameras available to record several consecutive strides), this solution is less than optimal. Gait analysis systems using sensors attached to the horse (e.g. accelerometers) generally do not suffer from this limitation to the same extent, since quite often, more strides are easily recorded with such systems using wireless data transmission or continuous on-board data logging. 


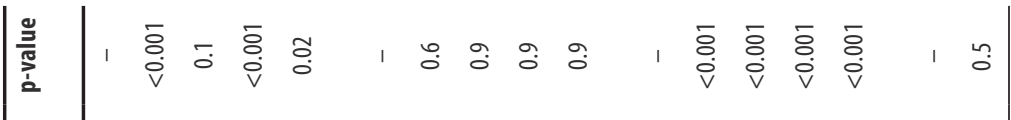

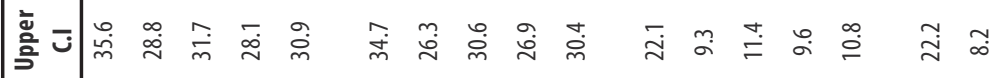

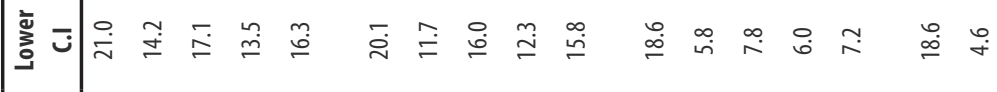

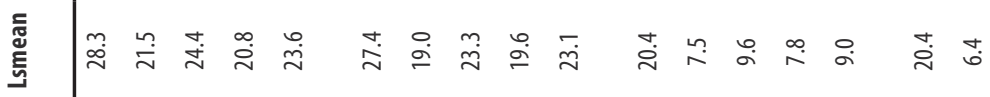

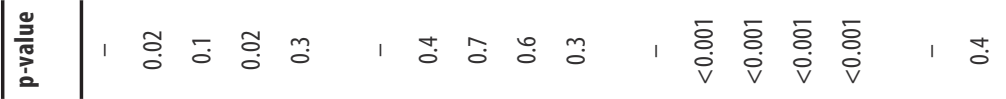

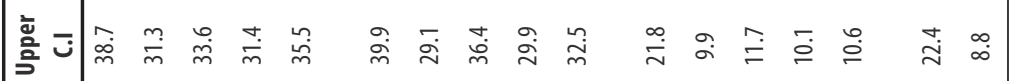

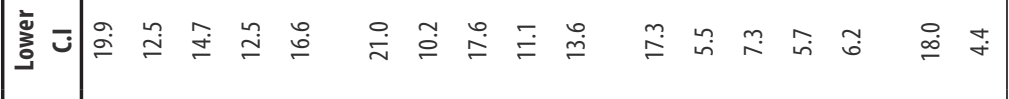

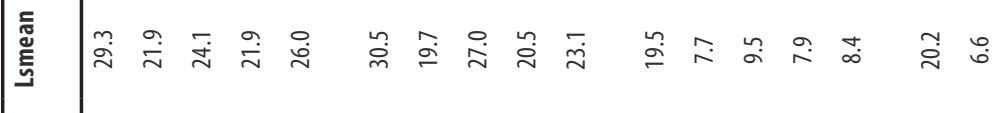

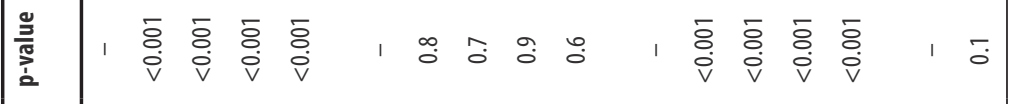
产

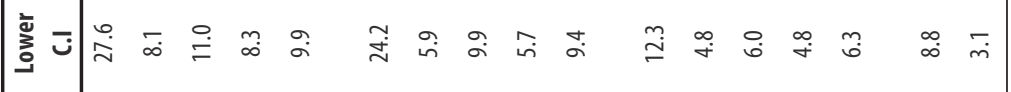

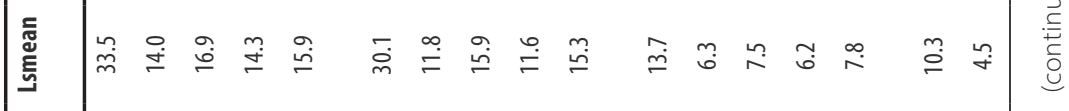

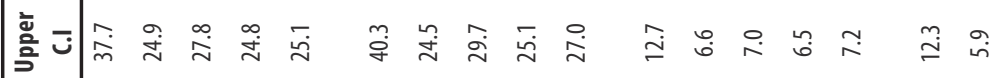

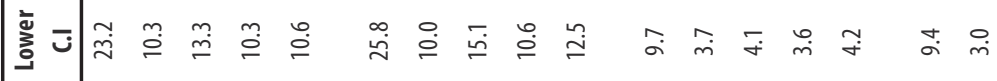

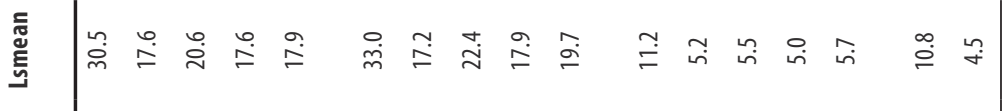

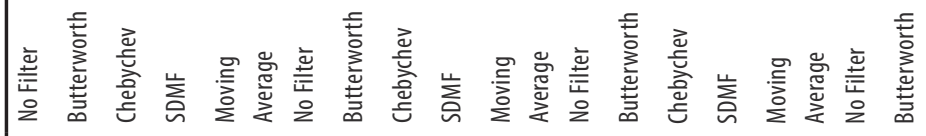
홈 䓌 흠 흄 


$$
\begin{aligned}
& \text { ำ }
\end{aligned}
$$

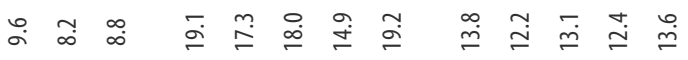

$$
\begin{aligned}
& \text { ஏ }
\end{aligned}
$$

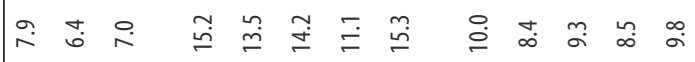

$$
\begin{aligned}
& \text { m }
\end{aligned}
$$

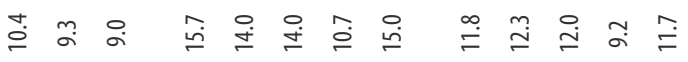

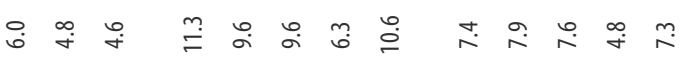

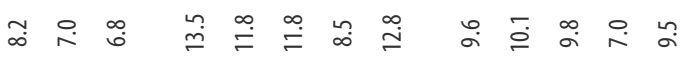

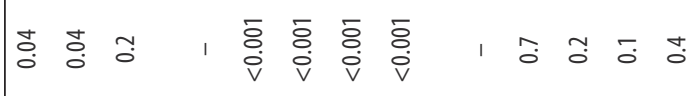

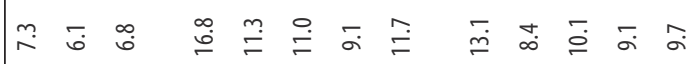

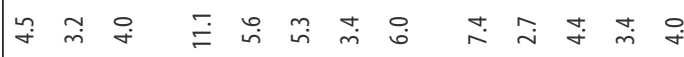

$$
\begin{aligned}
& \text { 虫 F }
\end{aligned}
$$

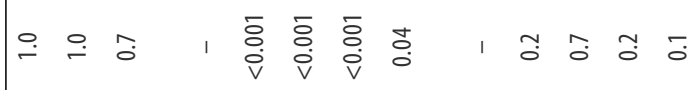

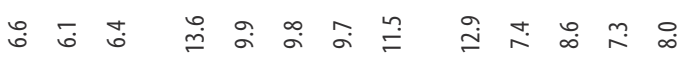

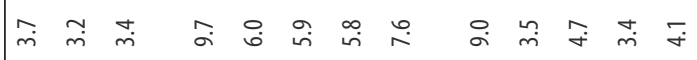

$$
\begin{aligned}
& \text { ர் }
\end{aligned}
$$

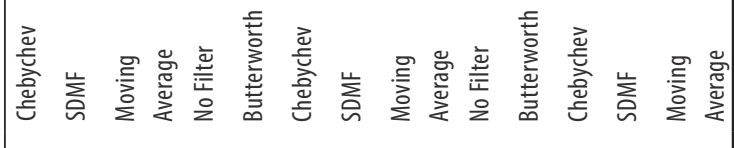

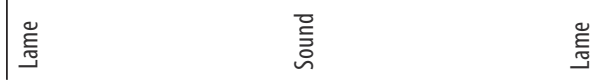

$$
\begin{aligned}
& \frac{n}{\overline{2}}
\end{aligned}
$$




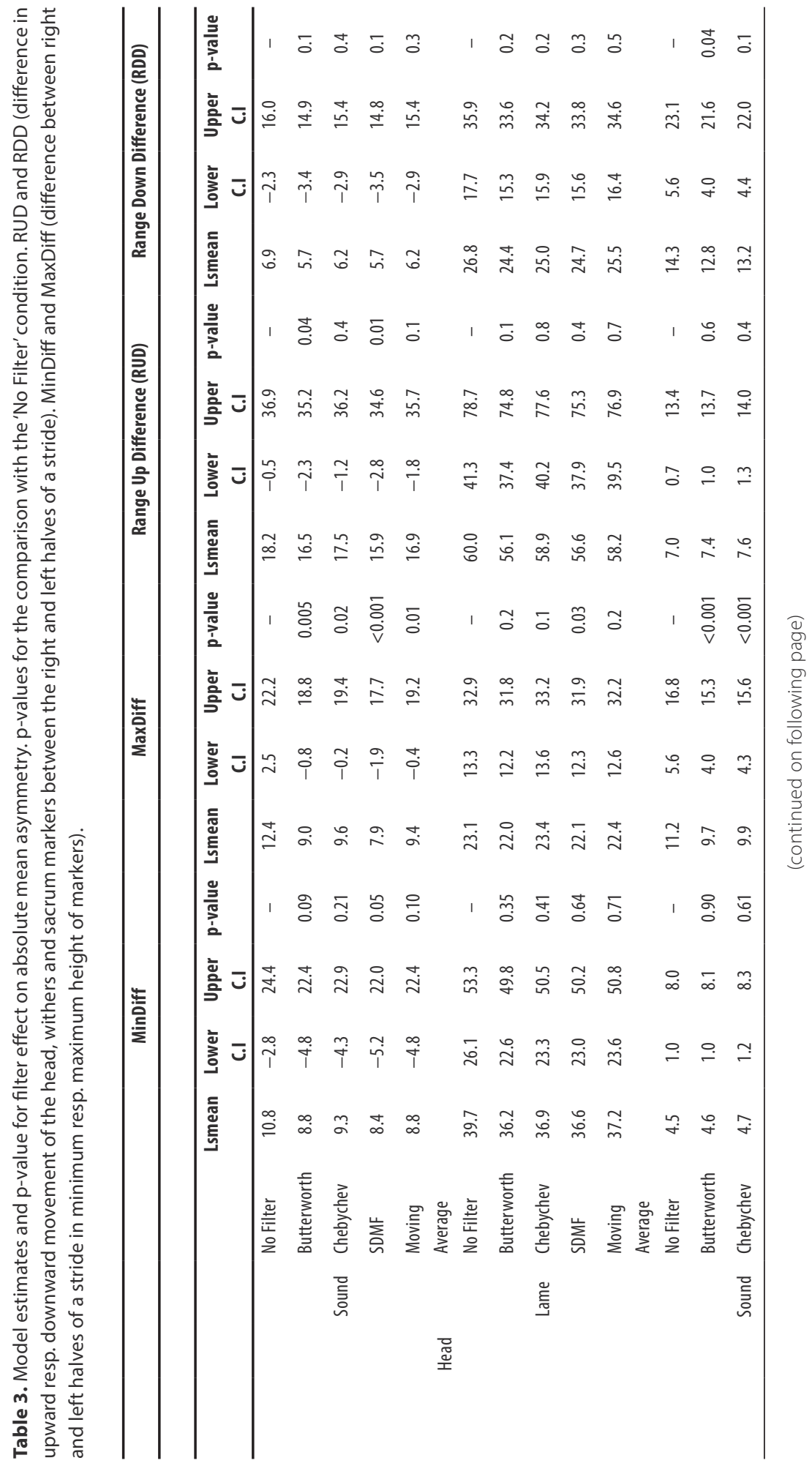




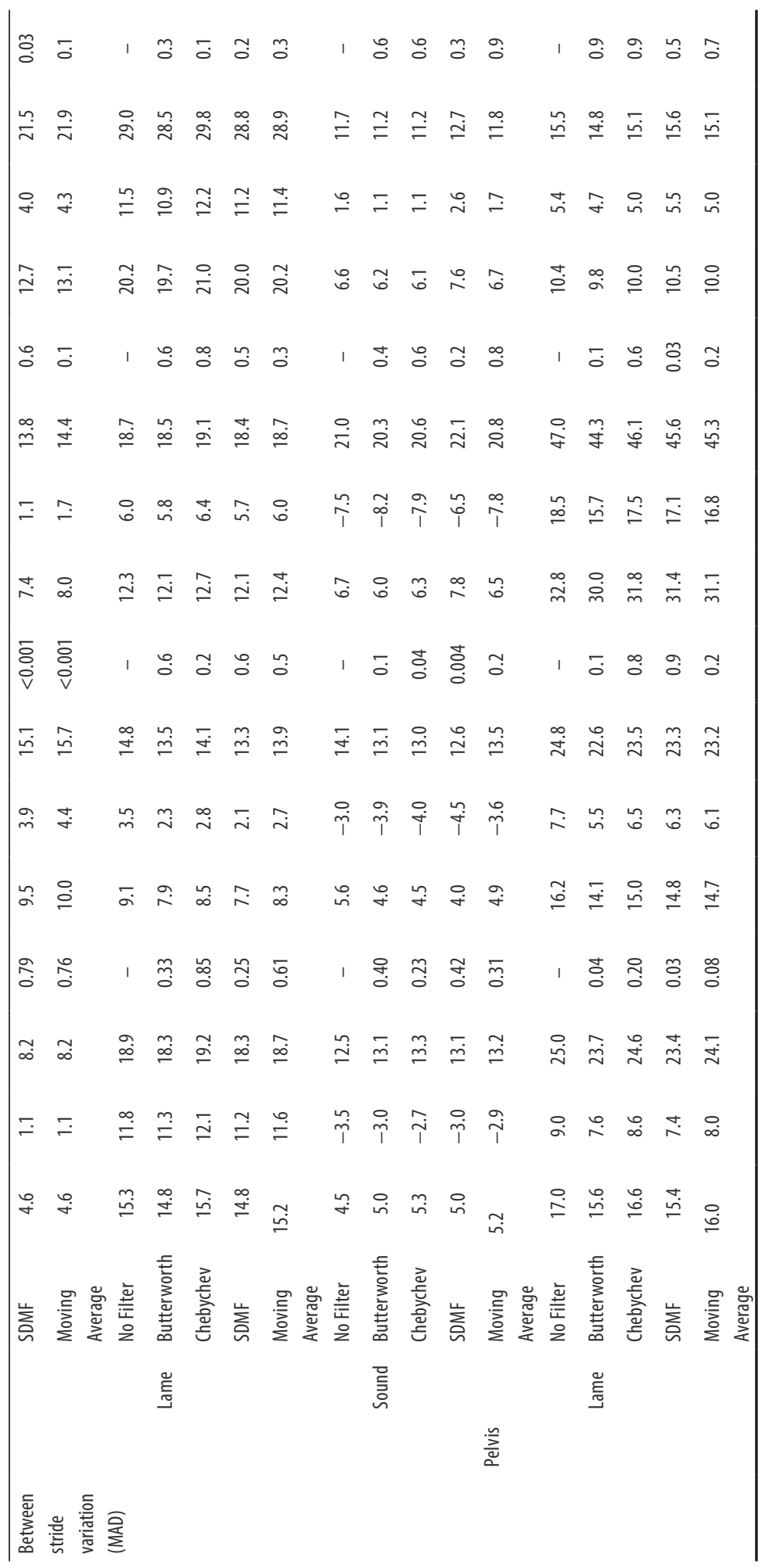




\section{Filter effects in real data from horses with induced lameness: effect on the commonly calculated symmetry parameters}

Our results suggest that the choice of filtering technique has mainly an effect on the between-stride variation. In our results, this is confirmed by an overall reduction in between-stride variation on the calculated symmetry parameters for all filters, when compared to the no filter situation. Fig. 6 illustrates the effect of each filter technique on the MinDiff of the head, withers and pelvis VDS before (sound) and after (lame) lameness induction. Tables 2 and 3 describe the detailed model estimates and the comparison of the performance of the different outputs (Diagram 1).

Regarding the between-stride variation, all tested filter techniques were able to significantly reduce this source of variation in the symmetry parameters, when compared to no filter (Table 2). The filter effect was more pronounced on the symmetry parameters of the head, and withers, when compared to the sacrum. A higher natural between-stride variation has previously been reported for the head [9]. This was also obvious in our data, where the model estimates for all filters were smaller for the pelvis symmetry between-stride variation when compared to the head. The Butterworth and the SDMF filters performed well for all body parts, with the SDMF achieving in some occasions, greater reduction of between-stride variation (Table 2), although the difference between the Butterworth and SDMF was not statistically significant (comparison not shown). We hypothesise, as the authors who originally published the technique [4], that the small difference in favour of the SDMF is due to the continuous adjustment to the stride frequency for each curve fitting operation (Diagram 1). Therefore, the technique is well-suited when a measurement takes place overground, during which changes in trotting speed may occur naturally (Fig. 5). Since the IIR filters need to be tuned to the frequency of the entire VDS of the measurement, these might fail to remove some of the unwanted components of the signal. While technically performing slightly better, the SMDF has a main drawback that affects user friendliness. The IIR filters outperform the SMDF regarding the speed with which the filter operation is performed because the SDMF filter requires several optimisations and curve-fitting operators that are comparatively computer intensive.

We also found overall smaller values for between-stride variation, independent of the filter technique used, for horses after lameness induction, compared to before (Table 2). In other words, when horses are suffering from orthopaedic pain, the betweenstride variation is reduced as an effect of pain. This explains why the filter effect is more obvious before lameness induction. The phenomenon of low stride variability in animals with orthopaedic pain has been observed previously [31], and can possibly be related to constrained movements, as an attempt to reduce variation in speed and acceleration. 
Regarding the mean asymmetry values calculated, the filter technique has more pronounced effects on the head and withers for some of the parameters (Table 3). Interestingly, this was more obvious for the head and withers before lameness induction. This finding is in line with the reasoning above and highlights that the filtering operation does not affect the true asymmetry present in the signal and that its primary function is to reduce the unwanted components present in the signal and to calculate asymmetry parameters with higher overall precision.
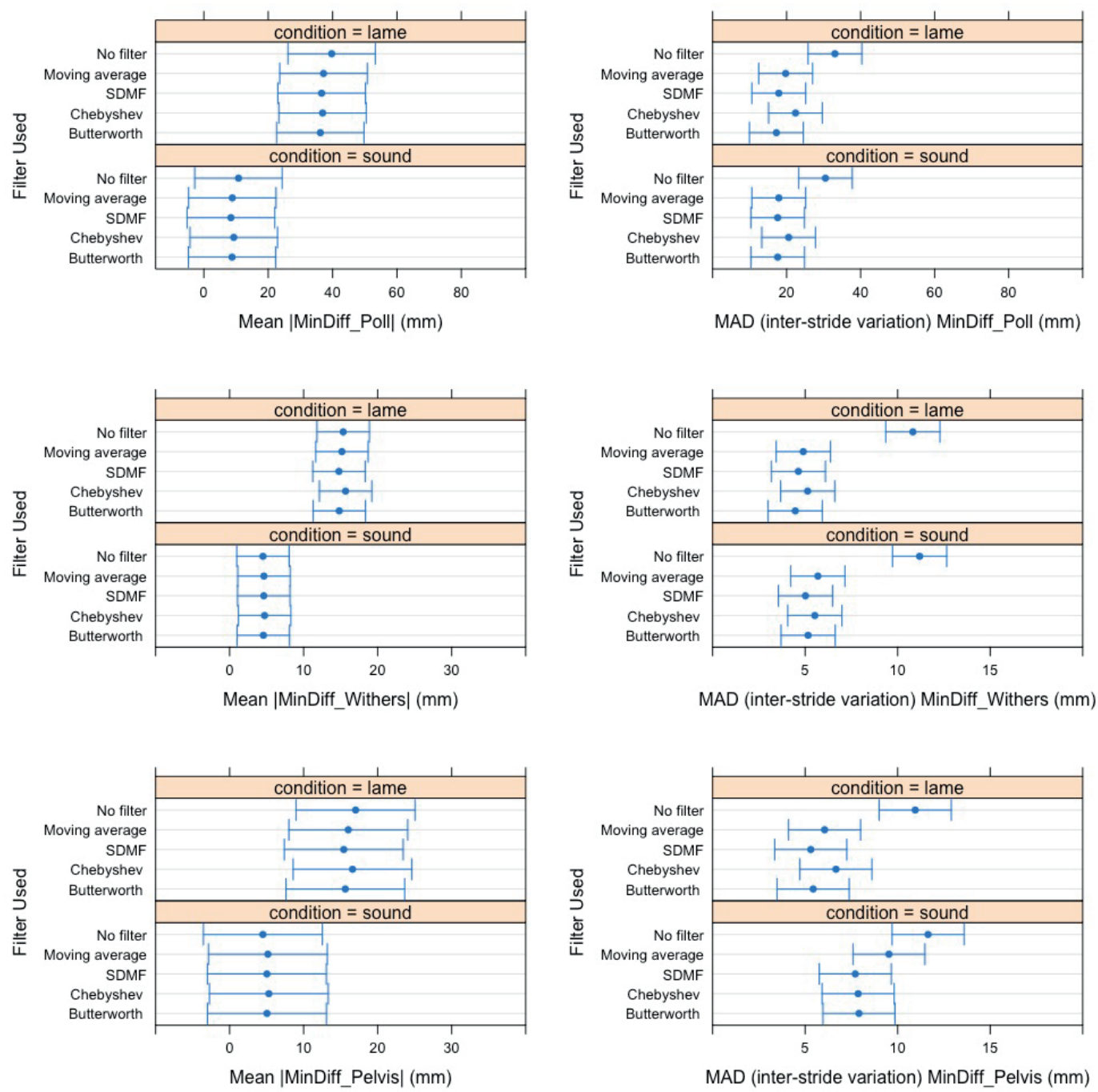

Fig. 6. Least square means (blue dot) and confidence intervals (error bar) for the two models, for the symmetry parameter MinDiff, for head, withers and pelvis. 
One important factor that was not evaluated in this study is the relation between between-stride variation of symmetry parameters and the number of collected strides. It can be anticipated that in measurements where a high between-stride variation is present, a higher confidence in the calculated symmetry values can be achieved by collecting more strides. There are likely a number of confounding factors related to this such as variations in acceleration/speed and demeanor as well as a gradual change in movement asymmetry when a horse is 'warming out of' a lameness or the lameness increases with repeated loading cycles. This evaluation was beyond the scope of this manuscript, but further research is needed to fully understand the relation between between-stride variation and the number of collected strides.

\section{Conclusions}

This study shows the importance of choosing appropriate signal analysis techniques, when processing data acquired using quantitative gait analysis equipment and how these choices may influence commonly used symmetry parameters for objective lameness assessment in horses. Cut-off frequencies that are very close or even higher than the frequency of the first harmonic $(\mathrm{H} 1)$ of the VDS will, depending on the filter type that is used, ultimately distort the measured signal and may result in mean calculated symmetry outside the reference values. On the other hand, when filter operations are suboptimal, this can result in higher between-stride variation that can affect the significance of calculated symmetry parameters. There is hence a considerable impact of filtering on the calculated parameters used for objective lameness assessment, and detailed knowledge of how filters work and what effects their applications may have is a prerequisite for any biomechanical researcher working in this field. Further work is needed to better understand the biological significance of all the different components of the VDS of trotting horses and further signal analysis techniques such as wavelet analysis should be then implemented. 


\section{Sources of funding}

Swedish Research Council Formas funded

the study (201412003-28225-26).

\section{Acknowledgement}

We would like to thank Prof. Kevin

Keegan for his valuable input during the development of this manuscript.

\section{Declaration of Competing} Interest

C. Roepstorff is an employee of Qualisys $A B$. No other author of this manuscript has a financial or personal relationship with other people or organisations that could inappropriately influence or bias the content of the paper. 


\section{Appendix A.}

The VDS of a horse during trot can be thought of as a harmonicoscillator described by the equation:

$$
F(t)=-k y(t)
$$

where $\mathrm{k}$ is the spring constant and $\mathrm{y}$ is the displacement. Togetherwith Newton's second law,

$$
F(t)=m \frac{d^{2} y(t)}{d t^{2}}
$$

we get a differential equation on the form,

$$
m \frac{d^{2} y(t)}{d t^{2}}+k y(t)=0
$$

which has the solution

$$
y(t)=A \cdot \cos (w t+\theta)
$$

where $A 2 A$ is the amplitude of the sinusoid, $w=\sqrt{\frac{k}{m}} \mathrm{w}=\sqrt{\frac{\mathrm{k}}{\mathrm{m}}}$ and $\theta \theta$ is the phase shift. We define wswsas the angular frequencyof the horse's stride, thus leading to an equation describing thesymmetric step component of the movement $(\mathrm{H} 2)$,

$y_{1}(t)=A_{2} \cos \left(2 w_{s} t+\theta_{1}\right)$

When a horse is experiencing orthopaedic pain, this motioncycle becomes asymmetrical $[3,22]$. This asymmetric stride com-ponent $(\mathrm{H} 1)$ of the movement can be theoretically described as:

$$
y_{2}(t)=A_{1} \cos \left(w_{s} t+\theta_{2}\right)
$$

The total vertical displacement, including both the step (2ws)and stride wsfrequency component, ends up as the sum of the lasttwo equations:

$y_{t}(t)=A_{1} \cos \left(w_{s} t+\theta_{2}\right)+A_{2} \cos \left(2 w_{s} t+\theta_{1}\right)$

As the phase shift describes how the two sinusoids are shiftedabout what is considered zero in time, we can, for the sake of sim-plicity, define t0t0to always occur so that $1=01=0$, resultingin the following formula:

$y_{t}(t)=A_{1} \cos \left(w_{s} t+\theta_{2}\right)+A_{2} \cos \left(2 w_{s} t\right)$

where $A 1 A 1$ is the amplitude of the asymmetric $(\mathrm{H} 1)$ component, $A 2 A 2$ is the amplitude of the symmetric $(\mathrm{H} 2)$ component and 22is the phase shift of the asymmetric stride component.When a horse is trotting overground and to a smaller extendalso on a 
treadmill, additional unwanted components nt(t)nt(t)are added to this signal. These are mainly due to the random non-cyclical motion unrelated to the primary locomotion movement ordue to non-horizontal ground reference (e.g. if the horse is movingon an inclined plane). Previously [4,24], these unwanted compo-nents have been described as a sum of a moving average (C1), anda third order polynomial funtion:

$$
n_{t}(t)=C_{1}+\sum_{K=1}^{3} A_{k} t^{k}
$$

Therefore, the final description of the VDS of a moving horse willbe the sum of the two equations describing both the dorsoventralmovement (sum of the first [H1] and second [H2] harmonic) of thehorse and the unwanted components of the movement as follows:

$$
y_{t}(t)=A_{1} \cos \left(w_{s} t+\theta_{2}\right)+A_{2} \cos \left(2 w_{s} t\right)+A_{3}+A_{4} t+A_{5} t^{2}+A_{6} t^{3}
$$

\section{Appendix B.}

Supplementary dataSupplementary material related to this article can be found,in the online version, at doi:https://doi.org/10.1016/j.bspc.2019.101674. 


\section{References}

[1] F.M.M. Serra Braganc, a, M. Rhodin, P.R.R. van Weeren, On the brink of dailyclinical application of objective gait analysis: What evidence do we have sofar from studies using an induced lameness model? Vet. J. 234 (2018) 11-23,http://dx.doi.org/10.1016/j.tvjl.2018.01.006.

[2] P.R. van Weeren, T. Pfau, M. Rhodin, L. Roepstorff, F. Serra Braganc, a, M.A.Weishaupt, Do we have to redefine lameness in the era of quantitative gaitanalysis? Equine Vet. J. 49 (2017) 567-569, http://dx.doi.org/10.1111/evj.12715.

[3] H.H.F. Buchner, H.H. Savelberg, H.C. Schamhardt, A. Barneveld, Head andtrunk movement adaptations in horses with experimentally induced foreorhindlimb lameness, Equine Vet. J. 28 (1996) 71-76, http://dx.doi.org/10.1111/j.2042-3306.1995.tb04911.x.

[4] K.G. Keegan, P.F. Pai, Da Wilson, B.K. Smith, Signal decomposition method ofevaluating head movement to measure induced forelimb lameness in horsestrotting on a treadmill, Equine Vet. J. 33 (2001) 446-451, http://dx.doi.org/10.2746/042516401776254781.

[5] C. Peham, T. Licka, D. Girtler, M. Scheidl, Supporting forelimb lameness:clinical judgement vs. computerised symmetry measurement, Equine Vet. J.31 (1999) 417-421.

[6] J.G. Peloso, J.A. Stick, R.W. Soutas-Little, J.C. Caron, C.E. DeCamp, D.H. Leach,Computer-assisted three-dimensional gait analysis of amphotericin-inducedcarpal lameness in horses, Am. J. Vet. Res. 54 (1993) 1535-1543.

[7] E. Persson Sjödin, F. Serra Braganca, T. Pfau, A. Egenvall, M.A. Weishaupt, M.Rhodin, Movement symmetry of the withers can be used to discriminateprimary forelimb lameness from compensatory forelimb asymmetry inhorses with induced lameness, Equine Vet. J. 48 (2016) 32-33, http://dx.doi.org/10.1111/evj.64 12595.

[8] M. Rhodin, E. Persson-Sjodin, A. Egenvall, F.M. Serra Braganc, a, T. Pfau, L.Roepstorff, M.A. Weishaupt, M.H. Thomsen, P.R. van Weeren, E. Hernlund,Vertical movement symmetry of the withers in horses with induced forelimband hindlimb lameness at trot, Equine Vet. J. 50 (2018) 818-824, http://dx.doi.org/10.1111/evj.12844.

[9] K.G. Keegan, J. Kramer, Y. Yonezawa, H. Maki, P.F. Pai, E.V. Dent, T.E.Kellerman, D.A. Wilson, S.K. Reed, Assessment of repeatability of a wireless,inertial sensor-based lameness evaluation system for horses, Am. J. Vet. Res.72 (2011) 1156-1163, http://dx.doi.org/10.2460/ajvr.72.9.1156.

[10] K.G. Keegan, Y. Yonezawa, F. Pai, Da. Wilson, J. Kramer, Evaluation of asensor-based system of motion analysis for detection and quantification offorelimb and hind limb lameness in horses, Am. J. Vet. Res. 65 (2004)665-670, http://dx.doi.org/10.2460/ajvr.2004.65.665.

[11] J. Kramer, K.G. Keegan, G. Kelmer, D.A. Wilson, Objective determination ofpelvic movement during hind limb lameness by use of a signal decompositionmethod and pelvic height differences, Am. J. Vet. Res. 65 (2004) 741-747,http://dx.doi.org/10.2460/ajvr.2004.65.741.

[12] T. Pfau, C. Spicer-Jenkins, R.K. Smith, D.M. Bolt, a Fiske-Jackson, T.H. Witte,Identifying optimal parameters for quantification of changes in pelvicmovement symmetry as a response to diagnostic analgesia in the hindlimbs ofhorses, Equine Vet. J. 46 (2014) 759-763, http://dx.doi. org/10.1111/evj.12220.

[13] F. Audigié, P. Pourcelot, C. Degueurce, J.M. Denoix, D. Geiger, C. Bortolussi,Asymmetry in placement of bilateral skin markers on horses and effects ofasymmetric skin marker placement on kinematic variables, Am. J. Vet. Res. 59(1998) 938-944.

[14] B.T. Torres, D. Whitlock, L.R. Reynolds, Y.-C. Fu, J.A. Navik, A.L. Speas, A.Sornborger, S.C. Budsberg, The effect of marker location variability onnoninvasive canine stifle kinematics, Vet. Surg. 40 (2011) 715-719, http://dx.doi.org/10.1111/j.1532-950X.2011.00852.x.

[15] P.R.vanWeeren, a J.van den Bogert, a Barneveld, A quantitative analysis ofskin displacement in the trotting horse, Equine Vet. J. Suppl. (1990) 101-109,http://dx.doi.org/10.1111/j.2042-3306.1990. tb04746.x. 
[16] P.R. van Weeren, A.J. van den Bogert, A. Barneveld, Quantification of skindisplacement near the carpal, tarsal and fetlock joints of the walking horse,Equine Vet. J. 20 (1988) 203-208.

[17] C. Peham, Signals from materials, in: W. Back, H.M. Clayton (Eds.), EquineLocomotion, 2013, pp. 61-71.

[18] H.C. Schamhardt, A.J. van den Bogert, W. Hartman, Measurement techniquesin animal locomotion analysis, Acta Anat. (Basel). 146 (1993) 123-129.

[19] S. Schreven, P.J. Beek, J.B.J. Smeets, Optimising filtering parameters for a 3Dmotion analysis system, J. Electromyogr. Kinesiol. (2015), http://dx.doi.org/10.1016/j.jelekin.2015.06.004.

[20] D.A. Winter, H.G. Sidwall, D.A. Hobson, Measurement and reduction of noisein kinematics of locomotion, J. Biomech. (1974), http://dx.doi.org/10.1016/0021-9290(74)90056-6.

[21] M.F. Sepulveda Caviedes, B.S. Forbes, T. Pfau, Repeatability of gait analysismeasurements in Thoroughbreds in training, Equine Vet. J. 50 (2018)513-518, http://dx.doi.org/10.1111/ evj.12802.

[22] P. Kübber, J. Kastner, D. Girtler, P.F. Knezevic, Erkenntnisse über den Einflußder tiefen Palmarnervanästhesie auf das Gangbild des lahmheitsfreienPferdes mit Hilfe einer kinematischen Meßmethode, Pferdeheilkunde 10(1994) 11-21.

[23] S.D. Starke, E. Willems, Sa. May, T. Pfau, Vertical head and trunk movementadaptations of sound horses trotting in a circle on a hard surface, Vet. J. 193(2012) 73-80, http://dx.doi.org/10.1016/j. tvjl.2011.10.019.

[24] C. Peham, M. Scheidl, T. Licka, A method of signal processing in motionanalysis of the trotting horse, J. Biomech. 29 (1996) 1111-1114, http://dx.doi.org/10.1016/0021-9290(95)00179-4.

[25] T. Pfau, T.H. Witte, A.M. Wilson, A method for deriving displacement dataduring cyclical movement using an inertial sensor, J. Exp. Biol. 208 (2005)2503-2514, http://dx.doi.org/10.1242/ jeb.01658.

[26] S.D. Starke, S.A. May, T. Pfau, Understanding hind limb lameness signs inhorses using simple rigid body mechanics, J. Biomech. 48 (2015) 3323-3331,http://dx.doi.org/10.1016/j. jbiomech.2015.06.019.

[27] S.D. Starke, K.J. Raistrick, Sa. May, T. Pfau, The effect of trotting speed on theevaluation of subtle lameness in horses, Vet. J. 197 (2013) 245-252, http://dx.doi.org/10.1016/j.tvjl.2013.03.006.

[28] S.M. Warner, T.O. Koch, T. Pfau, Inertial sensors for assessment of backmovement in horses during locomotion over ground, Equine Vet. J. 42 (2010)417-424, http://dx.doi.org/10.1111/ j.2042-3306.2010.00200.x.

[29] K. Ask, J.P.A.M. van Loon, F.M. Serra Braganc, a, E. Hernlund, M. Rhodin, P.Haubro Andersen, Objective pain assessment during rest and locomotion inhorses with two types of induced lameness, Comp. Exerc. Physiol. 14 (2018)42.

[30] M.A. Weishaupt, H.P. Hogg, J.A. Auer, T. Wiestner, Velocity-dependentchanges of time, force and spatial parameters in Warmblood horses walkingand trotting on a treadmill, Equine Vet. J. 42 (2010) 530-537, http://dx.doi.org/10.1111/j.2042-3306.2010.00190.x.

[31] C. Peham, T. Licka, D. Girtler, M. Scheidl, The influence of lameness on equinestride length consistency, Vet. J. 162 (2001) 153-157, http://dx.doi.org/10.1053/tvjl.2001.0593. 

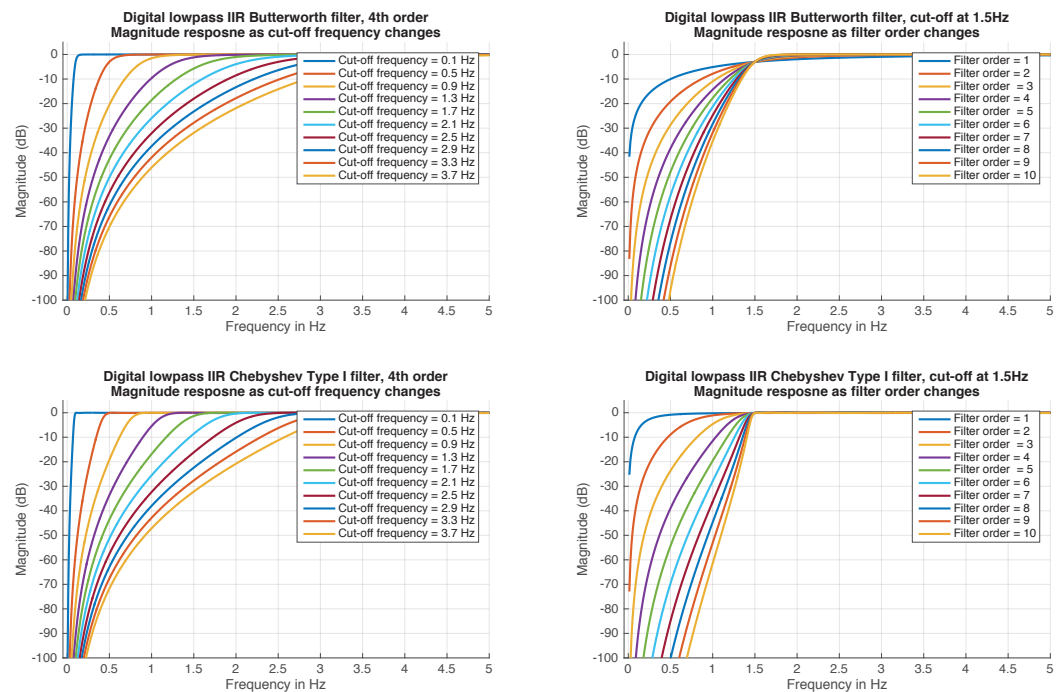

Figure 1. Magnitude response of the used IIR filters (Butterworth and Chebyshev) vs signal frequency as the filter order or filter cut-off frequency increases.

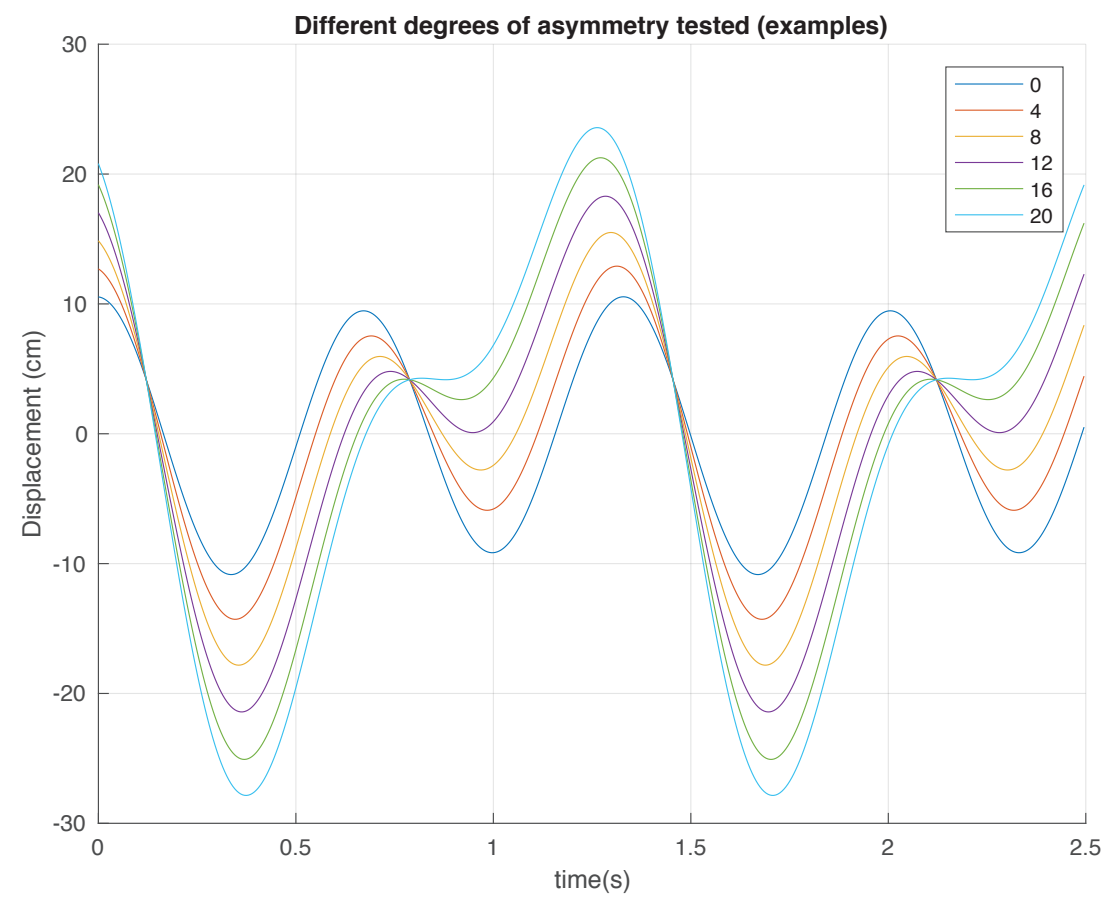

Figure 2. Different degrees of theoretical vertical displacement signal (VDS) asymmetry generated. The signals range from an asymmetry of 0 (no asymmetry) to a very asymmetrical signal (20), where the peak and minima from one stride are lost. 


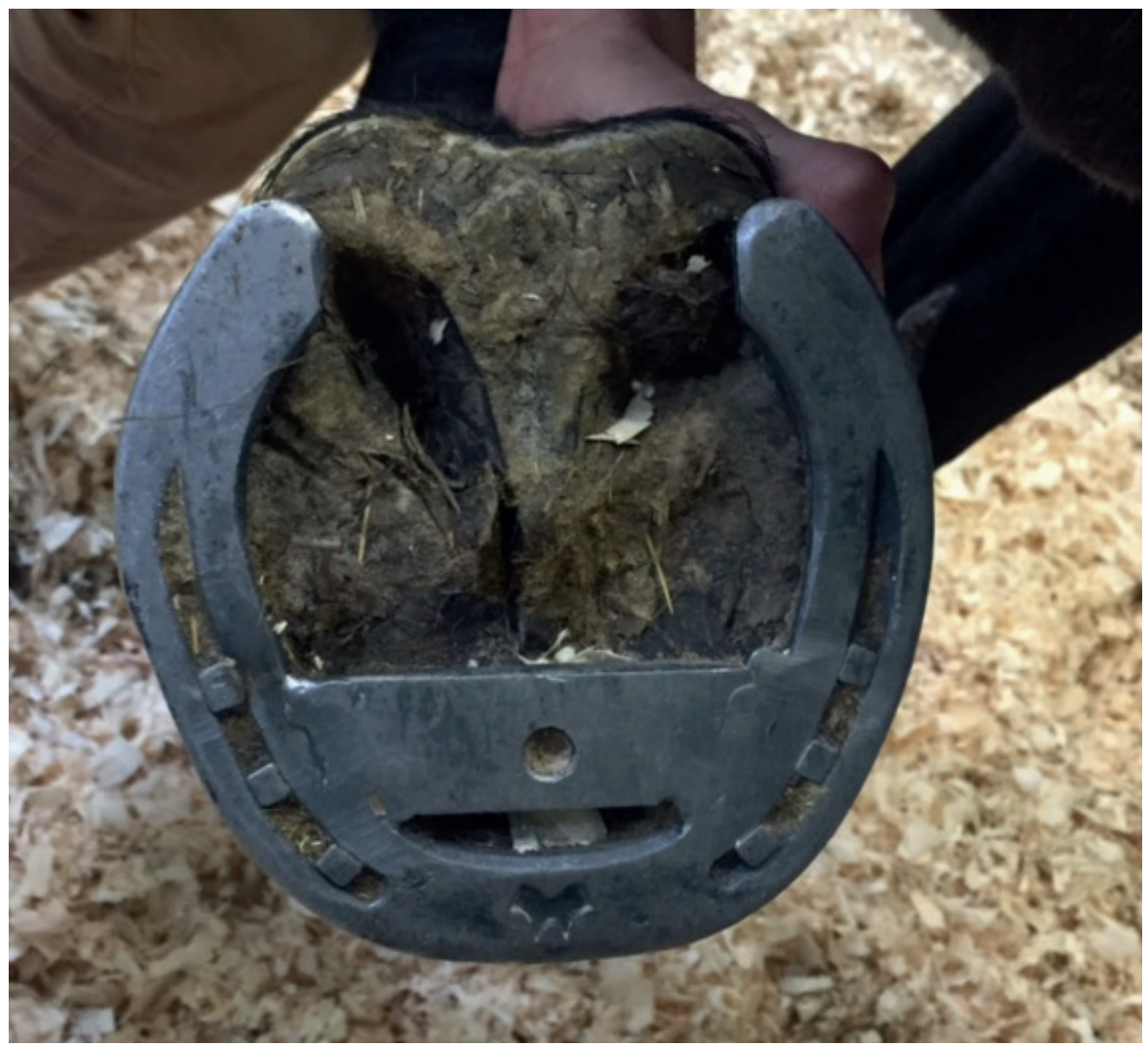

Figure 3: Modified heart-bar horseshoe. Note the central whole, at the tip of the frog, where a screw is inserted to induce temporary lameness. 


\section{Summary}

Background: Inertial measurement unit (IMU) sensor-based techniques are becoming more popular in horses as a tool for objective locomotor assessment.

Objectives: To describe, evaluate and validate a method of stride detection and quantification at walk and trot using distal limb mounted IMU sensors.

Study design: Prospective validation study comparing IMU sensors and motion capture with force plate data.

Methods: A total of seven Warmblood horses equipped with metacarpal/metatarsal IMU sensors and reflective markers for motion capture were hand walked and trotted over a force plate. Using four custom built algorithms hoof-on/hoof-off timing over the force plate were calculated for each trial from the IMU data. Accuracy of the computed parameters was calculated as the mean difference in milliseconds between the IMU or motion capture generated data and the data from the force plate, precision as the s.d. of these differences and percentage of error with accuracy of the calculated parameter as a percentage of the force plate stance duration.

Results: Accuracy, precision and percentage of error of the best performing IMU algorithm for stance duration at walk were $28.5,31.6 \mathrm{~ms}$ and $3.7 \%$ for the forelimbs and $-5.5,20.1 \mathrm{~ms}$ and $-0.8 \%$ for the hindlimbs, respectively. At trot the best performing algorithm achieved accuracy, precision and percentage of error of $-27.6 / 8.8 \mathrm{~ms} /-8.4 \%$ for the forelimbs and $6.3 / 33.5 \mathrm{~ms} / 9.1 \%$ for the hindlimbs.

Main limitations: The described algorithms have not been assessed on different surfaces.

Conclusions: Inertial measurement unit technology can be used to determine temporal kinematic stride variables at walk and trot justifying its use in gait and performance analysis. However, precision of the method may not be sufficient to detect all possible lameness-related changes. These data seem promising enough to warrant further research to evaluate whether this approach will be useful for appraising the majority of clinically relevant gait changes encountered in practice. 


\section{Introduction}

Many gait events can be effectively evaluated through subjective visual lameness appraisal by an experienced clinician [1]. However, although it has been shown that experienced clinicians are more repeatable and have a higher interobserver agreement in detection of gait asymmetries when compared with inexperienced observers [2], even the most experienced clinicians are reliant on the limitations of the human visual perception of motion [3]. Inertial measurement unit (IMU) sensorbased technology for objective gait analysis in horses has been under constant development. These systems often rely on sensors mounted in the midline of the horse (e.g. pelvis and head) that make use of a signal decomposition routine [4] to describe and record motion in the vertical plane. This method provides reliable and objective quantification of head and pelvis movement asymmetry which is related to changes in weightbearing and propulsion due to lameness. Quantification of limb kinematics or spatial and temporal stride variables might be a useful addition to the current technology, providing extra information that might be related to specific gait changes due to lameness. To achieve this, characterisation of the gait and motion patterns of each individual limb, which are known to influence trunk and head motion symmetry $[5,6]$, is necessary.

The accurate and precise detection of the stride, i.e. the accurate detection of hoofon/off events, is a crucial prerequisite for the proper determination of temporal and spatial stride characteristics and the currently used IMU-based systems can only achieve this partially. Since these sensors are commonly mounted on the upper body of the horse they can only obtain limited information regarding limb gait events like hoof-on/off at trot [7] or at walk [8], thereby severely limiting their application for detection of limb kinematics.

The purpose of this study was to describe, evaluate and validate a new method of stride detection and characterisation using limb mounted IMU sensors at walk and trot. It was hypothesised that the use of IMU sensors with a higher G range than usual and using multi-level algorithms would enable accurate and precise detection of hoof-on and hoof-off gait events that would be comparable to the performance of motion capture as the other alternative to the use of a force plate, the use of which principally is limited to laboratory situations. 


\section{Materials and methods}

\section{Horses}

A total of seven Warmblood horses (six mares and one gelding) with a body mass range of 506-608 kg (mean $564.4 \mathrm{~kg}$ ), height at the withers range 1.58-1.75 m (mean $1.65 \mathrm{~m}$ ) and age range of 5-21 years (mean 7.5 years) were used for this study. All subjects had no history of lameness and no lameness was observed during visual examination at walk and trot on a straight line prior to data collection.

\section{Data collection}

All subjects were instrumented with one IMU sensor (Promove-mini) a on each limb. Each sensor (mass $20 \mathrm{~g}$ ) was firmly attached to the lateral aspect of each metacarpal/metatarsal bone using a custom made holster (Fig 1). Additionally, IMUs were attached to the right front and hind hooves for data collection for another, unrelated study. The sensors were set to a sampling rate of $200 \mathrm{~Hz}$, with the low $g$ accelerometer set at $\pm 16 \mathrm{~g}$ and the high $g$ accelerometer set at $\pm 200 \mathrm{~g}$. Data was stored using the internal memory of each sensor (2 Gb microSD). Synchronisation between all sensors was guaranteed with an error of less than $100 \mathrm{~ns}$. Reflective markers $(12.5 \mathrm{~mm} \varnothing \text {, spherical passive marker })^{\mathrm{b}}$ were glued proximally and distally to each of the limb mounted IMUs and three additional markers attached to each right hoof (lateral heel, lateral toe area and lateral coronet). Motion capture data was recorded at $200 \mathrm{~Hz}$ using 6 infrared cameras (ProReflex 240) $)^{b}$, positioned along the y axis of a force plate (Z4852C) c. The force plate was covered with a $5 \mathrm{~mm}$ rubber mat. The analogue force plate signal was fed in to an $A / D$ converter ${ }^{\mathrm{b}}$, processed at $1 \mathrm{kHz}$ with 12 bit resolution and sampled by the motion capture software (QTM) ${ }^{\mathrm{b}}$ at $200 \mathrm{~Hz}$ ensuring that the sampling moments between measurements of the two systems have a fixed and known timing relationship. Speed over the force plate was measured using two pairs of photoelectric sensors spaced $2 \mathrm{~m}$ apart, centred over the force plate. All trials were videorecorded using standard equipment for retrospective analysis of the collected data. Prior to data collection, all instruments were calibrated according to manufacturers' instructions.

All subjects were fitted with the instruments and were led over the force plate by an experienced handler in walk and trot for $5 \mathrm{~min}$ as a warm-up exercise before the data collection. A minimum of five valid force plate impacts of the right front hoof and right hind hoof were collected at walk and trot from all subjects. In order to collect five valid measurements for each limb, an average of 25 trials were needed for trot and 19 for walk. A trial was considered to be valid if the impact of the hoof was 
located within the force plate measuring limits; only one limb was in contact with the plate at a time, if the horse was trotting straight at a constant pace and within a preset speed range of $0.8-1.4 \mathrm{~m} / \mathrm{s}$ at walk and $1.7-2.7 \mathrm{~m} / \mathrm{s}$ at trot.

\section{Kinematic analysis}

All collected data was processed and analysed in custom written scripts using Matlab (r2015a) ${ }^{\text {d }}$. The IMU collected data was frame synchronized with the motion capture system by evaluating the cross correlation function between the metacarpal/ metatarsal angular velocity measured by the IMU and the motion capture system. A threshold of $30 \mathrm{~N}$ was used for the force plate calculations. The hoof-on event was determined as the moment when the load along the vertical axis ( $\mathrm{z}$ ) passed $30 \mathrm{~N}$ and hoof-off as the first moment after hoof-on, when the force along the $z$ axis dropped below $30 \mathrm{~N}$. Detailed information on the synchronisation method used is provided as Supplementary Item 1.

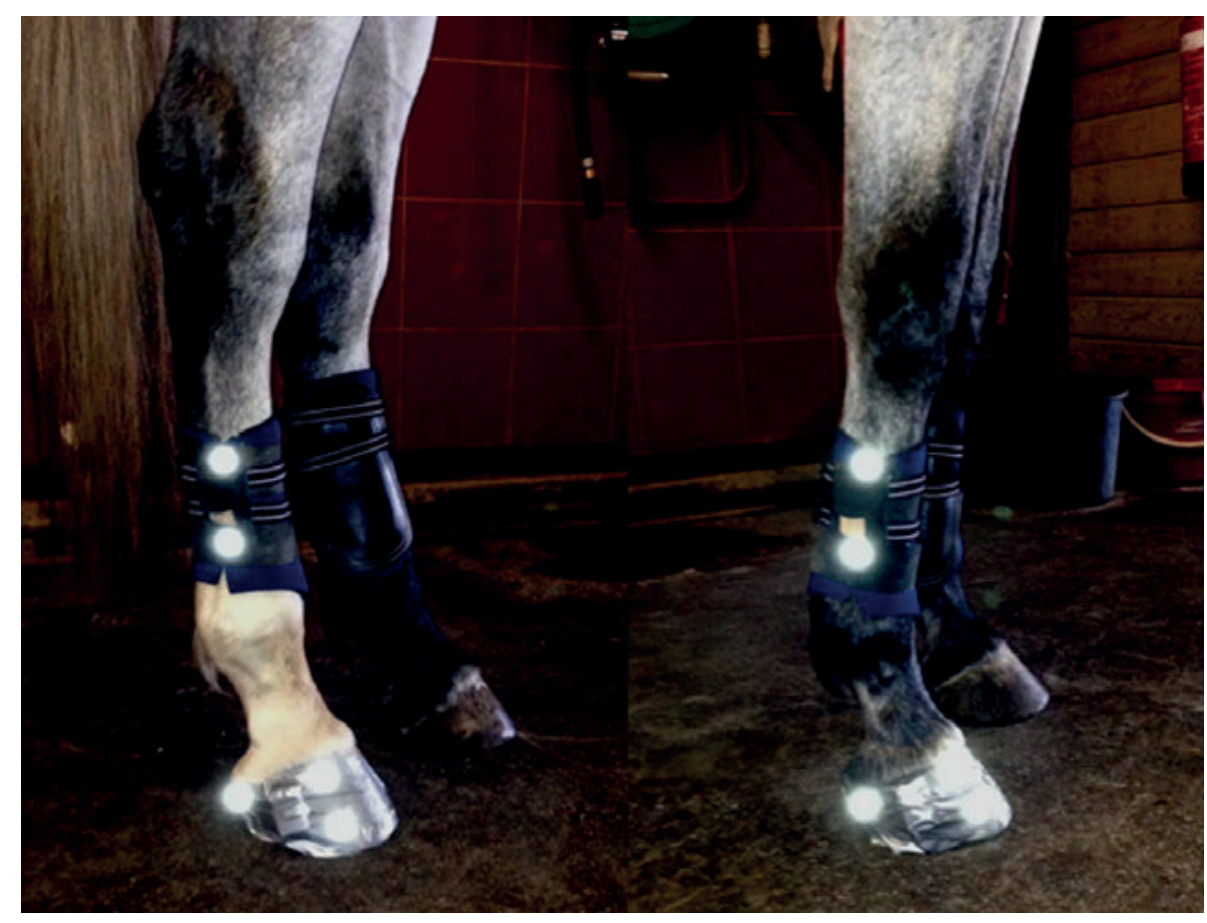

Fig 1. Reflective motion capture markers and inertial measurement unit (IMU) sensors attached to a horse in standardised locations. The IMU sensors were attached to the right lateral metatarsal and metacarpal bones, one reflective marker was placed above and beneath each sensor. Also, three markers were attached to the right fore- and right hind hooves (heel, lateral toe and lateral coronet), but only the lateral heel and lateral toe markers were used for the motion capture detection algorithm in the current study. 


\section{Inertial measurement unit event detection algorithm}

A total of four algorithms were used to calculate the hoof-on/off events. Algorithm 1 is a novel algorithm based on direct inertial measures (acceleration and rate of turn), requiring very low computing power and suitable for running in a real-time configuration. Algorithm 2 is an implementation of a previously described algorithm [8]. A post-processing routine based on the vector magnitude of the acceleration signal (acceleration magnitude peak) calculated by the IMU accelerometer was developed as an attempt to increase the accuracy and precision of algorithms 1 and 2. This routine was applied to algorithms 1 and 2 resulting in two new algorithms, 3 and 4, respectively. A detailed description of the IMU algorithms is provided as Supplementary Item 2.

\section{Motion capture event detection algorithm}

Using the data from heel and toe reflective markers, an algorithm was designed to detect the toe/heel-on/off events. The algorithm is based on direct kinematic data collected by the motion capture cameras [9]. A detailed description of the motion capture algorithms is provided as Supplementary Item 3.

\section{Data analysis}

Using the force plate as the gold standard reference for stride characterisation timing, accuracy of the computed parameters (i.e. hoof- on/off, toe-on/off, heel-on/ off) was calculated as the difference in milliseconds between the IMU or motion capture generated data and the data from the force plate and precision as the s.d. of the accuracy. A positive accuracy indicates an overestimation (i.e. IMU or motion capture detection of event later than force plate) of the parameter calculated by the IMU or motion capture system and a negative accuracy indicates an underestimation of that parameter (i.e. IMU or motion capture detection of event before force plate). Performance of the algorithms was judged based on primarily demonstrating the best precision (closest to zero) combined with the best accuracy (closest to zero).

For further comparison of the algorithms' performance, the accuracy of IMU stance duration was determined as described above for hoof-on/off, with the force plate calculated stance duration as a reference and with stance duration defined as the time between hoof-on and the subsequent hoof-off. Combination of algorithms for stance duration calculation were also evaluated and tested to identify the combination that obtained the best overall accuracy and precision. For the motion capture data, stance duration was calculated for both limbs and gaits, based on four possible combinations (i.e. toe-on toe-off; toe-on heel-off; heel-on heel-off and heel- on toe-off). Accuracy and precision of motion capture stance duration were calculated as described above for the IMU. The percentage of error in stance duration was calculated with the 
accuracy as a percentage of the force plate measured stance duration. If any of the IMU or motion capture algorithms failed to perform detection of an event (e.g. hoofon/off), the calculation of that specific event for that trial was not included in the final calculations. This was verified in a number of trials in our experiment for algorithms 1,3 and algorithm combination ( $n=2 ; n=3$, respectively) and in eight events for the motion capture detection. However, the remaining calculated parameters not related to that specific event for that trial were kept.

Open software (R version 3.2.3) was used for statistical analysis using the package 'nlme' (version 3.1-121) for linear mixed effects model and 'BlandAltmanLeh' (version 0.1.0) for calculation of IMU and motion capture stance duration limits of agreement. For statistical comparison of the 4 different IMU algorithms and the algorithm combination, the calculated square root transformed absolute accuracy for the stance duration was used as the outcome variable. Horse Id was used as random effect to account for the correlated observations within horse; explanatory variables are algorithm, gait, limb and the interaction between limb and algorithm. A constant variance function (varldent) for algorithms was added to the model to take the different variances between algorithms into account. Model adequacy (normality and constancy of variance) was confirmed using visualisation of the scatter plot residuals vs. fitted values and explanatory variables respectively and QQ-plots. The Akaike's information criterion was used to select the best model.

\section{Results}

A total of 150 stance phases were collected; 77 for the front limb (37 for walk; 40 at trot) and 73 for the hindlimb (36 at walk and 37 at trot). Visual assessment of the force plate ground reaction forces data showed the typical patterns for each specific gait and three measurements were excluded from the final analysis due to abnormal ground reaction force curves.

\section{Inertial measurement unit-based determination of hoof-on/ hoof-off events compared with force plate data (descriptive statistics)}

The four different tested algorithms performed differently for both limbs and gaits as demonstrated in Table 1. Algorithm 3 had the best performance for hoof-on, at walk in the front limb (accuracy: $0.3 \mathrm{~ms}$; precision: $11.5 \mathrm{~ms}$ ). For the hoof-on detection algorithm 2 had an overall negative accuracy that after the acceleration magnitude peak post- processing routine (algorithm 4) becomes closer to zero in the front limb 
and in the hindlimb becomes positive; however, precision hardly changes. The hoof-off detection for most algorithms shows a negative accuracy. Algorithm 1, after the postprocessing acceleration magnitude peak routine (algorithm 3), for hoof-off detection, shows an improvement in accuracy for both front and hindlimb at walk and trot. When comparing within the same algorithm, the hoof-off and hoof-on moments, the latter had better accuracy and precision than the former.

\section{Motion capture-based determination of hoof-on/off events compared with force plate (descriptive statistics)}

The performance of our motion capture-based detection is summarised in Table 2 and a descriptive comparison with the IMU algorithms is illustrated in Figure 2 . The hoof-on event defined as heel-on measured by the motion capture system showed the best overall performance, except at walk for the hindlimbs where the toe-on moment appears to be the most accurate and precise method for this purpose. The hoof-off moment defined as the toe-off measured by the motion capture system shows the best overall accuracy and precision combination. Similar to the IMU-based determination of hoof-on/off events, the hoof-on detection has a better overall performance when compared with hoof-off detection. However, the IMU approach performed overall better for hoof-off detection.

\section{Inertial measurement unit stance duration accuracy, precision, limits of agreement and model estimates}

The stance duration calculation performance of the IMU algorithms and the algorithm combination is resumed in Table 3 and illustrated in Figure 3. Bland-Altman limits of agreement can be found in Table 3, Figure 4 and model estimates are resumed in Supplementary Item 4.

When taking the algorithm combination as a reference and with a $95 \%$ confidence interval $(\mathrm{Cl})$, our model shows that for the front limbs, the difference in predicted absolute accuracy of the algorithm combination (reference) is not significantly different from algorithm $1(P=0.7)$, but the differences between algorithm $2(P<0.05)$, algorithm $3(P=0.05)$ and algorithm $4(P<0.05)$ are significant. For the hindlimbs, the difference in predicted absolute accuracy of the algorithm combination (reference) with algorithms 1,2 and 4 is significant $(P<0.05)$, but this difference is not significant for algorithm 3 $(P=0.7)$. A significantly higher (further away from zero) estimated absolute stance duration accuracy $(5.45,95 \% \mathrm{Cl}: 4.67-6.23)$ was also observed for trot when compared with walk $(\mathrm{P}<0.001)$. Also, a significantly lower (closer to zero) estimated absolute accuracy $(3.69,95 \% \mathrm{Cl}: 2.59-4.80)$ was observed for the hindlimbs when compared with the front limbs $(P=0.02)$. 
Table 1. Tabular representation of the descriptive statistics for Inertial measurement unit (IMU) hoofon and hoof-off detection vs. the 'gold standard' force plate (FP)

\begin{tabular}{|c|c|c|c|c|c|c|}
\hline & & & \multicolumn{2}{|c|}{ Hoof-on } & \multicolumn{2}{|c|}{ Hoof-off } \\
\hline & & Algorithm & Accuracy (ms) & Precision (ms) & Accuracy (ms) & Precision (ms) \\
\hline \multirow[t]{8}{*}{ Walk } & Front & 1 & 10.9 & 27.2 & 28.8 & 26.0 \\
\hline & & 2 & -71.0 & 31.1 & -45.2 & 51.5 \\
\hline & & 3 & 0.3 & 11.5 & 14.2 & 31.0 \\
\hline & & 4 & -58.8 & 46.1 & -40.5 & 53.2 \\
\hline & Hind & 1 & 14.1 & 8.1 & -42.7 & 12.9 \\
\hline & & 2 & -18.3 & 13.5 & -15.1 & 21.2 \\
\hline & & 3 & 2.0 & 11.5 & -5.4 & 14.3 \\
\hline & & 4 & 0.1 & 14.8 & -9.8 & 26.6 \\
\hline \multirow[t]{8}{*}{ Trot } & Front & 1 & -3.8 & 23.9 & 28.8 & 17.5 \\
\hline & & 2 & -99.2 & 58.0 & -26.8 & 19.2 \\
\hline & & 3 & 7.9 & 6.7 & -3.7 & 35.4 \\
\hline & & 4 & -82.6 & 61.8 & -19.7 & 7.5 \\
\hline & Hind & 1 & 16.3 & 10.1 & 17.6 & 29.1 \\
\hline & & 2 & -10.8 & 12.5 & -17.9 & 46.7 \\
\hline & & 3 & 11.3 & 9.1 & -2.3 & 46.9 \\
\hline & & 4 & 11.3 & 9.1 & -19.9 & 32.7 \\
\hline
\end{tabular}

$\mathrm{n}=7$ horses. Accuracy, mean difference in milliseconds between IMU and FP; precision, the s.d. of the accuracy between IMU and FP. Accuracy and precision are deemed better if closer to zero.

Table 2. Descriptive statistics for motion capture determined hoof-on and hoof-off detection vs. force plate (FP) measured stance duration events

\begin{tabular}{cccccccccc}
\hline & & \multicolumn{2}{c}{ Toe-on } & \multicolumn{2}{c}{ Heel-on } & \multicolumn{2}{c}{ Toe-off } & \multicolumn{2}{c}{ Heel-off } \\
\hline & & $\begin{array}{c}\text { Accuracy } \\
(\mathbf{m s})\end{array}$ & $\begin{array}{c}\text { Precision } \\
(\mathbf{m s})\end{array}$ & $\begin{array}{c}\text { Accuracy } \\
(\mathbf{m})\end{array}$ & $\begin{array}{c}\text { Precision } \\
(\mathbf{m s})\end{array}$ & $\begin{array}{c}\text { Accuracy } \\
(\mathbf{m s})\end{array}$ & $\begin{array}{c}\text { Precision } \\
(\mathbf{m s})\end{array}$ & $\begin{array}{c}\text { Accuracy } \\
(\mathbf{m s})\end{array}$ & $\begin{array}{c}\text { Precision } \\
(\mathbf{m s}\end{array}$ \\
\hline \multirow{2}{*}{ Walk } & Front & 4.0 & 51.9 & -5.1 & 13.0 & -27.1 & 20.7 & -132.1 & 18.3 \\
& Hind & 18.4 & 8.1 & -15.8 & 17.4 & -57.7 & 39.1 & -136.4 & 16.9 \\
\multirow{3}{*}{ Trot } & Front & 15.5 & 12.4 & 3.9 & 8.3 & -23.2 & 17.0 & -75.8 & 10.0 \\
& Hind & 14.5 & 7.4 & 5.6 & 10.0 & -27.0 & 25.8 & -78.0 & 7.8 \\
\hline
\end{tabular}

Accuracy, mean difference in milliseconds (ms) between the motion capture calculated and the FP measured stance duration; precision, s.d. of the mean difference between the motion capture calculated and FP measured stance duration (accuracy). Accuracy and precision are deemed better if closer to zero. 

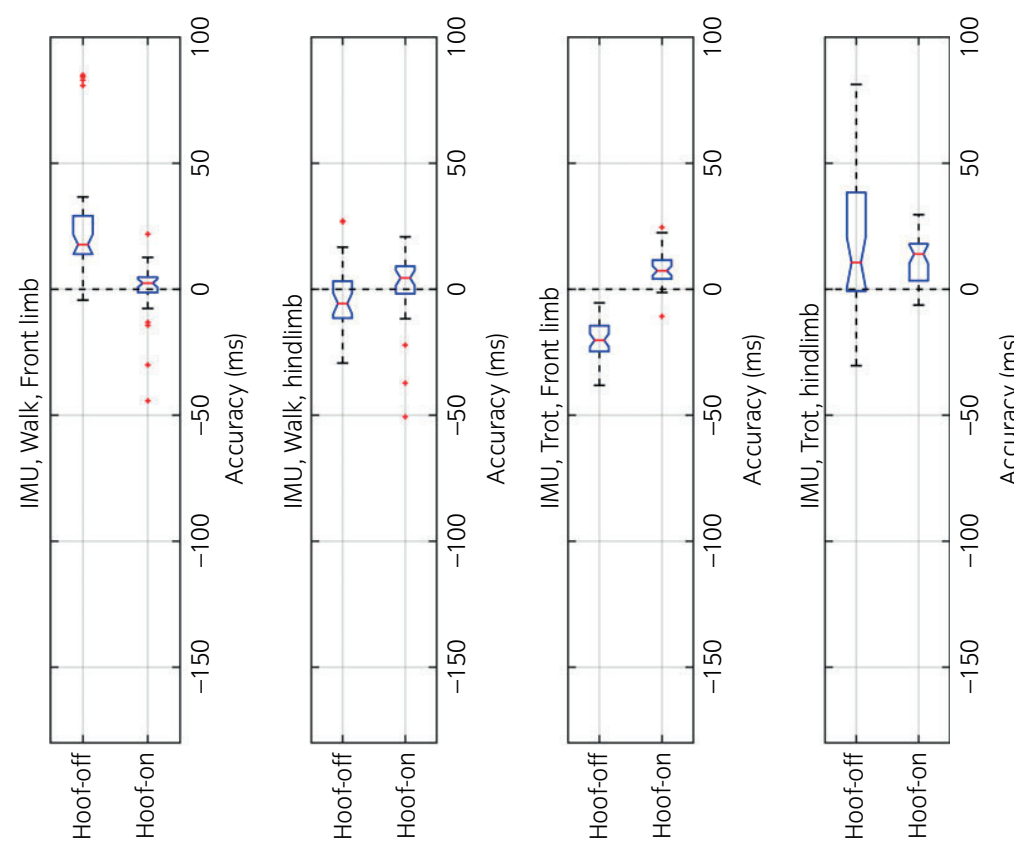

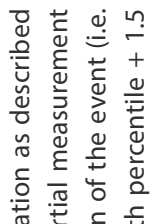

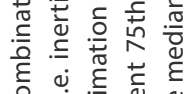

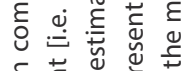

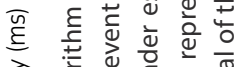

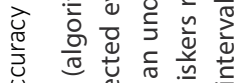

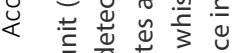
5 苞

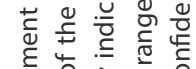
ह

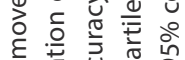
ह

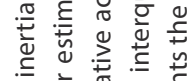

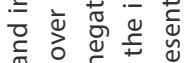

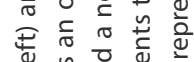
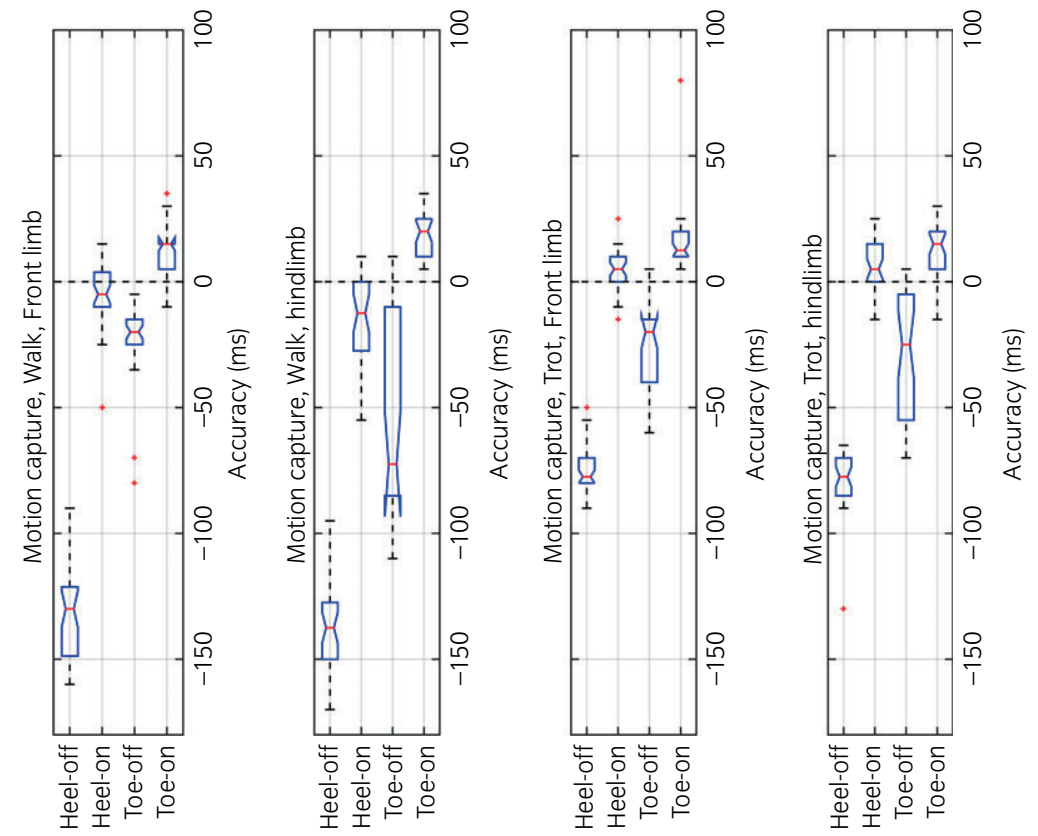

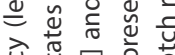
ปे

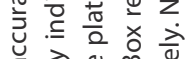

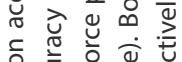
든

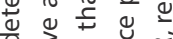

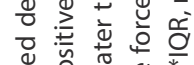

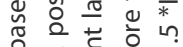
号《

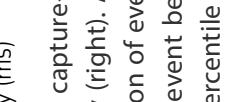
든 원

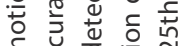
范 응 응 冚

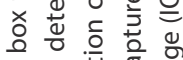

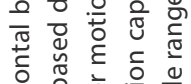

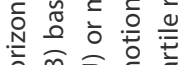
오 구응 흥

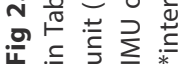


Table 3. Descriptive statistics of stance duration of the different Inertial measurement unit (IMU) algorithms vs. 'gold standard' force plate (FP)

\begin{tabular}{|c|c|c|c|c|c|c|c|}
\hline & & Algorithm & Accuracy (ms) & Precision (ms) & Accuracy (ms) & Precision (ms) & error (\%) \\
\hline \multirow[t]{10}{*}{ Walk } & Front & & 10.9 & 27.2 & 28.8 & 26.0 & \\
\hline & & 2 & 25.8 & 51.2 & -74.5 & 126.2 & 3.4 \\
\hline & & 3 & 13.9 & 31.49 & -47.8 & 75.6 & 1.8 \\
\hline & & 4 & 18.3 & 60.3 & -99.8 & 136.5 & 2.4 \\
\hline & & $\begin{array}{l}\text { Combination } \\
(3+1)\end{array}$ & 28.5 & 31.6 & -33.5 & 90.4 & 3.7 \\
\hline & Hind & 1 & -56.8 & 12.5 & -81.1 & -32.3 & -7.4 \\
\hline & & 2 & 3.2 & 23.6 & -43.1 & 49.5 & 0.5 \\
\hline & & 3 & -7.4 & 17.8 & -42.3 & 27.4 & -1 \\
\hline & & 4 & -9.8 & 29.9 & -68.5 & 48.8 & -1.2 \\
\hline & & $\begin{array}{l}\text { Combination } \\
(4+3)\end{array}$ & -5.5 & 20.1 & -44.8 & 33.8 & -0.8 \\
\hline \multirow[t]{10}{*}{ Trot } & Front & 1 & 32.6 & 28.1 & -22.4 & 87.6 & 10.2 \\
\hline & & 2 & 72.4 & 55.7 & -36.8 & 181.6 & 21.9 \\
\hline & & 3 & -11.6 & 34.6 & -79.4 & 56.2 & -3.8 \\
\hline & & 4 & 62.9 & 64.0 & -62.5 & 188.3 & 18.8 \\
\hline & & $\begin{array}{l}\text { Combination } \\
\qquad(3+4)\end{array}$ & -27.6 & 8.8 & -44.8 & -10.4 & -8.4 \\
\hline & Hind & 1 & 1.3 & 34.4 & -66.1 & 68.8 & 1.3 \\
\hline & & 2 & -7.1 & 50.1 & -105.3 & 91.1 & -2.2 \\
\hline & & 3 & -13.6 & 48.9 & -109.4 & 82.3 & -4.2 \\
\hline & & 4 & -31.2 & 31.6 & -93.1 & 30.8 & -10.6 \\
\hline & & $\begin{array}{c}\text { Combination } \\
(3+1)\end{array}$ & 6.3 & 33.5 & -59.4 & 72.0 & 3 \\
\hline
\end{tabular}

$\mathrm{n}=7$ horses. Accuracy, mean difference in milliseconds (ms) between IMU and FP stance duration; precision, the s.d. of the accuracy; error, the relative mean difference between IMU and FP stance duration (accuracy) as a percentage of the FP stance duration. Accuracy, precision and error are deemed better if closer to zero.

\section{Motion capture stance duration accuracy, precision, limits of agreement and percentage of error (descriptive statistics)}

The stance duration calculation performance (accuracy, precision, percentage of error and limits of agreement) of the algorithms and their combinations is resumed in Supplementary Item 5) and illustrated in Figure 3 for the algorithm combination. Using stance duration defined by heel-on/toe-off moments, we achieved the best overall performance for stance duration calculation. The best performance was achieved for the front limbs at walk (accuracy: -22.0 ms, 

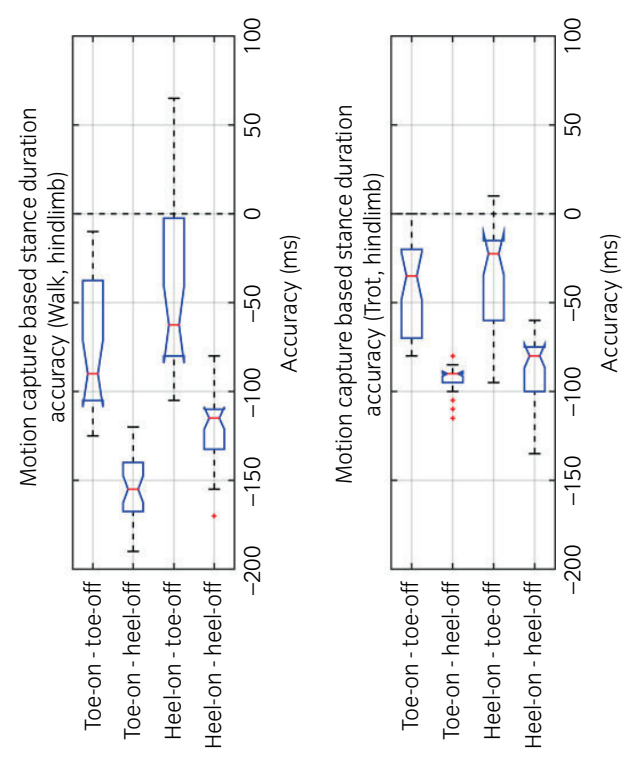

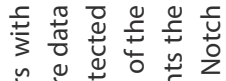

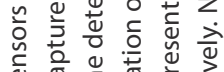

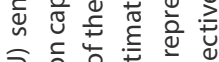

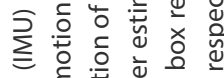

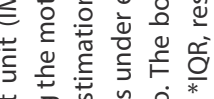

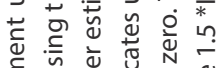

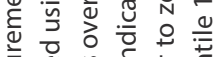

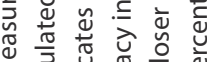

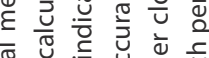
茫

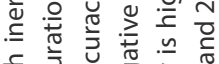
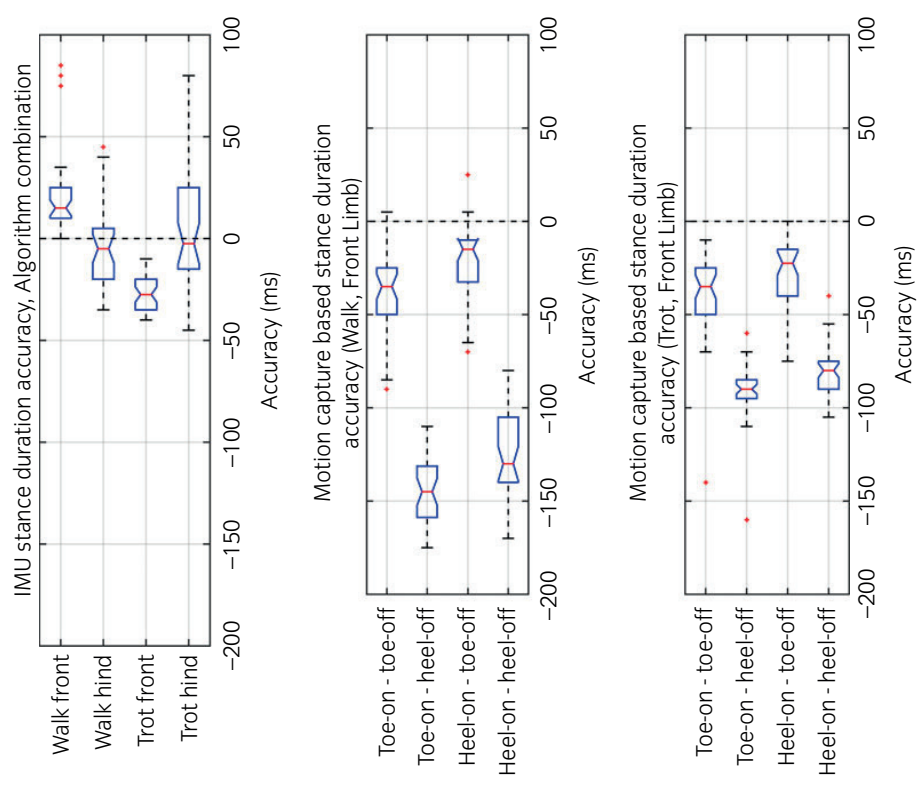

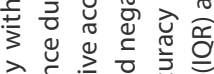

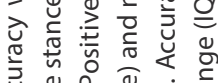
鸟 范这 웡

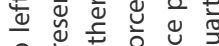
ㅇํㅇ 흔

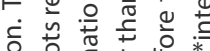

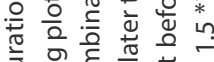

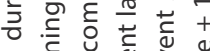

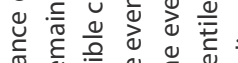

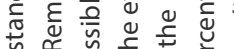

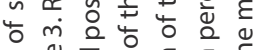
入ั

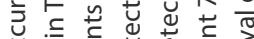

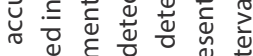
๘

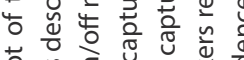

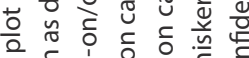
× त्ञ टे है 호 है m

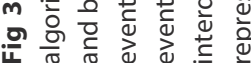




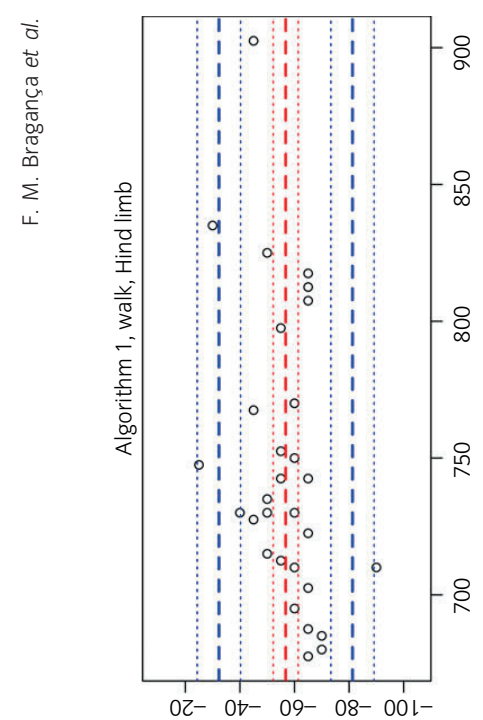

(sw) dঊ pue กWI иәәмұәq әэиәдән!!

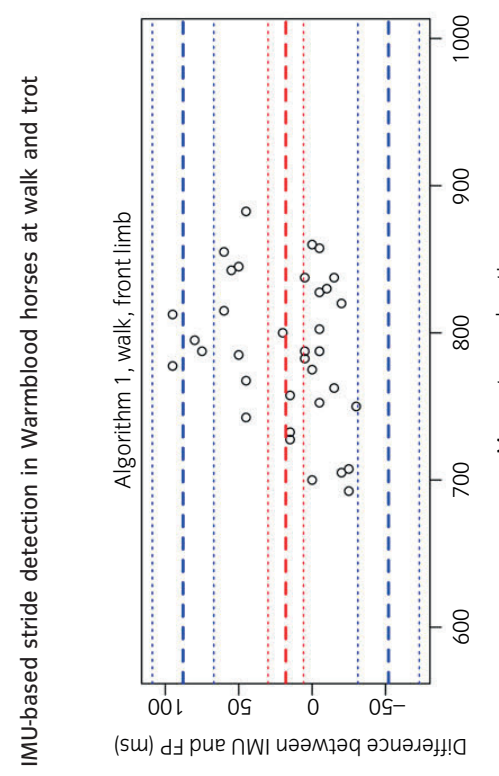

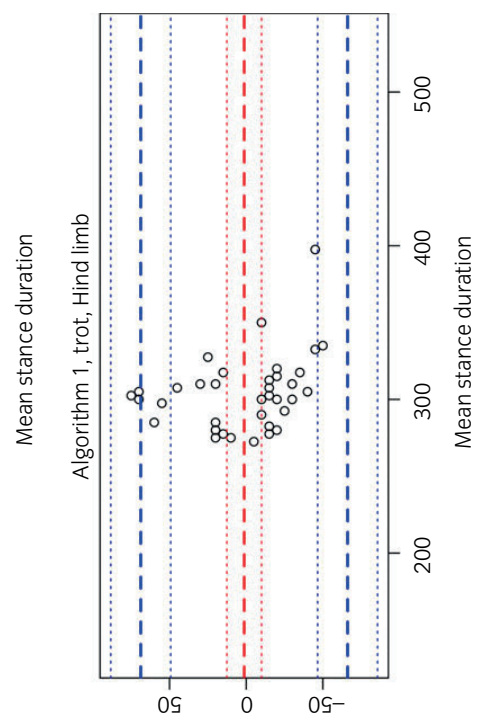

(su) dঊ pue กWI иәәмұәq әวนәләң!!

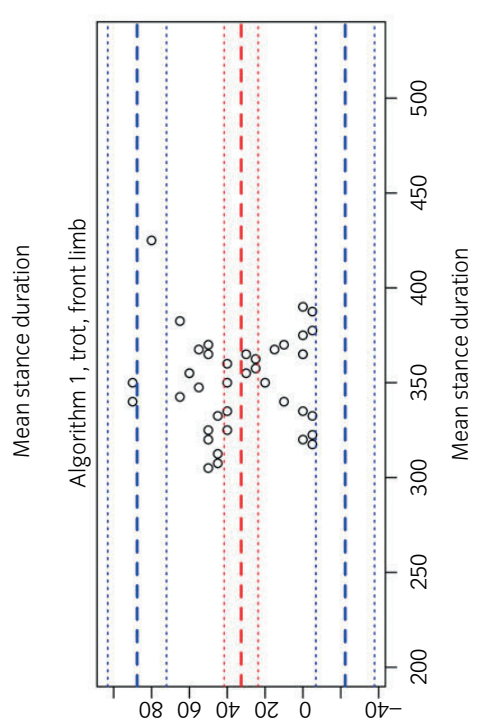

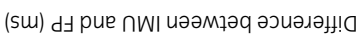

速学

응 흔

$\stackrel{2}{\circ}$

을

吾

藏

焉

용

吾选

¿ै

중 웅

5 
precision: $21.6 \mathrm{~ms}$, percentage of error: 3.1\%) and at trot (accuracy: $-27.2 \mathrm{~ms}$, precision: $19.7 \mathrm{~ms}$, percentage of error: $8.0 \%$ ).

\section{Discussion}

Our study addressed four different challenges related to stride detection and calculation of stride parameters based on IMU sensors placed on the lower limbs. 1) Different functional and kinematic properties between front and back limb $[10,11]$, 2) different kinematic features between walk and trot [12],3) detection of hoof events, based on sensors placed on an adjacent body segment, and 4) interindividual variations in limb kinematics [13].

We limited ourselves to collect data from the right limbs since all quadrupedal vertebrates exhibit bilateral movement symmetry between limb pairs (i.e. front pair and hind pair) [14], reducing the number of force plate trials demanded for each subject. We have assumed that the IMU represented the absolute 3D motion of the cannon bone, deliberately ignoring the artefact caused by skin displacement since previous research demonstrated that this effect is minimal in the equine lower limb [15].

Stance duration accuracy was used as the reference parameter for comparison of the four algorithms and the algorithm combinations since the parameter intrinsically depends on both the hoof-on/off moments, can be easily and with great reliability calculated using a force plate and motion capture $[9,16]$ and is known to be significantly influenced by lameness [17].

A lower percentage of error in IMU stance duration calculation is observed for walk (3.7 and 1.9\%) when compared with trot (8.4 and 9.1\%). This can be attributed to the shorter stance duration at trot, since the overall precision of the algorithms is comparable for both gaits. The combination of different algorithms demonstrated to be a successful method to improve the overall performance of our IMU calculations, as has been demonstrated previously [9]. Our implementation of the previously described algorithm (algorithm 2) showed comparable performances to the initially reported algorithm, proving a good reproducibility of this approach [8].

During hoof impact there is a pronounced acceleration peak that can be measured at the level of the hoof $[18,19]$ and also of the metacarpal bone $[8,20]$. Previous research demonstrated that an attenuation of up to $87 \%$ of the initial impact vibrations can be expected at the level of the third metacarpal bone [21], with most of the attenuation 
happening at the interface between the hoof wall and distal phalanx. The signal will thus be measured at the level of the cannon bone after a time lapse, when compared with the first registration of the impact peak by the force plate [20]. This attenuation and retardation effect can help explain the positive IMU accuracy observed in some instances for the detection of the hoof-on moment in the algorithms dependent on the acceleration magnitude peak feature (i.e. algorithms 3 and 4). The algorithms dependent on this acceleration feature were able to effectuate significant improvement. However, this presumes that the primary algorithms were capable of performing successful initial processing. Failure of the primary algorithm may result in inappropriate AMP detection, as a local acceleration peak not related to hoof-on/ off may be selected resulting in poor event detection.

When evaluating the accuracy of the hoof events calculated by the motion capture system, it becomes clear that the heel-on moment is the closest event to force plate hoof-on and toe-off is the closest event to force plate hoof-off. Also, our IMU approach demonstrated a better overall accuracy in detecting the hoof-off moment. We suggest that this can be explained by the fact that the motion capture detection algorithm is more affected by hoof conformation and variation in foot placement [22], since the algorithm depends on how the toe/heel are elevated from the ground and this can be affected by hoof conformation, whereas the IMU measures the actual limb movement resulting from the hoof-off event. Recent research reported that there was a high degree of variation in foot placement in horses [22,23] and this is thus more likely to affect our described motion capture algorithm than the IMU method.

Our motion capture algorithm also shows a promising accuracy and precision for determining the hoof events (i.e. heel/toe-on/off), although further development of this technique is needed in order to achieve further improvements. Motion capture technology has been previously used, based on different algorithmic approaches $[9,16]$ for the determination of stance duration but to the authors' knowledge, not for the differentiation of the toe/heel events and this might provide important insights when evaluating balance, rolling and conformation of the hoof. These observations stress the value of using both techniques in conjunction (IMU and motion capture) for biomechanical research and clinical applications in horses. However, the advantages of the IMU system (most importantly its low cost and versatility), make the IMU the best single alternative for daily use in practice.

Previous research demonstrated that in lame horses the stance duration, as a proportion of stride duration, increases significantly (3\% in the forelimbs and $2 \%$ in the hindlimbs) in the lame limb [24,25], as does absolute stance duration [26]. These 
reported changes in stance duration are small and might in certain cases fall below the limits of detection of the techniques here proposed, as reflected in the wide limits of agreement observed (Fig 4). However, further research into the actual effects of lameness on the calculated parameters is needed to assess this, since most research so far was either performed on a treadmill forcing the horse to a constant speed, or by using stationary force plates permitting evaluation of single individual strides only and thus susceptible to effects of intertrial variation.

\section{Conclusions}

This study shows that IMU sensors placed on the lower limbs of horses can be used for the accurate and fairly precise stride detection and characterisation in horses at walk and trot. The quantitative establishment of temporal and spatial gait variables, such as stride duration and stance time, based on IMU technology that offers the great advantages of easy applicability in the field and relatively low costs, then becomes possible. Although stance duration calculation using our proposed IMUbased approach is quite accurate, it is less precise, as reflected in the wide limits of agreement observed. Further research is needed in order to investigate to what extent the proposed algorithmic approaches are capable of detecting kinematic changes due to lameness and other abnormal gaits (e.g. ataxia). Nevertheless, the presented approach can serve as an easy method of determining the necessary gait events (i.e. hoof-on/off), justifying further development of this modern technology. 


\section{Authors' declaration of interests}

None.

\section{Ethical animal research}

The study was approved by the local ethics committee in compliance with the Dutch Act on Animal Experimentation.

\section{Sources of funding}

This study was funded by STW

Valorisation Grant 13448.

\section{Acknowledgements}

Special thanks to the technical assistance of the students and animal care takers

of the department.

\section{Authorship}

F. Braganca contributed to data processing, statistics and the writing of the manuscript. S. Bosch, M. MarinParianu and B.J. Van der Zwaag contributed to algorithm and scripts development and data processing. J. Voskamp contributed to data collection, algorithm and scripts development and data processing. R. van Weeren and W. Back contributed to writing the manuscript. J. Vernooij contributed to statistical analysis.

\section{Supporting Information}

Additional Supporting Information may be found in the online version of this article at the publisher's website:

Supplementary Item 1: Inertial measurement unit and motion capture synchronisation.

Supplementary Item 2: Inertial measurement unit algorithms.

Supplementary Item 3: Camera event detection.

Supplementary Item 4: Linear mixed model estimates and confidence intervals (square root transformed).

Supplementary Item 5: Stance duration descriptive statistics of motion capture stance duration calculation. 


\section{References}

1. Dyson, S. (2014) Recognition of lameness: man vs. machine. Vet. J. 201, 245-248.

2. Hammarberg, M., Egenvall, A., Pfau, T. and Rhodin, M. (2015) Rater agreement of visual lameness assessment in horses during lungeing. Equine Vet. J. 48, 78-82.

3. Parkes, R.S.V., Weller, R., Groth, A.M., May, S. and Pfau, T. (2009) Evidence of the development of "domain-restricted" expertise in the recognition of asymmetric motion characteristics of hindlimb lameness in the horse. Equine Vet. J. 41, 112-117.

4. Pfau, T. (2005) A method for deriving displacement data during cyclical movement using an inertial sensor. J. Exp. Biol. 208, 2503-2514.

5. Buchner, H.H., Savelberg, H.H., Schamhardt, H.C. and Barneveld, A. (1996) Head and trunk movement adaptations in horses with experimentally induced fore- or hindlimb lameness. Equine Vet. J. 28, 71-76.

6. Uhlir, C., Licka, T., Ku€bber, P., Peham, C., Scheidl, M. and Girtler, D. (1997)

7. Compensatory movements of horses with a stance phase lameness. Equine Vet. J. 29, Suppl. 23, 102-105.

8. Starke, S.D., Witte, T.H., May, S. and Pfau, T. (2012) Accuracy and precision of hind limb foot contact timings of horses determined using a pelvis-mounted inertial measurement unit. $J$. Biomech. 45, 1522-1528.

9. Olsen, E., Andersen, P.H. and Pfau, T. (2012) Accuracy and precision of equine gait event detection during walking with limb and trunk mounted inertial sensors. Sensors 12, 8145-8156.

10. Boye, J.K., Thomsen, M.H., Pfau, T. and Olsen, E. (2014) Accuracy and precision of gait events derived from motion capture in horses during walk and trot. J. Biomech. 47, 1220-1224.

11. Back, W., Schamhardt, H.C., Savelberg, H.H., van den Bogert, A.J., Bruin, G., Hartman, W. and Barneveld, A. (1995) How the horse moves: 1. Significance of graphical representations of equine forelimb kinematics. Equine Vet. J. 27, 31-38.

12. Back, W., Schamhardt, H.C., Savelberg, H.H., van den Bogert, A.J., Bruin, G., Hartman, W. and Barneveld, A. (1995) How the horse moves: 2. Significance of graphical representations of equine hind limb kinematics. Equine Vet. J. 27, 39-45.

13. Roach, J.M., Pfau, T., Bryars, J., Unt, V., Channon, S.B. and Weller, R. (2014) Sagittal distal limb kinematics inside the hoof capsule captured using high-speed fluoroscopy in walking and trotting horses. Vet. J. 202, 94-98.

14. Degueurce, C., Pourcelot, P., Audigi,e, F., Denoix, J.M. and Geiger, D. (1997) Variability of the limb joint patterns of sound horses at trot. Equine Vet. J. 29, Suppl. 23, 89-92.

15. Abourachid, A. (2003) A new way of analysing symmetrical and asymmetrical gaits in quadrupeds. C. R. Biol. 326, 625-630.

16. van Weeren, P.R., van den Bogert, A.J. and Barneveld, A. (1990) A quantitative analysis of skin displacement in the trotting horse. Equine Vet. J. 22, Suppl. 9, 101-109.

17. Starke, S.D. and Clayton, H.M. (2015) A universal approach to determine footfall timings from kinematics of a single foot marker in hoofed animals. Peer J, e783.

18. Weishaupt, M.A. (2008) Adaptation strategies of horses with lameness. Vet. Clin. North Am. Equine Pract. 24, 79-100.

19. Witte, T.H. (2004) Determination of peak vertical ground reaction force from duty factor in the horse (Equus caballus). J. Exp. Biol. 207, 3639- 3648.

20. Witte, T.H., Hirst, C.V. and Wilson, A.M. (2006) Effect of speed on stride parameters in racehorses at gallop in field conditions. J. Exp. Biol. 209, 4389-4397.

21. GustOas, P., Johnston, C., Roepstorff, L. and Drevemo, S. (2001) In vivo transmission of impact shock waves in the distal forelimb of the horse. Equine Vet. J. 33, Suppl. 33, 11-15. 
22. Willemen, M.A., Jacobs, M.W. and Schamhardt, H.C. (1999) In vitro transmission and attenuation of impact vibrations in the distal forelimb. Equine Vet. J. 31, Suppl. 30, 245-248.

23. Wilson, A., Agass, R., Vaux, S., Sherlock, E., Day, P., Pfau, T. and Weller, R. (2016) Foot placement of the equine forelimb: relationship between foot conformation, foot placement and movement asymmetry. Equine Vet. J. 48, 90-96.

24. van Heel, M.C.V., Kroekenstoel, A.M., van Dierendonck, M.C., van Weeren, P.R. and Back, W. (2006) Uneven feet in a foal may develop as a consequence of lateral grazing behaviour induced by conformational traits. Equine Vet. J. 38, 646-651.

25. Weishaupt, M.A., Wiestner, T., Hogg, H.P., Jordan, P. and Auer, J.A. (2006) Compensatory load redistribution of horses with induced weight-bearing forelimb lameness trotting on a treadmill. Vet. J. 171, 135-146.

26. Weishaupt, M.A., Wiestner, T., Hogg, H.P., Jordan, P. and Auer, J.A. (2010) Compensatory load redistribution of horses with induced weightbearing hindlimb lameness trotting on a treadmill. Equine Vet. J. 36, 727-733.

27. Ishihara, A., Bertone, A.L. and Rajala-Schultz, P.J. (2005) Association between subjective lameness grade and kinetic gait parameters in horses with experimentally induced forelimb lameness. Am. J. Vet. Res. 66, 1805- 1815. 



\section{Clinical application of gait analysis for studies on lameness and general locomotion}




\section{EquiMoves: A Wireless Networked Inertial} Measurement System for Objective Examination of
Horse Gait

Stephan Bosch ${ }^{1,5,}{ }^{*}$, Filipe Serra Bragança ${ }^{2}$, Mihai Marin-Perianu', Raluca Marin-Perianu', Berend Jan van der Zwaag', John Voskamp ${ }^{3}$, Willem Back ${ }^{2,4}$, René van Weeren ${ }^{2}$ and Paul Havinga ${ }^{5}$

1. Inertia Technology B.V., 7521 AG Enschede, The Netherlands; mihai@inertia-technology. com (M.M.-P.); raluca@inertia-technology.com (R.M.-P.); berendjan@inertia-technology.com (B.J.v.d.Z.)

2. Department of Equine Sciences, Faculty of Veterinary Medicine, Utrecht University, 3584 CM Utrecht, The Netherlands; F.M.SerraBraganca@uu.nl (F.S.B.); W.Back@uu.nl (W.B.); r.vanweeren@ uu.nl (R.v.W.)

3. Rosmark Consultancy, 6733 AA Wekerom, The Netherlands; info@rosmark.nl

4. Department of Surgery and Anaesthesia of Domestic Animals, Faculty of Veterinary Medicine, Ghent University, 9820 Merelbeke, Belgium

5. Department of Computer Science, Pervasive Systems Group, University of Twente, 7522 NB Enschede, The Netherlands; p.j.m.havinga@utwente.nl
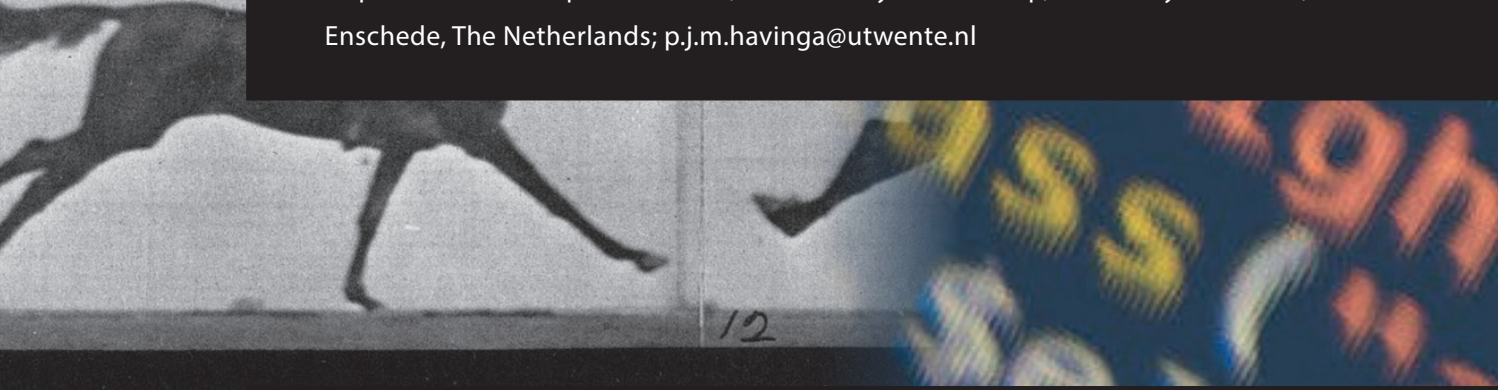


\section{Abstract}

In this paper, we describe and validate the EquiMoves system, which aims to support equine veterinarians in assessing lameness and gait performance in horses. The system works by capturing horse motion from up to eight synchronized wireless inertial measurement units. It can be used in various equine gait modes, and analyzes both upper-body and limb movements. The validation against an optical motion capture system is based on a Bland-Altman analysis that illustrates the agreement between the two systems. The sagittal kinematic results (protraction, retraction, and sagittal range of motion) show limits of agreement of \pm 2.3 degrees and an absolute bias of 0.3 degrees in the worst case. The coronal kinematic results (adduction, abduction, and coronal range of motion) show limits of agreement of -8.8 and 8.1 degrees, and an absolute bias of 0.4 degrees in the worst case. The worse coronal kinematic results are most likely caused by the optical system setup (depth perception difficulty and suboptimal marker placement). The upper-body symmetry results show no significant bias in the agreement between the two systems; in most cases, the agreement is within $\pm 5 \mathrm{~mm}$. On a trial-level basis, the limits of agreement for withers and sacrum are within $\pm 2 \mathrm{~mm}$, meaning that the system can properly quantify motion asymmetry. Overall, the bias for all symmetry-related results is less than $1 \mathrm{~mm}$, which is important for reproducibility and further comparison to other systems. 


\section{Introduction}

Lameness in horses can be defined as an alteration of the normal gait due to a functional or structural disorder of the loco-motor system, and can commonly be attributed to orthopedic pain [1]. It is by far the most expensive health issue in the equine field, with economic costs estimated between $\$ 680$ million and $\$ 1$ billion in the USA alone [2]. It has been demonstrated that equine veterinarians spend up to $40 \%$ of their working time assessing lameness [3]. Currently, most veterinarians rely on subjective visual examination of gait to detect movement asymmetries that are the common clinical sign of lameness. However, subjective lameness assessment has been shown to have some substantial drawbacks, most due to the limitations of human visual symmetry perception [4] and the bias effect [5], which ultimately leads to a poor agreement between veterinarians [6-9].

Objective quantification of lameness has been a topic of investigation in the field of equine research for several years now [10]. The solutions that were devised can be broadly divided into two categories: kinetic methods and kinematic methods. Kinetic methods analyze the forces resulting from movement, whereas kinematic methods analyze movement of internal and external body segments during locomotion.

Force platforms were among the first instruments used for objective lameness assessment [11], and are still described today as the "gold standard" for kinetic gait analysis. Force platforms measure the ground reaction force (GRF), as exerted on a limb during the stance phase, in three dimensions [12]. Force platforms are very precise and accurate instruments, but the data collection process is laborious and time-consuming: since only very few strides are captured as the horse moves over the limited surface of the force platform, several runs are necessary to collect the necessary number of strides. To address this problem, force-measuring horse shoes $[13,14]$ and a force-measuring treadmill [15] were developed. However, these are not yet widely available as a practical tool for daily gait analysis. For kinematic analysis, optical motion capture (OMC) systems $[16,17]$ have been applied successfully $[18,19]$. These systems use reflective markers attached to the body of the subject and several (infra-red) cameras distributed across the room that track the 3D position of the markers. These systems are highly accurate and precise: the average position error is usually better than a few millimeters $[17,20]$. Generic motion parameters that can reveal early signs of lameness have been defined and validated [19,21,22]. Therefore, OMC systems are considered the "gold standard" for kinematic analysis [23]. However, for a full-body capture of a horse moving through a large volume, a significant number of OMC cameras and supporting infrastructure is needed, which incurs significant 
cost. Due to the scale, size, and complexity of the system, it is difficult to relocate it to other venues $[23,24]$; e.g., each time it is relocated, a calibration procedure needs to be followed by an expert in order to ensure data quality [17]. Therefore, the application of OMC systems is mostly limited to a fixed laboratory environment [23], and in some exceptional cases, large clinics.

Inertial measurement units (IMUs) [25] have been considered as a promising costeffective alternative to OMC systems [8,26-33]. By rigidly attaching an IMU to a body segment, the orientation and (less reliably) the displacement of that body segment can be determined, making a set of these devices applicable as a kinematic measurement system [34]. Recent technological progress in microelectromechanical (MEMS) inertial sensors, combined with the abrupt drop of sensor prices thanks to the smartphone market, made small, low-cost, low-power, yet accurate IMUs available. Moreover, the development of low-power wireless technologies has made it possible to explore a new paradigm: wireless networked IMUs, which avoids the need to draw cables between the sensor locations.

This is what the EquiMoves system described in the present study provides: a wireless IMU-based solution that operates as a network capturing relevant horse motion variables at a high sample rate, at eight bodily positions, in real time and accurately synchronized.

In this article, we compare the EquiMoves system to a well-established OMC system for a set of well-defined kinematic horse locomotion parameters that both systems can produce. Since the EquiMoves system is designed for everyday use by a veterinarian, we performed experiments that best match that scenario. This precludes the use of a treadmill, for example, since that may influence the horse's gait [35,36].

Although we use the OMC system as a source of an accurate ground truth, we do not consider it the gold standard per se; we are interested mainly in the level of agreement between the two systems and what may cause the observed differences. Both IMU-based and OMC-based systems have limitations; e.g., IMU systems suffer from drift errors that accumulate in the underlying integration calculations [25], while OMC measurements are influenced by the number of cameras that have each marker in view and the distance between each camera and each marker $[17,20]$. We chose to focus on differences caused by errors in the displacement and orientation measurements of both systems. Therefore, timing-related differences are eliminated by choosing one of the two systems as the timing reference for both. 
Our contributions are as follows:

- We present a system that provides real-time wireless data acquisition with the potential for real-time feedback to the user. The system can handle various equine gaits (e.g., walk and trot). It registers and analyzes movements for all individual limbs, rather than only upper-body movement, for example, which is what the previously described systems [21,37] do. Most existing systems only work for a horse trotting along a straight line, and involve only sensors to measure asymmetry on the vertical displacement of head and/or pelvis [34,37]. In contrast, the EquiMoves system can be used for walking and trotting horses, for arbitrary paths, and can also measure limb motion.

- We provide an in-depth analysis of the agreement of the measurements of our system with an OMC system, looking at both upper-body and limb-related parameters.

- We provide a detailed description of a data-based algorithm for time synchronization and the alignment of position and orientation between the IMU and OMC data sets.

In the following sections, we describe the EquiMoves system in detail. We start by positioning it with respect to related work; then, we present background information on horse gait analysis. Subsequently, the main system components and methods are described. Next, we discuss the practical trials and results obtained for validating the system. We conclude with a discussion of the results, current limitations, and points of improvement as future work.

\section{Related Work}

The most widely-used method for equine gait analysis is currently visual examination, which is prone to the subjectivity and limited accuracy of the human eye [4]. This has been suggested as one of the reasons why agreement between equine vets evaluating lameness in horses is often low [8]. There is also a susceptibility to bias during the orthopedic exam [5]. Particularly in cases of mild lameness, studies showed that vets agreed whether a limb was lame or not in only $62 \%$ of the cases with mild lameness (i.e., having a mean score of less than 1.5 on the AAEP lameness scale $[6,38]$ ). When given the task of deciding whether the horse was lame and choosing the limb, vets agreed in less than $52 \%$ of the cases [6]. As discussed previously in Section 1, optical motion capture (OMC) systems have been applied successfully for kinematic gait analysis $[18,19]$. Generic motion parameters that can be used to assess the soundness 
of the horse objectively have been defined and validated for data produced by such systems $[21,22]$. Some of the disadvantages of these OMC systems are that they are quite expensive and mostly confined to a laboratory $[23,24,28]$.

Those limitations can pose problems for practitioners who wish to make these assessments in the field, which includes outdoor locations. Apart from practical considerations, it can also be very important in general to perform such experiments in the horse's familiar environment [39]. Another disadvantage is that an OMC system is limited to a specific motion capture volume, constrained by space and equipment [23]. Thus, unless that volume is large, only a small number of strides can be recorded for gait analysis $[23,28,40]$. Additionally, OMC systems use reflective markers that need to stay in view of a sufficient number of the OMC system's cameras: it is not always possible to prevent occlusions (particularly self-occlusions), which results in missing or less-reliable data $[24,41]$.

An alternative to OMC systems is the use of inertial measurement units (IMUs) $[42,43]$. These devices can be attached at key locations on the body of the subject and measure acceleration and angular velocity using accelerometers and gyroscopes, respectively (both are inertial sensors). Using these measurements, the kinematic variables like displacement and orientation of the body at these locations can be determined [34].

IMUs have been applied extensively and successfully for human motion capture applications, particularly in healthcare $[23,40,42,44,45]$ and sports [46-51]. In equine research, inertial sensor systems are also quickly gaining popularity [34,52,53], particularly for objective lameness assessment [8,26-33]. Some older systems only used a single-axis accelerometer and/or gyroscope, which means that those systems rely only on one-dimensional data. Therefore, for those systems, the rotation of the sensors during movement and variation in sensor attachment influence the signals and their quality [26]. More recent works use full IMUs on several locations of the body $[26,31,54,55]$.

For human motion capture applications, IMU technology has been validated using OMC systems $[23,49,50,56-59]$ and normal video recordings [60]. So far, the IMUbased horse gait analysis systems have only been sparsely evaluated: there is work comparing IMU-based systems with subjective assessment [7,8,61-63], there is work comparing IMU-based systems with force platform systems [62,64,65], and there are studies comparing between IMU-based kinematic systems [30,66,67]. However, the agreement of IMU-based and OMC-based kinematic horse gait analysis systems is barely explored: earlier work is either limited to stride timing or frequency [28], 
limited to upper-body [32,34], limited to limb measurements [68,69], or performs no agreement analysis $[34,70,71]$. In this work, we perform an extensive comparison of our IMU-based system with a well-established OMC system, for both limb and upperbody parameters.

There are three known initiatives in the market to provide portable sensor-based systems for assisting equine veterinarians with gait analysis, which are related to the EquiMoves system presented here. A well-known commercial system is the Lameness Locator from the company Equinosis (Columbia, MO, USA) [27,72]. The Lameness Locator is based on three sensors: two single-axis accelerometers on the head and sacrum (see Section 3.1), and one single-axis gyroscope on the right forelimb, for determining the stance or swing phase of the diagonal pair of limbs in trot. The measured vertical acceleration of the torso is used to determine asymmetries in head and pelvic position between left and right halves of stride in trot. Due to the limited number and type of sensors, the Lameness Locator is usable only in trot, and the produced results relate only to the upper body of the horse.

Another commercial system is GaitSmart Pegasus (Codicote, Hitchin, Hertfordshire, UK) [73], which mainly uses the gyroscope in two directions attached to the limbs, so it focuses on limb-related parameters. Some of the main outputs of Pegasus are the temporal phase-lag between limb cycles and the (angular) range of motion. However, none of these parameters are fully validated with respect to the goldstandard laboratory equipment [69], and their biological significance still needs to be investigated with respect to their correlation with lameness. For the Pegasus system, the angular range of motion was compared with an OMC system similar to ours in an earlier study by Roepstorff et al. [69]. Their results show a rather large bias between the two systems, yet the agreement between the two systems looks quite good. However, as we demonstrate in the discussion of our own results in Section 7.3, Roepstorff et al. analyzed the agreement on a trial level, rather than on a per stride basis, which means that their agreement results are somewhat diluted, potentially painting an unrealistic picture of the true error. Additionally, the agreement was calculated on a mixed data set of walk and trot trials, thereby diluting the effect of gait.

Finally, the EquiGait system [74] (Brickendon, Hertford, Hertfordshire, UK) uses IMUs on the upper body to measure either gait symmetry, back movement, or horse-rider interaction (with one IMU on the rider). Alternatively, a mobile phone can be used over the pelvic area. Although the EquiGait system is validated [34] for the upperbody parameters that it can produce, it is currently not used to assess limb-related parameters (to the best of our knowledge). 


\section{Background}

In this section, we provide the necessary background on equine locomotion theory.

\section{Horse Anatomy}

Figure 1 shows a horse equipped with the EquiMoves hardware. Parts of the anatomical structure of the horse that are relevant to this work are annotated.

The poll position is on top of the head of the horse between the ears. The withers is a position on the horse's back between the shoulder blades. The sternum is the breastbone in the middle of the horse's chest, which is located on the underside of the horse, just behind the forelimbs. The sacrum or pelvis is on the back of the horse above the hindlimbs. The cannon bone is the bone just beneath the knee in the forelimbs and beneath the hock in the hindlimbs.

As shown in Figure 2, horse motion can be analyzed in the following imaginary planes (among others):

- Sagittal (anterior-posterior) plane: divides body in left/right; describes forward backward motion

- Coronal (medial-lateral) plane: divides body in front/back; describes left/right sideways motion

\section{Horse Locomotion Parameters}

\section{Stride Timing}

For a single limb, strides are delimited by the moment the hoof touches the ground; the stride duration is the time that passes between these events. The stride frequency is the reciprocal of the stride duration. Strides can be divided in a swing phase and a stance phase. The swing phase starts at the moment the hoof is lifted from the ground (the hoof-off moment) and ends when it touches the ground once more (the hoof-on moment). The stance phase is the period of time the hoof is on the floor.

\section{Limb Angle Parameters}

The protraction is the forward extension of a limb, while the retraction of a limb is the backward extension [75]. The protraction and retraction angles of the cannon bone are defined here as the sagittal (forward/backward) swing angles of that bone during a stride relative to vertical. The (sagittal) range of motion (ROM) is the full angular distance between retraction and protraction. This definition matches what is used by Roepstorff et al. [69]. The limb can also have a coronal angle during a stride; 


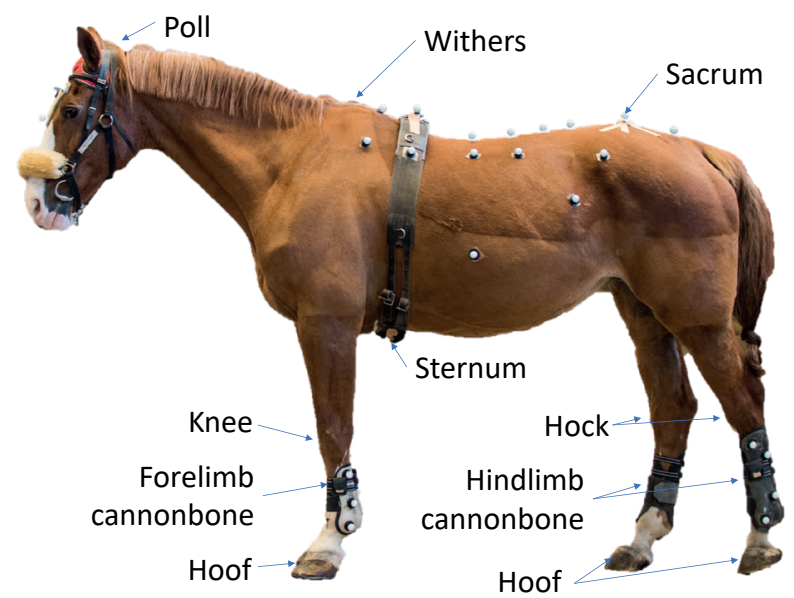

Figure 1. Relevant anatomical positions on a horse.

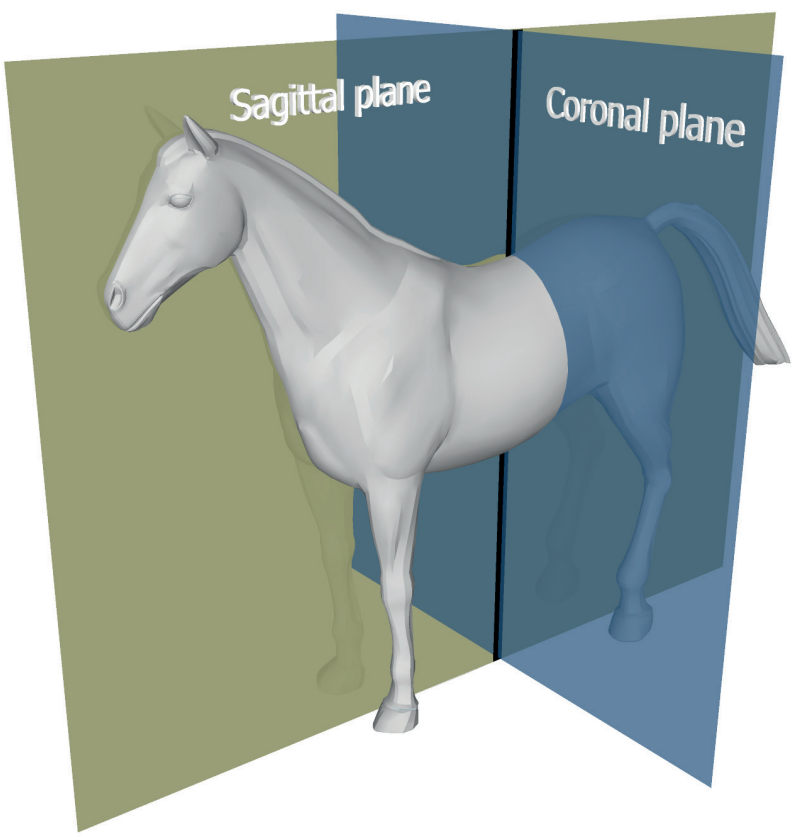

Figure 2. Planes for horse motion. 
when the limb is tilted outwards, it is called an abduction angle, and, when it is tilted inwards, it is an adduction angle. In this article, the protraction and retraction angles are determined at the respective hoof-on and hoof-off moments. In contrast, the abduction and adduction angles are determined as the coronal angle extrema.

The protraction and retraction angles for the forelimbs are shown schematically in Figure 3 on the left side. The sagittal angles for the hindlimbs are defined identically. On the right, Figure 3 also shows the coronal abduction/adduction angle for one hindlimb.

\section{Upper-Body Symmetry Parameters}

Upper-body symmetry parameters can be calculated at several upper-body locations: poll, withers, sternum, and sacrum. At each of these positions, the vertical displacement of the body is measured. At each stride, the upper body typically moves up and down two times for the successive left and right limb steps, so there are two peaks and two troughs in the signal, as shown in Figure 4. If the horse moves perfectly symmetrically, these extrema are at the same level [21].

The following parameters are derived from the vertical displacement signal:

- Max_diff: the difference between the two peaks ( $\operatorname{Max}_{1}$ and $\operatorname{Max}_{2)}$ of the vertical displacement signal [21].

- Min_diff: the difference between the two troughs ( $\operatorname{Min}_{1}$ and $\left.\operatorname{Min}_{2}\right)$ of the vertical displacement signal [21].

- Range $_{u p, 1 / 2}$ : The upwards range or amplitude is the difference between a trough and the next peak in the vertical displacement signal. Since there are two troughs, there are two separate values.

- Range down, $1 / 2$ : The downwards range or amplitude is the difference between a peak and the next trough in the vertical displacement signal. Since there are two peaks, there are two separate values.

- Range_diff up: the difference between the two upwards ranges.

- Range_diff down $_{\text {: }}$ the difference between the two downwards ranges.

The upwards or downwards symmetry index $(\mathrm{SI})$ can be derived from these parameters as follows [21]:

$$
S I_{\text {up } / \text { down }}=\frac{\text { Range }_{\text {up/down }, 1}-\text { Range }_{\text {up } / \text { down }, 2}}{\max \left\{\text { Range }_{\text {up } / \text { down }, 1}, \text { Range }_{\text {up } / \text { down }, 2}\right\}} .
$$


A value of \pm 1 indicates maximum asymmetry (the sign depending on the affected limb) and a value of 0 indicates perfect symmetry.

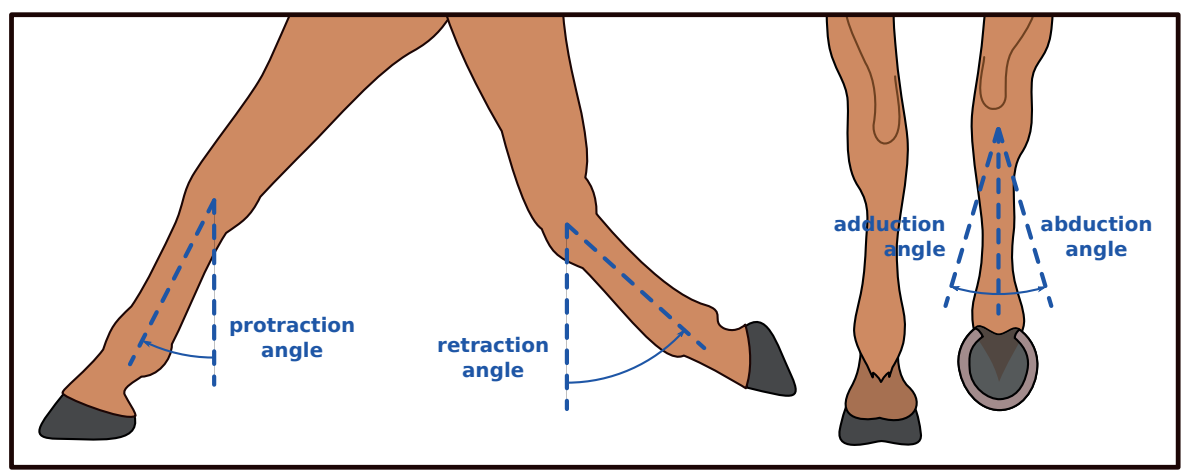

Figure 3. Forelimb protraction and retraction angles, and hindlimb adduction and abduction angles.

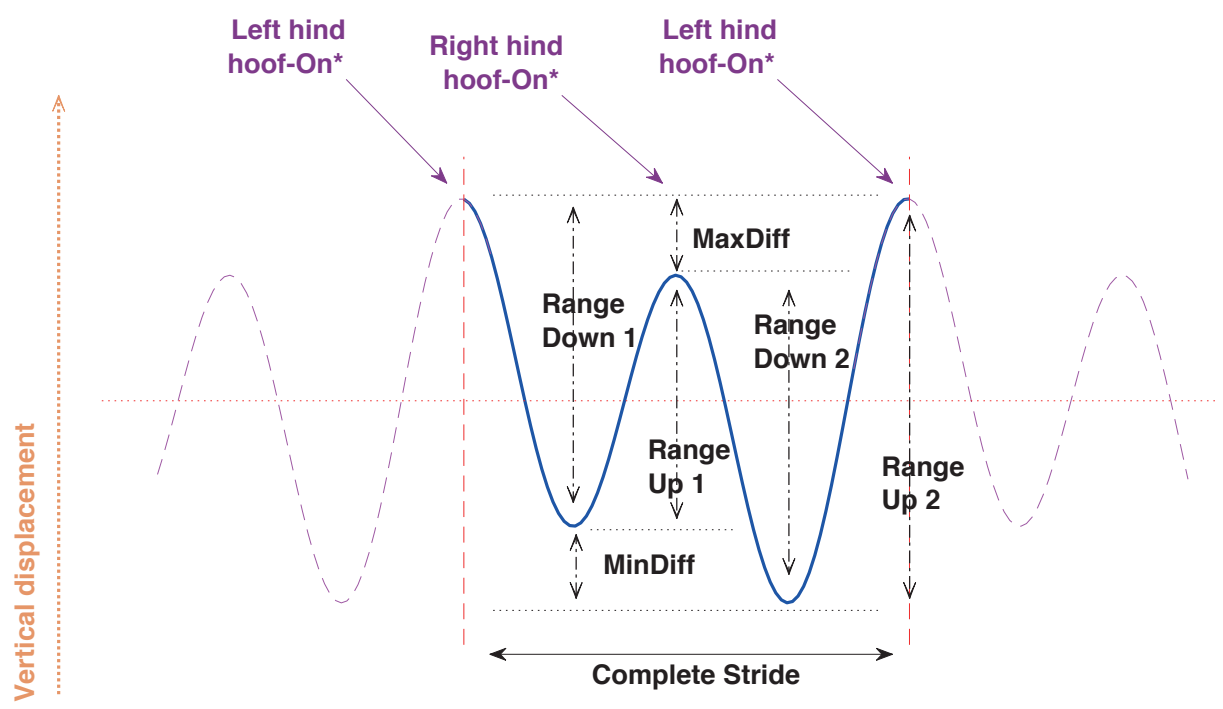

Time

Figure 4. Upper-body vertical displacement annotated with symmetry parameters. The timing of hoof-on instances is approximate. 


\section{System Overview}

In this section, we provide an overview of the EquiMoves system in terms of hardware and software. Figure 5 provides a schematic overview of the system.

\section{IMU Hardware}

As shown in Figure 5, the hardware of the EquiMoves system consists of up to eight ProMove-mini wireless IMUs (Inertia Technology B.V., Enschede, The Netherlands) [76] for capturing motion data, one wireless receiver (the Inertia Gateway), and a (laptop) computer or tablet that runs the EquiMoves software. A ProMove-mini IMU (see Figure 6) weighs $20 \mathrm{~g}$ and features a set of 3D digital sensors providing acceleration, angular velocity (gyroscope), and magnetic field intensity (compass). The ProMove-mini has two separate aligned accelerometers that can simultaneously measure low- $g$ acceleration with a range of $\pm 16 \mathrm{~g}$ and high- $g$ acceleration with a range of $\pm 400 \mathrm{~g}$. With this two-sensor setup, a single fused signal can be obtained with a high precision and range, even when the registered acceleration exceeds $\pm 16 \mathrm{~g}$-for example, at foot impacts during trot or canter. The gyroscope can measure angular velocity within range of $\pm 2000 \%$ s. More limited ranges can be configured for all sensors to attain higher precision.

The wireless network operates in the $2.4 \mathrm{GHz}$ ISM band using a proprietary protocol. The Inertia Gateway acts as the coordinator in a network of ProMove-mini nodes with a star topology; all nodes in the network communicate only directly with the gateway. The transmission range is up to $30 \mathrm{~m}$ in ideal conditions. Sensor data from all IMUs is streamed through the gateway to the computer running the EquiMoves software. The IMUs are continuously and actively time-synchronized within a precision of $100 \mathrm{~ns}$, practically guaranteeing sampling at precisely the same time instance in all measurement points.

The gateway can handle a wireless network of up to 39 ProMove-mini IMUs sampling and streaming data from all inertial sensors (accelerometers and gyroscope) at 200 $\mathrm{Hz}$ and the compass at its maximum sample rate of $100 \mathrm{~Hz}$. When using fewer nodes, sampling rates up to $1 \mathrm{kHz}$ are possible for the inertial sensors; i.e., the EquiMoves system could be configured for $1 \mathrm{kHz}$ with the full network of eight nodes, which could be necessary for measuring gallop, for example. For trot, $200 \mathrm{~Hz}$ is ample [70,77].

To mitigate packet loss in the wireless network and to facilitate performing measurements (briefly) outside the wireless transmission range, the sensor data can be stored simultaneously on the on-board 2 Gb SD-card memory of each node. After 
the experiment, the recorded data can be retrieved wirelessly through the gateway or through USB by connecting each IMU to the computer.

Figure 1 shows a horse equipped with the EquiMoves hardware. Refer to Section 5.3 for details on horse instrumentation.

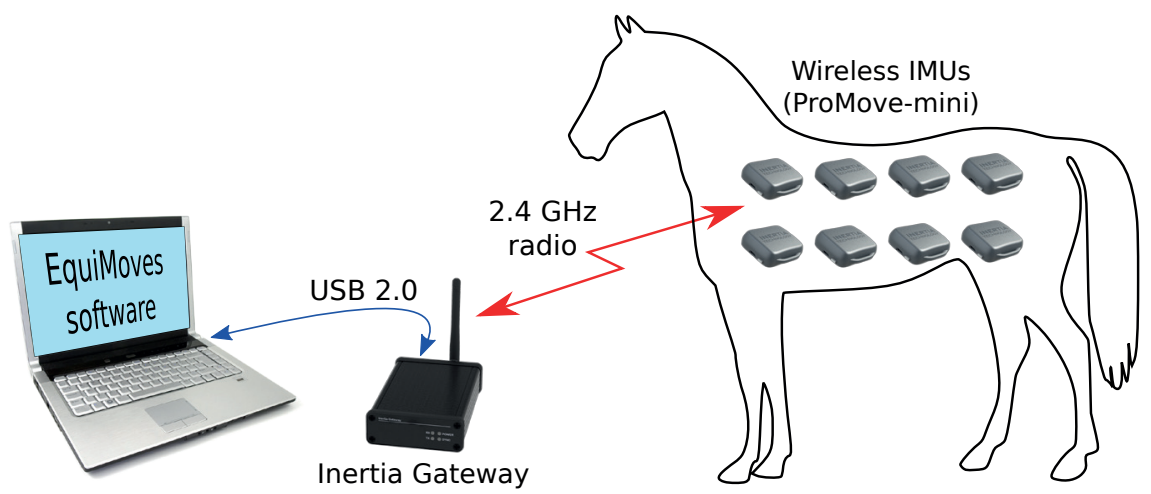

Figure 5. System overview. IMU: inertial measurement unit.

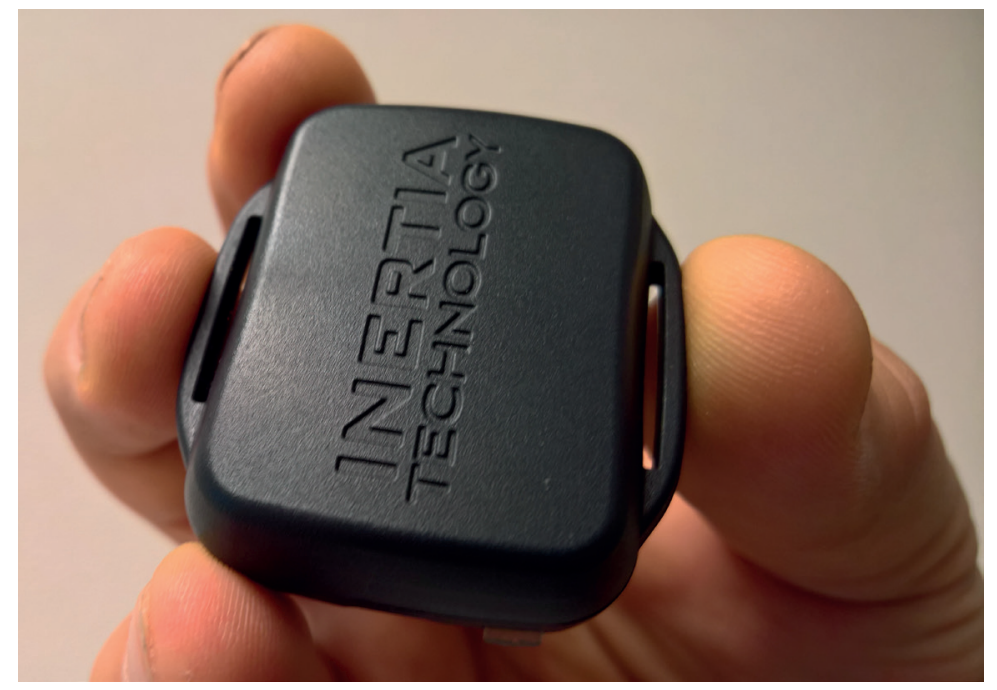

Figure 6. ProMove-mini. 


\section{Motion Processing}

The EquiMoves motion processing software (see Figure 5) receives the raw sensor data from the IMU network through USB and computes the relevant parameters described in Section 3.2 for analyzing the horse's gait with respect to lameness and performance assessment. This is a complex process that involves the following main processing steps, as depicted in Figure 7. This section provides a high-level overview of motion data processing for the EquiMoves system; the details are described in Section 6.

During Step Detection, the raw IMU sensor data from each limb is used to identify the exact motion cycles broken down into strides, and each stride into its stance and swing phases. The main challenges here are to detect the hoof-on and hoofoff moments (see Section 3.2.1) with maximum accuracy, from the inherently noisy sensor signals. A detailed analysis of the developed detection algorithms, and the comparison with existing methods, is provided in an earlier study by Bragança et al. [78]. The outputs of this step are: hoof-off and hoof-on moments, and the stride duration, distinguishing between stance and swing durations.

In the Orientation processing step, the raw IMU sensor data is fused to obtain 3D orientation information. The angular velocity from the gyroscope sensor is integrated into a quaternion orientation. Measurements from the accelerometer are used as a means of correcting the orientation with respect to the direction of gravity, thus limiting the gyroscope drift. Although a compass sensor is available (see Section 4.1), it is not used in this framework: practical experience with the compass sensor demonstrates that it is often too unreliable, especially when used inside a concrete or steel building. This means that there is no absolute heading reference. However, such a heading reference is not strictly necessary, since the absolute heading of the horse is currently not relevant to the calculated gait parameter. With the obtained $3 \mathrm{D}$ orientation, the acceleration measured by the IMUs is rotated from the body reference frame of each IMU to a navigation reference frame in which the $z$-axis is aligned with gravity. The outputs of this step are the IMU orientation represented as a quaternion, and the IMU acceleration represented in the navigation frame.

In the Limb Angles processing step, the orientation of the IMU sensor on the limbs is used to determine the angle of the limb at that position relative to the vertical. The orientation at the start and end of the swing phase is used to determine the axis of the sagittal (forward) rotation. Using a so-called swing-twist decomposition (refer to Section 6.7), both the sagittal and coronal (sideways) swing angles of the limb are calculated for the whole swing phase. The outputs of this phase are: protraction and retraction angles, abduction and adduction angles (see Section 3.2.2). 

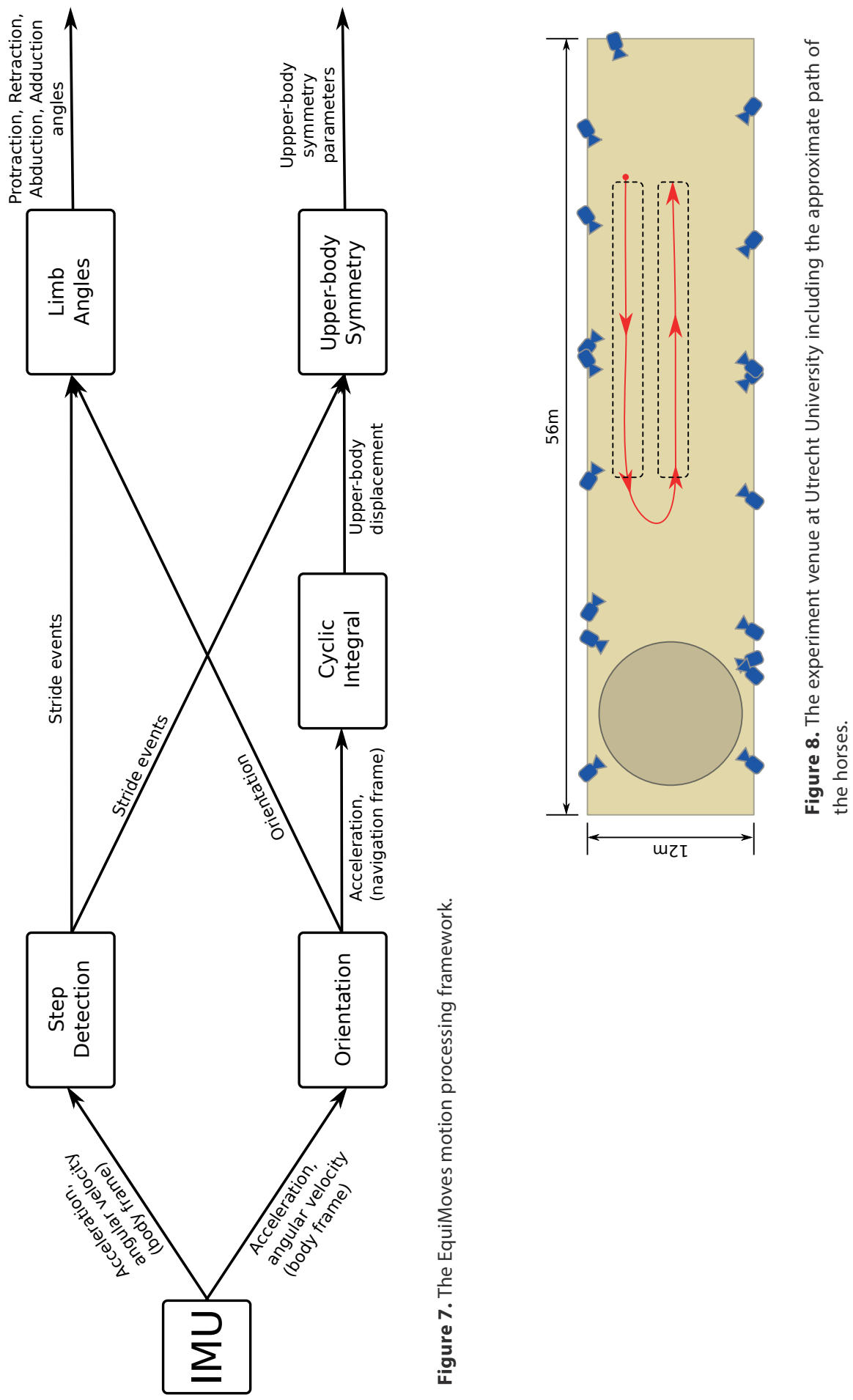
In the Cyclic Integral processing step, upper-body velocity and displacement are computed in a manner similar to the Limb Displacement step, but instead of zerovelocity reset per step, a cyclic integration process is applied, as described in [34]. Through this process, the unbounded integration drift is removed by subtracting the mean of the current and adjacent strides at each integration step. In the Upper-Body Symmetry processing step, the upper-body displacement is segmented per stride, and the position and magnitude of the signal extrema are determined and used in the calculation of the symmetry parameters (see Section 3.2.3). The outputs of this processing step are, for each location (withers, sacrum, sternum, and poll), as follows: Min_diff, Max_diff, Range_diff ${ }_{\text {up/down' }} S I_{\text {up/down }}$.

\section{Experiments}

We analyze the relative performance of the IMU-based EquiMoves system by comparing its measurements to an OMC system. This section describes how the experiments were conducted.

\section{Venue}

Experiments were performed in the Equine Clinic of Utrecht University, at the Department of Equine Sciences. The clinic is equipped with an OMC system (Qualisys Oqus 700+, Qualisys AB, Göteborg, Sweden) with 18 infra-red camera's (12 MP, 4096 $\times 3072$ pixels) mounted at a height of approximately $8 \mathrm{~m}$ (aimed downwards) that record the position of reflective markers attached to the horse at key positions. Figure 8 shows a schematic overview of the room, including the location and aim of the cameras. The cameras are distributed across the hall by the manufacturer such that a subject is sufficiently in view of at least two cameras at all times. The relative precision of the OMC system after calibration as deployed was determined to be $1.9 \mathrm{~mm}$.

\section{Horses}

As shown in Table 1, seven Warmblood clinic-owned mares with body mass between 512 and $593 \mathrm{~kg}$, height at the withers in the range of 1.61 to $1.69 \mathrm{~m}$, and age between 10 to 21 years were used for this study. The listed horse numbers are used in the results in Section 7. None of the subjects had a recent history of lameness.

\section{Data Collection}

All subjects were instrumented with eight IMU sensors (refer to Section 4.1) on the poll, withers, sacrum, sternum, and each limb (refer to Section 3.1). On the limbs, each sensor node was firmly attached to the lateral aspect of each cannon bone using a 
custom-made holster (see Figure 9). At the withers and sternum of the horse, the sensor nodes were mounted on a girth, a cap was used at the poll, and double-sided tape was used at the sacrum. Figure 10 shows an overview of the sensor locations.

Table 1. Properties of the horses involved in the experiments.

\begin{tabular}{llll}
\hline Horse & Weight $(\mathbf{k g})$ & Height $(\mathbf{m})$ & Age (years) \\
\hline $\mathbf{1}$ & 534 & 1.69 & 12 \\
$\mathbf{2}$ & 512 & 1.62 & 11 \\
$\mathbf{3}$ & 593 & 1.61 & 10 \\
$\mathbf{4}$ & 578 & 1.66 & 10 \\
$\mathbf{5}$ & 514 & 1.65 & 16 \\
$\mathbf{6}$ & 593 & 1.66 & 21 \\
$\mathbf{7}$ & 587 & 1.66 & 14 \\
\hline Mean & 559 & 1.65 & 13 \\
\hline
\end{tabular}

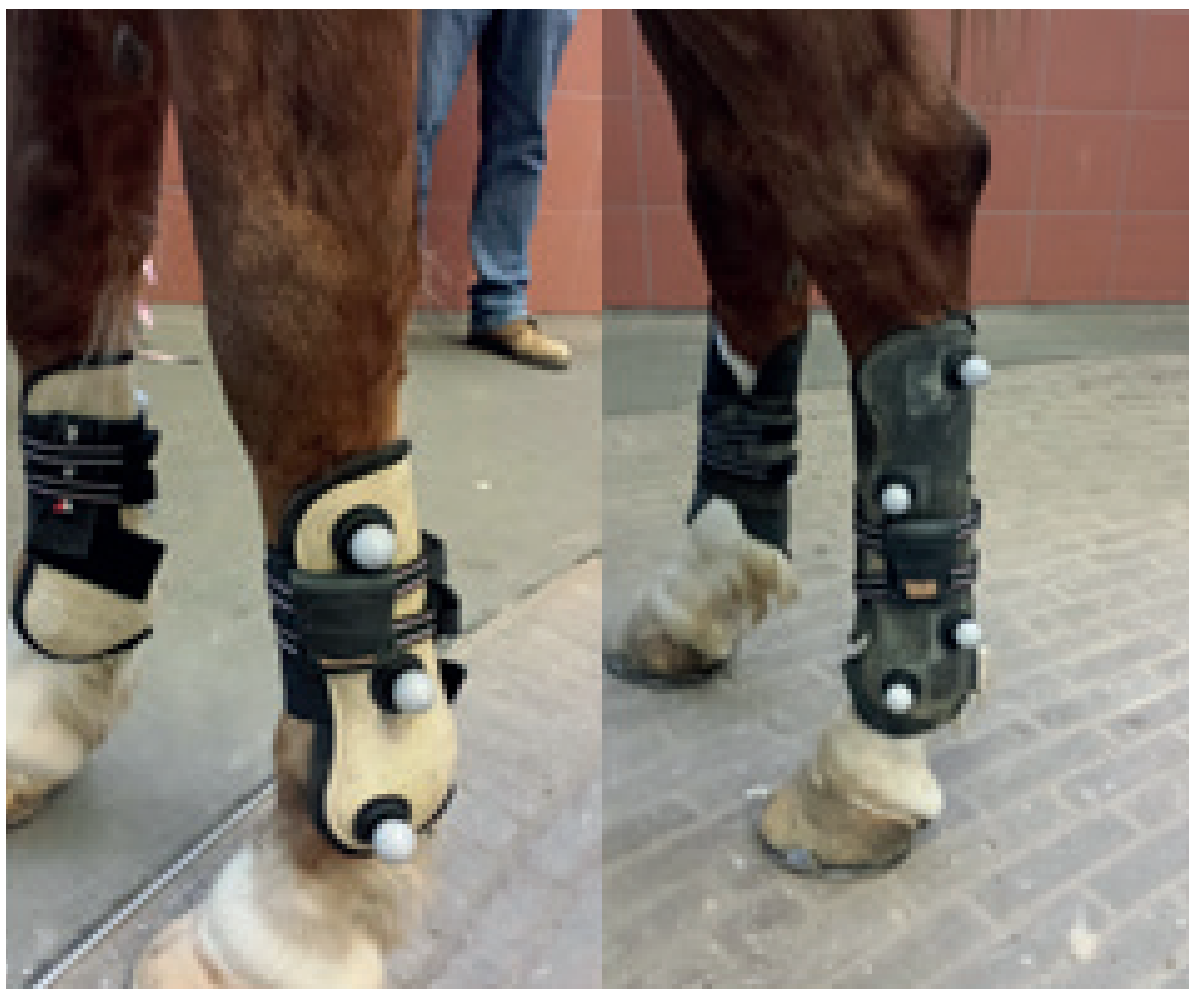

Figure 9. Placement of the IMU sensors and optical motion capture markers on fore- and hindlimbs. 
The sensors were configured with a sampling rate of $200 \mathrm{~Hz}$. For the sensors attached to the limbs, the range for the low- $g$ accelerometer was configured at its maximum range of $\pm 16 \mathrm{~g}$ and the high- $g$ accelerometer at a mid-level range of $\pm 200 \mathrm{~g}$, which is sufficient for trot. The sensors at the upper-body locations were configured with the low- $g$ accelerometer at $\pm 8 g$ for better accuracy.

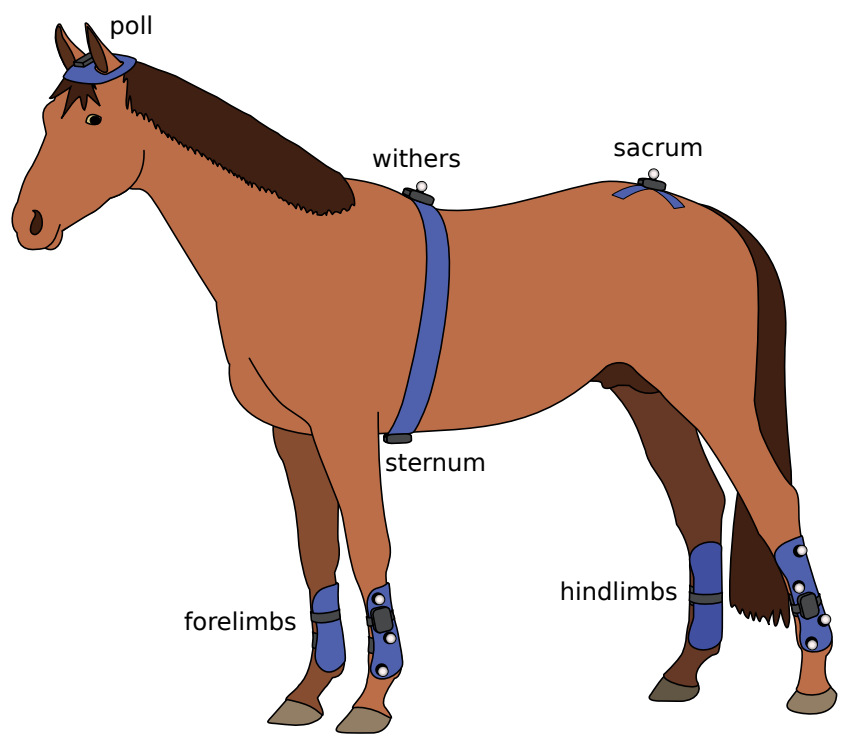

Figure 10. Overview of the equipment attached to each horse.

During the experiment, the IMU sensors transmitted their samples wirelessly to a nearby laptop computer in real time. To prevent data loss, the data was also stored in the internal memory of each individual sensor (see Section 4.1). At the end of the experiment, any samples missing in the laptop's data file were filled in from the internal memory of each sensor by downloading those wirelessly.

Several reflective markers were placed on the IMU sensor holsters on the limbs, so that the OMC system could determine both position and orientation at these locations (refer to Section 6.2). Four reflective markers $(25 \mathrm{~mm} 0$, spherical soft passive markers) were glued around each of the hindlimb-mounted IMUs, and three on the forelimbs also around the IMUs. Furthermore, three reflective markers were glued on the poll (head), three on the girth, and three on the pelvis (tuber sacrale, left and right tuber coxale). The IMU sensors on the upper body had only a single reflective marker located on or near the IMU sensor, which limited those OMC measurements to displacement only. 
Motion capture data was recorded at $200 \mathrm{~Hz}$ using 18 infrared cameras (refer to Section 5.1) previously calibrated per manufacturer instructions to a global coordinate system. All trials were also recorded on normal video using standard equipment for retrospective analysis of the collected data. These video recordings were hardwaresynchronized to the OMC system.

During the measurements, the three-dimensional coordinates of each marker were automatically tracked by the motion capture software (QTM, version 2.11a, Qualisys AB, Göteborg, Sweden). After each measurement, visual inspection of the 3D-tracked data confirmed that all markers were properly tracked and data was suitable for analysis. Measurements with poor marker tracking or irregular gait patterns were discarded and repeated.

Due to occlusions caused by the horse's ears and due to the camera positioning at our venue, no marker could be placed directly on the IMU sensor at the poll location; therefore, the nearest marker was too far away from that sensor for a reliable comparison. This could have been achieved by performing this experiment on a treadmill. Nevertheless, it was our goal to perform this comparison overground, for which situation the EquiMoves system is designed and aimed to collect data. This means that the poll location measurements were excluded from our analysis.

All subjects were fitted with the instruments and were led by an experienced handler in walk and trot in a straight line while motion capture and IMU data was collected. Two experiments were performed for each horse at walk and trot, back and forth along a straight path, as shown by the arrow track in Figure 8.

\section{Data Processing}

We analyzed the relative performance of the IMU-based EquiMoves system by comparing its measurements to an OMC system. We are mainly interested in the differences caused by the errors in the displacement and orientation measurements of both systems.

\section{Missing Data}

Our comparisons skip time instances where data from either system is missing. To prevent problems with time synchronization (see Section 6.5.1) between the two systems, any gaps in the data of either system were filled with placeholder samples. As explained in Section 4.1, the EquiMoves system prevents data loss by storing a 
copy of the data locally on the SD-card in each node, which can be downloaded after the experiment. This means that the data is always complete for the duration of the experiment. The OMC system is not wireless, so packet loss is not an issue there. However, the reflective markers can become occluded, which means that an insufficient number of OMC cameras has the marker in view and the position of that marker cannot be determined at that time. This happened during some of our experiments, meaning that the OMC data set has minor gaps. Since the gaps were minor, these were skipped in the processing, rather than interpolated.

\section{Orientation}

The orientation of the IMU sensors was determined using an attitude and heading reference system (AHRS) algorithm by Valenti et al. [79]. At its core, it integrates the rotational velocity from the gyroscope sensor into an orientation represented as a quaternion. Measurements from the accelerometer are used as a means to correct the orientation with respect to the direction of gravity. In terms of Euler angles, this means that gyroscope drift errors in the pitch and roll angles are compensated. However, without an additional reference (e.g., the heading vector provided by a compass sensor, refer to Section 4), the yaw angle is left uncompensated. The static accelerometer filter gain $a^{-}$for the Valenti algorithm was set to 0.0001 for these experiments (refer to Equation (61) in [79]).

In these experiments, orientation data for the OMC system is only available for the limbs, since, at those locations, several reflective markers were placed that together formed a so-called rigid body. For such a rigid constellation of markers, the OMC system can calculate the orientation and position for each captured camera frame. At those limb positions, the IMU was placed in the middle of the markers so that its displacement and orientation would directly match the movements of the OMC system's rigid body.

For both systems, the orientation is represented in unit quaternions $[79,80]$. In essence, a unit quaternion can $I$ describe a rotation from one orientation to another around an axis or vector $\boldsymbol{v}=\left[v_{x} v_{y} v_{z}\right]$ by an angle $\theta$. Such a rotation quaternion $q r$ is composed as follows:

$$
\boldsymbol{q}_{r}=\left[\begin{array}{ll}
\cos \frac{\theta}{2} & \boldsymbol{v} \sin \frac{\theta}{2}
\end{array}\right]^{T}
$$




\subsection{Position and Displacement}

The OMC system produces position measurements for individual markers or a rigid body, as described in the previous section. From an absolute position, displacement can be readily calculated. In contrast, IMU systems need to integrate the acceleration twice to obtain displacement estimates. First, the orientation measurement is used to rotate the acceleration measurements from the sensor reference frame to a navigation reference frame, which has the z-axis aligned with gravity. Subsequently, the acceleration signal is integrated twice to successively obtain velocity and displacement values.

As described in Section 6.8, a special integration algorithm is used to limit the drift in the integrals that arises from IMU measurement errors [25].

\section{Noise Filtering}

The acceleration, velocity, and angular velocity signals calculated from the position and orientation measurements produced by the OMC system were noisy (mostly spikes) (see, for example, Figure 12), likely due to the occasional marker occlusions and inherent to its position estimation algorithms. The same signals from the IMU were less noisy in most cases, but these were not completely noise-free either. Thus, to prevent the noise from having an effect on our agreement analysis, the data for both systems was first low-pass filtered using a fourth-order Butterworth filter with a cut-off frequency of $30 \mathrm{~Hz}$. This is well beyond the highest frequency component of interest at two times the stride frequency (around 3 to $4 \mathrm{~Hz}$ ) [81,82]. To prevent group delay from having an effect on our synchronization, zero-phase filtering was used at all times. The filter was applied to displacement and angular signals identically for both systems where necessary; more details are provided in subsequent sections.

\section{Alignment with Camera Data}

Both the EquiMoves IMU-based system (see Section 4.1) and the OMC system yield data sets that are intrinsically synchronized across all of their measurement locations. However, to compare the data between the two systems, the data sets need to be aligned in time and space. This was performed in post-processing.

\section{Time-Synchronization}

At the time of data collection, there was no means available to achieve hardwarebased time synchronization between the IMU and OMC systems. Therefore, time-synchronization between the two systems was achieved by calculating the correlation coefficient on a signal that could be readily obtained from both systems. The peak in the resulting correlation curve yields the lag between the two data sets. 
The clock skew (frequency difference) between the two systems was assumed to be negligible for the length of the experiment. Time-synchronization is therefore a matter of applying the calculated lag to the time stamps of one of the two data sets. This method is similar to what Howard et al. [83] use to synchronize their IMU and force platform signals.

We chose to use the angular velocity of one limb as input signal for the correlation, since this is easily and reliably calculated from both systems. For the IMU, this is the raw output from the gyroscope. For the OMC system, this can be calculated from the rigid body quaternion orientation $q$ signal by quaternion differentiation.

Equation (3) describes the computation of the orientation of a gyroscope sensor at time tk by numerical integration of the angular velocity signal from that sensor $[79,80]$ using sample period $\Delta \mathrm{t}=t_{k}-t_{k-1}$. The angular velocity is represented in the sensor body reference frame. The orientation of the sensor is represented as a quaternion $q_{w}=\left[\begin{array}{llll}q_{w, 1} & q_{w, 2} & q_{w, 3} & q_{w, 4}\end{array}\right]^{T}$, which describes a rotation from the global reference frame to the sensor body reference frame. The integration process estimates the required quaternion derivative $q_{w}\left(t_{k}\right)$ from the angular velocity $w=\left[w_{x} w_{y} w_{z}\right]^{\top}$ in Equation (3b).

The $\otimes$ operator is the quaternion multiplication:

$$
\begin{gathered}
\boldsymbol{q}_{\omega}\left(t_{k}\right)=\boldsymbol{q}_{\omega}\left(t_{k-1}\right)+\dot{\boldsymbol{q}}_{\omega}\left(t_{k}\right) \Delta t \\
\dot{\boldsymbol{q}}_{\omega}\left(t_{k}\right)=\frac{1}{2} \boldsymbol{q}_{\omega}\left(t_{k-1}\right) \otimes\left[\begin{array}{c}
0 \\
\omega\left(t_{k}\right)
\end{array}\right] .
\end{gathered}
$$

To obtain the angular velocity signal $\omega(t)$ from the existing quaternion orientation signal $q(t)$ from the OMC system, the numerical integration of Equation (3) can be reversed into a numerical derivative as follows:

$$
\begin{gathered}
{\left[\begin{array}{c}
0 \\
\boldsymbol{\omega}\left(t_{k}\right)
\end{array}\right]=2 \dot{\boldsymbol{q}}^{*}\left(t_{k}\right) \otimes \boldsymbol{q}\left(t_{k-1}\right),} \\
\dot{\boldsymbol{q}}\left(t_{k}\right)=\frac{\boldsymbol{q}\left(t_{k}\right)-\boldsymbol{q}\left(t_{k-1}\right)}{\Delta t} .
\end{gathered}
$$


At this point, we have obtained an angular velocity signal $\omega(t)$ for each system. However, these signals are three-dimensional. To make these signals scalar andmore importantly - to remove the influence of the relative orientation between the IMU and OMC system data, the magnitude $\|\omega(t)\|$ (Equation (5)) is used as input for the correlation coefficient. An example of the correlation coefficient between two angular velocity magnitude signals is shown in Figure 11. Figure 12 shows the raw angular velocity magnitude signals after synchronization.

$$
\|\boldsymbol{\omega}(t)\|=\sqrt{\omega_{x}(t)^{2}+\omega_{y}(t)^{2}+\omega_{z}(t)^{2}}
$$

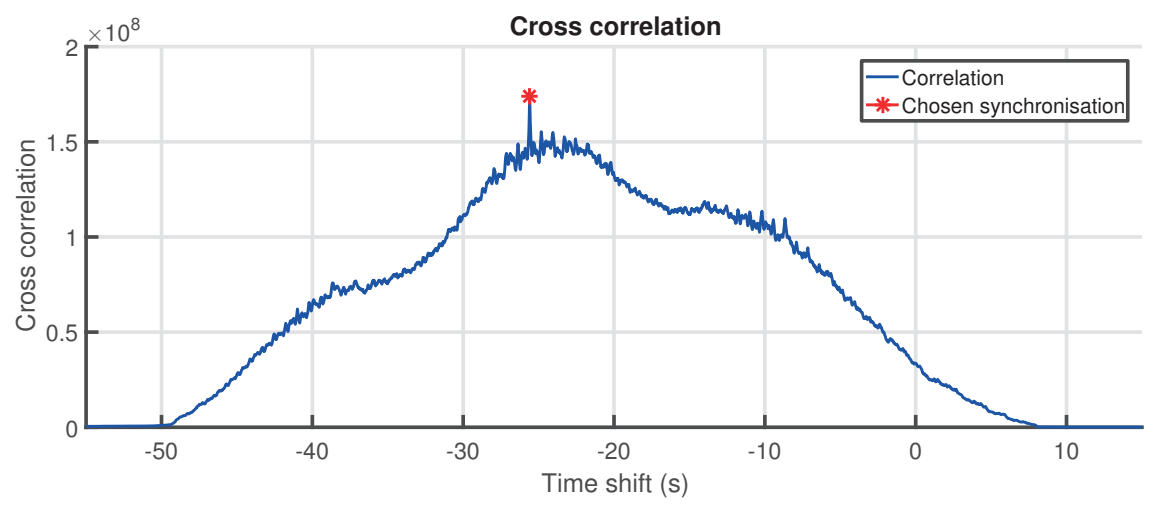

Figure 11. Example of the cross-correlation between angular velocity magnitude between IMU and optical motion capture (OMC).

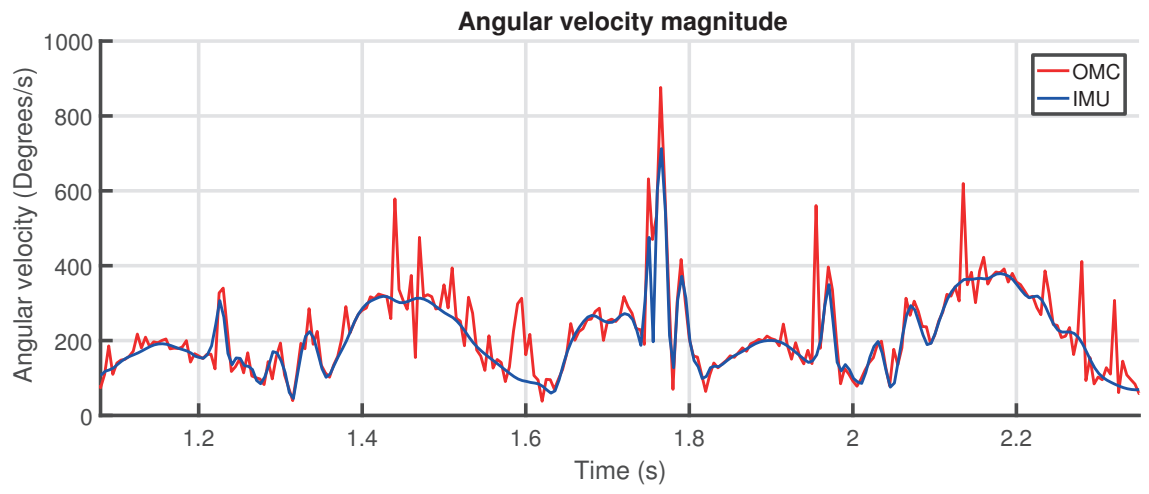

Figure 12. Example of the synchronization of angular velocity magnitude between IMU and OMC. 
The time resolution of the peak location in the correlation coefficient is dictated by the sample frequency of both systems. In our case, these frequencies are identical at $200 \mathrm{~Hz}$. To obtain a more accurate estimate of the lag between the two systems, the location of the peak is determined more precisely by quadratic interpolation over three points. By visual inspection, the accuracy of the achieved synchronization is estimated to be better than $1 \mathrm{~ms}$. For the comparison between the two systems, the OMC signals were resampled to synchronize them with their IMU equivalents, based on the time lag found by the method described above.

\section{Orientation and Position Alignment}

Before evaluating the high-level results, it is useful to compare the data sets a lower level in terms of their position and orientation values. For this comparison, the data sets need to be aligned: the OMC system uses an absolute room-referenced coordinate system, whereas the IMU system uses a navigational reference frame that is not anchored to anything, apart from the $z$-axis, which is aligned with the gravity vector.

At the limb positions, the OMC system's markers that form a rigid body and the IMU sensor were mounted rigidly on the same position (see Section 6.2), which means that the motion sequence measured by both systems will be identical, apart from a fixed relative translation and rotation between the two systems. Since the positions are deemed identical and only displacement values are compared, any translation between the two systems will be ignored. Therefore, we only need to find the rotation value, which should remain constant for the whole experiment, assuming that the physical attachment of the hardware does not change during the experiment. The data sets are assumed to be already synchronized in time by the procedure described in the previous section, so we can correctly pair measurements between the two systems.

To determine the rotation between the two systems, we need to have a signal from each system that depends on the orientation of its measurement reference frame. We use the angular velocity signals that we used for time synchronization in the previous section. In this case, we use the actual 3D signals and not their magnitude. The gyroscope measures the angular velocity in the sensor's body reference frame, whereas the OMC angular velocity is calculated relative to the reference frame of the defined rigid body. Therefore, the rotation that maps the IMU's angular velocity measurements to the corresponding signal calculated for the OMC system is equal to the rotation between the two systems, which is the desired rotation value. 
We determined the translation and rotation between the two signals using the Kabsch algorithm [84]. This is a method for obtaining the optimal rotation and translation between two spatial structures defined by a set of paired points, which minimizes the distance between the paired points. To use this algorithm, we considered our angular velocity signals to be structures in 3D space. The individual samples are the points that define each structure. The points are paired per time instance between the systems.

The rotation resulting from the Kabsch algorithm directly describes the relation between the orientation of the IMU sensor reference frame and the orientation of the rigid body defined for that location by the OMC system. Note that, considering the nature and origin of the angular velocity signals and the fact that both signals describe the same motion sequence, there should be very little translation apart from some gyroscope bias. Applying this mapping to one of the angular velocity signals allows these to be compared directly, as shown in Figure 13.
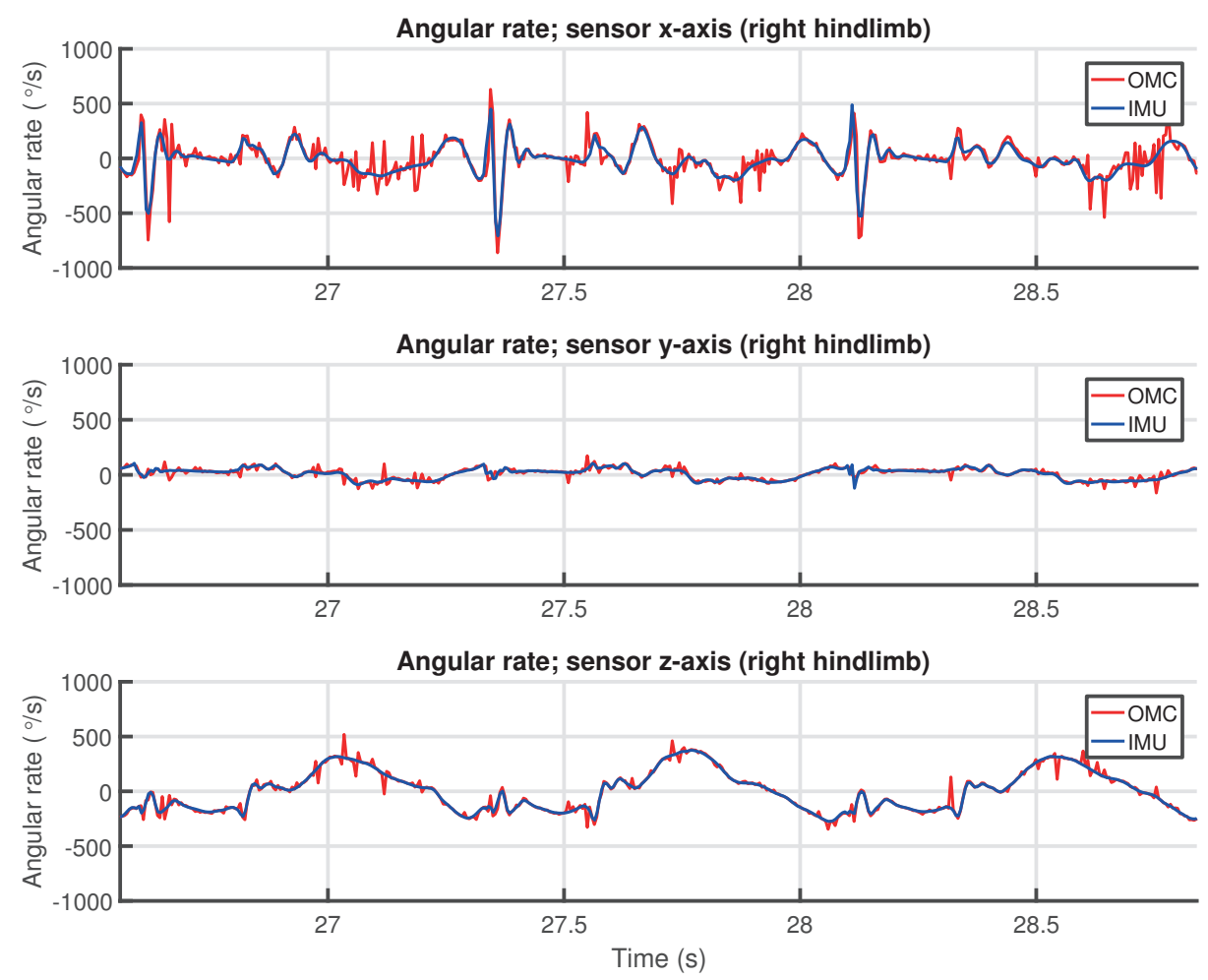

Figure 13. Example of the alignment of angular velocity between IMU and OMC. 
As stated earlier in Section 6.4, OMC system signals can be very noisy, especially derivatives from such signals (as seen in Figure 13). Therefore, to prevent the alignment from being affected, we excluded periods where the absolute difference in the variance of the magnitude of the two signals exceeded a threshold of $1.0 \times 10^{-3}$ $(\mathrm{o} / \mathrm{s})^{2}$ over a window of 10 samples.

\section{Hoof Event Detection}

As described earlier in Section 1, this work focuses on the comparison of displacement and angular measurements. Using different hoof event timing for the two systems would distort the results and make it difficult to pinpoint what is causing the difference. Since we have pre-existing experience with extracting timing information from the IMU data, we used the IMU as the timing reference; e.g., the stride segmentation was performed based solely on the IMU data. We used the algorithm published earlier by Bragança et al. [78], denoted as Algorithm 1 therein.

\section{Limb Angles}

The orientation of the limbs at the cannon bone was determined for both the IMU and OMC systems using the procedures explained earlier in Section 6.2. Equally for both systems, this orientation was used to determine the sagittal and coronal limb angles (see Section 3.2.2) during each stride.

Since the orientation is determined in a global/room (OMC) or navigation (IMU) reference frame, the heading of the horse is part of the orientation. Therefore, it is necessary to distinguish the forward swing (sagittal) direction for each stride individually. This is performed by determining the rotation axis between the orientation at the hoof-off and hoof-on moments (refer to Section 3.2.1). This axis is perpendicular to the sagittal plane. To obtain this axis, we calculate the quaternion that transforms between these orientations:

$$
\boldsymbol{q}_{r}=\boldsymbol{q}_{o n} \otimes \boldsymbol{q}_{o f f}^{*}
$$

The sagittal part of rotation is subsequently determined using a swing-twist decomposition [85] around the z-axis in the respective system's global/navigation reference frame. The swing-twist decomposition is used to decompose a rotation $\boldsymbol{q}_{r}$ into a rotation $\boldsymbol{q}_{t}$ around a specified axis $\boldsymbol{v}$ (the twist) and the remaining rotation $\boldsymbol{q}_{s}$ around another axis (the swing), so that:

$$
\boldsymbol{q}_{r}=\boldsymbol{q}_{t} \otimes \boldsymbol{q}_{s}
$$


In our case, the resulting twist quaternion $\boldsymbol{q}_{t}$ is the component that consists of a rotation around the $z$-axis, and the swing quaternion $\boldsymbol{q}_{s}$ is the residual rotation around a different (horizontal) axis, which is the sagittal part of the rotation we are looking for. The sagittal axis is subsequently extracted from the swing quaternion qs as its vector part $\boldsymbol{v}$ (see Section 6.2). Then, we perform another swing-twist decomposition-this time on each sample of the limb orientation signal for each stride. This is used to determine the twist rotation around the sagittal axis for the duration of each stride. The sagittal angle signal is readily extracted from the resulting twist quaternion signal (see Section 6.2). Subsequently, the sagittal axis is rotated 90 degrees around the z-axis to obtain the coronal axis. Again using a swing-twist decomposition, the coronal angle signal is determined.

A problem that arises with these calculations is the definition of where the sagittal and coronal angles are zero. A logical choice would be that these angles are zero when the limb-or rather the cannon bone (refer to Section 3.1)—is vertical. This situation is not trivial to determine from either the OMC or the IMU data sets. Since finding an accurate algorithm for this is outside the scope of this work, we defined a position in the stride that we can determine reliably on both systems and that still approximates the vertical orientation quite well. We chose to use the $50 \%$ of stance (mid-stance) moment; i.e., exactly in the middle of the stance phase of the stride. As long as both systems use this time-based reference, our results will not be biased by this definition. As before (see Section 6.6), we used the IMU as reference for stride segmentation; therefore, the derived mid-stance moment is exactly the same time instance for the IMU and OMC systems.

To implement this zero reference, the limb orientation $\boldsymbol{q}_{r, m}$ is calculated as a rotation relative to the limb orientation at the mid-stance $\boldsymbol{q}_{m}$ (Equation (8)). The resulting quaternion $\boldsymbol{q}_{r, m}$ is used instead of the limb orientation qr itself in the process described above:

$$
\boldsymbol{q}_{r, m}(t)=\boldsymbol{q}_{r}(t) \otimes \boldsymbol{q}_{r}^{*}\left(t_{\text {midstance }}\right)
$$

To remove any noise, the angular signals were subsequently filtered using the filter described in Section 6.4. Finally, the protraction, retraction, adduction and abduction angles were determined as the coronal and sagittal angles at the respective hoof-on and hoof-off moments (see Section 3.2.2). Figure 14 shows an example of the limb angle signals resulting from this process; the plot shows several strides of the right hindlimb. 


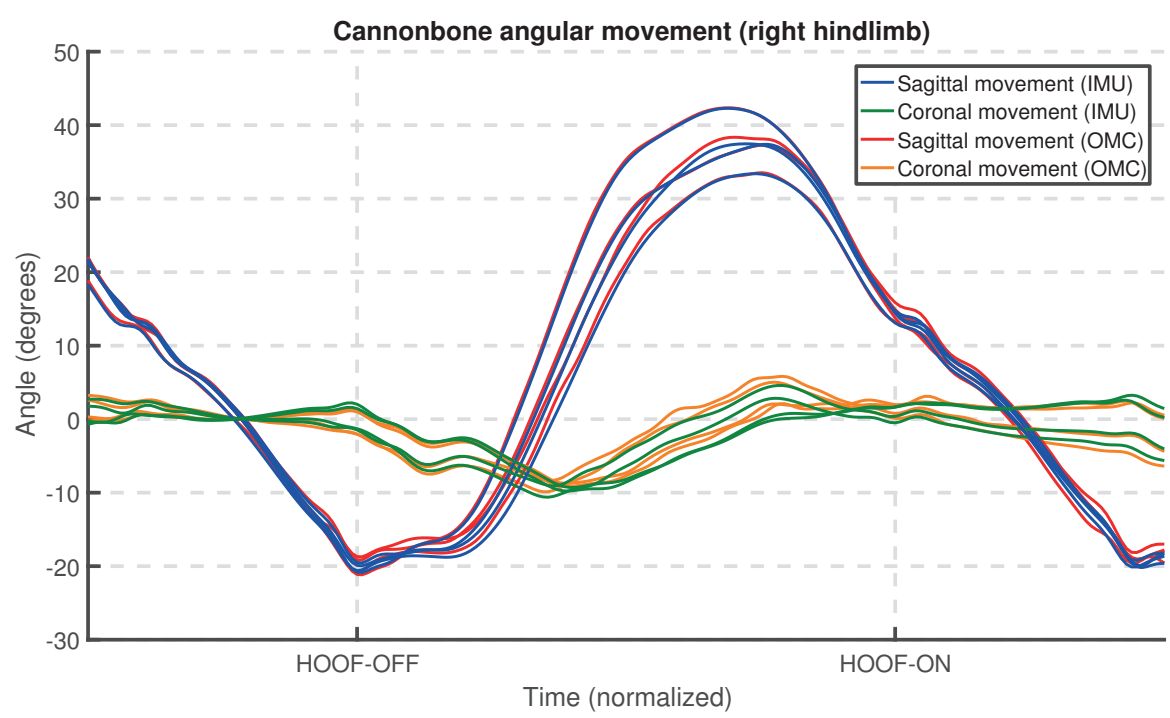

Figure 14. Example of the cannon bone angular motion for IMU and OMC systems.

\section{Upper-Body Symmetry}

As described briefly in Section 3.2.3, the upper-body symmetry parameters are used to estimate to what extent the horse's gait is symmetrical at key positions on the upper body of the horse. These parameters are entirely based on vertical motion. At each of these positions, the horse's body moves up and down in a cyclic fashion exactly two times each stride. In sound (i.e., healthy) horses, this signal is symmetrical and the two maxima and minima are at the same level.

The vertical displacement of the relevant upper-body locations is readily calculated from the position measurements of the OMC system. In contrast, for the IMU-based EquiMoves system, the accelerometer data needs to be integrated twice to obtain a displacement value. As described earlier in Section 6.3, the accelerometer data was first rotated to a navigation reference frame, so that the $z$-axis acceleration lined up with the gravity vector. Subsequently, the vertical displacement was obtained using a cyclic integration method first described by Pfau et al. [34]. In essence, this subtracts the mean value of the current, present, and next stride from the acceleration and velocity, respectively, so that drift is effectively removed at each integration step. To remove any noise, the resulting displacement signal for both systems was low-passfiltered using the filter described in Section 6.4. 
The vertical displacement signal is not only determined by the horse locomotion itself. For both systems, this signal is also affected by an uneven or slanted floor surface. Additionally, the IMU signal is still subject to some drift, since the displacement resulting from the double cyclic integral is not mean-subtracted. To mitigate this problem, the displacement signal was high-pass-filtered using another fourth-order Butterworth filter. For maximum effectiveness and flexibility, this filter was tuned to the step-frequency of the horse, so that the cut-off frequency was optimized for the gait type. The stride frequency is determined as the reciprocal of twice the median time between two successive peaks in the displacement signal. The cut-off frequency for the filter was set to $2 / 3$ of the stride frequency. The stride frequency was determined for all locations based on the vertical displacement at the sacrum, since it was determined most reliably there. For walk, the resulting cutoff frequency ranged from $0.5 \mathrm{~Hz}$ to $0.6 \mathrm{~Hz}$ over all experiments, and, for trot, it laid between $0.8 \mathrm{~Hz}$ and $0.9 \mathrm{~Hz}$. To prevent group delay from having an effect on our synchronization, zero-phase filtering was used.

The resulting vertical displacement signal was cut into stride-delimited segments. For each stride, the extrema were determined, and using these values the upperbody symmetry parameters were calculated (refer to Section 3.2). Figure 15 shows the vertical displacement at the sacrum for several strides for the IMU and OMC systems.

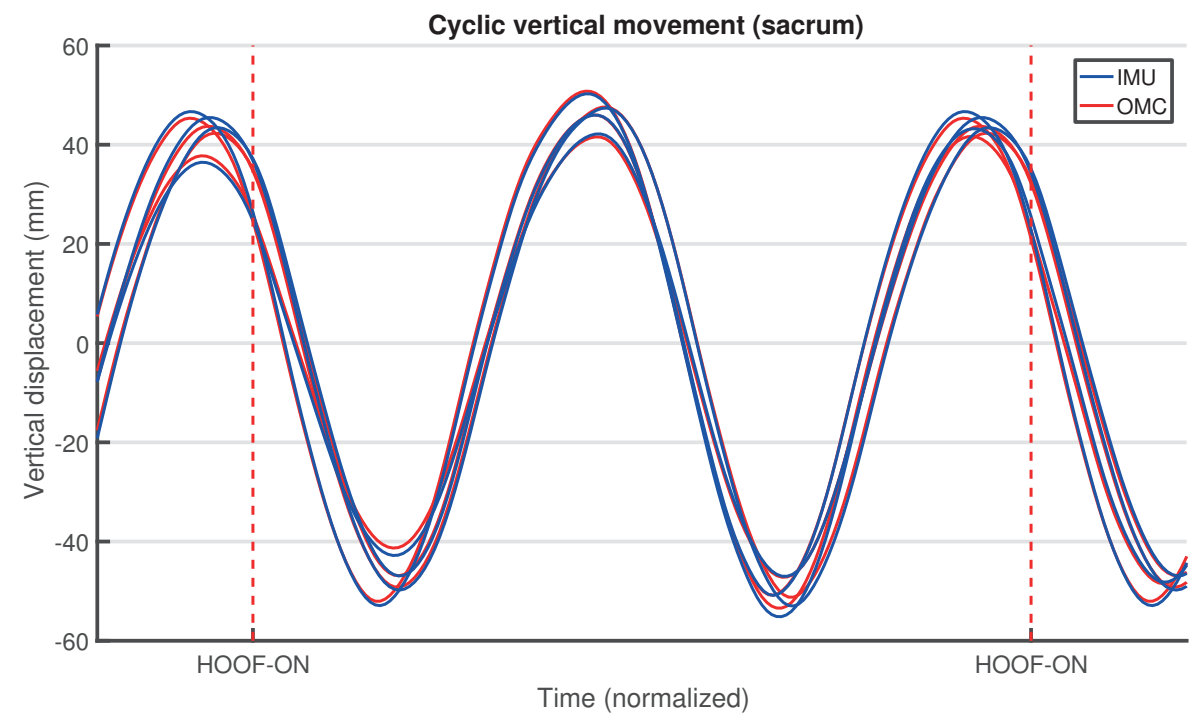

Figure 15. Example of the vertical displacement at the sacrum for IMU and OMC systems. The vertical dashed lines indicate the left hindlimb hoof-on moments used for stride segmentation. 


\section{Results}

\section{Overview}

We used Bland-Altman analysis (using the R package BlandAltmanLeh, version 0.3.1, RStudio, Boston, Massachusetts, USA) to study the agreement between measurements of the IMU and OMC systems [86,87]. This method allows for the comparison of two measurement systems that can potentially both have errors; no instrument is ever perfect. This method consists of making a scatter plot of the differences between the measurements of the two systems as a function of the mean of those measurements. The plot shows a line for the agreement bias as the mean difference between the systems, and two lines for the limits of agreement (LOAs) are plotted at a distance of 1.96 standard deviations above and below that bias line (see Sections 7.3 and 7.4). Ideally, there is no bias (mean difference is zero) and the bias line is located at zero. The LOAs indicate the boundaries of the agreement interval in which $95 \%$ of differences are contained. This is a measure for the expected difference between the two systems based on the experiments. Ideally, the LOAs are very close to the bias line, indicating that the spread of the differences is very small in the majority of cases. Since there are multiple measurements (strides) per individual horse, confidence intervals were generated for the LOAs [88]. We included regression lines in the Bland-Altman plots to indicate whether the bias was (mostly) constant over the measurements in our data set and to visually assess homoscedasticity. Earlier work by Pfau et al. [67] presented the data in a similar way.

We also calculated the intra-class correlation (ICC) using the R package psychometric (version 2.2). ICC is a measure for the reproducibility/consistency of our measurements [87]. The ICC was calculated from a linear mixed model to account for repeated measurements, since we had the data calculated on a per stride basis. The horse ID was used as the grouping variable (random effect) and the ICC was calculated as $t_{00} /$ $\left(t_{00}+\sigma^{2} / n_{j}\right)$, where $t_{00}$ is the variance of the intercept of the model, $\sigma^{2}$ is the residual variance for the model, and $n_{j}$ is the group size. The obtained values for the ICC will range between zero and one. A value of zero indicates a poor reproducibility between the two systems, and an ICC of one indicates a perfect reproducibility.

\section{Low-Level Observations}

To understand where differences between OMC and IMU measurements may originate, we first discuss observations on a few low-level signals that are produced as part of the signal processing performed to obtain these measurements (refer to Section 6). 


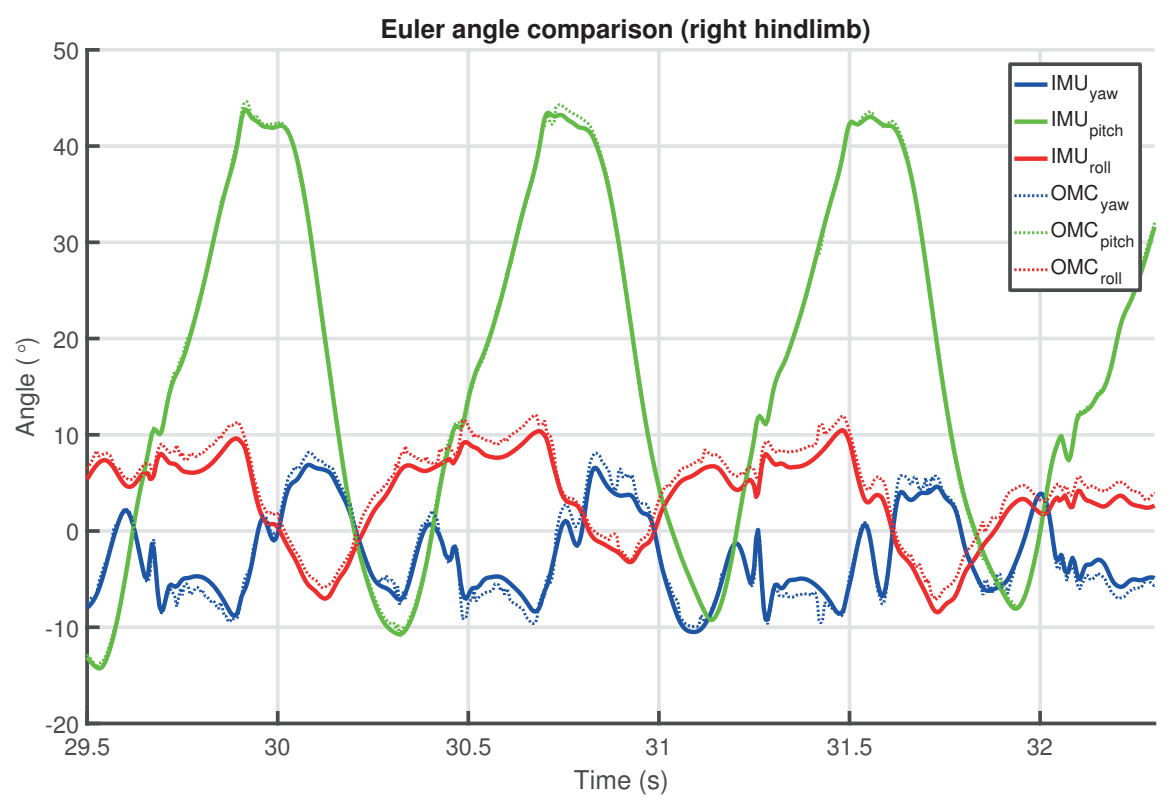

Figure 16. Example of the limb orientation match between IMU and OMC systems for the right hindlimb.

Figure 16 shows an example of the limb orientation measurements from the IMU and OMC systems represented in Euler angles. No additional filtering beyond what each system itself performs was applied. The orientations were aligned using the algorithm discussed in Section 6.5 in an effort to remove any static orientation difference. The example shows that the IMU orientation is more smooth/less noisy than the OMC orientation. The OMC orientation also shows some signal artifacts that are not present in the IMU output (e.g., at time 31.4 s).

We can only speculate as to what caused these differences. Since there are some small transients in the OMC output, it is plausible that at least some of these differences were caused by marker occlusions. On other occasions, high acceleration may influence the gravity vector tracking of the Valenti algorithm [79], which we used for the IMU (refer to Section 6.2). Another factor, which would mainly affect the coronal angle measurements for the limbs, is the depth perception of the OMC cameras [89]. This is likely aggravated by the manner in which these are installed in the clinic (i.e., high above the floor looking down). This is near-optimal for upper-body motion capture but is less suitable for measuring limb movements. Additionally, the three markers on the forelimbs were mounted almost colinearly (see Figure 9), which, as it turns 
out, is not optimal for reliably determining the rigid body orientation. In contrast, the hindlimbs have four markers in a rectangular shape.

Further evaluation of the OMC limb data shows that the results of the left forelimb were quite unreliable, particularly the rigid body orientation (refer to Section 6.2). The results suffer from full marker occlusions (i.e., missing position data for some of the markers), and as a consequence the rigid body orientation was noisy and at times implausible. The occlusions were likely caused by the handler obstructing the view of the cameras to the markers on that limb (i.e., the handler was too close to the horse). This is why the comparison for that location shows much poorer results than the other limbs.

Therefore, the left forelimb was excluded from the summary results. However, we do present the specific results for this location to demonstrate the effect of this issue.

Figure 17 shows an example of the match between the IMU and OMC measurements of the vertical velocity at the sacrum. A static offset in the IMU velocity is removed by subtracting the mean of the whole signal. The OMC signal directly results from differentiating the marker position. Both signals are otherwise unfiltered. Overall, the signals are very similar. However, while the signals line up almost perfectly in the middle, offset differences are visible at the beginning and end, likely due to drift in the IMU velocity. Additionally, there is noise in the OMC signal.

The vertical displacement for the same experiment is shown in Figure 18. Noise in the OMC signal is no longer evident. IMU drift stands out much more, as is visible from the varying offset difference between the two signals. This drift was removed in the next step by the high-pass filter tuned to the stride frequency (see Section 6.8), which, after stride segmentation, resulted in the output of Figure 15.

\subsection{Limb Angles}

Table 2 presents a summary of the difference statistics for the limb angle signals used to calculate the limb angle parameters. When comparing the sagittal and coronal results in Table 2, the angle signals for the sagittal plane show less difference between the two systems when compared with the coronal plane. As discussed in Section 7.2, we speculate that the coronal angles for the OMC system were influenced by the depth perception of the OMC cameras and the manner in which these cameras are installed in the clinic. 


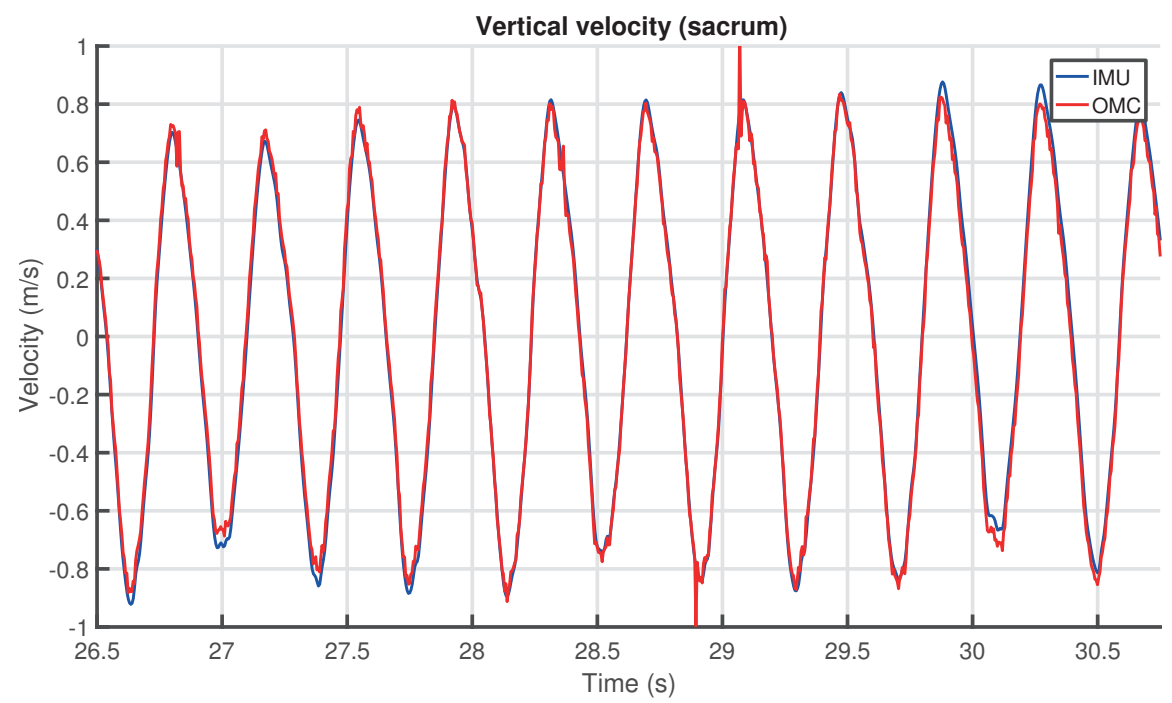

Figure 17. Example of the vertical velocity match between IMU and OMC systems for the sacrum.

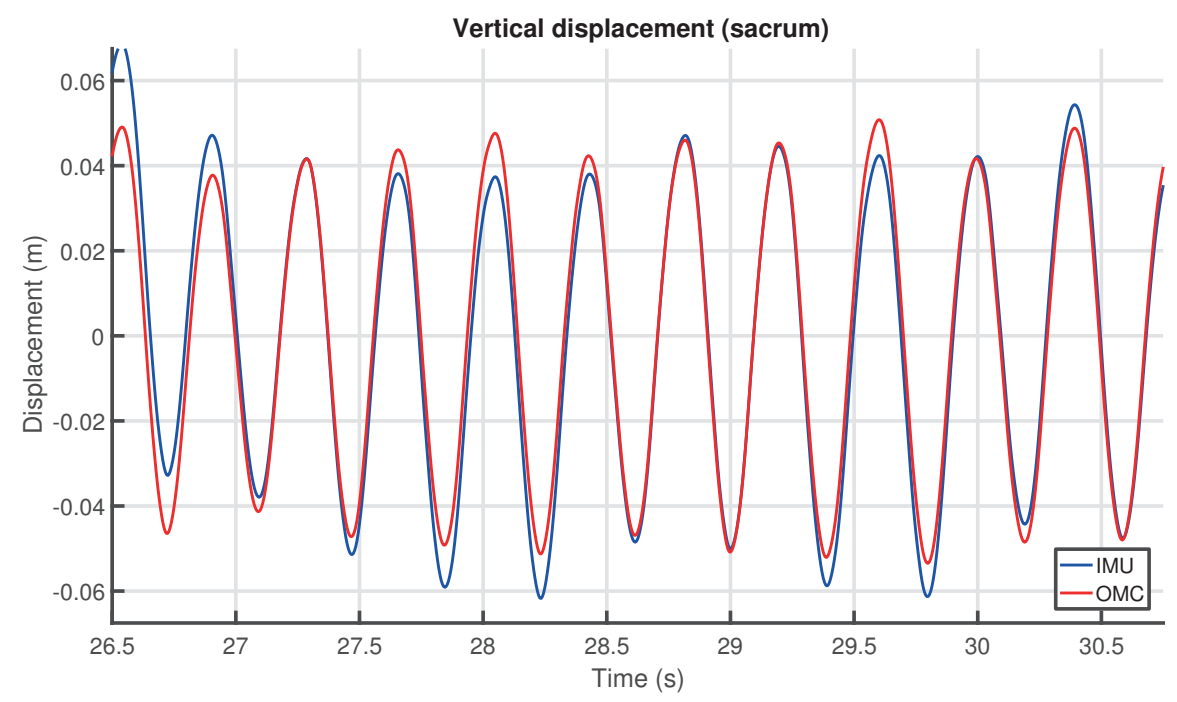

Figure 18. Example of the vertical displacement match between IMU and OMC systems for the sacrum. 
Table 2. Summary of difference statistics for the limb angle signals (values in degrees). RMSE: rootmean-square error; S.D: standard deviation.

\begin{tabular}{lcccccccc}
\hline & \multicolumn{3}{c}{ Walk } & \multicolumn{2}{c}{ Trot } \\
\hline & \multicolumn{2}{c}{ Sagittal } & \multicolumn{2}{c}{ Coronal } & \multicolumn{2}{c}{ Sagittal } & \multicolumn{2}{c}{ Coronal } \\
\hline & Forelimb & Hindlimb & Forelimb & Hindlimb & Forelimb & Hindlimb & Forelimb & Hindlimb \\
\hline RMSE & 0.67 & 0.67 & 1.27 & 1.01 & 1.05 & 0.95 & 1.79 & 1.21 \\
Mean Residual & 0.02 & 0.02 & -0.06 & -0.03 & -0.03 & -0.02 & -0.03 & 0.04 \\
S.D. of Residuals & 0.25 & 0.24 & 0.43 & 0.34 & 0.55 & 0.50 & 0.95 & 0.66 \\
\hline
\end{tabular}

Detailed box plots for the limb angle parameters clustered by gait and limb can be found in Appendix $A$ in Figures $A 1$ and $A 2$. The difference between fore- and hindlimbs for the angles in the sagittal plane is noteworthy: the higher range of motion in the sagittal plane has been described previously using IMU techniques [69]. We also observed a higher sagittal ROM at trot when compared to walk, also in line with previous publications [69].

While the per-horse variation is low (small height of the boxes in the box plots), which highlights the repeatability of our measurements, a large variation is noticeable between horses in all calculated limb parameters. Nevertheless, the analysis of variation in the measured parameters between horses is outside the scope of this manuscript: future work should investigate the variation in the calculated parameters between horses in more detail.

We performed a Bland-Altman analysis of the protraction, retraction, abduction, and adduction angles (see Section 3.2.2), respectively, in Figures 19-22. The plots show a small bias between the two systems. In most cases, the bias is less than one degree, with the abduction angle at trot as a notable exception at about two degrees. The limits of agreement show similar performance for protraction and retraction angles at walk and trot, with a deviation between the systems ranging up to three degrees in most cases. The regression lines in the plot show no clear trend and no obvious indication of heteroscedasticity. In contrast, the adduction and abduction angles show significantly less agreement: while the bias is still relatively small for all coronal angles, the limits of agreement show a deviation of up to nine degrees between the two systems. We speculate once again that the relatively poor coronal agreement is due to the poor depth perception of the OMC system. 


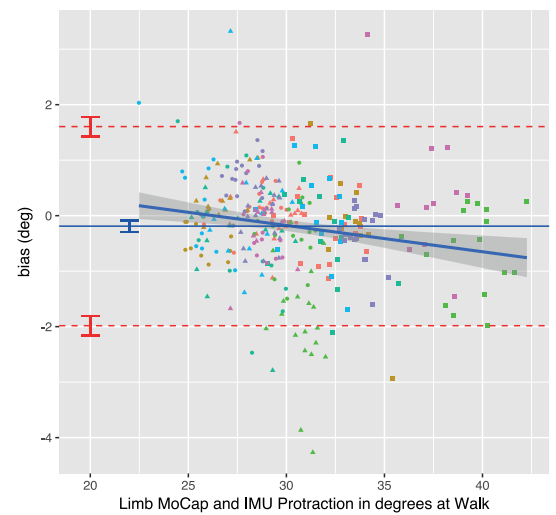

(a) Walk

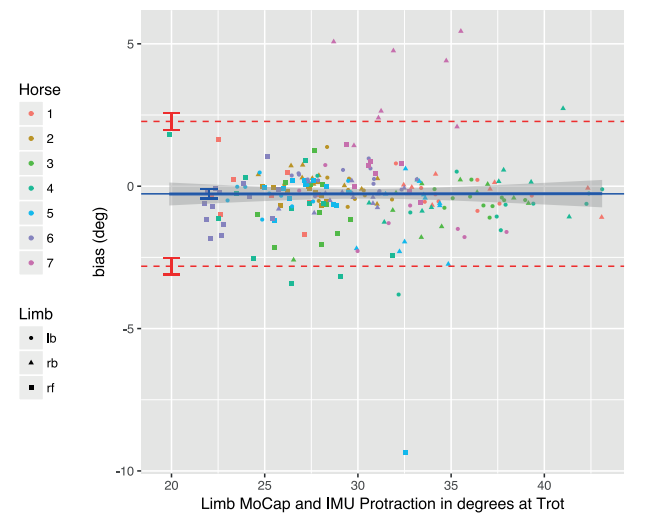

(b) Trot

Figure 19. Bland-Altman analysis for protraction angles at walk and trot.

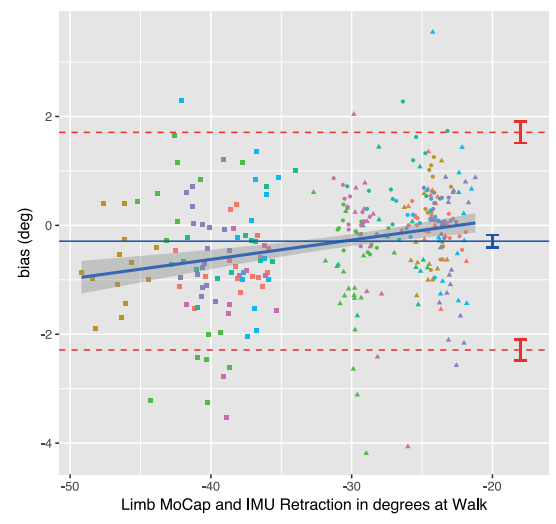

(a) Walk

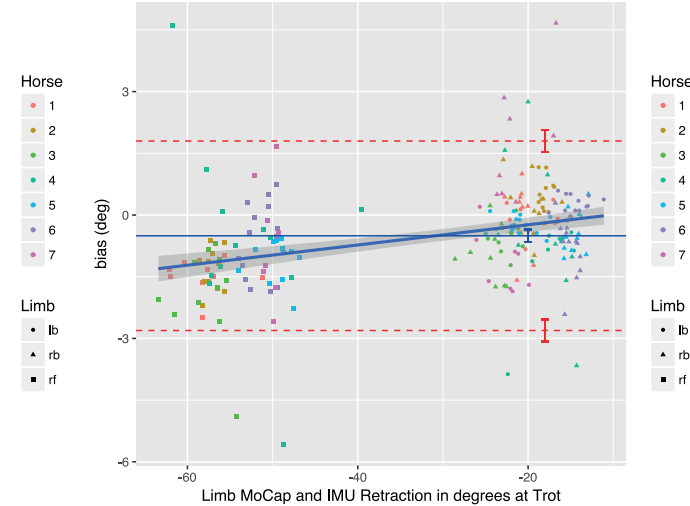

(b) Trot

Figure 20. Bland-Altman analysis for retraction angles at walk and trot.

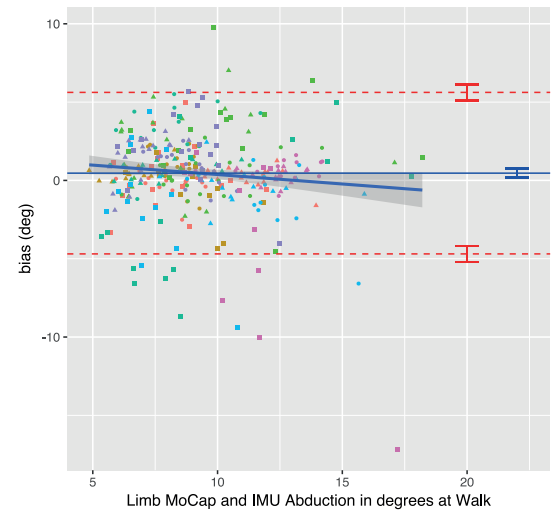

(a) Walk

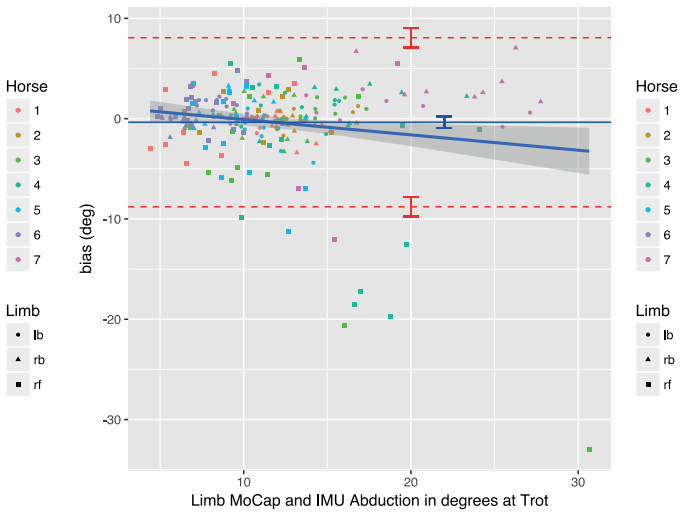

(b) Trot

Figure 21. Bland-Altman analysis for abduction angles at walk and trot. 
For the parameters tested, the regression lines in the Bland-Altman plots seem to indicate that the bias is relatively constant throughout the measured ranges; therefore, no heteroscedasticity was visible. The small slope in some of the plots is caused by the fact that there is a significant difference between fore- and hindlimbs, which causes clustering in the data, particularly for the retraction at walk and trot (see Figure 20).

We performed a Bland-Altman analysis of the angular range of motion (ROM) for the sagittal and coronal planes (see Section 3.2.2), respectively in Figures 23 and 24. The bias is mostly insignificant, with the confidence interval (nearly) containing zero. The agreement is within around 2.5 degrees for the sagittal plane. Again, the coronal plane performs worse at five degrees for walk and about eight degrees for trot. A summary of the agreement statistics for the sagittal and coronal angular limb parameters is presented in Tables 3-6 for walk and trot. The agreement is presented in the tables both per stride and per trial.

Results indicate that in most cases the OMC and IMU systems agreed within 2-3 degrees for protraction, retraction, and sagittal ROM measurements. In horses with gait abnormalities, angular changes greater than three degrees have been described [90], so-considering the OMC as a validity reference-the IMU system can theoretically measure biologically significant differences. The picture is less clear for the adduction angles, abduction angles, and coronal ROM, since the agreement interval is at worst \pm 9 degrees for those. We theorize that the poor agreement is due to problems in the OMC system, mainly caused by depth perception of the cameras [89], although there is no way to prove that with the present data set. As discussed, for the forelimbs, the placement of the markers may also be a factor.

The reason why the per trial results are presented here is to compare these with earlier work by Roepstorff et al. [69]. As described in Section 2, the per trial results may prove to be too optimistic about the agreement. The tables show this effect quite clearly. The per trial results are always almost twice better than the per stride agreement, demonstrating this problem. From plots in the paper by Roepstorff et al., we estimate the limits of agreement for their experiment to be within about two degrees. They only present sagittal ROM measurements, for which our system consistently performed better, both in terms of bias and limits of agreement. 


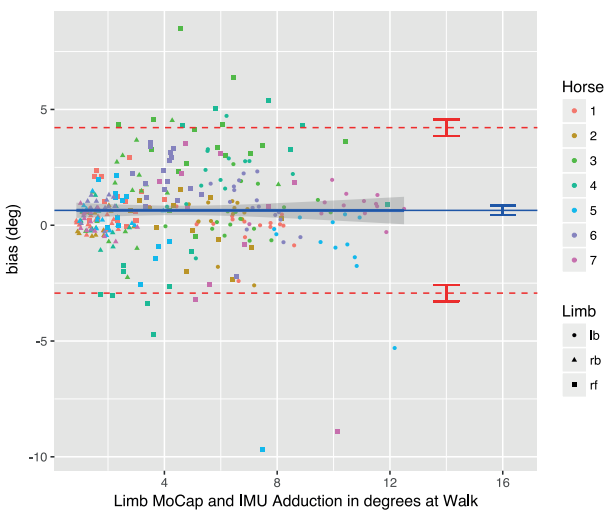

(a) Walk

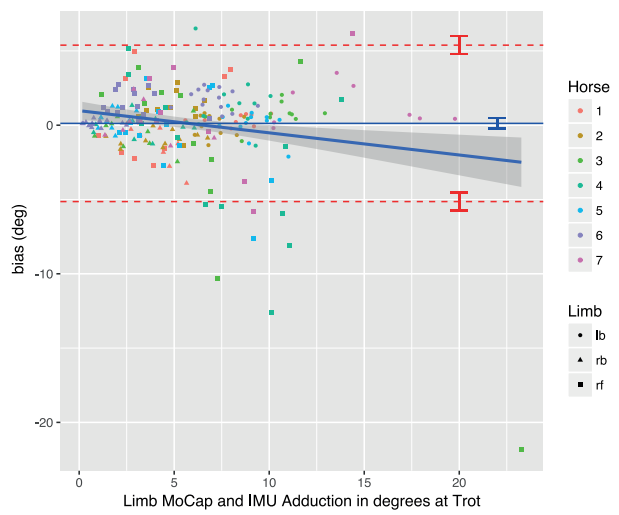

(b) Trot

Figure 22. Bland-Altman analysis for adduction angles at walk and trot.

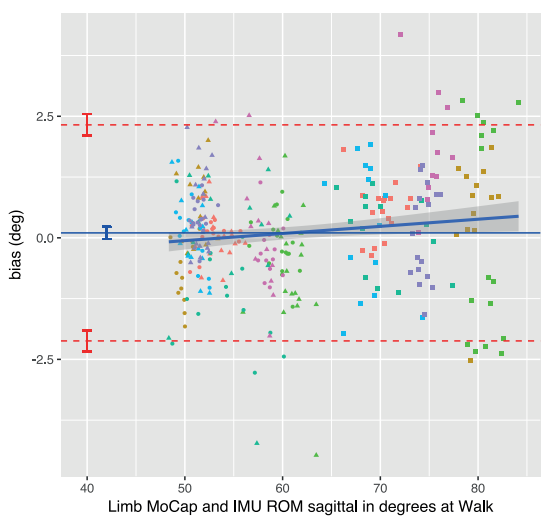

(a) Walk

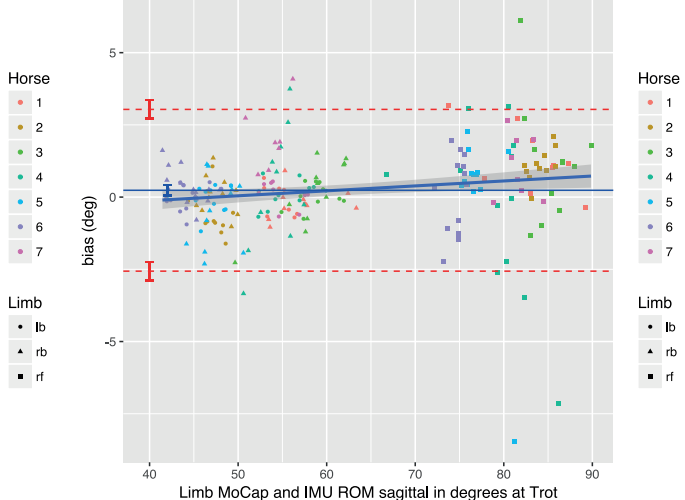

(b) Trot

Figure 23. Bland-Altman analysis for sagittal range of motion (ROM) at walk and trot.

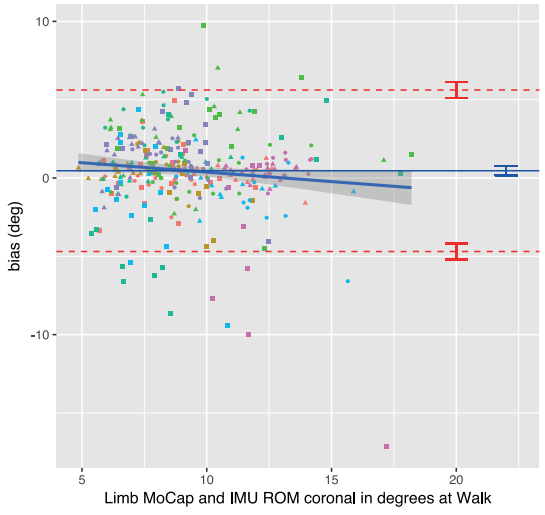

(a) Walk

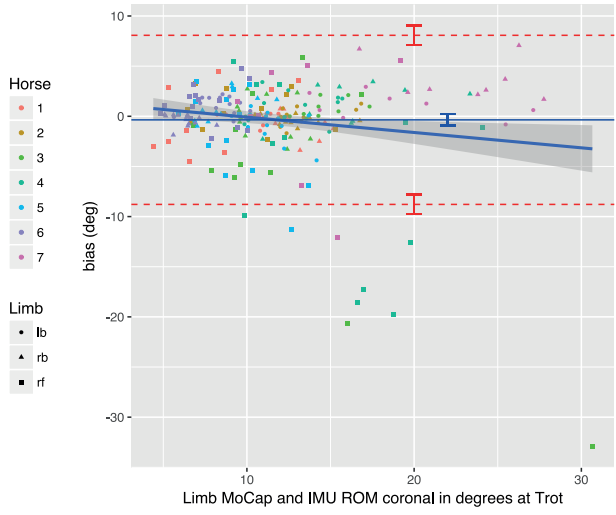

(b) Trot

Figure 24. Bland-Altman analysis for coronal ROM at walk and trot. 
The ICC results show high reproducibility of the measurements between the two systems (close to 1) for almost all experiments, with the coronal angles for the forelimbs as a notable exception. This is in line with the Bland-Altman analysis, where we also observed narrow limits of agreement, indicating a good agreement between the two instruments. As before, we speculate that the lower ICC observed for the angles in the coronal plane are related to the poor depth perception of the OMC due to the camera set-up in our venue.

Table 3. Summary of measurement agreement statistics for the sagittal limb angles at walk (values in degrees). ICC: intra-class correlation; LOA: limit of agreement; ROM: range of motion.

\begin{tabular}{|c|c|c|c|c|c|c|}
\hline & \multicolumn{2}{|c|}{ Retraction } & \multicolumn{2}{|c|}{ Protraction } & \multicolumn{2}{|c|}{ Sagittal ROM } \\
\hline & Per Stride & Trial Mean & Per Stride & Trial Mean & Per Stride & Trial Mean \\
\hline Upper LOA & 1.70 & -0.75 & 1.61 & 0.84 & 2.32 & 1.29 \\
\hline Lower LOA & -2.29 & -1.30 & -1.98 & -1.15 & -2.12 & -1.06 \\
\hline Bias & -0.29 & -0.27 & -0.19 & -0.16 & 0.10 & 0.12 \\
\hline ICC R. Forelimb & \multicolumn{2}{|c|}{0.99} & \multicolumn{2}{|c|}{0.99} & \multicolumn{2}{|c|}{0.99} \\
\hline ICC R. Hindlimb & \multicolumn{2}{|c|}{0.99} & \multicolumn{2}{|c|}{0.97} & \multicolumn{2}{|c|}{0.99} \\
\hline ICC L. Hindlimb & \multicolumn{2}{|c|}{0.99} & \multicolumn{2}{|c|}{0.98} & \multicolumn{2}{|c|}{0.99} \\
\hline ICC Final & \multicolumn{2}{|c|}{0.99} & \multicolumn{2}{|c|}{0.98} & \multicolumn{2}{|c|}{0.99} \\
\hline
\end{tabular}

Table 4. Summary of measurement agreement statistics for the coronal limb angles at walk (values in degrees).

\begin{tabular}{lcccccc}
\hline & \multicolumn{2}{c}{ Adduction } & \multicolumn{2}{c}{ Abduction } & \multicolumn{2}{c}{ Coronal ROM } \\
\hline & Per Stride & Trial Mean & Per Stride & Trial Mean & Per Stride & Trial Mean \\
\hline Upper LOA & 4.22 & 2.51 & 5.61 & 3.14 & 5.62 & 3.41 \\
Lower LOA & -2.93 & -1.36 & -4.69 & -2.73 & -4.69 & -2.72 \\
Bias & 0.64 & 0.58 & 0.46 & 0.34 & 0.46 & 0.34 \\
\hline ICC R. Forelimb & & 0.91 & & 0.82 & 0.81 & 0.98 \\
ICC R. Hindlimb & 0.87 & & 0.98 & & 0.97 \\
ICC L. Hindlimb & 0.98 & 0.96 & 0.92 \\
ICC Final & 0.92 & 0.92 & & 0 \\
\hline
\end{tabular}


Table 5. Summary of measurement agreement statistics for the sagittal limb angles at trot (values in degrees).

\begin{tabular}{|c|c|c|c|c|c|c|}
\hline & \multicolumn{2}{|c|}{ Retraction } & \multicolumn{2}{|c|}{ Protraction } & \multicolumn{2}{|c|}{ Sagittal ROM } \\
\hline & Per Stride & Trial Mean & Per Stride & Trial Mean & Per Stride & Trial Mean \\
\hline Upper LOA & 1.79 & 1.07 & 2.27 & 1.17 & 3.03 & 1.52 \\
\hline Lower LOA & -2.81 & -2.04 & -2.81 & -2.09 & -2.56 & -0.97 \\
\hline Bias & -0.50 & -0.48 & -0.27 & -0.21 & 0.25 & 0.27 \\
\hline ICC R. Forelimb & \multicolumn{2}{|c|}{0.96} & \multicolumn{2}{|c|}{0.97} & \multicolumn{2}{|c|}{0.97} \\
\hline ICC R. Hindlimb & \multicolumn{2}{|c|}{0.98} & \multicolumn{2}{|c|}{0.96} & \multicolumn{2}{|c|}{0.99} \\
\hline ICC L. Hindlimb & \multicolumn{2}{|c|}{0.97} & \multicolumn{2}{|c|}{0.98} & \multicolumn{2}{|c|}{0.99} \\
\hline ICC Final & \multicolumn{2}{|c|}{0.97} & \multicolumn{2}{|c|}{0.97} & \multicolumn{2}{|c|}{0.98} \\
\hline
\end{tabular}

Table 6. Summary of measurement agreement statistics for the coronal limb angles at trot (values in degrees).

\begin{tabular}{|c|c|c|c|c|c|c|}
\hline & \multicolumn{2}{|c|}{ Adduction } & \multicolumn{2}{|c|}{ Abduction } & \multicolumn{2}{|c|}{ Coronal ROM } \\
\hline & Per Stride & Trial Mean & Per Stride & Trial Mean & Per Stride & Trial Mean \\
\hline Upper LOA & 5.39 & 2.32 & 8.07 & 4.05 & 8.07 & 4.06 \\
\hline Lower LOA & -5.14 & -2.09 & -8.78 & -4.62 & -8.79 & -4.62 \\
\hline Bias & 0.12 & 0.12 & -0.36 & -0.28 & -0.36 & -0.28 \\
\hline ICC R. Forelimb & \multicolumn{2}{|c|}{0.79} & \multicolumn{2}{|c|}{0.86} & \multicolumn{2}{|c|}{0.86} \\
\hline ICC R. Hindlimb & \multicolumn{2}{|c|}{0.92} & \multicolumn{2}{|c|}{0.99} & \multicolumn{2}{|c|}{0.99} \\
\hline ICC L. Hindlimb & \multicolumn{2}{|c|}{0.98} & \multicolumn{2}{|c|}{0.98} & \multicolumn{2}{|c|}{0.98} \\
\hline ICC Final & \multicolumn{2}{|c|}{0.90} & \multicolumn{2}{|c|}{0.94} & \multicolumn{2}{|c|}{0.94} \\
\hline
\end{tabular}

\section{Upper-Body Symmetry}

Table 7 presents difference statistics for the upper-body vertical displacement signals. The root mean square error (RMSE), mean residual, and standard deviation (S.D.) of residuals at both withers and sacrum indicate that the vertical displacement signal measured by the two systems is highly comparable. The mean of residuals is zero, indicating that there is no bias between the two systems on a signal level. As seen earlier in our ICC and Bland-Altman analysis, the coronal results for RMSE and standard deviation of residuals demonstrate a poorer performance when compared to the sagittal angles. As previously discussed, this could be attributed to the poor depth perception of the cameras. Nevertheless, these results demonstrate a good reproducibility between the two systems, not only taking into account the moments used to calculate the gait parameters (i.e., peaks and valleys), but also along the entire signal. 
Earlier work by Warner et al. [32] evaluated the signal differences between a generic IMU-based system and an OMC system. The authors reported a mean difference in the vertical displacement signal of $0.0 \mathrm{~mm}$ (S.D. $2.3 \mathrm{~mm}$ ) at the withers and $0.0 \mathrm{~mm}$ (S.D. $4.1 \mathrm{~mm}$ ) at the sacrum. These results are in line with the corresponding results of our study in Table 7, although we achieved a better precision, especially at the sacrum. This difference may be attributed to the lower sampling frequency used by Warner et al. $(100 \mathrm{~Hz})$ and possibly due to differences in the applied filters.

Table 7. Summary of difference statistics for the upper-body vertical displacement signals (values in $\mathrm{mm}$ ).

\begin{tabular}{lcc}
\hline & Withers & Sacrum \\
\hline RMSE & 2.43 & 1.85 \\
Mean Residual & 0.01 & -0.02 \\
S.D. of Residuals & 2.43 & 1.85 \\
\hline
\end{tabular}

Table 8. Summary of measurement agreement statistics for the withers (values in $\mathrm{mm}$ ).

\begin{tabular}{lcccccccc}
\hline & \multicolumn{2}{c}{ Min_diff } & \multicolumn{2}{c}{ Max_diff } & \multicolumn{2}{c}{ Range_diff $_{\text {up }}$} & \multicolumn{2}{c}{ Range_diff down } \\
\hline & Per Stride & Trial Mean & Per Stride & Trial Mean & Per Stride & Trial Mean & Per Stride & Trial Mean \\
\hline Upper LOA & 5.00 & 1.40 & 4.10 & 1.70 & 8.20 & 2.01 & 4.70 & 1.63 \\
Lower LOA & -5.10 & -1.30 & -4.10 & -1.76 & -7.40 & -3.00 & -4.80 & -1.45 \\
Bias & 0.04 & 0.05 & 0.02 & -0.03 & 0.43 & -0.47 & 0.01 & 0.09 \\
ICC & & 0.98 & \multicolumn{2}{c}{0.98} & & 0.99 & 0.97 \\
\hline
\end{tabular}

Table 9. Summary of measurement agreement statistics for the sacrum (values in $\mathrm{mm}$ ).

\begin{tabular}{|c|c|c|c|c|c|c|c|c|}
\hline & \multicolumn{2}{|c|}{ Min_diff } & \multicolumn{2}{|c|}{ Max_diff } & \multicolumn{2}{|c|}{ Range_diff } & \multicolumn{2}{|c|}{ Range_diff $_{\text {down }}$} \\
\hline & Per Stride & Trial Mean & Per Stride & Trial Mean & Per Stride & Trial Mean & Per Stride & Trial Mean \\
\hline Upper LOA & 3.20 & 2.09 & 3.50 & 2.61 & 5.40 & 4.59 & 3.90 & 4.05 \\
\hline Lower LOA & -3.80 & -1.16 & -4.30 & -1.47 & -6.50 & -2.90 & -4.50 & -3.18 \\
\hline Bias & 0.31 & 0.46 & 0.41 & 0.57 & 0.51 & 0.85 & 0.30 & 0.43 \\
\hline ICC & \multicolumn{2}{|c|}{0.94} & \multicolumn{2}{|c|}{0.95} & \multicolumn{2}{|c|}{0.91} & \multicolumn{2}{|c|}{0.94} \\
\hline
\end{tabular}

Figure A3 in Appendix A shows box plots for the statistics of the differences between the IMU and OMC systems for the upper-body symmetry parameters (see Section 3.2.3) at the withers and sacrum, respectively. The statistics are presented for the individual horses. In most cases, the statistics are similar between the two systems, apart from a few outliers. 
We performed a Bland-Altman analysis of the Range_diff ${ }_{\text {up/down }}$ parameters for the withers and sacrum in Figures 25 and 26. The agreement of the Min_diff and Max diff parameters at those locations is shown in another set of Bland-Altman plots in Figures 27 and 28. Overall, there is no significant bias in the agreement between the two systems: the zero line lies within the confidence interval of each bias line. The limits of agreement show that in most cases and for most parameters the systems agree within about $5 \mathrm{~mm}$. The regression lines in the Bland-Altman plots show no clear trends. A summary of the agreement statistics is presented in Tables 8 and 9 for the the withers and sacrum, respectively.

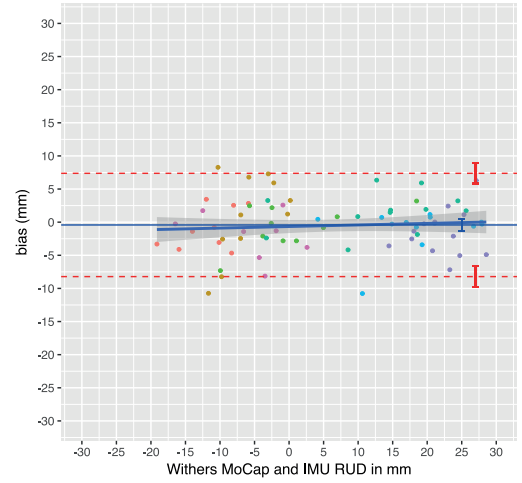

(a) Withers

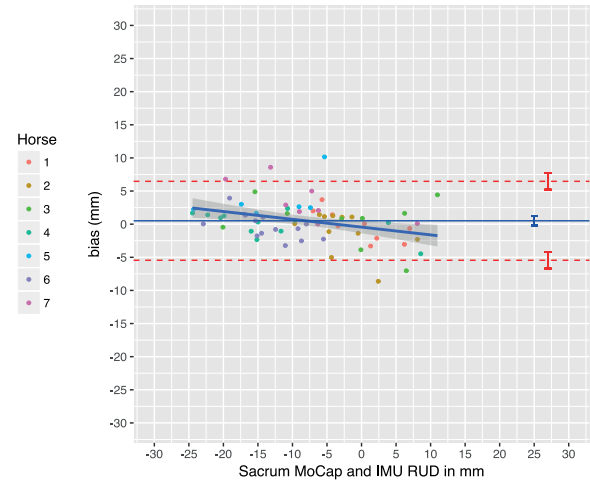

(b) Sacrum

Figure 25. Bland-Altman analysis for Range_diff $u$ parameter.

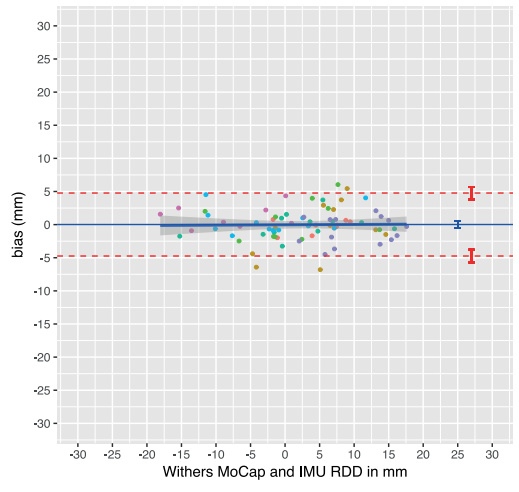

(a) Withers

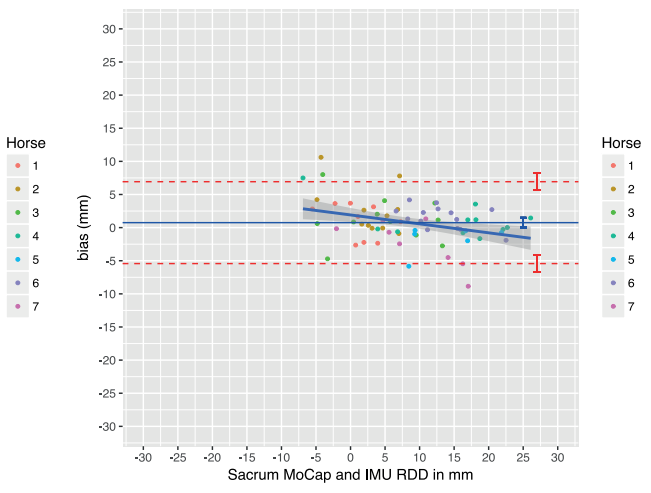

(b) Sacrum

Figure 26. Bland-Altman analysis for Range_diff ${ }_{\text {down }}$ parameter. 


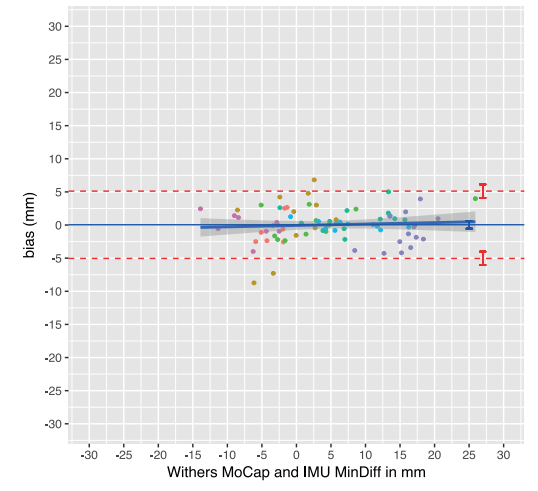

(a) Withers

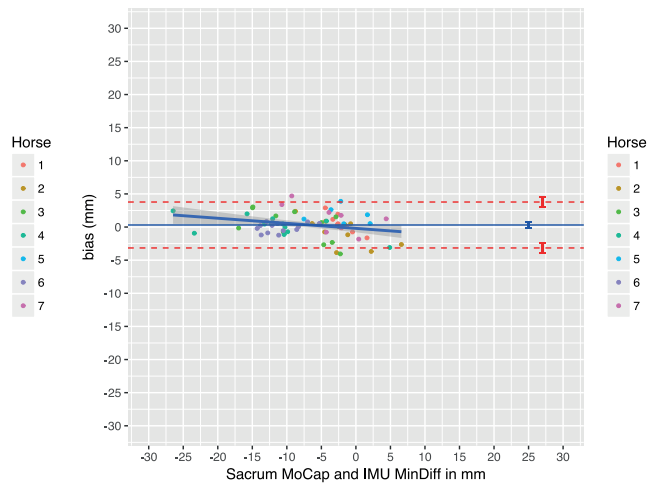

(b) Sacrum

Figure 27. Bland-Altman analysis for Min_diff parameter.

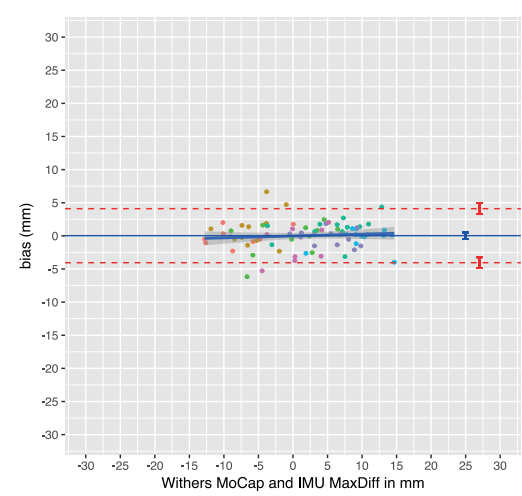

(a) Withers

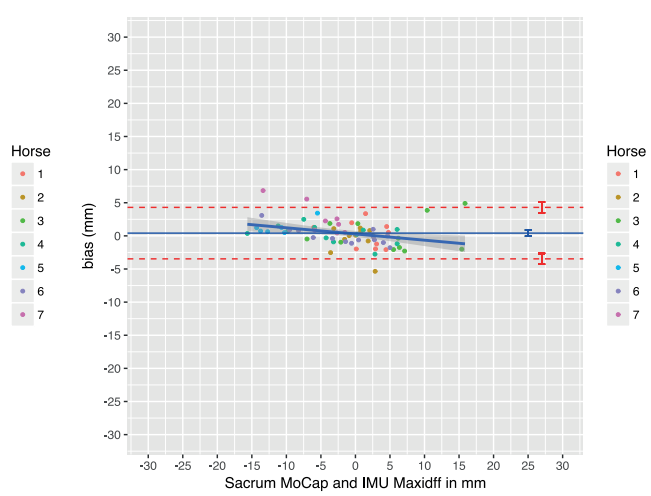

(b) Sacrum

Figure 28. Bland-Altman analysis for Max_diff parameter.

It would be useful to compare our agreement results with existing systems: the Lameness Locator [27,37,72] and EquiGait [34,74] systems both yield upper-body symmetry parameters. However, to the best of our knowledge, there is no earlier work presenting an ICC or Bland-Altman analysis that compares either of these systems to some form of (gold-standard) reference system. Therefore, our results are difficult to compare with systems already on the market. One previous study by Warner et al. [32] evaluated the agreement between a generic IMU-based system and an OMC system. However, since the Bland-Altman agreement analysis is performed on signals rather than parameters, we have no common ground to compare our results with theirs. 
Recently, an agreement analysis between the Lameness Locator and the EquiGait systems was performed on a trial level (trial mean) [67]. The authors found not only wide limits of agreement for the straight line trot (Min_diff poll $\pm 6.4 \mathrm{~mm}$ and Min diff sacrum $4.4 \mathrm{~mm}$ ), but also a systematic bias between the systems. Our results for agreement between OMC and our IMU-based system have a better agreement. It is important to mention that, in the work of Pfau et al. [67], some differences between the two systems might explain their findings: mainly the different filters used by the two systems (EquiGait uses an infinite impulse response (IIR) filter and the Lameness Locator uses a signal decomposition based on a curve fitting method [82]). Additionally, the EquiGait system determines displacement in a global coordinate frame, while the Lameness Locator uses a local coordinate frame, which is particularly prone to deviations when the sensor is not aligned with the horse's vertical axis (which happens during locomotion).

Previous research has used thresholds to declare horses as lame or sound, based on the level of measured asymmetry, although this has recently been criticized [1]. Nevertheless, if we take

these thresholds into consideration, our limits of agreement for withers and sacrum on a trial level (see Tables 8 and 9) are still within the proposed threshold of less than $6 \mathrm{~mm}$ for Min_diff poll and less than $3 \mathrm{~mm}$ for Min_diff sacrum (although we cannot actually compare poll results directly, as described in Section 5.3). This indicates that, on a trial level, our system can be used to quantify motion asymmetry within the required resolution.

Additionally, our system shows a bias of less than $1 \mathrm{~mm}$ for all calculated symmetry parameters, which makes comparison of calculated symmetry parameters between the two systems possible. This is especially important for reproducibility and when comparing research output using different systems to measure motion symmetry, which increases the reproducibility of scientific work. Furthermore, if a patient is measured by different veterinarians, using these two different systems, the results can be readily compared without the need of repeating measurements.

\section{Future Work}

Based on experience gained from these experiments, the experimental setup should be adjusted in a few points for future experiments. Firstly, the handler needs to be farther away from the horse to prevent OMC marker occlusion on the forelimbs. 
Additionally, the placement of the markers on the forelimbs is too linear-the markers need to be spread more. The OMC system company provides special rigid marker clusters now, which should be used instead of placing markers individually. Furthermore, the IMU and/or OMC markers at the poll should be moved such that a reliable comparison between the systems is possible for that location. Finally, it is better to also have cameras closer to the ground to capture limb motion reliably. However, expanding the OMC system is costly.

In future experiments, we aim to calculate more horse locomotion parameters. For the limbs, we currently only measure angles, but it is also useful to determine limb displacement parameters such as stride length, average stride speed, and the maximum hoof elevation [91]. Conversely, for the upper body, we currently rely solely on parameters based on vertical displacement. However, for example, the pelvis roll angle, which is the coronal attitude of the pelvis relative to the horizontal, has merit as well [92].

The scope of future experiments will be extended. In the present study, we performed an agreement analysis involving only horses that have no known locomotion issues. To perform actual lameness detection, we will perform a proof-of-concept study with induced lameness. Furthermore, it is important to evaluate our system and algorithms with gaits other than walk and trot, and trials with horses moving in a nonlinear path; e.g., circular (lungeing) [9,33,93].

\section{Conclusions}

The agreement between the OMC and EquiMoves systems was overall good, except for the adduction and abduction. We attribute this to the setup of the OMC system: the cameras have difficulty with depth perception at this distance, and the marker placement at the forelimbs was not optimal. This may in fact highlight the strength of IMU-based systems, especially for measuring gait variables that are not easily tracked by OMC systems.

The results suggest that the EquiMoves system can be a good aid for veterinarians during gait analysis (e.g., for lameness exam [10] or sports performance analysis [94]). It can measure several important parameters within a level of accuracy that is capable of detecting gait changes due to lameness or performance degradation. 


\section{Acknowledgments}

This study was partly funded by STW

Valorisation Grant 13448. The authors

wish to thank all the students and

animal caretakers that helped with the

data collection.

\section{Author Contributions}

Stephan Bosch contributed to the design of the experiments, algorithm development, data analysis, and writing of the manuscript. Filipe Serra Bragança planned, designed and performed the experiments, and contributed to data analysis, and writing of the manuscript. Mihai Marin-Perianu, Raluca Marin-Perianu and Berend Jan van der Zwaag provided insights in algorithm development, and assisted with the writing and revision of the manuscript. John Voskamp contributed with designing of the experiments and provided insights in data analysis. Willem Back conceived and designed the experiments. René van Weeren assisted with the planning of the experiments, contributed with essential insights in data analysis and performed substantial revisions to the paper. Paul Havinga provided crucial insights in data analysis and provided significant revisions to the paper.

\section{Conflicts of Interest}

Mihai Marin-Perianu, Raluca MarinPerianu and Paul Havinga founded Inertia-Technology (Enschede, The Netherlands), which sells the inertial sensor system (ProMove-mini) that is used as the basis of the EquiMoves system, which is evaluated in this study. Stephan Bosch and Berend-Jan van der Zwaag are employees of InertiaTechnology B.V..

\section{Ethical Animal Research}

The study was approved by the local ethics committee in compliance with the Dutch Act on Animal Experimentation (project no. AVD108002015307). 


\section{References}

1. Van Weeren, P.R.; Pfau, T.; Rhodin, M.; Roepstorff, L.; Serra Bragança, F.; Weishaupt, M.A. Do we have to redefine lameness in the era of quantitative gait analysis? Equine Vet. J. 2017, 49, 567-569.

2. United States; National Animal Health Monitoring System (U.S.). National Economic Cost of Equine Lameness, Colic, and Equine Protozoal Myeloencephalitis (EPM) in the United States; Number 3 p. in APHIS Veterinary Services Info Sheet; U.S. Department of Agriculture, APHIS: Fort Collins, CO, USA, 2001.

3. Loomans, J.B.A.; Stolk, P.W.T.; van Weeren, P.R.; Vaarkamp, H.; Barneveld, A. A survey of the workload and clinical skills in current equine practices in The Netherlands. Equine Vet. Educ. 2007, 19, 162-168.

4. Parkes, R.S.V.; Weller, R.; Groth, A.M.; May, S.; Pfau, T. Evidence of the development of 'domainrestricted' expertise in the recognition of asymmetric motion characteristics of hindlimb lameness in the horse. Equine Vet. J. 2009, 41, 112-117.

5. Arkell, M.; Archer, R.M.; Guitian, F.J.; May, S.A. Evidence of bias affecting the interpretation of the results of local anaesthetic nerve blocks when assessing lameness in horses. Vet. Rec. 2006, 159, 346-348.

6. Keegan, K.G.; Dent, E.V.; Wilson, D.A.; Janicek, J.; Kramer, J.; Lacarrubba, A.; Walsh, D.M.; Cassells, M.W.; Esther, T.M.; Schiltz, P.; et al. Repeatability of subjective evaluation of lameness in horses. Equine Vet. J. 2010, 42, 92-97.

7. Thomsen, M.H.; Persson, A.B.; Jensen, A.T.; Sørensen, H.; Andersen, P.H. Agreement between accelerometric symmetry scores and clinical lameness scores during experimentally induced transient distension of the metacarpophalangeal joint in horses. Equine Vet. J. 2010, 42, 510-515.

8. McCracken, M.J.; Kramer, J.; Keegan, K.G.; Lopes, M.; Wilson, D.A.; Reed, S.K.; LaCarrubba, A.; Rasch, $M$. Comparison of an inertial sensor system of lameness quantification with subjective lameness evaluation. Equine Vet. J. 2012, 44, 652-656.

9. Hammarberg, M.; Egenvall, A.; Pfau, T.; Rhodin, M. Rater agreement of visual lameness assessment in horses during lungeing. Equine Vet. J. 2016, 48, 78-82.

10. Serra Bragança, F.M.; Rhodin, M.; van Weeren, P.R. On the brink of daily clinical application of objective gait analysis: What evidence do we have so far from studies using an induced lameness model? Vet. J. 2018, 234, 11-23.

11. Morris, E.A.; Seeherman, H.J. Redistribution of ground reaction forces in experimentally induced equine carpal lameness. Equine Exerc. Physiol. 1987, 2, 553-563.

12. Ishihara, A.; Bertone, A.L.; Rajala-Schultz, P.J. Association between subjective lameness grade and kinetic gait parameters in horses with experimentally induced forelimb lameness. Am. J. Vet. Res. 2005, 66, 1805-1815.

13. Kai, M.; Aoki, O.; Hiraga, A.; Oki, H.; Tokuriki, M. Use of an instrument sandwiched between the hoof and shoe to measure vertical ground reaction forces and three-dimensional acceleration at the walk, trot, and canter in horses. Am. J. Vet. Res. 2000, 61, 979-985.

14. Munoz-Nates, F.; Chateau, H.; Hamme, A.V.; Camus, M.; Pauchard, M.; Ravary-Plumioen, B.; Denoix, J.M.; Pourcelot, P.; Crevier-Denoix, N. Accelerometric and dynamometric measurements of the impact shock of the equine forelimb and hindlimb at high speed trot on six different tracksPreliminary study in one horse. Comput. Methods Biomech. Biomed. Eng. 2015, 18, 2012-2013.

15. Weishaupt, M.A.; Hogg, H.P.; Wiestner, T.; Denoth, J.; Stüssi, E.; Auer, J.A. Instrumented treadmill for measuring vertical ground reaction forces in horses. Am. J. Vet. Res. 2002, 63, 520-527.

16. Guerra-filho, G.B. Optical motion capture: Theory and implementation. J. Theor. Appl. Inform. (R/TA) 2005, 12, 61-89.

17. Eichelberger, P.; Ferraro, M.; Minder, U.; Denton, T.; Blasimann, A.; Krause, F.; Baur, H. Analysis of accuracy in optical motion capture-A protocol for laboratory setup evaluation. J. Biomech. 2016, 49, 2085-2088. 
18. Alvarez, C.B.G.; Bobbert, M.F.; Lamers, L.; Johnston, C.; Back, W.; van Weeren, P.R. The effect of induced hindlimb lameness on thoracolumbar kinematics during treadmill locomotion. Equine Vet. J. 2008, 40, 147-152.

19. Persson Sjödin, E.; Serra Braganca, F.; Pfau, T.; Egenvall, A.; Weishaupt, M.A.; Rhodin, M. Movement Symmetry of the Withers Can Be Used to Discriminate Primary Forelimb Lameness From Compensatory Forelimb Asymmetry in Horses with Induced Lameness. Equine Vet. J. 2016, 48, 32-33.

20. Windolf, M.; Götzen, N.; Morlock, M. Systematic accuracy and precision analysis of video motion capturing systems-Exemplified on the Vicon-460 system. J. Biomech. 2008, 41, 2776-2780.

21. Starke, S.D.; Willems, E.; May, S.A.; Pfau, T. Vertical head and trunk movement adaptations of sound horses trotting in a circle on a hard surface. Vet. J. 2012, 193, 73-80.

22. Starke, S.D.; May, S.A.; Pfau, T. Understanding hind limb lameness signs in horses using simple rigid body mechanics. J. Biomech. 2015, 48, 3323-3331.

23. Bolink, S.A.A.N.; Naisas, H.; Senden, R.; Essers, H.; Heyligers, I.C.; Meijer, K.; Grimm, B. Validity of an inertial measurement unit to assess pelvic orientation angles during gait, sit-stand transfers and step-up transfers: Comparison with an optoelectronic motion capture system. Med. Eng. Phys. 2016, 38, 225-231.

24. Kong, W.; Sessa, S.; Cosentino, S.; Zecca, M.; Saito, K.; Wang, C.; Imtiaz, U.; Lin, Z.; Bartolomeo, L.; Ishii, H.; et al. Development of a real-time IMU-based motion capture system for gait rehabilitation. In Proceedings of the 2013 IEEE International Conference on Robotics and Biomimetics (ROBIO), Shenzhen, China, 12-14 December 2013; pp. 2100-2105.

25. Titterton, D.; Weston, J.L. Strapdown Inertial Navigation Technology; IET: Stevenage, Hertfordshire, UK, 2004; Volume 17.

26. Pfau, T.; Robilliard, J.J.; Weller, R.; Jespers, K.; Eliashar, E.; Wilson, A.M. Assessment of mild hindlimb lameness during over ground locomotion using linear discriminant analysis of inertial sensor data. Equine Vet. J. 2007, 39, 407-413.

27. Keegan, K.G. The Lameness Locator (wireless inertial sensors for detection of lameness in horses). In Proceedings of the Congress of the European Society of Veterinary Orthopaedics and Traumatology, Bologna, Italy, 15-18 September 2010; Volume 15, pp. 215-217.

28. Nankervis, K.; Hodgins, D.; Marlin, D. Comparison between a sensor (3D accelerometer) and ProReflex motion capture systems to measure stride frequency of horses on a treadmill. Comp. Exerc. Physiol. 2008, 5, 107-109.

29. Lopes, M.A.F.; Dearo, A.C.O.; Lee, A.; Reed, S.K.; Kramer, J.; Pai, P.F.; Yonezawa, Y.; Maki, H.; Morgan, T.L.; Wilson, D.A.; et al. An attempt to detect lameness in galloping horses by use of bodymounted inertial sensors. Am. J. Vet. Res. 2016, 77, 1121-1131.

30. Brighton, C.; Olsen, E.; Pfau, T. Is a standalone inertial measurement unit accurate and precise enough for quantification of movement symmetry in the horse? Comput. Methods Biomech. Biomed. Eng. 2015, 18, 527-532.

31. Pfau, T.; Fiske-Jackson, A.; Rhodin, M. Quantitative assessment of gait parameters in horses: Useful for aiding clinical decision making? Equine Vet. Educ. 2016, 28, 209-215.

32. Warner, S.M.; Koch, T.O.; Pfau, T. Inertial sensors for assessment of back movement in horses during locomotion over ground. Equine Vet. J. 2010, 42, 417-424.

33. Rhodin, M.; Roepstorff, L.; French, A.; Keegan, K.G.; Pfau, T.; Egenvall, A. Head and pelvic movement asymmetry during lungeing in horses with symmetrical movement on the straight. Equine Vet. J. 2016, 48, 315-320.

34. Pfau, T.; Witte, T.H.; Wilson, A.M. A method for deriving displacement data during cyclical movement using an inertial sensor. J. Exp. Biol. 2005, 208, 2503-2514.

35. Buchner, H.H.; Savelberg, H.H.; Schamhardt, H.C.; Merkens, H.W.; Barneveld, A. Kinematics of treadmill versus overground locomotion in horses. Vet. Q. 1994, 16 (Suppl. 2), 87-90. 
36. Gómez Alvarez, C.B.; Rhodin, M.; Byström, A.; Back, W.; van Weeren, P.R. Back kinematics of healthy trotting horses during treadmill versus over ground locomotion. Equine Vet. J. 2009, 41, 297-300.

37. Keegan, K.G.; Kramer, J.; Yonezawa, Y.; Maki, H.; Pai, P.F.; Dent, E.V.; Kellerman, T.E.; Wilson, D.A.; Reed, S.K. Assessment of repeatability of a wireless, inertial sensor-based lameness evaluation system for horses. Am. J. Vet. Res. 2011, 72, 1156-1163.

38. AAEP. Guide to veterinary services for horse shows, 7th ed.; American Association of Equine Practitioners, Lexington, KY, USA, 1999.

39. Calisi, R.M.; Bentley, G.E. Lab and field experiments: Are they the same animal? Horm. Behav. 2009, $56,1-10$.

40. Van den Noort, J.C.; Ferrari, A.; Cutti, A.G.; Becher, J.G.; Harlaar, J. Gait analysis in children with cerebral palsy via inertial and magnetic sensors. Med. Biol. Eng. Comput. 2013, 51, 377-386.

41. El-Gohary, M.; McNames, J. Shoulder and Elbow Joint Angle Tracking With Inertial Sensors. IEEE Trans. Biomed. Eng. 2012, 59, 2635-2641.

42. Muro-de-la Herran, A.; Garcia-Zapirain, B.; Mendez-Zorrilla, A. Gait Analysis Methods: An Overview of Wearable and Non-Wearable Systems, Highlighting Clinical Applications. Sensors 2014, 14, 33623394.

43. Picerno, P. 25 years of lower limb joint kinematics by using inertial and magnetic sensors: A review of methodological approaches. Gait \& Posture 2017, 51, 239-246.

44. Wang, Q.; Markopoulos, P.; Yu, B.; Chen, W.; Timmermans, A. Interactive wearable systems for upper body rehabilitation: A systematic review. J. NeuroEng. Rehabil. 2017, 14, 20.

45. Iosa, M.; Picerno, P.; Paolucci, S.; Morone, G. Wearable inertial sensors for human movement analysis.

46. Expert Rev. Med. Devices 2016, 13, 641-659.

47. Chambers, R.; Gabbett, T.J.; Cole, M.H.; Beard, A. The Use of Wearable Microsensors to Quantify Sport-Specific Movements. Sports Med. 2015, 45, 1065-1081.

48. Ahmadi, A.; Destelle, F.; Monaghan, D.; O'Connor, N.E.; Richter, C.; Moran, K. A framework for comprehensive analysis of a swing in sports using low-cost inertial sensors. In Proceedings of the 2014 IEEE SENSORS, Valencia, Spain, 2-5 November 2014; pp. 2211-2214.

49. Neville, J.G.; Rowlands, D.D.; Lee, J.B.; James, D.A. A Model for Comparing Over-Ground Running Speed and Accelerometer Derived Step Rate in Elite Level Athletes. IEEE Sens. J. 2016, 16, 185-191.

50. King, K.; Hough, J.; McGinnis, R.; Perkins, N.C. A new technology for resolving the dynamics of a swinging bat. Sports Eng. 2012, 15, 41-52.

51. Philpott, L.K.; Weaver, S.; Gordon, D.; Conway, P.P.; West, A.A. Assessing wireless inertia measurement units for monitoring athletics sprint performance. In Proceedings of the 2014 IEEE SENSORS, Valencia, Spain, 2-5 November 2014; pp. 2199-2202.

52. Stamm, A.; Thiel, D.V. Investigating Forward Velocity and Symmetry in Freestyle Swimming Using Inertial Sensors. Procedia Eng. 2015, 112, 522-527.

53. Thompson, R.; Kyriazakis, I.; Holden, A.; Olivier, P.; Plötz, T. Dancing with Horses: Automated Quality Feedback for Dressage Riders. In Proceedings of the 2015 ACM International Joint Conference on Pervasive and Ubiquitous Computing (UbiComp '15), Osaka, Japan, 7-11 September 2015; ACM: New York, NY, USA, 2015; pp. 325-336.

54. Martin, P.; Cheze, L.; Pourcelot, P.; Desquilbet, L.; Duray, L.; Chateau, H. Effects of the rider on the kinematics of the equine spine under the saddle during the trot using inertial measurement units: Methodological study and preliminary results. Vet. J. 2017, 221, 6-10.

55. Knapkiewicz, P.; Kosek, W.; Jozwiak, P.; Dziuban, J.; Jaskowski, J. Animals Dedicated, MEMS Sensors Based Mechatronics Movement Assessment System. Procedia Eng. 2014, 87, 576-579.

56. Keegan, K.G.; Yonezawa, Y.; Pai, P.F.; Wilson, D.A. Accelerometer-based system for the detection of lameness in horses. Biomed. Sci. Instrum. 2002, 38, 107-112.

57. Bailey, G.P.; Harle, R. Assessment of Foot Kinematics During Steady State Running Using a Footmounted IMU. Procedia Eng. 2014, 72, 32-37. 
58. Van der Kruk, E.; Schwab, A.L.; van der Helm, F.C.T.; Veeger, H.E.J. Getting the Angles Straight in Speed Skating: A Validation Study on an IMU Filter Design to Measure the Lean Angle of the Skate on the Straights. Procedia Eng. 2016, 147, 590-595.

59. Yuan, Q.; Chen, I.M.; Caus, A. Human velocity tracking and localization using 3 IMU sensors. In Proceedings of the 2013 6th IEEE Conference on Robotics, Automation and Mechatronics (RAM), Manila, Philippines, 12-15 November 2013; pp. 25-30.

60. Wundersitz, D.; Gastin, P.; Robertson, S.; Davey, P.; Netto, K. Validation of a Trunk-mounted Accelerometer to Measure Peak Impacts during Team Sport Movements. Int. J. Sports Med. 2015, $36,742-746$.

61. Bichler, S.; Ogris, G.; Kremser, V.; Schwab, F.; Knott, S.; Baca, A. Towards high-precision IMU/GPS-based stride-parameter determination in an outdoor runners' scenario. Procedia Eng. 2012, 34, 592-597.

62. Keegan, K.G.; Wilson, D.A.; Kramer, J.; Reed, S.K.; Yonezawa, Y.; Maki, H.; Pai, P.F.; Lopes, M.A.F. Comparison of a body-mounted inertial sensor system-based method with subjective evaluation for detection of lameness in horses. Am. J. Vet. Res. 2012, 74, 17-24.

63. Donnell, J.R.; Frisbie, D.D.; King, M.R.; Goodrich, L.R.; Haussler, K.K. Comparison of subjective lameness evaluation, force platforms and an inertial-sensor system to identify mild lameness in an equine osteoarthritis model. Vet. J. 2015, 206, 136-142.

64. Rungsri, P.; Sfaecker, W.; Leelamankong, P.; Estrada, R.; Rettig, M.; Klaus, C.; Lischer, C. Agreement between a body-mounted inertial sensors system and subjective observational analysis when evaluating lameness degree and diagnostic analgesia response in horses with forelimb lameness. Pferdeheilkunde 2014, 30, 644-650.

65. Keegan, K.G.; MacAllister, C.G.; Wilson, D.A.; Gedon, C.A.; Kramer, J.; Yonezawa, Y.; Maki, H.; Pai, P.F. Comparison of an inertial sensor system with a stationary force plate for evaluation of horses with bilateral forelimb lameness. Am. J. Vet. Res. 2012, 73, 368-374.

66. Bell, R.P.; Reed, S.K.; Schoonover, M.J.; Whitfield, C.T.; Yonezawa, Y.; Maki, H.; Pai, P.F.; Keegan, K.G. Associations of force plate and body-mounted inertial sensor measurements for identification of hind limb lameness in horses. Am. J. Vet. Res. 2016, 77, 337-345.

67. Pfau, T; Weller, R. Comparison of a standalone consumer grade smartphone with a specialist inertial measurement unit for quantification of movement symmetry in the trotting horse. Equine Vet. J. 2015, 49, 124-129.

68. Pfau, T.; Boultbee, H.; Davis, H.; Walker, A.; Rhodin, M. Agreement between two inertial sensor gait analysis systems for lameness examinations in horses. Equine Vet. Educ. 2016, 28, 203-208.

69. Olsen, E.; Pfau, T.; Ritz, C. Functional limits of agreement applied as a novel method comparison tool for accuracy and precision of inertial measurement unit derived displacement of the distal limb in horses. J. Biomech. 2013, 46, 2320-2325.

70. Roepstorff, L.; Wiestner, T.; Weishaupt, M.A.; Egenvall, E. Comparison of microgyro-based measurements of equine metatarsal/metacarpal bone to a high speed video locomotion analysis system during treadmill locomotion. Vet. J. 2013, 198 (Suppl. 1), e157-e160.

71. Keegan, K.G.; Yonezawa, Y.; Pai, P.F; Wilson, D.A.; Kramer, J. Evaluation of a sensor-based system of motion analysis for detection and quantification of forelimb and hind limb lameness in horses. Am. J. Vet. Res. 2004, 65, 665-670.

72. Moorman, V.J.; Reiser, R.F., II; Mcllwraith, C.W.; Kawcak, C.E. Validation of an equine inertial measurement unit system in clinically normal horses during walking and trotting. Am. J. Vet. Res. 2012, 73, 1160-1170.

73. Equinosis LLC. The Equinosis with Lameness Locator. Equinosis LLC: Columbia, MO, USA. Available online: https://equinosis.com (accessed on 6 March 2018).

74. GaitSmart. GaitSmart Pegasus-Sensor-Based Gait Analysis for Equines. GaitSmart: Codicote, Hitchin, Hertfordshire, UK. Available online: http://www.gaitsmart.com/gaitsmart-pegasus (accessed on 6 March 2018). 
75. EquiGait. EquiGait-Sensor Based Gait Analysis. EquiGait: Brickendon, Hertford, Hertfordshire, UK. Available online: http://www.equigait.co.uk (accessed on 6 March 2018).

76. Back, W.; Clayton, H. (Eds.) Equine Locomotion, 2nd ed.; W.B. Saunders, Elsevier Health: London, UK, 2013.

77. Inertia Technology. ProMove MINI-Wireless Motion Capture Sensor from Inertia Technology. Inertia Technology: Enschede, The Netherlands. Available online: http://inertia-technology. com/product/motion- capture-promove-mini (accessed on 6 March 2018).

78. Olsen, E.; Andersen, P.H.; Pfau, T. Accuracy and Precision of Equine Gait Event Detection during Walking with Limb and Trunk Mounted Inertial Sensors. Sensors 2012, 12, 8145-8156.

79. Bragança, F.M.; Bosch, S.; Voskamp, J.P.; Marin-Perianu, M.; Van der Zwaag, B.J.; Vernooij, J.C.M.; van Weeren, P.R.; Back, W. Validation of distal limb mounted inertial measurement unit sensors for stride detection in Warmblood horses at walk and trot. Equine Vet. J. 2017, 49, 545-551.

80. Valenti, R.G.; Dryanovski, I.; Xiao, J. Keeping a Good Attitude: A Quaternion-Based Orientation Filter for IMUs and MARGs. Sensors 2015, 15, 19302-19330.

81. Madgwick, S.O.H.; Harrison, A.J.L.; Vaidyanathan, R. Estimation of IMU and MARG orientation using a gradient descent algorithm. In Proceedings of the 2011 IEEE International Conference on Rehabilitation Robotics, Zurich, Switzerland, 29 June-1 July 2011; pp. 1-7.

82. Peham, C.; Scheidl, M.; Licka, T. A method of signal processing in motion analysis of the trotting horse. J. Biomech. 1996, 29, 1111-1114.

83. Keegan, K.G.; Pai, P.F.; Wilson, D.A.; Smith, B.K. Signal decomposition method of evaluating head movement to measure induced forelimb lameness in horses trotting on a treadmill. Equine Vet. J. 2001, 33, 446-451.

84. Howard, R.; Conway, R.; Harrison, A.J. Estimation of force during vertical jumps using body fixed accelerometers. In Proceedings of the 25th IET Irish Signals Systems Conference 2014 and 2014 China-Ireland International Conference on Information and Communications Technologies (ISSC 2014/CIICT 2014), Limerick, Ireland, 26-27 June 2014; pp. 102-107.

85. Coutsias, E.A.; Seok, C.; Dill, K.A. Using quaternions to calculate RMSD. J. Comput. Chem. 2004, 25, 1849-1857.

86. Dobrowolski, P. Swing-twist decomposition in Clifford algebra. arXiv 2015, arXiv:1506.05481.

87. Giavarina, D. Understanding Bland Altman analysis. Biochem. Med. 2015, 25, 141-151.

88. Barnhart, H.X.; Yow, E.; Crowley, A.L.; Daubert, M.A.; Rabineau, D.; Bigelow, R.; Pencina, M.; Douglas, P.S. Choice of agreement indices for assessing and improving measurement reproducibility in a core laboratory setting. Stat. Methods Med. Res. 2016, 25, 2939-2958.

89. Bland, J.M.; Altman, D.G. Agreement Between Methods of Measurement with Multiple Observations Per Individual. J. Biopharm. Stat. 2007, 17, 571-582.

90. Schamhardt, H.C.; van den Bogert, A.J.; Hartman, W. Measurement Techniques in Animal Locomotion Analysis. Cells Tissues Organs 1993, 146, 123-129.

91. Clayton, H.M.; Schamhardt, H.C.; Willemen, M.A.; Lanovaz, J.L.; Colborne, G.R. Kinematics and ground reaction forces in horses with superficial digital flexor tendinitis. Am. J. Vet. Res. 2000, 61, 191-196.

92. Buchner, H.H.F.; Savelberg, H.H.C.M.; Schamhardt, H.C.; Barneveld, A. Limb movement adaptations in horses with experimentally induced fore- or hindlimb lameness. Equine Vet. J. 1996, 28, 63-70.

93. Starke, S.D.; Witte, T.H.; May, S.A.; Pfau, T. Accuracy and precision of hind limb foot contact timings of horses determined using a pelvis-mounted inertial measurement unit. J. Biomech. 2012, 45, 1522-1528.

94. Dyson, S. Recognition of lameness: Man versus machine. Vet. J. 2014, 201, 245-248.

95. Clayton, H.M.; Hobbs, S.J. The role of biomechanical analysis of horse and rider in equitation science. Appl. Anim. Behav. Sci. 2017, 190, 123-132. 


\section{Appendix A}

This Appendix contains box plots for the sagittal and coronal limb angles measured by IMU and $\mathrm{OMC}$ in Figures $\mathrm{A} 1$ and $\mathrm{A} 2$, respectively. Additionally, box plots for the the upper body vertical displacement parameters of IMU and OMC are presented in Figure A3.
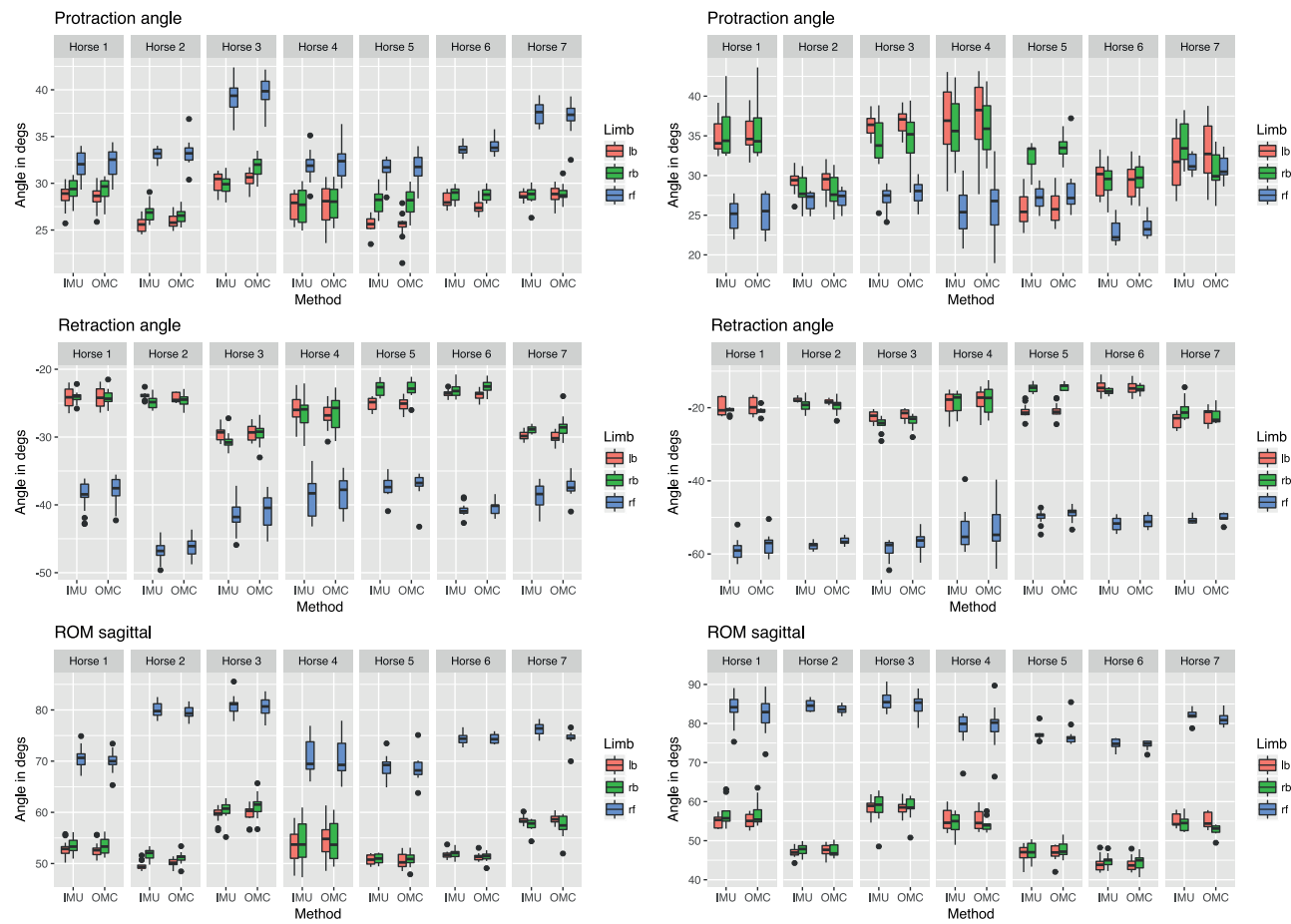
(a) Walk
(b) Trot

Figure A1. Box plots for the sagittal limb angles measured by IMU and OMC. 

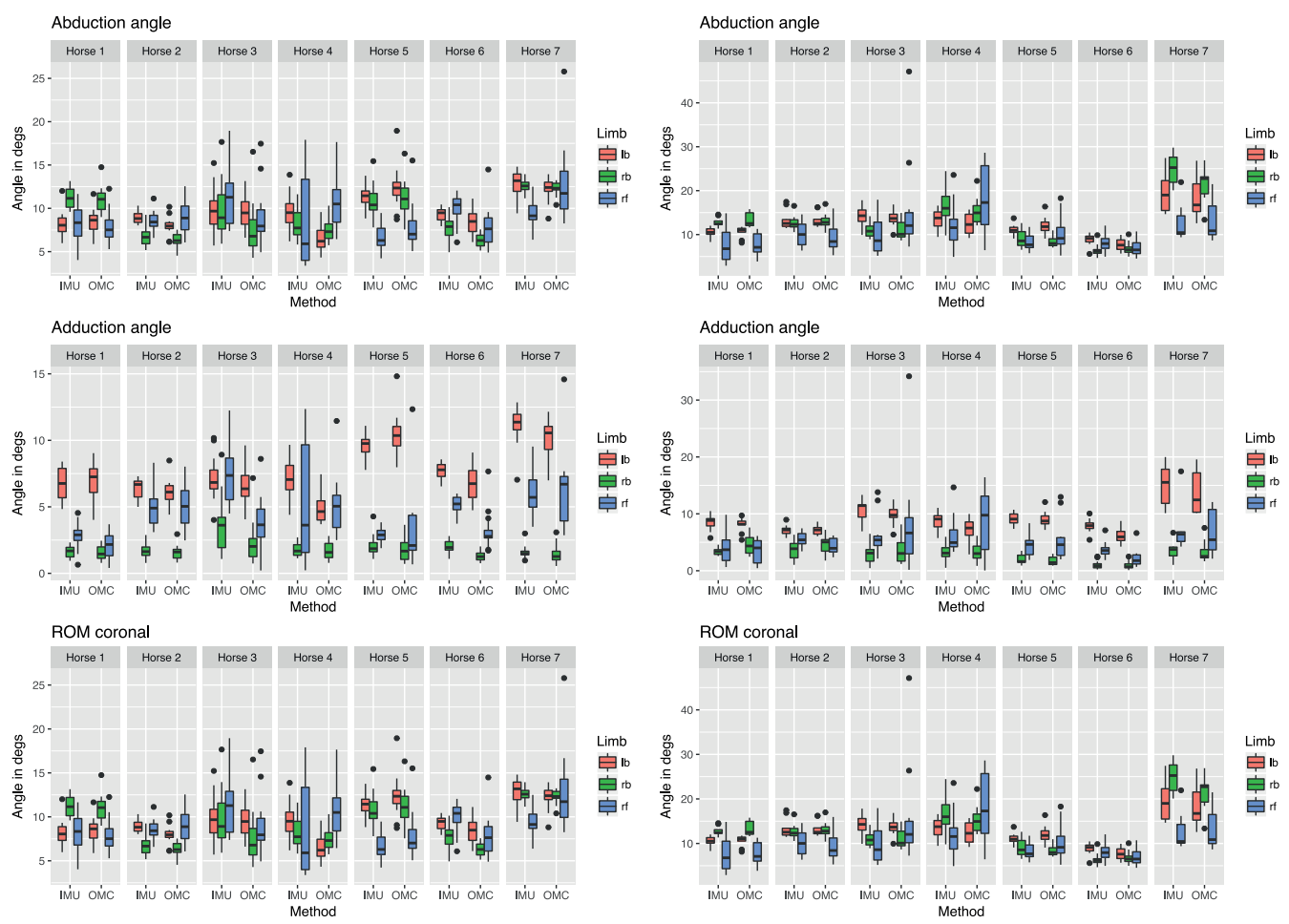

(a) Walk

(b) Trot

Figure A2. Box plots for the coronal limb angles measured by IMU and OMC. 


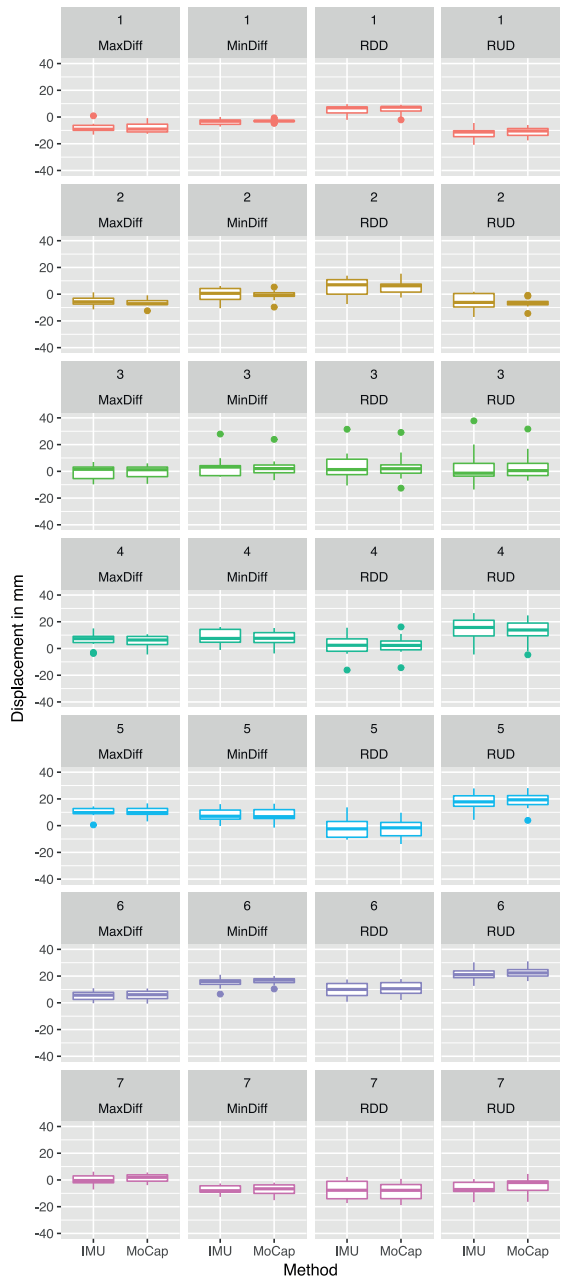

(a) Withers

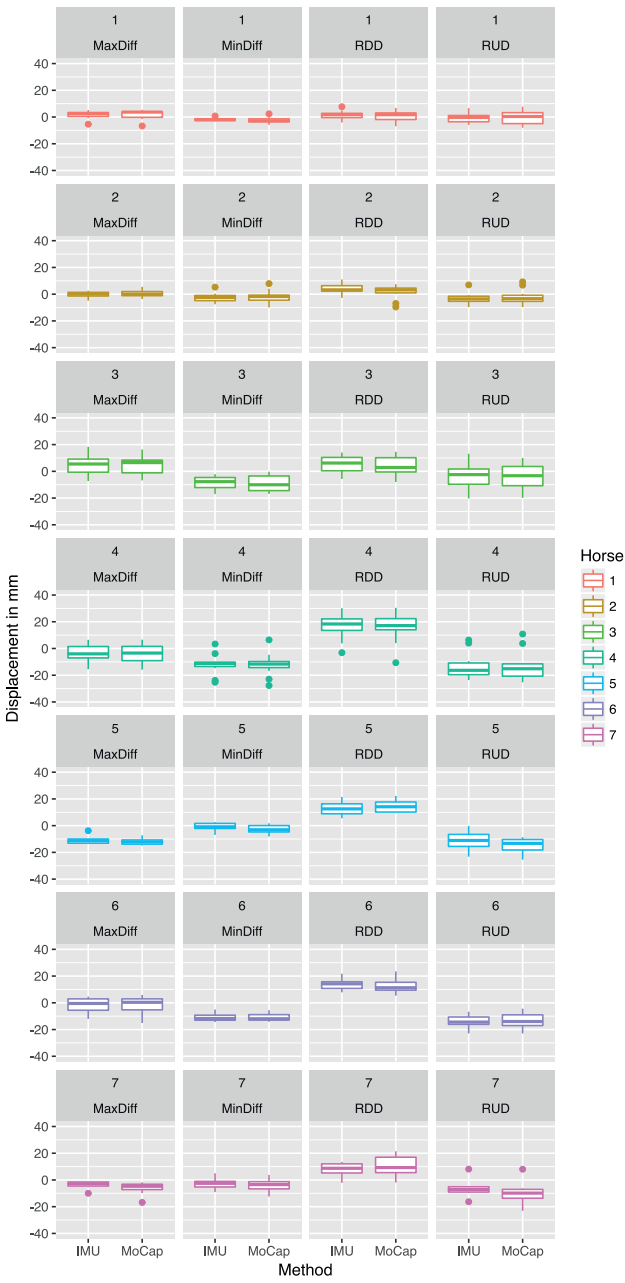

(b) Sacrum

Figure A3. Box plot for the upper-body vertical displacement parameters of IMU and OMC. 


\section{Variation in gait parameters} used for objective lameness assessment in sound horses at the trot on the straight line and the lunge

A. M. Hardeman ${ }^{\dagger \ddagger \S^{*}}$, F. M. Serra Braganc. $a^{\ddagger}$, J. H. Swagemakers ${ }^{\dagger}$, P. R. Van Weeren ${ }^{\ddagger}$ and L. Roepstorff ${ }^{\S}$

† Tierklinik Luesche GmbH, Luesche, Germany

‡ Department of Equine Sciences, Faculty of Veterinary Medicine, Utrecht University, Utrecht, the Netherlands

$\S$ Department of Anatomy, Physiology and Biochemistry, Swedish University of Agricultural Sciences, Uppsala, Sweden.

* Correspondence email: ahardeman@tierklinik-luesche.de; Received: 12.04.18; Accepted: 06.01.19
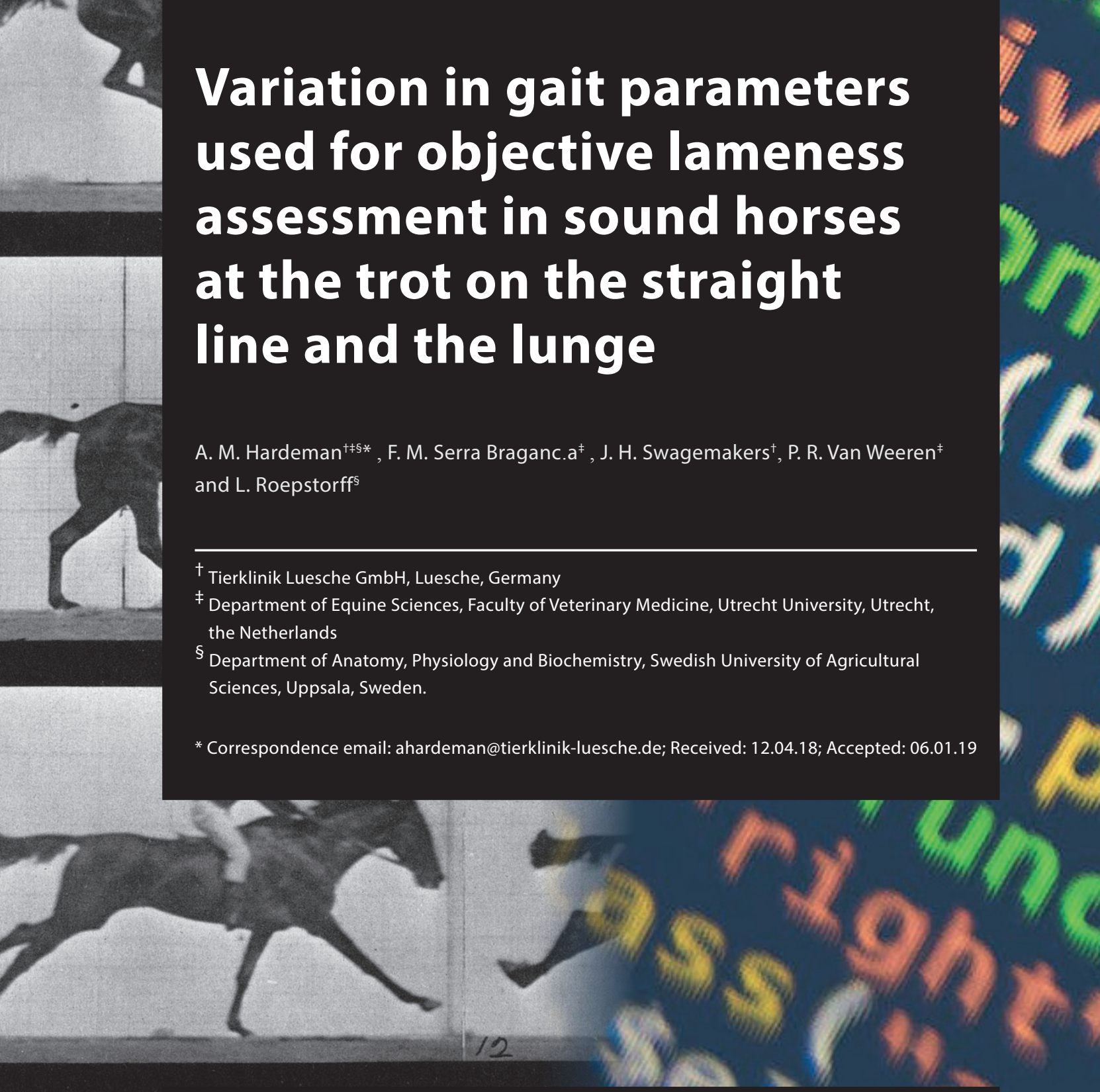


\section{Summary}

Background: Objective lameness assessment is gaining more importance in a clinical setting, necessitating availability of reference values.

Objectives: To investigate the between -path, -trial and -day variation, between and within horses, in the locomotion symmetry of horses in regular use that are perceived sound.

Study design: Observational study with replicated measurement sessions.

Methods: Twelve owner-sound horses were trotted on the straight line and on the lunge. Kinematic data were collected from these horses using 3D optical motion capture. Examinations were repeated on 12 occasions over the study which lasted 42 days in total. For each horse, measurements were grouped as five replicates on the first and second measurement days and two replicates on the third measurement day. Between measurement days 2 and 3, every horse had a break from examination of at least 28 days. Previously described symmetry parameters were calculated: RUD and RDD (Range Up/Down Difference; difference in upward/downward movement between right and left halves of a stride); MinDiff and MaxDiff (difference between the two minima/maxima of the movement); HHDswing and HHDstance (Hip Hike Difference-swing/-stance; difference between the upward movement of the tuber coxae during swingphase/stancephase). Data are described by the betweenmeasurement variation for each parameter. A linear mixed model was used to test for the effect of time, surface and path. Intraclass correlation coefficients (ICC) were calculated to access repeatability.

Results: Mean between-measurement variation was (MinDiff, MaxDiff, RUD, RDD): 13, 12, 20, $16 \mathrm{~mm}$ (head); 4, 3, 6, $4 \mathrm{~mm}$ (withers) and 5, 4, 6, $6 \mathrm{~mm}$ (pelvis); (HHDswing, HHDstance): 7 and $7 \mathrm{~mm}$. More between-measurement variation is seen on the first measurement day compared to the second and third measurement days. In general, less variation is seen with increasing number of repetitions. Less betweenmeasurement variation is seen on hard surface compared to soft surface. More between-measurement variation is seen on the circle compared to the straight line. Between-horse variation was clearly larger than within-horse variation. ICC values for the head, withers and pelvis symmetry parameters were 0.68 (head), 0.76 (withers), 0.85 (pelvis). 
Main limitations: Lunge measurements on a hard surface were not performed.

Conclusions: Between-measurement variation may be substantial, especially in head motion. This should be considered when interpreting clinical data after repeated measurements, as in routine lameness assessments. 


\section{Introduction}

Objective gait assessment is gradually becoming a standard procedure during lameness exams in equine clinics worldwide, as it overcomes some of the inherent limitations of subjective gait analysis [1]. Whereas the ability of experienced observers to detect (subtle) gait irregularities/asymmetries is well recognised [2], there are known limitations to visual subjective gait assessment. These are mainly related to a possible bias effect when performing regional nerve blocks [3] and to the limitations of the human eye in asymmetry perception [4]. These confounding factors ultimately contribute to a low repeatability/agreement in subjective lameness assessments [5].

Commonly used systems for objective lameness assessment are based on measurements of movement symmetry of the vertical (i.e. dorsoventral) displacement of the head, pelvis and sometimes withers at trot [1]. More pronounced movement asymmetries are commonly related to orthopaedic pain [1]. However, movement asymmetry might also be related to a certain extent with non-pain-related causes such as handedness [6] and is, as any biological parameter in living beings, subject to biological variation [7]. Discrimination between pathological asymmetry and asymmetry due to non-pathological reasons is essential for the clinical interpretation of the outcome of objective gait analysis [7], as is knowledge of the biological variation in lameness asymmetry for the correct interpretation of repeated measurements, which are common practice in lameness work-ups.

During those repeated lameness assessments, horses will not change their movement pattern by more than a certain amount, unless as a result of some intervention (e.g. flexion test, diagnostic analgesia). Although there is no strict universal protocol for lameness assessments in the horse, some guidelines that are commonly adhered to exist [7]. The lameness exam commonly starts with a trot-up on the straight and some circles on a hard and a soft surface. After this, flexion tests may be performed if, often followed by diagnostic analgesia. In general, the lameness examination consists more often than not of repeated observations of the same subject under several different conditions. One of the most important outcomes of the examination is a determination of differences between these repeated observations. To avoid over interpretation, it is therefore of utmost importance to establish the extent of normal biological variation between repeated observations that can be expected in healthy horses.

Previous research found a low degree of between-day repeatability using motion capture in horses, but the outcome was thought to be influenced by the limitations of the 2D motion capture system that was used [8]. In both sound and lame horses, 
good repeatability was found between subsequent measurements spaced five minutes apart using a body-mounted accelerometer sensor, for head and sacrum vertical displacement symmetry [9].

The objectives of this study were to describe the magnitude of the betweenmeasurement variation and repeatability of movement symmetry parameters in horses in regular work and judged sound by their owners. This was studied with intervals of 5 and $10 \mathrm{~min}$, within a day, over consecutive days and over a longer period of a time. We hypothesised that there would be a small proportion of biological variation between repeated measurements in this group of horses and that this variation would be smaller within than between horses.

\section{Materials and methods}

\section{Horses}

Twelve sports horses in regular work ( 3 geldings and 9 mares) with a body mass range of $450-652 \mathrm{~kg}$ (mean $551 \mathrm{~kg}$ ) and an age range of 5-15 years (mean: 8.3 years) were used in this study. The horses were in regular use and deemed sound by their owner or rider. An experienced equine veterinarian examined the horses and graded them as sound or nearly sound (defined as grades 0 or less than 1 on the 0 to 5 AAEP scale [10]), on the day before the first measurement. The judgment was based on a subjective assessment of a straight-line trot up on a soft surface (hard surface was not available). A detailed description of the population can be found in the Supplementary Item 1.

\section{Marker placement}

Each subject was equipped with clusters of spherical reflective markers (soft spherical marker, $25 \mathrm{~mm}$ diameter ${ }^{a}$ ), attached to the skin using double-sided adhesive tape. Three markers were placed in the frontal plane of the head (whereby the lowest marker is used as the reference marker), three markers on the withers (one on the highest point, two markers $20 \mathrm{~cm}$ lateral to the central one, one on each side) and three on a T-shaped strip on respectively the tuber sacrale and the craniodorsal aspect of both tuber coxae (Fig 1). Additional markers were attached to the skin above the dorsal spinous processes of $\mathrm{T} 12, \mathrm{~T} 15, \mathrm{~T} 18, \mathrm{~L} 3, \mathrm{~L} 5$ and the sacrum (S5); these were not used in this study. The location of each marker was identified by clipping a small proportion of hair to ensure exact replacement of markers on the following days. 


\section{Data collection}

Optical motion capture (OMC) data in 3D were recorded using the Qualisys Motion

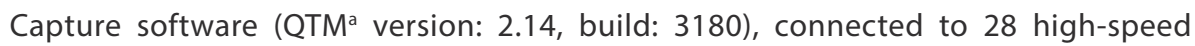
infrared cameras (Oqus $700+^{\mathrm{a}}$ ) set to a sampling frequency of $100 \mathrm{~Hz}$. The total covered area in this set-up was approximately $250 \mathrm{~m}^{2}$, height covered was at least 5 $\mathrm{m}$. Calibration before the start of the measurements was done daily according to the manufacturer's instructions. The average calibration residual was $3.2 \mathrm{~mm}$.

\section{Measuring protocol}

The horses were divided into two groups (Fig 2). Each group was subjected to the same measuring protocol (details in Supplementary Item 2). Examinations were repeated on 12 occasions over the study which lasted 42 days in total. For each horse, measurements were grouped as five replicates on the first and second measurement days and two replicates on the third measurement day. Between measurement days 2 and 3, every horse had a break from examination of at least 28 days.

Although at different time points, measurements were performed with a 5-minute interval between the first two measurements of each day (M1-M2, M6-M7, M11-M12) and with 10 minutes in between the remaining measurements of that day (M2-M3M4-M5, M7-M8-M9-M10) (Fig 2). The same handler always handled all horses in each group.

Each measurement started with a warm-up period of $5 \mathrm{~min}$ hand walking and 10 min lungeing. After the warm-up up period, markers were placed. Each measurement (M1 to M12) consisted of a hard surface straight line (2920 m) a soft surface straight line $(2930 \mathrm{~m}$ ) and lungeing on a soft surface (diameter approximately $10 \mathrm{~m}$, length of lunge- line standardised by a knot) on both reins. This protocol is typical for a standard lameness work-up at the clinic where the study was performed. During the measurements, care was taken to minimise changes in speed, ensuring a steady-state movement during the whole measurement. Straight line turning was done outside the covered volume.

On the lunge, data were collected for $25 \mathrm{~s}$. The sequence of all measurements (M1M12) was hard (tarmac) straight line, soft straight line, left lunge (soft) and right lunge (soft). The soft surface consisted of a combination of sand and synthetic fibre, which was harrowed daily before the first measuring session. Horses were trotted at their preferred speed. 


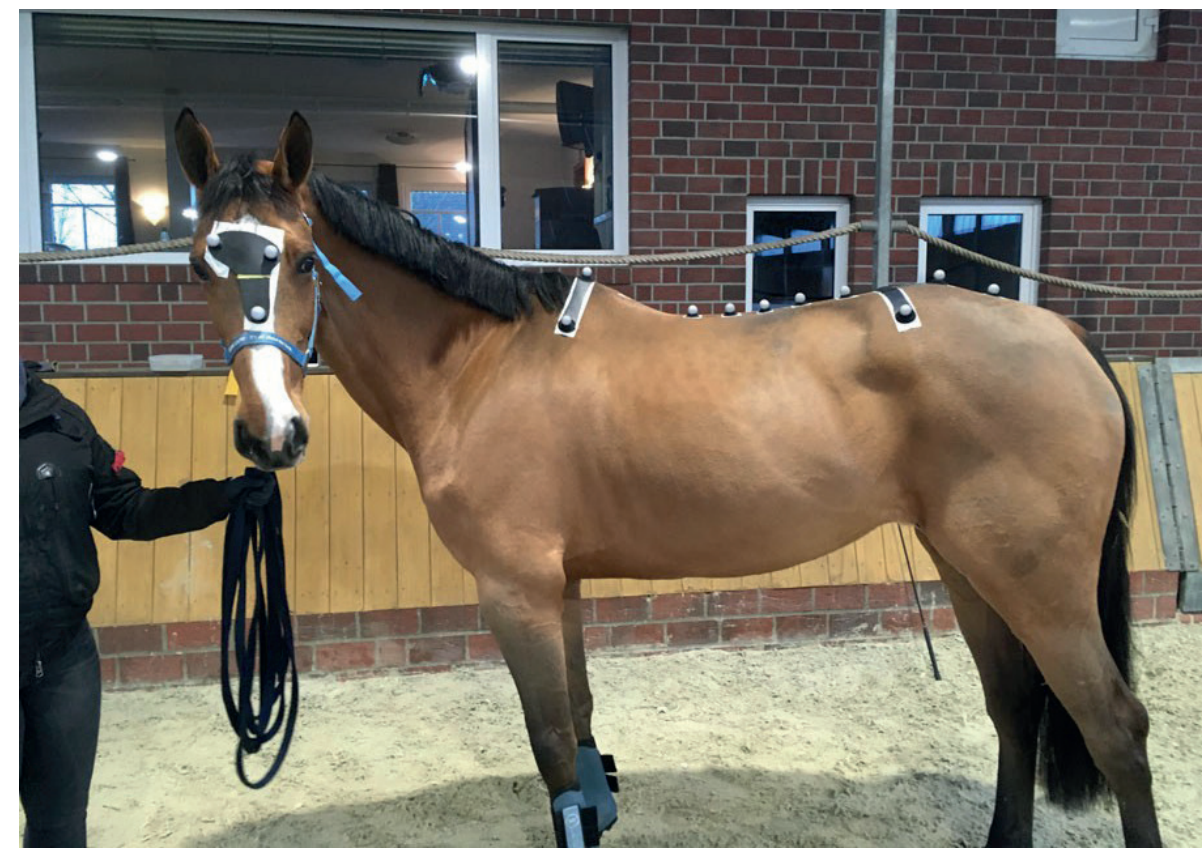

Fig 1. Marker placement in one of the study subjects.

After each measurement, the 3D tracked data were visually inspected ensuring that all markers had been tracked adequately and data were suitable for analysis. Measurements with poor marker tracking or insufficient number of collected strides (five or less complete strides) were discarded. Synchronised video recordings of each measurement were made.

\section{Kinematic data analysis}

Kinematic data were analysed using proprietary software (Qhorsea), and several symmetry parameters were calculated, based on the vertical displacement of the different body parts (head, withers, pelvis). These parameters are RUD (Range Up Difference; difference in upward movement between right and left halves of a stride) and RDD (Range Down Difference; difference in downward movement between right and left halves of a stride); MinDiff (difference between the two minima of the movement) [11] and MaxDiff (difference between the two maxima of the movement) [11]; HHDswing (Hip Hike Difference-swing; difference between the upward movement of the tuber coxae during swingphase) [12] and HHDstance (Hip Hike Difference-stance; difference between the upward movement of the tuber coxae during stance). This gives a total of 14 parameters (Table 1). Parameters are visualised in Supplementary Item 3. 


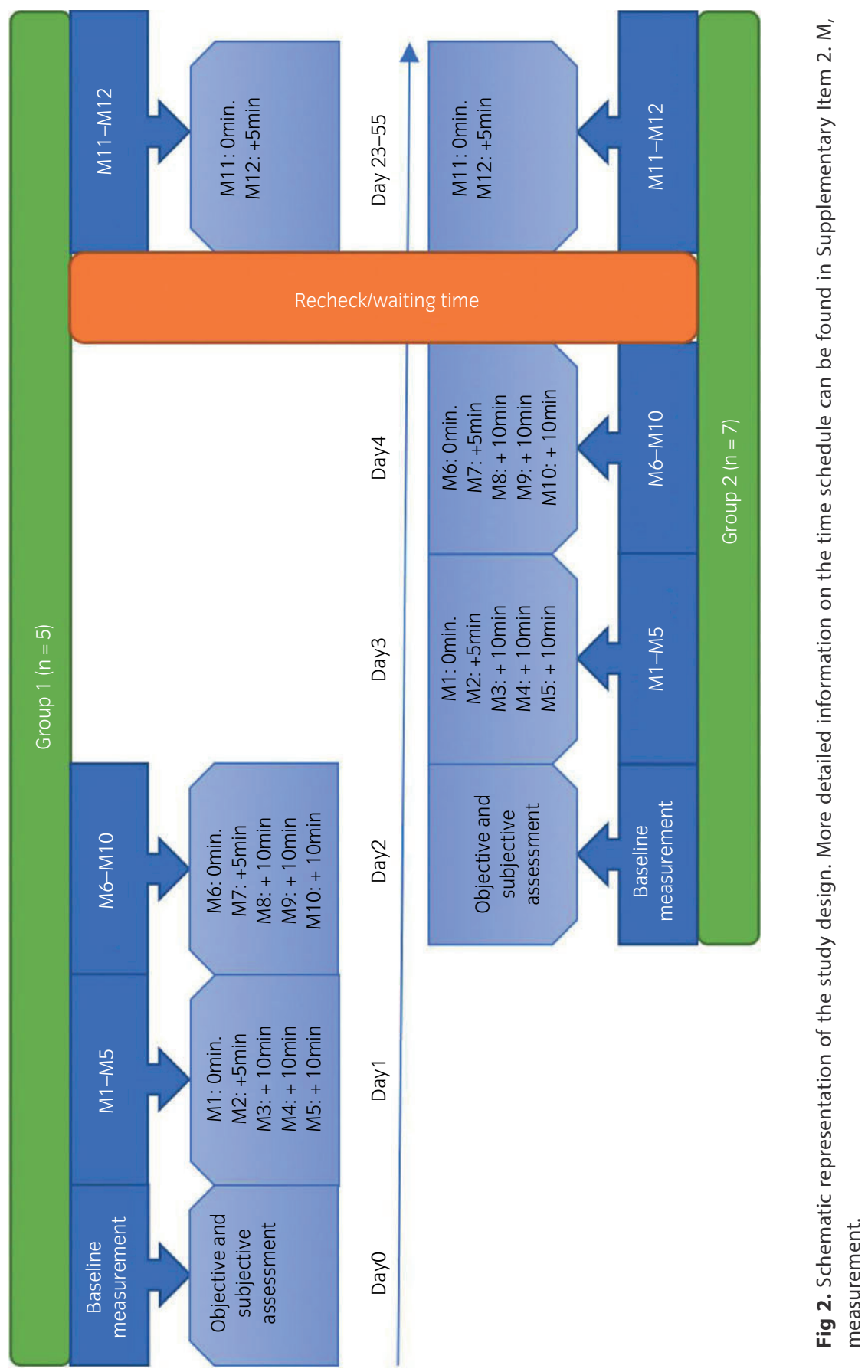


Filtering of the data was done according to earlier investigated methods (F. M. Serra Braganca, unpublished data). A fourth order Butterworth filter with cutoff frequency adjusted to the stride frequency was used. Cutoff frequencies ranged from 1.2 to $1.5 \mathrm{~Hz}$.

\section{Data analysis}

From the data collected, two datasets were generated:

- 'Non-offset adjusted'; these are the original data, without any transformations

- 'Offset adjusted data'; for this data set, each symmetry variable calculated for each horse and each path separately (soft straight, hard straight, soft left and soft right), was offset by subtracting the mean of all measurements from each measurement. This generated a data set centred around zero that allows a better comparison of the between- measurement variation between horses.

Table 1. Between-measurement variation (in $\mathrm{mm}$ ), given as the (absolute) prediction interval, per condition and per parameter. Calculated absolute mean variation per (type of) parameter given in the last two columns

\begin{tabular}{lcccccc}
\hline & $\begin{array}{c}\text { Hard } \\
\text { straight }\end{array}$ & $\begin{array}{c}\text { Soft } \\
\text { straight }\end{array}$ & $\begin{array}{c}\text { Soft } \\
\text { left }\end{array}$ & $\begin{array}{c}\text { Soft } \\
\text { right }\end{array}$ & $\begin{array}{c}\text { Mean } \\
\text { variation }\end{array}$ & $\begin{array}{c}\text { Mean } \\
\text { variation }\end{array}$ \\
\hline Head & 12 & 16 & 12 & 13 & 13 & 13 \\
MinDiff & 9 & 12 & 11 & 14 & 12 & \\
MaxDiff & 22 & 20 & 17 & 21 & $\mathbf{2 0}$ & $\mathbf{1 8}$ \\
RUD & 15 & 18 & 16 & 14 & $\mathbf{1 6}$ & \\
RDD & & & & & & \\
Withers & 3 & 3 & 5 & 4 & 4 & $\mathbf{4}$ \\
MinDiff & 3 & 3 & 3 & 3 & $\mathbf{3}$ & \\
MaxDiff & 6 & 5 & 5 & 7 & $\mathbf{6}$ & $\mathbf{5}$ \\
RUD & 4 & 3 & 6 & 4 & 4 & \\
RDD & & & & & & \\
Pelvis & 4 & 4 & 5 & 5 & $\mathbf{5}$ & $\mathbf{5}$ \\
MinDiff & 4 & 4 & 3 & 3 & 4 & \\
MaxDiff & 6 & 5 & 6 & 6 & $\mathbf{6}$ & $\mathbf{6}$ \\
RUD & 5 & 6 & 6 & 6 & $\mathbf{6}$ & \\
RDD & 7 & 7 & 7 & 7 & $\mathbf{7}$ & $\mathbf{7}$ \\
HHDsw & 6 & 7 & 7 & 6 & $\mathbf{7}$ & \\
HHDst & & & & &
\end{tabular}


Open software R (3.3.1) ${ }^{\mathrm{b}}$ was used for statistical analysis. The package Ime4 (version 1.1) was used for the linear mixed effect model and the package merTools (version 0.3.0) for calculating prediction intervals. The linear mixed model analysis was performed on the mean offset adjusted data, for each different path (hard straight, soft straight, soft left, soft right) with the horse ID used as a random effect and repetition used as a fixed effect. For each variable, the prediction intervals were calculated.

To test the effect of time, surface and path, a linear mixed model was used with the offset adjusted between-measurement variation of each variable (absolute value) as an outcome variable, repetition, day, surface and path as a fixed effect and horse ID as random effect. Normality was checked using $q-q$ plots and box-plots and homoscedasticity was checked by plotting the fitted values vs. the residuals. Due to skewness of the residuals, a square root transformation was done and this successfully achieved a normal distribution of the model residuals. Significance was set at $\mathrm{P}<0.05$.

To calculate the repeatability between the different measurements of each parameter, the intra-class correlation coefficient (ICC) of the non- offset adjusted data was calculated with the R function ICC.Ime (version v 2.2) using the horse ID, surface and path as grouping variables.

\section{Results}

Three horses (horses 3, 8, 10) were not available for the last measuring session (M1112). Also, due to a technical problem, one measurement was lost (horse $2, M 2$, soft left circle).

For the straight-line trials, the mean (s.d.) of measured strides per trial was 14 (3.8); trotting speed was $3.7(0.3) \mathrm{m} / \mathrm{s}$. For the lunge trials, the mean (s.d.) of measured strides per trial was 36.8 (5.6); trotting speed was $3.4(0.2) \mathrm{m} / \mathrm{s}$ and circle diameter was $9.7(0.6) \mathrm{m}$. The average calibration residuals value was $3.2 \mathrm{~mm}$. The baseline asymmetry (M1) of each horse can be found in Supplementary Item 4. Throughout the study period, none of the horses had a lameness score higher than the chosen threshold of $1 / 5$. Therefore, none of the subjects was excluded from the study.

\section{Between-measurement variation}

The between-measurement variation is visualised in Figures 3-6. The prediction intervals (Table 1) show the different values of the between- measurement variation for the various parameters and anatomical locations. Mean between-measurement 
variation (over all measurements and over all horses) was: (MinDiff, MaxDiff, RUD, $\mathrm{RDD}), 13,12,20,16 \mathrm{~mm}$ (head); 4, 3, 6, $4 \mathrm{~mm}$ (withers) and 5, 4, 6, $6 \mathrm{~mm}$ (pelvis); (HHDswing, HHDstance), 7 and $7 \mathrm{~mm}$.

At all anatomical locations, between-measurement variation of MinDiff and MaxDiff was lower than that of the RUD and RDD (Table 1). The head symmetry parameters showed significantly more variation compared to the withers and pelvis (Table 1, Figures 3-6).

The mean intra-class correlation coefficient (ICC) values obtained for the head $(0.68)$ were lower than for the withers $(0.76)$ or pelvis $(0.85)$.
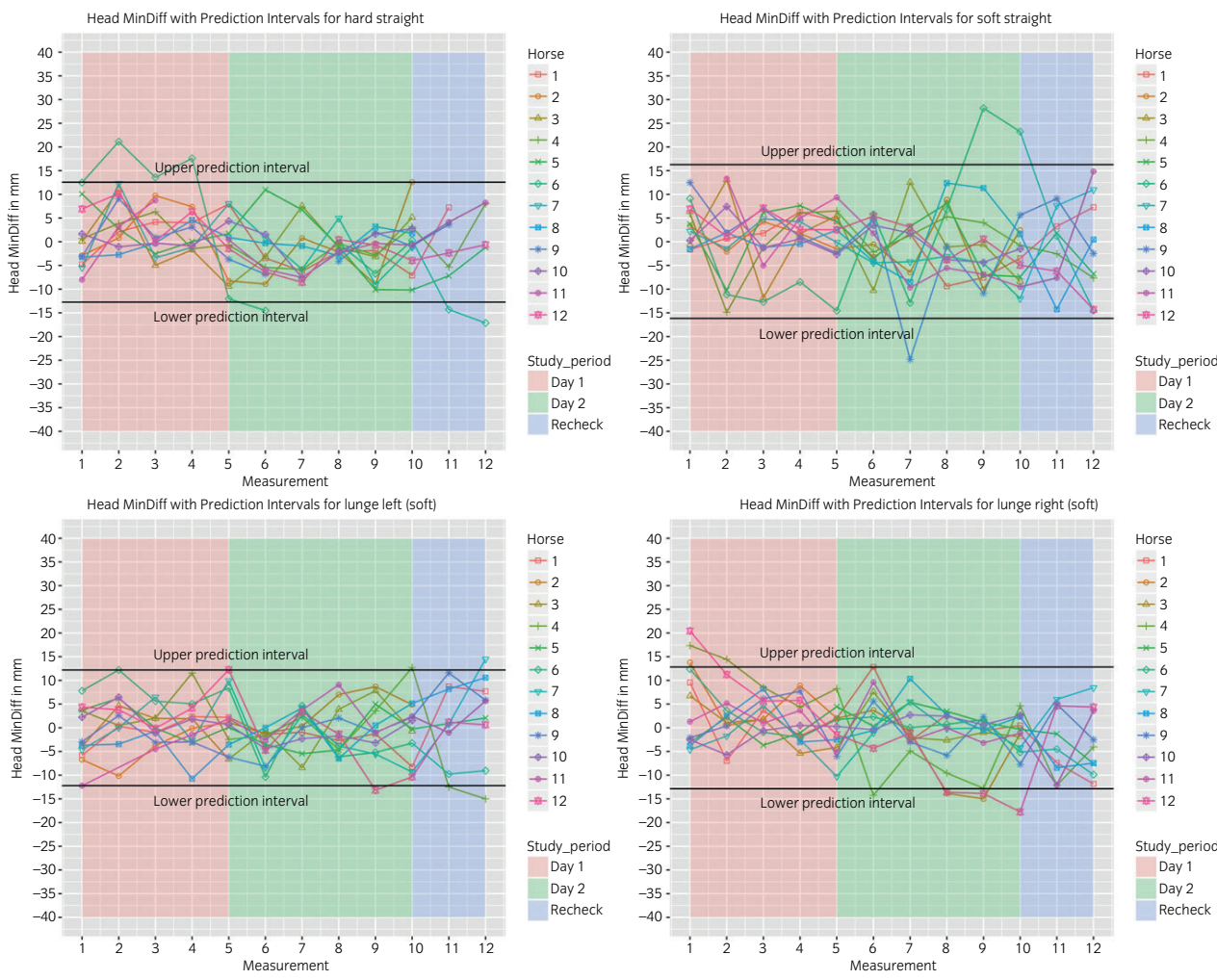

Fig 3. Between-measurement variation (Offset adjusted data) for 'MinDiff Head', per measurement, per day and per horse. Each plot contains one path (hard straight, soft straight, left lunge, right lunge). These data enable the evaluation of the between-measurement variation between and within horses and between and within days. 

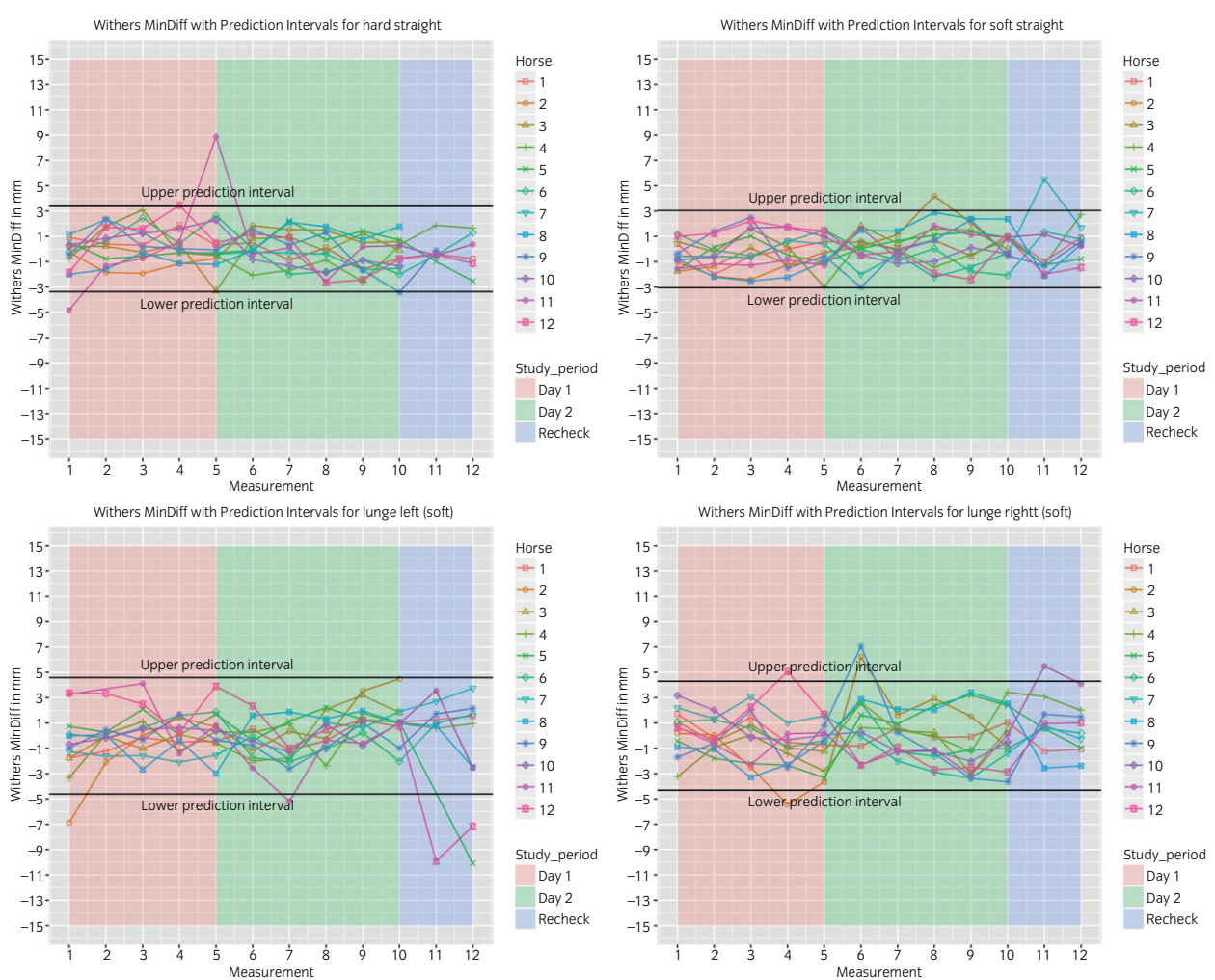

Fig 4. Between-measurement variation (Offset adjusted data) for 'MinDiff Withers', per measurement, per day and per horse. Each plot contains one path (hard straight, soft straight, left lunge, right lunge). These data enable the evaluation of the between-measurement variation between and within horses and between and within days.

\section{Effect of time, surface and path on the variation}

A reduction of the between-measurement variation was seen on day 2 and day 3 compared to day 1 . In general, there is a tendency to reduced variation with an increasing number of repetitions (for example, M4 and M5 have less variation than M1). This is true for all parameters, but not at all time points.

Less variation was seen on hard surface (straight line) compared to soft surface (straight line).

More variation was seen on the circle compared to the straight line $(P<0.01)$. Detailed model outcomes can be found in the Supplementary Item 5. 

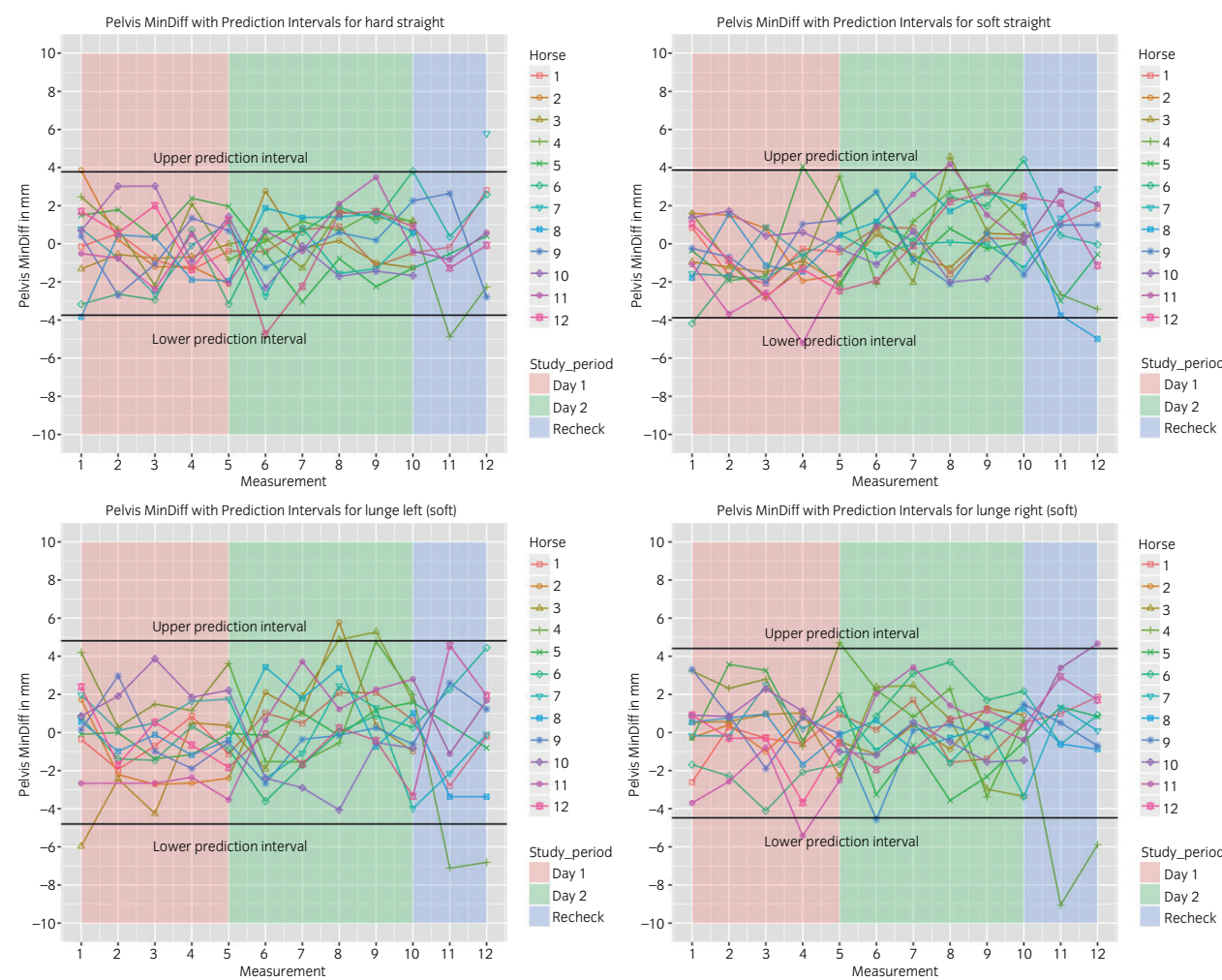

Fig 5. Between-measurement variation (Offset adjusted data) for 'MinDiff Pelvis', per measurement, per day and per horse. Each plot contains one path (hard straight, soft straight, left lunge, right lunge). These data enable the evaluation of the between-measurement variation between and within horses and between and within days.

\section{Between vs. within horse variation}

Over all measurements, between-horse variation was substantially higher than within-horse variation. This becomes graphically evident in the Supplementary Items 6 and 7 as the relatively small individual boxes per horse, compared to the more substantial differences between the different box plots. The observation is also supported by the high ICC values.

\section{Discussion}

This study investigated the amount of 'between-measurement variation that can be attributed to biological variation in symmetry parameters over time, over different surfaces and paths (straight line and circles), within and between horses. Knowledge 
of this variation is paramount for correct interpretation of quantitative gait analysis data in the clinical situation, such as when comparing repeated measurements before and after diagnostic analgesia.

The horses used in this study were assumed to be sound by their owner and in regular training. To clarify, sound in this context is meant as non-lame. Defining lameness has been discussed before and can also for this study be described as 'a clinical interpretation of one or more signs indicating a pathological condition of the locomotor system'[13].
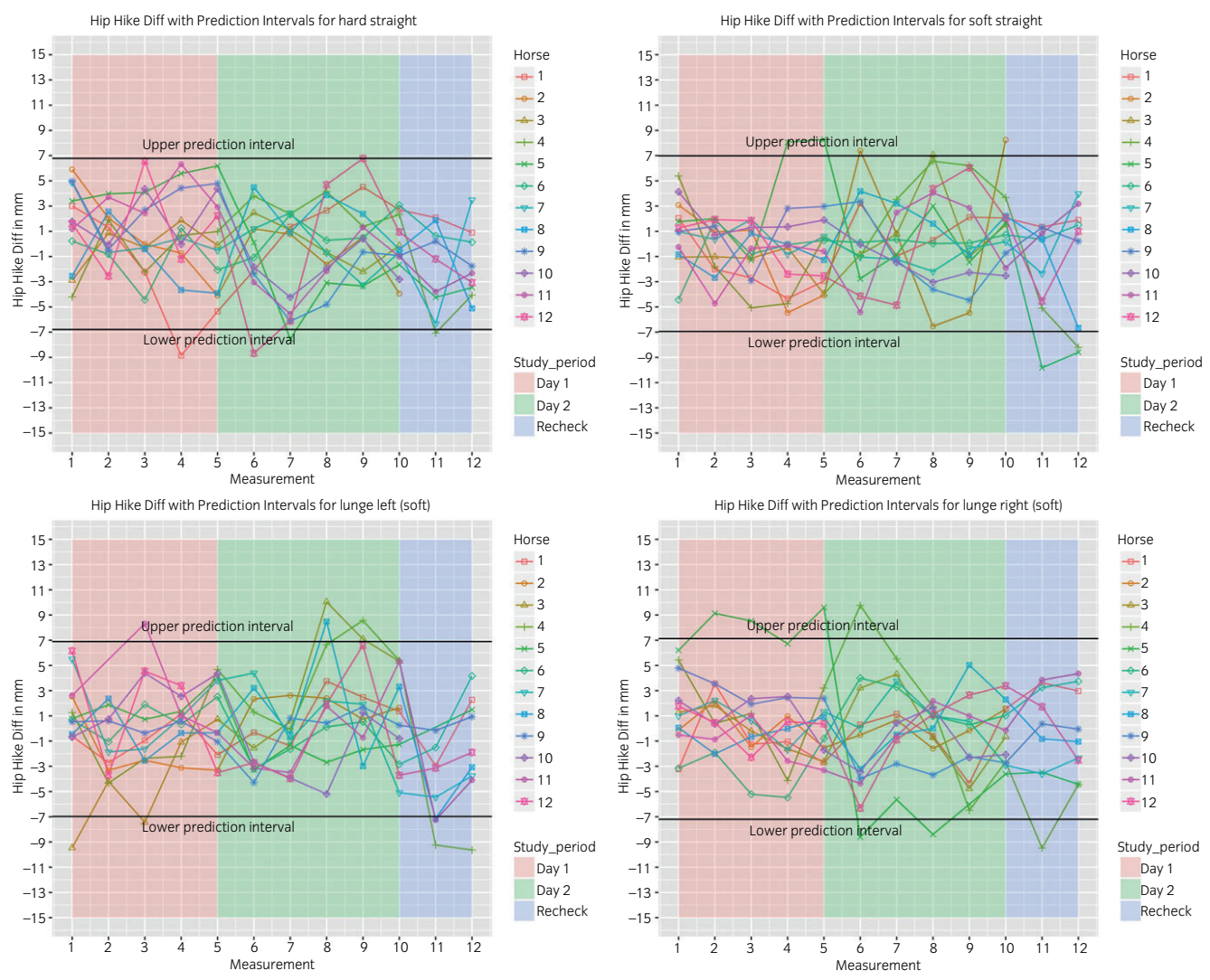

Fig 6. Between-measurement variation (Offset adjusted data) for 'Hip Hike Diff', per measurement, per day and per horse. Each plot contains one path (hard straight, soft straight, left lunge, right lunge). These data enable the evaluation of the between-measurement variation between and within horses and between and within days. 
Additionally, the horses were examined subjectively by a clinician and found to have a maximum lameness score of $1 / 5$ on the AAEP scale on the day before the first measurement. Grade 1 of the AAEP scale is described as: 'Lameness difficult to observe; not consistently apparent regardless of circumstances (e.g. weight carrying, circling, inclines, hard surface).' It was a deliberate choice to include this scale and not only horses with a grade 0 ('Lameness not perceptible under any circumstances'), because we wanted to include horses that would be representative of the sports horses population in general (in a recent study $75 \%$ of all sports horses in regular work, presumed to be sound by their owners, were subjectively graded as lame by an experienced clinician [14]).

For all measured symmetry parameters, the prediction intervals show a certain amount of between-measurement variation. However, between- measurement variation is higher for the head parameters compared to those of the pelvis and withers. This is also reflected in the ICC values mentioned above. This difference is in line with previous studies using body mounted accelerometers [9], in which asymmetry parameters of the pelvis on the straight line had better repeatability than head symmetry parameters.

A recent publication showed a lower variation in head parameters compared to our results [21]. Possible explanations are the differences in marker placement (our head cluster vs. a single poll sensor) and differences in filtering processes in our motion capture system compared to their sensor-based system. Our marker placement on the frontal plane introduces extra variation because of the flexion and extension of the atlantico-occipital joint many horses exhibit when moving. This motion is independent of the displacement of the poll along the Z-axis, which is the basis for the symmetry parameters.

For all measured anatomical locations, the MinDiff and MaxDiff variation was smaller compared to the RUD and RDD variation, which might be due to the differences in the method used to calculate these symmetry parameters; the MinDiff and MaxDiff consider either the highest or the lowest point of the sinusoidal curves, whereas the RUD and RDD comprise both. This is visualised in the Supplementary Item 3. Variation in the hiphike parameters, which also take into consideration the complete range of motion from minima to maxima, is of the same order as the RUD and RDD (Table 1).

These differences in the amount of between-measurement variation for the different parameters have to be considered, as different objective gait systems use different parameters and one can thus expect different amounts of betweenmeasurement variation. 
We did observe a tendency of increased between-measurement variation on day 2 and day 3, compared to day 1 . Overall, less variation is seen as the repetition increases during a day (for example, M4 and M5 have less variation compared to M1). This is true for all symmetry parameters, but not at all time points. This may be a training effect, although our study objects were accustomed to the measuring environment by a 5-min hand walk and a 10-min warming up on the lunge. This training effect has been described earlier on the treadmill [15]. For the clinical situation, one should consider this effect and take a, probably horse-specific, time to let them get familiar to the measuring environment, as these differences in between-measurement variation might also affect subjective gait evaluation, depending on the magnitude of these differences.

Less variation is seen on hard surface (straight line) compared to soft surface (straight line). We assume this has to do with the more even surface of the hard (tarmac) surface compared to the soft surface (a combination of sand and synthetic fibre). Horses probably need to compensate more for the soft surface, thereby showing more variation in their locomotion pattern and their symmetry parameters.

On the lunge, movement asymmetries are forcibly induced by the circular path [7]. Whether the total amount of between-measurement variation on the lunge would be different compared to the straight had not been investigated yet.

More variation is seen on the circle compared to the straight line. We hypothesise that this might be due to horses experiencing more freedom to change their own speed, circle diameter and body direction on the lunge compared to the straight line. In our circle data, a slight reduction of the average speed over time was observed (comparison not shown), supporting this finding. It might also be more difficult for the handler to perform continuously the same circle speed and diameter between measurements and specially, between days. It is known that these factors affect the degree of measured asymmetry [16].

Nevertheless, the average ICC values for the lunge are higher, indicating less withinhorse variation on the circle compared to the straight line.

The symmetry of both peak vertical displacement and acceleration of the withers is high in sound horses [17]. This symmetry was shown to decrease as a result of lameness induction [17]. This study demonstrated that the between-measurement variation of the withers is similar to the pelvis, where a lower between-measurement variation was found compared to the head parameters (Table 1, Figs 3-6). 
We hypothesise that the higher between-measurement variation of all head parameters compared to the withers might be a consequence of the relatively high freedom of movement of the head (allowed by the neck) when compared to the withers and pelvis. This high degree of head movement allows the horse to react quickly and with a relatively large amplitude of motion to external stimuli (such as the handler), thus increasing variation in movement symmetry. This difference between anatomical locations has been pointed out earlier in studies with horses in different head and neck positions $[18,19]$. Some handler effect is inevitable; as the handler will always to a certain extent influence head and neck position and thus head motion. In our study, we tried to minimise this effect as far as possible by letting the horses get accustomed to the test environment and by using the same handler during the entire experiment.

The lower between-measurement variation of the withers markers compared to the head markers might make it a good candidate aiding in the quantification of forelimb lameness [20].

The substantially higher between-horse variation compared to the within-horse variation emphasises the consistency of the locomotion pattern of individual horses, which gives the clinician the obvious possibility to compare the horse with itself over repeated measurements (Supplementary Items 6 and 7).

Previous studies have proposed thresholds to distinguish between sound and lame horses using a sensor-based system as being $6 \mathrm{~mm}$ for the vertical displacement of the head and $3 \mathrm{~mm}$ for the pelvis [22,23]. These values are lower than the variation measured with our optical motion capture system. Whereas the use of fixed thresholds for lameness detection can be questioned anyhow [13], the observation underlines that sharply delineated 'universal thresholds' can never be established. Differences in outcome are not only influenced by horse- related factors, but also by system specifications. A previous study concluded that, when comparing two sensor-based systems, differences in average asymmetry values could be related to differences in sensor hardware, filtering technique, the processing algorithms that derive displacements from the recorded acceleration signals, and the stride detection technique [21]. When using optical motion capture, there are comparable technical factors possible that affect the outcome. Standardisation can help here. A recent study showed that, when similar filtering and data processing techniques are applied to both optical motion capture and sensor-based systems synchronously, a good agreement between the two can be found [24]. 
It should be kept in mind that, when measuring horses on different locations and at different time points, the practical measurement conditions (i.e. the environment) can also influence outcome and thereby the variation, like the technical aspects alluded to above. These environmental factors include effects on the head and neck position of the horse (by the influence of the handler) $[18,19]$, surface, the demeanour of the horse [25], circle size [16], speed [6,16] and probably warming-up. Besides, one could expect more between-stride variation in the MinDiff and Maxdiff if the surface is uneven, for example.

When taking all these factors into account, one could still have a poor quality measurement due to unexpected influences (anxious horse, noise from outside). The authors would recommend repeating such measurements or increase the number of collected strides. In that way, variability can be limited to a maximal extent, which is preferable to handling a high stride-to-stride variability with a forcibly less accurate mean trial value and high standard deviation. Use of such data can be compared to interpreting bad quality radiographs.

Clinicians should be aware of all these potential influences and outcomes when performing objective gait analysis and/or interpreting data captured elsewhere.

This study has several limitations. The study was performed on a small population of sports horses. Due to limitations of the study location, horses were before inclusion only evaluated on the straight on a soft surface, which is uncommon in clinical practice. Hard surface circles were not included which are nevertheless commonly performed in the clinical situation.

\section{Conclusion}

This study provides data on the variation between measurements in symmetry parameters which can be introduced by the fact that in orthopaedic work-ups, repeated measuring under different conditions and at different moments is common practice. Repeated measuring was performed at different time intervals on the same day, on consecutive days and after a longer time interval. Measurements were performed on hard and soft surface, on the straight line and on the lunge.

More variation was seen on the first day compared to the second and third measurement day. In general, less variation was seen with increasing number of repetitions. Also, less variation was seen on hard surface (straight line) compared to 
soft surface (straight line) and more variation on the circle compared to the straight line. The variation within a horse was significantly smaller than the variation between horses.

The results are important for all use of quantitative gait analysis systems and ideally similar studies should be performed with other systems, as this information is a prerequisite for the proper clinical interpretation of data from this type of equipment. 


\section{Authors' declaration of interests}

No competing interests have been declared.

\section{Ethical animal research}

Research ethics committee oversight not required by this journal: noninvasive observational study.

\section{Owner informed consent}

Owners gave consent for their animals' inclusion in the study.

\section{Sources of funding}

None.

\section{Acknowledgements}

The authors would like to sincerely thank the owners of the horses and staff of 'Tierklinik Luesche' for their assistance.

\section{Authorship}

A.M. Hardeman and F. Serra Braganc.a contributed to planning the experiment, data processing, statistics and preparation of the manuscript.

L. Roepstorff contributed to planning the experiment, data collection and preparation of the manuscript. J. Hein Swagemakers and R. van Weeren contributed to planning of the experiment and preparation of the manuscript. All authors have approved the final version of the manuscript.

\section{Manufacturers' addresses}

a Qualisys AB, Motion Capture Systems, Go€teborg, Sweden.

${ }^{\mathrm{b}}$ R-Studio, Boston, Massachusetts, USA.

\section{Supporting Information}

Additional Supporting Information may be found in the online version of this article at the publisher's website:

Supplementary Item 1: Description of the horses used in the study.

Supplementary Item 2: Time schedule of all measurements.

Supplementary Item 3: Visualisation of the symmetry parameters.

Supplementary Item 4: Baseline asymmetry (M1) of each horse. Supplementary Item 5: Model estimates square root transformed for the between measurement 'absolute deviation'.

Supplementary Item 6: Betweenmeasurement-variation (non offset data) for MinDiff head, withers and pelvis. Supplementary Item 7: Betweenmeasurement-variation (offset data) for MinDiff head, withers and pelvis. 


\section{References}

1. Serra Braganc.a, F.M., Rhodin, M. and van Weeren, P.R. (2018) On the brink of daily clinical application of objective gait analysis: what evidence do we have so far from studies using an induced lameness model? Vet. J. 234, 11-23.

2. Dyson, S. (2014) Recognition of lameness: man versus machine. Vet. J. 201, 245-248.

3. Arkell, M., Archer, R.M., Guitian, F.J. and May, S.A. (2006) Evidence of bias affecting the interpretation of the results of local anaesthetic nerve blocks when assessing lameness in horses. Vet. Rec. 159, 346-349.

4. Parkes, R.S.V., Weller, R., Groth, A.M., May, S. and Pfau, T. (2009) Evidence of the development of "domain-restricted" expertise in the recognition of asymmetric motion characteristics of hindlimb lameness in the horse. Equine Vet. J. 41, 112-117.

5. Keegan, K.G. (2007) Evidence-based lameness detection and quantification. Vet. Clin. N. Am.: Equine Pract. 23, 403-423.

6. Starke, S.D., Raistrick, K.J., May, S.A. and Pfau, T. (2013) The effect of trotting speed on the evaluation of subtle lameness in horses. Vet. J. 197, 245-252.

7. Rhodin, M., Roepstorff, L., French, A., Keegan, K.G., Pfau, T. and Egenvall, (2015) Head and pelvic movement asymmetry during lungeing in horses with symmetrical movement on the straight. Equine Vet. J. 48, 315-320.

8. Poore, L.A.B. and Licka, T.L. (2011) A quantitative review of the equinalysis system for equine locomotion analysis. J. Equine. Vet. Sci. 31, 717-721.

9. Keegan, K.G., Kramer, J., Yonezawa, Y., Maki, H., Frank Pai, P., Dent, E.V., Kellerman, T.E., Wilson, D.A. and Reed, S.K. (2011) Assessment of repeatability of a wireless, inertial sensor-based lameness evaluation system for horses. Am. J. Vet. Res. 72, 1156-1163.

10. AAEP. (1999) Guide to Veterinary Services for Horse Shows, 7th edn., American Association of Equine Practitioners, Lexington, $\mathrm{KY}$.

11. Kramer, J., Keegan, K.G., Kelmer, G. and Wilson, D.A. (2004) Objective determination of pelvic movement during hind limb lameness by use of a signal decomposition method and pelvic height differences. Am. J. Vet. Res. 65, 741-747.

12. Starke, S.D., Willems, E., May, S.A. and Pfau, T. (2012) Vertical head and trunk movement adaptations of sound horses trotting in a circle on a hard surface. Vet. J. 193, 73-80.

13. van Weeren, P.R., Pfau, T., Rhodin, M., Roepstorff, L., Serra Braganc.a, F. and Weishaupt, M.A. (2017) Do we have to redefine lameness in the era of quantitative gait analysis? Equine Vet. J. 49, 567-569.

14. Dyson, S. and Greve, L. (2016) Subjective gait assessment of 57 sports horses in normal work: a comparison of the response to flexion tests, movement in hand, on the lunge, and ridden. $J$. Equine. Vet. Sci. 38, 1-7.

15. Buchner, H.H.F., Savelberg, H.H.C.M., Schamhardt, H.C., Merkens, H.W. and Barneveld, A. (1994) Habituation of horses to treadmill locomotion. Equine Vet. J. 26, Suppl. 17, 13-15.

16. Pfau, T., Stubbs, N.C., Kaiser, L.J., Brown, L.E.A. and Clayton, H.M. (2012) Effect of trotting speed and circle radius on movement symmetry in horses during lunging on a soft surface. Am. J. Vet. Res. 73, 1890-1899.

17. Buchner, H.H., Savelberg, H.H., Schamhardt, H.C. and Barneveld, A. (1996) Head and trunk movement adaptations in horses with experimentally induced fore- or hindlimb lameness. Equine Vet. J. 28, 71-76.

18. Rhodin, M., A lvarez, C.B.G., Bystro€m, A., Johnston, C., Weeren, P.R., Roepstorff, L. and Weishaupt, M.A. (2009) The effect of different head and neck positions on the caudal back and hindlimb kinematics in the elite dressage horse at trot. Equine Vet. J. 41, 274-279. 
19. Waldern, N.M., Wiestner, T., Peinen, K., A Ivarez, C.G.G., Roepstorff, L., Johnston, C., Meyer, H. and Weishaupt, M.A. (2009) Influence of different head-neck positions on vertical ground reaction forces, linear and time parameters in the unridden horse walking and trotting on a treadmill. Equine Vet. J. 41, 268-273.

20. Rhodin, M., Persson-Sjodin, E., Egenvall, A., Serra Bragan.ca, F.M., Pfau, T., Roepstorff, L., Weishaupt, M.A., Thomsen, M.H., van Weeren, P.R. and Hernlund, E. (2018) Vertical movement symmetry of the withers in horses with induced forelimb and hindlimb lameness at trot. Equine Vet. J. 50, 818-824.

21. Sepulveda Caviedes, M.F., Forbes, B.S. and Pfau, T. (2018) Repeatability of gait analysis measurements in Thoroughbreds in training. Equine Vet. J. 50, 513-518.

22. Keegan, K.G., MacAllister, C.G., Wilson, D.A., Gedon, C.A., Kramer, J., Yonezawa, Y., Maki, H. and Frank Pai, P. (2012) Comparison of an inertial sensor system with a stationary force plate for evaluation of horses with bilateral forelimb lameness. Am. J. Vet. Res. 73, 368-374.

23. Keegan, K.G., Wilson, D.A., Kramer, J., Reed, S.K., Yonezawa, Y., Maki, H., Pai, P.F. and Lopes, M.A.F. (2013) Comparison of a body-mounted inertial sensor system-based method with subjective evaluation for detection of lameness in horses. Am. J. Vet. Res. 74, 17-24.

24. Bosch, S., Serra Braganc.a, F., Marin-Perianu, M., Marin-Perianu, R., van der Zwaag, B., Voskamp, J., Back, W., van Weeren, R. and Havinga, P. (2018) Equimoves: a wireless networked inertial measurement system for objective examination of horse gait. Sensors 18, 850 .

25. Lo pez-Sanrom an, F.J., Holmbak-Petersen, R., Santiago, I., Go mez de Segura, I.A. and Barrey, E. (2012) Gait analysis using 3D accelerometry in horses sedated with xylazine. Vet. J. 193, 212-216. 


\section{Adaptation strategies of horses with induced forelimb lameness walking on a treadmill}

F.M. Serra Bragança ${ }^{1 *}$, E. Hernlund ${ }^{2}$, M.H. Thomsen ${ }^{3}$, N.M. Waldern ${ }^{4}$, M. Rhodin'2, A. Byström², P.R. van Weeren', and M.A. Weishaupt ${ }^{4}$

${ }^{1}$ Department of Equine Sciences, Faculty of Veterinary Medicine, Utrecht University, Yalelaan 112 114, NL-3584 CM Utrecht, The Netherlands

${ }^{2}$ Department of Anatomy, Physiology and Biochemistry, Swedish University of Agricultural Sciences, S-750 07 Uppsala, Sweden

${ }^{3}$ Department of Veterinary Clinical Sciences, Faculty of Health Sciences, University of Copenhagen, Hoejbakkegaard alle 5, DK-2630 Taastrup, Denmark

${ }^{4}$ Equine Department, Vetsuisse Faculty, University of Zurich, CH-8057 Zurich, Switzerland

* Corresponding author. Tel.: 0031302533856

E-mail address: * f.m.serrabraganca@uu.nl 


\section{Authorship}

M.A. Weishaupt, M. Rhodin, M.H.

Thomsen, N.M. Waldern, and E. Hernlund designed and executed the study. F.M.

Serra Bragança, M.A. Weishaupt, and E. Hernlund analysed the data, interpreted the results and prepared the manuscript. All authors revised the manuscript critically and gave the final approval of the manuscript.

\section{Ethical considerations}

The experimental protocol was approved by the Animal Health and Welfare Commission of the canton of Zürich (permission number 51/2013) and informed consent for data collection was obtained from the horse owners prior to the study.

\section{Acknowledgements}

The authors would like to thank Lea Bächi-Ramseier, Vera Kubli, Porrakote Rungsri and Pitiporn Leelamankong for the assistance running the experiment. We would also like to sincerely thank Thomas Wiestner, Lars Roepstorff and Martin Holmberg for all professional help with technical equipment and measurements during the study

\section{Conflicts of interest}

The authors have declared no competing interests.

\section{Sources of funding}

The Swedish Research Council Formas funded the study.

\section{Data Accessibility Statement}

All relevant data are within the manuscript and its Supporting Information files. 


\section{Summary}

Background: There is a paucity of research describing the gait pattern of lame horses at the walk.

Objectives: To describe the changes in motion pattern and vertical ground reaction forces (GRFz) in horses with induced forelimb lameness at the walk and compare those changes with the changes observed at the trot.

Study Design: Experimental study.

Methods: In 10 clinically sound Warmblood horses, moderate forelimb lameness was induced using a sole pressure model followed by walk and trot on a treadmill. Kinematic data were collected using 3D optical-motion-capture, and GRFz by an instrumented treadmill. Mixed models were used to compare sound baseline versus forelimb lameness (significance was set at $p<0.05$ ).

Results: Lameness induction significantly reduced peak GRFz on the second force peak, and vertical impulse in the lame limb. Stride and stance duration in all limbs were reduced. Lameness significantly affected the vertical movement symmetry of the head and withers. Maximal retraction angle, fetlock extension and protraction speed were reduced in the lame limb. Body centre of mass translation was reduced in the side-to-side direction and increased in the vertical and fore-aft directions. Several compensatory kinetic and kinematic changes were observed in the non-lame limbs. The observed changes in both kinetics and kinematics were generally smaller at walk with fewer variables being affected, compared to the trot.

Main Limitations: Only one degree and type of orthopaedic pain (sole pressure) was studied.

Conclusions: Compensatory strategies of forelimb lameness at the walk include alteration of several kinetic and kinematic parameters and show some specific patterns and inter-individual differences that are not seen at the trot. However, much like at the trot, the head movement and forelimb vertical force symmetry seems to be the most useful parameters to detect forelimb lameness. 


\section{Introduction}

Movement symmetry parameters at the trot are the main tools for subjective and objective gait assessment in the horse. Several kinetic and kinematic parameters have been validated as clinically relevant lameness indicators [1]. These include vertical ground reaction forces [2] and symmetries of the vertical excursions of the head, withers and pelvis [3] and reflect compensatory mechanisms generally related to load redistribution [4-6].

At the walk, compensatory strategies for lameness are not well understood and no specific gait parameters have yet been proposed for clinical use. However, lameness evaluation at the walk can be essential in horses with conditions prohibiting the support of loads associated with trot, e.g. in the immediate post-surgical period. A head and neck nod has been described as a visual indicator of forelimb lameness in horses. Also, some locomotor disorders due to mechanical or neurological pathology may manifest more obviously at walk [7]. It has even been suggested that gait analysis at the walk may be more sensitive in detection of subtle lameness than trot [8]. Despite this, kinematic and kinetic variables suitable for objective lameness detection at walk have received little attention. In one study on single supporting limb lameness at walk the reported results were decreased vertical ground reaction force (GRFz) in the lame limb, compensated by an increased GRFz in the remaining limbs. Also a reduction of the horizontal ground reaction force (GRFy) in the lame limb with increased GRFy in the contralateral and ipsilateral hindlimb were seen [9]. In another experiment stride and stance duration, joint angles and head movement adaptations were changing in a similar way in both walk and trot, but to a lesser extent at the walk. Vertical movement symmetry indices of withers and croup were deemed not useful as lameness indicators for walk, as the changes were too small [3].

While the trot is a diagonal gait with a suspension phase, the walk is a four-beat, symmetric gait without suspension. At the walk diagonal and ipsilateral bipedal support alternate with tripedal support phases. The withers and croup are raised and lowered out of phase, with the highest position of the withers occurring at mid stance of each forelimb and for the croup at mid stance of each hindlimb [3]. The head is raised and lowered out of phase with the withers and in phase with the croup, which is seen as an energy conserving mechanism [10]. The vertical ground reaction force curve has a double-peak shape with the dip coinciding with fore-/hindlimb midstance [11]. This pattern is best explained by a spring-mass model with overlaps of contralateral limb support [12]. 
Because of the differences in gait mechanics between walk and trot it can be presumed that lameness has a different influence on the two gaits. The aim of this study was to get a better insight into the changes in motion pattern and vertical ground reaction forces in horses with induced forelimb lameness at the walk. We specifically aimed to identify kinematic and kinetic variables with a reasonable sensitivity and specificity to discriminate between lame and non-lame measurements that can be further explored for objective assessment at the walk in clinical lameness cases.

\section{Material and methods}

\section{Horses}

The data set used for this study was collected during experimental sessions described earlier [13]. In short, ten horses were included in this study and all were considered clinically sound when examined by a veterinarian surgeon experienced in orthopaedic exams (MAW). All were Warmblood geldings with an age range of 5-21 years and a mean height at the withers of $169 \pm 6.3 \mathrm{~cm}$ (range 161-180 cm). Horses were trained regularly and used in jumping and/or dressage competitions at amateur level. Prior to the experiment, horses were fully accustomed to the treadmill and experimental setup [14].

\section{Lameness induction}

Each horse was shod with modified horseshoes having M10 nuts welded to the inner rim of each branch [15]. Before nailing on the shoes, the soles were cleaned and trimmed to a consistent thickness. Lameness was induced by screwing bolts with flat tips into the nuts, thereby using pressure to induce a nociceptive stimulus to the corium of the sole. The procedure was controlled using a torque meter with 0.1 $\mathrm{Nm}$ increments (Type 757, Rahsol Dremotec1) to ensure that the same torque was applied to the medial and lateral half of the hoof. The goal was to induce different degrees of reversible supporting lameness in each horse, evaluated subjectively by 2 experienced clinicians (MHT, MAW) using the following convention: degree $1 / 5$ (subtle lameness), irregularity not visible on every stride at the trot degree $2 / 5$ (mild lameness), visible on every stride at the trot degree 3/5 (moderate lameness), distinctly visible on every stride at the trot but without obvious disturbance to the cadence of movement. 


\section{Data collection}

Kinetic data were collected with an instrumented treadmill (Mustang 2200²) [16]; kinematic data were recorded with 10 infra-red 3D optical motion capture (OMC) cameras (Oqus $300+{ }^{3}$ ) that registered the positions of 52 skin mounted spherical reflective markers. For detailed marker placement, see Supplementary Item 1. Both measurement systems were synchronized in time using hardware-based synchronization. Sampling frequency was set at $512 \mathrm{~Hz}$ for force and $256 \mathrm{~Hz}$ for OMC data. Data collection lasted 20 seconds for each trial. Measurements were taken at the horse's preferred speed which was set based on visual assessment of locomotion regularity.

Before lameness induction, each horse was subjected to a baseline measurement at walk and trot. Subsequently, the 3 lameness degrees were induced successively and measured at the same gait speed as the baseline measurements. The trot measurement with the highest lameness degree was immediately followed by a measurement at walk. Left and right limb lameness were induced on the same day in random order; the lameness induction trial in the contralateral limb took place as soon as kinetic data had returned to baseline values.

\section{Data processing}

The ground reaction force (GRF) exerted by each limb during stance was calculated by the treadmill software (HP2, \{blinded for peer review\}).) as previously described [16]. During the measurements, the three-dimensional coordinates of each marker were automatically tracked by the motion capture software (QTM, version 2.9) ${ }^{3}$. Complete data sets were exported to Matlab2018b4 for further analysis using custom-written scripts. Force parameters were normalized to horse body mass. Stride segmentation was performed using the hoof-on moments of the left forelimb. The beginning and end of stance phase of each limb was determined by the intersection of the linear approximation to the initial and terminal slope of the force curve with the zerobaseline [16]. The inbuilt speedometer registered treadmill belt speed.

An overview of the measured or calculated temporal, kinetic and kinematic variables is presented in Table 1. Variables included in the analysis were selected based on previous publications investigating induced lamenesses at walk and trot [1-3,5,17-20].

\section{Selection of left or right measurement trial:}

To ensure that the most relevant trials were submitted to statistical analysis, one trot trial per horse and the corresponding walk trial was selected based on (1) the larger difference in minimum head position between left and right stride half-cycle 
(MinDiff), and (2) the larger difference in peak vertical forces between front limbs measured at trot, since these two parameters have been shown to be well correlated to forelimb lameness [1].

For the purposes of this manuscript, only the baseline data and the data of the highest degree of induced forelimb lameness at walk and trot (3/5) of each horse were used. Symmetry parameters from right forelimb lameness were multiplied by -1 to mirror the indices and thus categorize all data as if they were derived from left limb inductions only, reported as results of the 'lame' (left front) limb.

\section{Dynamics of the centre of force at walk}

In order to better understand the compensatory load redistribution between limbs in weight bearing lameness at walk, the centre of force (COF) relative to the horse's centre of mass (COM) was calculated. The approximate position of the COM was calculated based on the method previously described by Buchner et al. [21] using solely the $3 \mathrm{D}$ coordinates of the markers located at the sternum and the dorsal spinal process of the lumbar vertebra L3 [22]. For calculating COF, both force and OMC data were used, and OMC data was resampled to match the frame rate of the force data. For each frame, the relative COF was calculated as:

$$
C O F_{x, y}=\frac{\left(L F_{F z} * L F_{x, y}\right)+\left(R F_{F z} * R F_{x, y}\right)+\left(L H_{F z} * L H_{x, y}\right)+\left(R H_{F z} * R H_{x, y}\right)}{L F_{F z}+R F_{F z}+L H_{F z}+R H_{F z}}
$$

where $L F=$ left front limb, RF = right front limb, LH = left hind limb, RH = right hind limb, Fz = vertical ground reaction force and $(x, y)=$ hoof position in the horizontal plane, relative to the treadmill coordinate system.

\section{Statistical analysis}

In order to identify the temporal, kinetic and kinematic variables that on a group level would be likely to be associated to lameness at the walk, sensitivity and specificity of the variables listed in Table 1 were calculated on a horse level. Thereafter, parameters with high sensitivity and specificity on a group level were investigated by averaging the sensitivity and specificity of all horses. This approach avoided investigating parameters with a very high inter-individual variation and also allowed to explore the individual pattern for movement adaptation and load redistribution strategy of each horse. 


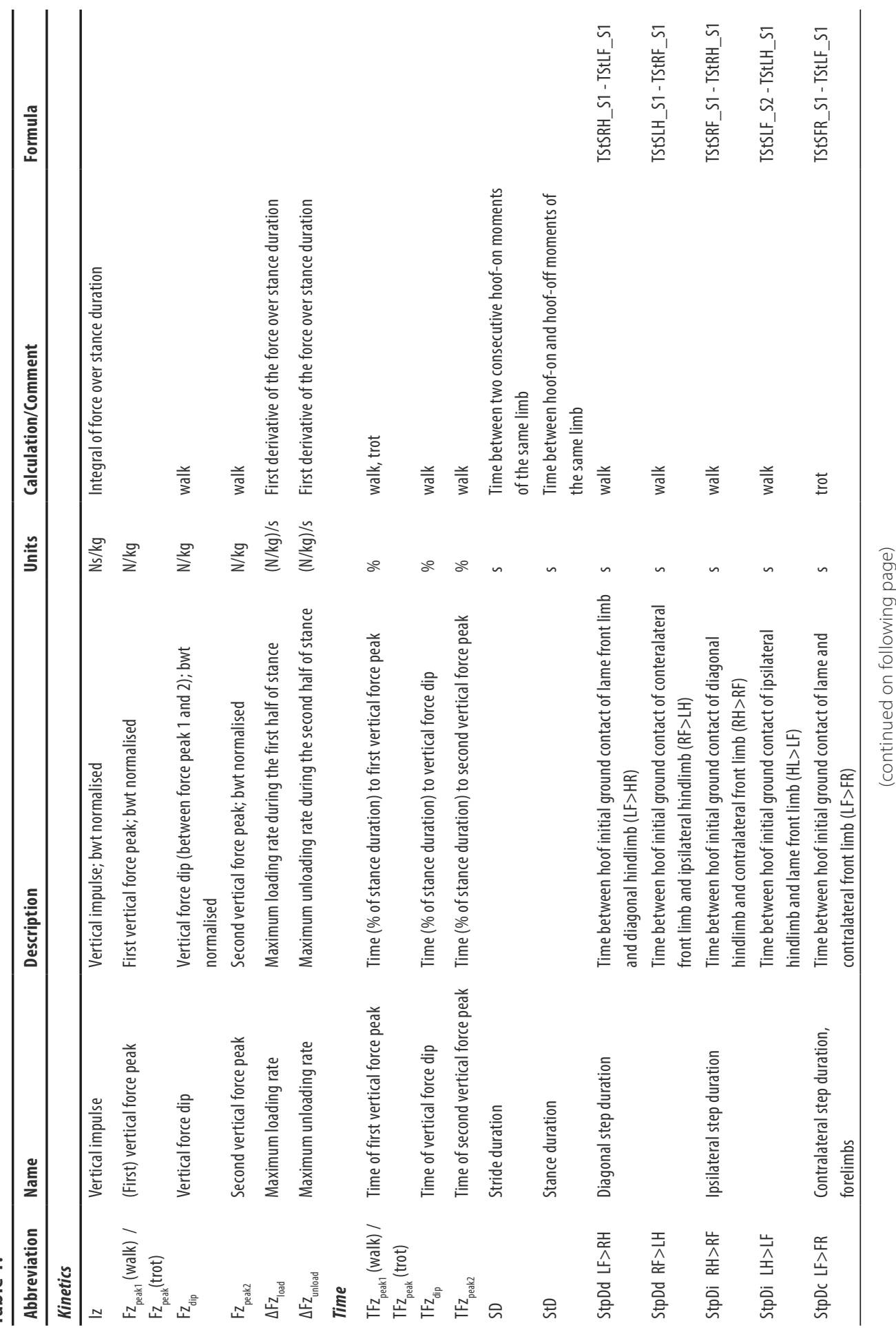




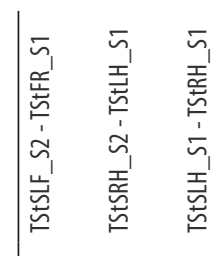

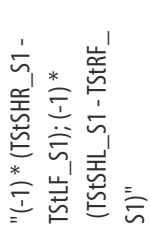

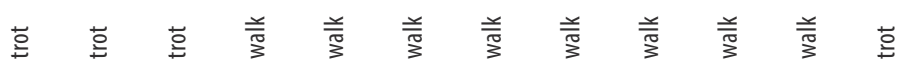

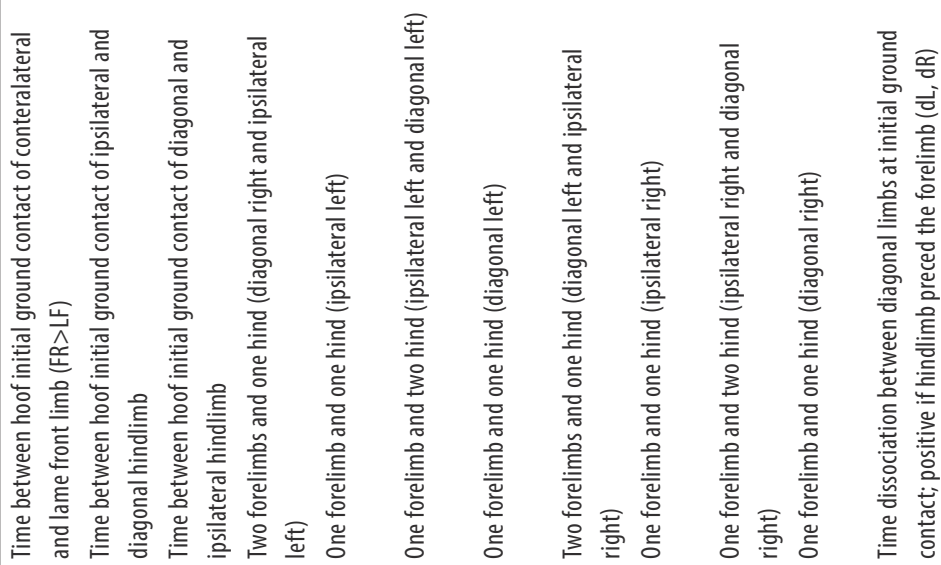

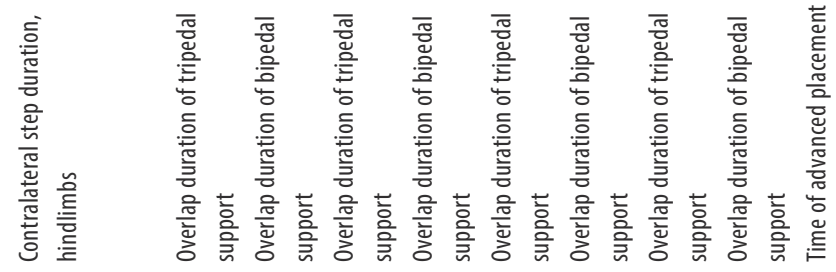

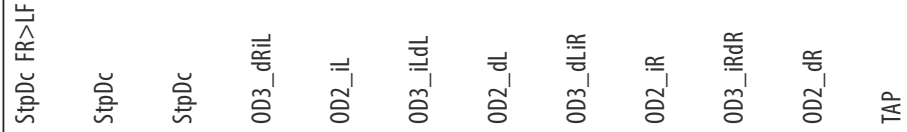




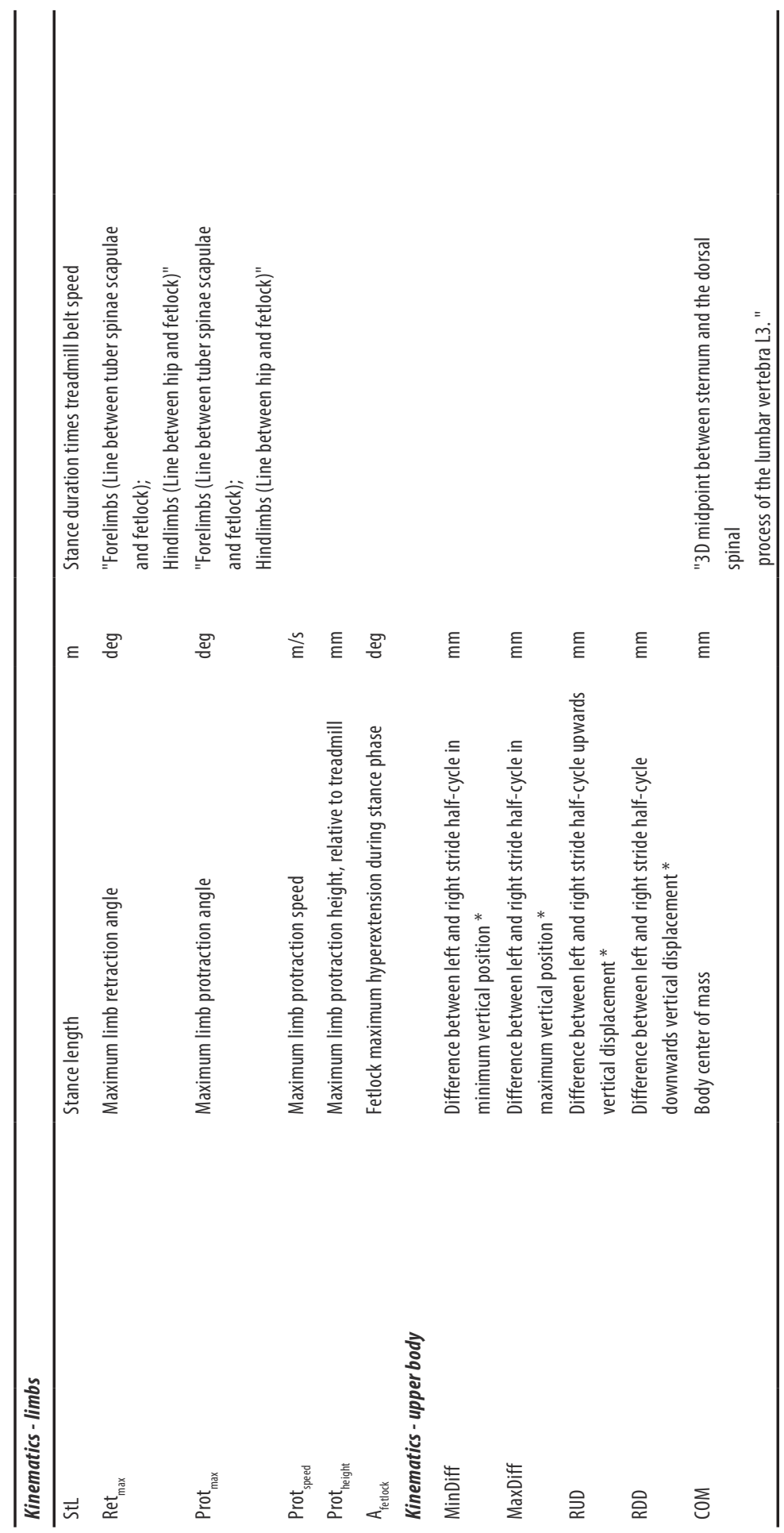


In order to compare between walk and trot, variables were preferentially selected which could be calculated for both gaits. The sensitivity and specificity were calculated in R-studio ${ }^{5}$ with the package pROC (version 1.10.0) using all collected strides from each horse, for walk and trot separately. The results were plotted in a heat map (Figs 1-2) for visual review. The parameters with the highest sensitivity and specificity on a group level were selected for further modelling.

Linear mixed models were created with each variable selected based on the sensitivity and specificity analysis as outcome. Stride level data for these variables were entered into the model from the baseline measurements and the induced lameness measurement at walk and trot from each horse. The models were calculated in R-studio ${ }^{5}$ using the package Ime4 (version 1.1-15). In each model, horse was used as a random effect and the lameness condition (not lame = baseline and lame = induction) as fixed effect. Model fit was evaluated using q-q plots and box-plots of the residuals. Model estimates were represented as least square means. P-values were adjusted for multiple comparison using the Bonferroni correction.

\section{Results}

The average walking speed was $1.68 \mathrm{~m} / \mathrm{s}$ (range $1.57-1.79 \mathrm{~m} / \mathrm{s}$ ) and the average trotting speed was $3.87 \mathrm{~m} / \mathrm{s}$ (range 3.78-3.94 m/s). For the walk, an average of 14.6 strides (range 11-17 strides) and for the trot trials, an average of 24 strides (range 1529 strides) were used for statistical analysis. One lameness induction from one horse was lost due to a technical problem. For this subject, only the available induction (right front limb) and baseline measurements were used in the analysis. For the trials used in the statistical analysis, the lameness scores at the trot were in average 2.7 .

\section{Temporal parameters}

The effect of induced lameness at walk and trot on temporal parameters is summarised in Table 2. Significant changes in stride temporal parameters at walk included a reduction of stride duration (SD; -2.05\%), reduction of absolute stance duration $\left(S t D_{a b s}\right)$ in all four limbs (more pronounced in the front limbs), a delay of the occurrence of the first force peak (+8.4\%) in the lame forelimb and in both hindlimbs as the most prominent observed changes. Other variables were also observed to change on an individual level (Fig 1) reflecting a more individual pattern of compensation. SD was shortened at both walk and trot with induced lameness. In contrast to the walk, StD ${ }_{\text {abs }}$ at the trot increased, in the lame and contralateral front limb. Relative stance duration (duty factor, $S_{t} D_{\text {rel }}$ ) increased only slightly by $+0.4 \%$ at 


\section{Walk}

Trot

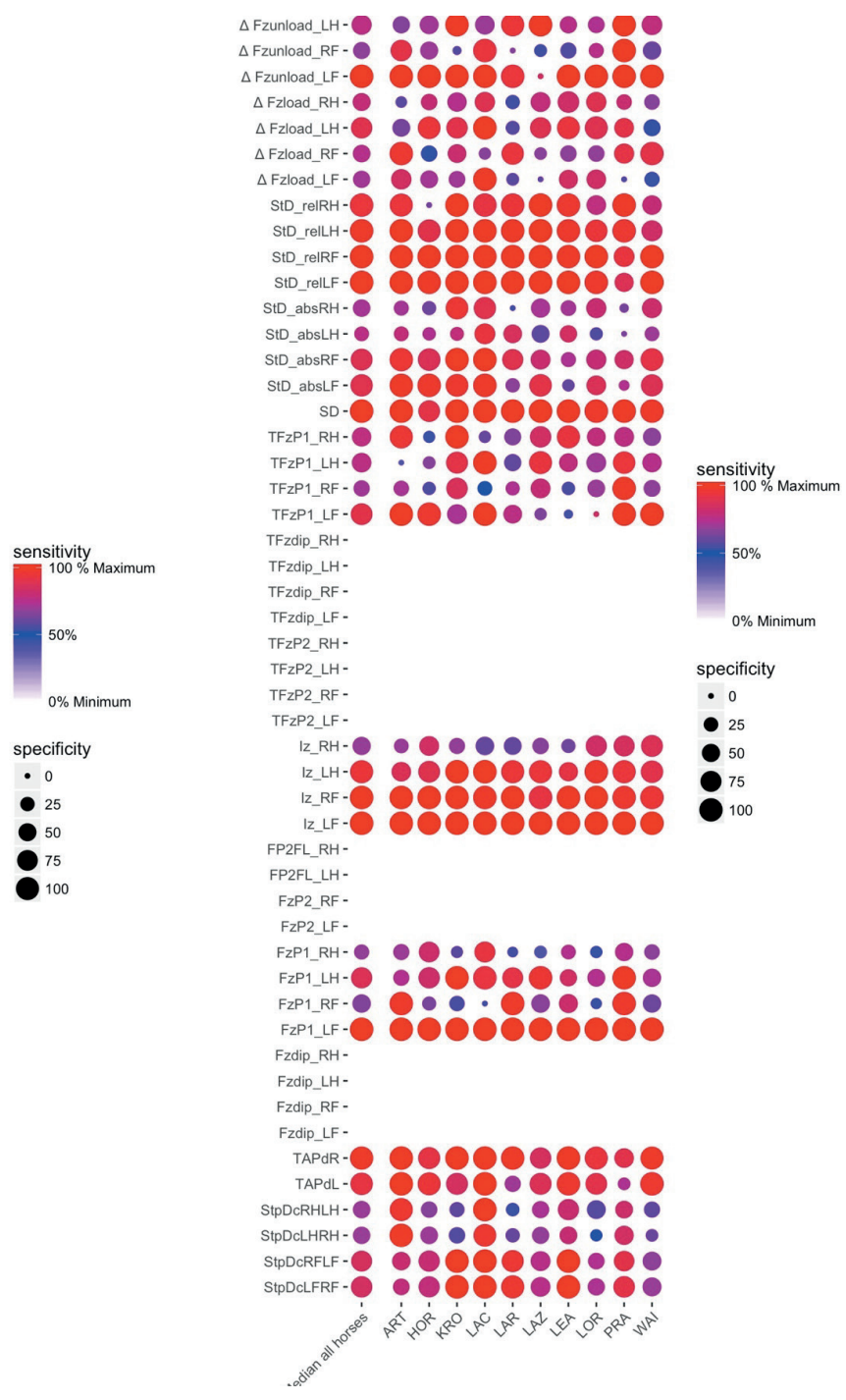

specificity

- 0

- 25

- 50

75

100

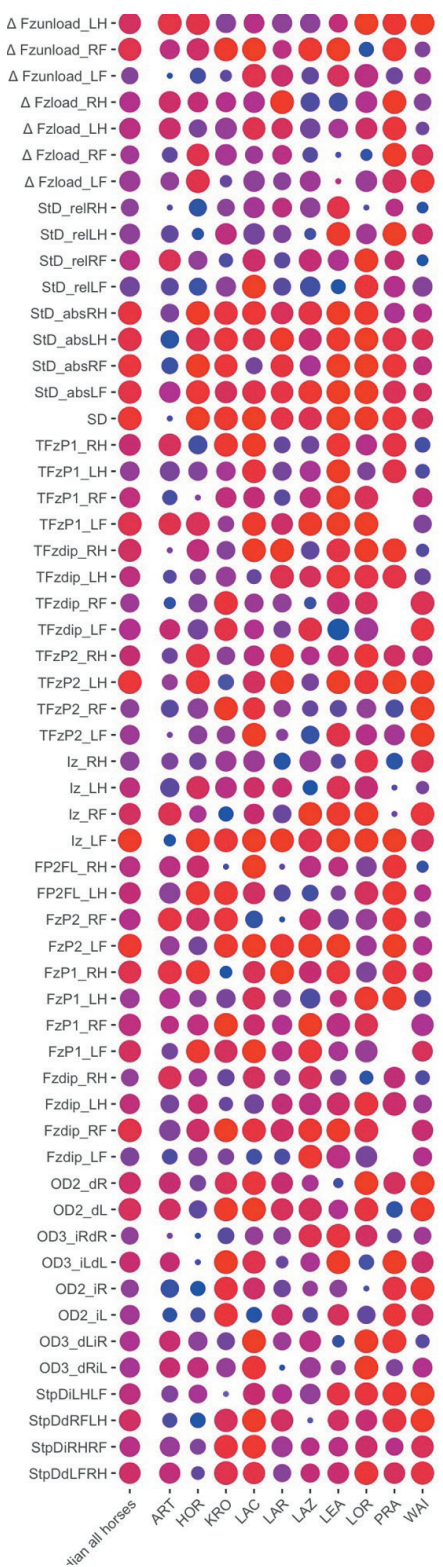

Figure 1. Heat map for the kinetic variables at walk (left) and trot (right). Each variable is located on the $y$-axis and each horse on the x-axis. Sensitivity is described by the colour pallet and specificity by the size of each dot. For variable names, please refer to table 1. 


\section{Walk}

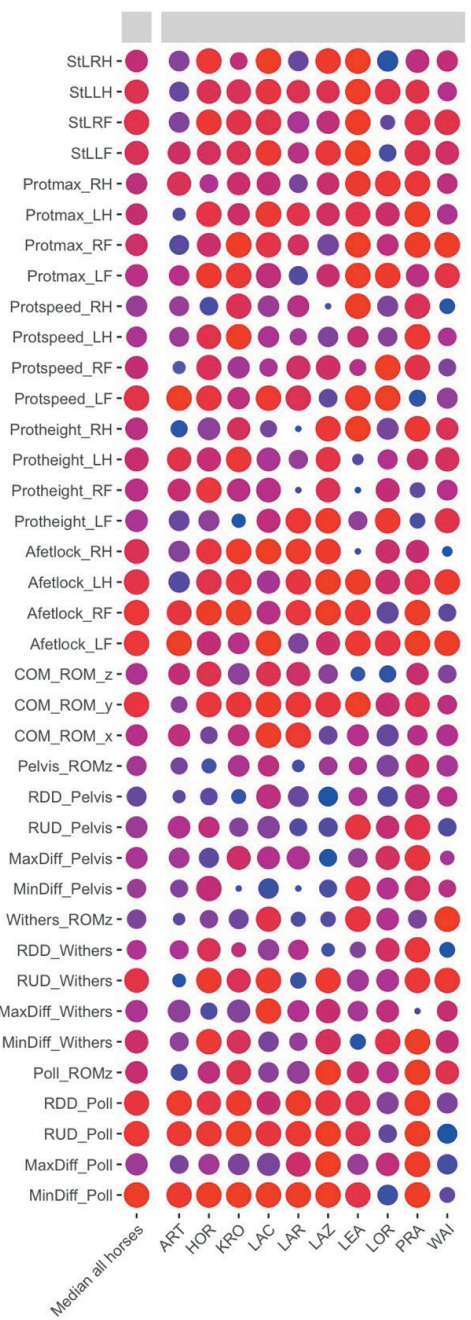

\section{Trot}

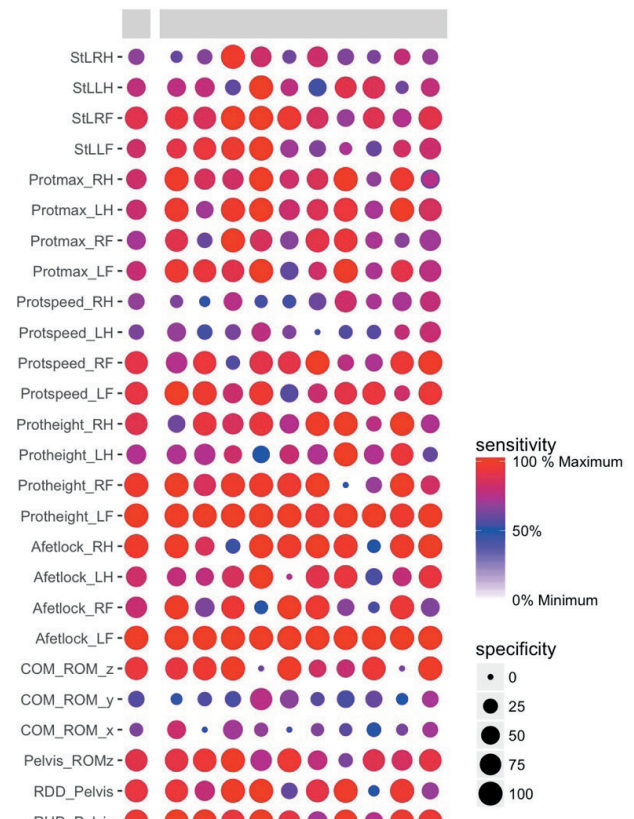
MaxDiff_Pelvis - 0000000000 MinDiff_Pelvis- 00000 Withers_ROMz-O 00000 RDD_Withers - 000000000 RUD_Withers - 000000000 MaxDiff_Withers - 000000000 MinDiff_Withers - 0000000000 Poll_ROMz-O 000000000 RDD_Poll-O 0000000000 RUD_Poll-O 0000000000 MaxDiff_Poll-O 000000000 MinDiff_Poll-O 100000000 sen

Figure 2. Heat map for the kinematic variables at walk (left) and trot (right). Each variable is located on the $y$-axis and each horse on the x-axis. Sensitivity is described by the colour pallet and specificity by the size of each dot. For variable names, please refer to table 1. 
the walk on the lame limb and ipsilateral hindlimb whilst at the trot, StD rel had a more pronounced increase on all four limbs, mainly on both front limbs $(+5.5 \%)$.

The inter-limb step duration at walk was mainly affected in terms of the decreased duration between ipsilateral hindlimb and lame front limb impacts, and increased duration between diagonal hindlimb and contralateral front limb impacts (see StpDi in Table 2). At trot, the main observed change in inter-limb timing was a reduction of the step duration between the lame limb and contralateral front limb (StpDc). The time dissociation between hoof contacts of the diagonal limbs (TAP) was affected for both diagonals with the horses landing relatively earlier with the front limbs after lameness induction.

At the walk, the most obvious changes with regard to the duration of the 2- and 3-limb support phases involved the shortening of both diagonal 2-limb support phases and the prolongation of the 3-limb support phase which included the lame forelimb (Table 2).

\section{Force parameters}

The effect of induced lameness at walk and trot on kinetic parameters is summarised in Table 2. At the walk, the primary effect was observed in the lame limb (Fig 3): vertical impulse $(\mathrm{Iz})$ was reduced by $-5.1 \%$, vertical force of the first peak $\left(\mathrm{Fz}_{\text {peak } 1}\right)$ by $-1.9 \%$ and vertical force of the second peak $\left(\mathrm{Fz}_{\text {peak } 2}\right)$ by $-6.1 \%$. In the diagonal hindlimb $\mathrm{Fz}_{\text {peak } 1}$ increased by $+4.8 \%$. In the contralateral forelimb the loading rate $\left(\Delta \mathrm{Fz}_{\text {load }}\right)$ increase by $+16.5 \%$ and the unloading rate $\left(\Delta \mathrm{Fz}_{\text {unload }}\right)$ by $+15 \%$.

In general, the changes were similar but more pronounced at trot $\left(\mathrm{Iz}-14.3 \%, \mathrm{Fz}_{\text {peak }}\right.$ $-17.7 \%$ of the lame limb) than at the walk. The $\Delta \mathrm{Fz}_{\text {load }}$ and $\Delta \mathrm{Fz}_{\text {unload }}$ appeared to be more affected in the lame limb at the trot, while at walk the differences were occurring mainly in the contralateral front limb.

\section{Kinematic parameters}

The effects of induced lameness at walk and trot on kinematic parameters are summarised in Table 3. At the walk, the most prominent changes in upper body kinematics were observed for the MinDiff and in the Range up difference (RUD) and Range down difference (RDD) of the vertical displacement of the head (poll) (Fig 4). The vertical displacement of the withers was affected but to a much smaller magnitude. The range of motion of the vertical displacement $\left(\mathrm{ROM}_{\mathrm{z}}\right)$ of the head was only affected at the trot and increased by $+50.5 \%$ after lameness induction. 


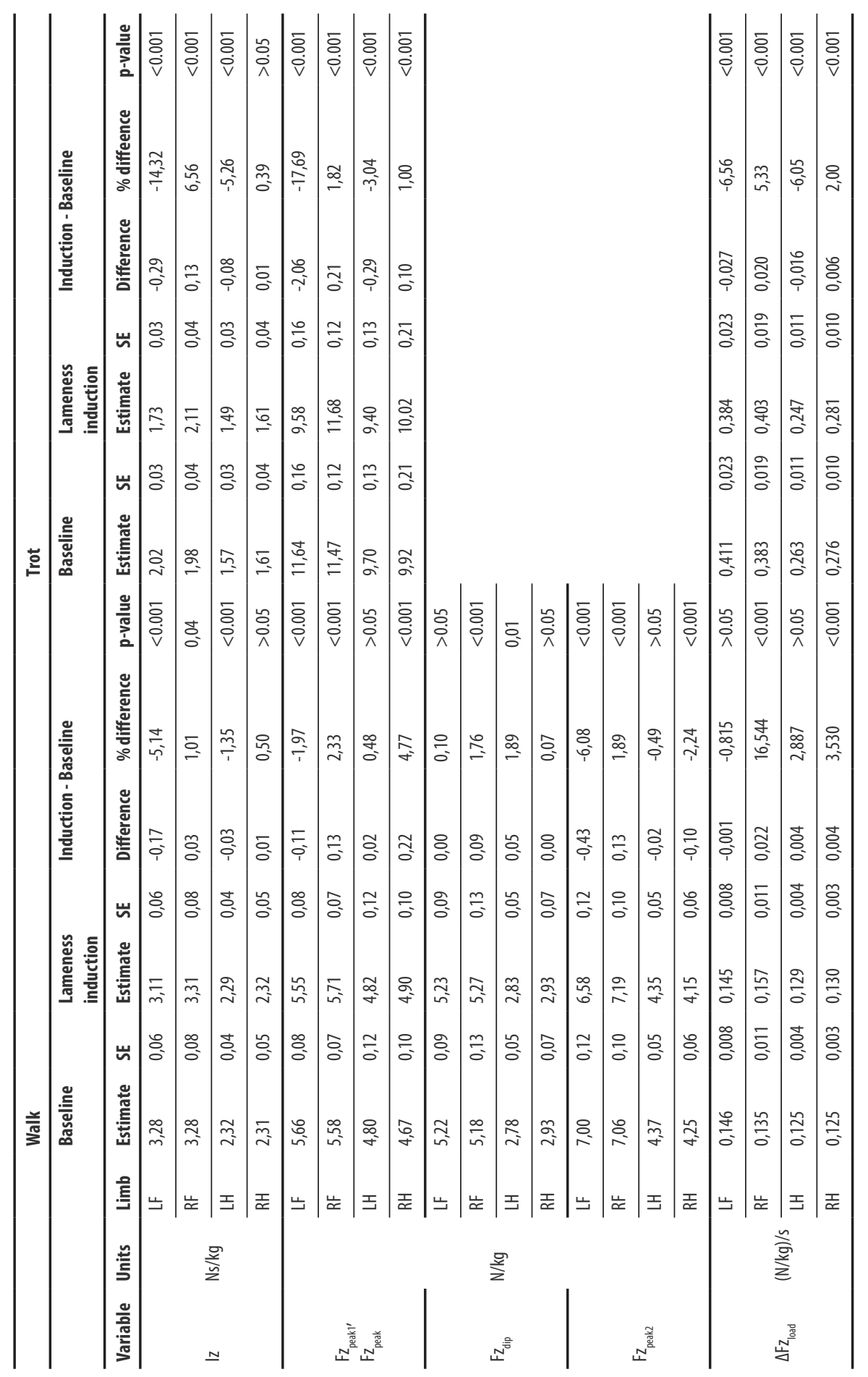




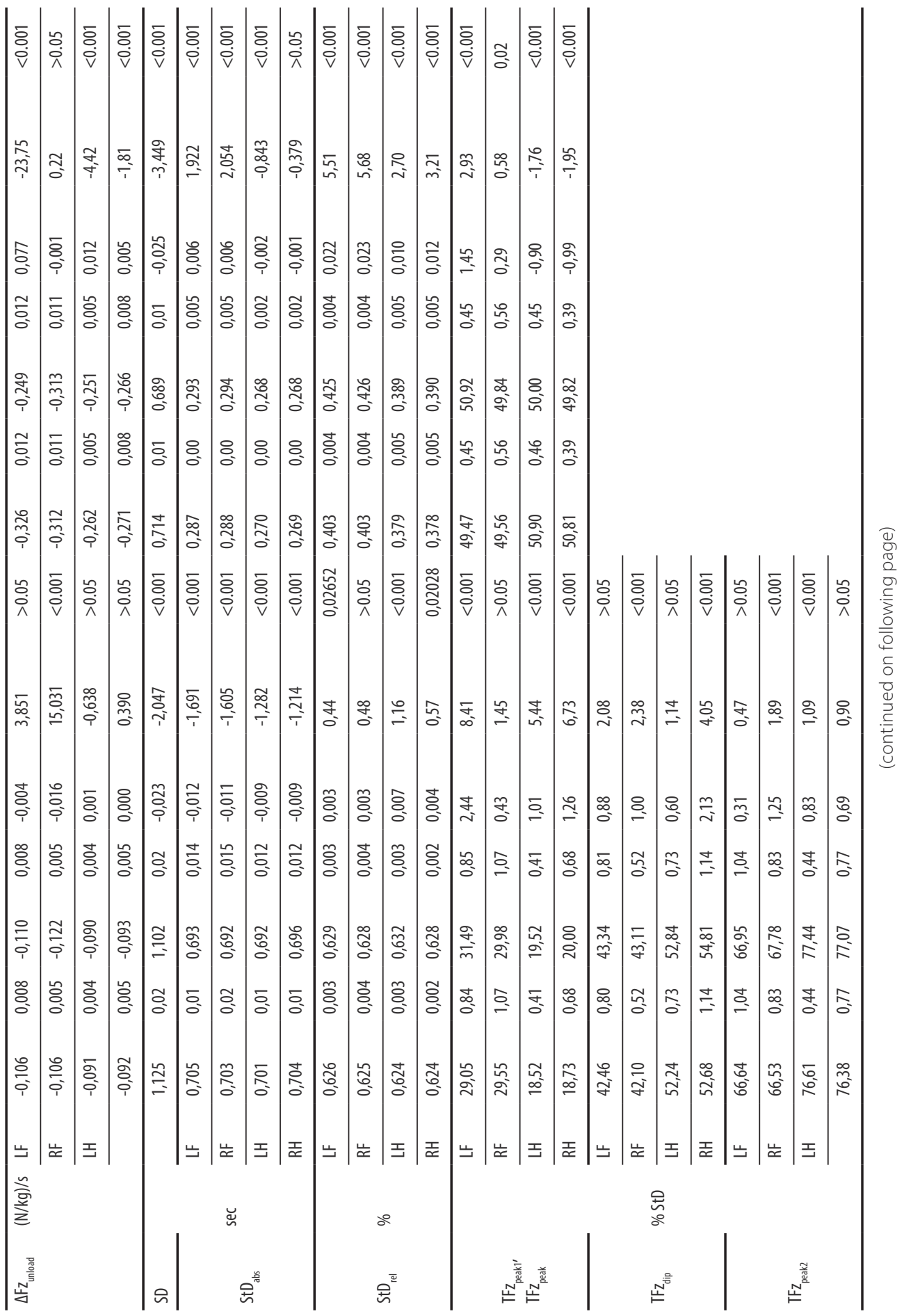




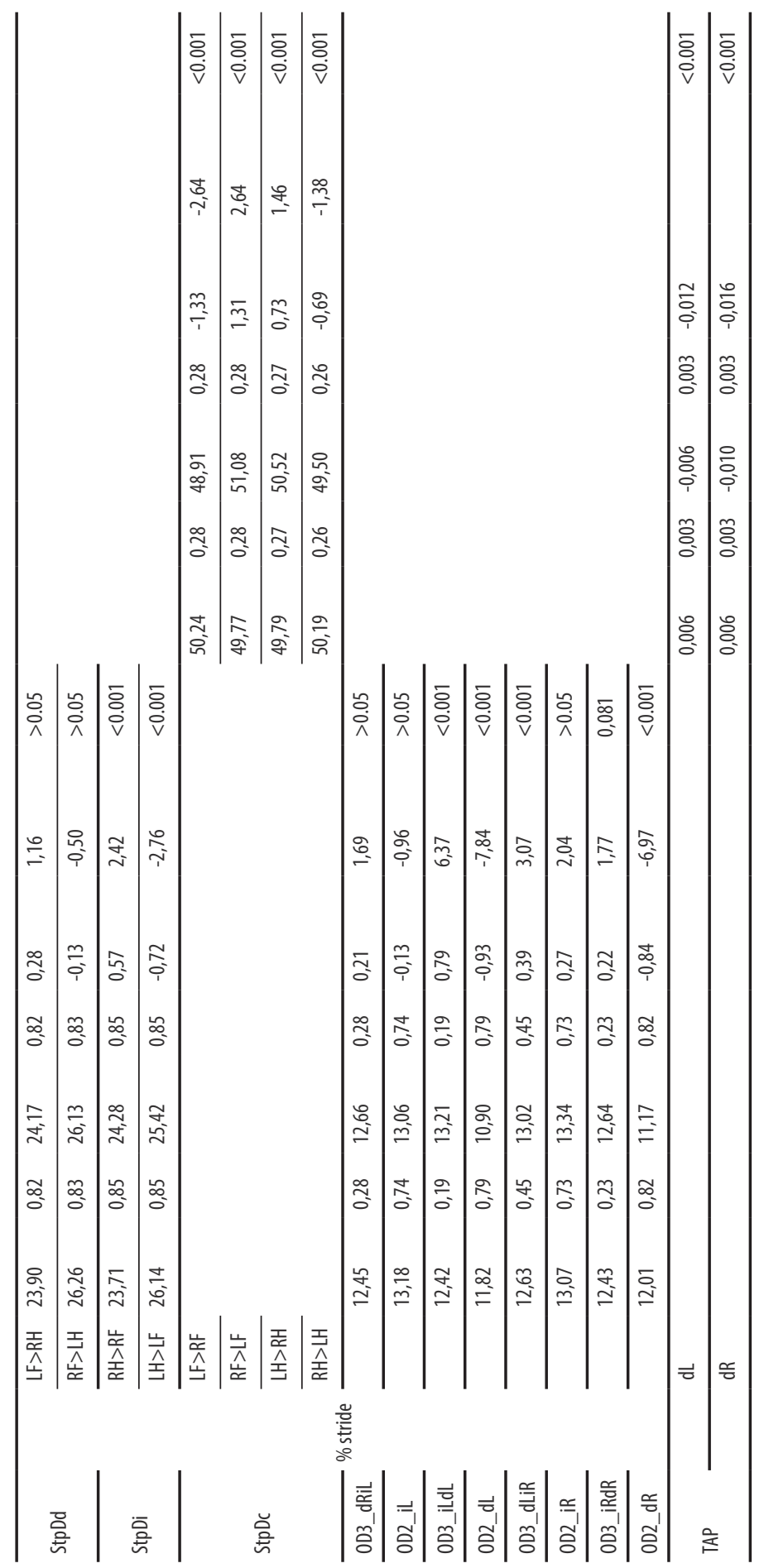




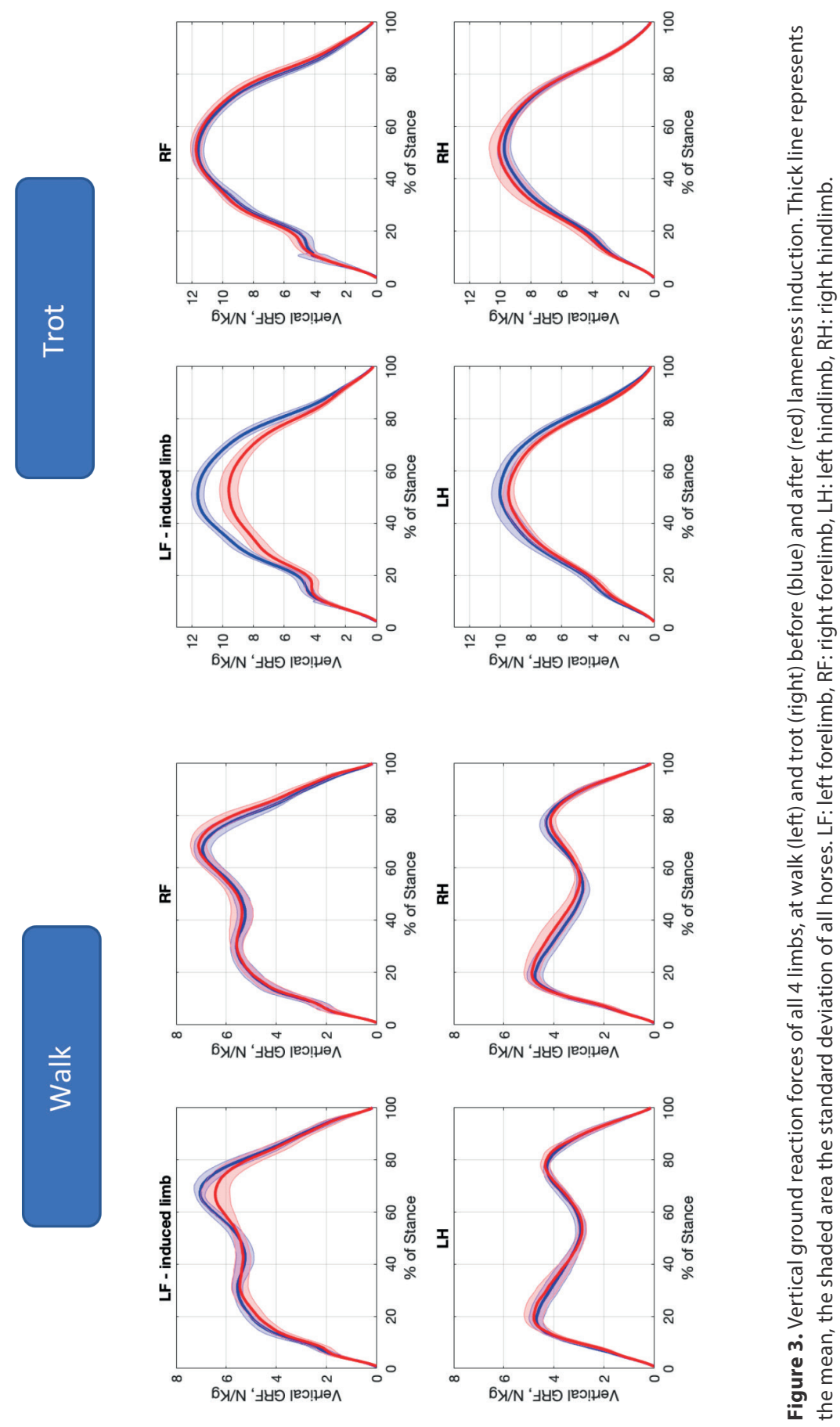




$$
\begin{aligned}
& \mathbf{1} \leq 1 \\
& \mathbf{1} \leq \|
\end{aligned}
$$




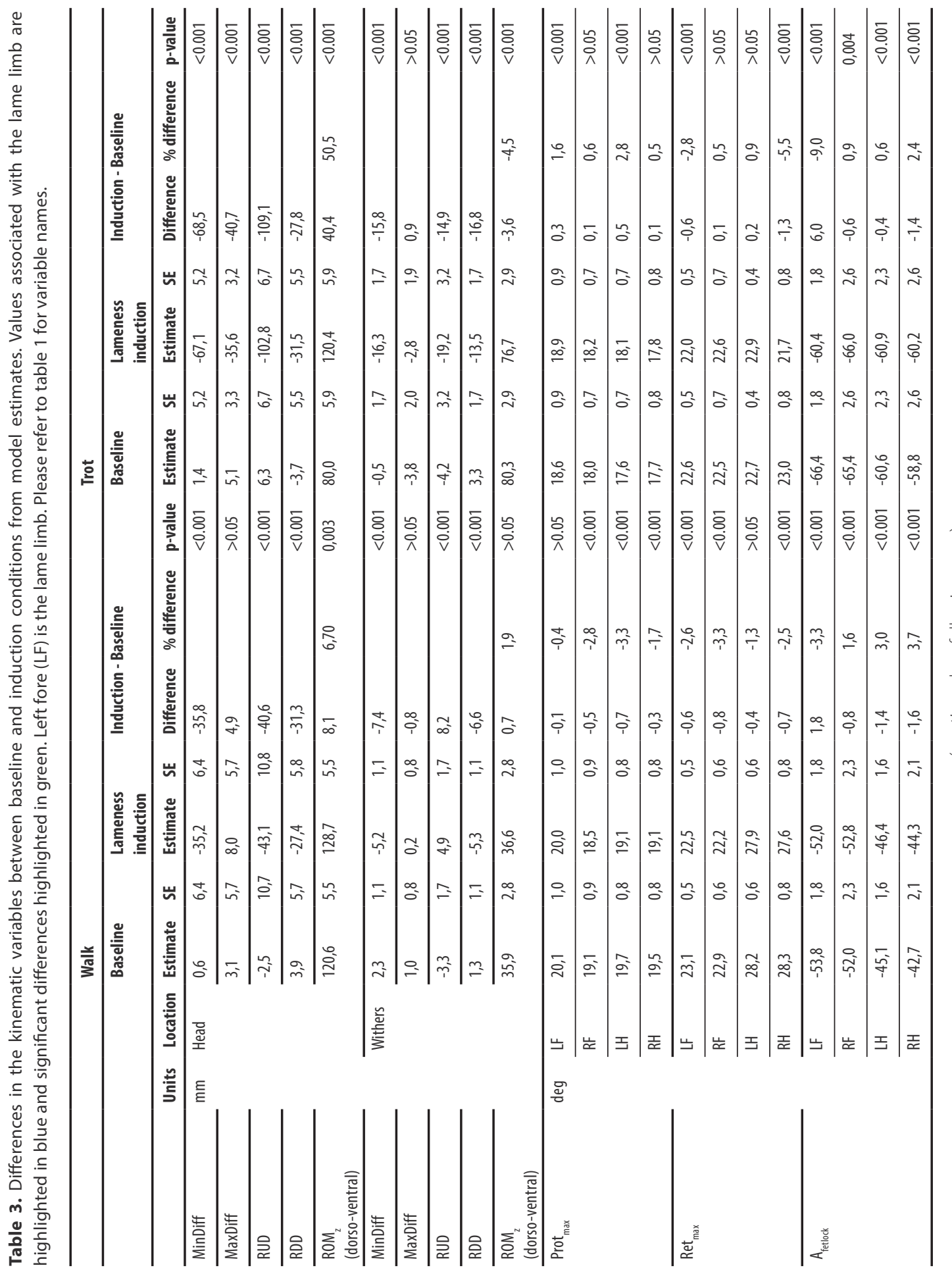




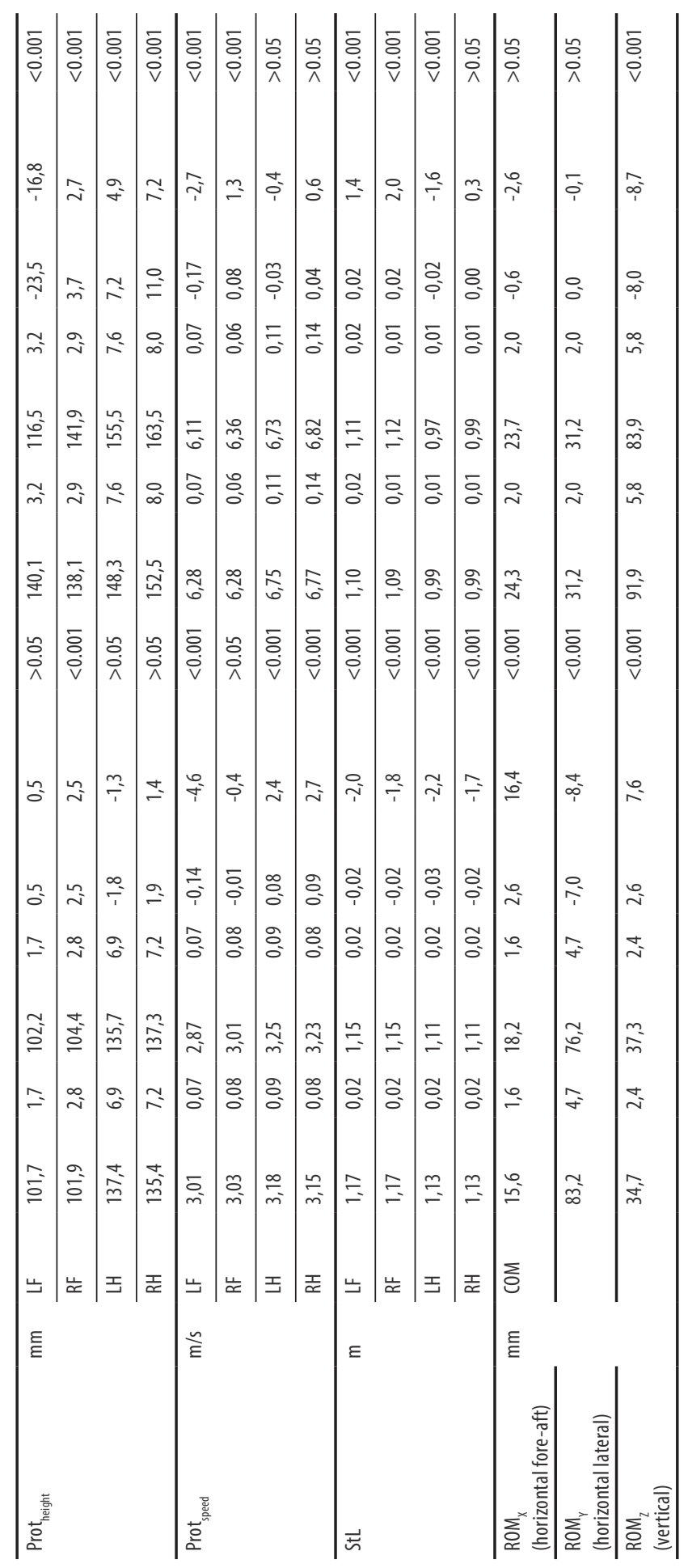


Regarding limb kinematics at walk, both maximal protraction and retraction angles were reduced, except maximal protraction of the lame limb and maximal retraction of the ipsilateral hindlimb (LH). Maximal fetlock hyperextension (Fig 5) was reduced in the lame limb (-3.3\%) and increased in the other limbs. Maximal limb speed during swing phase was also reduced in the lame limb (-4.6\%) and increased in both hindlimbs $\left(+2.4 \%\right.$ and $+2.7 \%$, respectively). As for $\mathrm{StD}_{\text {abs' }}$ stance length (StL) was reduced in all 4 limbs. Other variables were also observed to change on an individual level (Fig 2) reflecting a more individual pattern of compensation.

Maximal protraction height at the walk only increased in the contralateral front limb $(2.5 \%)$ and at the trot, the most pronounced change was a decrease in the lame limb after lameness induction (-16.8\%). Maximal protraction was increased in the lame limb (+1.6\%) at the trot, in contrast to the walk where maximal protraction remained unaffected. Maximal retraction of the lame limb was reduced for both walk and trot $(-2.6 \%$ and $-2.8 \%$ respectively).

\section{COM translations}

At walk the main translation of the body COM relative to the treadmill was in the laterolateral direction (Fig 6). This was significantly reduced after lameness induction with an increase of the remaining translations (horizontal fore-aft and dorso-ventral). At the trot, the main translation of the COM was in the vertical (dorso-ventral) direction and this was significantly reduced after lameness induction.

\section{Movement of the COF}

The general pattern of the COF path at walk was very characteristic (butterfly-like) and similar between horses (Fig 7, Supplementary Item 2 and 3). Based on visual inspection of these figures, after lameness induction at the walk, horses reduced the maximal cranial translation of the COF position, relative to the COM, towards the lame limb (Fig 7), bringing the COF during stance of the lame limb, closer to the horse's COM. This was observed in $70 \%$ of the selected lameness inductions.

\section{Discussion}

Understanding the compensatory mechanisms of adaptation to lameness and the different strategies employed at different gaits is essential to evaluate lameness in horses. The compensatory mechanisms are complex and demonstrate that in general, kinetic and kinematics of the non-lame limbs are also affected by lameness induction in a single limb (here front limb), making visual lameness assessment challenging. 

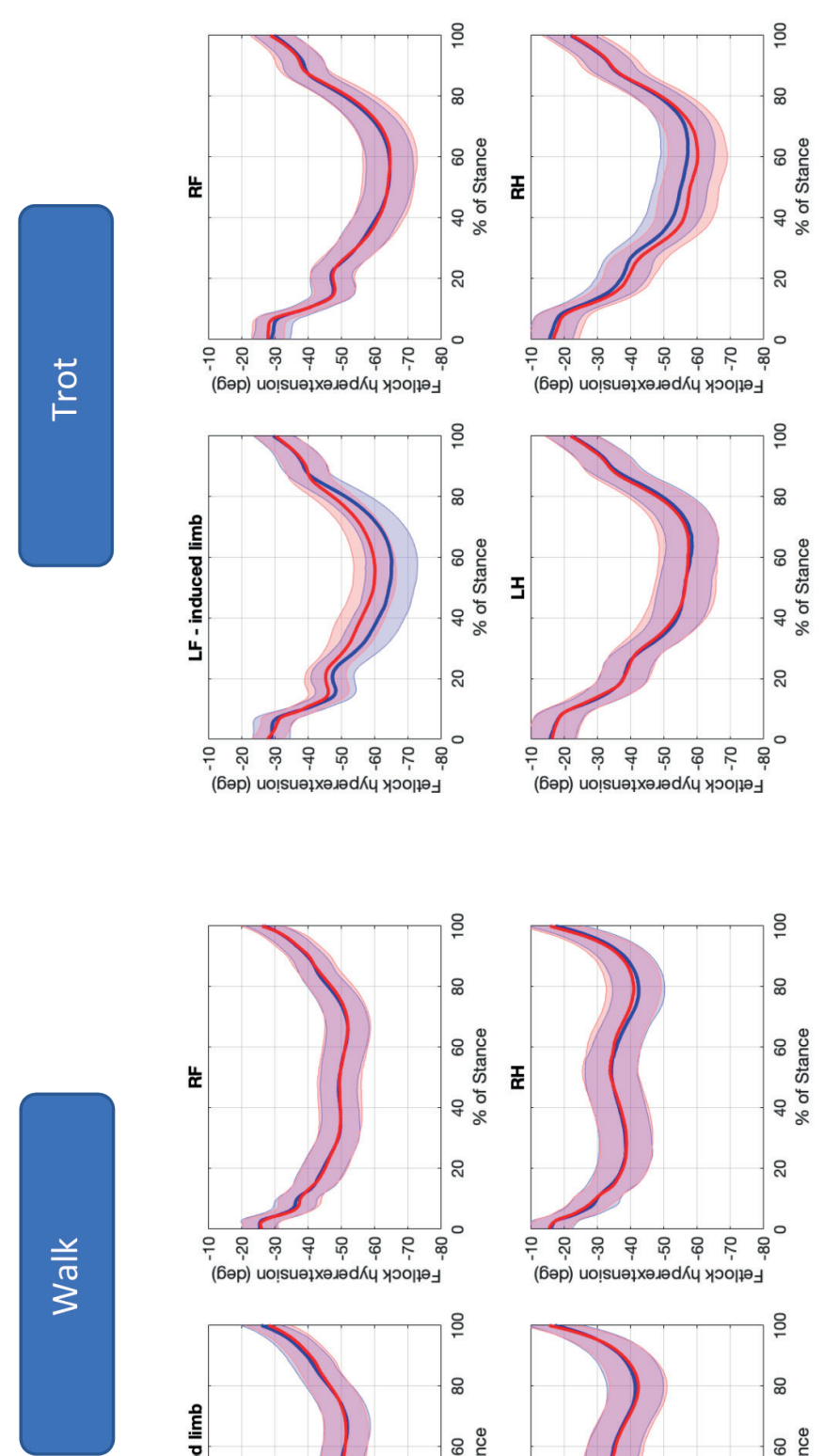

낟

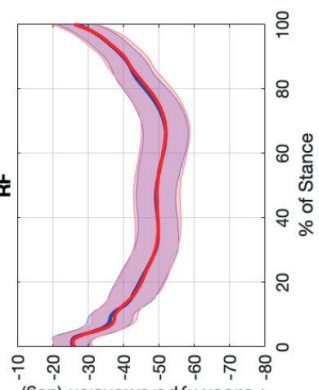

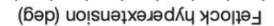

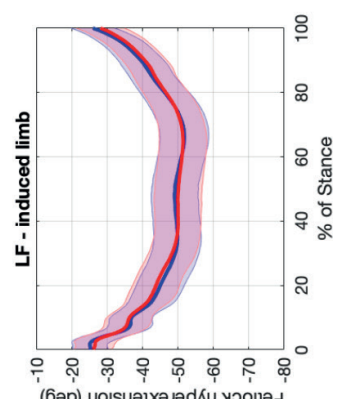

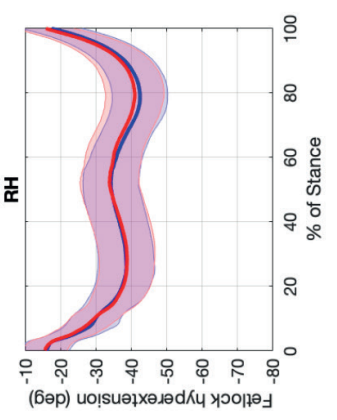

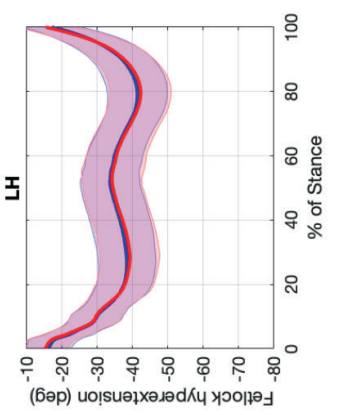

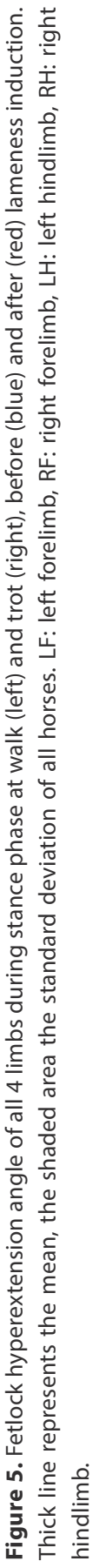




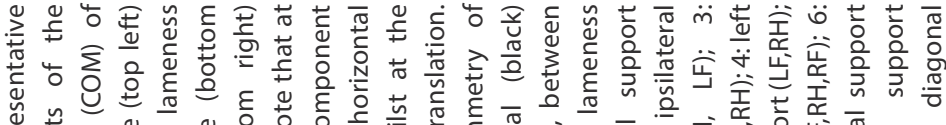

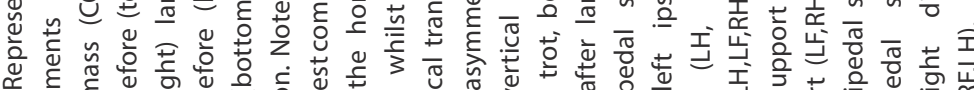

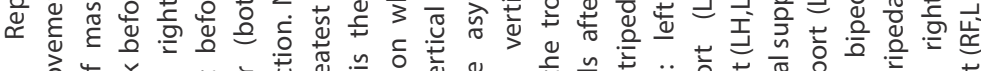
.

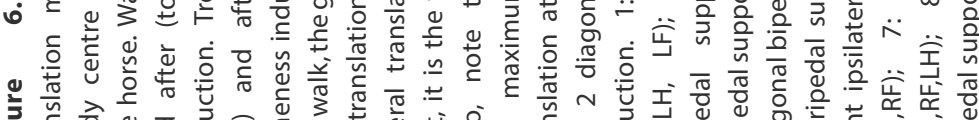

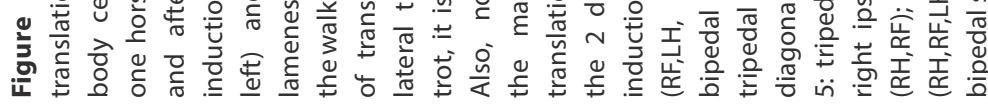
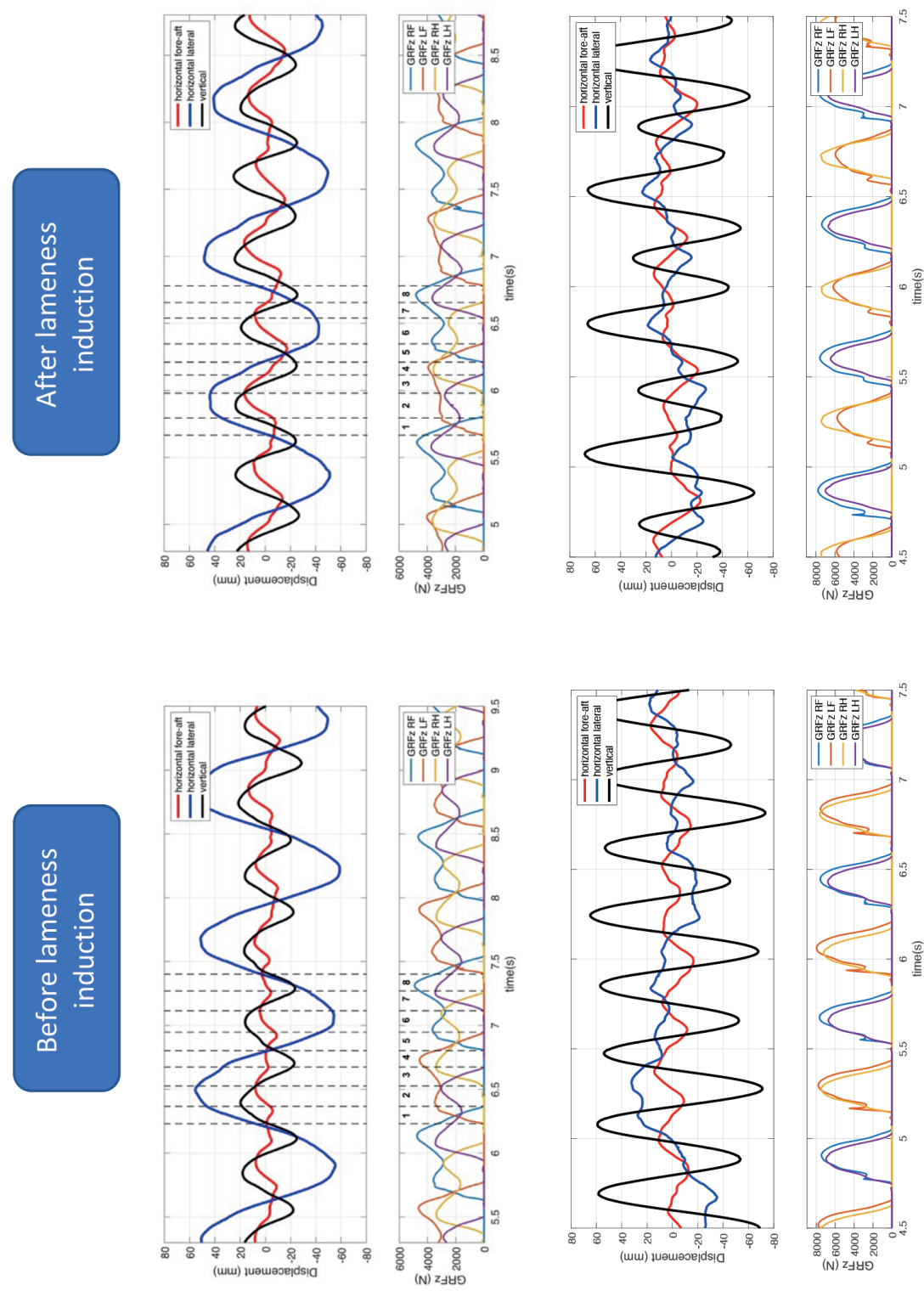

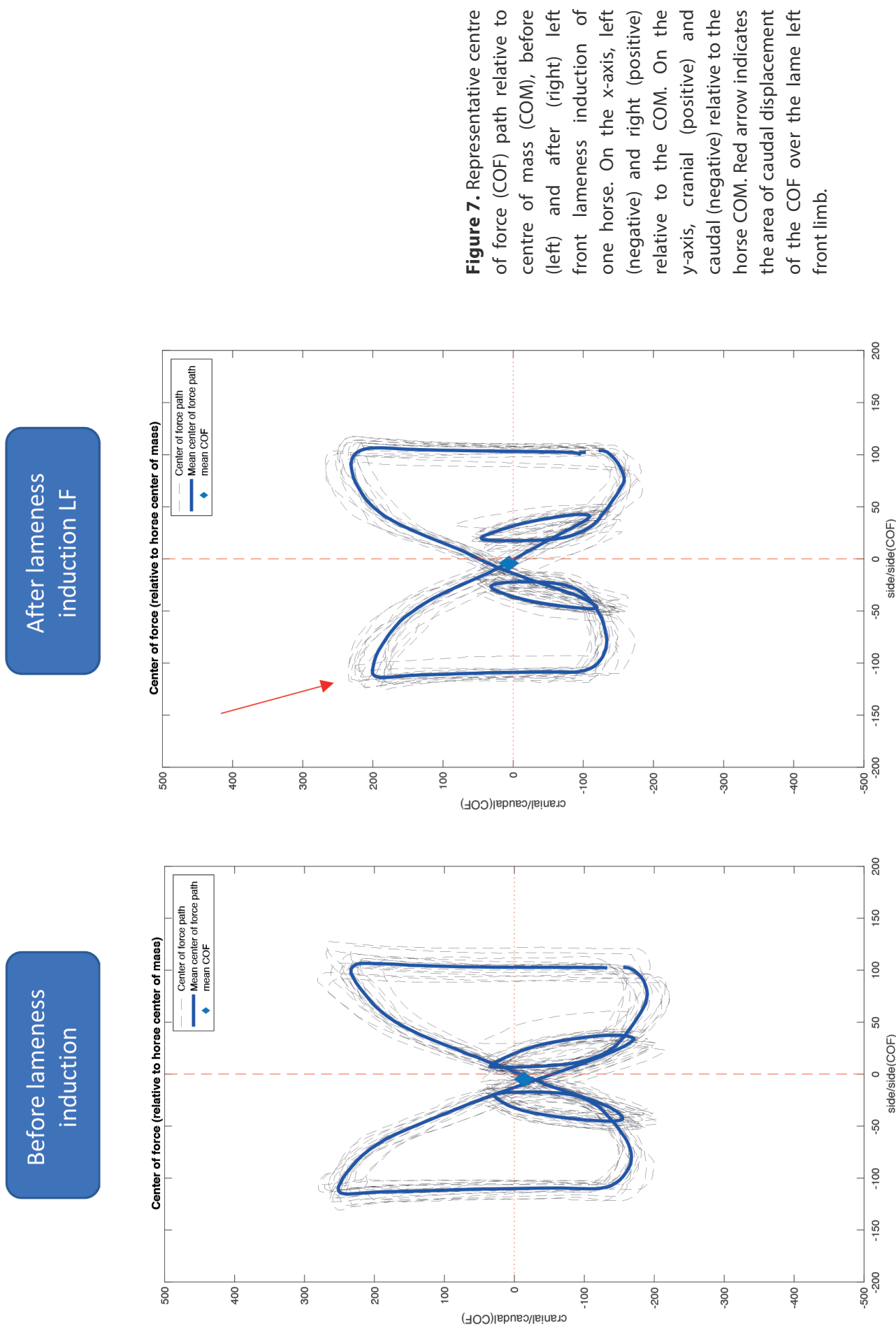
There seems to be different compensatory strategies employed for the different gaits; parameters with known relation to lameness at trot, will hence not automatically apply to lameness at the walk.

We believe that our approach for identifying useful variables on an individual basis, using heat maps, allowed us to better understand individual variation in adaptation to lameness. The heat maps showed that there was indeed individual variation in strategies for adapting to sole pressure induced lameness. They further showed that these inter-individual differences in compensatory strategies were less pronounced at trot than at walk, e.g. for vertical impulse (Iz) (Figs 1-2). We hypothesise that this is related to the fact that walk with its bipedal and tripedal support phases, increases the possible strategies to compensate.

The lameness-induced changes in both kinetics and kinematics were much smaller at walk than at trot. This has been previously described in other studies on the walk after lameness induction $[3,17]$ and is the reason why the trot is the preferred gait to visually assess lameness in a clinical setting as described by Ross M.W. and colleges [23]. The phenomenon can possibly be explained by the fact that horses are moving at higher speed and stride frequency, only have bipedal support and, the COM translation is mainly happening in the vertical direction, which results in the higher peak GRFz observed at trot compared to the walk (Table 2). Ultimately this will result in higher levels of pain/ discomfort experienced by the horse during the stance phase of the lame limb at the trot.

\section{Kinetics}

The changes in limb loading observed in this study at the trot, were in agreement with previous publications $[5,19,24-28]$ with the reduction of $\mathrm{Fz}_{\text {peak }}$ and $\mathrm{Iz}$ in the lame limb as most significant changes. Interestingly, at both gaits only a very mild increase in contralateral front limb $\mathrm{Fz}_{\text {peak }}$ was observed compared to the reduction in the lame limb (Fig 4). Previous publications have reported even no increased loading with regards to $\mathrm{Fz}_{\text {peak }}$ of the contralateral limb in front limb [5] and hindlimb [4] induced lameness at trot. This was interpreted as the result of the prolonged $S t D_{a b s}$ of the lame as well as in the contralateral limb $[4,5,29]$.

When looking at vertical impulse (Iz) there was an increase in the contralateral front limb and reduction in the ipsilateral hind limb at the trot, and a corresponding pattern has been described for hindlimb lameness [4]. At the walk, Iz was reduced in the lame limb and in the ipsilateral hindlimb without significant increases in contralateral limbs. This is likely related to the observed reduction in SD and StD ${ }_{\text {abs }}$ of all four limbs which is in contrast to the trot where front limb $\mathrm{StD}_{\mathrm{abs}}$ increases after lameness induction. 
Changes in limb loading at walk as a result of lameness were previously reported in a study using stationary force plates. That study showed a reduction of both force peaks and a flattening of the force dip in the lame limb [19]. We can confirm these observations, as we have found a reduction of both force peaks (predominantly of forelimb $\mathrm{Fz}_{\text {peak2 }}$ ) although we have failed to find an increase/flattening of the force dip in the lame limb. Furthermore, $\mathrm{Fz}_{\text {peak }}$ was increased in the diagonal hindlimb and contralateral front limb (incl. $\mathrm{Fz}_{\text {peak } 2}$ ), which reflects the mechanism of force redistribution from the lame limb to the following limbs in the step sequence [30].

The interlimb timing at walk was mainly affected with regard to the step duration from the ipsilateral hindlimb to the lame limb, indicating an attempt to place the lame forelimb relatively earlier in the stride cycle. This compensatory mechanism has been previously mentioned [29]. In combination with the subsequent prolonged tripedal support phases, the horse tries to distribute the load away from the affected limb to the diagonal hindlimb and contralateral forelimb. Furthermore, the shortened diagonal bipedal support phases indicated that one of the main strategies of lameness adaptation at the walk is to reduce the lateral oscillation and sidewise de- and accelerations of the COM (Fig 6).

The time dissociation between diagonal limbs (TAP) at the trot was affected for both diagonals with the horses landing earlier with the respective front limbs after lameness induction (Table 2), confirming earlier observations [5]. This is likely due to the increased $\mathrm{StD}_{\mathrm{abs}}$ of the front limbs after lameness induction.

\section{Kinematics}

Changes in upper body kinematics was more obvious at trot than at walk. Total range of motion of the vertical displacement of the head (ROMz) was increased after lameness induction by $50 \%$ at trot, but there was no change seen at walk. Still, based on our heat map analysis and the significant differences between lame and sound measurements, motion symmetry of the poll was one of the most sensitive and specific parameters on a group level, supporting previous publications that suggest that head motion symmetry can be of significant importance, also at walk [3,8]. In our study, one horse (Figs 1-2, LAZ) had a significant baseline asymmetry of the vertical displacement of the poll, yet the horse showed no weight-bearing asymmetry on the GRFz of the front limbs and the poll asymmetry was not present at the trot. This indicates that a head nod at the walk could render false positive results if used for detection of weight bearing lameness. Therefore, the sensitivity of the poll motion asymmetry for lameness detection at walk needs to be determined in a larger population of horses. 
Withers motion symmetry was also affected, but in a smaller magnitude compared to the head, as described earlier [3]. Asymmetry of the vertical displacement of the withers has been related to maximal protraction and retraction angle of the forelimbs and might not be entirely due to lameness, as it can be related to motor laterality [31]. Therefore, motion symmetry of the withers at the walk should be interpreted with caution in the light of lameness diagnosis.

The reduced maximal cranial displacement of the COF towards the lame limb occurred at the moment of transition between tripedal support and the following ipsilateral bipedal support phase (see Supplementary items 2-3). This occurred just prior to $\mathrm{Fz}_{\text {peak } 1}$ of the forelimb and the moment of force dip of the ipsilateral hindlimb. We hypothesise that the reduction of the most cranial displacement of COF towards the lame limb, in comparison to the contralateral front limb, (Fig 7) is the explanation for the reduced Iz and force peaks of the lame limb. We believe that this mechanism is an attempt to bring the COF closer to the COM, reducing loading of the lame limb. This is likely also coupled to the reduced latero-lateral translation of the body COM after lameness induction. Further research is needed to better describe and investigate this COF path and the observed changes in body COM.

\section{Limitations of the study:}

Horses have been investigated on a treadmill at a constant speed; it may therefore not be appropriate to extrapolate the results to over ground locomotion. Further studies are needed to assess the validity of the variables used in this study over ground, where a higher inter-stride variation is expected that will ultimately affect the sensitivity and specificity of some of the variables presented here. There is also a need to confirm these results in horses with naturally occurring lameness caused by different orthopaedic pathologies and with pain arising from different anatomical locations in the limb.

\section{Conclusions}

Marked differences exist between the compensatory mechanisms of adaptation to lameness between walk and trot. Specifically, we suggest that the kinetic variables $\mathrm{Iz}, \mathrm{Fz}_{\text {peak } 1^{\prime}} \mathrm{Fz}_{\text {peak2 }}$ and StpDi are interesting candidate parameters that can be used for objective lameness assessment at the walk. For the kinematics we suggest that the symmetry variables for the head MinDiff, RUD, RDD, Prot ${ }_{\text {speed }}$ and $A_{\text {fetlock' }}$ are also interesting candidates. Nevertheless, some of the described parameters may not be easily perceived in a clinical situation and are possibly only measurable on a treadmill. Based on current IMU and OMC technology available, the head symmetry parameters 
are likely good candidates for objective forelimb lameness assessment at walk in a clinical setting.

\section{Manufacturers' details}

${ }^{1}$ Rahsol Dremotec, Gedore Group, Remscheid, Germany.

${ }^{2}$ Kagra AG, Fahrwangen, Switzerland.

${ }^{3}$ Qualisys AB, Motion Capture Systems, 411 05, Göteborg, Sweden.

${ }^{4}$ MathWorks, 3 Apple Hill Drive, 01760, Natick, USA.

${ }^{5}$ R-Studio, 250 Northern Ave, MA 02210, Boston, USA.

\section{Supporting Information}

Supplementary Item 1: One of the study subjects, equipped with 52 reflective markers at trot. The markers used for the analysis were: pool, withers, dorsal spinal process of $L 3$, tuber sacrale, left/right tuber coxae, sternum, left/right spina scapulae, left/right lateral aspect of the carpus, left/rightfront/hind lateral aspect of the fetlock, left/right-front-hind lateral aspect of the proximal dorsal hoof wall, left/right trochanter major of the femur(hip), left/ right lateral aspect of hock(tarsus).

Supplementary Item 2: Animation of the COF path from one study subject, before lameness induction.

Supplementary Item 3: Animation of the COF path from one study subject, after lameness induction on the left front limb. 


\section{References}

1. Serra Bragança, F.M.M., Rhodin, M. and Weeren, P.R.R. van (2018) On the brink of daily clinical application of objective gait analysis: What evidence do we have so far from studies using an induced lameness model? Vet. J. 234, 11-23.

2. Weishaupt, M.A. (2008) Adaptation Strategies of Horses with Lameness. Vet. Clin. North Am. Equine Pract. 24, 79-100.

3. Buchner, H.H.F., Savelberg, H.H., Schamhardt, H.C. and Barneveld, A. (1996) Head and trunk movement adaptations in horses with experimentally induced fore- or hindlimb lameness. Equine Vet. J. 28, 71-76.

4. Weishaupt, M.A., Wiestner, T., Hogg, H.P., Jordan, P. and Auer, J.A. (2010) Compensatory load redistribution of horses with induced weightbearing hindlimb lameness trotting on a treadmill. Equine Vet. J. 36, 727-733.

5. Weishaupt, M. a., Wiestner, T., Hogg, H.P., Jordan, P. and Auer, J. a. (2006) Compensatory load redistribution of horses with induced weight-bearing forelimb lameness trotting on a treadmill. Vet. J. 171, 135-146.

6. Bell, R.P., Reed, S.K., Schoonover, M.J., Whitfield, C.T., Yonezawa, Y., Maki, H., Pai, P.F. and Keegan, K.G. (2016) Associations of force plate and body-mounted inertial sensor measurements for identification of hind limb lameness in horses. Am. J. Vet. Res. 77, 337-45.

7. Ross, M.W. and Dyson, S.J. (2011) Movement. In: Diagnosis and management of lameness in the Horse, second., Elsevier. pp 89-90.

8. Barrey, E. and Descbrosse, F. (1996) Lameness detection using an aaccelerometric device. Pferdeheikunde 12, 617-622.

9. Merkens, H.W. and Schamhardt, H.C. (1988) Evaluation of equine locomotion during different degrees of experimentally induced lameness II: Distribution of ground reaction force patterns of the concurrently loaded limbs. Equine Vet. J. 20, 107-112.

10. Loscher, D.M., Meyer, F., Kracht, K. and Nyakatura, J.A. (2016) Timing of head movements is consistent with energy minimization in walking ungulates. Proc. R. Soc. B Biol. Sci. 283, 20161908.

11. Merkens, H.W., Schamhardt, H.C., Hartman, W. and Kersjes, A.W. (1986) Ground reaction force patterns of Dutch Warmblood horses at normal walk. Equine Vet. J. 18, 207-14.

12. Geyer, H., Seyfarth, A. and Blickhan, R. (2006) Compliant leg behaviour explains basic dynamics of walking and running. Proc. R. Soc. B Biol. Sci. 273, 2861-2867.

13. Rhodin, M., Persson-Sjodin, E., Egenvall, A., Serra Bragança, F.M., Pfau, T., Roepstorff, L., Weishaupt, M.A., Thomsen, M.H., Weeren, P.R. van and Hernlund, E. (2018) Vertical movement symmetry of the withers in horses with induced forelimb and hindlimb lameness at trot. Equine Vet. J. 50, 818-824.

14. Bächi, B., Wiestner, T., Stoll, A., Waldern, N.M., Imboden, I. and Weishaupt, M.A. (2018) Changes of Ground Reaction Force and Timing Variables in the Course of Habituation of Horses to the Treadmill. J. Equine Vet. Sci. 63, 13-23.

15. Merkens, H.W. and Schamhardt, H.C. (1988) Evaluation of equine locomotion during different degrees of experimentally induced lameness. I: Lameness model and quantification of ground reaction force patterns of the limbs. Equine Vet. J. Suppl. 20, 99-106.

16. Weishaupt, M.A., Hogg, H.P., Wiestner, T., Denoth, J., Stüssi, E. and Auer, J.A. (2002) Instrumented treadmill for measuring vertical ground reaction forces in horses. Am. J. Vet. Res. 63, 520-727.

17. Buchner, H.H., Savelberg, H.H., Schamhardt, H.C. and Barneveld, A. (1996) Limb movement adaptations in horses with experimentally induced fore- or hindlimb lameness. Equine Vet. J. 28, 63-70.

18. Weishaupt, M. a., Wiestner, T., Hogg, H.P., Jordan, P. and Auer, J. a. (2004) Compensatory load redistribution of horses with induced weightbearing hindlimb lameness trotting on a treadmill. Equine Vet. J. 36, 727-733. 
19. Merkens, H.W. and Schamhardt, H.C. (1988) Evaluation of equine locomotion during different degrees of experimentally induced lameness. II: Distribution of ground reaction force patterns of the concurrently loaded limbs. Equine Vet. J. Suppl. 20, 107-12.

20. Keegan, K.G. (2007) Evidence-Based Lameness Detection and Quantification. Vet. Clin. North Am. Equine Pract. 23, 403-423.

21. Buchner, H.H.F., Savelberg, H.H.C.M., Schamhardt, H.C. and Barneveld, A. (1997) Inertial properties of dutch warmblood horses. J. Biomech. 30, 653-658.

22. Buchner, H.H., Obermüller, S. and Scheidl, M. (2000) Body centre of mass movement in the sound horse. Vet. J. 160, 225-34.

23. Ross, M.W. (2011) Movement. In: Diagnosis and Management of Lameness in the Horse, second edi., Eds: S.J. Dyson and M.W. Ross, Elsevier. pp 65-67.

24. Ishihara, A., Bertone, A.L. and Rajala-Schultz, P.J. (2005) Association between subjective lameness grade and kinetic gait parameters in horses with experimentally induced forelimb lameness. Am. J. Vet. Res. 66, 1805-15.

25. Morris, E. and Seeherman, H. (1987) Redistribution of ground reaction forces in experimentally induced equine carpal lameness. Equine Exerc Physiol 2, 553-563.

26. Keg, P.R., Barneveld, A., Schamhardt, H.C. and Belt, A.J.M. van den (1994) Clinical and force plate evaluation of the effect of a high plantar nerve block in lameness caused by induced midmetatarsal tendinitis. Vet. Q. 16, 70-75.

27. Clayton, H.M., Schamhardt, H.C., Willemen, M.A., Lanovaz, J.L. and Colborne, G.R. (2000) Kinematics and ground reaction forces in horses with superficial digital flexor tendinitis. Am. J. Vet. Res. 61, 191-6.

28. Khumsap, S., Lanovaz, J.L., Rosenstein, D.S., Byron, C. and Clayton, H.M. (2003) Effect of induced unilateral synovitis of distal intertarsal and tarsometatarsal joints on sagittal plane kinematics and kinetics of trotting horses. Am. J. Vet. Res. 64, 1491-5.

29. Buchner, H.H.F., Savelberg, H.H.C.M., Schamhardt, H.C. and Barneveld, A. (1995) Temporal stride patterns in horses with experimentally induced fore- or hindlimb lameness. Equine Vet. J. 27, 161-165.

30. Merkens, H.W., Schamhardt, H.C., Hartman, W. and Kersjes, A.W. (1988) The use of H(orse) INDEX: a method of analysing the ground reaction force patterns of lame and normal gaited horses at the walk. Equine Vet. J. 20, 29-36.

31. Byström, A., Egenvall, A., Roepstorff, L., Rhodin, M., Bragança, F.S., Hernlund, E., Weeren, R. Van, Weishaupt, M.A. and Clayton, H.M. (2018) Biomechanical findings in horses showing asymmetrical vertical excursions of the withers at walk. PLoS One 13, e0204548. 


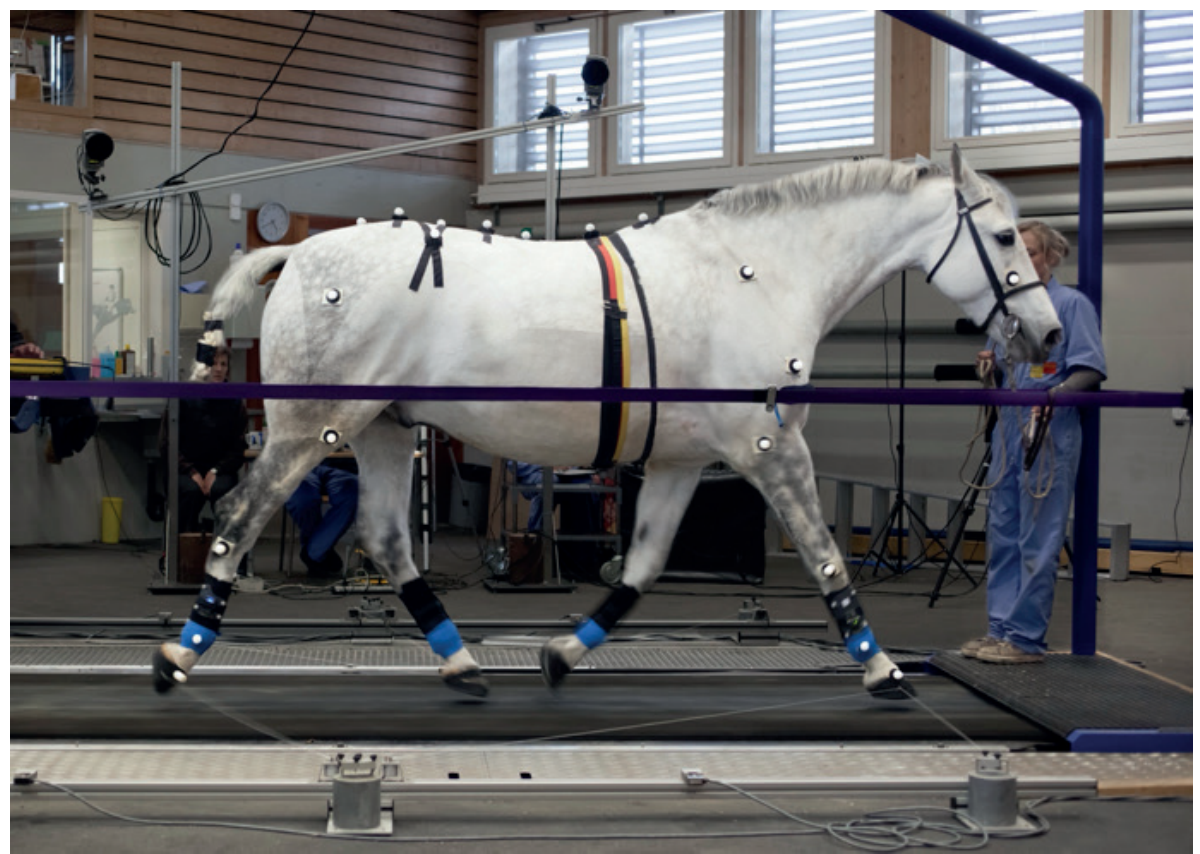

Supplementary Item 1: One of the study subjects, equipped with 52 reflective markers at trot. The markers used for the analysis were: pool, withers, dorsal spinal process of L3, tuber sacrale, left/right tuber coxae, sternum, left/right spina scapulae, left/right lateral aspect of the carpus, left/right-front/ hind lateral aspect of the fetlock, left/right-front-hind lateral aspect of the proximal dorsal hoof wall, left/right trochanter major of the femur(hip), left/right lateral aspect of hock(tarsus). 
[Chapter 9]

\section{The development of hoof balance and landing preference in the post-natal period}

B. M. C. Gorissen ${ }^{\dagger}$, F. M. Serra Braganc0 $a^{* *}$, C. F. Wolschrijn ${ }^{\dagger}$, W. Back ${ }^{\ddagger \S}$ and P. R. Van Weeren ${ }^{\ddagger}$

${ }^{\dagger}$ Department of Pathobiology, Anatomy and Physiology Division, Faculty of Veterinary Medicine, Utrecht University, Utrecht, the Netherlands

‡ Department of Equine Sciences, Faculty of Veterinary Medicine, Utrecht University, Utrecht, the Netherlands

$\S$ Department of Surgery and Anaesthesiology of Domestic Animals, Faculty of Veterinary Medicine, Ghent University, Merelbeke, Belgium.

*Correspondence email: f.m.serrabraganca@uu.nl; Received: 14.07.17; Accepted: 31.03.18
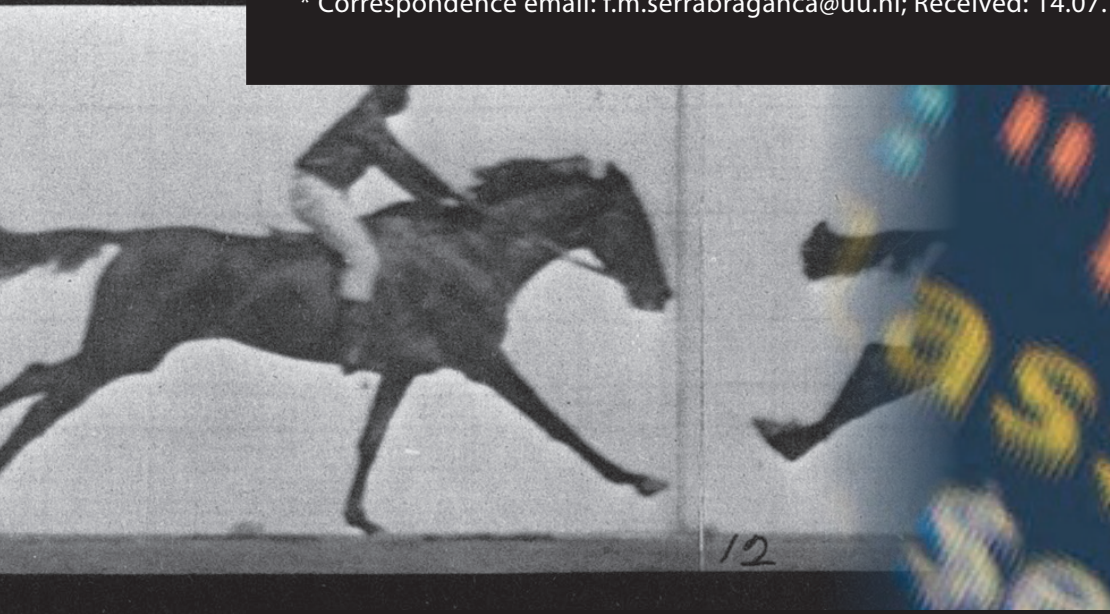

The veterinary Journal. 2018 Nov;50(6):809-817. doi: 10.1111/evj.12961

Keywords horse, foal, gait development, kinetics, hoof balance 


\section{Summary}

Background: Foals can follow the herd within hours of birth, but it has been shown that kinetic gait parameters and static balance still have to mature. However, development of dynamic balance has not been investigated.

Objectives: To objectively quantify landing and pressure pattern dynamics under the hoof during the first half year of life.

Study design: Prospective, cohort study performed at a single stud farm.

Methods: Pressure plate measurements at walk and trot from ten Dutch warmblood foals during the first 24 weeks of life were used to quantify toe- heel and mediallateral hoof balance asymmetry indexes and to determine preferred landing strategy. Concurrently, radiographs of the tarsocrural and femoropatellar joints were taken at 4-6 weeks and after 6 months to check for osteochondrosis. A linear mixed model was used to determine the effects of time point, limb pair (front/hind), side (left/ right) and osteochondrosis status of every foal.

Results: At $25 \%$ of stance duration at walk, front limbs were more loaded in the heel region in weeks 6-20 $(P \leq 0.04)$, the medial-lateral balance was more to the lateral side from week 6 onwards at both walk and trot $(P \leq 0.04)$. Landing preference gradually changed in the same directions. Variability in pressure distribution decreased over time. (Subclinical) osteochondrosis did not influence any of the measured parameters.

Main limitations: This study is limited by the relatively small sample size only containing one breed from a single stud farm.

Conclusions: Dynamic hoof balance in new-born foals is more variable and less oriented towards the lateral side of the hoof and to the heel than in mature horses. This pattern changes gradually during the first weeks of life. Knowledge of this process is essential for the clinician when considering interventions in this area in early life. 


\section{Introduction}

As precocious fright-and-flight animals, foals stand and walk within hours after birth. While being able to keep up with their dam immediately after birth, their gait has to mature $[1,2]$. This also applies to their static balance, as stabilographic measurements showed that both amplitude and velocity of the body's centre of pressure (COP) movements decrease rapidly after birth [3]. Simultaneously, the variability of stance duration at walk and trot is reduced, suggesting maturation of the musculoskeletal system and gait control [2]. It is not unlikely that dynamic balance, i.e. the way of landing and the pressure pattern under the hoof during stance phase, also goes through rapid development during this period; this requires further investigation.

Pressure plate systems can objectively quantify pressure distribution underneath the hoof during the stance phase [4]. Previous studies have successfully used this technique to quantify toe-heel and medial-lateral hoof balance using asymmetry indices (ASI) in the forefeet of adult warmblood horses and ponies [5,6] and by determination of COP patterns in adult horses [7]. These results suggested that adult horses present a distinct loading pattern at the walk, generally loading the lateral side of the hooves more [5]. Although van Heel et al. [4] reported lateral landing as preferred way in both front and hindlimbs at trot, Oosterlinck et al. [5] reported contralateral differences in medial-lateral loading pattern between front hooves at impact, whereas at the end of stance, lateral parts of both front feet were loaded more. In ponies, these contralateral differences were not observed [6]. Using high-speed video recordings, Wilson et al. [8] reported a substantial variation, both within horses and between them, in front hoof placement. Nevertheless, the authors reported that for the studied population of adult horses (age range 4-23 years), the most common hoof placement pattern at walk was the lateral heel and at trot the lateral hoof wall.

For this study, we hypothesised that foals initially show a relatively high degree of variation in their toe-heel and medial-lateral loading patterns during the stance phase at walk and trot due to immature coordination. This would be translated as relatively high variability in medial-lateral and toe-heel ASIs, which would then gradually decrease, stabilising in the patterns observed in adult horses. For hoof placement at landing, we similarly hypothesised that young foals would show more variation in their preferred landing than older foals. 


\section{Materials and methods}

\section{Foals}

The data for this study were collected during the experimental sessions that have also yielded data for another study on the longitudinal development of kinetic gait parameters and the possible influence of osteochondrosis (OC) in warmblood foals [2]. In brief, 11 privately owned Royal Dutch Sport Horse foals (5 fillies and 6 colts) bred for showjumping, were used. All foals were born and housed at the same stud farm and kept together with their dams in a stable bedded with straw and daily access to pasture. After weaning, between weeks 20 and 24, the foals were housed in a large, half-open group stable with straw bedding. During the study period, no hoof trimming was performed.

One colt was excluded from this study due to asymmetrical front feet. Before each measurement session, foals were observed by an experienced equine veterinarian (B.M.C.G.) at walk and trot on a straight line and hard surface to ensure that they were clinically sound. Radiographic evaluation assessed the OC status of the femoropatellar, femorotibial and tarsocrural joints at the age of 4-6 weeks and at the age of at least 6 months (age range 6-9 months). Three radiographs (dorso-plantar, latero-medial and dorsomedial-planterolateral oblique) were taken of the tarsocrural joints, and two (latero-medial and caudolateral-craniomedial oblique) from the femoropatellar and femorotibial joints. Two board-certified veterinary radiologists evaluated the radiographs.

\section{Data collection}

Data were collected using a pressure plate with a measuring surface of 1.9590 .32 m, (Footscan 3D, 2 m system) a , at a sampling rate of $125 \mathrm{~Hz}$, connected to a laptop computer with the dedicated software (Gait Scientific, version 7.99-27.05.2014) . The $^{\text {a }}$ pressure plate was embedded in a wooden frame, with a small ramp in front of and behind the plate to avoid stumbling. The runway, including the pressure plate, was covered with a $10 \mathrm{~m}$ long, $1.5 \mathrm{~m}$ wide and $5 \mathrm{~mm}$ thick rubber matb (natural rubber/ styrene-butadiene rubber, shore hardness $65 \pm 5$ ) to protect the plate. Before each measuring session, the pressure plate was calibrated according to the manufacturer's instructions and offset was manually adjusted to avoid sensor saturation.

All measurements were performed at the stud farm in an empty stable building. After a short warm-up period, foals were consistently led over the pressure plate at their preferred speed by an experienced handler. Before weaning the foals followed their dams, led by another person next to the pressure plate; after weaning, foals were 
handled alone. A trial was considered valid if the foal looked ahead, moved over the pressure plate in a consistent way and the hooves made full ground contact within the measuring area. When the foals were small, all limbs could be measured during one run, but with increasing size, left and right-side data needed to be recorded in separate trials. At each measuring session, at least five valid measurements were collected from each hoof at walk and trot. For this, in general between 10-25 trails were needed.
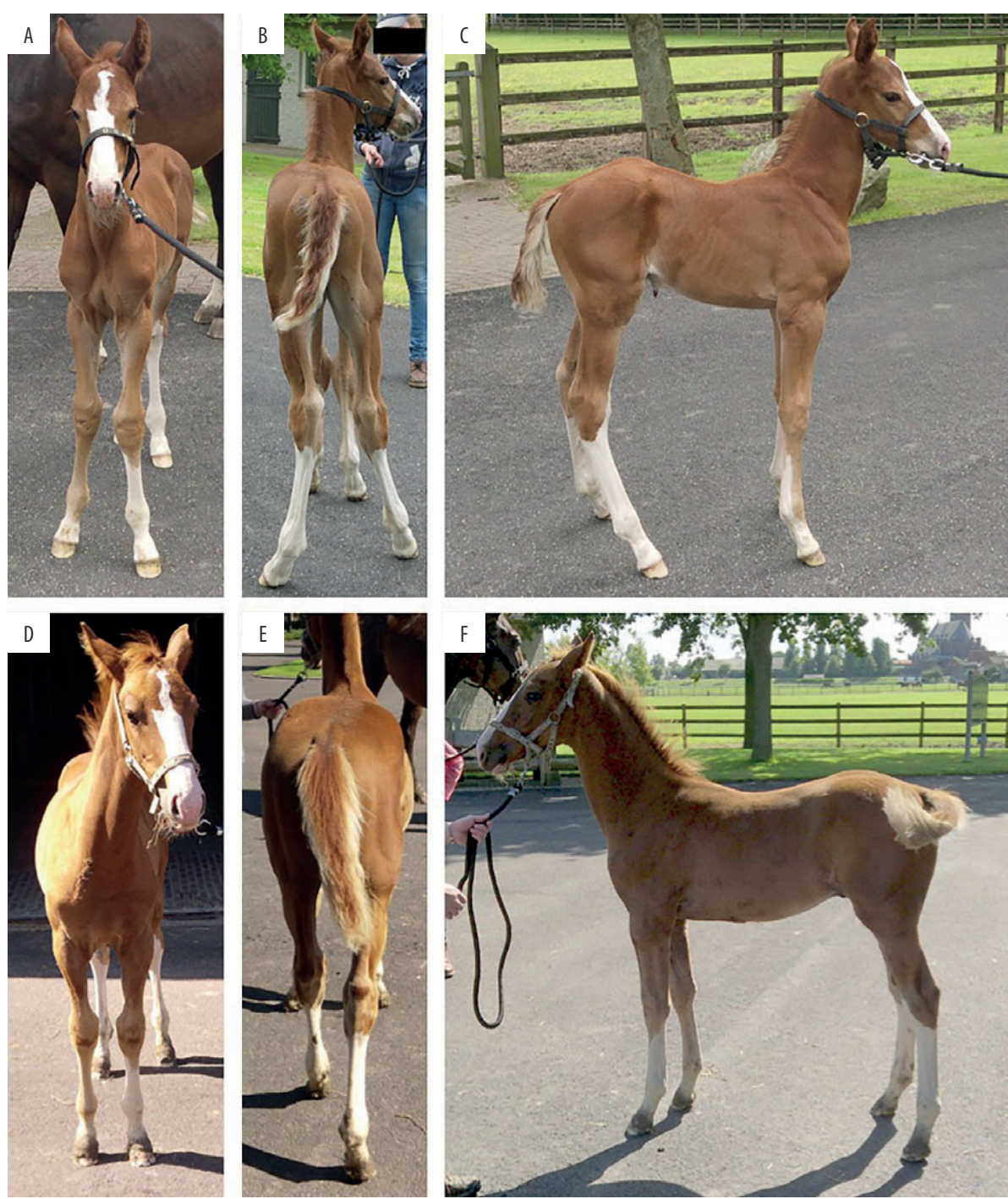

Fig 1. Front a) \& d), hind b) \& e) and lateral c) \& f) views of the same foal at the age of 1 week a), b) and c) and 12 weeks d), e) and f) illustrating conformational changes over time. Note the subtle valgus deviation at week 1 in all 4 limbs. 

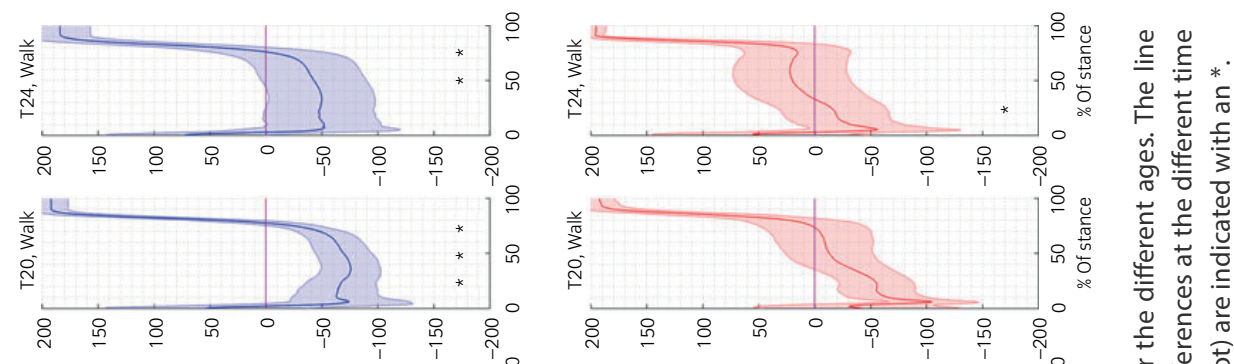

立芒
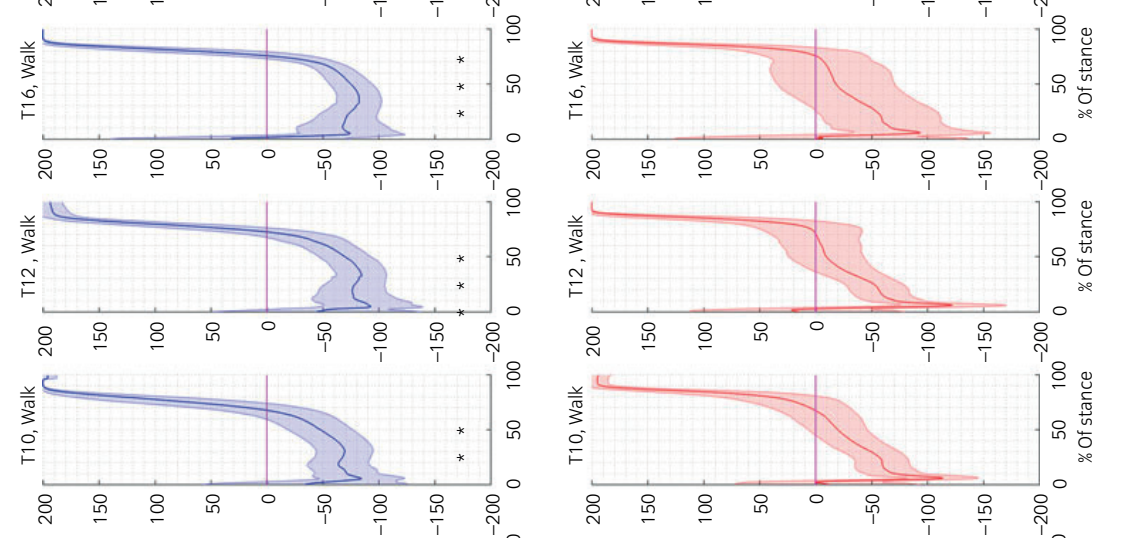
¿

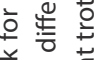

范

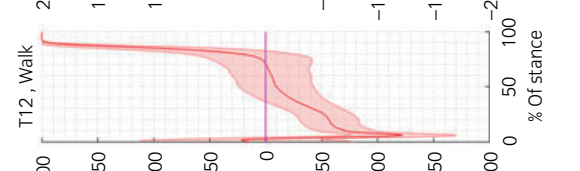

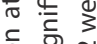

듬ำ

난

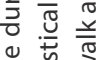

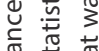

究

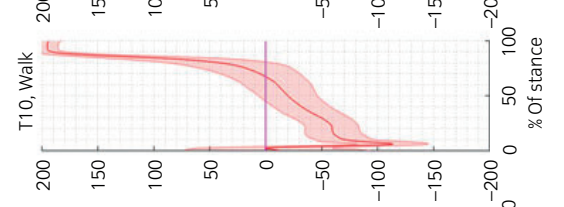

苋 $\frac{n}{\pi}$

हो

论

‡ 들
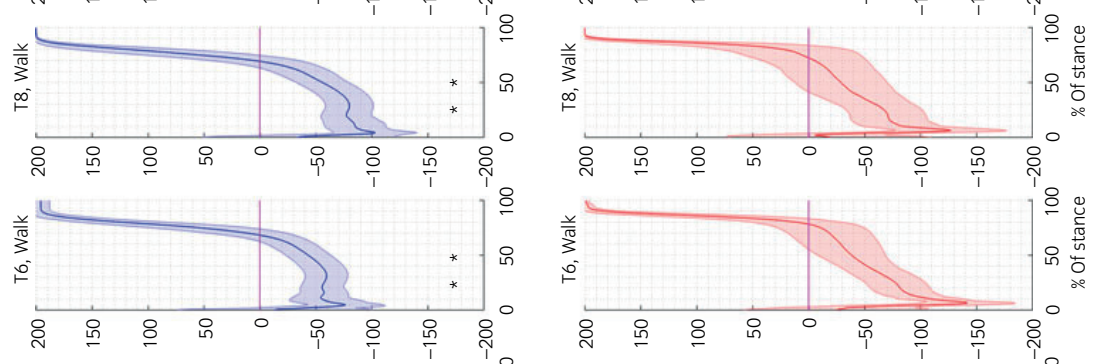

ᄒᄒ

రृ

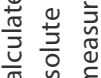

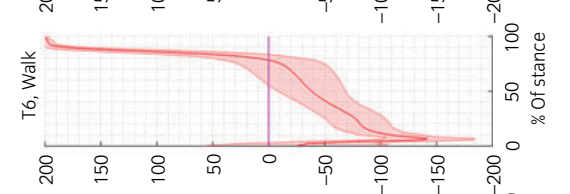

i $\frac{0}{\pi}$

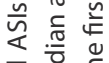

ब

동

غ่
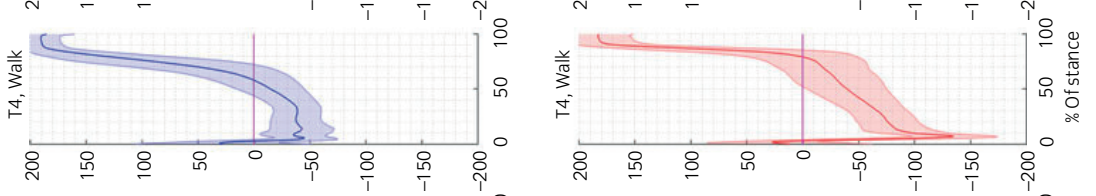

这

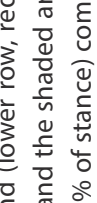
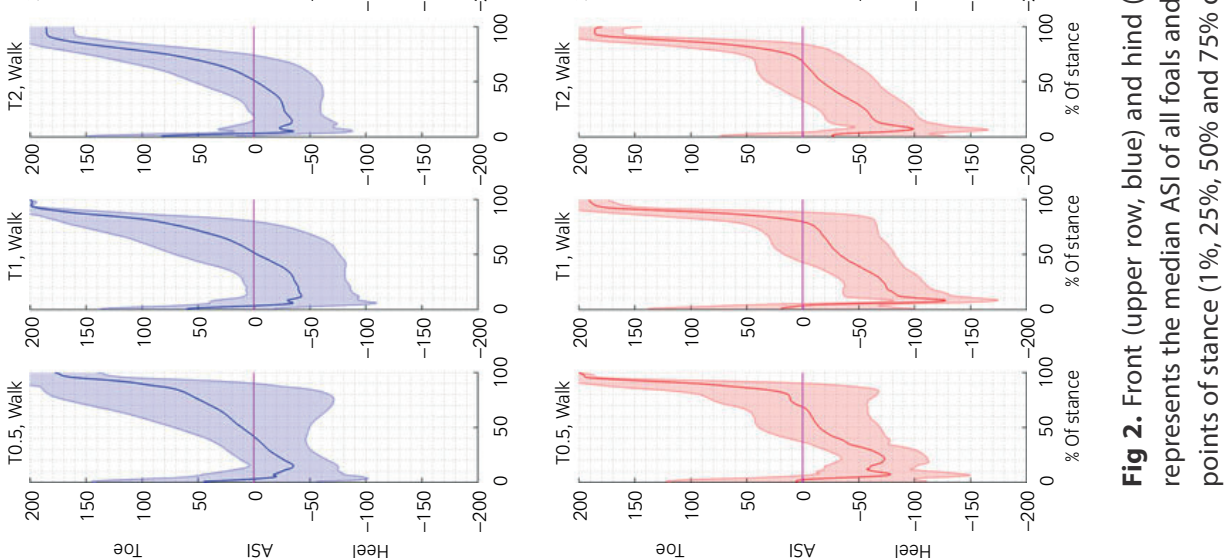

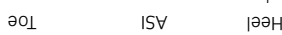



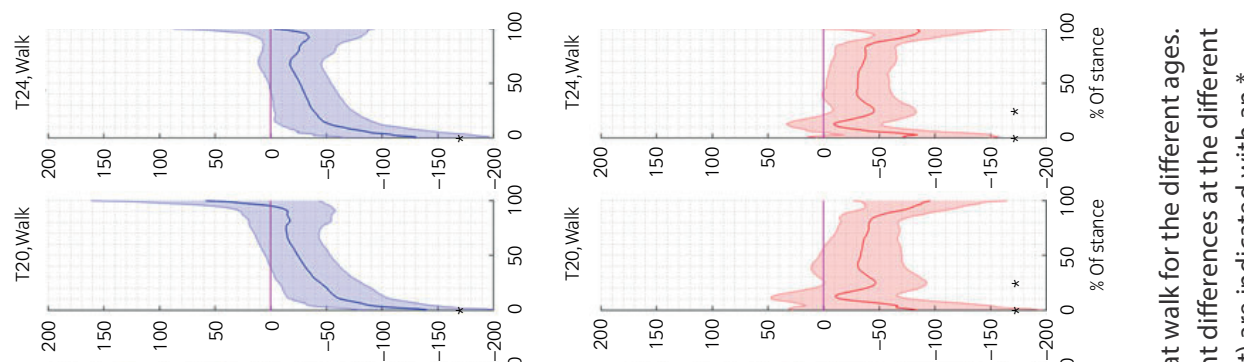

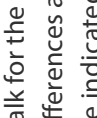
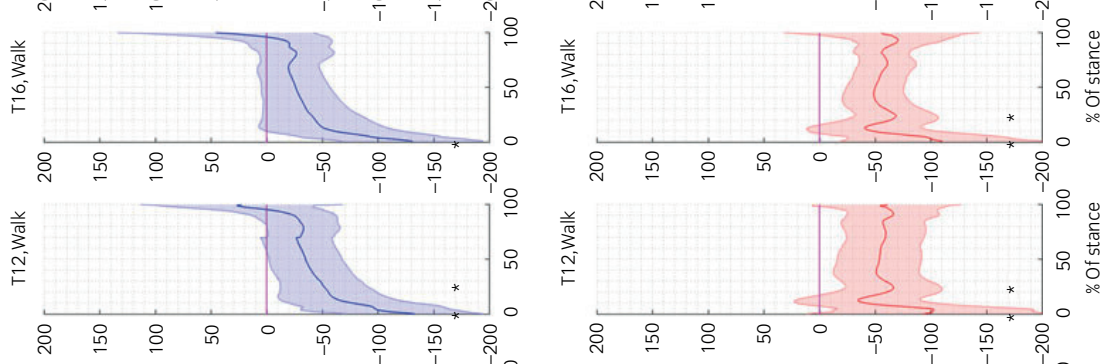

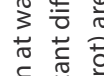

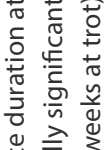

घㅊ

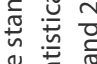

吾焉

है ज

웡
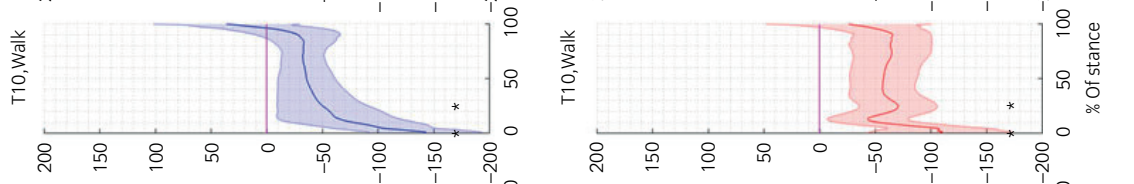

$\Phi \frac{\tilde{v}}{\bar{\sigma}}$

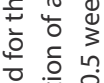

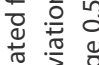

雪
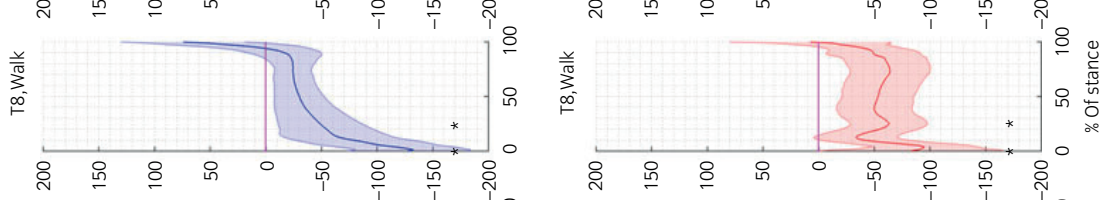

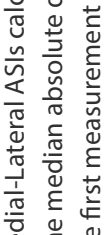
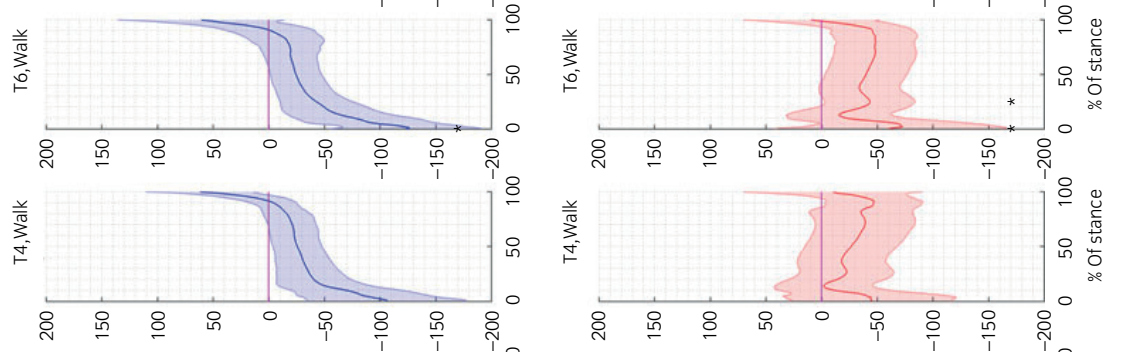

$\sum_{0}^{\infty} \underset{\pi}{ \pm}$

웧

उั

㐫

芩

至

ป $\frac{n}{\pi} \frac{\omega}{0}$
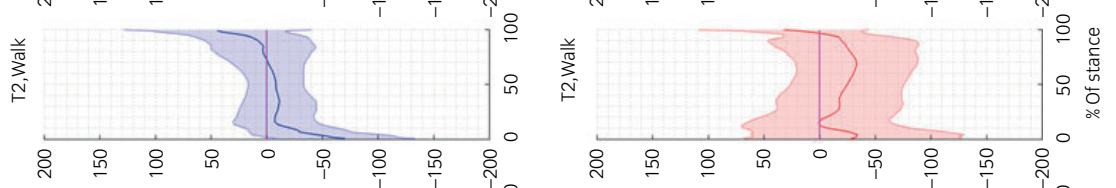

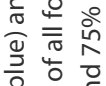

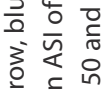

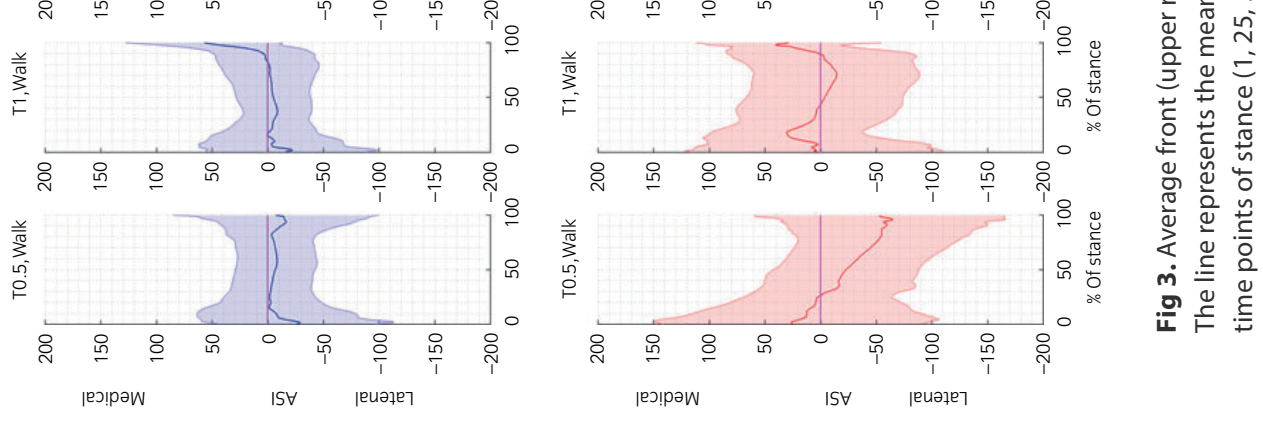


During the first 2 weeks after birth, data were recorded solely at the walk. From week 2 until week 12, foals were measured every fortnight at both walk and trot and subsequently at 16, 20 and 24 weeks. All trials were recorded with a small digital video camera (Philips full HD 1080p camcorder)c for retrospective visual control.

\section{Data processing}

Collected footprints were manually assigned to left fore (LF), right fore (RF), left hind $(\mathrm{LH})$ or right hind $(\mathrm{RH})$ based on the video images. With the help of the RsScan softwarea, hoof prints were manually divided in a toe and heel region by a line through the maximal hoof width and in a medial and lateral zone by a line through the middle of the hoof, as described by Oosterlinck et al. [5]. Any footprints that were not aligned with the pressure plate coordinate system were excluded from the analysis. After exporting the raw data from the pressure plate system, data were processed using custom-written matlabd scripts. Toe-heel and medial-lateral hoof balance ASI of each data frame was calculated using the vertical forces obtained for the four hoof zones by the following formulas [5]:

$$
\begin{aligned}
& \mathrm{ASI}(\text { toe }- \text { heel })=\frac{\mathrm{VF}(\text { toe })-\mathrm{VF}(\text { heel })}{0.5 *(\mathrm{VF}(\text { toe })+\mathrm{VF}(\text { hee }))} * 100 \\
& \mathrm{ASI}(\text { medial }- \text { lateral })=\frac{\mathrm{VF}(\text { medial })-\mathrm{VF}(\text { lateral })}{0.5 *(\mathrm{VF}(\text { medial })+\mathrm{VF}(\text { lateral }))} * 100
\end{aligned}
$$

For the toe-heel ASI, a positive value indicates higher loading towards the toe zone and a negative value higher loading towards the heel zone. For the medial-lateral ASI, a positive value indicates higher loading towards the medial zone and a negative value higher loading towards the lateral zone.

All ASI data were normalised to the percentage of stance time to compare the data obtained from the different measurements. This was performed by interpolating each measurement to 200 samples using a shape-preserving, piecewise cubic interpolation method. For each hoof- impact, the preferred hoof placement zone was determined based on the force distribution over the four zones at impact with the plate (first recorded data frame). For this, we have analysed the four zones in two pairs, mediallateral and toe-heel. Based on the zone pair which had the highest force value, the measurement was later classified as toe or heel first and as lateral or medial first.

\section{Data analysis}

Open software ( $R$ version 3.3.1)e was used for statistical analysis using the package 'nlme' (version 3.1-121) for linear mixed effects model, package 'Ime4' (version 1.1- 

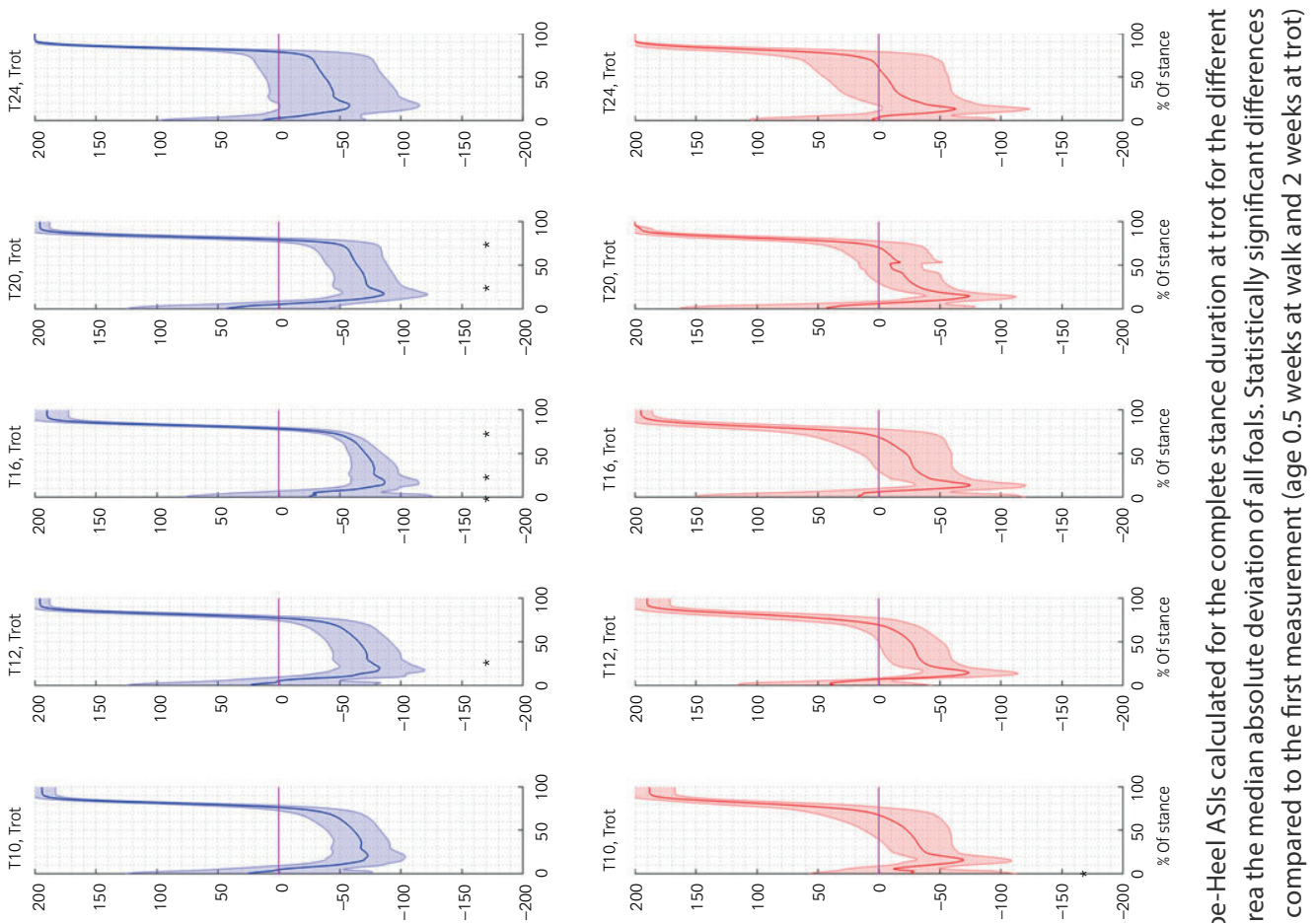

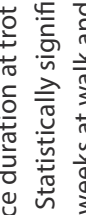

पू $\frac{\pi}{\pi}$ in

जे

嵌

을 눙

है

단

离

竞起

ज 응 웅

पे है

ญ ㅇํㅇ

T尌

응
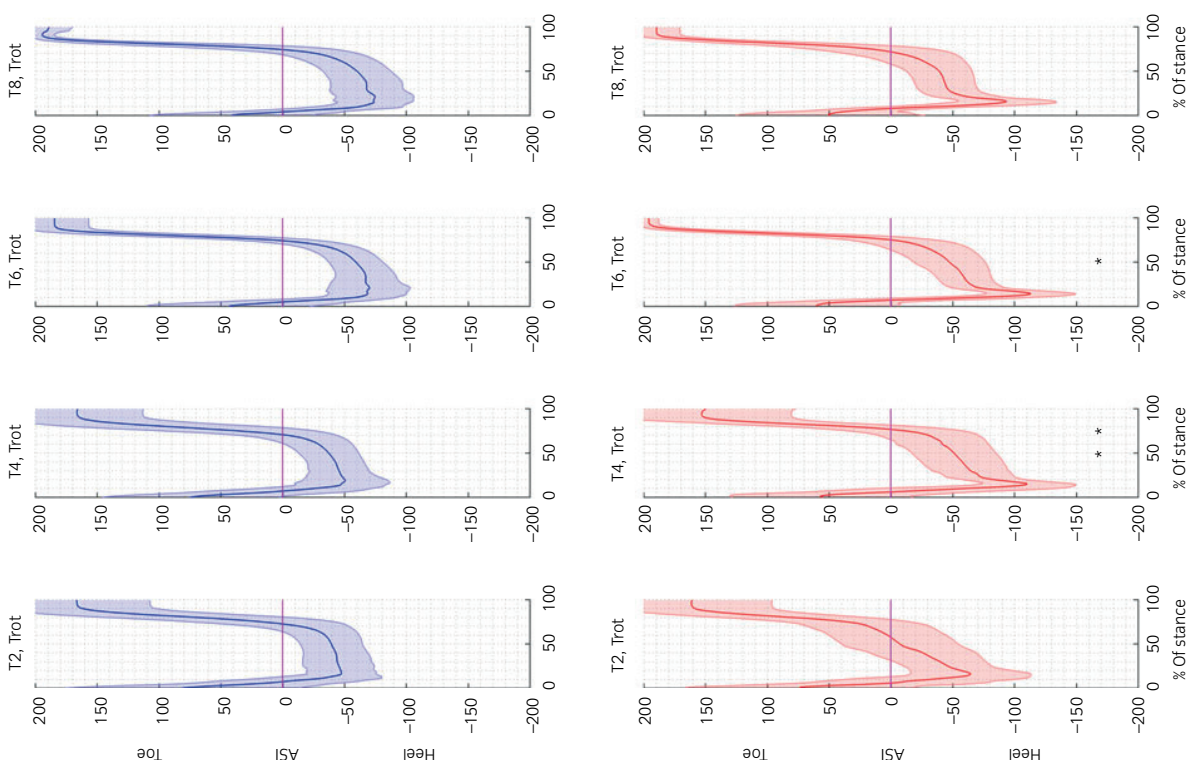

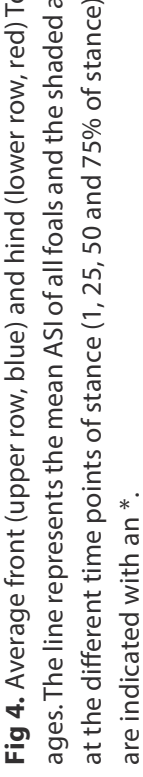


12) for logistic regression analysis. To evaluate the preferred landing site, data from all hoof impacts was used. For each trial, relative frequencies of lateral/medial and toe/ heel landing were calculated and used in a logistic regression analysis model. Odds ratios for preferred landing sites were determined by calculating the exponential function of the model estimates [9].

Both for walk and trot, a linear mixed effect model, with foal ID used as a random effect and time point, limb pair (front/hind), side (left/right) and OC status as fixed effects, were used for statistical evaluation of the data. Correction for multiple comparisons was done for both models with the False Discovery Rate method of Benjamini-Hochberg [10].

For all models, the first measurement moment (i.e. week 0.5 for walk and week 2 for trot) was used as a reference for the comparison between time points.

\section{Results}

\section{Foals}

All foals were considered clinically sound at visual inspection before each measurement session, except for two foals at 24 weeks. As these animals were judged to be sound again 1 week later, pressure plate measurements were taken then and included in the dataset as being representative for week 24 . At the first radiographic screening, five foals were negative for $\mathrm{OC}$, whereas in the other five at least one lesion was found. At the second screening moment, two out of the five foals were still positive for OC.

Figure 1 presents a front, hind and lateral view of a representative foal used in the study, illustrating the changes in conformation observed between week 1 and 12. At birth, this foal showed a subtle valgus deviation and relatively wide base of support. At the next measuring moment limbs were straight with a relatively smaller base of support.

\section{Hoof balance - walk ASI}

Details of model estimates and significances for the toe-heel/medial-lateral ASIs can be found in the Supplementary Item 1.

Median toe-heel ASI values during the whole stance phase are presented in Fig 2. At one percent of the stance phase, only the front limbs showed significantly more loading of the heel region at week 12 in comparison with the first measurement at 

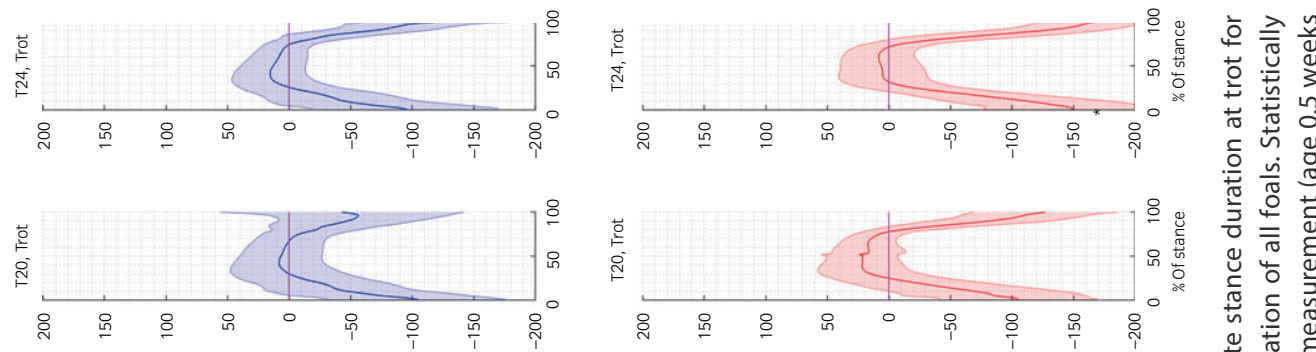

은 봉

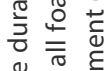

论

苟 으 는

\&

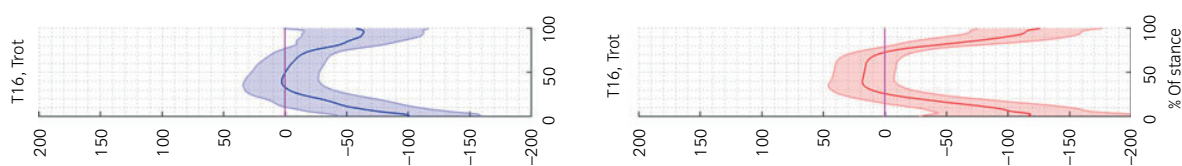

을 항

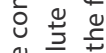

든

흐웜

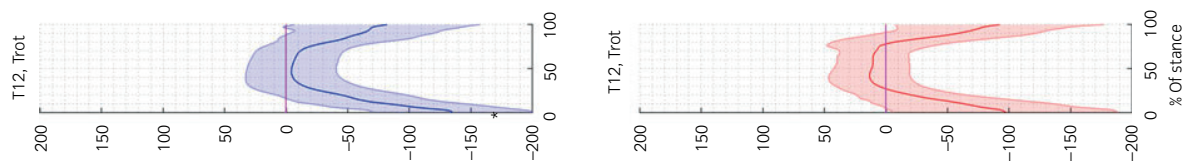

월 $\frac{0}{0}$

ป ह

ปับ

荙市离离

중

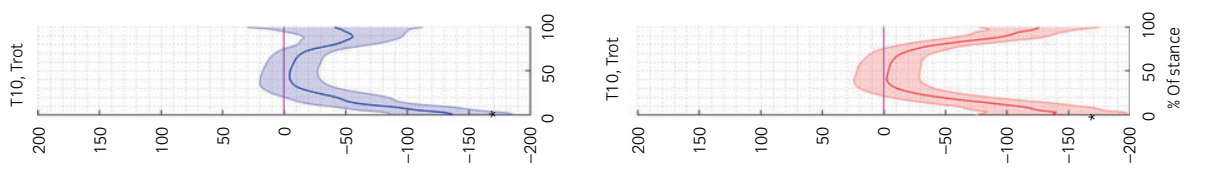

¿

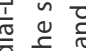

$\sum_{\Sigma}^{\infty}$

के

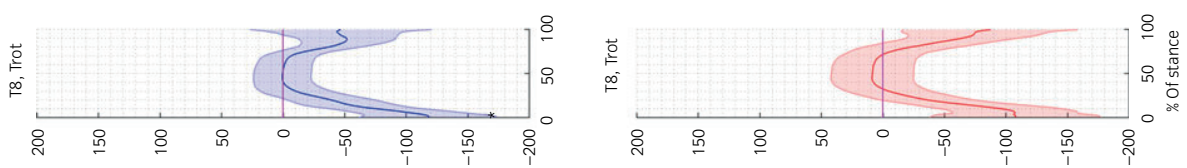

วั 윤

은

㐫

눈

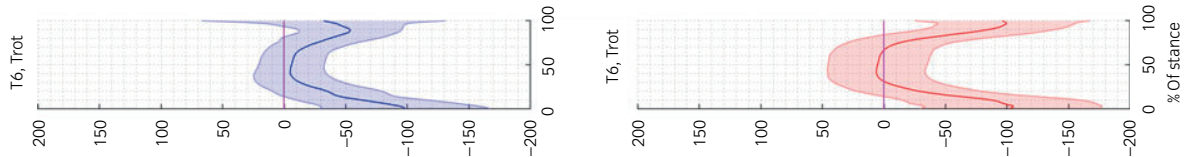

들 든
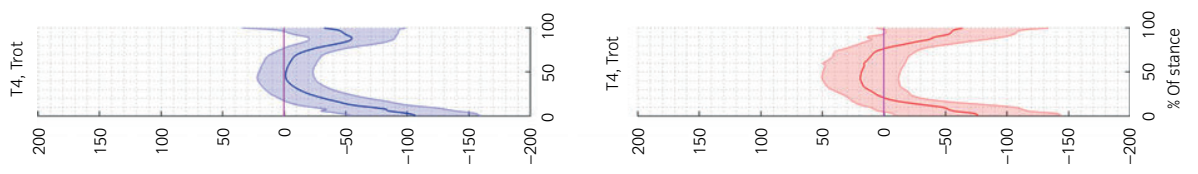

ซ ह 2

$\stackrel{\text { ⿷ }}{=}$

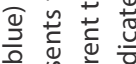

थ 屯

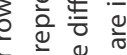

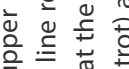

을 䒕

단

需

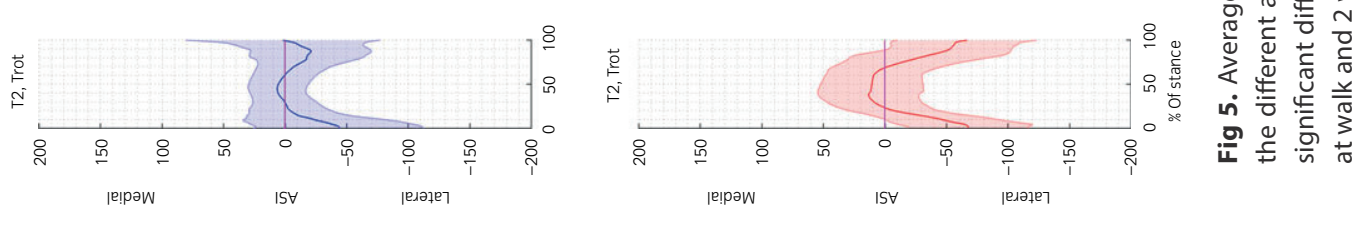


week 0.5 (P-value 0.04 ). At $25 \%$ of the stance duration, front limbs showed significantly more loading of the heel region in weeks 6 until 20 ( $P \leq 0.04)$, whereas in the hindlimbs the difference in this phase of stance with the first measurement was only significant at week 24 (P-value 0.001), which was the only significant difference found in the hindlimbs. In the front limbs, there were also differences at 50\% from week 6 until week $24(P \leq 0.01)$ and at 75\% from week 16 until week $24(P \leq 0.04)$. Statistical analysis at the end of stance (i.e. 99\%), was not possible due to skewness of the data, even after transformation. No significant effects of side (left/right) or OC status were found on the toe-heel balance.

Medial - lateral ASI at the walk is presented in Fig 3. At one percent of the stance duration, both the front $(P \leq 0.02)$ and hindlimbs $(P \leq 0.04)$ showed significantly more loading of the lateral side of the hooves from week 6 until 24 . At $25 \%$ of stance, the same trend was visible with significantly more loading of the lateral side of the front hoofs at weeks 8-12 ( $\leq \leq 0.04)$ and from week 6 until $24(P \leq 0.04)$ for the hindlimbs.

At half and $75 \%$ of stance, no significant changes in the medial - lateral loading distribution were found. A significant difference between the left and right limb, with more lateral loading of the right side was observed at 1 (P-value 0.0002), 25 (P-value 0.0001 ) and $50 \%$ (P-value 0.002 ) of the stance duration, but not at $75 \%$. No significant effect of OC status was found for the medial-lateral balance.

\section{Hoof balance - trot ASI}

For the toe-heel ASI at trot, only at week 16 (P-value 0.02) for the front and week 10 (P-value 0.02 ) in the hindlimbs, statistically significant differences, indicative of more loading of the heel region, were found at the beginning of the stance phase (1\%) (Fig 4). At $25 \%$ of stance, the front limbs showed significantly more loading of the heel at weeks 12-20 ( $\leq 0.05)$. During mid- stance, significantly more loading towards the heel was observed at weeks 4 and $6(P \leq 0.012)$ in the hindlimbs. At $75 \%$ of stance, significantly more loading of the heel region in the front limbs was observed in weeks 16 and $20(P \leq 0.03)$, for the hindlimbs this was only the case at week 4 ( $P$-value 0.04). No significant effects of side (left/right) or OC status were found on the toe-heel balance.

Medial-lateral hoof balance at trot is presented in Fig 5. At one percent of stance, significantly more loading of the lateral part of the front hooves was observed at weeks 8 until $12(P \leq 0.02)$. For the hindlimbs, this was only the case at weeks 10 and $24(\mathrm{P} \leq 0.04)$. 
At all points during stance, the right hooves showed significantly more loading of the lateral side $(P \leq 0.01)$. There were no effects of $O C$ status on the medial-lateral hoof loading pattern.

\section{Variation in hoof balance}

A general trend of decreasing intra-trial variability over time was observed, which was more prominent in the hindlimbs (Table 1). At walk, front limb intra-trial variability of the toe-heel ASI only changed significantly at 25\% (week 16, P-value 0.02 ) and $50 \%$ (weeks 8,16 and 20, $\mathrm{P} \leq 0.03$ ) of stance. In all cases, variability was lower than during the first measurement. Hindlimb variability of the toe-heel balance showed, besides significantly lower variability at weeks 10 and 16 ( $P \leq 0.03)(25 \%$ of stance) and in week 16 (P-value 0.03 ) (50\% of stance), also significantly lower variability at $75 \%$ of stance at weeks $6,8,16$ and $24(P \leq 0.03)$. At trot, only one difference was significant, in the hindlimbs at week 10 at $75 \%$ percent of stance ( $P$-value 0.05$)$.

Front limb medial-lateral balance did not show much change over time with only week 20 (P-value 0.04 ) at walk and $1 \%$ of stance duration having significantly lower variability. Also at $75 \%$ of stance, a significant difference was found for the front limbs at week 1 (P-value 0.01), however, in this case, variability was more compared to the first measurement a few days earlier. In contrast, hindlimb variability showed many significant differences for the medial-lateral ASI, all decreasing over time when compared to baseline. At trot, there was no change in the front limbs, but many changes over time, again all to values less than baseline, in the hindlimbs (Table 1).

\section{Hoof placement at landing}

During the first measurements at walk, more toe landing was observed (OR 1.5), which changed to more heel landing from week six onwards, although no significant changes compared to the first measurement were found (Table 2). At trot, the same trend was observed with young foals showing relatively more toe landing compared to later in life. This difference was significant from week eight on. No effects of OC or differences between front and hindlimbs were observed. However, there was at trot a significant left/right difference with more pronounced heel landing on the right side.

After 2 weeks, foals landed significantly more on the medial side of their hooves when walking. Also, a significant difference between front and hind and left and right was found, whereas OC status did not have a significant effect. Hindlimbs showed relatively more medial landing, and the right side showed more lateral landing. At trot, there was from the beginning more lateral landing compared to medial, which difference increased over time and became significantly different from baseline 
Table 1. Average intra-trial variability (median absolute variation) of the Toe-heel ASI and Mediallateral ASI of the front and hind limbs at walk and trot at 1,25,50 and $75 \%$ of stance duration

\begin{tabular}{|c|c|c|c|c|c|c|c|c|c|c|}
\hline \multirow[b]{2}{*}{ Time (weeks) } & \multirow[b]{2}{*}{ Limb } & \multirow[b]{2}{*}{ Gait } & \multicolumn{4}{|c|}{ Toe-heel } & \multicolumn{4}{|c|}{ Medial-lateral } \\
\hline & & & $1 \%$ & $25 \%$ & $50 \%$ & $75 \%$ & $1 \%$ & $25 \%$ & $50 \%$ & $75 \%$ \\
\hline 0.5 & Front & Walk & 49.18 & 23.86 & 23.41 & 18.04 & 54.14 & 20.41 & 18.19 & 20.25 \\
\hline 1 & & & 48.28 & 18.30 & 18.11 & 19.31 & 64.85 & 24.47 & 26.14 & $37.28^{*}$ \\
\hline 2 & & & 33.16 & 30.57 & 22.69 & 21.56 & 51.19 & 23.97 & 22.96 & 23.49 \\
\hline 4 & & & 49.97 & 19.17 & 16.92 & 23.85 & 36.11 & 27.68 & 21.59 & 22.04 \\
\hline 6 & & & 61.99 & 14.66 & 15.47 & 17.96 & 32.69 & 20.97 & 21.70 & 23.36 \\
\hline 8 & & & 49.82 & 15.01 & $13.25^{*}$ & 23.41 & 36.17 & 16.11 & 20.23 & 21.25 \\
\hline 10 & & & 33.63 & 14.22 & 14.70 & 19.66 & 22.09 & 18.72 & 15.57 & 16.97 \\
\hline 12 & & & 41.13 & 18.23 & 16.56 & 22.47 & 29.11 & 26.24 & 19.85 & 19.15 \\
\hline 16 & & & 34.02 & $12.85^{*}$ & $13.07^{*}$ & 17.43 & 27.87 & 18.68 & 17.63 & 18.91 \\
\hline 20 & & & 50.81 & 18.76 & $13.89^{*}$ & 15.35 & $18.00^{*}$ & 15.91 & 15.93 & 16.50 \\
\hline 24 & & & 48.67 & 15.07 & 14.75 & 15.15 & 33.51 & 26.37 & 17.65 & 20.06 \\
\hline 0.5 & Hind & Walk & 54.47 & 24.81 & 24.15 & 27.05 & 44.39 & 24.15 & 31.13 & 33.76 \\
\hline 1 & & & 43.80 & 26.60 & 27.37 & 25.16 & 41.51 & 32.41 & 32.05 & 32.09 \\
\hline 2 & & & 34.70 & 17.33 & 18.25 & 21.31 & 50.43 & 25.65 & $20.86^{*}$ & $23.45^{*}$ \\
\hline 4 & & & 60.59 & 19.55 & 23.05 & 24.59 & 46.24 & 16.52 & 26.65 & $26.36^{*}$ \\
\hline 6 & & & 37.51 & 19.70 & 19.47 & $16.91^{*}$ & 35.27 & 21.34 & $14.94^{*}$ & $16.92^{*}$ \\
\hline 8 & & & 53.61 & 18.40 & 17.34 & $15.85^{*}$ & 41.24 & 17.84 & $15.32^{*}$ & $17.21^{*}$ \\
\hline 10 & & & 45.51 & $16.06^{*}$ & 20.47 & 21.64 & 27.68 & 19.62 & $17.29^{*}$ & $14.91^{*}$ \\
\hline 12 & & & 52.32 & 20.39 & 23.02 & 17.88 & 33.80 & 24.12 & 23.42 & $15.78^{*}$ \\
\hline 16 & & & 21.55 & $14.06^{*}$ & $14.25^{*}$ & $16.06^{*}$ & 23.62 & 15.01 & $13.37^{*}$ & $17.70^{*}$ \\
\hline 20 & & & 52.98 & 16.20 & 21.32 & 16.50 & 38.72 & 14.48 & $16.56^{*}$ & $16.66^{*}$ \\
\hline 24 & & & 55.40 & 18.92 & 19.04 & $15.11^{*}$ & 42.20 & 25.76 & $20.99^{*}$ & $21.62^{*}$ \\
\hline 2 & Front & Trot & 39.23 & 23.60 & 20.58 & 22.96 & 49.32 & 19.54 & 18.07 & 19.89 \\
\hline 4 & & & 46.32 & 17.30 & 17.77 & 19.80 & 32.75 & 25.84 & 19.91 & 20.85 \\
\hline 6 & & & 63.08 & 14.84 & 14.99 & 18.38 & 55.45 & 20.20 & 13.53 & 15.65 \\
\hline 8 & & & 68.24 & 18.20 & 17.15 & 22.69 & 25.78 & 22.93 & 18.23 & 18.45 \\
\hline 10 & & & 56.27 & 14.05 & 11.61 & 17.16 & 23.43 & 18.24 & 15.09 & 16.54 \\
\hline 12 & & & 43.34 & 18.10 & 15.91 & 14.72 & 24.52 & 23.34 & 18.56 & 22.27 \\
\hline 16 & & & 46.27 & 15.64 & 10.73 & 16.27 & 28.52 & 17.15 & 13.18 & 18.68 \\
\hline 20 & & & 45.61 & 14.28 & 12.82 & 13.95 & 42.52 & 17.21 & 11.74 & 14.84 \\
\hline 24 & & & 64.54 & 16.71 & 15.13 & 16.77 & 29.45 & 17.08 & 12.96 & 12.88 \\
\hline 2 & Hind & Trot & 54.23 & 24.98 & 21.08 & 34.85 & 51.64 & 32.21 & 27.67 & 41.86 \\
\hline 4 & & & 48.00 & 16.37 & 22.58 & 22.84 & 37.65 & 19.42 & 17.56 & $20.16^{*}$ \\
\hline 6 & & & 40.65 & 17.56 & 16.36 & 22.83 & 40.72 & $17.06^{*}$ & $14.67^{*}$ & $18.26^{*}$ \\
\hline 8 & & & 55.86 & 15.49 & 14.05 & 22.36 & 33.52 & $18.31^{*}$ & 16.28 & $18.00^{*}$ \\
\hline 10 & & & 60.22 & 14.68 & 19.18 & $18.81^{*}$ & 28.07 & $18.13^{*}$ & $14.78^{*}$ & $16.52^{*}$ \\
\hline 12 & & & 42.12 & 17.17 & 17.68 & 29.99 & 29.75 & $19.75^{*}$ & 17.58 & $23.53^{*}$ \\
\hline 16 & & & 32.76 & 19.44 & 20.13 & 35.11 & $23.68^{*}$ & 20.62 & 16.55 & $19.63^{*}$ \\
\hline 20 & & & 27.27 & 19.65 & 16.10 & 25.96 & 33.68 & 23.20 & 15.75 & $15.33^{*}$ \\
\hline 24 & & & 38.28 & 14.40 & 15.60 & 24.08 & 27.56 & 21.89 & $16.83^{*}$ & $18.41^{*}$ \\
\hline
\end{tabular}

An asterisk indicates a significant difference when compared with the first measurement $(0.5$ week for walk and 2 weeks for trot). 
in weeks 8-12 to get back to the original level afterwards. At trot, no significant differences were found when comparing front and hind and again, significantly more lateral loading was observed at the right side.

Table 2. Odds ratios (OR) with $95 \%$ confidence intervals $(95 \% \mathrm{Cl})$ for toe or heel $(\mathrm{T}-\mathrm{H})$ and medial or lateral $(\mathrm{M}-\mathrm{L})$ landing at walk and trot at the different time points

\begin{tabular}{|c|c|c|c|c|c|c|c|c|}
\hline \multirow[b]{2}{*}{ Time (weeks) } & \multirow[b]{2}{*}{ Limb/side } & \multirow[b]{2}{*}{ Gait } & \multicolumn{3}{|c|}{ Toe-heel } & \multicolumn{3}{|c|}{ Medial-lateral } \\
\hline & & & Odds ratio & $95 \% \mathrm{Cl}$ & $P$ value & Odds ratio & $95 \% \mathrm{Cl}$ & $P$ value \\
\hline 0.5 & Front limbs & Walk & 1.5 & $0.8 / 2.6$ & & 1.1 & $0.7 / 0.2$ & \\
\hline 1 & & & 1.1 & $0.6 / 2.0$ & 0.8 & 0.7 & $0.4 / 1.2$ & 0.3 \\
\hline 2 & & & 1.1 & $0.6 / 2.1$ & 0.8 & $0.4^{*}$ & $0.2 / 0.8$ & 0.03 \\
\hline 4 & & & 1.3 & $0.7 / 2.2$ & 0.6 & $0.3^{*}$ & $0.2 / 0.5$ & $<0.001$ \\
\hline 6 & & & 0.7 & $0.4 / 1.3$ & 0.5 & $0.2^{*}$ & $0.1 / 0.3$ & $<0.001$ \\
\hline 8 & & & 0.6 & $0.4 / 1.1$ & 0.3 & $0.2^{*}$ & $0.1 / 0.3$ & $<0.001$ \\
\hline 10 & & & 0.6 & $0.4 / 1.1$ & 0.2 & $0.1^{*}$ & $0.1 / 0.3$ & $<0.001$ \\
\hline 12 & & & 0.6 & $0.4 / 1.1$ & 0.3 & $0.2^{*}$ & $0.1 / 0.3$ & $<0.001$ \\
\hline 16 & & & 1.1 & $0.6 / 1.8$ & 0.9 & $0.2^{*}$ & $0.1 / 0.3$ & $<0.001$ \\
\hline 20 & & & 0.9 & $0.5 / 1.5$ & 0.8 & $0.2^{*}$ & $0.1 / 0.3$ & $<0.001$ \\
\hline \multirow[t]{3}{*}{24} & & & 1.6 & $0.9 / 2.9$ & 0.2 & $0.2^{*}$ & $0.1 / 0.4$ & $<0.001$ \\
\hline & Hind limbs & & 0.9 & $0.7 / 1.1$ & 0.5 & $2.2^{*}$ & $1.7 / 2.9$ & $<0.001$ \\
\hline & Right side & & 0.9 & $0.7 / 1.1$ & 0.6 & $0.5^{*}$ & $0.4 / 0.7$ & $<0.001$ \\
\hline 2 & Front limbs & Trot & 4.1 & $2.3 / 7.1$ & & 0.7 & $0.4 / 1.2$ & \\
\hline 4 & & & 0.8 & $0.4 / 1.4$ & 0.6 & 0.5 & $0.3 / 0.9$ & 0.1 \\
\hline 6 & & & 0.7 & $0.4 / 1.2$ & 0.4 & 0.5 & $0.3 / 0.9$ & 0.1 \\
\hline 8 & & & 0.5 & $0.3 / 1.0$ & 0.1 & $0.4^{*}$ & $0.2 / 0.8$ & 0.03 \\
\hline 10 & & & $0.3^{*}$ & $0.2 / 0.6$ & $<0.001$ & $0.3^{*}$ & $0.1 / 0.5$ & $<0.001$ \\
\hline 12 & & & 0.5 & $0.3 / 0.9$ & 0.1 & $0.4^{*}$ & $0.2 / 0.7$ & 0.02 \\
\hline 16 & & & $0.3^{*}$ & $0.2 / 0.5$ & $<0.001$ & 0.5 & $0.3 / 0.9$ & 0.1 \\
\hline 20 & & & 0.5 & $0.3 / 0.9$ & 0.1 & 0.6 & $0.3 / 1.1$ & 0.2 \\
\hline \multirow[t]{3}{*}{24} & & & $0.4^{*}$ & $0.2 / 1.4$ & 0.02 & 0.6 & $0.3 / 1.0$ & 0.2 \\
\hline & Hind limbs & & 1.1 & $0.9 / 1.4$ & 0.7 & 1.0 & $0.7 / 1.3$ & 0.9 \\
\hline & Right side & & $0.7^{*}$ & $0.5 / 0.9$ & 0.01 & $0.4^{*}$ & $0.3 / 0.5 f$ & $<0.001$ \\
\hline
\end{tabular}

A value $>1$ is indicative of preferential toe or medial landing, $<1$ is indicative of preferential heel or lateral landing. An asterisk indicates a significant difference when compared with the first measurement. ( $T=0.5$ for walk and $T=2$ for trot). Significance between left and right and front and hind is also indicated with an asterisk. 


\section{Discussion}

This study confirmed our initial hypothesis that foals would show a relatively high variation in foot placement patterns that decreases over time. We also saw a systemic shift in dynamic hoof balance in this period. In young foals, there is relatively more loading towards the toe and towards the medial hoof side than in mature horses. The dynamic balance changes to be more like the mature horse within the first 24 weeks of life.

In general, intra-trial variability decreases over time as expected, although this was not the case for all parameters investigated. The most prominent reduction in intratrial variability was observed for the medial- lateral hoof balance of the hind limbs.

The hoof balance in mature horses is influenced by conformation, their locomotor pattern, the quality and frequency of trimming and the equestrian discipline the horse is bred for or competing in $[5,11,12]$. In the foal, subtle limb deviations are a common finding with carpal and fetlock valgus deviations being most prevalent [13]. Newborn foals also tend to splay their limbs, hereby increasing the width of their base of support $[14,15]$. This is thought to be a compensation for poor balance and muscle tone early in life [3]. In the current study population, mild deviations in conformation were also observed (Fig 1) during the first few weeks of life. Where these were mild and resolved spontaneously without treatment or farrier intervention, they might help to explain the relatively higher loading of the medial part of the hooves observed during the first weeks of life. Their gradual resolution can be related to the decrease in percentage and odds ratios for medial landing over time, as observed primarily in the hindlimbs at walk. Retrospective evaluation of photographs taken before each measurement showed a gradual increase in hock straightness after birth, and it is more likely that the change in loading pattern is related to this phenomenon. The toe-heel balance shows less evolution over time and better resembles the situation in adult warmblood horses from the start [5]. During the first weeks, hindlimbs are relatively more loaded at the heel than front limbs. This could be related to some degree of flexor tendon laxity and consequent digital hyperextension, as frequently seen in new-born foals [16], but clear clinical cases were not seen in our population.

Especially at trot, there is a marked preference to start loading at the lateral side of the hoof; after that, loading becomes more even with the hoof balance centring around zero and at the end of the stance phase, the lateral side is again loaded more. This resembles the loading patterns described previously in adult warmblood horses $[4,5]$. We observed significant side influences, with right limbs being loaded more laterally than left limbs. This observation is in line with the findings of Oosterlinck 
et al. [5] in adult Warmbloods, but the phenomenon was not observed in the work of van Heel et al. [4], or in adult ponies [6]. Possible explanations are the effect of the handler [5], laterality [17-19], functional differences between the limbs as also encountered in humans [5,20], and conformational differences between warmblood horses and ponies. In our study, the pressure plate was positioned next to the wall (at the right side of the foal). Most likely, due to the effects of the handler, who has been shown to play a role in very young and untrained foals [21], and of the mare, the foals leant slightly to the right side, probably responsible for the significantly higher loading of the lateral side of their right hooves.

A substantial decrease in the variability of the hoof loading pattern over time was observed confirming our initial hypothesis. The hypothesis was based on the observation that static balance development in young foals, as studied using stabilography, is characterised by relatively large swaying amplitudes and velocities immediately after birth that decreases later in life [3]. Comparable suboptimal balance during locomotion could lead to inconsistent pressure patterns in the different zones of the hooves during subsequent strides and hence to increased variation when calculating the intra-trial variability of an individual foal. Most prominent changes were observed in the medial-lateral hoof balance of the hindlimbs in the second part of the stance phase. Already during the first weeks of life, a significant reduction in variability was observed. This is in line with the rapid initial improvement of static balance [3] and the significant reduction in variability of the stance duration [2] observed in young foals and is likely due to better control thanks to the maturation of the neuromuscular system. In a stabilographic study cranio-caudal sway amplitudes that were larger than those in medial-lateral direction shortly after birth [3]. In our study, the reverse was the case. The difference might be explained by the momentum along the line of progression that is created by motion, which has a stabilising action along that line but naturally not perpendicular to it. Similar observations were made in horses suffering from spinal ataxia, a situation that is to some extent comparable with an immature neurological system. These horses also showed increased forces in the medial-lateral, but not in the sagittal plane [22].

The fact that the age-related decrease in variability was much more apparent in the hindlimbs than in the front limbs may have several explanations. The stabilising effect of the handler that mainly acts on the forequarter of the horse may be a factor here.

Another difference is that the placement of the front limbs can benefit from visual input, whereas hindlimbs solely have to rely on proprioception [22]. Post-natal development of the proprioceptive system may, therefore, be responsible for the 
gradual decrease in variability observed in the hindlimbs. The functional difference between the front limbs that carry more weight and the hindlimbs that are more involved in propulsion may play a role here too.

Some between-foal variability was seen at weeks 20 and 24, as can be deduced from the larger shaded area at these time points in Figs $2-5$. This may have been related to the fact that at week 20 about half of the foals and week 24 , all foals were weaned and consequently handled without their dam. Whereas handling of the foals without the presence of the mare was uneventful and all animals were accustomed to the location and procedure of the pressure plate data collection, the absence of the dam may have led to more variability in the trials. In the earlier study, an increase in variability of kinetic gait parameters was also observed in the stressful period directly after weaning [2].

Osteochondrosis was not a significant factor in our models, while there was a small, yet significant effect of OC on kinetic parameters in our previous study [2]. Hence, the minor changes observed in kinetic parameters due to subclinical lameness (resulting in a reduction of $n P V F$ in the affected limb) are not reflected in the hoof-balance ASI. This might be explained by the higher sensitivity of the force plate, which directly measures absolute ground reaction forces, for detecting lameness [23] compared to the pressure plate measures the relative distribution of load.

Through the study period, hoof development and conformation was normal, and no hoof trimming was performed, which is considered standard practice in horses with acceptable limb conformation [24]. This was a deliberate choice. Whereas uneven hoof growth could have induced some variability in this study due to changes in hoofbalance [4], hoof trimming would most likely have induced more variation unrelated to development, ultimately inducing a bias in the data.

There were several limitations to this study. The number of animals included in the study was limited, and all animals were bred for showjumping, making it impossible to draw firm conclusions regarding the whole warmblood population. The hoof regions were visually determined, which is more prone to error than the recently published approach that uses a hoof-bound coordinate system [7]. However, that approach was used for a static situation concerning hoof size, not for repeated measurements of growing foals with changing hoof shapes. Furthermore, only the hoof prints that were aligned with the pressure plate coordinate system could be used, which made it necessary to collect more hoof prints. The number of trials needed to collect sufficient hoof prints was variable between foals and measurement sessions; this can potentially influence the results due to possible differences in intra- trial variability. 
For the understanding of the development of hoof asymmetries as often observed in adult horses and their relation to lameness, further studies monitoring hoof pressure patterns for more extended periods than the first weeks of life are needed.

\section{Conclusions}

In the foal, dynamic hoof balance is changing substantially in the first few weeks of life. These alterations seem to follow the conformational changes in this same period. The toe-heel balance gradually shifts to the heel and the medial-lateral balance to lateral. This is accompanied by a gradual shift of landing preference in the same directions. Variability in pressure distribution, especially of the medial-lateral balance in the hindlimbs, decreased, which concurs with the decrease in the variability of some kinematic parameters in the same phase of life. Knowledge of this phenomenon of gradual stabilisation of hoof balance and preferred landing is helpful for the clinician when considering interventions in hoof balance of foals in early life. 


\section{Authors' declaration of interests}

No competing interests have been declared.

\section{Ethical animal research}

This study was reviewed and approved by the ethical committee of Utrecht University (DEC no.2014.III.04.038). Informed consent was obtained from the owner of the animals.

\section{Sources of funding}

None.

\section{Acknowledgements}

The authors would like to sincerely thank the owner and staff of the stud farm for permission to use the foals and M. Oosterlinck and S. Nauwelaerts for their valuable input, discussing the methods and results. Furthermore, A.L Wiertz, S.P. Kooij and M. den Heijer are acknowledged for their assistance with the data analysis and J.C.M. Vernooij for his advice on the statistical analysis.

\section{Authorship}

B. Gorissen contributed to the study design, data collection and data analysis. F. Serra Braganc0a contributed to data collection and analysis. $C$. Wolschrijn, W. Back and P.R. van Weeren contributed to study design. All authors contributed to writing the manuscript.

\section{Manufacturers' addresses}

${ }^{a}$ RsScan International N.V., Paal, Belgium.

${ }^{b}$ De Mulder Rubber and Plastics, Gent, Belgium. ${ }^{C}$ Koninklijke Philips N.V., Eindhoven, the Netherlands. $\mathrm{d}_{\text {MathWorks, Natick, Massachusetts, }}$ USA.

e R-Studio, Boston, Massachusetts, USA.

\section{Supporting Information}

Additional Supporting Information may be found in the online version of this article at the publisher's website:

Supplementary Item 1: Model estimates and significances. 


\section{References}

1. Denham, S.F., Staniar, W.B., Dascanio, J.J., Phillips, A.B. and Splan, R.K. (2012) Linear and temporal kinematics of the walk in Warmblood foals. J. Equine. Vet. Sci. 32, 112-115.

2. Gorissen, B.M.C., Wolschrijn, C.F., Serra Braganc0a, F.M., Geerts, A.A.J., Leenders, W.O.J.L., Back, W. and van Weeren, P.R. (2017) The development of locomotor kinetics in the foal and the effect of osteochondrosis. Equine Vet. J. 49, 467-474.

3. Nauwelaerts, S., Malone, S.R. and Clayton, H.M. (2013) Development of postural balance in foals. Vet. J. 198, 70-74.

4. Van Heel, M.C., Barneveld, A., van Weeren, P.R. and Back, W. (2004) Dynamic pressure measurements for the detailed study of hoof balance: the effect of trimming. Equine Vet. J. 36, 778-782.

5. Oosterlinck, M., Hardeman, L.C., van der Meij, B.R., Veraa, S., van der Kolk, J.H., Wijnberg, I.D., Pille, F. and Back, W. (2013) Pressure plate analysis of toe-heel and medial-lateral hoof balance at the walk and trot in sound sport horses. Vet. J. 198, Suppl. 1, e9-e13.

6. Oosterlinck, M., Royaux, E., Back, W. and Pille, F. (2014) A preliminary study on pressure-plate evaluation of forelimb toe-heel and mediolateral hoof balance on a hard vs. a soft surface in sound ponies at the walk and trot. Equine Vet. J. 46, 751-755.

7. Nauwelaerts, S., Hobbs, S.J. and Back, W. (2017) A horse's locomotor signature: COP path determined by the individual limb. PLoS ONE 12, e0167477.

8. Wilson, A., Agass, R., Vaux, S., Sherlock, E., Day, P., Pfau, T. and Weller, R. (2016) Foot placement of the equine forelimb: relationship between foot conformation, foot placement and movement asymmetry. Equine Vet. J. 48, 90-96.

9. Hogan, J.W. and Blazar, A.S. (2000) Hierarchical logistic regression models for clustered binary outcomes in studies of IVF-ET. Fertil. Steril. 73, 575- 581.

10. Benjamini, Y. and Hochberg, Y. (1995) Controlling the false discovery rate: a practical and powerful approach to multiple testing. J. R. Stat. Soc. Series B Stat. Methodol. 57, 289-300.

11. Johnston, C. and Back, W. (2006) Hoof ground interaction: when biomechanical stimuli challenge the tissues of the distal limb. Equine Vet. J. 38, 634-641.

12. Trotter, G.W. (2004) Hoof balance in equine lameness. J. Equine. Vet. Sci. 24, 494-495.

13. Robert, C., Valette, J.P. and Denoix, J.M. (2013) Longitudinal development of equine forelimb conformation from birth to weaning in three different horse breeds. Vet. J. 198, Suppl. 1, e75-e80.

14. Adams, R. and Mayhew, I.G. (1984) Neurological examination of newborn foals. Equine Vet. J. 16, 306-312.

15. Acworth, N.R.J. (2003) The healthy neonatal foal: routine examinations and preventative medicine. Equine Vet. Educ. 6, 45-49.

16. Korosue, K., Endo, Y., Murase, H., Ishimaru, M., Nambo, Y. and Sato, F. (2015) The cross-sectional area changes in digital flexor tendons and suspensory ligament in foals by ultrasonographic examination. Equine Vet. J. 47, 548-552.

17. McGreevy, D. and Rogers, L.J. (2005) Differences in motor laterality between breeds of performance horse. Appl. Anim. Behav. Sci. 99, 183- 190.

18. Van Heel, M., Kroekenstoel, A.M., Van Dierendonck, M.C., Van Weeren, P.R. and Back, W. (2006) Uneven feet may develop as a consequence of lateral grazing behaviour induced by the conformation of a foal. Equine Vet. J. 38, 646-651.

19. Kroekenstoel, A.M., Van Heel, M.C.V., Van Weeren, P.R. and Back, W. (2006) Developmental aspects of distal limb conformation in the horse: potential consequences of uneven feet in foals. Equine Vet. J. 38, 652- 656.

20. Sadeghi, H., Allard, P., Prince, F. and Labelle, H. (2000) Symmetry and limb dominance in ablebodied gait: a review. Gait Posture. 12, 34-45. 
21. Lucidi, P., Bacco, G., Sticco, M., Mazzoleni, G., Benvenuti, M., Bernabo', N. and Trentini, R. (2012) Assessment of motor laterality in foals and young horses (Equus caballus) through an analysis of derailment at trot. Physiol. Behav. 109, 8-13.

22. Ishihara, A., Reed, S.M., Rajala-Schultz, P.J., Robertson, J.T. and Bertone, A.L. (2009) Use of kinetic gait analysis for detection, quantification, and differentiation of hind limb lameness and spinal ataxia in horses. J. Am. Vet. Med. Assoc. 234, 644-651.

23. Weishaupt, M.A., Wiestner, T., Hogg, H.P., Jordan, P. and Auer, J.A. (2004) Compensatory load redistribution of horses with induced weightbearing hindlimb lameness trotting on a treadmill. Equine Vet. J. 36, 727-733.

24. O'Grady, S.E. (2017) Routine trimming and therapeutic farriery in foals. Vet. Clin. N. Am.: Equine Pract. 33, 267-288. 
[Chapter 10]

\section{Mouldable, thermoplastic, glue-on frog-supportive shoes change hoof kinetics in normal and obese} Shetland ponies

J. Sleutjens ${ }^{+*}$, F. M. Serra Braganca ${ }^{\dagger}$, M. W. Van Empelen ${ }^{\dagger}$, R. E. Ten Have ${ }^{\dagger}$, J. De Zwaan ${ }^{\dagger}$, E. Roelfsema ${ }^{\dagger}$, M. Oosterlinck ${ }^{\ddagger}$ and W. Back ${ }^{\dagger \ddagger}$

${ }^{\dagger}$ Department of Equine Sciences, Faculty of Veterinary Medicine, Utrecht University, Utrecht, the Netherlands

${ }^{\ddagger}$ Department of Surgery and Anaesthesia of Domestic Animals, Faculty of Veterinary Medicine, Ghent University, Merelbeke, Belgium.

*Correspondence email: j.sleutjens@uu.nl; Received: 25.01.17; Accepted: 10.01.18
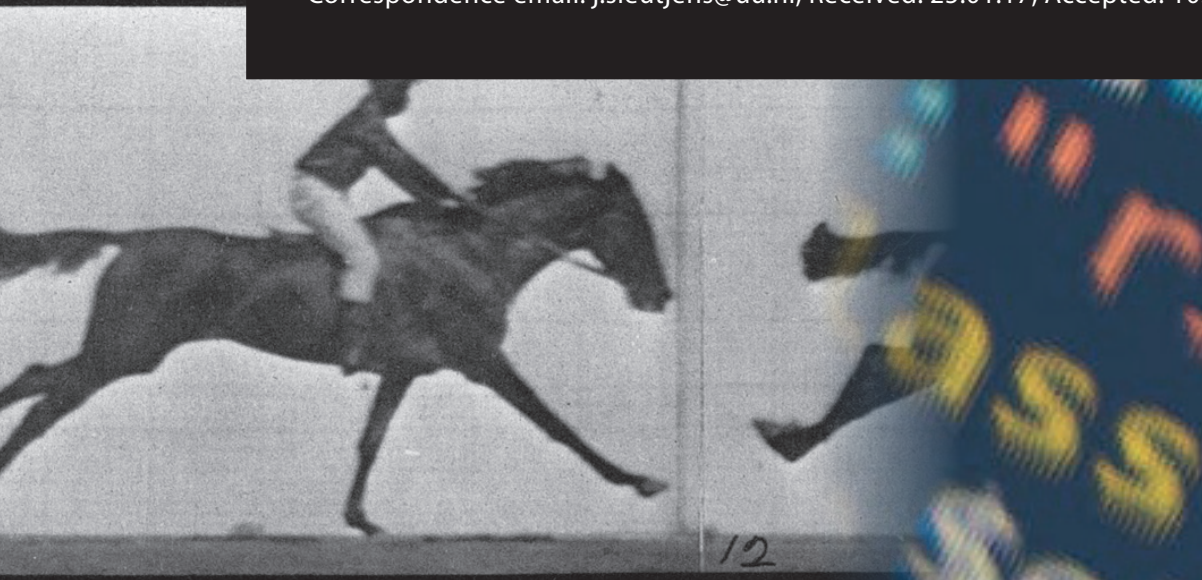

Keywords horse, ponies, hoof kinetics, force and pressure plate, body condition score, subclinical laminitis, shoe 


\section{Summary}

Background: Obesity and hyperinsulinaemia are frequently encountered in the equine population and risk factors for the development of laminitis. There are many options for hoof support that claim a beneficial effect, but often the scientific evidence is scarce.

Objectives: To quantify the effect of frog-supportive shoes on hoof kinetics in normal and obese ponies.

Study design: Controlled in vivo trial.

Methods: Ten Shetland mares $(n=10)$ with a normal $(n=5)$ or obese $(n=5)$ body condition were led over a dynamically calibrated pressure plate before (T0), immediately after (T1) and $72 \mathrm{~h}$ (T2) after application of the shoes. The following locomotor variables were measured: stance duration (StDur), vertical impulse (VI), peak vertical force (PVF), time to PVF and time from PVF to lift off. The hoof print was divided into a toe and heel region and the StDur toe-heel index was calculated. The toe-heel hoof balance curves of the vertical force were plotted throughout the stance phase.

Results: The VI and PVF increased significantly $72 \mathrm{~h}$ after application of the shoes, when compared with T0 and T1. The StDur toe-heel index and toe- heel balance curves were significantly different between the normal and obese ponies. These variables became more comparable between the groups after application of the frog-supportive shoes.

Main limitations: It would have been interesting to measure the effect of the shoe in patients with acute laminitis. However, this would have had major welfare implications.

Conclusions: The obese ponies moved more carefully than the normal group, demonstrated by a decreased loading of the toe area. The data illustrate that the ponies became more comfortable $72 \mathrm{~h}$ after application of the shoes, with a pronounced effect in the obese group. Thus, these results suggest that frog-supportive shoes could be beneficial, especially for obese ponies. 


$\begin{array}{ll}\text { Abbreviations } \\ \text { BCS } & \text { Body condition score } \\ \text { BW } & \text { Body weight } \\ \text { EMS } & \text { Equine metabolic syndrome } \\ \text { Glucauc } & \text { The area under the curve for glucose } \\ \text { lauc } & \text { The area under the curve for insulin } \\ \text { IQR } & \text { Interquartile range } \\ \text { PVF } & \text { Peak vertical force } \\ \text { StDur } & \text { Stance duration } \\ \text { TPVF to lift off } & \text { Time from peak vertical force to lift off } \\ \text { TPVF } & \text { Time to peak vertical force } \\ \text { VF } & \text { Vertical force } \\ \text { VI } & \text { Vertical impulse }\end{array}$

\section{Introduction}

Laminitis is a common condition in horses and ponies, with major welfare implications in the short- and long term. A study carried out in the UK, which was based on an owner questionnaire, reported that $15 \%$ of horses and ponies had a previous history of laminitis; of these, $46.2 \%$ were reported to have suffered from more than one episode, and the majority of patients (75.9\%) with recurrent episodes were ponies [1]. The prevalence of endocrine conditions such as pars pituitary intermedia dysfunction (PPID) and equine metabolic syndrome (EMS), potential underlying causes, was estimated to be as high as $89 \%$ in a group of 36 cases of laminitis, among which most patients were ponies [2]. EMS is defined as a phenotype of obesity, insulin dysregulation and laminitis or a predisposition to developing laminitis [3]. Obesity and hyperinsulinaemia are identified as risk factors for the development of pastureassociated laminitis [4]. Laminitis due to hyperinsulinaemia leads to specific lamellar pathology in natural occurring cases [5].

The current study was designed to measure in vivo the effect of a mouldable, thermoplastic, glue-on, frog-supportive shoe (Imprint shoe ${ }^{\circledast}$ )a. In this study, the effects of these shoes on hoof kinetics in normal and obese ponies were measured using a combined force and pressure plate system, which is a validated method to assess hoof balance and the clinical effect of different types of shoes [6-9]. 
This study tested the hypothesis that there would be a significant difference in hoof kinetics (StDur, TPVF, PVF, TPVF to lift off, VI) between normal and obese ponies and that there would be an overall change in hoof kinetics after application of the shoes. Furthermore, it was hypothesised that the effect of the shoes on hoof kinetics would differ between the normal and obese ponies.

\section{Materials and methods}

\section{Ponies}

Shetland ponies from the research herd of the Faculty of Veterinary Medicine of Utrecht University were used for this study. The ponies were part of a larger study into the epigenetic effects of equine metabolic syndrome in embryos. The ponies that participated in the study were clinically sound, unshod for a period of at least 6 months and their feet were routinely trimmed every 6-8 weeks. The ponies had no clinical signs of current or previous laminitic episodes. The obese ponies $(n=5)$ had a mean ( \pm s.d.) body mass of $244 \pm 36 \mathrm{~kg}$, age of $5 \pm 1.8$ years, height at the withers of $1.00 \pm 0.05 \mathrm{~m}$ and a median ( $\pm \mathrm{IQR}$ ) body condition score $(\mathrm{BCS})$ of $9.0 \pm 0.75$, using a validated scoring system with a scale from 1 to 10 [10]. The normal ponies $(n=5)$ had a mean ( \pm s.d.) body mass of $185 \pm 19 \mathrm{~kg}$, age of $4 \pm 1.5$ years, height at the withers of $0.99 \pm 0.02 \mathrm{~m}$ and a median ( $\pm \mathrm{IQR}) \mathrm{BCS}$ of $6.0 \pm 1.75[10]$.

\section{Oral glucose tolerance test}

Before the start of this study, an oral glucose tolerance test was performed [11]. The ponies were starved during $12 \mathrm{~h}$. A jugular catheter was placed, after disinfecting and locally anaesthetising the injection area with $2 \%$ lidocaine. Next, a nasogastric tube was placed and $1.0 \mathrm{~g} / \mathrm{kg}$ BW glucose, dissolved in $2 \mathrm{~L}$ water, was given through the tube within $2 \mathrm{~min}$. Blood samples ( $8 \mathrm{~mL}$ ) were collected at $\mathrm{t}=0,30,60,90,120$, 180,240 and $300 \mathrm{~min}$ after administration of glucose. Glucose concentrations were measured in all blood samples using an enzymatic spectrophotometerb, serum insulin concentrations were measured only in samples taken at $\mathrm{t}=0,30,60,90$ and $120 \mathrm{~min}$, using a new commercially available solid- phase, enzyme-labelled chemiluminiscent immunometric assayc (CLIA - Immulite 2000 Insulin) designed for human insulin. The area under the curves for glucose (Glucauc) and insulin (lauc) were calculated by integration (using a linear trapezoidal method) and compared between the normal and obese ponies. 


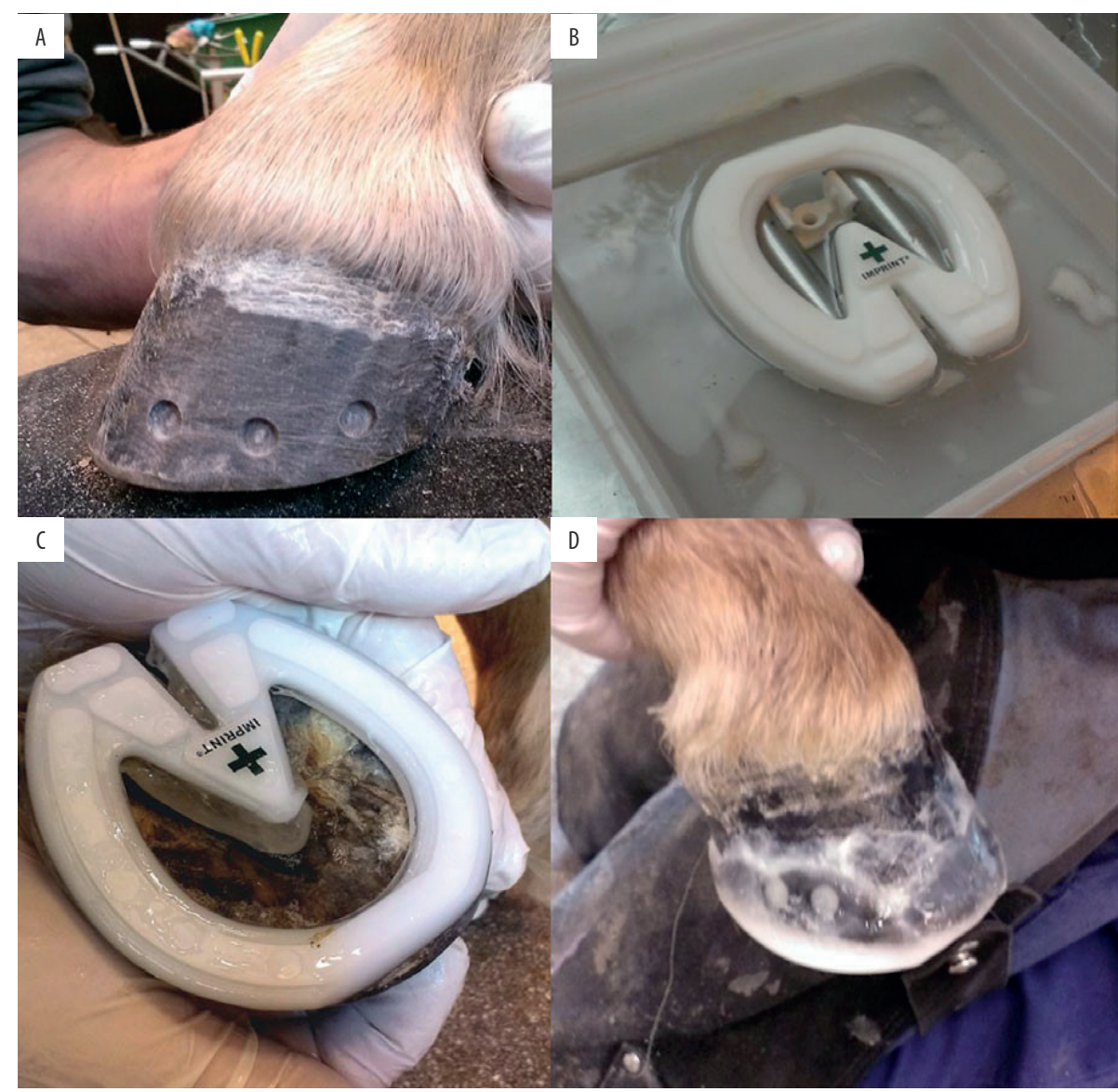

Fig 1. Schematic illustration that summarises the application process of the frog-supportive mouldable shoes: a) Six superficial indentations are drilled in the dorsal hoof wall to increase the contact area between the hoof wall and the mouldable plastic. This is followed by the application of an adhesive glue to the hoof wall. b) The upper rim of the shoe becomes mouldable after it has been emerged in boiling water. c) The correct size frog-supportive shoe is fitted on the foot. d) The mouldable thermoplastic hardens out within minutes with the application of a freezer spray.

\section{Application of the mouldable, thermoplastic, frog- supportive shoes}

The ponies were studied on the combined force and pressure plate system immediately after routine foot trimming (maintaining a straight hoof axis, conserving the frog and trimming the hoof wall as needed) (T0). After the first measurements had been taken (as described below), Imprint ${ }^{\circledR}$ shoes were applied to both front feet as instructed by the manufacturera (Fig 1 ) and immediately after application, the measurements were repeated $(T=1)$. Finally, the measurements were repeated $72 \mathrm{~h}$ 
after application of the shoes $(T=2)$. The trimming, as well as the application of the shoes, was performed by a single experienced farrier (J.d.Z.). The study was approved by the animal ethical committee of Utrecht University.

\section{Data collection}

After a 5-min warming-up period, which consisted of walking in-hand in straight lines, the ponies were led over the measuring system, first at the walk and subsequently at the trot. The measuring system consisted of a pressure plate (Footscan 3D $1 \mathrm{~m}$ system)d with a spatial resolution of 2.6 sensors/cm2, and a pressure range of $0-200$ $\mathrm{N} / \mathrm{cm} 2$, mounted on top of a force platform (Z4852C)e in the middle of a 20-m long track, covered with a 5-mm thick rubber mat with a shore hardness of 655 (NR/SBR)f, as used in previous studies $[7,8,12]$. The force and pressure plate were sampling at 250 $\mathrm{Hz}$ and recording was triggered at contact with the force/ pressure plate. The pressure plate was dynamically calibrated by the force plate. Two pairs of photoelectric sensors (WE260-S270)g that were positioned $2 \mathrm{~m}$ apart, perpendicular to the track were used to record the average speed. Although acceleration was not measured directly, the length of the track ensured that the effect of acceleration and deceleration at the start and end of each trial was minimised over the central measuring area. Five valid measurements were collected for each front hoof at both the walk and trot. A trial was considered valid if the pony looked straight ahead and maintained a constant pace over the measuring system, if a complete print of at least one front hoof was recorded, and if the speed was within a preset range of $0.8-1.4 \mathrm{~m} / \mathrm{s}$ at the walk and $2.5-3.5 \mathrm{~m} / \mathrm{s}$ at the trot [12].

\section{Data processing}

The mean from five valid trials of each of the following parameters was calculated for the right and left front hoof; this was done for each individual pony at both walk and trot. Therefore, at each time point, 20 measurements (5 ponies; left and right hoof; walk and trot) were collected for the normal and obese group. For each front hoof, the following variables were calculated at the walk and the trot: stance duration (StDur), expressed in milliseconds (ms); vertical impulse (VI), calculated by time integration of the force-time curves $(\mathrm{N} \mathrm{s})$ and normalised for individual body mass (kg); peak vertical force (PVF), calculated as the maximal vertical force (N) normalised for individual body mass (kg); time to peak vertical force (TPVF), which is the time at which the maximal force occurred (ms); and time from peak vertical force to lift off (TPVF to lift off) (ms) $[8,12]$. Data are presented as mean \pm s.d. All temporal variables were calculated from the pressure plate; the force plate was used to calibrate the force data (PVF and $\mathrm{VI}$ ) recorded by the pressure plate. Each individual hoof print was divided visually into a toe and a heel region by a line through the maximal 


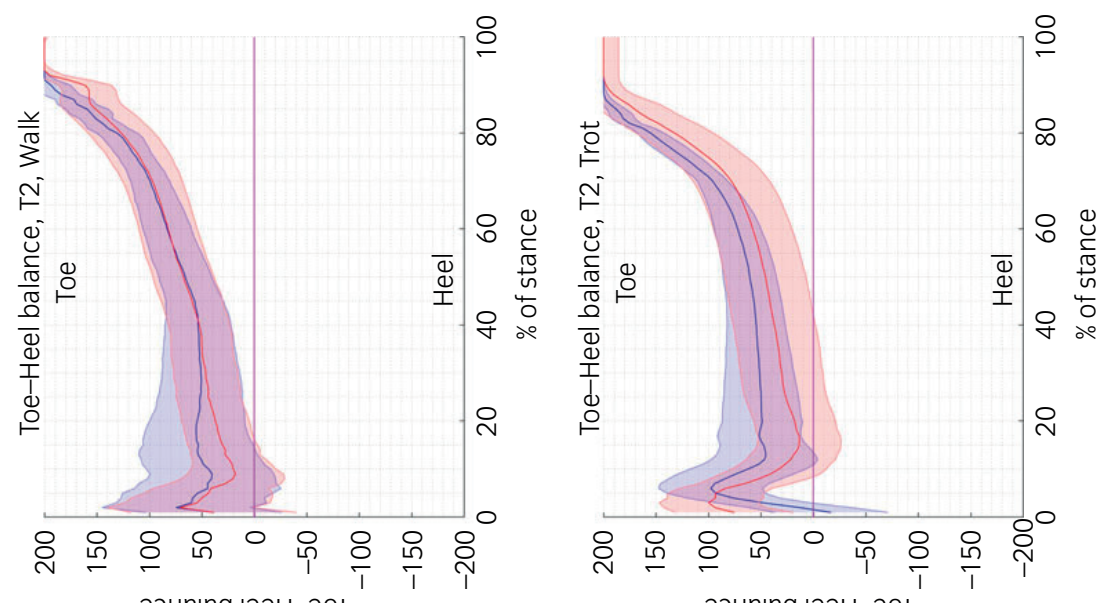

әэиеје |әәН-әо।

әэиејеq юәнН-әо।

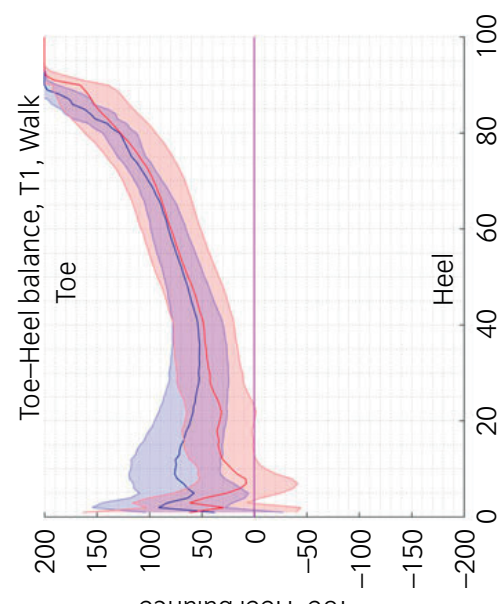

әэие|еq |әән-әо।

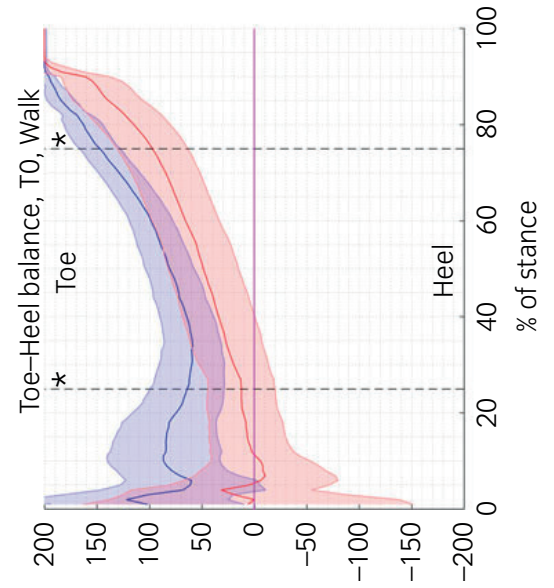

әэие|еq |әән-әо।

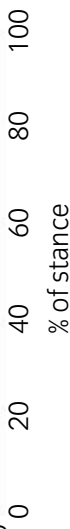

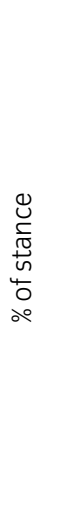

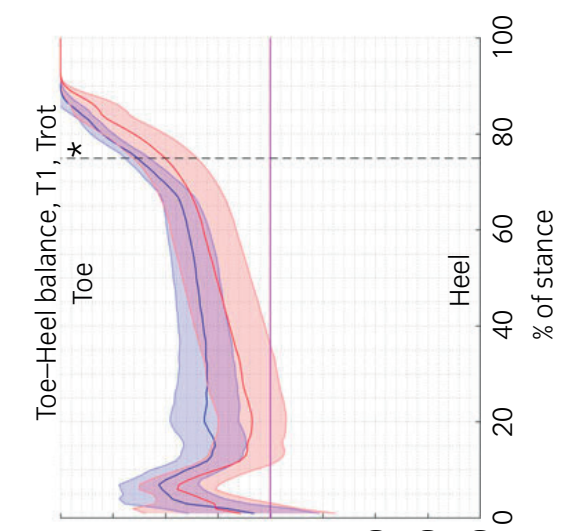

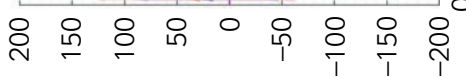

әэиеје |әән-әо।

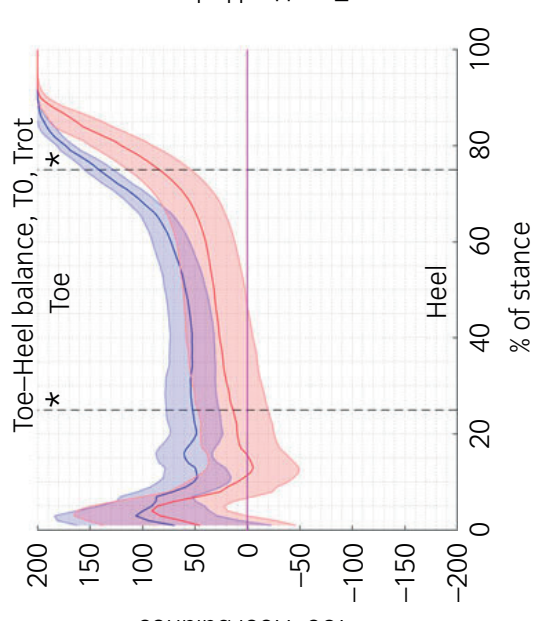

әэиеје |әән-әо।

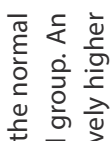

岳 $\frac{0}{0}$

के 항

है व

등

尊带

¿

$\because \frac{0}{\pi}$

כํํㅇ है

ภ บ

든 들 의

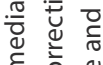

워

돈

일

है

ㄷํㅇ ᅯ

는 文

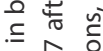

ㅎํ응

힌

둥

क ष

원

告

t。

प ฮ

步号

ष 흉

纯

$\frac{\pi}{\pi} *$

$\bar{\Phi}$

등

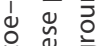

$+\frac{0}{0}$

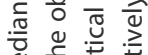

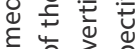

ฯ

다일

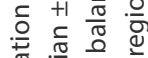

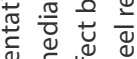

घ

히웜

웜

웡

है $\subseteq$ 吾

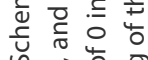

认ั

순 
hoof width, as described previously [7]. Subsequently, the StDur toe-heel index was calculated as [(StDurToe StDurHeel)/0.5(- StDur ${ }_{\text {Toe }}+$ StDur $\left._{\text {Heel }}\right)$ * 100\% and presented as median \pm interquartile range $(\mathrm{IQR})$. The toe-heel balance was calculated as $\left[\left(\mathrm{VF}_{\mathrm{Toe}}\right.\right.$

$\left.\left.-\mathrm{VF}_{\text {Heel }}\right) / 0.5\left(\mathrm{VF}_{\text {Toe }}+\mathrm{VF}_{\text {Heel }}\right)\right] * 100 \%$ [7]. Using this method, an index of 0 indicates equal contribution of the toe and heel region for the measured variable, whereas positive or negative values (range 200 to -200\%) indicate a relatively higher contribution of the toe or heel region, respectively. The toe- heel balance data are presented as \pm median median absolute deviation (mad) curves throughout the stance phase (Fig 2) [7].

\section{Data analysis}

Custom-made Matlab scripts (Matlab R2015a) ${ }^{\mathrm{h}}$ were used for processing the data and IBM SPSS Statistics $22^{i}$ for the statistical analysis. A Shapiro- Wilk test and Levene's test were performed on the variables Gluc $_{\text {auc }}$ and lauc to assure the assumptions of normality and equal variances. A natural log transformation was applied to $\mathrm{I}_{\text {auc }}$ in order to meet the assumption of normality. An independent $t$-test was used to calculate the difference in Gluc $_{\text {auc }}$ and $\mathrm{I}_{\text {auc }}$ between both groups. The hoof kinetic variables were checked for normality by the Shapiro-Wilk test and normal distribution of the residuals was verified using $\mathrm{Q}-\mathrm{Q}$ plots. A natural log transformation was applied to the variable TPVF in trot in order to meet the assumption of normality. The variables TPVF, PVF, TPVF to lift off, StDur, VI and speed were tested with a linear mixed model. The model was constructed with 'pony' as a random effect, time point (T0, T1, T2), BCS, limb, and interaction between time point and BCS were tested as fixed factors. The best model was chosen on the basis of the lowest Akaike information criterion (AIC) score. Pairwise comparisons were performed and a post hoc Bonferonni correction was applied by dividing the alfa of $\mathrm{P}<0.05$ by the number of pairwise comparisons. The StDur toe-heel index and the toe- heel balance at five selected time points (1, 25, 50,75 and $100 \%$ of the stance phase) were not distributed normally. Consequently, independent nonparametric Kruskal-Wallis tests or Mann-Whitney $U$ tests were applied with pairwise comparisons. A post hoc Bonferroni correction was applied by dividing the alpha of $\mathrm{P}<0.05$ by the number of pairwise comparisons. $\mathrm{A} P \leq 0.05$ was used to indicate statistical significance unless stated otherwise.

\section{Results}

\section{Oral glucose tolerance test}

The Gluc auc $\mathrm{mmol} \mathrm{min} / \mathrm{L}$ (mean \pm s.d.) was $2259 \pm 599$ in the normal and $1725 \pm 214$ in the obese group. The $I_{\text {auc }} \mu \mathrm{U} \mathrm{min} / \mathrm{mL}$ (mean \pm s.d.) was $584 \pm 400$ in the normal group and $6219 \pm 8043$ in the obese group $(P<0.03)$. 


\section{Effect of limb}

There was no significant difference between the left and right hoof, except for the variable PVF to lift off in walk. Therefore, the measured variables from both hooves were pooled, and the difference between the left and right hoof for PVF to lift off is mentioned in the appropriate section.

\section{Effect of BCS}

The differences between the normal and obese group were analysed irrespective of time point. Therefore, for each group, 60 measurements were included (5 ponies; 3 time points; left and right hoof; walk and trot). At the walk, the StDur (ms) was $675.6 \pm$ 41.6 in the normal and $582.7 \pm 51.4(P<0.002)$ in the obese group. The StDur toe-heel index was $13.5 \pm 6.3$ in the normal and $9.2 \pm 2.9(P<0.001)$ in the obese group, which means that the heel region contributed relatively more than the toe region to the total StDur in the obese group. The VI ( $\mathrm{N} \mathrm{s} / \mathrm{kg})$ was $2.6 \pm 0.4$ in the normal and $2.0 \pm$ $0.5(P<0.017)$ in the obese group. The time from PVF to lift off $(\mathrm{ms})$ was $230 \pm 12.4$ in the normal and $194 \pm 17.9(P<0.001)$ in the obese group. The other variables did not differ significantly between the BCS groups.

At the trot, the PVF $(\mathrm{N} / \mathrm{kg})$ was $9.5 \pm 1.8$ in the normal and $7.8 \pm 1.4$ in the obese group $(P<0.02)$. The StDur toe-heel index was $16.6 \pm 4.9$ in the normal and $11.6 \pm 2.5$ $(P<0.001)$ in the obese group. The other variables did not differ significantly between the BCS groups (Table 1).

\section{Effect of the mouldable, thermoplastic, frog- supportive shoes}

After Bonferonni correction, a $\mathrm{P}<0.017$ was used to indicate statistical significance. The differences between time points were analysed irrespective of BCS. Therefore, at each time point, 40 measurements were included (10 ponies; left and right hoof; walk and trot). At the walk, the $\mathrm{VI}(\mathrm{N} \mathrm{s} / \mathrm{kg})$ decreased from T0 $(2.3 \pm 0.5)$ to T1 $(2.0 \pm 0.4)$ and increased again at T2 $(2.6 \pm 0.5)$; the differences were significant between T0 and the subsequent time points $(\mathrm{P}<0.002)$ and between T1 and T2 $(\mathrm{P}<0.001)$. The PVF $(\mathrm{N} / \mathrm{kg})$ decreased from T0 (5.4 \pm 1.0$)$ to T1 $(4.8 \pm 0.9)$ and increased at T2 $(6.1 \pm 0.9)$; the difference between T0 and T2 $(P<0.003)$ and between T1 and T2 was significant $(P<0.001)$. The other variables did not change significantly between time points.

At the trot, the $\mathrm{VI}(\mathrm{N} \mathrm{s} / \mathrm{kg})$ was increased at T2 $(1.3 \pm 0.2)$ compared with T0 $(1.1 \pm 0.3)$ and $\mathrm{T} 1$ (1.1 \pm 0.3$)$; the differences between $\mathrm{T} 2$ and the previous time points were significant $(\mathrm{P}<0.001)$. The PVF $(\mathrm{N} / \mathrm{kg})$ was increased at T2 $(9.8 \pm 1.6)$ compared with T0 $(8.1 \pm 1.7)$ and $\mathrm{T} 1$ (8.0 \pm 1.7$)$; the differences between $\mathrm{T} 2$ and the previous time points were significant $(P<0.001)$. The other variables did not change significantly between time points (Table 2 ). 


\section{Interaction between BCS and the frog-supportive shoes}

After Bonferonni correction, a $\mathrm{P}<0.017$ was used to indicate statistical significance. The differences between the normal and obese ponies were analysed at each time point separately. Therefore, 20 measurements were included ( 5 ponies; left and right hoof; walk and trot) for each BCS group at separate time points. At the walk, the StDur (ms) was higher in the normal than in the obese group at T0 $(690.2 \pm 35.9$ vs. $568.7 \pm 42.7 ; \mathrm{P}<0.001)$, at T1 (681.2 \pm 22.3 vs. $578.5 \pm 50.1 ; \mathrm{P}<0.001)$, and at T2 (655.2 \pm 55.2 vs. $601.0 \pm 59.7$ ), but not significantly. The TPVF to lift off (ms) was longer in the normal than in the obese group at T0 (232 \pm 10.2 vs. $192 \pm 19.0 ; \mathrm{P}<0.001)$, at T1 (230 \pm 9.8 vs. $191 \pm 17.6 ; \mathrm{P}<0.001)$, and at T2 (228 \pm 16.8 vs. $199 \pm 18.1 ; \mathrm{P}<0.001)$. There was a significant difference between limbs $(P<0.02)$. In the left hoof, the TPVF to lift off (ms) was longer in the normal than in the obese group at T0 ( $233 \pm 11.3$ vs. $197 \pm$ 17.4; $\mathrm{P}<0.002)$, at T1 ( $235 \pm 8.5$ vs. $197 \pm 18.9 ; \mathrm{P}<0.001)$ and at T2 $(225 \pm 14.9$ vs. $205 \pm$ 19.6), but not significantly. In the right hoof, the TPVF to lift off ( $\mathrm{ms}$ ) was longer in the normal than in the obese group at T0 (231 \pm 10.1 vs. $188 \pm 21.3 ; \mathrm{P}<0.001)$, at T1 (225 \pm 8.9 vs. $185 \pm 15.4 ; \mathrm{P}<0.001)$ and at $\mathrm{T} 2(230 \pm 19.8$ vs. $192 \pm 15.4 ; \mathrm{P}<0.001)$. The StDur toe- heel index was also higher in the normal as compared with the obese group at T0 (14.2 \pm 5.8 vs. $9.4 \pm 3.6 ; \mathrm{P}<0.002)$, at T1 (14.2 \pm 6.4 vs. $9.5 \pm 2.4 ; \mathrm{P}<0.002)$, and at T2 $(12.5 \pm 7.9$ vs. $9.1 \pm 2.7 ; \mathrm{P}<0.011)$. The speed $(\mathrm{m} / \mathrm{s})$ of the obese ponies at T0 $(1.2 \pm 0.1)$ was slightly higher than that of the normal ponies $(1.1 \pm 0.1 ; \mathrm{P}<0.01)$. Other variables did not differ significantly between the groups at different time points.

At the trot, the PVF $(\mathrm{N} / \mathrm{kg})$ was higher in the normal as compared with the obese group at all time points, but only significantly at $\mathrm{T} 2(11.1 \pm 1.1 \mathrm{vs} .8 .5 \pm 0.7 ; \mathrm{P}<0.002)$. The StDur toe-heel index was higher in the normal than in the obese group at T0 $(17.1 \pm 4.4$ vs. $11.8 \pm 2.1 ; \mathrm{P}<0.001)$ and at T1 $(15.9 \pm 6.5$ vs $11.2 \pm 1.9 ; \mathrm{P}<0.015)$. The other variables did not differ significantly between the groups at different time points (Table 3).

\section{Hoof balance curves}

After Bonferonni correction, a $\mathrm{P}<0.017$ was used to indicate statistical significance. At the walk, overall the VF toe-heel index was significantly higher in the normal than in the obese group at $25 \%(P<0.019)$ and $75 \%(P<0.004)$ of the stance phase. At T0, the VF toe-heel index was significantly higher in the normal than in the obese group at $25 \%(P<0.009)$ and $75 \%(P<0.002)$ of the stance phase. There was no significant difference between the groups at $\mathrm{T} 1$ and $\mathrm{T} 2$. 
At the trot, overall the VF toe-heel index was significantly higher in the normal than in the obese group at 25\% $(\mathrm{P}<0.002), 50 \%(\mathrm{P}<0.014)$, and $75 \%(\mathrm{P}<0.001)$ of the stance phase. At T0, the VF toe-heel index was significantly higher in the normal than in the obese group at $25 \%(\mathrm{P}<0.007)$ and $75 \%(\mathrm{P}<0.001)$ of the stance phase. At $\mathrm{T} 1$, the VF toe-heel index was significantly higher in the normal than in the obese group at $75 \%(P<0.009)$ of the stance phase. There was no significant difference between the groups at T2 (Fig 2).

Table 1. The effect of body condition score on hoof kinetics in the walk and trot. The data are presented as mean \pm s.d., the StDur toe- heel index is presented as median \pm IQR

\begin{tabular}{ccccccccc}
\hline & BCS & $\begin{array}{c}\text { TPVF } \\
(\mathbf{m s})\end{array}$ & $\begin{array}{c}\text { PVF } \\
(\mathbf{N} / \mathbf{k g})\end{array}$ & $\begin{array}{c}\text { TPVF lift } \\
\text { off }(\mathbf{m s})\end{array}$ & $\begin{array}{c}\text { StDur } \\
(\mathbf{m s})\end{array}$ & $\begin{array}{c}\text { VI } \\
(\mathrm{N} \mathrm{s} / \mathbf{k g})\end{array}$ & $\begin{array}{c}\text { StDur toe-heel } \\
\text { index }\end{array}$ & $\begin{array}{c}\text { Speed } \\
(\mathbf{m} / \mathbf{s})\end{array}$ \\
\hline \multirow{2}{*}{ Walk } & Normal & $430 \pm 37$ & $5.7 \pm 1.0$ & $230 \pm 12.4$ & $675.6 \pm 41.6$ & $2.6 \pm 0.4$ & $13.5 \pm 6.3$ & $1.1 \pm 0.1$ \\
& Obese & $399 \pm 36$ & $5.1 \pm 1.0$ & $194 \pm 17.9^{*}$ & $582.7 \pm 51.4^{*}$ & $2.0 \pm 0.5^{*}$ & $9.2 \pm 2.9^{*}$ & $1.2 \pm 0.1$ \\
\multirow{2}{*}{ Trot } & Normal & $126 \pm 22$ & $9.5 \pm 1.8$ & $165 \pm 33.2$ & $239.6 \pm 24.9$ & $1.3 \pm 0.3$ & $16.6 \pm 4.9$ & $2.8 \pm 0.1$ \\
& Obese & $126 \pm 19$ & $7.8 \pm 1.4^{*}$ & $138 \pm 28.8$ & $226.0 \pm 30.5$ & $1.1 \pm 0.3$ & $11.6 \pm 2.5^{*}$ & $2.8 \pm 0.2$ \\
\hline
\end{tabular}

*Significant difference $\mathrm{P}<0.05$ compared with the normal group.

Table 2. The effect of the frog-supportive shoes on hoof kinetics in the walk and trot T0 $=$ the reference (control) value, T1 = immediately after application of the frog-supportive shoes, $\mathrm{T} 2=72 \mathrm{~h}$ after application of the frog-supportive shoe. The data are presented as mean \pm s.d., the StDur toeheel index is presented as median \pm IQR

\begin{tabular}{ccccccccc}
\hline & Time & $\begin{array}{c}\text { TPVF } \\
(\mathbf{m s})\end{array}$ & $\begin{array}{c}\text { PVF } \\
(\mathbf{N} / \mathbf{k g})\end{array}$ & $\begin{array}{c}\text { TPVF to lift } \\
\text { off }(\mathbf{m s})\end{array}$ & $\begin{array}{c}\text { StDur } \\
(\mathbf{m s})\end{array}$ & $\begin{array}{c}\text { VI } \\
(\mathrm{N} \mathrm{s} / \mathbf{k g})\end{array}$ & $\begin{array}{c}\text { StDur toe-heel } \\
\text { index }\end{array}$ & $\begin{array}{c}\text { Speed } \\
(\mathbf{m} / \mathbf{s})\end{array}$ \\
\hline Walk & 0 & $410 \pm 39$ & $5.4 \pm 1.0$ & $212 . \pm 25.1$ & $629.5 \pm 73.2$ & $2.3 \pm 0.5$ & $10.8 \pm 5.8$ & $1.2 \pm 0.1$ \\
& 1 & $416 \pm 35$ & $4.8 \pm 0.9$ & $211 \pm 24.4$ & $629.8 \pm 64.8$ & $2.0 \pm 0.4^{*}$ & $10.8 \pm 5.7$ & $1.2 \pm 0.1$ \\
& 2 & $417 \pm 46$ & $6.1 \pm 0.9^{*}$ & $213 \pm 22.5$ & $628.1 \pm 62.5$ & $2.6 \pm 0.5^{*}$ & $9.6 \pm 4.7$ & $1.2 \pm 0.0$ \\
\multirow{2}{*}{ Trot } & 0 & $128 \pm 22$ & $8.1 \pm 1.7$ & $151 \pm 35.6$ & $235.1 \pm 30.9$ & $1.1 \pm 0.3$ & $14.0 \pm 5.5$ & $2.8 \pm 0.1$ \\
& 1 & $127 \pm 19$ & $8.0 \pm 1.7$ & $152 \pm 33.5$ & $235.3 \pm 25.8$ & $1.1 \pm 0.3$ & $12.3 \pm 5.3$ & $2.8 \pm 0.1$ \\
& 2 & $122 \pm 20$ & $9.8 \pm 1.6^{*}$ & $151 \pm 33.6$ & $228.0 \pm 29.3$ & $1.3 \pm 0.2^{*}$ & $13.6 \pm 5.4$ & $2.9 \pm 0.1$ \\
\hline
\end{tabular}

*Significant difference $\mathrm{P}<0.017$ after Bonferonni correction compared with T0. Significant difference $\mathrm{P}<0.017$ after Bonferonni correction compared with T1. 
Table 3. The effect of the interaction between body condition score and the frog-supportive shoes on hoof kinetics in the walk and trot $\mathrm{T} 0=$ the reference (control) value, $\mathrm{T} 1=$ immediately after application of the frog-supportive shoes, $\mathrm{T} 2=72 \mathrm{~h}$ after application of the frog- supportive shoe. The data are presented as mean \pm s.d., the StDur toe-heel index is presented as median \pm IQR

\begin{tabular}{cccccccccc}
\hline & T & BCS & $\begin{array}{c}\text { TPVF } \\
(\mathbf{m s})\end{array}$ & $\begin{array}{c}\text { PVF } \\
(\mathbf{N} / \mathbf{k g})\end{array}$ & $\begin{array}{c}\text { TPVF to lift } \\
\text { off }(\mathbf{m s})\end{array}$ & $\begin{array}{c}\text { StDur } \\
(\mathbf{m s})\end{array}$ & $\begin{array}{c}\mathbf{V I} \\
(\mathbf{N ~ s} / \mathbf{k g})\end{array}$ & $\begin{array}{c}\text { StD toe- } \\
\text { heel index }\end{array}$ & $\begin{array}{c}\text { Speed } \\
(\mathbf{m} / \mathbf{s})\end{array}$ \\
\hline Walk & 0 & Normal & $435 \pm 26$ & $5.4 \pm 1.0$ & $232 \pm 10.2$ & $690.2 \pm 35.9$ & $2.5 \pm 0.5$ & $14.2 \pm 5.8$ & $1.1 \pm 0.1$ \\
& 0 & Obese & $386 \pm 35$ & $5.3 \pm 1.0$ & $192 \pm 19.0^{*}$ & $568.7 \pm 42.7^{*}$ & $2.1 \pm 0.5$ & $9.4 \pm 3.6^{*}$ & $1.2 \pm 0.1^{*}$ \\
& 1 & Normal & $435 \pm 29$ & $5.2 \pm 0.7$ & $230 \pm 9.8$ & $681.2 \pm 22.3$ & $2.3 \pm 0.3$ & $14.2 \pm 6.4$ & $1.1 \pm 0.1$ \\
& 1 & 0bese & $398 \pm 33$ & $4.5 \pm 0.9$ & $191 \pm 17.6^{*}$ & $578.5 \pm 50.1^{*}$ & $1.7 \pm 0.4$ & $9.5 \pm 2.4^{*}$ & $1.2 \pm 0.1$ \\
& 2 & Normal & $422 \pm 53$ & $6.6 \pm 0.8$ & $228 \pm 16.8$ & $655.2 \pm 55.2$ & $2.9 \pm 0.3$ & $12.5 \pm 7.9$ & $1.2 \pm 0.1$ \\
& 2 & 0bese & $412 \pm 39$ & $5.6 \pm 0.8$ & $199 \pm 18.1^{*}$ & $601.0 \pm 59.7$ & $2.3 \pm 0.5$ & $9.1 \pm 2.7^{*}$ & $1.2 \pm 0.0$ \\
Trot & 0 & Normal & $125 \pm 21$ & $8.6 \pm 1.7$ & $165 \pm 34.8$ & $240.4 \pm 23.3$ & $1.2 \pm 0.3$ & $17.1 \pm 4.4$ & $2.8 \pm 0.2$ \\
& 0 & 0bese & $131 \pm 25$ & $7.5 \pm 1.7$ & $136 \pm 31.7$ & $229.8 \pm 37.6$ & $1.0 \pm 0.3$ & $11.8 \pm 2.1^{*}$ & $2.9 \pm 0.1$ \\
& 1 & Normal & $130 \pm 21$ & $8.8 \pm 1.5$ & $165 \pm 35.2$ & $243.9 \pm 21.6$ & $1.2 \pm 0.3$ & $15.9 \pm 6.5$ & $2.8 \pm 0.1$ \\
& 1 & 0bese & $125 \pm 17$ & $7.3 \pm 1.6$ & $140 \pm 28.0$ & $226.6 \pm 27.8$ & $1.0 \pm 0.3$ & $11.2 \pm 1.9^{*}$ & $2.8 \pm 0.1$ \\
& 2 & Normal & $123 \pm 25$ & $11.1 \pm 1.1$ & $164 \pm 33.3$ & $234.5 \pm 30.7$ & $1.5 \pm 0.1$ & $15.6 \pm 6.8$ & $2.9 \pm 0.1$ \\
& 2 & 0bese & $122 \pm 14$ & $8.5 \pm 0.7^{*}$ & $138 \pm 29.8$ & $221.5 \pm 27.9$ & $1.1 \pm 0.2$ & $12.0 \pm 3.0$ & $2.9 \pm 0.1$ \\
\hline
\end{tabular}

*Significant difference $\mathrm{P}<0.017$ after Bonferonni correction compared with the normal group.

\section{Discussion}

The current study demonstrated a biomechanical effect of the frog- supportive shoes and an overall difference in hoof kinetic variables between normal and obese, hyperinsulinaemic ponies. This is the first study to demonstrate a significant effect of BCS on hoof kinetics. This finding is clinically relevant because horses with access to pasture for $\geq 6$ h daily had a $35.4 \%$ prevalence of a $B C S \geq 7 / 9$ during summer and $27.08 \%$ at the end of winter [13]. These numbers are comparable with the prevalence of obesity reported by studies based on owner questionnaires [14]. At the walk and trot, the hoof balance curves of the obese ponies showed increased loading of the heel region as compared with the toe region (Fig 2). Furthermore, the StDur toeheel index demonstrated that the heel region contributed relatively more to the total stance time than the toe region. At the walk, the total StDur and the TPVF to lift off, which could also be described as the time of breakover, were significantly lower in the obese group than in the normal group, without a significant difference in speed between the BCS groups (Table 1). The combination of these findings could indicate that the obese ponies experienced some degree of discomfort or pain in their toe region, possibly because they were in a subclinical stage of laminitis, given that obesity and hyperinsulinaemia are risk factors for the development of laminitis [4]. 
Important aspects in the treatment of (acute) laminitis are to support the feet in order to 1) reduce stress on the dorsal hoof wall, 2) reduce pressure on the sensitive area of the sole immediately below the dorsal margin of the distal phalanx and 3) in some cases to decrease the tension exerted by the deep digital flexor tendon [15]. This can be accomplished using foam sole support, which in healthy horses has been shown to increase the total foot contact surface, decrease the total foot contact pressure as well as peak foot contact pressure and position the centre of pressure

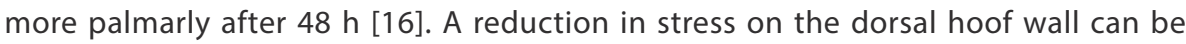
achieved by recruiting the palmar structures of the hoof, including the frog, into the weightbearing surface, as shown in vitro by the application of a hoof cast with heel wedge and a therapeutic shoe with an open toe and palmar bar [17]. Similarly, an in vivo study demonstrated that the peak strain in the deep digital flexor tendon is reduced by the application of an egg-bar shoe and a shoe with heel wedge [18]. Finally, the use of a rolled- toe shoe may be considered, as this shoe causes a more gradual and smooth hoof-enrolment pattern but it does not reduce the total stance time or breakover duration [19].

The frog-supportive shoes tested in the current study have been developed to support the feet in patients with acute laminitis. The proposed theory behind the shoe is that, owing to the heart bar shape, the palmar structures of the hoof contribute to the weightbearing surface and the rolled toe should ease breakover [19]. In the present study, we compared the effect of the shoes between normal and obese ponies with hyperinsulinaemia. This study demonstrated that several variables of hoof kinetics, mainly the StDur toe-heel index and the hoof balance curves, became more similar between normal and obese ponies after the application of the frog-supportive shoes. Compared with the hoof support applied in the aforementioned studies [17-19], no nailing is required with the application of the thermoplastic frog-supportive shoes. Furthermore, the studied shoes can stay on for several weeks, compared with the foam support which needs to be replaced more frequently [16].

Overall, the frog-supportive shoes mainly affected VI and PVF at the walk and trot. Without a significant change in StDur, it is logical that a difference in PVF is followed by a comparable change in VI. Both variables demonstrated a significant increase at T2 compared with the previous time points. Based on an earlier study in which PVF increased in lame horses, treated with a nonsteroidal anti-inflammatory drug resulting in improved lameness scores [20], the measured increase in PVF in the current study could suggest that overall the ponies became more comfortable after application of the frog-supportive shoes. 
In conclusion, the increase in PVF and VI $72 \mathrm{~h}$ after the application of the frogsupportive shoes, and the more comparable StDur toe-heel index and toe-heel balance curves between normal and obese ponies after application of the shoes, would suggest a beneficial effect of the shoe in normal and especially in obese, hyperinsulinaemic ponies. 


\section{Authors' declaration of interests}

None of the authors of this paper has a financial or personal relationship with other people or organisations that could inappropriately influence or bias the content of the paper. The authors are grateful to Andrew Poynton (http:// www.imprintshoes.co.uk/) for providing the required shoes and materials.

\section{Ethical animal research}

The study was approved by the Ethical Committee of Utrecht University (approval number DEC 2014. III.02.021).

\section{Sources of funding}

None.

\section{Acknowledgements}

We thank our reproduction certified specialists Dr M. de Ruijter-Villani for her logistical support and Hans Vernooij for his statistical advice.

\section{Author contributions}

J. Sleutjens contributed to study design, data analysis and interpretation, and preparation of the manuscript. F.M. Serra Braganc_a contributed to study design, data analysis and interpretation, and preparation of the manuscript. W.M van Empelen contributed to study design, study execution, initial data analysis and interpretation. R.E. ten Have contributed to study design, study execution, initial data analysis and interpretation. J. de Zwaan contributed to study execution. E. Roelfsema contributed to execution and data analysis of the oral glucose tolerance test, and preparation of the manuscript. M. Oosterlinck contributed to study design and preparation of the manuscript. W. Back contributed to study design and preparation of the manuscript. All authors gave their final approval of the manuscript.

\section{Manufacturers' addresses}

a Imprint Equine foot care, Poynton Ltd, Malmesbury, Wiltshire, UK. (http:// www. imprintshoes.co.uk/)

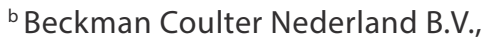
Woerden, The Netherlands.

'Siemens Diagnostic Products Corp, Los Angeles, California, USA.

${ }^{\mathrm{d} R S s c a n}$ International NV, Paal, Belgium.

e Kistler, Winterthur, Switzerland.

${ }^{f}$ De Mulder Rubber and Plastics, Gent, Belgium.

g Sick AG, Du€sseldorf, Germany.

${ }^{\text {h } M a t h W o r k s, ~ N a t i c k, ~ M a s s a c h u s e t t s, ~}$ USA.

'IBM Corporation, New York, USA. 


\section{References}

1. Ireland, J.L., Wylie, C.E., Collins, S.N., Verheyen, K.L.P. and Newton, J.R. (2013) Preventive health care and owner-reported disease prevalence of horses and ponies in Great Britain. Res. Vet. Sci. 95, 418-424.

2. Karikoski, N.P., Horn, I., McGowan, T.W. and McGowan, C.M. (2011) The prevalence of endocrinopathic laminitis among horses presented for laminitis at a first-opinion/referral equine hospital. Domest. Anim. Endocrinol. 41, 111-117.

3. Frank, N., Geor, R.J., Bailey, S.R., Durham, A.E. and Johnson, P.J. (2010) American college veterinary internal medicine - equine metabolic syndrome. J. Vet. Intern. Med. 24, 467-475.

4. Carter, R.A., Treiber, K.H., Geor, R.J., Douglass, L. and Harris, P.A. (2009) Prediction of incipient pasture-associated laminitis from hyperinsulinaemia, hyperleptinaemia and generalised and localised obesity in a cohort of ponies. Equine Vet. J. 41, 171-178.

5. Karikoski, N.P., McGowan, C.M., Singer, E.R., Asplin, K.E., Tulamo, R.-M. and Patterson-Kane, J.C. (2015) Pathology of natural cases of equine endocrinopathic laminitis associated with hyperinsulinemia. Vet. Pathol. 52, 945-956.

6. Rogers, C.W. and Back, W. (2007) The effect of plain, eggbar and 6 degrees-wedge shoes on the distribution of pressure under the hoof of horses at the walk. N. Z. Vet. J. 55, 120-124.

7. Oosterlinck, M., Hardeman, L.C., van der Meij, B.R., Veraa, S., van der Kolk, J.H., Wijnberg, I.D., Pille, F. and Back, W. (2013) Pressure plate analysis of toe-heel and medio-lateral hoof balance at the walk and trot in sound sport horses. Vet. J. 198, e9-e13.

8. Oomen, A.M., Oosterlinck, M., Pille, F., Sonneveld, D.C., Gasthuys, F. and Back, W. (2012) Use of a pressure plate to analyse the toe-heel load redistribution underneath a normal shoe and a shoe with a wide toe in sound warmblood horses at the walk and trot. Res. Vet. Sci. 93, 1026-1031.

9. Back, W. and Pille, F. (2013) The role of hoof and shoeing. In: Equine Locomotion, 2nd ed. Eds: W. Back and H. Clayton. Elsevier Health, London. pp 147-174.

10. Henneke, D.R., Potter, G.D., Kreider, J.L. and Yeates, B.F. (1983) Relationship between condition score, physical measurements and body fat percentage in mares. Equine Vet. J. 15, 371-372.

11. de Laat, M.A. and Sillence, M.N. (2017) The repeatability of an oral glucose test in ponies. Equine Vet. J. 49, 238-243.

12. Oosterlinck, M., Royaux, E., Back, W. and Pille, F. (2014) A preliminary study on pressure-plate evaluation of forelimb toe-heel and mediolateral hoof balance on a hard vs. a soft surface in sound ponies as the walk and trot. Equine Vet. J. 46, 751-755.

13. Giles, S.L., Rands, S.A., Nicol, C.J. and Harris, P.A. (2014) Obesity prevalence and associated risk factors in outdoor living domestic horses and ponies. Peer J 2, e299.

14. Robin, C.A., Ireland, J.L., Wylie, C.E., Collins, S.N., Verheyen, K.L.P. and Newton, J.R. (2015) Prevalence of and risk factors for equine obesity in Great Britain based on owner-reported body condition scores. Equine Vet. J. 47, 196-201.

15. O'Grady, S.E. (2010) Farriery for chronic laminitis. Vet. Clin. N. Am.: Equine Pract. 26, 407-423.

16. Schleining, J.A., McClure, S.R., Derrick, T.R. and Wang, C. (2011) Effects of industrial polystyrene foam insulation pads on the center of pressure and load distribution in the forefeet of clinically normal horses. Am. J. Vet. Res. 72, 628-633.

17. Hansen, N., Buchner, H.H.F., Haller, J. and Windischbauer, G. (2005) Evaluation using hoof wall strain gauges of a therapeutic shoe and a hoof cast with a heel wedge as potential supportive therapy for horses with laminitis. Vet. Surg. 34, 630-636.

18. Riemersma, D.J., Bogert, A.J., Jansen, M.O. and Schamhardt, H.C. (1996) Influence of shoeing on ground reaction forces and tendon strains in the forelimbs of ponies. Equine Vet. J. 28, 126-132. 
19. van Heel, M.C.V., van Weeren, P.R. and Back, W. (2010) Shoeing sound Warmblood horses with a rolled toe optimises hoof-unrollment and lowers peak loading during breakover. Equine Vet. J. 38, 258-262.

20. Back, W., MacAllister, C.G., van Heel, M.C.V., Pollmeier, M. and Hanson, P.D. (2009) The use of force plate measurements to titrate the dosage of a new COX-2 inhibitor in lame horses. Equine Vet. J. 41, 309-312. 


\section{Abstract}

At Fédération Equestre Internationale (FEI) competitions horses pass a veterinary inspection for judgement of 'fit-to-compete'. However, FEl Veterinary Delegates (VDs) often differ in opinion. The aim of the present study was to evaluate intraand inter-observer agreements of 'fit-to-compete' judgement and compare these with objective gait analysis measurements. Twelve horses were evaluated by three experienced VDs and one veterinary specialist and video-recorded for re-evaluation later. Simultaneously, quantitative gait analysis measurements (Qhorse ${ }^{\circledR}$ ) were acquired. Inter-observer agreement during live evaluations was fair $(\kappa=0.395,58 \%$ agreement). Intra-observer agreement between live observations and videos at one month and one year was $71 \%$ and $73 \%$ respectively. Sensitivity and specificity of motion symmetry measured with quantitative gait analysis system were $83.3 \%$ and $66.7 \%$ respectively, against the consensus of all observers as a reference. Our findings might suggest that more VDs should be used to adequately judge 'fit-to-compete'. Quantitative-gait-analysis may be useful to support decision making during fit-tocompete judgement. 
The Fédération Equestre Internationale (FEI) is the global governing body for equestrian sports, responsible for ensuring the fitness, health and animal welfare of the competing horses at major equestrian events. Each horse at an FEl competition must pass a veterinary inspection for'fit-to-compete' or'unfit-to-compete'judgement, performed by an FEl certified veterinarian delegate (VD) or a Veterinary Committee together with the Ground Jury. This judgement is based on visual inspection of the horse, followed by a subjective assessment of the gait at walk and trot on a straight line (Fédération Equestre Internationale, 2018). The judgement sometimes gives rise to controversies.

Previous studies have shown that lameness is one of the main risk factors for failing a fit-to-compete judgement (Bennet and Parkin, 2018; Nagy et al., 2014, 2010). However, there are very few studies reporting on motion symmetry of competition horses (Lopes et al., 2018; Nissen, 2016). Recently, quantitative methods of gait analysis have been developed that allow for practical, on the spot and real-time measurement of gait parameters. These gait parameters may assist subjective lameness grading by providing objective and unbiased gait information (Serra Bragança et al., 2018). This can be helpful, as previous studies have shown less than optimal observer agreement when grading lameness (Keegan, 2007). The aims of this study were: 1) To compare the intra and inter-observer agreement in fit-to-compete judgement; 2) To compare the ratings performed live with the ratings of simultaneously taken videos 1 and 12 months later; 3 ) To compare the live ratings with simultaneously recorded quantitative motion symmetry parameters commonly used for objective lameness assessment. We hypothesised that: 1) fit-to-compete judgement would have an acceptable inter-observer agreement, similar to studies in lameness assessment; 2 ). Scores based on live assessment, video evaluation and from different view angles will differ; 3) Fit-to-compete judgement is correlated to motion symmetry as measured using objective gait analysis.

Twelve horses that were in regular use for low-level dressage and pleasure riding were included in this study. The horses were evaluated according to the FEl horse inspection procedure for jumping competition (Fédération Equestre Internationale, 2018) (Supplement Figure 1). In short, all observers were placed at the beginning of the inspection track, so that they first saw the horse moving away, and then towards them, as prescribed by the standard FEI protocol. For each run, the observers were asked to rate the horse as 'fit-to-compete' or 'unfit-to-compete'. Each observer was blinded to the scores of the remaining ones. At the same time, two video cameras recorded each run. One camera was placed at the same location as the observers, the other perpendicular to the inspection track (Supplement Figure 1), mimicking 
the spectators' perspective by viewing the horse from the side. The observers were asked one month later and also one year later to judge the horses again from the videos. The videos had been anonymized and were presented in random order for these evaluations.

For the measurements, horses were led by an experienced handler on the inspection track (25 meters, not slippery, hard surface) where the horses performed a minimum of 15 strides. First, the horses were allowed to perform one or two runs without gait analysis markers attached to the skin and they were scored by the VDs. After these first run(s), each horse was equipped with clusters of spherical ( $19 \mathrm{~mm} \varnothing$ a) reflective markers, (three markers were placed in the frontal plane of the head, three markers on the withers and three on the pelvis (left/right tuber coxae and tuber sacrale) attached to the skin using double-sided adhesive tape. Horses were then walked and trotted over the inspection track for kinematic measurements and simultaneous judging by the judges for a second time. The four veterinarians graded the horses as "fit-to-compete" or "not fit-to-compete" according to the official FEl regulation. Detailed description of the data analysis and statistical methods can be found in the supplementary material section.

When comparing the live runs with and without gait analysis markers (Figure 1a and supplement figure 2), the inter-observer agreement was fair (Table 1, Figure $1 \mathrm{~b}$ and supplement figure 2 ) and higher for the runs without markers $(k=0.53)$ when compared to the runs with markers $(\kappa=0.39)$. The intra-observer agreement between the runs with and without gait analysis markers was almost perfect (ranging between $\mathrm{K}=0.8$ and $\mathrm{K}=1)$.

When comparing the scores among horses and observers for the video evaluation, between the back and side perspective a total of 14 scores changed at the evaluation one month later and 5 scores one year later (supplement figure 3). When comparing the scores among horses and observers, between the video evaluation one month later (supplement figure 3) and the live evaluation (supplement figure 2) in total 13 scores changed. Video evaluation one year later differed from live evaluation in a total of 13 scores as well. Intra-observer agreement ranged between $70 \%$ and $90 \%$ (supplement table 1).

Overall asymmetry values were higher for the consensus of all observers when horses were judged as not fit-to-compete, but the difference between the 2 groups was not significant ( $t$-test, $\mathrm{p}=0.06$ ) (supplement figure 4,5 and supplementary table 2.). Receiver operation characteristic (ROC) curves for the overall asymmetry (supplement 
figure 6) (sum of head and pelvis vector-sum [VS]) showed the highest sensitivity and specificity, $83.3 \%$ and $66.7 \%$ respectively while symmetry of the withers shows the lowest sensitivity and specificity, $44.4 \%$ and $0 \%$ respectively.

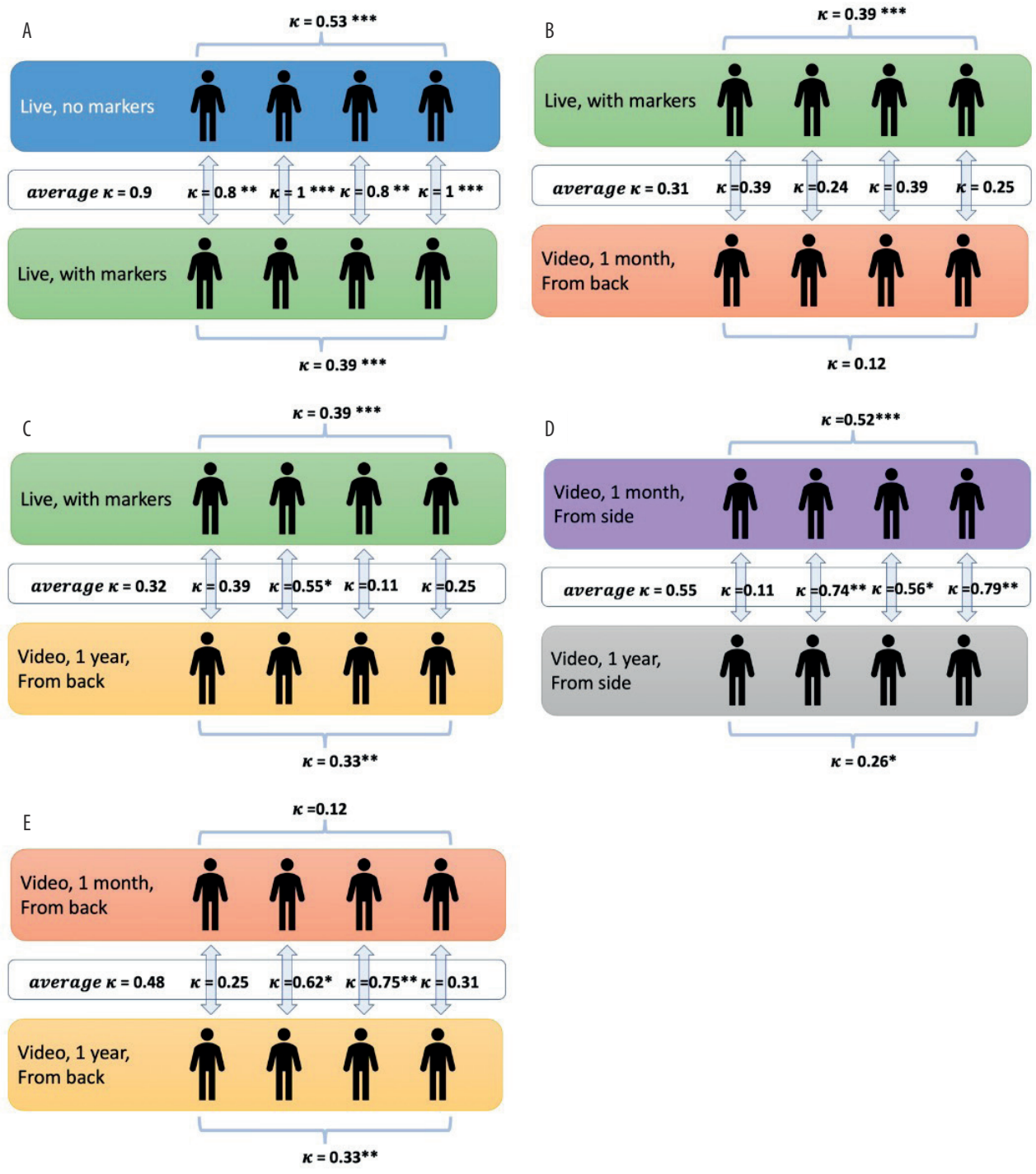

Figure 1. Fleiss kappa for inter and intra observer agreement. Intra-observer agreement is indicated in the vertical arrows and inter-observer agreement is indicated in the horizontal brace. a) Inter- and intraobserver agreement between the live scorings with and without markers; b) Inter- and intra-observer agreement between the live scorings with markers and video observation one month later from the back; c) Inter- and intra-observer agreement between the live scorings with markers and video observation one year later from the back; d) Inter- and intra-observer agreement between the video observation one year and one month later from the side; e) Inter- and intra-observer agreement between the video observation one year and one month later from the back; ${ }^{*} p<0.05,{ }^{* *} p<0.01,{ }^{* *} p<0.001$ 
Table 1. Inter-observer agreement (Fleiss $\mathrm{k}$ ) and \% of agreement for the live, and video conditions (1 month and 1 year). For the video observations, side and front videos are described separately.

\begin{tabular}{lcccccc}
\hline & \multicolumn{3}{c}{ Front-back } & \multicolumn{3}{c}{ Side } \\
\cline { 2 - 6 } & Fleiss-k & p-value & \% agreement & Fleiss-k & p-value & $\%$ agreement \\
\hline Live ratings & 0.39 & $<0.001$ & $58 \%$ & - & - & - \\
Vide0 1 month & 0.12 & 0.3 & $42 \%$ & 0.51 & $<0.001$ & $67 \%$ \\
Vide0 1 year & 0.33 & 0.005 & $50 \%$ & 0.26 & 0.027 & $50 \%$ \\
\hline
\end{tabular}

The results support our hypothesis that 'fit-to-compete' judgement has an acceptable inter-observer agreement, similar to previously published studies for lameness assessment (Keegan, 2007) and that the intra-observer agreement is substantially higher than the inter-observer agreement. We have also confirmed that when judging horses for a 'fit-to-compete' judgement from different perspectives (back vs side), the same observer can come to different verdicts. Furthermore, we have also demonstrated that quantitative gait analysis has an acceptable sensitivity and specificity to detect motion asymmetries that are taken into account when judging fitness to compete.

The inter-observer agreement for the live observations in our study is classified as fair but remains far from perfect. When comparing the scores between the different video observations and comparing the video observations to the live observations, it is clear that there are substantial differences in scoring performed by the observers. Inter-observer agreement for the live scorings was substantially better than for the video scorings. Previous studies have proposed that video recordings can negatively affect the assessor's ability to assess gait (Strobach et al., 2006) due to less and potentially worse auditory and two-dimensional visual information. Another issue is the position of the observer. Further, video scoring is clearly different to live scoring and comparing the different modalities should be done with caution. It is also important to notice that VDs assess unridden horses, whereas during competition horses are ridden and consequently, gait evaluation between ridden and unridden exercise may lead to different conclusions.

In this study there was no clear cut-off value based on objective measurements, but based on the low agreement between observers, we hypothesise that the subjective judgement of VDs could benefit from an additional objective assessment of motion symmetry. There is today enough evidence to relate lameness to some parameters of motion symmetry and also to support the incorporation of quantitative gait analyses in a clinical setting (Keegan, 2007; Serra Bragança et al., 2018), hence, the 
incorporation of this technology in other activities of a veterinarian, such as the work of a VD in an FEl inspection, should be considered. This is further supported by a recent study reporting the incorporation of quantitative gait analysis at veterinary inspections for endurance competitions (Lopes et al., 2018).

Quantitative tools are far from all-deciding in such complex matter as "fit-to-compete" judgement, but they may be helpful in improving the current standards and in defining reference values for motion symmetry that could be used in such conditions. This is not different to the quantification of some other biological parameters such as heart rate, already used by VDs in endurance competitions. 


\section{Conflict of interest statement}

None of the authors of this paper has a

financial or personal relationship with other people or organisations that could inappropriately influence or bias the content of the paper.

\section{Ethical animal research}

The study was approved by the local ethics committee in compliance with the Dutch Act on Animal Experimentation.

\section{Sources of funding}

This study was partly supported by the FEl that bought the videos without markers for teaching purposes.

\section{Acknowledgement}

Special thanks to the technical assistance of the students and animal care takers of the department.

\section{Appendix A:}

\section{Supplementary material}

Supplementary figures and text associated with this article can be found, in the online version

\section{Appendix B:}

\section{Supplementary material}

The complete data set used in this study, including raw OMC data, processed OMC data, and videos (side and back views) can be accessed at: DOI: 10.24416/ UU01-CLV1F1.

\section{Manufacturers' addresses}

a Qualisys AB, Motion Capture Systems, Göteborg, Sweden.

b R-Studio, 250 Northern Ave, MA 02210, Boston, USA. 


\section{References}

1. Bennet, E.D., Parkin, T.D.H., 2018. Fédération Equestre Internationale endurance events: Risk factors for failure to qualify outcomes at the level of the horse, ride and rider (2010-2015). Vet. J. 236, 44-48. https://doi.org/10.1016/j.tvjl.2018.04.011

2. Fédération Equestre Internationale, 2018. Veterinary Regulations. Fédération Equestre Internationale. https://inside.fei.org/sites/default/files/2018 VRs final.pdf (acessed 28/05/2018), pp. 28-29.

3. Keegan, K.G., 2007. Evidence-Based Lameness Detection and Quantification. Vet. Clin. North Am. Equine Pract. 23, 403-423. https://doi.org/10.1016/j.cveq.2007.04.008

4. Lopes, M.A.F., Eleuterio, A., Mira, M.C., 2018. Objective Detection and Quantification of Irregular Gait With a Portable Inertial Sensor-Based System in Horses During an Endurance Race-a Preliminary Assessment. J. Equine Vet. Sci. 70, 123-129. https://doi.org/10.1016/j. jevs.2018.08.008

5. Nagy, a., Murray, J.K., Dyson, S.J., 2014. Descriptive epidemiology and risk factors for eliminations from Federation Equestre Internationale endurance rides due to lameness and metabolic reasons (2008-2011). Equine Vet. J. 46, 38-44. https://doi.org/10.1111/evj.12069

6. Nagy, A., Murray, J.K., Dyson, S., 2010. Elimination from elite endurance rides in nine countries: A preliminary study. Equine Vet. J. 42, 637-643. https://doi.org/10.1111/j.2042-3306.2010.00220.

7. Nissen, A.L., 2016. Movement symmetry and the influence of long-term exercise, in: University of Copenhagen, PhD Thesis. pp. 161-177.

8. Serra Bragança, F.M.M., Rhodin, M., van Weeren, P.R.R., 2018. On the brink of daily clinical application of objective gait analysis: What evidence do we have so far from studies using an induced lameness model? Vet. J. 234, 11-23. https://doi.org/10.1016/j.tvjl.2018.01.006

9. Strobach, A., Kotschwar, A., Mayhew, I.G., Peham, C., Licka, T., 2006. Gait pattern of the ataxic horse compared to sedated and nonsedated horses. Equine Vet. J. 36, 423-6. https://doi. org/10.1111/j.2042-3306.2006.tb05580. 


\section{Supplementary material}

\section{Data analysis}

The motion capture data was processed using designated software (QHorse v1.0) and the symmetry parameters MinDiff/MaxDiff (difference in minimum resp. maximum height during limb stance between right and left halves of a stride) from head, withers and pelvis at the trot were calculated. These parameters were chosen based on their know correlation with lameness. From these, vector sums (VS) of

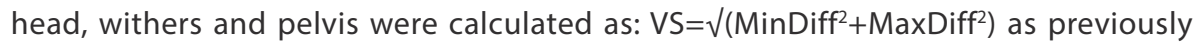
described. Since the fit-to-compete judgement is an overall appraisal of how the horse moves and not only based on a single biological parameter of symmetry (e.g. head or pelvis), outcome of quantitative gait analysis was also expressed as a comprehensive overall symmetry parameter calculated as: Overall symetry = $\frac{V S \text { head }}{2}+$ VS pelvis. This resulted in a single symmetry value for each measurement that could be directly compared to the observers scoring.

\section{Statistics}

Statistical analysis and data visualization were performed using R-studio (version 1.1.453). The Fleiss- $k$ and the percentage of agreement were calculated to evaluate the inter- and intra-observer agreements using the package IIR (version 0.84). Interpretation of the $\mathrm{k}$ values was performed according to the classification of agreement proposed by Landis and Koch (1977): < 0 (poor); $0.01-0.20$ (slight); 0.21 0.40 (fair); $0.41-0.60$ (moderate); $0.61-0.80$ (substantial); 0.81 - 1.00 (almost perfect). Receiver operation characteristic (ROC) plots were generated using the package pROC (version 1.10.0) and from these, sensitivity and specificity were also calculated, using the consensus of all 4 veterinarians on the fit-to-compete judgement as a reference. Horses were classified as fit-to-complete if all veterinarians agreed on the judgement and horses were classified as not fit-to-compete if at least one veterinarian classified the horse as not fit. 


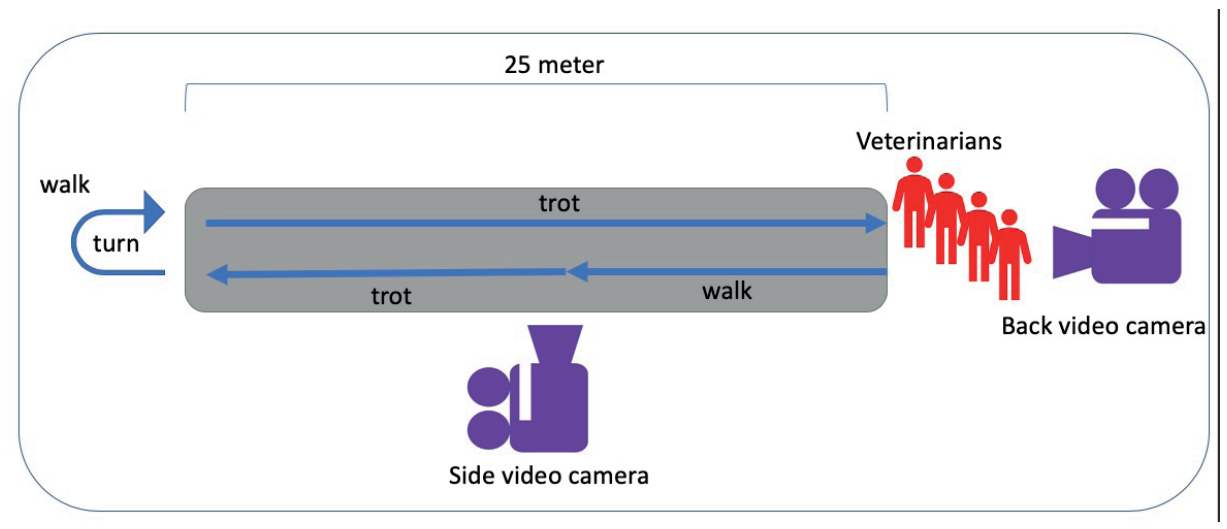

Figure 1. The experimental setup. The experimental setup was designed according to the FEI regulations for the horse inspection procedure.

Live rating from behind, without gait analysis markers

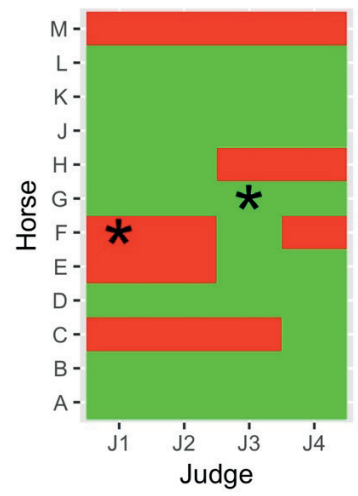

Live rating from behind, with gait analysis markers

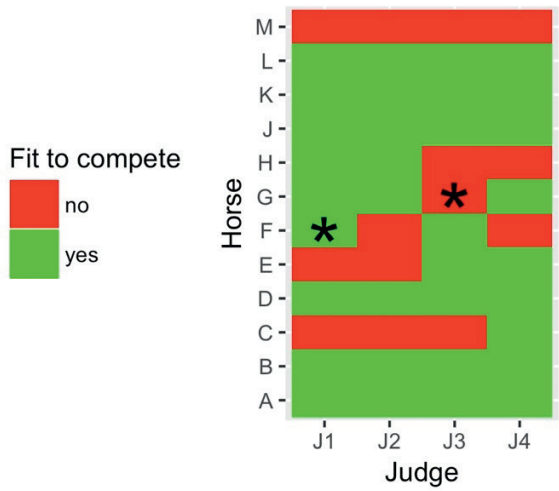

Fit to compete

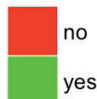

Figure 2. Heat map of the live ratings. X-axis observers 1 to 4 . Y-axis, horses $A$ to $M$. * Indicates the scorings that differ between the different timepoints. 
1 month video rating from behind

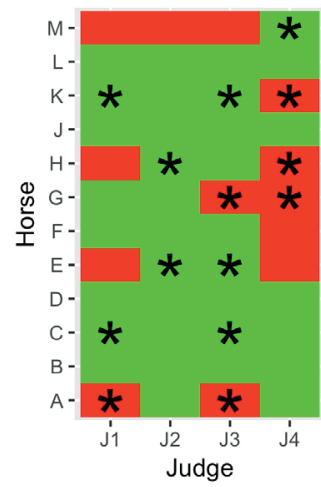

1 year video rating from behind

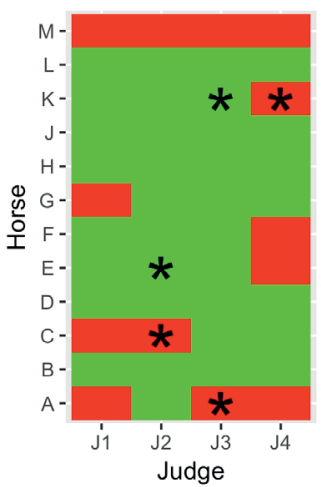

1 month video rating from side

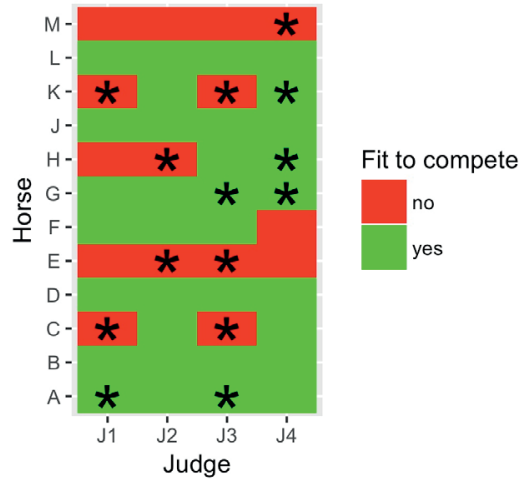

1 year video rating from side

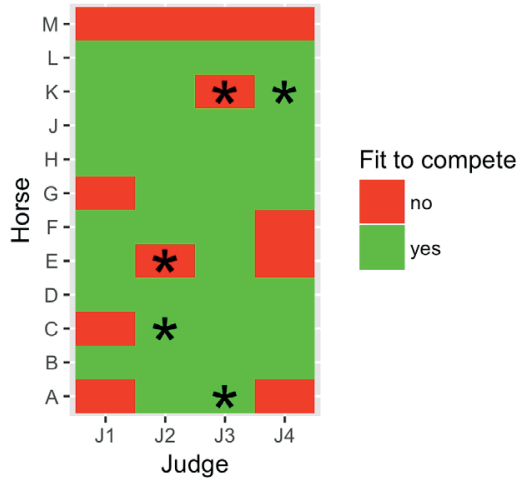

Figure 3. Heat map of the video ratings. X-axis observers (judges) 1 to 4 . $Y$-axis, horses A to M. Top left, video ratings after 1 month from behind; top right: video ratings after 1 month from the side. Bottomleft: video ratings after 1 year from behind. Bottom-right: video ratings 1 year after from the side. * Indicates the scorings that differ between the different view angles (back and side)

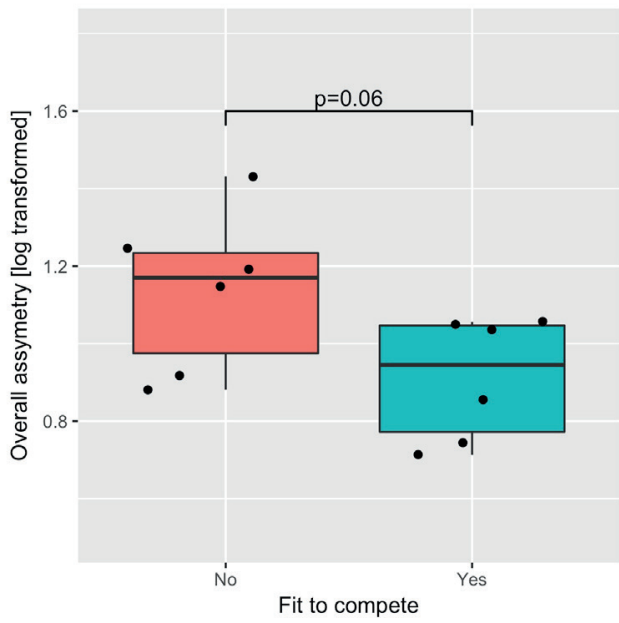

Figure 4. Box plot of the overall motion asymmetry log (Head VS + Pelvis VS) between the 2 classifications. Horses were deemed fit to compete only if all 4 observers agreed on the classification same classification (fit-to-compete). The difference between the 2 groups is not significant $(p=0.06)$ 

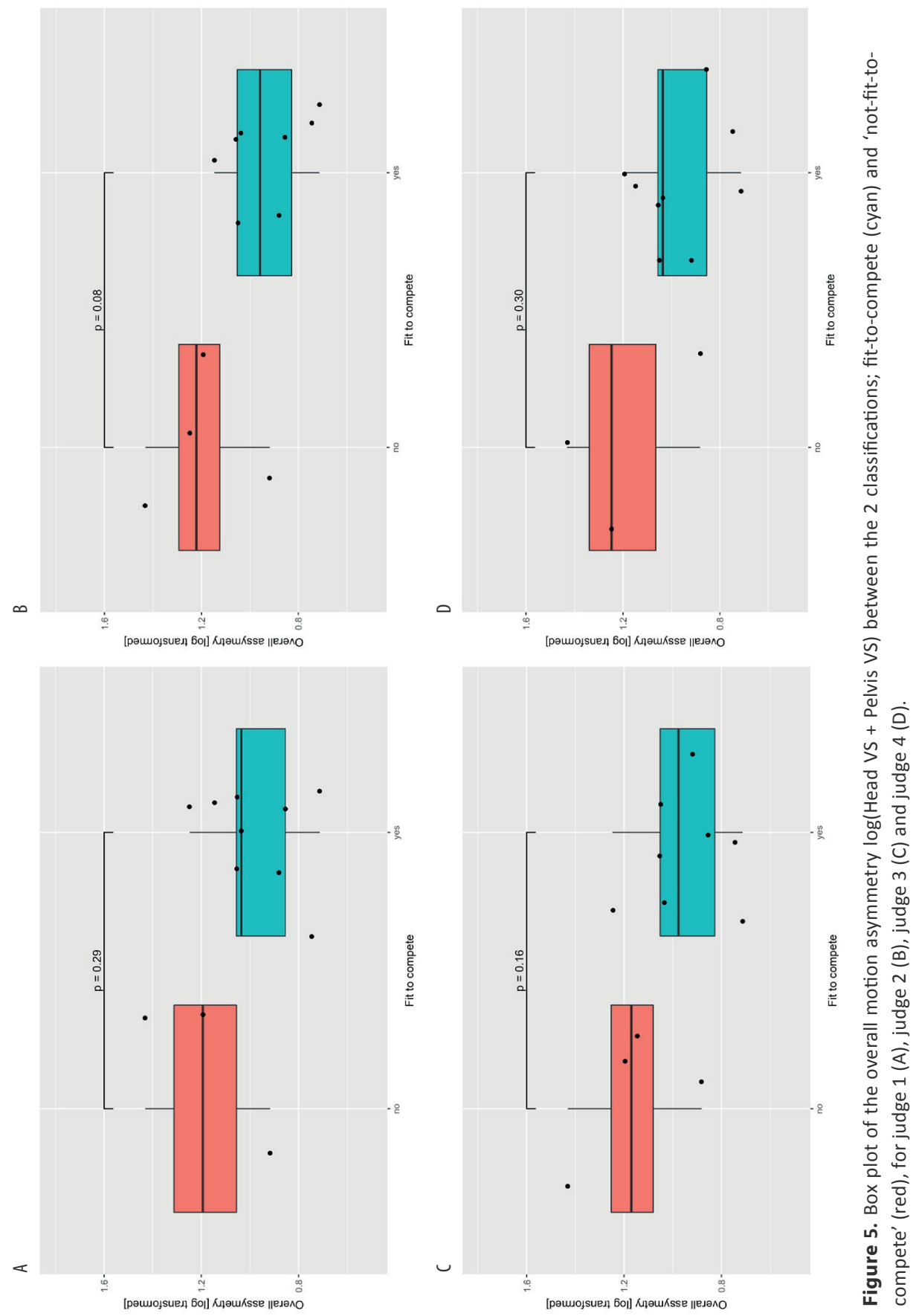

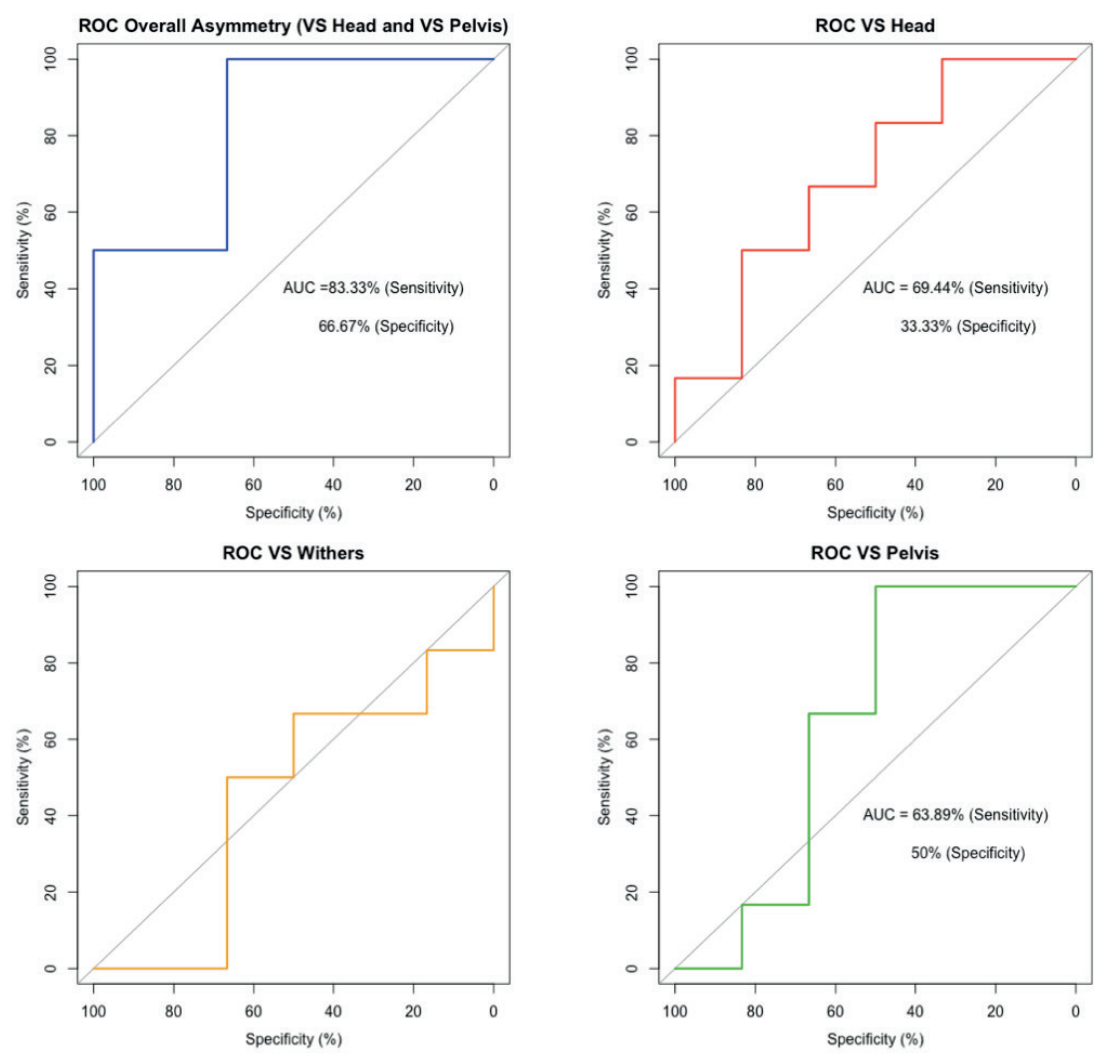

Figure 6. ROC curves for fit-to-compete judgement compared to motion asymmetry. The highest sensitivity and specificity is for the overall asymmetry log(Head VS + Pelvis VS). Sensitivity (area under the curve (AUC)) and specificity indicated for each parameter inside the plot. 
Table 1. Intra-observer agreement.

\begin{tabular}{|c|c|c|c|c|c|}
\hline \multicolumn{6}{|c|}{ Intra-observer agreement } \\
\hline \multicolumn{5}{|c|}{ Comparison } & \multirow[t]{2}{*}{$\%$ agreement (mean \pm s.d. of all observers) } \\
\hline Live & 1 Month behind & 1-month side & 1-year behind & 1-year side & \\
\hline$x$ & $x$ & & & & $71 \pm 5 \%$ \\
\hline \multirow[t]{5}{*}{$\mathrm{x}$} & & & $x$ & & $73 \pm 8 \%$ \\
\hline & $x$ & $x$ & & & $70 \pm 11 \%$ \\
\hline & & & $x$ & $x$ & $90 \pm 8 \%$ \\
\hline & $x$ & & $x$ & & $79 \pm 14 \%$ \\
\hline & & $x$ & & $x$ & $81 \pm 16 \%$ \\
\hline
\end{tabular}

Table 2. Mean and s.d for each asymmetry parameter calculated for each horse during the live ratings in $\mathrm{mm}$.

\begin{tabular}{ccccccc}
\hline Horse ID & HDMin & HDMax & WithMin & WithMax & PDmin & PDmax \\
\hline A & $2.6 \pm 9.5$ & $-9 \pm 12.2$ & $2.3 \pm 1.8$ & $-6.5 \pm 2.1$ & $2.3 \pm 3.4$ & $-0.9 \pm 1.9$ \\
B & $6.4 \pm 6.1$ & $5 \pm 6.8$ & $-1.2 \pm 2.1$ & $0.1 \pm 2.2$ & $-1.5 \pm 2.1$ & $0 \pm 1.6$ \\
C & $22.8 \pm 12.9$ & $-4.4 \pm 11.8$ & $-1.4 \pm 1.5$ & $-4.9 \pm 1.9$ & $-4 \pm 2.6$ & $0.2 \pm 1.6$ \\
D & $12.6 \pm 5.3$ & $5.2 \pm 7.6$ & $-1.9 \pm 2$ & $-6.6 \pm 1.9$ & $-2.8 \pm 2.8$ & $2.9 \pm 1.3$ \\
E & $10.8 \pm 7$ & $-7.4 \pm 10.2$ & $1.8 \pm 2.3$ & $2.2 \pm 1.1$ & $-0.3 \pm 1.6$ & $1.7 \pm 1.8$ \\
F & $6.8 \pm 5.4$ & $0.8 \pm 5.7$ & $-9.9 \pm 2.6$ & $-3.9 \pm 2.2$ & $9.4 \pm 2.5$ & $10.7 \pm 2.7$ \\
G & $13.1 \pm 16.7$ & $-9.4 \pm 8.4$ & $0.2 \pm 1.1$ & $-2.1 \pm 1$ & $-4.6 \pm 1.9$ & $3.8 \pm 2.3$ \\
H & $-10.4 \pm 4.1$ & $-6.7 \pm 5.7$ & $1.9 \pm 1.8$ & $-3.5 \pm 1.7$ & $0.9 \pm 2.3$ & $1.1 \pm 2.4$ \\
J & $-4.3 \pm 8.3$ & $12.2 \pm 9$ & $5.1 \pm 1.7$ & $0.4 \pm 2$ & $-4.6 \pm 2.4$ & $-1.7 \pm 1.9$ \\
K & $15.3 \pm 8.8$ & $-7.9 \pm 10.8$ & $-1.5 \pm 2.2$ & $-1.8 \pm 2.2$ & $2 \pm 3$ & $1.7 \pm 2.5$ \\
L & $1 \pm 6.3$ & $5 \pm 8.7$ & $-3 \pm 3.4$ & $1.4 \pm 1.6$ & $-1.9 \pm 3.6$ & $-1.8 \pm 1.7$ \\
M & $39.9 \pm 8.9$ & $9.3 \pm 13.9$ & $14.8 \pm 3.3$ & $12.5 \pm 3$ & $0.1 \pm 1.8$ & $-6.5 \pm 2.6$ \\
\hline
\end{tabular}




\section{Pain-related facial expressions and movement asymmetry in horses with induced low- degree orthopaedic pain}

Johannes P.A.M. van Loon ${ }^{\text {* }}$, F.M. Serra Bragançaa ${ }^{a}$ K. Ask ${ }^{b}$, E. Hernlund ${ }^{b}$, M. Rhodin' ${ }^{\text {, }}$ P. Haubro Andersen ${ }^{c}$

a Department of Equine Sciences, Faculty of Veterinary Medicine, Utrecht University, Yalelaan 114, NL-3584 CM Utrecht, The Netherlands.

${ }^{b}$ Department of Anatomy, Physiology and Biochemistry, Swedish University of Agricultural Sciences, Uppsala, Sweden

'Department of Clinical Sciences, Swedish University of Agricultural Sciences, Uppsala, Sweden
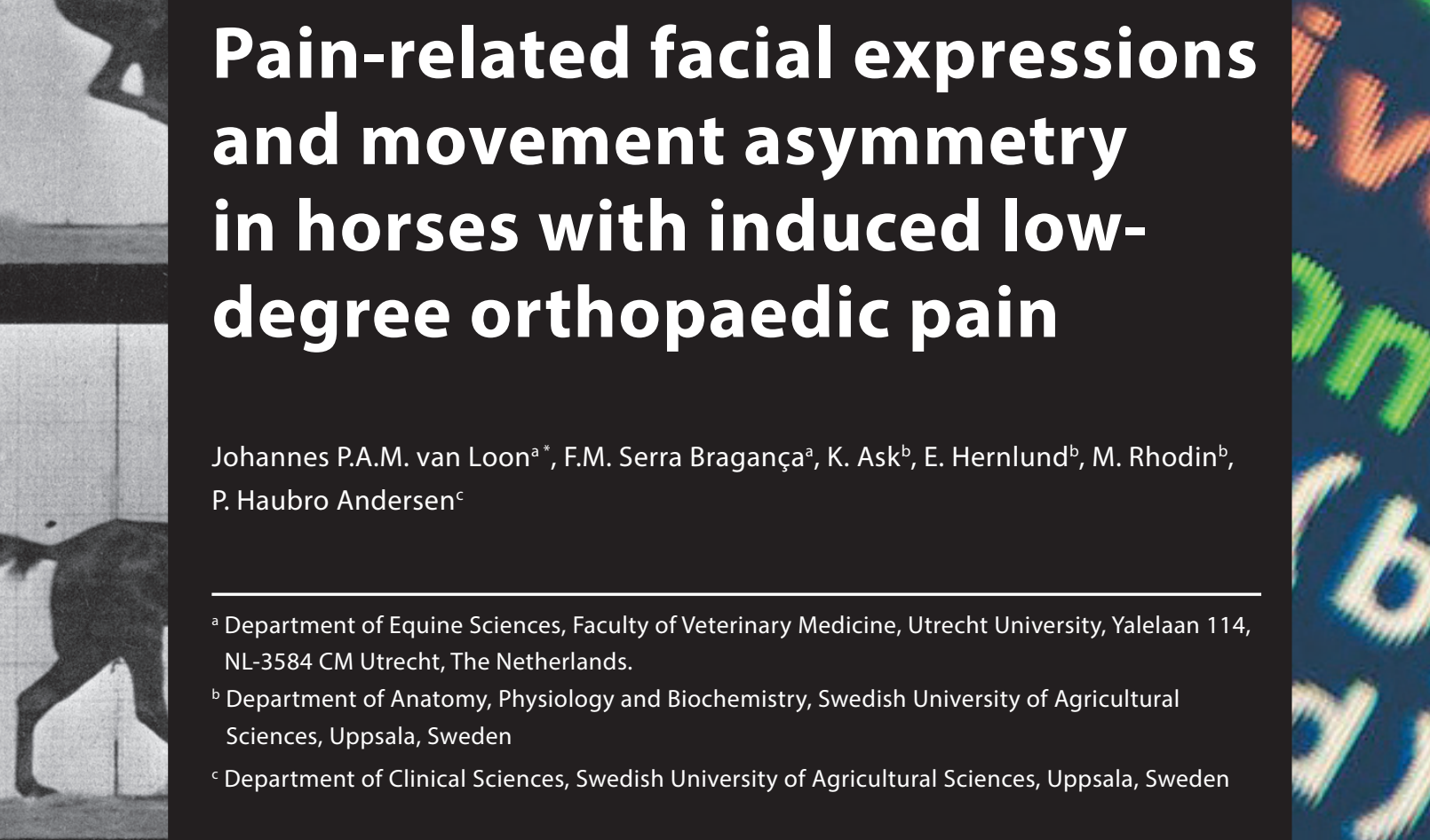

Keywords facial expression, composite pain scale, orthopaedic pain, equine, gait analysis 


\section{Abstract}

Objective gait analysis and composite pain scales have been used as parameters for assessment of orthopaedic pain, but so far, the relation between these two methods has not been thoroughly investigated.

In this study, the validity of the Equine Utrecht University Scale for Facial Assessment of Pain (EQUUS-FAP) was assessed in horses with induced orthopaedic pain and compared to a validated composite pain scale (CPS) during boxrest. A restricted number of facial expression parameters that were possible to score during direct observation during locomotion (EQUUS-FAPpartial), were assessed, together with their relationship with upper body movement asymmetry. Lameness was induced using a modified horseshoe providing pressure to the frog and by intra-articular lipopolysaccharide administration (2.5 ng in middle carpal joint or in talocrural joint) in eight Warmblood mares, with a two-week interval. Direct pain assessment was performed in the stables by two independent observers using CPS and EQUUSFAP, and during straight line trot using EQUUS-FAPpartial. Objective gait analysis parameters were measured to assess gait asymmetry.

Differences in EQUUS-FAP scores were found between baseline and 3-5 hours after LPS administration $(\mathrm{P}<0.05)$ in box-rested horses. EQUUS-FAP showed excellent interobserver reliability (Cronbach's $a=0.93$, low bias and limits of agreement). In moving horses, an increase in EQUUS-FAPpartial was present when comparing baseline with induced lameness $(P<0.001)$ and asymmetry indices significantly increased with increasing pain scores.

Facial expression-based pain scales showed to be a promising tool in assessing induced orthopaedic pain in box-rested and moving horses and facial expressionderived parameters significantly increased with lameness-induced asymmetry. 


\section{Introduction}

Objective recognition of pain is essential for recognition of certain pathological conditions and their treatment. For pain in animals, the definition of Molony and Kent (1997) is often used: 'Pain is an aversive sensory and emotional experience, representing an awareness by the animal of damage or threat to the integrity of its tissues; it changes the animal's physiology and behaviour to reduce or avoid damage, to reduce the likelihood of recurrence and to promote recovery; unnecessary pain occurs when the integrity or duration of the experience is inappropriate for the damage sustained or when the physiological and behavioural responses to it are unsuccessful at alleviating it'. Since pain contains, apart from the sensory discriminative components, an emotional component as well, it is a subjective experience, closely related to emotions as fear and stress that cannot be verbally communicated by animals. Much attention has been given to the development of techniques for objective pain assessment in horses in the last decades (Gleerup and Lindegaard, 2016; de Grauw and van Loon, 2016).

Composite pain scales (CPS) have been developed to assess pain in horses. Apart from physiological parameters, they comprise selections of simple descriptive behavioural scales, and have been described for different types of pain in horses like acute orthopaedic pain (Bussières et al., 2008), pain after colic surgery (Graubner et al., 2011), acute colic pain (van Loon and van Dierendonck, 2015) and post-castration pain (Taffarel et al., 2015). Facial expression-based pain scales have also been developed. Gleerup et al. (2015) described facial expression in horses with experimentally induced acute pain. Facial expressions have also been studied in surgically castrated horses (Dalla Costa et al., 2014) and in horses with acute laminitis (Dalla Costa et al., 2016). The Equine Utrecht University Scale for Facial Assessment of Pain (EQUUS-FAP) has been described in horses with acute colic pain, with head-related pain and with postoperative or traumatic orthopaedic pain (van Loon and van Dierendonck; 2015, 2017, 2019).

However, for assessment of orthopaedic pain in horses during locomotion, previously described composite pain scales cannot be used. The validity of facial characteristics to assess pain in unridden horses during locomotion has yet to be evaluated. Also, relatively little is known about the correlations between movement symmetry and pain in horses (Rhodin et al., 2017). With the increasing use of asymmetry-based gait analysis as an objective aid for lameness assessment (Serra Bragança et al., 2018) and the increasing interest for recognition of pain in moving horses, the need is growing for more knowledge on how orthopaedic pain relates to gait characteristics and modern pain scales. 
This study aimed at investigating the usefulness and validity of facial expression characteristics as a research tool in acute orthopaedic pain by 1 ) assessing the validity of EQUUS-FAP or a subset of parameters of EQUUS-FAP (EQUUS-FAPpartial) in horses with experimentally induced acute orthopaedic pain during box-rest and locomotion and 2) comparing EQUUS-FAPpartial with objective gait analysis parameters. EQUUSFAP during box-rest was compared to the validated CPS by Bussières et al. (2008). The hypotheses were that EQUUS-FAPpartial would be able to differentiate between baseline and induced lameness during dynamic/locomotion conditions and that all individual parameters of EQUUS-FAPpartial would increase with increasing locomotion asymmetry.

\section{Materials and methods}

\section{Study design}

The study design and experimental protocol were approved by the Ethics Committee on the Care and Use of Experimental Animals in compliance with Dutch legislation on animal experimentation (permission number: AVD108002015307WP16, date of approval 18-08-2017). The horses were subjected to induction of two different types of acute lameness which was assessed both on soft and hard surface on the straight line. The experimental limbs were randomized. Prior to lameness induction, horses had been accustomed to being trotted up and lunged, including baseline pain behaviour and objective gait analysis assessment. Lameness induction was followed by direct observation of pain behaviour during rest and by observation of pain behaviour plus objective gait analysis during trot. Health monitoring protocols, including general clinical examination, assessment of limb loading and degree of lameness, were performed 6 times daily during the study. Rescue analgesia consisting of morphine $0.1 \mathrm{mg} / \mathrm{kg}$ IV (Centrafarm, the Netherlands) and subsequent meloxicam $0.6 \mathrm{mg} / \mathrm{kg}$ IV (Boehringer-Ingelheim, the Netherlands) if morphine did not improve lameness within 1 hour, was administered when lameness was $>3$ out of 5 on the American Association of Equine Practitioners (AAEP) scale. If lameness did not reduce to a degree of less than 3 out of 5 within 4 hours after first meloxicam administration, the humane endpoint would be reached and the horse should need to be euthanized. If lameness did not reduce to maximally 1 out of 5 within 18 hours, another administration of meloxicam would be given. In case of development of septic arthritis after LPS-administration, diagnosed by means of synovial fluid sample analysis with leucocyte count and bacterial culture, and unresponsiveness to NSAID treatment, humane endpoint would be reached as well. 


\section{Animals}

Eight female warmblood horses were used, with a mean age (standard deviation SD) of 7.7 (3.1) years and a mean body mass (SD) of 559 (36.1) $\mathrm{Kg}$. An experienced equine veterinarian examined the horses before the experiment and horses were only used if they had a lameness score of 1 or less according to the AAEP lameness scale (0-5) (Baseline objective gait analysis parameters in Supplementary material 1).

\section{Equine Utrecht University Scale for Facial Assessment of Pain (EQUUS-FAP)}

The EQUUS-FAP is a multifactorial Simple Descriptive Scale (SDS) based on nine parameters scored by direct observation for 2 minutes (Supplementary material 2). EQUUS-FAP was used to assess pain in horses during static/stable resting conditions. During dynamic/locomotion conditions, five individual parameters of the EQUUS-FAP (eyelids, nostrils, corners mouth/lips, muscle tone head, ears) could be recognized during movement and were therefore assessed (EQUUS-FAPpartial) (Supplementary material 3).

\section{Composite Pain Scale (CPS)}

The CPS by Bussières et al. (2008) is a multifactorial simple descriptive scale (SDS) based on 13 parameters, scored by direct observation for 5 minutes. It includes physiologic parameters, responses to stimuli, and spontaneous behavioural parameters (Supplementary material 4). It has been used for assessment of horses during box-rest for validation of EQUUS-FAP, since the CPS by Bussières et al. (2008) has been described in horses with induced synovitis as well.

\section{Pain observations}

Before starting the study, the observers trained themselves with the CPS and EQUUS-FAP in healthy horses. Observations were performed by two observers (one veterinarian and one veterinary master student) who scored independently and simultaneously. Horses were observed before (4 baseline observations) and after lameness induction during box rest: For the shoe model, observations were performed 10 minutes after trot (D0T10), 30 minutes after trot (D0T30), first day after lameness induction in morning (D1AM), first day after lameness induction in afternoon (D1PM). For the LPS-induced lameness model, observations were performed at 2 hours after LPS administration (T2), 3-5 hours after LPS administration (T3-5), 6.5-8.5 hours after LPS administration (T6.5-8.5), 24 hours after LPS administration (T24) and 48 hours after LPS administration (T48) ( $n=43$ baseline observations, $n=72$ observations after lameness induction). EQUUS-FAPpartial was performed during trot on a straight line for 25 meters, by direct observations of 1 observer $(n=31$ for baseline conditions 
and $n=54$ for induced lameness, 37 with the shoe model lameness, 17 with the LPS induced lameness)

\section{Quantitative gait analysis}

Before each measurement session, the horses were equipped with 57 spherical markers (19 mm diameter, Qualisys AB Sweden) on pre-determined anatomical landmarks using cyanoacrylate glue and/or double sided tape. The landmarks of each marker were clipped beforehand to minimize measurement errors. Two markers placed in the sagittal plane over the poll and the tubera sacrale for analysis of vertical movement asymmetry of the head and pelvis. Thirty infrared optical motion capture (OMC) cameras (Oqus 700+,Qualisys AB, Motion Capture Systems, Gothenburg, Sweden) recorded the marker positions at $200 \mathrm{~Hz}$. During the measurements, the 3D coordinates of each marker were automatically tracked by the motion capture software (QTM, version 2.16, Qualisys AB, Motion Capture Systems, Gothenburg, Sweden). A minimum of 18 strides were collected for each horse. After each measurement, the 3D data was visually checked for appropriateness for analysis. If necessary, the measurements were repeated. The data was exported into Matlab (MathWorks, 3 Apple Hill Drive, Natick, USA) and processed using custom-written scripts from previously described analysis routines (Rhodin et al., 2018). Vertical displacement of the two markers was high-pass filtered using a $4^{\text {th }}$ order zero-phase Butterworth filter with the cut-off frequency adjusted to the stride frequency of each horse (submitted data). The used symmetry parameters were the MinDiff and MaxDiff (difference between the two minima and between the two maxima that were obtained from the vertical position of the head and pelvis per stride). From these, a vector sum (VS) of head and pelvis respectively was calculated as: VS $=\sqrt{ }\left(M_{\text {MinDiff }}^{2}+\right.$ MaxDiff $\left.{ }^{2}\right)$.

\section{Lameness induction models}

For each horse, one limb was randomly assigned as the experimental limb. This led to 4 front limb lameness's ( 2 left front and 2 right front) in both lameness models and 4 hind limb lameness's (2 left hind and 2 right hind). Two weeks before the study, the hooves were trimmed and a modified heart-bar horseshoe was applied to the experimental limb while the remaining hooves were shod with standard shoes (with a similar weight as the heart-bar shoe). This shoe is a modification of the original model by Merkens et al. (1988) with a single M10 screw contacting the hoof at the tip of the frog (Supplementary material 5). Lameness was induced by tightening the screw, untill a degree of 2-3 on the AAEP scale (0-5) occurred. The LPS induction was performed in the same limb as the shoe induction, with a two week wash-out period between the 2 lameness inductions. Lameness was induced by the intra-articular administration of $2.5 \mathrm{ng}$ of LPS (E.coli O55:B5) in a $2 \mathrm{~mL}$ volume of saline using a routine 
aseptic technique, using a fresh LPS-solution each morning when lameness was induced. Middle carpal joints or talocrural joints were used. At each arthrocentesis, at least $2 \mathrm{~mL}$ of synovial fluid was collected before LPS-administration. Samples were centrifuged and stored at $-80^{\circ} \mathrm{C}$ for future studies.

\section{Data processing and statistical analysis Observer agreement:}

All data are expressed as medians and quartiles. Inter-observer reliability was assessed using intra-class correlation analysis (ICC) and calculation of Cronbach's alpha. Bland-Altman plots were generated in R studio (version: 3.3.1) using the package (BlandAltmanLeh, version 0.3.1) and used to visually evaluate agreement and determine bias (mean difference between 2 observers) and limits of agreement (average difference \pm 1.96 standard deviations of the difference) (Bland and Altman, 1986).

\section{The association between EQUUS-FAPpartial and objective gait analysis}

Mixed linear models were created using the R package Ime4 (Imer, version 1.1-15) to study the association between EQUUS-FAPpartial and movement asymmetry. In each model, movement asymmetry parameters Vector Sum (VS) head and VS pelvis were used as the outcome variable. EQUUS- FAPpartial scores and induction model (LPS and shoe) were entered as fixed effects. Horse ID and trial (hard/soft surface) within horse were used as random effects. Since differences between the two lameness inductions methods were expected, interaction between EQUUS-FAPpartial scores and induction model were used as fixed effects. Also, since differences in movement asymmetry between fore and hindlimb induction was expected, the interaction between EQUUS-FAPpartial scores and lameness induction location (fore and hind) was added as fixed effect. The goodness of fit for the model was visually appraised by evaluating the normality of the residuals (using box-plots and qq-plots), and homoscedasticity was evaluated plotting the residuals versus the fitted values. P-values were adjusted for multiple comparisons using the False Discovery Rate method of Benjamini-Hochberg (Benjamini and Hochberg, 1995).

\section{Evaluation of the occurrence of individual parameters of the EQUUS-FAPpartial}

The distribution of each parameter of the EQUUS-FAPpartial was evaluated individually, by analysing its relative frequency, in a logistic regression analysis model using the R package Ime4 (Imer, version 1.1-15). Horse ID and trial (type of surface) within horse were used as random effects, and the condition (baseline/lameness 
induction) was used as a fixed effect. Odds ratios for presence of each parameter were determined by calculating the exponential function of the model estimates.

\section{Differences in asymmetry and pain scores during box rest before and after lameness induction}

Differences in pain scores during boxrest before and after lameness induction $(n=115)$ were analysed using Friedman tests with post-hoc Wilcoxon signed rank tests. Asymmetry indices and EQUUS-FAPpartial during locomotion for baseline and lameness $(n=85)$ were assessed using Wilcoxon signed Rank tests. For all statistical tests, significance was set at $\mathrm{P}<0.05$.

\section{Results}

\section{Pain scores during static conditions (box resting)}

EQUUS-FAP scores showed significant increases from baseline in the LPS-induced lameness from 3 to 8.5 hours after LPS administration $(P<0.05$, Figure $1 B)$. For the shoe model lameness, no increases in EQUUS-FAP were found during box resting $(P=0.45$, Figure 1A). CPS scores showed significant increases for both lameness models, at 10 minutes after returning to the stable, when the screw was still in the shoe $(P<0.05$, Figure 1C), and from 3 to 8.5 hours after lameness induction after LPS administration $(P<0.05$, Figure 1D). Supplementary material 6 shows some example photos of facial expression.

\section{Pain scores during dynamic conditions (locomotion)}

During trot, five out of nine parameters of the EQUUS-FAP were showing scores higher than zero (corners mouth/lips, ears, eyelids, muscle tone head, nostrils). Of these, three scored significantly higher during induced lameness in trot than at baseline (Fig. 2). Figure 3 shows a significant increase $(P<0.01)$ in EQUUS-FAPpartial after lameness induction, both for the shoe model and LPS-induced lameness (Fig. 3A+3B). EQUUSFAPpartial discriminated well between baseline and induced lameness conditions, with the largest median differences seen for the LPS-induced pain (Fig. 3B).

\section{The relation between asymmetry and EQUUS-FAPpartial}

Normality of the residuals and homoscedasticity was only achieved after logarithmic transformation of the outcome variable. There were significant increases in asymmetry values (vector sum pol for front limb lameness and vector sum pelvis for hind limb lameness) for both lameness models (Fig. $4 \mathrm{~A}$ and 4B, $\mathrm{P}<0.01$ ). Pain scores increased together with increasing asymmetry parameters (Fig. 6C and 6D). 
A
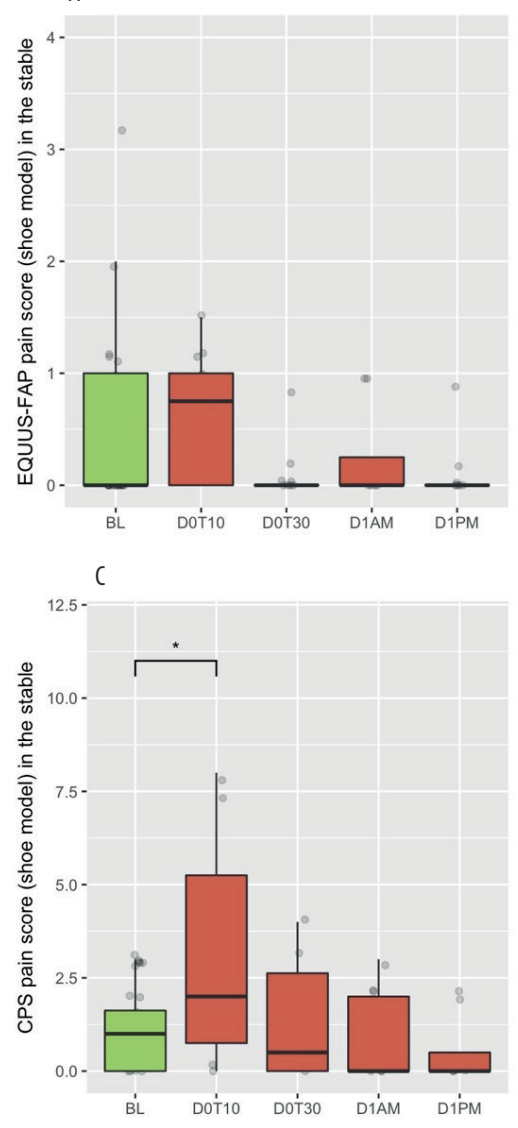

B

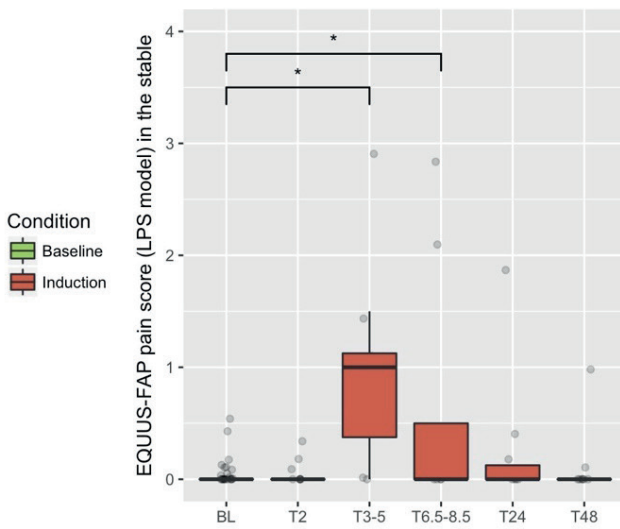

Condition

它Induction

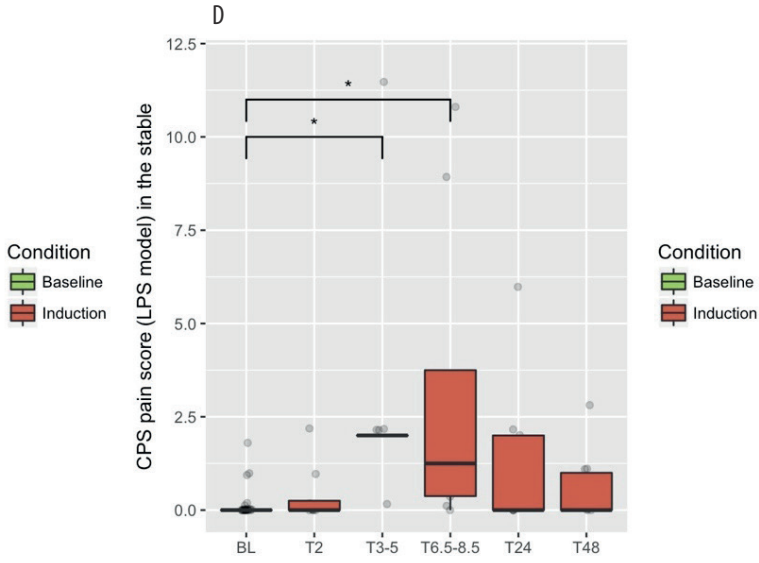

Fig 1. Composite Pain Scale (CPS by Bussières et al., 2008) and Equine Utrecht University Scale for Facial Assessment of Pain (EQUUS-FAP) in Shoe and LPS-induced lameness models during box-resting conditions. A) EQUUS-FAP score during observations during rest for shoe model. B) EQUUS-FAP score during observations in stable for LPS model. C) CPS scores during observations in stable for shoe model. D) CPS scores during observations in stable for LPS model. BL = baseline $(\mathrm{n}=48)$, D0T10 $=10$ minutes after trot with shoe induced lameness, D0T30 $=30$ minutes after trot with shoe induced lameness, D1AM = first day after lameness induction in morning, D1PM = first day after lameness induction in afternoon. T2 $=2$ hours after IA LPS administration, T3-5 = 3-5 hours after LPS administration, T6.5-8.5 $=6.5-8.5$ hours after LPS administration, T24 $=24$ hours after LPS administration, T48 $=48$ hours after LPS administration ( $n=8$ for each time point). ${ }^{*}=\mathrm{P}<0.05$. 


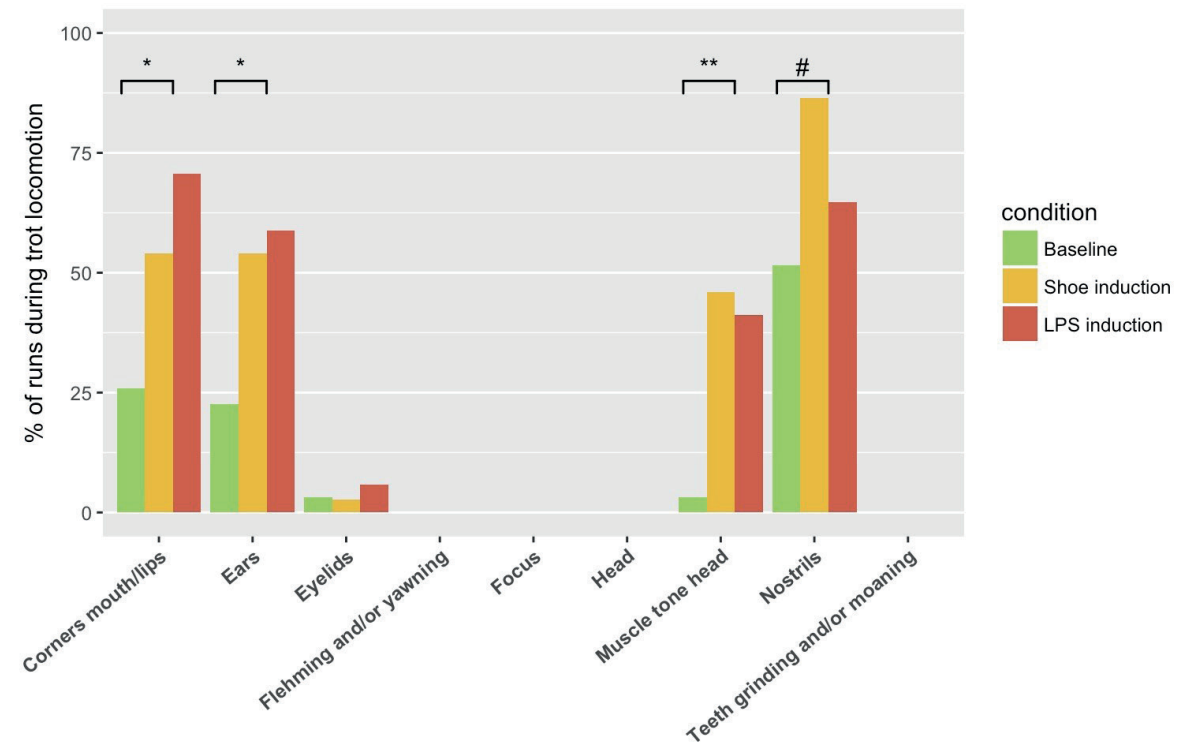

Fig 2. Equine Utrecht University Scale for Facial Assessment of Pain (EQUUS-FAP)partial individual parameter distribution. Percentages of runs in which certain behaviours were displayed at baseline and after lameness induction (both induction methods combined) ( $n=31$ runs for baseline conditions and $n=54$ runs for induced lameness, 37 with the shoe model lameness, 17 with the LPS induced lameness). Significances based on comparison of odds ratio (For more details, see Supplementary material 7) \#: $\mathrm{P}=0.06,{ }^{*}=\mathrm{P}<0.05,{ }^{* *}=\mathrm{P}<0.01$.
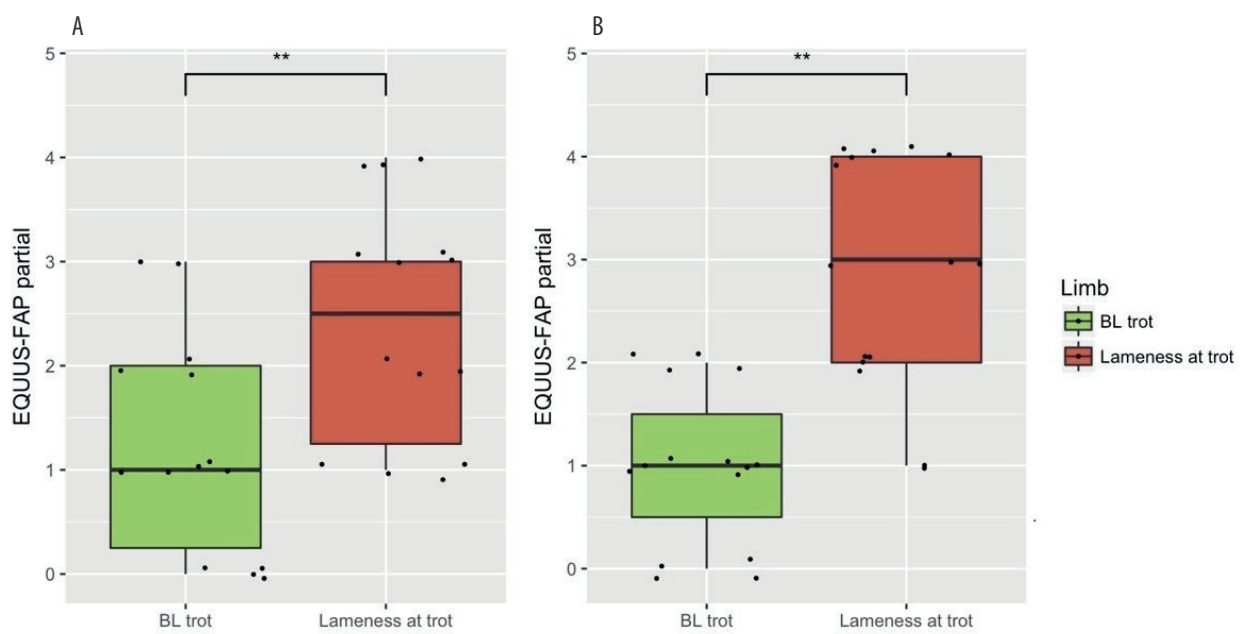

Fig 3. Equine Utrecht University Scale for Facial Assessment of Pain (EQUUS-FAP)partial in Shoe and LPS-induced lameness models during locomotion A) Shoe model lameness. B) LPS-induced lameness. BLtrot $=$ baseline measurement $(n=31)$, lameness trot $(n=37$ for shoe model, $n=17$ for LPS model). Box plots illustrate the median pain scores (bold line in box), the quartiles (box) and ranges (whiskers). The filled circles show individual pain scores. ${ }^{* *}=\mathrm{P}<0.01$. 

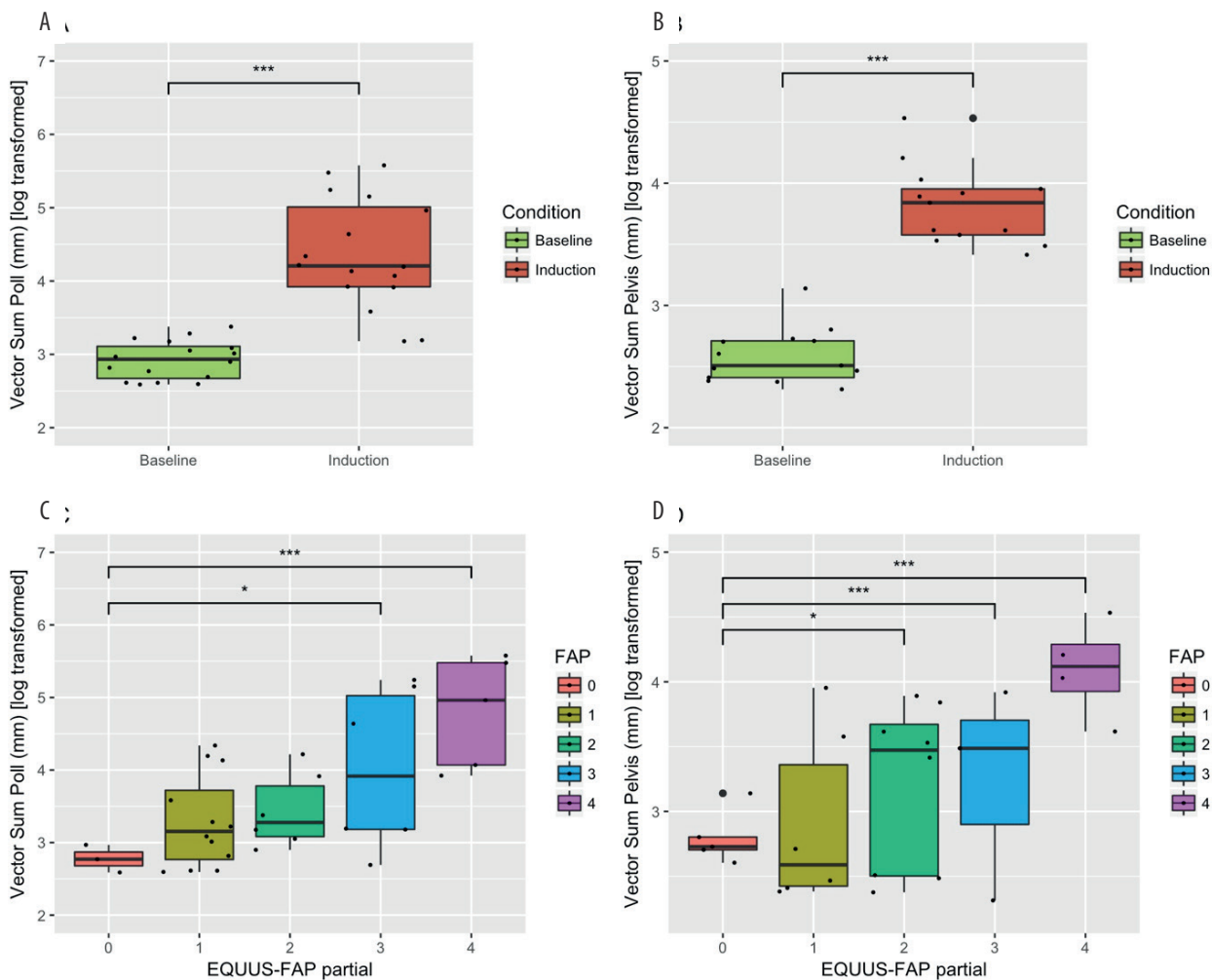

Fig 4. asymmetry and Equine Utrecht University Scale for Facial Assessment of Pain (EQUUS-FAP) partial pain scores during trot with both lameness induction models. A) Vector sum poll (indicating asymmetry index for poll) in front limb lameness before and after lameness induction, B) vector sum pelvis (indicating asymmetry index for pelvis) in hind limb lameness before and after lameness induction. ( $n=31$ for baseline conditions and $n=54$ for induced lameness) C) Vector sum poll (indicating asymmetry index for poll) for different EQUUS-FAP score classes in front limb lameness during trot, D) vector sum pelvis (indicating asymmetry index for pelvis) for different EQUUS-FAP score classes in hind limb lameness during trot. Significance levels indicated in plots C and D are based on the model estimates (Table 2). Box plots illustrate the median pain scores (bold line in box), the quartiles (box) and ranges (whiskers). The filled circles show individual pain scores. ${ }^{*}=\mathrm{P}<0.05,{ }^{* *}$ $=\mathrm{P}<0.01,{ }^{* * *}=\mathrm{P}<0.001$. For more details, see Supplementary material 8.

\section{Inter-observer reliability}

Both CPS and EQUUS-FAP showed significant correlation between two observers during box-rest (Cronbach's alpha $=0.99$ for CPS and 0.93 for EQUUS-FAP, $P<0.001$ ) (Fig. $5 A+C$ ). Bland Altman analysis showed a bias of 0.03 and limits of agreement of -0.81 to 0.86 for CPS and a bias of 0.03 and limits of agreement of -0.73 to 0.78 for EQUUS-FAP (Fig. 5B+D). 


\section{Rescue analgesia}

One horse developed a lameness grade of 4 out of 5 (AAEP-scale) at 4 hours after LPS-administration and was subsequently treated with morphine $0.1 \mathrm{mg} / \mathrm{kg} \mathrm{IV}$ and one hour later with meloxicam $0.6 \mathrm{mg} / \mathrm{kg}$ IV. After this treatment, lameness reduced to grade 2 out of 5 within one hour. After this, measurements were performed on this horse. At 18 hours after LPS administration, lameness grade was less than 1 out of 5 and no further analgesic treatment was provided.

\section{Discussion}

The hypothesis that the EQUUS-FAP pain scale would provide reliable and reproducible scales for assessment of orthopaedic pain in horses with induced lameness, both for the box-rest conditions (EQUUS-FAP) and during locomotion (EQUUS-FAPpartial) was confirmed. A significant relation between EQUUS-FAPpartial and movement asymmetry quantified with objective gait analysis was found, hence indicating a relationship between aysmmetry and pain. Especially for the LPS-induced lameness (that induces a higher level of pain compared to the shoe model), pain scales differentiated very well between baseline and induced lameness conditions and the results during box conditions corresponded to the previously validated CPS by Bussières et al. (2008).

Both pain scales showed good observer agreement, as evidenced by a significant correlation and low limits of agreement. The limits of agreement (LOI) that were found (-0.73 to 0.78 ) for EQUUS-FAP, were lower than the LOI reported for horses with acute colic and in horses with orthopaedic pain (van Loon and van Dierendonck, 2015, 2019).

The EQUUS-FAPpartial was used for observations during locomotion for the first time and proved equally useful to assess pain in these horses. The typical facial expressions that were displayed during locomotion after lameness induction were increased tonus of corners of the mouth, changes in the ear position, tension of the facial muscles and opening of the nostrils. These features also showed an increased incidence in horses after surgical castration (Dalla Costa et al., 2014), in horses with acute laminitis (Dalla Costa et al., 2016) and in experimentally induced acute pain (Gleerup et al., 2015). Some facial features, like opening or tightening of the eyelids were rarely observed in our study, maybe due to the fact that this can be difficult to assess during direct observations in trot. In a recent study by Dalla Costa et al. (2018), a statistical approach was used to determine the weight of the individual 

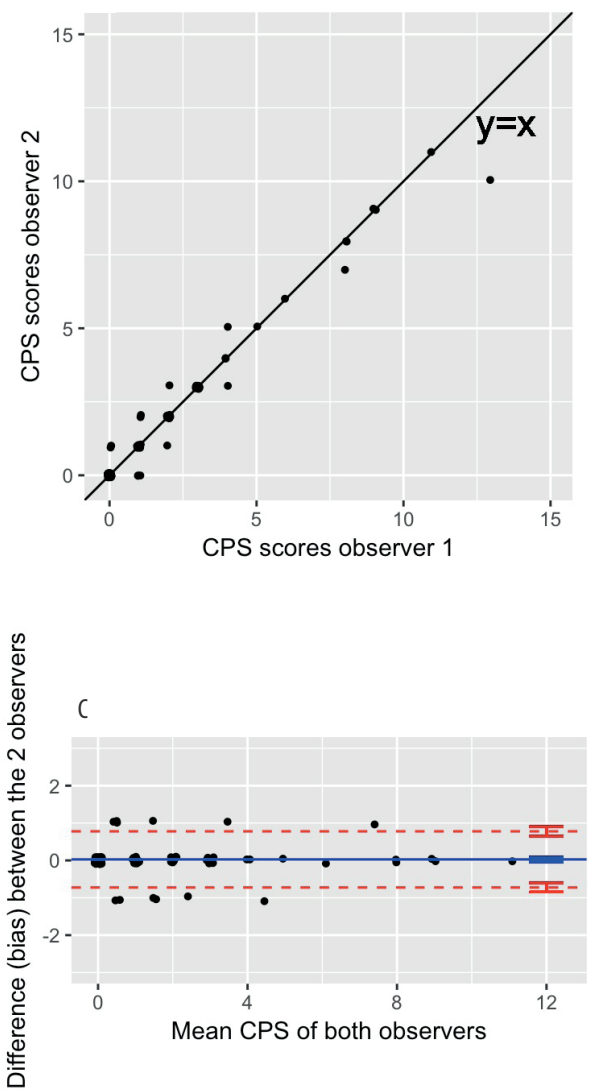

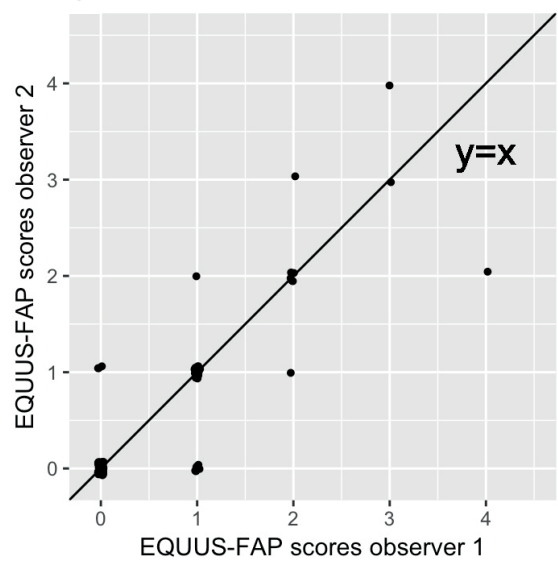

$D$

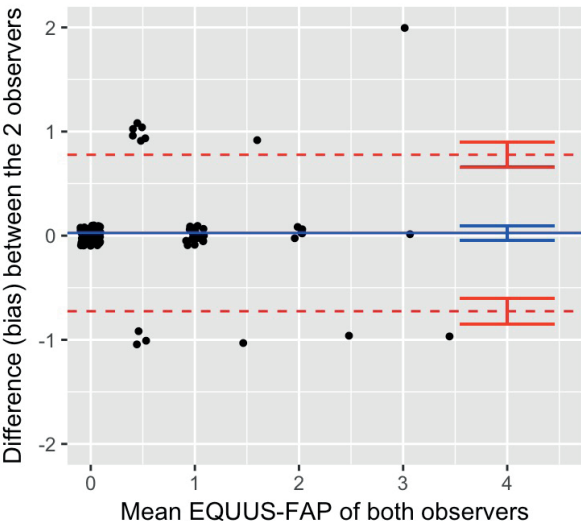

Fig 5. Inter-observer reliability of Composite Pain Scale (CPS by Bussières et al., 2008) and Equine Utrecht University Scale for Facial Assessment of Pain (EQUUS-FAP). A+C: CPS scatter plot (A) and Bland Altman plot $(\mathbf{C})$. Cronbach's alpha $=0.99(P<0.001)$, bias $=0.03$ and limits of agreement of -0.81 to $0.86(n=115)^{2}$ (lines 457-458). B+D: FAP scatter plot (B) and Bland Altman plot (D). Cronbach's alpha $=0.93(P<0.001)$, bias $=0.03$ and limits of agreement of -0.73 to $0.78(n=115)$. The dashed red horizontal line indicates the upper and lower limits of agreement and the blue horizontal line indicates the bias. Whiskers indicate the $95 \%$ confidence interval of the limits of agreement and bias.

facial action units for their earlier castration study (Dalla Costa et al., 2014). Four facial action units (stiffly backward ears, orbital tightening, tension above the eyes area and strained chewing muscles) were needed to build the optimal classifier and therefore of most importance for identification of pain in horses after castration. In contrast to our findings, opening of the nostrils was not necessary in this optimal classifier. This could be explained by the fact that the Horse Grimace Scale (HGS) was based on 
photos, leading to possible bias by missing of opened nostrils. In studies observing horses with acute colic and head-related pain (van Loon and van Dierendonck, 2015, 2017; van Dierendonck and van Loon, 2016), dynamic parameters (head movement, teeth grinding, moaning, flehming and yawning) were more often observed, as were opening or tightening of the eyelids. This resulted in higher pain scores compared to our findings in horses during locomotion.

Our study is the first systematic approach to correlate a known source of pain with changes in facial expression during movement and to correlate pain intensity (assessed by means of EQUUS-FAPpartial) with degree of asymmetry, which is not necessarily the same as the intensity of lameness (Serra Braganca et al., 2018). However, in our study, asymmetry was negligible during baseline measurements and increased significantly after induction of unilateral lameness. Recently, an ethogram that describes facial expressions in non-lame and lame horses was published (Dyson et al., 2017). The position of the ears was one of the best indicators of pain in ridden lame horses (together with twisting of the neck/head, and eye features). This is in accordance with our findings, since we also found significant increases in abnormal ear position during induced lameness. The backward position of the ears should however be interpreted with some caution, especially in non-experimental conditions or in "snap-shot" situations where states other than pain may cause the horse to move its ears, like during communication or during fear or conflict (Dalla Costa et al., 2017). In a recent study (Dyson et al., 2018) video footage was used to observe lame ridden horses and compared to non-lame horses using features of three facial areas: ear position, eyelids (closed or exposing sclera) and mouth (opening and shutting repeatedly and exposing the tongue). This study showed significant differences between nonlame and lame horses. However, more prominent differences were found for gait and body related parameters. Although this study featured many factors that potentially could have biased the results (influence of the rider, the different environments, the bit and the saddle not being standardized, non-lame horses being ridden by own riders while lame horses being ridden by skilled staff riders), the facial characteristics show similarities with our present and others findings (Dalla Costa et al., 2014, 2016; Gleerup et al., 2015).

We used the asymmetry measures as a proxy for the degree of induced pain. The Vector Sum (VS) of the movement asymmetry indeed reflected the effect of the lameness inductions, which is in line with previous publications (van Weeren et al., 2018). In horses with single limb lameness, movement asymmetry is an objective measure of the degree of lameness (Serra Bragança et al., 2018). The log-linear relationship between facial pain scores and the asymmetry indices underlines the 
quantitative character of the pain scale: increasing degrees of asymmetry came with increasing pain scores. We hypothesise that pain scores may aid in determining the reference values for "normal" asymmetry and asymmetry associated with lameness, if pain scores have been assessed in clinical cases and sensitivity and specificity for these will become available. Based on the findings in this study, a FAPpartial score > 2 would be associated with pain. It is however not possible to generalize our findings to clinical conditions, but if validated cut-off values could be established with known sensitivity and specificity, in a large clinical trial, such values could be used to assess asymmetry measures in a clinical context.

A limitation of our study was that pain was scored by direct observations without blinding the observers, which may create observer bias. Although this approach is commonly used under clinical conditions, it might be a potential source of bias that could not be quantified in the current study. In future studies, the possibilities for blinded assessment of pain from video footage will be investigated, including estimation of the correlation between live and video-based observations. This would possibly allow for randomized and blinded observations of the horses, although blinding the videos in the current study set-up would not eliminate the visible asymmetry that was caused by unilateral induced lameness.

\section{Conclusions}

EQUUS-FAP showed good inter-observer reliability and could differentiate between baseline and induced orthopaedic pain during boxrest. EQUUS-FAPpartial could differentiate between baseline and induced lameness during locomotion, it showed to be a feasible and promising tool to assess pain in horses during locomotion that needs further validation. 


\section{Conflict of interest statement}

None of the authors of this paper has a financial or personal relationship with other people or organisations that could inappropriately influence or bias the content of the paper.

Appendix 1: Supplementary material 1: Baseline degree of asymmetry recorded for each subject before the first lameness induction.

Appendix 2: Supplementary material 2: EQUUS-FAP by van Loon and van Dierendonck (2015).

Appendix 3: Supplementary material 3: EQUUS-FAPpartial for assessment during locomotion.

Appendix 4: Supplementary material 4: CPS by Bussières et al. (2008).

Appendix 5: Supplementary material 4: modified heart-bar shoe for lameness induction.

Appendix 6: Supplementary material 6: horses with different EQUUS-FAP scores. Appendix 7: Supplementary material 7: Odds ratio and $95 \%$ confidence intervals (C.I.) for each feature of the EQUUSFAPpartial scale

Appendix 8: Supplementary material 8: Model estimates (least square means) with $95 \%$ confidence intervals (C.I.) and multiple comparisons between EQUUSFAPpartial scores and asymmetry-values. 


\section{References}

1. Benjamini, Y. and Hochberg, Y. (1995) Controlling the false discovery rate: a practical and powerful approach to multiple testing. Journal Royal Statistical Society Series B Statistical Methodology 57, 289-300.

2. Bland, J.M., Altman, D.G., 1986. Statistical methods for assessing agreement between two methods of clinical measurement. Lancet 8, 307-310.

3. Bussières, G., Jacques, C., Lainay, O., Beauchamp, G., Leblond, A., Cadoré, J.L., Desmaizières, L.M., Cuvelliez, S.G., Troncy, E., 2008. Development of a composite orthopaedic pain scale in horses. Research Veterinary Science 85, 294-306.

4. Carregaro, A.B., Freitas, G.C., Ribeiro, M.H., Xavier, N.V., Dória, R.G., 2014. Physiological and analgesic effects of contimuous-rate infusion of morphine, butorphanol, tramadol or methadone in horses with lipopolysaccharide (LPS)-induced carpal synovitis. BMC Veterinary Research 21, 966.

5. Dalla Costa, E., Minero, M., Lebelt, D., Stucke, D., Canali, E., Leach, M.C., 2014. Development of the Horse Grimace Scale (HGS) as a pain assessment tool in horses undergoing routine castration. Plos One 9, e92281.

6. Dalla Costa, E., Stucke, D., Dai, F., Minero, M., Leach, M.C., Lebelt, D., 2016. Using the Horse Grimace Scale (HGS) to assess pain associated with acute laminitis in horses. Animals 6, 47.

7. Dalla Costa, E., Bracci, D., Dai, F., Lebelt, D., Minero, M., 2017. Do different emotional states affect the horse grimace scale score? A pilot study. Journal Equine Veterianry Science 54, 114-117.

8. Dalla Costa, E., Pascuzzo, R., Leach, M.C., Dai, F., Lebelt, D., Vantini, S., Minero, M., 2018. Can grimace scales estimate the pain status in horses and mice? A statistical approach to identify a classifier. Plos One, 13, e0200339.

9. De Grauw, J.C., van Loon, J.P.A.M., 2016. Systematic pain assessment in horses. The Veterinary Journal 209, 14-22.

10. Dyson, S., Berger, J.M., Ellis, A.D., Mullard, J., 2017. Can the presence of musculoskeletal pain be determined from the facial expressions of ridden horses (FEReq)? Journal Veterinary Behaviour 19, 78-89.

11. Dyson, S., Berger, J., Ellis, A.D., Mullard, J., 2018. Development of an ethogram for a pain scoring system in ridden horses and its application to determine the presence of musculoskeletal pain. Journal Veterinary Behaviour 23, 47-57.

12. Gleerup, K.B., Forkman, B., Lindegaard, C., Andersen, P.H., 2015. An equine pain face. Veterinary Anaesthesia Analgesia 42, 103-114.

13. Gleerup, K.B., Lindegaard, C., 2016. Recognition and quantification of pain in horses: a tutorial review. Equine Veterinary Education 28, 47-57.

14. Graubner, C., Gerber, V., Doherr, M., Spadavecchia, C., 2011. Clinical application and reliability of a post abdominal surgery pain assessment scale (PASPAS) in horses. The Veterinary Journal $188,178-183$.

15. Merkens, H.W., Schamhardt, H.C., 1988. Evaluation of equine locomotion during different degrees of experimentally induced lameness. I: Lameness model and quantification of ground reaction force patterns of the limbs. Equine Veterinary Journal Supplement 6, 99-106.

16. Molony, V., Kent, J.E., 1997. Assessment of acute pain in farm animals using behavioural and physiological measurements. Journal of Animal Science, 75, 266-272.

17. Rhodin, M., Egenvall, A., Haubro Andersen, P., Pfau, T., 2017. Head and pelvic movement asymmetries at trot in riding horses in training and perceived as free from lameness by the owner. Plos One. 12, e0176253. 
18. Rhodin, M., Persson-Sjodin, E., Egenvall, A., Serra Bragança, F.M., Pfau, T., Roepstorff, L., Weishaupt, M.A., Thomsen, M.H., van Weeren, P.R., Hernlund, E., 2018. Vertical movement symmetry of the withers in horses with induced forelimb and hindlimb lameness at trot. Equine Veterinary Journal 50, 818-824.

19. Serra Bragança, F.M., Rhodin, M., van Weeren, P.R., 2018. On the brink of daily clinical application of objective gait analysis: What evidence do we have so far from studies using an induced lameness model? The Veterinary Journal 234, 11-23.

20. Taffarel, M.O., Luna, S.P., de Oliveira, F.A., Cardoso, G.S., Alonso, J.M., Pantoia, J.C., Brondani, J.T., Love, E., Taylor, P., White, K., Murrell, J.C., 2015. Refinement and partial validation of the UNESPBotucatu multidimensional composite pain scale for assessing postoperative pain in horses. BMC Veterinary Research 11, 83.

21. Van Dierendonck, M.C., van Loon, J.P.A.M., 2016. Monitoring acute equine visceral pain with the Equine Utrecht University Scale for Composite Pain Assessment (EQUUS-COMPASS) and the Equine Utrecht University Scale for Facial Assessment of Pain (EQUUS-FAP): a validation study. The Veterinary Journal 216, 175-177.

22. Van Loon, J.P.A.M., van Dierendonck, M.C., 2015. Monitoring acute equine visceral pain with the Equine Utrecht University Scale for Composite Pain Assessment (EQUUS-COMPASS) and the Equine Utrecht University Scale for Facial Assessment of Pain (EQUUS-FAP): s scale-construction study. The Veterinary Journal 206, 356-364.

23. Van Loon, J.P.A.M., van Dierendonck, M.C., 2017. Monitoring equine head-related pain with the Equine Utrecht University Scale for Facial Assessment of Pain (EQUUS-FAP). The Veterinary Journal 220, 88-90.

24. Van Loon, J.P.A.M., van Dierendonck, M.C., 2019. Pain assessment in horses after orthopaedic surgery and with orthopaedic trauma. The Veterinary Journal 246, 85-91.

25. Van Weeren, P.R., Pfau, T., Rhodin, M., Roepstorff, L., Serra Bragança, F., Weishaupt, M.A., 2018. What is lameness and what (or who) is the gold standard to detect it? Equine Veterinary Journal 50, 549-551. 
Supplementary material 1.

\begin{tabular}{|c|c|c|c|c|c|c|c|c|c|c|c|c|}
\hline \multirow[b]{3}{*}{ Horse } & \multicolumn{4}{|c|}{ Poll } & \multicolumn{4}{|c|}{ Pelvis } & \multicolumn{4}{|c|}{ Withers } \\
\hline & \multicolumn{2}{|c|}{ MinDiff } & \multicolumn{2}{|c|}{ MaxDiff } & \multicolumn{2}{|c|}{ MinDiff } & \multicolumn{2}{|c|}{ MaxDiff } & \multicolumn{2}{|c|}{ MinDiff } & \multicolumn{2}{|c|}{ MaxDiff } \\
\hline & mean & SD & mean & SD & Mean & SD & mean & SD & mean & SD & mean & SD \\
\hline 1 & -11.86 & 11.47 & 5.62 & 8.49 & -10.01 & 6.76 & -5.46 & 6.14 & 2.74 & 4.76 & 8.43 & 5.22 \\
\hline 2 & 22.02 & 25.11 & 25.93 & 15.99 & -5.58 & 7.08 & 4.33 & 9.25 & -3.09 & 7.51 & 19.72 & 5.85 \\
\hline 3 & 4.69 & 22.21 & 13.78 & 13.06 & 8.30 & 5.34 & 9.77 & 4.89 & 5.24 & 3.22 & 0.88 & 5.60 \\
\hline 4 & -3.16 & 10.87 & -2.32 & 9.28 & -7.49 & 5.28 & 1.38 & 10.88 & -7.68 & 5.01 & 8.35 & 5.51 \\
\hline 5 & -10.96 & 18.39 & -3.68 & 16.37 & -3.70 & 10.73 & 7.43 & 10.90 & -0.26 & 9.26 & -9.28 & 9.57 \\
\hline 6 & 14.12 & 9.04 & 14.53 & 12.76 & -2.25 & 13.01 & -7.57 & 10.72 & -6.03 & 5.06 & 10.09 & 10.52 \\
\hline 7 & -8.24 & 16.14 & -16.57 & 16.72 & -2.11 & 7.28 & 6.12 & 7.85 & 5.09 & 3.65 & -11.07 & 8.77 \\
\hline 8 & 1.89 & 18.14 & 34.22 & 8.88 & 1.37 & 3.29 & 3.68 & 5.83 & 1.68 & 6.34 & 9.35 & 8.47 \\
\hline
\end{tabular}

Table: Baseline measurements before first lameness induction of each subject.

Supplementary material 2. Score sheet of the Equine Utrecht University Scale for Facial Assessment of Pain (EQUUS-FAP) scored for 2 minutes.

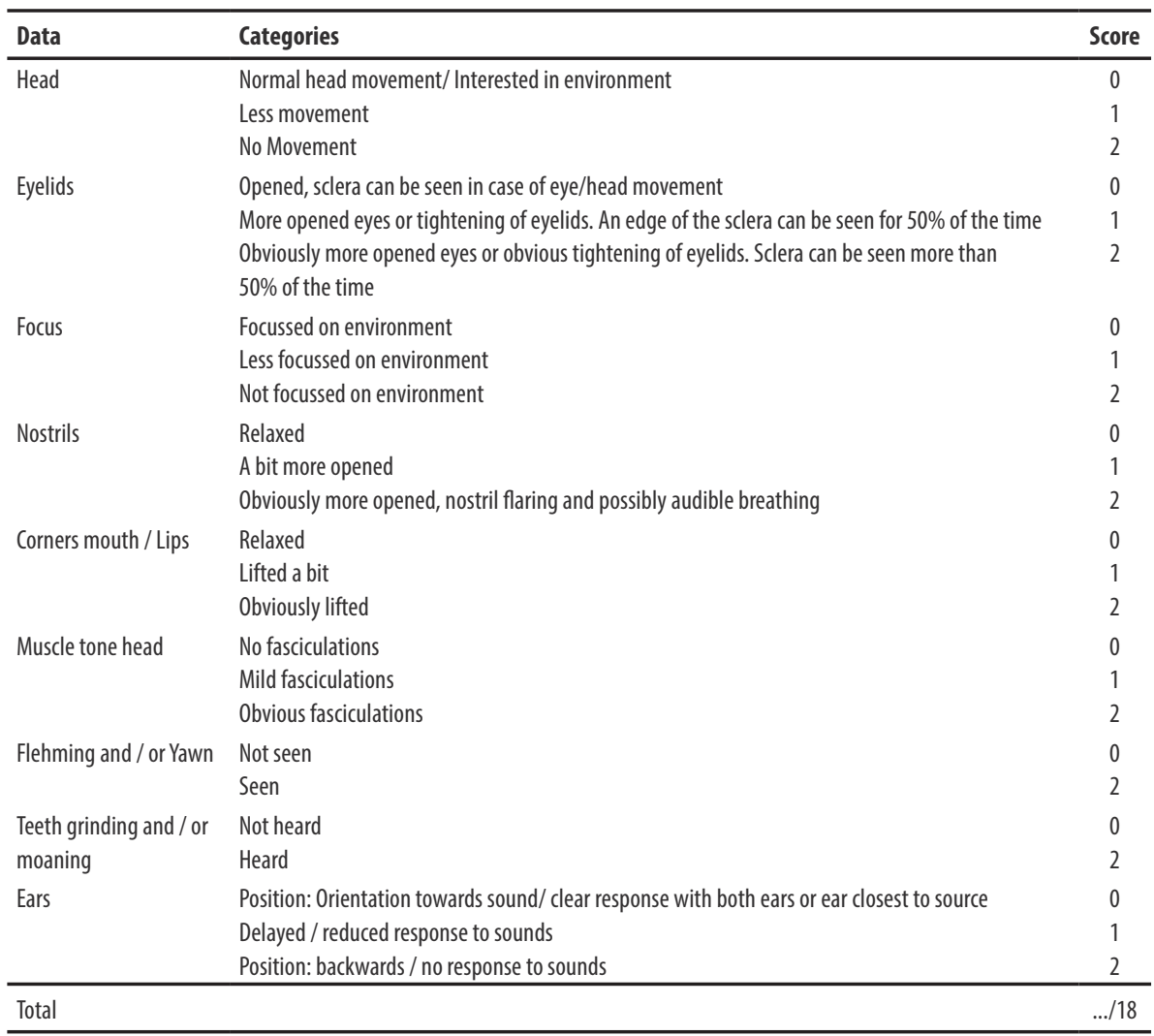


Supplementary material 3. Score sheet of the Equine Utrecht University Scale for Facial Assessment of Pain (EQUUS-FAPpartial) for assessment of horses during locomotion.

\begin{tabular}{|c|c|c|}
\hline Data & Categories & Score \\
\hline \multirow[t]{3}{*}{ Eyelids } & Opened, sclera can be seen in case of eye/head movement & 0 \\
\hline & More opened eyes or tightening of eyelids. An edge of the sclera can be seen for $50 \%$ of the time & 1 \\
\hline & $\begin{array}{l}\text { Obviously more opened eyes or obvious tightening of eyelids. Sclera can be seen more than } 50 \% \\
\text { of the time }\end{array}$ & 2 \\
\hline \multirow[t]{3}{*}{ Nostrils } & Relaxed & 0 \\
\hline & A bit more opened & 1 \\
\hline & Obviously more opened, nostril flaring and possibly audible breathing & 2 \\
\hline \multirow[t]{3}{*}{ Corners mouth/ Lips } & Relaxed & 0 \\
\hline & Lifted a bit & 1 \\
\hline & Obviously lifted & 2 \\
\hline \multirow[t]{3}{*}{ Muscle tone head } & No fasciculations & 0 \\
\hline & Mild fasciculations & 1 \\
\hline & Obvious fasciculations & 2 \\
\hline \multirow[t]{3}{*}{ Ears } & Position: Orientation towards sound/ clear response with both ears or ear closest to source & 0 \\
\hline & Delayed / reduced response to sounds & 1 \\
\hline & Position: backwards / no response to sounds & 2 \\
\hline Total & & $\ldots / 10$ \\
\hline
\end{tabular}

Supplementary material 4. Score sheet of the Composite Pain Scale (CPS) scored for 5 minutes (by Bussières et al. (2008) - physiological data slightly adapted).

\begin{tabular}{|c|c|c|}
\hline Data & Categories & Score \\
\hline \multirow[t]{2}{*}{ Physiological data } & $24-44$ beats/min & 0 \\
\hline & $45-52$ beats $/ \mathrm{min}$ & 1 \\
\hline \multirow[t]{2}{*}{ Heart rate } & $53-60$ beats/min & 2 \\
\hline & $>60$ beats $/ \mathrm{min}$ & 3 \\
\hline \multirow[t]{4}{*}{ Respiratory rate } & $8-13$ breaths/min & 0 \\
\hline & $14-16$ breaths/min & 1 \\
\hline & $17-18$ breaths/min & 2 \\
\hline & $>18$ breaths/min & 3 \\
\hline \multirow[t]{4}{*}{ Rectal temperature } & $36.9^{\circ} \mathrm{C}-38.5^{\circ} \mathrm{C}$ & 0 \\
\hline & $36.4^{\circ} \mathrm{C}-36.9^{\circ} \mathrm{C}$ or $38.5^{\circ} \mathrm{C}-39.0^{\circ} \mathrm{C}$ & 1 \\
\hline & $35.9^{\circ} \mathrm{C}-36.4^{\circ} \mathrm{C}$ or $39.0^{\circ} \mathrm{C}-39.5^{\circ} \mathrm{C}$ & 2 \\
\hline & $35.4^{\circ} \mathrm{C}-35.9^{\circ} \mathrm{C}$ or $39.5^{\circ} \mathrm{C}-40.0^{\circ} \mathrm{C}$ & 3 \\
\hline \multirow[t]{4}{*}{ Digestive sounds } & Normal motility & 0 \\
\hline & Decreased motility & 1 \\
\hline & No motility & 2 \\
\hline & Hypermotility or tympanic sounds & 3 \\
\hline Behaviour & Stands quietly, normal walk & 0 \\
\hline \multirow{3}{*}{ distribution, comfort) } & Occasional weight shift, slight muscle tremors & 1 \\
\hline & Non-weight bearing, abnormal weight distribution & 2 \\
\hline & Analgesic posture (attempts to urinate), prostration, muscle tremors & 3 \\
\hline \multirow[t]{4}{*}{ Appetite } & Eats hay readily & 0 \\
\hline & Hesitates to eat hay & 1 \\
\hline & Shows little interest in hay, eats very little hay in mouth but does not chew or swallow & 2 \\
\hline & Neither shows interest in nor eats hay & 3 \\
\hline
\end{tabular}




\begin{tabular}{|c|c|c|}
\hline \multirow[t]{4}{*}{ Sweating } & No signs of sweating & 0 \\
\hline & Warm or damp to touch, no sweat or wet spots visible & 1 \\
\hline & Wet spots visible, no droplets or streams & 2 \\
\hline & Excessive sweating, may include streams or droplets & 3 \\
\hline \multirow[t]{4}{*}{ Kicking at abdomen } & Quietly standing, no kicking & 0 \\
\hline & Occasional kicking at abdomen ( $1-2$ times $/ 5 \mathrm{~min}$ ) & 1 \\
\hline & Frequent kicking at abdomen ( $3-4$ times $/ 5 \mathrm{~min}$ ) & 2 \\
\hline & Excessive kicking at abdomen ( $>5$ times $/ 5 \mathrm{~min}$ ), intermittent attempts to lie down and roll & 3 \\
\hline \multirow{4}{*}{$\begin{array}{l}\text { Pawing at floor } \\
\text { (pointing, hanging } \\
\text { limbs) }\end{array}$} & Quietly standing, does not paw at floor & 0 \\
\hline & Occasional pawing at floor ( $1-2$ times $/ 5 \mathrm{~min}$ ) & 1 \\
\hline & Frequent pawing at floor ( $3-4$ times $/ 5 \mathrm{~min}$ ) & 2 \\
\hline & Excessive pawing at floor ( $>5$ times $/ 5 \mathrm{~min}$ ) & 3 \\
\hline \multirow[t]{5}{*}{ Head movements } & No evidence of discomfort, head straight ahead for the most part & 0 \\
\hline & Intermittent head movements laterally/vertically, occasional looking at flank (1-2/5 min), lip & 1 \\
\hline & curling ( $1-2$ times $/ 5 \mathrm{~min})$ & 2 \\
\hline & $\begin{array}{l}\text { Intermittent and rapid head movements laterally/vertically, frequent looking at flank (3-4/5 min), } \\
\text { lip curling ( } 3-4 \text { times } / 5 \mathrm{~min} \text { ) }\end{array}$ & 3 \\
\hline & $\begin{array}{l}\text { Continuous head movements, excessively looking at flank ( }>5 \text { times } / 5 \mathrm{~min} \text { ), lip curling ( }>5 \\
\text { times } / 5 \mathrm{~min} \text { ) }\end{array}$ & \\
\hline \multirow{4}{*}{$\begin{array}{l}\text { Appearance (reluctance } \\
\text { to move, restlessness, } \\
\text { agitation and anxiety) }\end{array}$} & Bright, no reluctance to move & 0 \\
\hline & Bright and alert, occasional head movements, no reluctance to move & 1 \\
\hline & Restlessness, pricked up ears, abnormal facial expressions, dilated pupils & 2 \\
\hline & Excited, continuous body movements, abnormal facial expression & 3 \\
\hline Response to treatment & Pays attention to people & 0 \\
\hline \multirow{4}{*}{ Interactive behaviour } & Exaggerated respon & 1 \\
\hline & se to auditory stimulus & 2 \\
\hline & Excessive-to-aggressive response to auditory stimulus & 3 \\
\hline & Stupor, prostration, no response to auditory stimulus & \\
\hline Response to palpation & No reaction to palpation & 0 \\
\hline \multirow[t]{3}{*}{ of the painful area } & Mild reaction to palpation & 1 \\
\hline & Resistance to palpation & 2 \\
\hline & Violent reaction to palpation & 3 \\
\hline Total & &...$/ 39$ \\
\hline
\end{tabular}




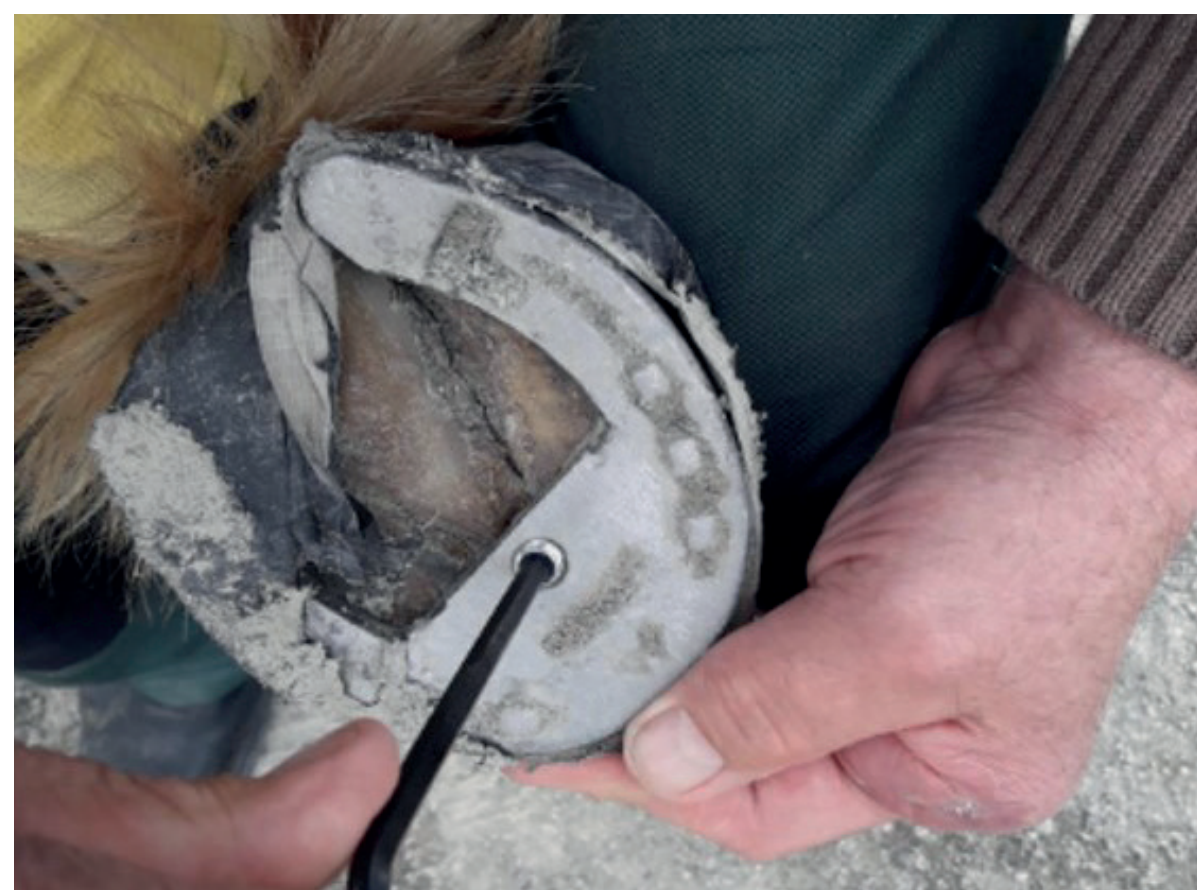

Supplementary material 5. Modified heart-bar horshoe that was applied to the selected limb (the remaining hooves were also shod with normal shoes). This shoe is a modification of the original model by Merkens et al. (1988) where only a single M10 screw is contacts with the hoof at the tip of the frog. 

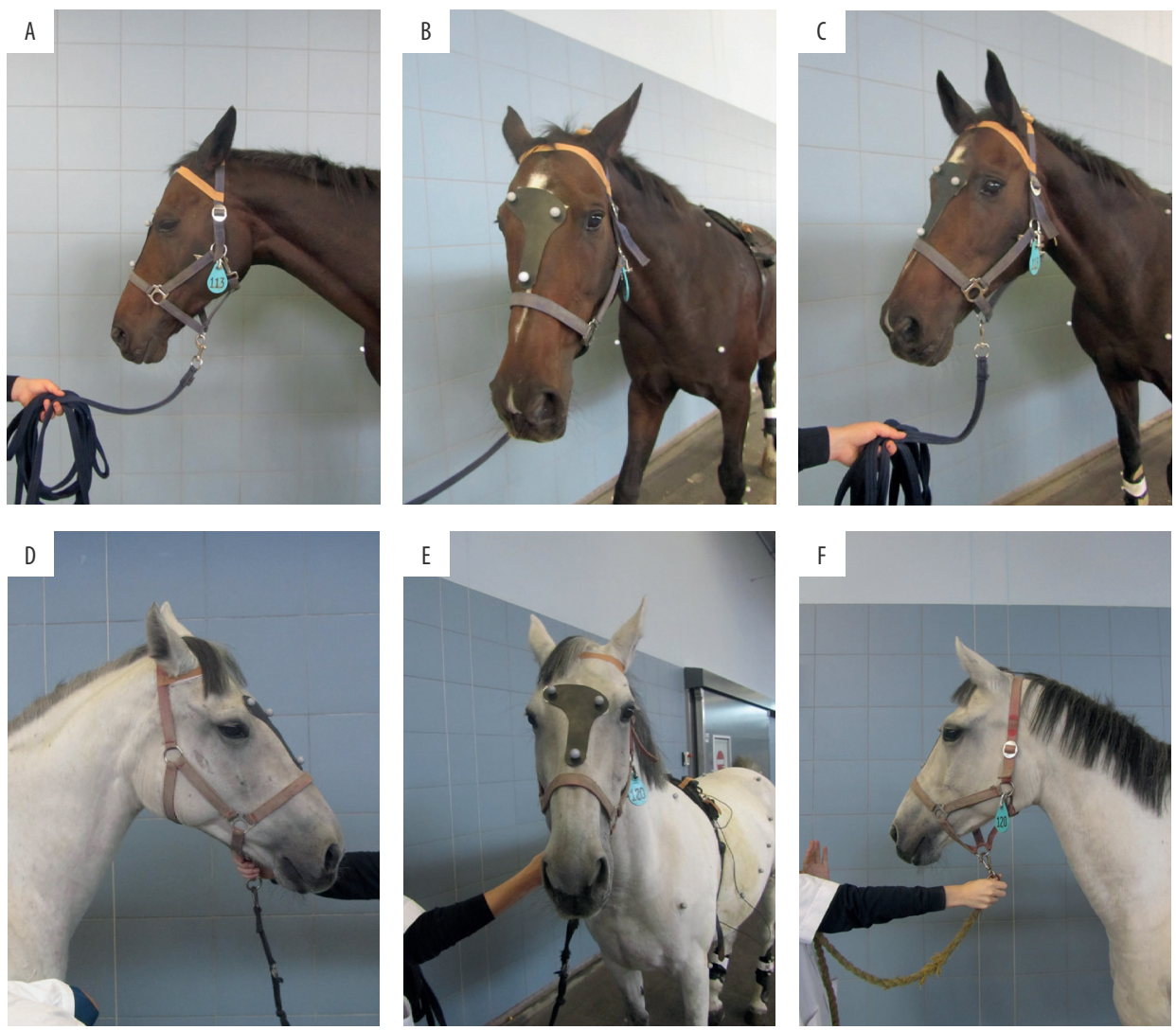

\section{Supplementary material 6. EQUUS-FAP parameters}

$A+B+C$ : shoe induction of lameness after trot $(\mathbf{A}$ : FAP score $=6$, B: FAP score $=4, C$ : FAP score $=2$ ). D+E: 6 hours after LPS induction of lameness after trot (D: FAP score $=7$, E: FAP score $=3$ ). F: baseline after trot (FAP score $=1)$. 
Supplementary material 7. Odds ratio and 95\% confidence intervals (C.I.) for each feature of the EQUUS-FAPpartial scale scored during locomotion, between baseline and lameness conditions (based on $\mathrm{n}=8$ horses in $\mathrm{n}=85$ observations).

\begin{tabular}{lcccc}
\hline & Lower Cl & Odds ratio & Upper C & P-value \\
\hline Corners mouth/lips & 1.35 & 4.76 & 16.72 & 0.02 \\
Ears & 1.35 & 4.62 & 15.87 & 0.02 \\
Eyelids & 0.04 & 1 & 26.07 & $>0.05$ \\
Flehming and/or yawning & 0.04 & 1 & 26.07 & $>0.05$ \\
Focus & 0.04 & 1 & 26.07 & $>0.05$ \\
Head & 0.04 & 1 & 26.07 & $>0.05$ \\
Muscle tone head & 4.35 & 57.71 & 765.16 & 0.002 \\
Nostrils & 0.97 & 4.29 & 18.99 & 0.06 \\
Teeth grinding and/or moaning & 0.04 & 1 & 26.07 & $>0.05$ \\
\hline
\end{tabular}

Supplementary material 8. Model estimates (least square means) with $95 \%$ confidence intervals (C.I.) and multiple comparisons between EQUUS-FAPpartial scores and asymmetry-values. *P-values adjusted for multiple comparisons. VS= Vector Sum, $†=$ Log transformed.

\begin{tabular}{|c|c|c|c|c|c|c|c|c|}
\hline & FAP score & $\begin{array}{c}\text { Least square mean } \\
\text { of VS }\end{array}$ & $\begin{array}{l}\text { Lower Cl } \\
\text { of VS }\end{array}$ & $\begin{array}{l}\text { Upper Cl } \\
\text { of VS }\end{array}$ & $\begin{array}{l}\text { Comparison } \\
\text { FAP scores }\end{array}$ & estimate & SE & P-value* \\
\hline \multirow{11}{*}{ 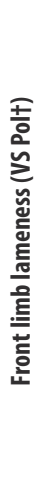 } & 0 & 2.78 & 1.97 & 3.59 & & & & \\
\hline & 1 & 3.19 & 2.65 & 3.75 & 0 vs 1 & -0.41 & 0.33 & 0.2 \\
\hline & 2 & 3.46 & 2.82 & 4.11 & 0 vs 2 & -0.68 & 0.37 & 0.09 \\
\hline & 3 & 4.11 & 3.46 & 4.76 & 0 vs 3 & -1.33 & 0.36 & 0.002 \\
\hline & 4 & 4.79 & 4.01 & 5.48 & 0 vs 4 & -2.00 & 0.38 & $<.0001$ \\
\hline & & & & & 1 vs 2 & -0.27 & 0.26 & 0.3 \\
\hline & & & & & 1 vs 3 & -0.91 & 0.27 & 0.003 \\
\hline & & & & & 1 vs 4 & -1.59 & 0.29 & $<.0001$ \\
\hline & & & & & 2 vs 3 & -0.64 & 0.30 & 0.05 \\
\hline & & & & & 2 vs 4 & -1.32 & 0.30 & 0.0003 \\
\hline & & & & & 3 vs 4 & -0.67 & 0.31 & 0.05 \\
\hline \multirow{11}{*}{ 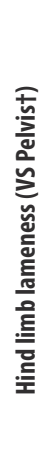 } & 0 & 2.53 & 1.58 & 3.12 & & & & \\
\hline & 1 & 2.76 & 2.06 & 3.46 & 0 vs 1 & -0.41 & 0.33 & 0.2 \\
\hline & 2 & 3.14 & 2.52 & 3.76 & 0 vs 2 & -0.79 & 0.31 & 0.02 \\
\hline & 3 & 4.3 & 3.31 & 5.29 & 0 vs 3 & -1.95 & 0.44 & 0.001 \\
\hline & 4 & 4.16 & 3.33 & 4.98 & 0 vs 4 & -1.81 & 0.41 & 0.001 \\
\hline & & & & & 1 vs 2 & -0.38 & 0.27 & 0.2 \\
\hline & & & & & 1 vs 3 & -1.53 & 0.43 & 0.003 \\
\hline & & & & & 1 vs 4 & -1.39 & 0.38 & 0.002 \\
\hline & & & & & 2 vs 3 & -1.15 & 0.40 & 0.01 \\
\hline & & & & & 2 vs 4 & -1.01 & 0.34 & 0.01 \\
\hline & & & & & 3 vs 4 & 0.14 & 0.44 & 0.8 \\
\hline
\end{tabular}




\section{Improving gait classification in horses by using inertial measurement unit (IMU) generated data and machine- learning}

Serra Bragança F.M. ${ }^{*}{ }^{*}$, Broomé S. ${ }^{2}$, Rhodin M. ${ }^{3}$, Björnsdóttir S. ${ }^{4}$, Gunnarsson V. ${ }^{5}$, Voskamp J. ${ }^{6}$, Back W. ${ }^{1,7}$, Lindgren G. ${ }^{8,9}$, Novoa-Bravo M. ${ }^{10}$, Roepstorff C. ${ }^{11}$, Van der Zwaag B.J. ${ }^{12}$, Van Weeren P.R. ${ }^{1}$, E. Hernlund ${ }^{3}$

Department of Equine Sciences, Faculty of Veterinary Medicine, Utrecht University, NL-3584CM Utrecht, The Netherlands.

2 Division of Robotics, Perception and Learning, KTH Royal Institute of Technology, Sweden.

3 Department of Anatomy, Physiology and Biochemistry, Swedish University of Agricultural Sciences, Sweden.

4 Agricultural University of Iceland, Hvanneyri, Borgarnes, Iceland.

5 Department of Equine Science, Hólar University College, Iceland.

6 Rosmark Consultancy, The Netherlands.

7 Department of Surgery and Anaesthesiology of Domestic Animals, Faculty of Veterinary Medicine, Ghent University, B-9820 Merelbeke, Belgium.

8 Department of Animal Breeding and Genetics, Swedish University of Agricultural Sciences, S-75007 Uppsala, Sweden.

9 Livestock Genetics, Department of Biosystems, KU Leuven, B-3001 Leuven, Belgium.

10 Genética Animal de Colombia Ltda. Bogotá, Colombia.

11 Equine Department, Vetsuisse Faculty, University of Zurich, Winterthurerstrasse 260, CH-8057 Zurich, Switzerland.

12 Inertia Technology B.V., The Netherlands. 


\section{Abstract}

For centuries humans have been fascinated by the natural beauty of horses in motion and their different gaits. For long the exact description of all gaits has therefore been a focus of scientific research. Gait classification (GC) i.e. determining the correct gait, has numerous applications like in harness-racing or competition disciplines for gaited horses, but is not trivial. Gait classification is performed through visual assessment, sometimes supported by high-speed video images. However, visual assessment is hampered by the limited spatio-temporal resolution of the human eye and prone to bias, which latter confounding factor applies to video assessment as well. Hence, reliable methods for real-time objective GC in horses are warranted. In this study we used a full body network of wireless, high sampling-rate $(200-500 \mathrm{~Hz})$ sensors combined with machine-learning to fully automatically classify gait. Using data from 120 horses of 4 different domestic breeds (Colombian Paso, Franche Montagne, Icelandic, Warmblood), equipped with seven IMU sensors (head, withers, pelvis and one on each limb), we included 727,215 strides from 8 different gaits (walk, trot, left/ right canter, pace, tölt, paso fino and trocha). GC was trained using several machinelearning approaches, both from feature extracted data (linear/quadratic discrimination, decision-tree, one-layer fully connected) and from raw sensor data (recurrent neural networks). Our approach partially confirmed and partially corrected the outcome of the 2D models used by Hildebrand in his 1965 landmark paper on equine gait. ) Our best model achieved $98 \%$ accuracy to classify these 8 gaits. Interestingly, the recurrent neural network method, using raw sensor data, also performed accurate classification (96\%). This technique demands no human preselection of variables and hence lends itself to potential use in other quadrupedal species without the need of developing gait/animal specific algorithms. The highest misclassification was found between the trot and trocha of the Colombian Paso horse. The combination of input from multiple IMU sensors proved to be crucial to accurately classify gait, disqualifying systems relying on a single sensor. The approach facilitated accurate, almost errorless, GC that enables in-depth biomechanical studies and allows for highly accurate phenotyping of gait for genetic research and breeding. 


\section{Introduction}

The horse, Equus caballus ferus, is a remarkable animal athlete with unique anatomical and physiological features that allow highly efficient locomotion realized by a variety of gaits. The different gaits are characterized by specific limb movement sequences, which can be described by spatiotemporal biomechanical parameters (1). These gait patterns are orchestrated by the nervous system. Networks of interspinal neurons, known as central pattern generators (CPGs), produce rhythmic output that coordinates the limbs and provides punctual control of hundreds of skeletal muscles (2). Walk, trot and canter are the standard gaits of all horses, but some breeds can display additional gaits. A gene mutation (DMRT3_Ser301STOP) that alters the CPGs has been found in some breeds such as the Icelandic horse, permitting exhibition of additional gaits, such as the tölt and pace (3). These breeds are known as 'gaited' and have been selectively bred by humans, most likely for the extra comfort these gaits offer to the rider (4).

Scientific work on gaits in animals was pioneered by Milton Hildebrand (5). In a ground-breaking article published in Science in 1965 he described a gait classification paradigm for quadrupeds based on two kinematic gait parameters - relative hind limb stance duration (duty factor) and lateral advanced placement (5). Hildebrand and others have categorized quadrupedal locomotion into walking and running, and into symmetrical and asymmetrical gaits (2). These relatively simple classification categories have, however, been questioned as to how accurate they are in reliably distinguishing gaits and to what extent they can explain the complex gait patterns built by the multiple components of the locomotor apparatus of quadrupedal animals. Recently, multi-dimensional approaches have been used $(6,7)$, challenging the old dogma.

The introduction of sensor technology in motion studies allows us to easily collect large amounts of high-resolution, high-sample rate data (8) that can be used to train models for gait classification. Here, we used sensor-based data to investigate the accuracy of different classification models, based on machine learning technology. We have focused on two main methodologies to train classification models. One approach used a previously described algorithm (9) for feature extraction by calculating locomotion parameters from limb-mounted IMU sensors. Using this approach, several models were trained, demonstrating that the most important feature for proper gait classification in this approach is the (complex) interlimb relation. Application of this technique largely confirmed Hildebrand's theory, but indeed resulted in more accurate gait classification than the original approach, 
allowing for a refinement of the concept. Further, we have showed that a deep-learning approach on raw IMU sensor data (i.e. not based on feature extraction) using a long-short term memory (LSTM) network can also be used to achieve high accuracy in gait classification. This indicates that the timeconsuming task of generating animal-specific and gait-specific algorithms can be overcome and opens wide perspectives for the application of this approach in other animal species that are much less researched than the horse.

\section{RESULTS}

The footfall pattern and the sequence of footfalls can be defined for each specific gait (Fig. 1 A). Specific features of each gait can easily be identified, such as symmetry and laterality. However, these variables do not fully discriminate between the gait classes. Specifically, for some gaits such as walk, tölt and paso fino, the footfall pattern sequence, symmetry and laterality, are not comprehensively discriminating features. Other discriminating features, such as the stride temporal variables (Fig. 1 B, Table 1), can be differentiating enough for some gaits, such as for example stance duration for the walk $(0.64 \pm 0.11 \mathrm{~s})$ and the trot $(0.28 \pm 0.05 \mathrm{~s})$, but in other gaits some of these features overlap, such as stance duration for paso fino $(0.21 \pm 0.01)$ and trocha $(0.2 \pm 0.02)$. This indicates that multidimensional classification models are indeed required for the comprehensive classification of all gaits.

Some features are also characteristic for specific breeds (Fig. $1 \mathrm{C}$ ) although some of these differences might also, to some extent, be attributed to conformation and speed. We have made an overlap of our data with data generated by the original classification formula for symmetrical gaits of Hildebrand (Fig. 1 D). Although each of our measured gaits falls grossly within the previously described regions, it is evident that the reality is more complex and less unambiguous than depicted by the original scheme: the overlap is not perfect, the spectra within each gait are broader and less 

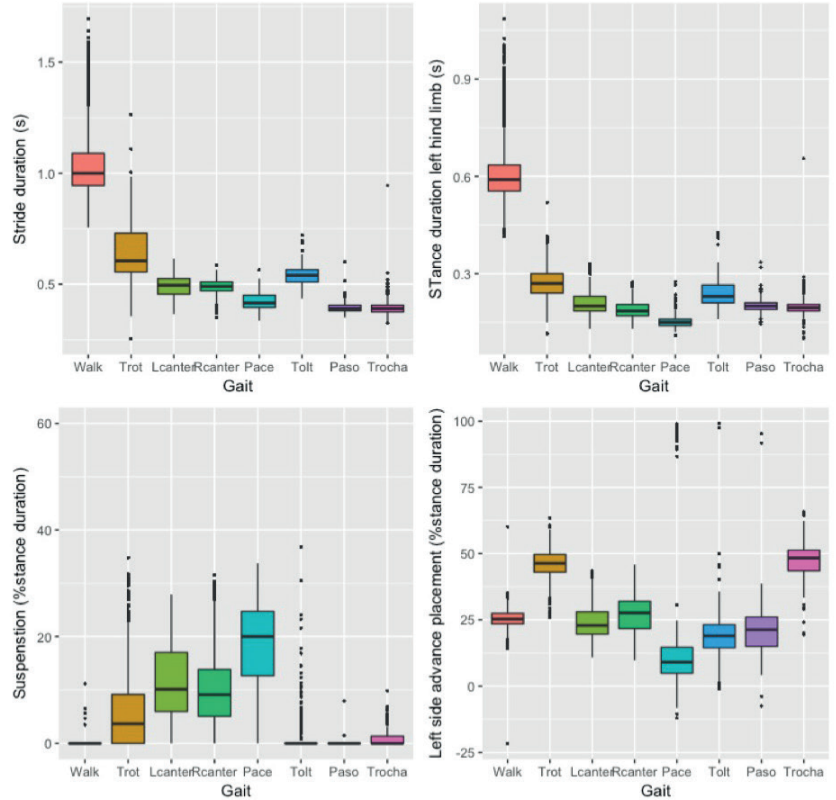
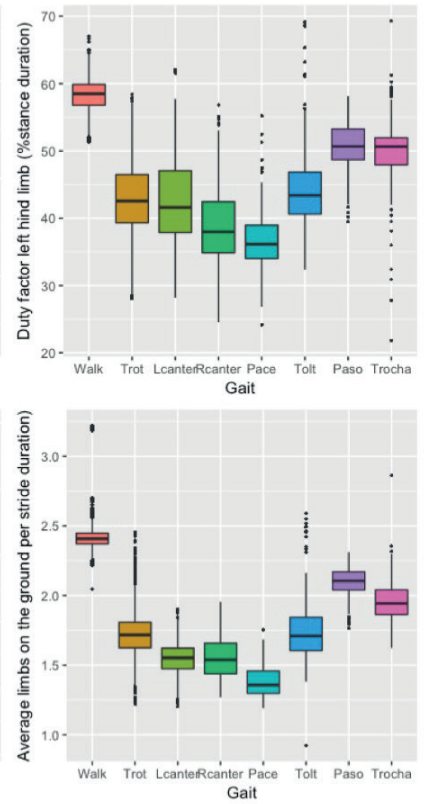

C

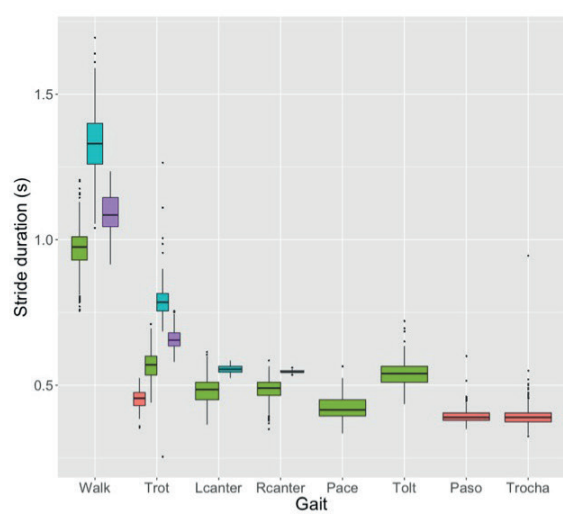

D

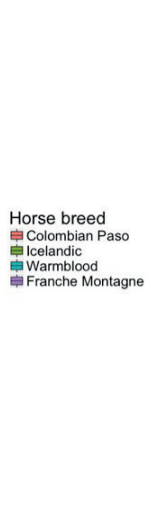

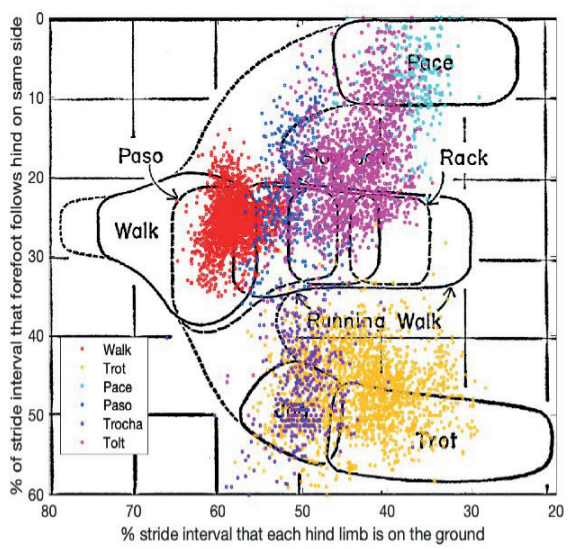

Fig. 1. Descriptive results for stride parameters for all gaits. A: Footfall pattern of each different gait. White swing, color stance phase. LF: Left front; RF: Right front; LB: Left hind; RB: Right hind B: Different stride parameters, calculated from the limb-mounted IMUs, grouped by gait. C: Stride duration clustered by gait and horse breed. Note the specific breed characteristics (i.e., clustering). D: Our data overlapping the original Hildebrand 1965 plot. 
distinct. Further, the grouping of the different gaits on the 2D plot, such as between pace and tölt, is not clear from the original drawing; these two gaits appear to have a large region of overlap.

Table 1. Descriptive statistics of the stride temporal variables for each gait.

\begin{tabular}{|c|c|c|c|c|c|c|c|c|c|}
\hline & \multirow[b]{2}{*}{ strides } & \multicolumn{2}{|c|}{ Stride duration } & \multicolumn{2}{|c|}{ Stride frequency } & \multicolumn{2}{|c|}{ Stance duration * } & \multicolumn{2}{|c|}{ Duty factor* } \\
\hline & & mean & sd & mean & $\mathrm{sd}$ & mean & sd & mean & $\mathrm{sd}$ \\
\hline Walk & 201720 & 1.05 & 0.17 & 0.97 & 0.14 & 0.64 & 0.11 & 60.69 & 1.69 \\
\hline Trot & 163820 & 0.64 & 0.11 & 1.62 & 0.26 & 0.28 & 0.05 & 43.75 & 3.62 \\
\hline Left Canter & 60278 & 0.49 & 0.05 & 2.05 & 0.21 & 0.19 & 0.02 & 39.64 & 3.32 \\
\hline Right Canter & 58315 & 0.49 & 0.04 & 2.06 & 0.17 & 0.2 & 0.02 & 40.24 & 3.18 \\
\hline Pace & 33916 & 0.42 & 0.04 & 2.38 & 0.2 & 0.15 & 0.02 & 36.19 & 2.65 \\
\hline Tölt & 193980 & 0.54 & 0.04 & 1.87 & 0.13 & 0.24 & 0.03 & 44.23 & 3.78 \\
\hline \begin{tabular}{|l|} 
Paso fino \\
\end{tabular} & 8353 & 0.39 & 0.03 & 2.54 & 0.15 & 0.21 & 0.01 & 53.82 & 2.39 \\
\hline Trocha & 6833 & 0.39 & 0.03 & 2.57 & 0.18 & 0.2 & 0.02 & 50.42 & 3.2 \\
\hline total $=$ & 727215 & & & & & & & & \\
\hline
\end{tabular}

\section{Gait classification based on feature extracted models.}

For all the different methods used, the highest accuracy for classification was achieved when all variables were used, achieving a classification accuracy of $97.9 \%$ using linear discrimination (Fig. $2 \mathrm{~A}$, Table 2A). If gait classification was based only on stride variables (e.g., stride duration, stance duration, duty factor) poor classification accuracy was achieved, with the classification based on the 2 variables of Hildebrand (duty factor and lateral advance placement) achieving a slightly higher accuracy, peaking at $83 \%$ using quadratic discrimination and a decision tree. When using all variables, high accuracies for gait classification were achieved along all models used. The highest confusion between classes was observed between the gaits trot and trocha for all classification models, followed by the confusion between pace and tölt (Fig. 2 A1). Removing the trocha from the models increased the final accuracy of the best performing model to $99 \%$ (Table $2 \mathrm{~A}$ and Figure $2 \mathrm{~A} 2$ ).

\section{Gait classification based on raw IMU data and LSTMs.}

Classification using the raw normalized sensor data (LSTMs) achieved a high classification accuracy, peaking at $95.5 \%$ (Table 2B). A longer window length had a negative effect, especially when fewer sensors were used (Table 2B). Using bidirectional vs unidirectional LSTMs did not affect the general accuracy of each model, although the highest accuracy was achieved with a bidirectional LSTM model. 
Gait classification based on a single sensor yielded poor accuracies, peaking at $79.9 \%$ only. Training based on sensors mounted on the upper body of horses, mainly head, withers and pelvis, yielded significantly higher accuracies (92.3\%) and adding to this model one limb sensor, pushed the accuracies only slightly higher (93.3\%), achieving similar accuracies of the models relying solely on all four limbs (92.7\%). The highest accuracy was observed using and training the network with the data from all available IMUs, this is, head withers, pelvis and all four limbs (95.5\%). For the best performing models, confusion was highest between the classes trot and trocha, in line with our results from the gait classification models based on feature extraction. Excluding trocha from the data set, yielded a classification accuracy of $98.9 \%$.

Table 2A. Results for feature extracted modes. LDA: Linear discriminant analysis; QDA: Quadratic discriminant analysis; FC: Fully connected ANN. *Training accuracy once the class 'Trocha' was excluded.

\begin{tabular}{lcccc}
\hline & \multicolumn{4}{c}{ Feature extracted data } \\
\cline { 2 - 5 } & LDA & QDA & Decision tree & FC \\
\hline Hildebrand et al. 1965 & 79.68 & 82.58 & 82.89 & 56.95 \\
Interlimb timing & 97.71 & 96.13 & 95.44 & 88.97 \\
Stride variables & 71.69 & 71.96 & 65.75 & 66.31 \\
All variables & 97.82 & 96.72 & 97.2 & $97.91\left(99.19^{*}\right)$ \\
\hline
\end{tabular}

Table 2B. Results for LSTM models based on raw IMU data. *Training accuracy once the class 'Trocha' was excluded.

\begin{tabular}{lc|c|c|ccc}
\hline & \multicolumn{7}{c}{ Raw data } \\
\cline { 2 - 8 } & \multicolumn{2}{c}{ 1 second window } & \multicolumn{2}{c}{ 2 second window } & \multicolumn{3}{c}{ 3 second window } \\
\hline Sensor used & LSTM & bi-LSTM & LSTM & bi-LSTM & LSTM & bi-LSTM \\
\hline Sacrum & 79.90 & 79.65 & 76.47 & 73.03 & 71.30 & 66.58 \\
Upper body & 92.31 & 91.05 & 85.88 & 85.03 & 84.34 & 73.69 \\
Upper body + one limb & 93.32 & 92.46 & 88.96 & 91.54 & 89.08 & 85.29 \\
Left diagonal limbs & 85.62 & 85.30 & 71.21 & 85.32 & 81.53 & 79.63 \\
Left side limbs & 87.61 & 88.02 & 84.61 & 82.58 & 79.35 & 80.34 \\
Front limbs & 82.31 & 78.26 & 79.70 & 76.07 & 73.15 & 78.68 \\
All four limbs & 91.94 & 92.73 & 91.84 & 90.99 & 89.58 & 89.02 \\
All seven IMUs & 93.33 & $95.47\left(98.9^{*}\right)$ & 93.88 & 93.35 & 92.76 & 92.42 \\
\hline
\end{tabular}




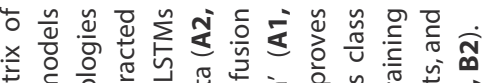

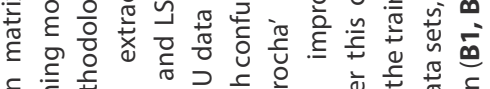
व

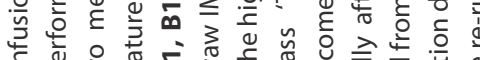

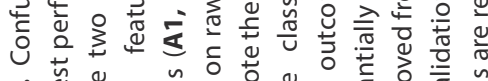

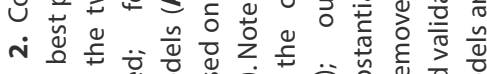

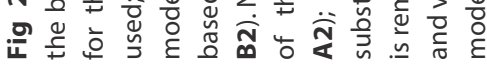
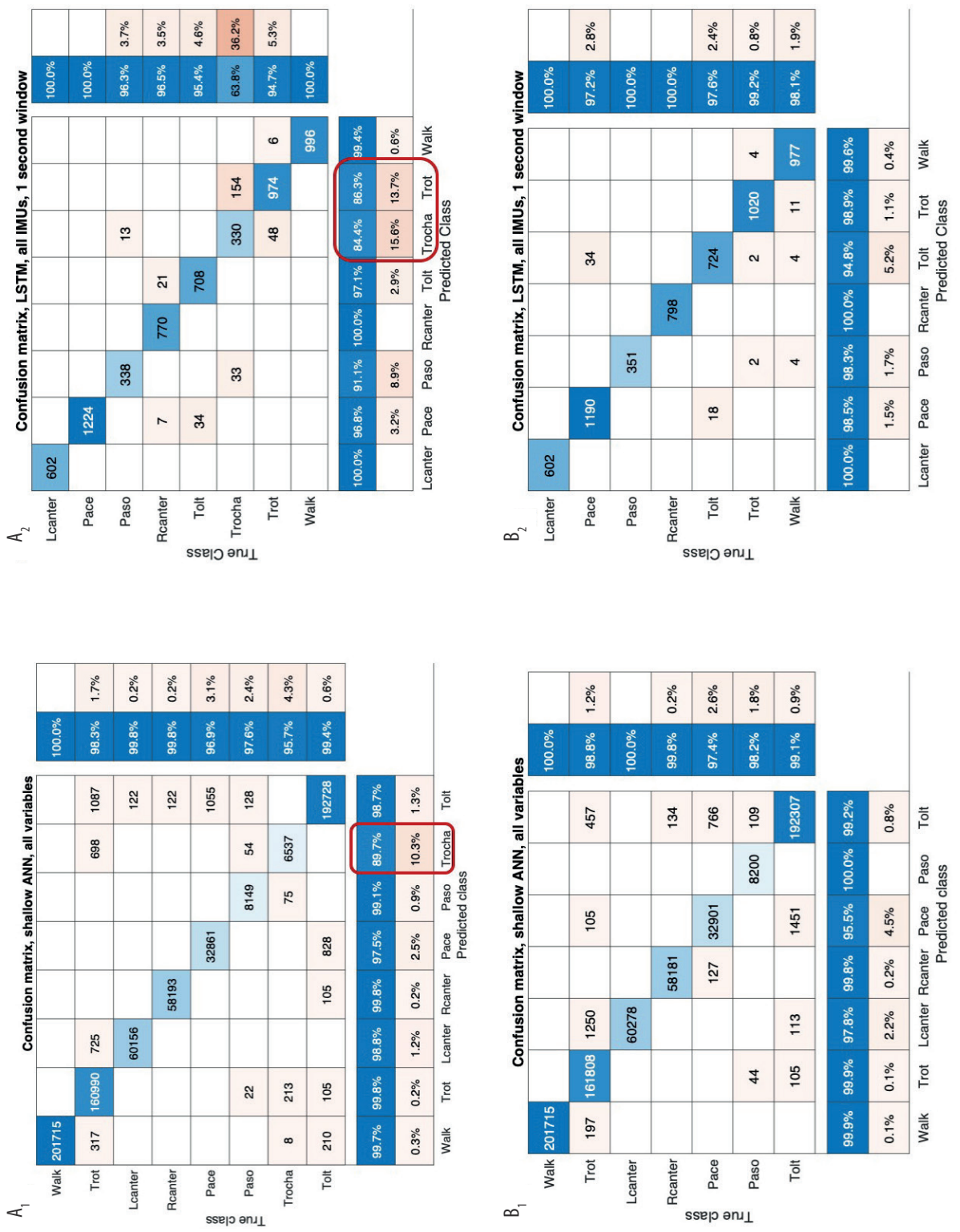


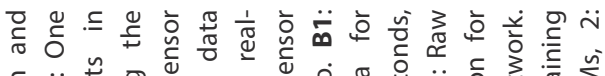

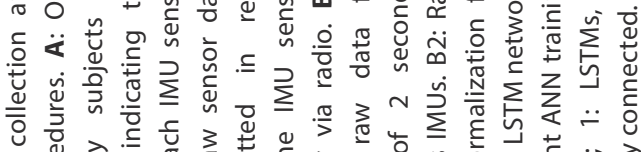

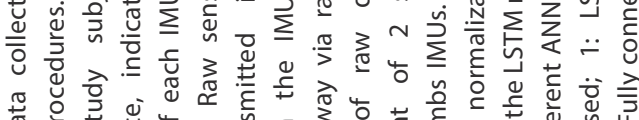

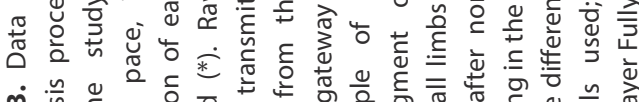

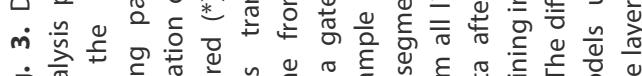

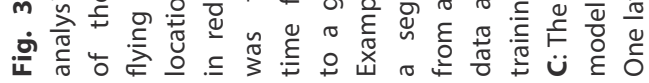

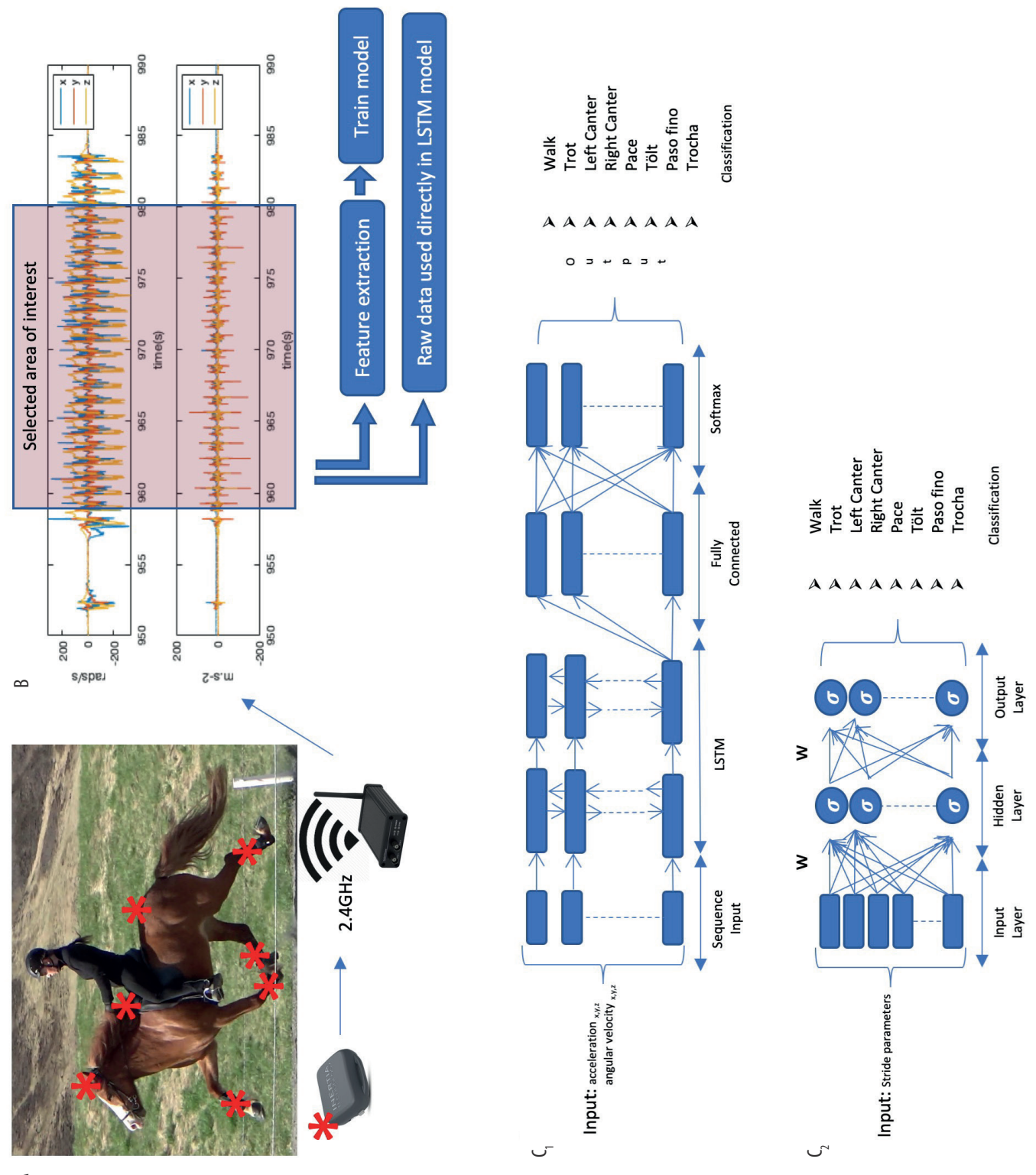


Table 3. Description of the data sets. Includes breed, gaits, number of horses and references to the studies of which the data were used.

\begin{tabular}{lllll}
\hline Breed & Number of trials & Condition & Gaits & Reference \\
\hline Warmblood & 52 & In-hand overground and treadmill & Walk, trot, canter & $(19-21)$ \\
Icelandic horse & 44 & Ridden and in-hand overground & Walk, trot, pace tölt, canter & (22) \\
Franche montagne & 24 & Treadmill & Walk, trot & (23) \\
Colombian criollo & 29 & Ridden & Paso fino, trot, trocha & \\
\hline total & 149 & & & \\
\hline
\end{tabular}

\section{DISCUSSION}

In this study we have demonstrated that accurate gait classification can be achieved using state of the art sensor technology in combination with multiple machine learning data analysis approaches. Through this technology we were able to partly experimentally confirm and partly extend Hildebrand's original equine gait paradigm (5), showing that reality is more complex, ambiguous and less straightforward than the original concept, as shown in Fig. 1. In fact, this is not unexpected, as Hildebrand's original model was based on a two-dimensional model only and gait is defined by more than two dimensions. Our results demonstrated that indeed multidimensional approaches are needed to reach optimal accuracy, as has been proposed earlier (7).

The human eye has thus far served as the 'gold standard' for gait classification. It is clear, however, that human visual assessment cannot serve for this. This is in line with other studies evaluating the human assessment of equine locomotion, mainly in relation to the evaluation of lameness in clinical situations. Here too, human subjective assessment was affected by both the spatiotemporal limitations of the human eye (10) and the proneness to bias (11).

Our models used in this study open a new world of possibilities for some fields such as research into genetics of gait. Most genetic equine genetic studies focusing on locomotion, either related to gait $(12,13)$ or sports performance $(14)$, require precise phenotyping in order to discriminate between trends in populations or subpopulations. Gait phenotyping is still performed subjectively in most of these studies and thus much less accurate than desirable; we therefore believe that our methods will allow forthcoming studies to understand the genotype-phenotype association in greater detail. 
Our models using raw sensor data (i.e., LSTMS) achieved a slightly lower accuracy when compared to the feature-extracted models. Nevertheless, the difference was marginal and there is great advantage in using raw sensor data-based models. It is extremely challenging and time consuming to develop specific algorithms for feature extraction (15-17). These algorithms require validation, and they risk being gait, surface and ultimately breed specific. Pre-selecting variables also brings the risk of missing information in the data that can be useful for complex classification tasks. When using raw sensor data, the models can be applied to any gait, horse breed and surface, provided that enough labeled training and validation data exist for the development of such models. This far wider applicable approach opens hence new possibilities for the study of all spectrums of gait, not only in the horse, but even in other quadrupedal species.

Window length had a significant effect on the accuracy of our models and we saw a decrease of accuracy with increasing window length (Table 2B). We hypothesize that this was related to the fact that, when the data is segmented in smaller windows, this results in more data units that are used as input for model training. Also, longer windows might include data points where transitions of gait or incorrect strides (e.g. stumbling) occur, and this will ultimately influence the overall accuracy of classification of the entire segment.

Despite the large influence speed has on temporal variables such as step duration (18), our models were able to achieve a high accuracy without a strict control of speed. Hence, we may hypothesize that speed is not a crucial parameter for gait classification.

We have found a high degree of confusion between trot and trocha in our study. This may of course be caused by misclassification of some of the horses used in the training and validation groups. Another important issue is the close relation between these two gaits (Fig 1 D). We may have had too few variables in our models to allow for a better separation of the two gaits, but a close observation of the distribution of trocha versus trot classifications in Fig. 1D also raises doubt whether what is called trocha is not just part of the spectrum of trot. Anyhow, further research seems warranted here.

One of the main limitations of the current study is the narrow band of horse breeds used. This will be a matter of time, however, the methods described in this study are made for continuous improvement and measuring more data, in other breeds, or even in different species will lead to improvements in the training of our models. 


\section{MATERIALS AND METHODS}

\section{Data set}

Data were collected between 2016 and 2019 using seven IMU sensors (Promovemini, Inertia Technology, The Netherlands) Figure 3A. Sensors were attached to the poll, withers and pelvis of all horses, and set to a sampling frequency between 200 and $500 \mathrm{~Hz}$, low-acceleration range of $+/-8 \mathrm{~g}$, high acceleration range of $+/-100 \mathrm{~g}$ and angular velocity of $2000 \mathrm{rad} / \mathrm{s}$. Each limb was also equipped with an IMU sensor, attached to the lateral aspect of the metacarpal/metatarsal bone, and set to a sampling frequency between 200 and $500 \mathrm{~Hz}$, low-acceleration range of $+/-16 \mathrm{~g}$, highacceleration range of $+/-200 \mathrm{~g}$ and angular velocity of $2000 \mathrm{rad} / \mathrm{s}$. Synchronization between sensors, initial data processing and limb stride parameter calculation were performed as previously described $(19,9)$.

Data sets (table 3) were collected for different research purposes, such as studying objective motion analysis methodology in sound speed-dependent motion patterns in warmblood riding horses and Franche Montagne horses and studying gaits and phenotype- genotypic associations in gaited horse breeds (Icelandic horses and Colombian horse breeds). All data included in the training and validation of our study, was from horses that were performing normally until the moment of data collection and that were, to the owners'/trainers' best knowledge not lame.

\section{Labeling of the data}

For the data sets of the Icelandic horses each measurement was synchronized with a video camera, since each measurement contains several segments of different gaits (walk, trot, pace, tölt and canter). This video was evaluated by a domain expert of gaits of the Icelandic horse (VG), who selected the segments of data that should be used for training and validation. For the Colombian criollo horses, the segments of data used for the analysis were selected based on visual inspection of the footfall pattern during live observation of the trials by an expert in locomotion of this horse breed (MN). For the remaining trials, selection of the segment of each gait was performed by live observation by an expert in equine biomechanics (FSB).

\section{Preparation of the dataset}

Based on the labeled segments of data used for training a data set was generated. The data set used in this study can be accessed at: https://doix..... \{will be added on the published version\}. The data set consists of two main parts Figure 3B, (1) features extracted from the raw IMU data, consisting of stride parameters calculated based on a previously described algorithm (9); (2) segments of the raw IMU data, prepared for 
the analysis using the LSTMs. Each segment was further cropped into subsections of one, two and three seconds of IMU data. All data were resampled to $200 \mathrm{~Hz}$ to match the temporal resolution among all used data sets.

\section{Data analysis}

Data processing, analysis and model training was performed in Matlab 2018b (MathWorks, Natick, Massachusetts, USA). Five supervised machine learning methods were applied to the gait classification task: linear and quadratic discriminant analysis (LDA and QDA), decision trees, a one-layer fully connected (FC) neural network Figure 3C2 and a Long-Short Term Memory (LSTM) neural network Figure 3C1. In LDA and QDA, we try to learn the decision boundaries that will maximally separate the different classes of our classification problem. In LDA and QDA, we model the data as Gaussian distributed. While in LDA models all classes have the same covariance matrix, QDA has a separate covariance matrix for each class and can thus model more complex decision boundaries. Decision trees are a non-parametric method where the model is trained to split the data according to the most distinguishing features for the different classes. FC and LSTM are artificial neural network methods, highly parametric as such, that are trained to approximate the function mapping between the input data (raw sensor data or features extracted from sensor data) and the gait class.

For the LSTM, the gyroscope and accelerometer data were normalized between 0 and 1, ensuring that the network will learn the specific gait pattern since we have observed gait-specific characteristics in the magnitude of the signals like for example, higher peak accelerations at trot when compared to walk. Also, gait classes with less data were duplicated in the data set to remove any unbalance present in the data prior to training. Training was performed on a single NVIDIA Tesla K80 GPU with 4992 CUDA cores.

The entire data set was randomly divided in two sub-data sets, one used for training and one for validation. We have ensured that strides of the same horses were never used for training and validation simultaneously, with the goal of avoiding overfitting. Each model was trained 5 times and the results presented in Table $2 \mathrm{~A}$ and $2 \mathrm{~B}$ are an average of 5 consecutive runs.

For the best models using either the feature extracted analysis or the one based on raw data, the class with the highest confusion was removed and the model retrained to assess the effect of that specific class in the overall model accuracy. 


\section{Funding}

The Conservation Fund of Pálmi

Jonsson, the Swedish Norwegian

foundation for Equine research and

FORMAS funded this study. 


\section{References and Notes}

1. Clayton, Hobbs, A Review of Biomechanical Gait Classification with Reference to Collected Trot, Passage and Piaffe in Dressage Horses. Animals (2019), doi:10.3390/ani9100763.

2. S. Grillner, Biological Pattern Generation:The Cellular and Computational Logic of Networks in Motion. Neuron (2006), doi:10.1016/j.neuron.2006.11.008.

3. L. S. Andersson et al., Mutations in DMRT3 affect locomotion in horses and spinal circuit function in mice. Nature. 488, 642-6 (2012).

4. S. Wutke et al., The origin of ambling horses. Curr. Biol. (2016), , doi:10.1016/j.cub.2016.07.001.

5. M. Hildebrand, Symmetrical gaits of horses. Science (80-.). 150, 701-708 (1965).

6. J. J. Robilliard, T. Pfau, A. M. Wilson, Gait characterisation and classification in horses. J. Exp. Biol. 210, 187-197 (2007).

7. S. D. Starke, J. J. Robilliard, R. Weller, A. M. Wilson, T. Pfau, Walk-run classification of symmetrical gaits in the horse: a multidimensional approach. J. R. Soc. Interface. 6, 335-42 (2009).

8. S. Egan, P. Brama, D. McGrath, Research trends in equine movement analysis, future opportunities and potential barriers in the digital age: A scoping review from 1978 to 2018. Equine Vet. J. (2019), , doi:10.1111/evj.13076.

9. F. M. Serra Bragança et al., Validation of Distal Limb Mounted Imu Sensors for Stride Detection and Locomotor Quantification in Warmblood Horses at Walk and Trot. Equine Vet. J. 48, 17-17 (2016).

10. K. G. Keegan, Evidence-Based Lameness Detection and Quantification. Vet. Clin. North Am. Equine Pract. 23, 403-423 (2007).

11. M. Arkell, R. M. Archer, F. J. Guitian, S. a May, Evidence of bias affecting the interpretation of the results of local anaesthetic nerve blocks when assessing lameness in horses. Vet. Rec. 159, 346-349 (2006).

12. M. Novoa-Bravo et al., Selection on the Colombian Paso horse's gaits has produced kinematic differences partly explained by the DMRT3 gene. PLoS One. 13, e0202584 (2018).

13. L. S. Andersson et al., Mutations in DMRT3 affect locomotion in horses and spinal circuit function in mice. Nature. 488, 642-646 (2012).

14. M. Ablondi, Å. Viklund, G. Lindgren, S. Eriksson, S. Mikko, Signatures of selection in the genome of Swedish warmblood horses selected for sport performance. BMC Genomics. 20 (2019), doi:10.1186/ s12864-019-6079-1.

15. F. M. Bragança et al., Validation of distal limb mounted inertial measurement unit sensors for stride detection in Warmblood horses at walk and trot. Equine Vet. J. 49 (2017), doi:10.1111/evj.12651.

16. D. Holt, L. B. St. George, H. M. Clayton, S. J. Hobbs, A simple method for equine kinematic gait event detection. Equine Vet. J. (2017), doi:10.1111/evj.12669.

17. E. Olsen, P. H. Andersen, T. Pfau, Accuracy and precision of equine gait event detection during walking with limb and trunk mounted inertial sensors. Sensors. 12, 8145-8156 (2012).

18. M. A. Weishaupt, H. P. Hogg, J. A. Auer, T. Wiestner, Velocity-dependent changes of time, force and spatial parameters in Warmblood horses walking and trotting on a treadmill. Equine Vet. J. 42, 530537 (2010).

19. S. Bosch et al., EquiMoves: A Wireless Networked Inertial Measurement System for Objective Examination of Horse Gait. Sensors. 18, 850 (2018).

20. K.Ask. et al., Objective pain assessment during rest and locomotion in horses with two types of induced lameness. Comp. Exerc. Physiol. 14, 42 (2018).

21. The use of surface electromyography for quantification of changes in biceps femoris and triceps brachii muscle activity during induced forelimb and hindlimb lameness. Equine Vet. J. 51, 28 (2019).

22. V. Gunnarsson et al., Objective evaluation of stride parameters in the five-gaited Icelandic horse. Comp. Exerc. Physiol. 14, S52 (2018).

23. M. A. Weishaupt et al., Speed dependence of limb and body kinematics of horses walking and trotting on a treadmill. Comp. Exerc. Physiol. 14, S43 (2018). 


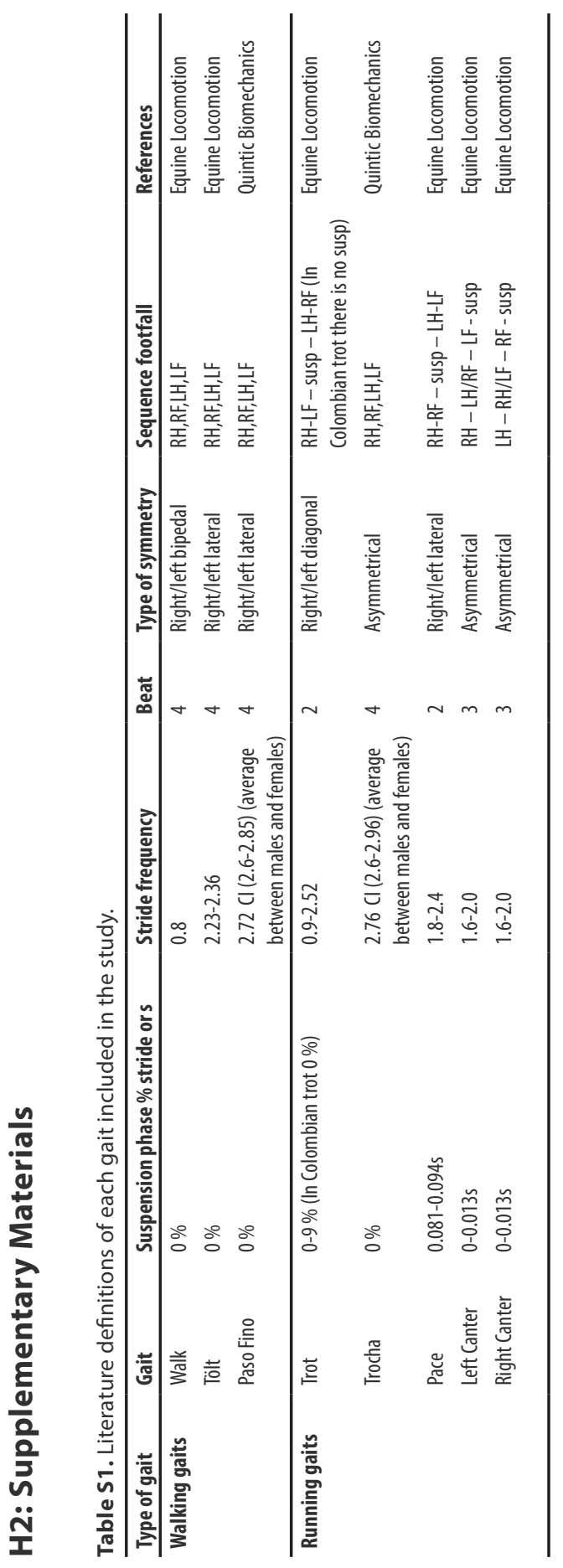




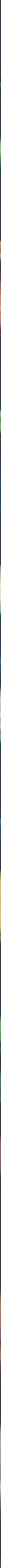


The modern equine clinician is surrounded by technology. As described in chapter 2 there is enough scientific evidence to support the acquisition of quantitative kinematic data during routine lameness assessment of horses. The low interobserver agreement when assessing lameness subjectively [1], or even when judging fitness of horses for competition (chapter 11), indicates that this traditional procedure is insufficiently repeatable and hence an important source of error and misunderstandings. Equine orthopaedic research (e.g., when studying effects of treatments, medication or rehabilitation protocols) can only be further developed when the outcome (i.e. gait) is measured and classified with the most objective, accurate and precise tools available that are not prone to bias. That means that these studies, to provide the best evidence possible, should be supported by the use of quantitative gait analysis. Scientists have long realized that humans are not good scientific instruments. That's why in science, we measure the inputs and outputs of our experiments with instruments and not with our senses. This has led to the realization that 'eyewitness testimony' is not a valid scientific form of evidence for studies into equine lameness.

There are several methods that can be used for collecting objective locomotion data from horses. At present, with the introduction of small, portable wireless and affordable sensor technology, inertial measurement units (IMU) sensors are quickly gaining popularity among the available methods. As demonstrated in chapters 5 and 6, these sensors can be as accurate or even more accurate than well-established methods like optical motion capture. Further, they do not interfere with the locomotion of the horse in any way that could interfere with the clinical examination, nor do they cause any pain or discomfort to the horse.

Kinetic methods such as force plates and pressures plates can offer extremely precise and accurate information regarding adaptation strategies to lameness (chapter 8), effects on gait of anatomical development (chapter 9), or even the effect of orthopaedic shoeing (chapter 10). Nevertheless, in contrast to several techniques to collect kinematic data, there is currently no technique that can generate kinetic data that meets the requirements in terms of ease of use and practicality as needed for use as a routine procedure in the field or in clinical situations. The first hurdle is data acquisition. For this, we need to be able to either instrument the horse with a kinetic measuring device that can easily and quickly be applied to the horse and that does not alter its locomotion (which is the main challenge with force measuring horseshoes), or we need to further develop the present force/pressure plate devices. These current devices are small (1-2-meter-long), which makes collection of several strides a time-consuming process and speed standardization a challenge. Force 
plates can be stacked, but these longitudinal arrays of force plates require a specific infrastructure and are very expensive. Secondly, specific data analysis and processing software needs to be developed in order to quickly analyse the data once acquired and to process them in such a way that the measurement results are presented in a logical, intuitive form that can easily be understood by the attending clinician. A treadmill with inbuilt force plate is an attractive solution [2]. However, apart from the high costs and the fact that treadmill locomotion is not in all aspects identical to over ground locomotion [3], the need to first train horses for use on a treadmill [25] precludes routine clinical use of such a device. Given the rapid developments in sensor technology it is to be expected that in the upcoming years, miniaturized sensors will be developed that can be mounted to either a shoe or the hoof wall and that will be able to generate useful kinetic data under clinical conditions.

It is important to have well-established protocols for data acquisition by quantitative gait analysis techniques since several factors can influence the results when acquiring this type of data in a clinical setting, as illustrated in chapter 7. Inaccurate marker placement (chapter 3) can influence the output of some variables used for lameness assessment. Further, for the data analysis use of the appropriate signal processing technique is also crucial (chapter 4 ) in order to properly calculate the clinically relevant kinematic parameters that are for example used to assess the effect of diagnostic anaesthesia in lameness cases.

In recent years, machine learning techniques are gaining popularity. These data analysis techniques allow for the analysis of large amounts of data ('big data') and are boosted by the ever-increasing computational power, allowing for ever faster and more accurate ways of data analysis. As seen in chapter 13, machine learning techniques applied to kinematic data from horses allowed us to explore large amounts of data and, based on these, to develop new gait classification models. It is expected that in the upcoming years, these methods will allow us to further explore into much more depth the complex and dynamic locomotor system of the equine athlete. Machine learning will speed up tremendously the way we process our gait analysis data and will become a much needed or even indispensable tool to explore the enormous amount of data collected with the newly available technology.

As more and more data is collected with gait analysis technology, such as IMUbased systems, large data sets will become available that might allow to identify specific locomotion patterns for certain conditions, which may help clinicians in the differentiation between lameness and ataxia, or even, to identify specific locations of lameness. Think of automatic identification of the lame limb and of the specific 
region of a limb (e.g. distal or proximal limb lameness).

It is not expected that technology will replace a vet (Annex I and II) but it is highly likely that the vet of tomorrow will be empowered by wireless, accurate, fast and smart sensor technology that will allow him/her to make a better diagnosis and to better test the effect of certain medications, treatments and rehabilitation procedures. It is important to consider that clinical lameness assessment is not just about locomotion analysis. Technology will not replace good clinical skills in differential diagnosis, palpation of anatomical structures and proper interpretation of clinical findings. Data emanating from quantitative gait analysis techniques, irrespective of the accuracy of these techniques, need to be interpreted. This interpretation will be done by the clinician, who has the last word and who will put the gait data in the perspective of many other factors and conditions, including (but not restricted to) the sport requirements of a specific individual horse, owner expectations, economic value and possibly even rider quality. For this reason, the use of rigid asymmetry thresholds that pretend to unambiguously classify horses as lame or sound should be avoided (Annex I and II). To this respect, it is expected that the term 'threshold' will ultimately be replaced with the term 'reference-value', as is the case for virtually all clinically relevant biological parameters as used for instance in clinical chemistry and haematology. For the novel gait parameters these reference values need to be established and refined for variables such as age, sex, breed and intended use (e.g. eventing, jumping, endurance). Still, quantitative gait data are hard data, just as clinical chemical values, and 'quantitative gait analysis in the horse is evidence-based medicine [4]' .

The upcoming years are full of challenges and opportunities. There is urgent need to teach and introduce gait analysis technology as part of the normal curriculum to new graduates.

Current gait analyses systems need further development in order to make them more user friendly, which will make their acceptance easier by established clinicians. There is need for the development of large modern databases where data from thousands of horses can be stored in a safe way. These data sets will form the basis for big data analysis (i.e. data mining) and the development of new analysis models using machine learning/Artificial-Intelligence. This approach will open the door to the analysis and understanding of kinematic data with a tremendous amount of complexity and will likely allow us one day to list a differential diagnosis simply based on the identification of specific locomotion patterns.

With the abovementioned developments in sensor technology and data analysis 
methods based on machine learning and large modern databases, daily monitoring of (sound) horses will be a logical next step. This, in combination with daily recorded behavioural data (activity monitoring), which also may include automatic recognition of facial expressions that may reveal discomfort, and training data will allow us to get closer to optimal injury prevention models.

In fact, monitoring of horses during training and even competition, might help us in preventing injuries, which should be the goal of modern equine sports medicine, rather than improving curative techniques. There will likely be a need to combine data from other sensor technologies, such as heart rate measuring devices, speed measuring sensors (e.g. GPS), etc. with the aim to collect all relevant data during training and competition. For instance, the combination of gait and heart rate data during endurance competitions might be able to prevent catastrophic injuries and prevent horses from becoming exhausted. In some specific sports such as racing, we will likely be able to develop better models to train horses, aiming at both increasing performance and reducing injury rates.

A research area that will likely be boosted by the introduction of modern gait analysis methods, is the field of equine genetics. The development of equine locomotion genetics is dependent on accurate phenotyping and thus far, this is commonly performed subjectively. It is now crystal clear that the visual, subjective, assessment of equine locomotion is not accurate and prone to bias. This affects also the phenotyping of specific traits used for selection. With support of modern gait analysis technology and the ability of collecting data from big populations of horses, new genomic studies will be possible in the near future, allowing us to better understand the genetic background of equine locomotion and to breed the best-adapted equine athlete of the future. This may to a certain extent improve performance, but, more importantly, will certainly enhance equine welfare. 


\section{References}

1. Schmidt, P.L. (2007) Evidence-Based Veterinary Medicine: Evolution, Revolution, or Repackaging of Veterinary Practice? Vet. Clin. North Am. Small Anim. Pract. 37, 409-417.

2. Weishaupt, M.A., Hogg, H.P., Wiestner, T., Denoth, J., Stüssi, E. and Auer, J.A. (2002) Instrumented treadmill for measuring vertical ground reaction forces in horses. Am. J. Vet. Res. 63, 520-727.

3. Buchner, H.H., Savelberg, H.H., Schamhardt, H.C., Merkens, H.W. and Barneveld, a (1994) Kinematics of treadmill versus overground locomotion in horses. Vet. Q. 16 Suppl 2, S87-S90.

4. Adair, S., Baus, M., Belknap, J., Bell, R., Boero, M., Bussy, C., Cardenas, F., Casey, T., Castro, J., Davis, W., Erskine, M., Farr, R., Fischer, T., Forbes, B., Ford, T., Genovese, R., Gottschalk, R., Hoge, M., Honnas, C., Hunter, G., Joyce, J., Kaneps, A., Keegan, K., Kramer, J., Lischer, C., Marshall, J., Oosterlinck, M., Radue, P., Redding, R., Reed, S.K., Rick, M., Santschi, E., Schoonover, M., Schramme, M., Schumacher, J., Stephenson, R., Thaler, R., Vedding Neilsen, J. and Wilson, D.A. (2018) Response to Letter to the Editor: Do we have to redefine lameness in the era of quantitative gait analysis. Equine Vet. J. 50, 415-417. 
I would not be where I am now if it wasn't for the support of so many friends and my family. We become who we are because of the people who surround us, give us support and guidance...

\section{"If I have seen further it is by standing on the shoulders of Giants."}

Sir Isaac Newton, 1675

These next few paragraphs are dedicated to all those 'Giants'....

First to my Promotors René and Lars. René, you have been the major driving force of my career in the last 5 years. I have to thank you for all the guidance, advice and patience. Your research career is something I admire, and you for sure has shaped the way I see and do science. From our first meeting in which you 'shipped' me up north to Sweden to meet the 'Swedish Research Gang' until today you have always supported my ideas and encouraged me to follow my intuitions in research. I believe you are guilty of the reunification of the UU-SLU-UZH gait analysis group who has produced so much fruitful research in the last years and hopefully, will continue to do so in the upcoming years. To all the time you have invested in our meetings in Sweden, in Switzerland, in Germany... To all the help with writing all our ideas on paper which ultimately resulted in this thesis... thanks.

Lars, you have for sure been an inspiration to me these last years. You are guilty of my addiction to matlab and many of the technical aspects of our research. Early in our first discussion I realized that we shared a very special interest for this research field. To all you have taught me, for all our discussions and ideas, to all our programing sessions and hospitality in Sweden, a big thanks.

To my co-promoters Mike and Marie a huge thanks. Marie, you have been a great colleague and a big friend. It was impossible to feel alone in this research group while working next to you. I admire your energy and the capacity you have to keep so many projects afloat. You always make me feel at home when I am in Sweden. You have been a driving force for our research from Sweden to Utrecht and from Iceland to Florida... For all you have done for this research group, for all the evenings we had discussing research and for all our future projects a huge thanks... Mike: When I started my PhD 
I quickly came across many of your publications. I pictured in my head this image of you and the Zurich group as something far-fetched and unreachable. Little did I know that only a year or so later I was there measuring horses alongside you and Thomas. You quickly made me feel at home and part of the team and I will never forget how you and Monika always make me feel at home. A huge thanks for all and I look forward for the continuation of all our projects... yes... because there are still a lot of Lusitano horses waiting to be measured in Portugal and around the world...

To my paranymph Elin. Thanks so much for all the good discussions we had and all the support. Also, thanks so much for all the guidance you and Marie have given me the last 5 years. I will never forget our writing sessions and research discussions in Sweden. You have been a source of inspiration and I look very much forward to our future research work.

Of course, to the reading committee a big thanks - this book would not be possible without you.

To Wim, who has been a big source of inspiration these last years, thanks. You have been an important part of this research group and have been in the lead of so many new ideas and innovations from QHorse to EquiMoves.

Dear Nikae. Thanks for all the good times we had. You are an amazing researcher and a good friend. I will never forget our research projects, our discussions, our coffee breaks and our R workshops. To the new team members Jeanne and Ineke, I wish you all good luck with the beginning of your $\mathrm{PhD}$ career and I look forward for all the good research projects we will develop. Also, Saskia, Nicoline and the rest of the 'centaur group', thanks. You all made me feel at home ever since I arrived in this group.

To Aagje, thanks. For being such a good friend and an important part of this book. I also wish you the best of luck in your PhD track.

To all my UKP colleagues from all departments, a big thanks for putting up with me these last years. Specially to the surgical department, Emi, Tjester, Hanneke, Jos, Eva, Emanuel, Stefan thanks for making me feel like I am part of the team and your enthusiasm when it comes to gait analysis of your patients. A special thanks to Tijn and Harold. You have supported my introduction to the Dutch orthopaedic work in the clinic and I am very grateful for all your teaching and for believing in our research which is now fully implemented in our clinic. Looking ahead now to the introduction of EquiMoves in the UKP. 
A big thanks to the anesthesia team, Janny and Thijs. I am very grateful of you help in all our projects. Also a big thanks to the Internal Medicine department and a special thanks to Marianne Sloet who is also an integral part of this thesis.

To all the animal care takers a big thanks. Thanks for helping with all the data collection, whether on the treadmill, on the force plate or at the monsterbaan. You are always available and always enthusiastic about our research work. For this I am very grateful, and this thesis would not have been possible if it wasn't for you. A big thanks to Bert and Peter who always helped me organize my activities around the teaching horses.

To the farriers Jan and Gerben also a big thanks for all your help... even when I had to drag you to cold and snowy Iceland to measure horses in freezing temperatures... To the friends in Iceland who helped and supported us with so many studies and always made us feel warm even when we had to measure horses outside in the cold Icelandic weather - Vikingur, Sigríður and Helga a big thanks.

To our good friend Emily. Thanks for your friendship and the good times we had together as a group when we were working in England. I wish you the best of luck with your new house And I hope we can continue friends for many, many years to come.

To my family thanks for giving me all the opportunities to get to where I am today. To my parents Isabel and Francisco who always believed in me and always supported me even when I decided to move to the cold and rainy England, and then decided to move to the Netherlands. To my brother Frederico and my sister in law Ana, a big thanks. To my parents in law Anita and Leon, thanks so much for all your support these last 5 years.

To my daughter's Elin and Mara, this book is also dedicated to you. You have changed my life forever and I hope one day you will read this book and realise that this is what daddy was doing while you were growing up.

To the entire SLU team in Sweden, Emma, Katrina, Agneta, Anna a big thanks for all your help and friendship - tack så mycket ! To the UZH team Christoffer, Sam, Eyrun, Annik thanks for all your support and friendship. 
To the EquiMoves team, John, Stephan, Berend Jan, Maarten, Mihai and Raluca a big thanks and I look forward to the further development of EquiMoves. I see a bright future in this project, and I can't wait to see EquiMoves conquering the equine gait analysis world.

To all the horses that participated in our studies a big thanks, none of the papers present in the book would be possible without you.

Last but not the least to my better half Janneke. Few would know that Janneke was the one who found the call for this PhD position. I remember you saying it was a good fit for me and I should apply. Well, you were right. This book is also dedicated to you. A lot has happened during these last 5 years of my PhD; we moved to the Nederland's, we became parents twice and we bought a house together... indeed, life became better with you next to me. For all the evenings I was working late on Matlab, for all the weekends I was collecting data abroad, for all the weeks I was away in conferences... a huge thanks. 


\section{Technology won't replace vets... but vets who use technology logically and carefully will replace those who don't a}

Technologie kan dierenartsen niet vervangen...maar dierenartsen die technologie op de juiste wijze inzetten zullen degene vervangen die dat niet doen

\section{Inleiding}

De capaciteiten van het bewegingsstelsel van het paard hebben mede geleid tot de domesticatie van dit dier, en bijna al de doelstellingen waarvoor paarden sindsdien worden gehouden zijn gerelateerd aan de kwaliteiten van het paard als atleet. Het dier werd tot enkele decennia geleden voornamelijk gehouden voor de landbouw, transport en oorlogsvoering, waarvoor het essentieel is dat zijn bewegingsstelsel goed functioneert. Het is dan ook begrijpelijk dat kreupelheid altijd werd beschouwd als een van de belangrijkste belemmeringen voor het functioneren van het paard. In het verleden en ook nu, is het begrijpen van kreupelheid een significante uitdaging voor dierenartsen en hoefsmeden, zeker in de huidige tijd waarin het hoge niveau van sportprestaties nog meer vraagt van het bewegingsstelsel van het paard.

a: Knottenbelt, D.C. (2017) Using the past to make the future better: the long and winding road. Plenary opening lecture, 56th British Equine Veterinary Association Congress, Liverpool, UK. pp 30- 31.

Er zijn twee prominente gebieden waarin onderzoek is gedaan naar de gang analyse van het paard in de afgelopen eeuw: algemene biomechanica gerelateerd aan sport/prestatie en bewegingsveranderingen als gevolg van kreupelheid. Er ligt ontzettend veel potentieel in beide gebieden maar tot op heden was de bestaande technologie niet geschikt voor het dagelijks toepassen van gang analyse methoden in een praktische situatie. Echter, in het laatste decennium is de situatie veranderd en er is een toenemende interesse in het kwantificeren van kreupelheid in een klinische situatie. Er zijn twee belangrijke factoren welke aan de basis staan van deze verandering en de implementatie van de eerste systemen in een klinische situatie. 
1) De introductie van betrouwbare en draagbare gang analyse systemen gebaseerd op microelectromechanische technologie, welke dankzij de snelle ontwikkelingen steeds betaalbaarder worden.

2) Het besef van de lage "interobserver agreement" en het bestaan van vaak een substantiële bias, waardoor er vraagtekens worden gezet bij de wetenschappelijke waarde van de subjectieve kreupelheid beoordeling door de dierenarts.

Dit proefschrift kan tot op zeker hoogte worden beschouwd als emblematisch voor de huidige overgangsperiode waarin de gang analyse van het paard zich ontwikkelt van een wetenschappelijk interessant vakgebied tot een vaak gebruikt hulpmiddel in de dagelijkse praktijk, waarin het zo vanzelfsprekend zal worden ingezet als andere diagnostische hulpmiddelen. Dit proefschrift exploreert het grote potentieel van objectieve gang analyse, draagt bij aan de technische ontwikkeling, onderzoekt de toegevoegde waarde, implicaties maar ook de beperkingen van de methode en ontwikkelt een visie voor de toekomst.

\section{Het doel en de inhoud van dit proefschrift}

Het deel van dit proefschrift wat het originele wetenschappelijke werk beschrijft is onderverdeeld in vier delen:

1. Een overzicht van de literatuur op het gebied van de klinische toepasbaarheid van gang analyse in relatie tot de kwantificatie van kreupelheid.

CHAPTER 2: 'On the brink of daily clinical application of objective gait analysis: What evidence do we have so far from studies using an induced lameness model?'. Dit hoofdstuk presenteert een overzicht van de literatuur beschikbaar op het gebied van het gebruik van objectieve gang analyseapparatuur ter beoordeling van kreupelheid. Hier worden de meest recente ontwikkelingen benoemd en de gebieden waarop meer onderzoek nodig is, geïdentificeerd.

2. Technische ontwikkelingen en validatie studies ten behoeve van de dagelijkse applicatie van gang analysetechnieken.

CHAPTER 3: 'Quantification of the effect of instrumentation error in objective 
gait assessment in the horse on hindlimb symmetry parameters.' Deze studie onderzoekt de verwachte meet onnauwkeurigheid gerelateerd aan instrumentale error in parameters welke gebruikt worden voor een objectieve kreupelheid beoordeling.

CHAPTER 4: 'Quantitative lameness assessment in the horse based on upper body movement symmetry: The effect of different filtering techniques on the quantification of motion symmetry'. In deze technische studie hebben we het effect geëvalueerd van verschillende filtertechnieken op de uitkomst van kinematische signalen welke gebruikt worden voor het objectief beoordelen van kreupelheid in paarden.

CHAPTER 5: 'Validation of distal limb mounted inertial measurement unit

sensors for stride detection in Warmblood horses at walk and trot.' In deze studie beschrijven we een methode om de kinematische gebeurtenissen rondom de landing /optillen van de hoef te meten met "inertial measurement units" (IMUs) op het been.

CHAPTER 6: 'EquiMoves: A Wireless Networked Inertial Measurement System for Objective Examination of Horse Gait.' In deze studie beschrijven we de technische validatie van een systeem gebaseerd op sensoren voor de kinematische analyse van de beweging van het gehele paard. Dit houdt in zowel de beschrijving van de functionaliteit van het systeem als de validatie van enkele kinematische parameters, vergeleken met de "gouden standaard", in dit geval de optical motion capture.

3. De klinische toepasbaarheid van de objectieve gang analysemethoden voor studies naar kreupelheid en algemene bewegingspatronen

CHAPTER 7: 'Variation in gait parameters used for objective lameness

assessment in sound horses at the trot on the straight line and the lunge.'

In deze studie hebben we de verwachtte variatie in kinematische parameters geëvalueerd tussen herhaalde metingen in een groep gezonde paarden.

CHAPTER 8: 'Adaptation strategies of horses with induced forelimb 
lameness walking on a treadmill'. Deze studie onderzoekt het effect van een kreupelheid aan het steunende been (impact kreupelheid) op verschillende kinematische en kinetische parameters in paarden in draf en stap op een loopband.

CHAPTER 9: 'The development of hoof balance and landing preference in the

post-natal period.' Dit hoofdstuk beschrijft de veranderingen in been kinetica en landing voorkeuren in warmbloed veulens van de geboorte tot 6 maanden leeftijd.

CHAPTER 10: 'Mouldable, thermoplastic, glue-on frog-supportive shoes change hoof kinetics in normal and obese Shetland ponies. Deze studie beschrijft het effect van kunststof plakschoenen op been kinetica in Shetland ponies met een normaal gewicht en met overgewicht.

CHAPTER 11: 'Subjective and objective evaluations of horses for fit-tocompete or unfit-to-compete judgement. In deze studie hebben we de inter en intra-observer agreement geëvalueerd terwijl paarden beoordeeld werden als fit of niet fit om deel te nemen aan een wedstrijd onder FEIregelementen en hebben we de subjectieve beoordeling vergeleken met de objectieve gang analyse metingen.

CHAPTER 12: 'Pain-related facial expressions and movement asymmetry in horses with induced low-degree orthopaedic pain.' Dit hoofdstuk vergelijkt de parameters gebruikt voor de objectieve gang analyse met de uitkomst van pijn score systemen in paarden met een geïnduceerde kreupelheid.

CHAPTER 13: 'Improving gait classification in horses by using inertial measurement unit (IMU) generated data and machine-learning.' Deze studie is de eerste in de ontwikkeling van het gebruik van verschillende "machine learning techniques" in de verwerking van IMU data tot de beoordeling van de gang classificatie in het paard en uiteindelijk in het experimenteel bevestigen of ontkennen van de classificatie van de gang zoals voorgesteld door Hildebrand in 1965 [3]. 
Het laatste en vierde hoofdstuk van dit proefschrift CHAPTER 14 bediscussieert de inhoud van de voorafgaande hoofdstukken en plaatst deze in perspectief tegen de achtergrond van de ontwikkelingen in de paardenpraktijk waarin, misschien langzaam naar zeker onomkeerbaar "vets who use technology logically and carefully will replace those who don't'. Het vervolg geeft inzicht in zowel de mogelijkheden van en behoefte voor verdere ontwikkelingen op dit gebied en de toekomstige uitdagingen welke onderzoekers mogelijk te wachten staan. Dit laatste hoofdstuk eindigt met een visie op hoe objectieve gang analyse en de ineenstrengeling met moderne ontwikkelingen in computerwetenschappen, ervoor zullen zorgen dat zowel de kwaliteit en de impact van het kreupelheid onderzoek en therapie in paarden zal verbeteren, maar ook een bijdrage kan leveren aan het algemene management en welzijn van het paard en mogelijke andere diersoorten. 
Anex 1

Do we have to redeffine

lameness in the era of quantitative gait analysis?
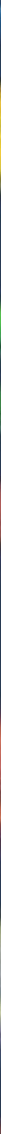
For ages, horses have been divided with respect to the functional status of their locomotor system in those classified as sound and those considered lame. This dichotomy has been and still is used by both the users of horses, irrespective of discipline, and veterinarians and there is a general perception common to both categories that lame horses should be considered unfit to perform, which implies that their continued use raises a welfare issue.

Whereas seemingly very useful and reassuringly simple, the matter is more complicated than that, as this approach immediately raises some questions. The first of these is how lameness should be defined. There are several definitions of lameness, including: "Lameness is an indication of a structural or functional disorder in one or more limbs or the back that is evident when the horse is standing or in movement" [1]; "Lameness is simply a clinical sign - a manifestation of the signs of inflammation, including pain, or a mechanical defect - that results in a gait abnormality characterized by limping" [2]; and "An alteration of the normal gait due to a functional or structural disorder in the locomotor system" [3]. There are more, but virtually all mention some disorder, defect or loss of function, hence a pathological condition, which makes lameness into a clinical problem. The second question is how lameness is detected, as this determines whether lameness (and thus a pathological condition) should be deemed present or not. The classical way to detect lameness has always been (and still is the mainstay in clinical practice) the visual evaluation of the gait of the horse under a number of different conditions whereby the presence or absence and degree of asymmetries is not the sole, but by far the most commonly used and most important criterion. Here, we enter a grey area, as it is well-known that interobserver agreement on subtle lameness, even if these observers are deemed experts, is meagre at best [4-7]. Another issue is that the standard lameness work-up protocol may vary from a simple trot-up on a hard surface with or without additional circling [8] to meticulous protocols including extensive assessments on hard and soft surface at all gaits and ridden [9]. As in the detection of osteochondrosis lesions, where horses may be declared 'free of osteochondrosis' after checking the hock, stifle and possibly the fetlock joints but may very well have lesions in other joints of the body [10], more subtle gait irregularities may be detected when horses are screened in more detail, making the qualification 'sound' much less absolute than generally perceived.

The disagreement on existence, localisation and degree of subtle lameness is not only limited to within the veterinary profession when examining horses presented for some kind of presumed locomotion or general performance disorder. The gap between the horse-using public and the veterinary profession seems to be even 
wider. A recent study used a population of 57 riding horses of different levels that were classified as 'owner-sound', i.e. the horses were in regular use without any complaints regarding their locomotor system from their riders or trainers and without encountering problems in competition due to perceived lameness. After a meticulous clinical examination, 37 (65\%) were deemed lame. Interestingly, of the remaining 20 sound horses, another 6 were found to be lame at a re-examination 14 days later, bringing the total number of lame horses in this supposedly sound population to 42 or $75 \%$ [9].

Interest in the gait of horses has a long history [11,12] and new developments such as the invention of photography or the introduction of cine film have always rapidly been used to further our understanding of equine gait $[13,14]$. The advent of computer technology in the modern era has enabled the detailed study and quantitation of the horse's gait [15] and in more recent times a variety of techniques has been developed, for the major part based on optic motion capture or the use of inertial measurement units (for a review, see [16]). After lingering in the laboratory environment for long due to technical and practical constraints, more recently, some of these techniques have become available for routine clinical use and are currently being used in an increasing number of places. These systems overcome the issue of limited temporal and spatial resolution of the human eye and consequently the low intra- and above all interobserver agreement of the classical subjective lameness assessment. However, whereas human individuals are known to be excellent in pattern recognition [17], these systems rely on one or a number of gait parameters to decide about lameness or not. In the current systems, this is typically done by symmetry measurements and the application of certain thresholds to these values [18]. Also, when these objective systems are used to quantify gait of 'owner-sound' horses, a large number of these fall outside the normal range and are hence deemed lame. In a study by Rhodin et al. [19] of 201 horses ridden regularly and functioning well in their work 107 (53\%) showed asymmetries surpassing the thresholds set for either head or pelvis asymmetry. In another study, of a total of 222 'owner-sound' horses, an astonishing $72.5 \%$ showed movement asymmetries above previously reported asymmetries thresholds while trotting on the straight [20].

It seems, therefore, that there is some agreement between the advanced, subjective clinical gait assessment based on expert opinion and the outcome of thresholdbased objective asymmetry measurements by modern gait analysis techniques with respect to a high prevalence of subtle gait alterations. However, should we qualify these horses that do not comply with criteria for optimal gait during a comprehensive and critical clinical lameness examination or that fall outside the 
threshold values set for the automated gait analysis systems as lame? This question is very relevant because of the strong association in public perception between the term 'lameness' and impaired welfare. Thresholds are forcibly based on a limited reference population and do only to a certain extent reflect the millions of horses in the world. Further, depending on the bandwidth chosen, they will always contain only a limited percentage of any normally distributed population, which can have great consequences for individual cases. With respect to the clinical assessment: to what extent are we looking for horses with an optimal gait under all circumstances, rather than for those with a clinically acceptable gait? Not unimportantly, what do we really know about day-to-day variation in subtle gait characteristics in horses, or of variation over longer periods? What about the effects of the environment or even the mental condition of the horse on these measured or clinically observed asymmetries and irregularities, which are too small to impede daily use of the horse and/or participation in competitions? Can we state with certainty that these subtle gait alterations affect equine welfare to some significant extent?

The issue is not that easy and we have far more than 50 shades of grey here. The most logical avenue to follow seems to establish whether or not those horses experience pain. That, however, is an art in itself and far from trivial. Apart from the fact that horses, like human individuals, have different pain thresholds, there are various forms of pain. Direct peripheral pain may be relatively easy to detect, but in chronic conditions (which are very frequent in equine musculoskeletal pathology) pain pathways may have been altered and pain sources may have become different and much less easy to detect [21]. Even if the existence of pain can be proven, the next question arises, which is to what level the existence of pain can be deemed acceptable. There is no human athlete pursuing their career without experiencing pain. It would be more than naïve to suppose that the situation for the horse would, or even could, be different. But where should the line be drawn and based on what criteria? Here, also ethics come in beyond the biology.

It can be concluded that the interpretation of the subtle asymmetries or gait irregularities that can be detected through either very comprehensive clinical examinations by highly experienced orthopaedists or are (with increasing frequency) detected by the various asymmetry- detection based gait analysis systems that are gradually spreading over the equine veterinary world, is far from straightforward. The use of the term 'lameness' in relation to these subtle gait alterations is questionable in a scientific sense and may be dangerous in the more societal context due to the negative connotation of the word lameness and its association with impairment of welfare and unfitness to compete. There is a strong need to better investigate the 
background and true meaning of these subtle gait alterations and to put them in the (largely unknown) context of normal variation, as well as to determine their true effect on equine welfare.

As long as there is insufficient information to this respect, one should be very cautious with the use of the term 'lameness', and probably more cautious than in the older days when the human eye was the only available tool for the evaluation of equine gait. We advise strongly that researchers and clinicians should discriminate clearly between 'asymmetry' and 'lameness' and not to use these as interchangeable terms when interpreting gait analysis data, irrespective of whether these are generated by classical observation or by advanced and sophisticated quantitative motion capture systems. In this concept and following the definition by Ross [2], lameness is a clinical interpretation of abnormal (and in the vast majority of cases asymmetric) gait that implies some kind of pathological aberration, which is probably, but even not always, located in the musculoskeletal system and of which the severity and importance can vary. Asymmetries and pain are frequent, but by no means ever-present hallmarks of lameness. Horses with bilateral lameness may show a symmetrical gait and mechanical lameness may very well lead to large asymmetries, but can be pain free. The term asymmetry, by contrast, is just a technical term describing a larger or smaller deviation of perfectly symmetric motion. Symmetry is a relative notion as the classification as symmetrical or asymmetrical depends on the accuracy and precision with which gait is measured. As pointed out above, asymmetry may be, and very often is, a hallmark of lameness, but is in itself not a clinical term, whereas lameness is. This notion is important when discussing the use of thresholds. In a scientific sense, the concept of overlapping Gaussian distributions allows for dividing horses into more or less symmetric individuals and the group of horses below a certain level ('threshold') is likely to contain a higher proportion of sound horses than the group above that threshold, in which the proportion of lame horses will be higher. The knowledge of to which group a horse belongs may certainly help in clinical decision making. However, we should realise that this reasoning is based on population dynamics and does not justify the direct application of the thresholds as sole criteria for the use of the term 'lameness' to individual cases. We also should realise that we know too little at present about the biological meaning of (subtle) asymmetries captured by our quantitative gait analysis systems. What we are measuring is motion (kinematics) whereas changes in loading of limbs (kinetics) may be more directly related to biologically relevant processes, as these often reflect the presence of pain. Reliable and repeatable measurement of ground reaction forces is not yet feasible in a clinical setting, but it might become possible in the near future to measure changes in ground reaction forces in relation to total weight, 
which could be a most useful and possibly more direct parameter than the current asymmetries.

It can be foreseen that the developments in the automated, objective quantification of equine gait (thus not 'of lameness detection') will continue, driven by the enormous progress in the IT industry. This will probably bring quantitative gait analysis in equine orthopaedics to the same level as currently taken by diagnostic imaging: a very well appreciated and indispensable additional tool for clinical decision- making. With this process currently starting, it is important, however, to define very sharply the use of terminology in order to avoid confusion and to prevent the formation of wrong perceptions, either amongst professionals or by the lay public. Using the term 'lame' for any horse falling beyond thresholds set for quantitative gait analysis or not showing the ideal motion pattern when assessed clinically does not seem a wise thing to do. We should reserve the use of that term for horses deemed unfit to compete based on a comprehensive assessment of the animal that includes, but does not rely entirely on, the appreciation of the degree of gait asymmetry.

\section{Authorship}

This editorial was written by R. van Weeren, extensively discussed with all authors and adapted where necessary. This is a consensus document from four major research groups in quantitative gait analysis. All authors have approved the final document.

P. R. van Weeren*†, T. Pfau ${ }^{\ddagger}$, M. Rhodin§, L. Roepstorff§, F. Serra Braganca ${ }^{\dagger}$ and M. A. Weishaupt"

${ }^{\dagger}$ Department of Equine Sciences, Utrecht University, Utrecht, the

Netherlands; 'Department of Clinical Science and Services, The Royal Veterinary College, University of London, Hatfield, UK; ${ }^{\circledR}$ Department of Clinical Sciences, Swedish University of Agricultural Sciences, Uppsala, Sweden and "Equine Department, University of Zürich,Zurich, Switzerland

*E-mail: prvw@evj.co.uk 


\section{References}

1. Stashak, T.S. (2002) Examination for lameness. In: Adams' Lameness in Horses, 5th edn., Ed: T.S. Stashak, Lippincott, Williams \& Wilkins, Philadelphia. p 113.

2. Ross, W. (2011) Lameness in horses: basic facts before starting. In: Diagnosis and Management of Lameness in the Horse, 2nd edn., Eds: M.W. Ross and S.J. Dyson, Elsevier Saunders, St Louis. p 3.

3. Buchner, H.H.F. (2013) Gait adaptation in lameness. In: Equine Locomotion, 2nd edn., Eds: H.M. Clayton and W. Back, Elsevier, Philadephia. p 175.

4. Fuller, C.J., Bladon, B.M., Driver, A.J. and Barr, A.R.S. (2006) The intra- and inter-assessor reliability of measurement of functional outcome by lameness scoring in horses. Vet. J. 171, 281-286.

5. Hammarberg, M., Egenvall, A., Pfau, T. and Rhodin, M. (2016) Rater agreement of visual lameness assessment in horses during lungeing. Equine Vet. J. 48, 78-82.

6. Hewetson, M., Christley, R.M., Hunt, I.D. and Voute, L.C. (2006) Investigations of the reliability of observational gait analysis for the assessment of lameness in horses. Vet. Rec. 158, 852-857.

7. Keegan, K.G., Dent, E.V., Wilson, D.A., Janicek, J., Kramer, J., Lacarrubba, A., Walsh, D.M., Cassells, M.W., Esther, T.M., Schiltz, P., Frees, K.E., Wilhite, C.L., Clark, J.M., Pollitt, C.C., Shaw, R. and Norris, T. (2010) Repeatability of subjective evaluation of lameness in horses. Equine Vet. J. 42, 92-97.

8. Stashak, T.S. (2002) Examination for lameness. In: Adams' Lameness in Horses, 5th edn., Ed: T.S. Stashak, Lippincott, Williams \& Wilkins, Philadelphia. pp 117-118.

9. Dyson, S.J. and Greve, L. (2016) Subjective gait assessment of 57 sports horses in normal work: a comparison of the response to flexion tests, movement in hand, on the lunge, and ridden. J. Equine. Vet. Sci. 38, 1-7.

10. Van Weeren, P.R. (2016) Osteochondritis dissecans. In: Joint Disease in the Horse, 2nd edn., Eds: C.W. Mcllwraith, D.D. Frisbie, C.E. Kawcak and P.R. van Weeren, Elsevier, St Louis. pp 57-84.

11. Cavendysh, G. (1674) M'ethode nouvelle et invention extraordinaire de dresser les chevaux et les travailler selon la nature, Tho. Milbourne, London. pp 119-126.

12. Goiffon, G.C. and Vincent, A.F. (1779) M'emoire artificielle des principes relatifs $a^{\prime}$ la fidelle r'epresentation des animaux tant en peinture, qu'en sculpture. I. Partie concernant le cheval. Ecole Royale Ve,te,rinaire, Alfort.

13. Schmaltz, R. (1922) Analyse der Gangarten des Pferdes durch den Film. Berl. Tiera€rztl. Wochenschr. 38, 523-527.

14. Walter, K. (1925) Der Bewegungsablauf an den freien Gliedmaßen des Pferdes im Schritt, Trab und Galopp. Arch. Wissensch. Prakt. Tierheilk. 53, 316-352.

15. Fredricson, I. and Drevemo, S. (1971) A new method of investigating equine locomotion. Equine Vet. J. 3, 137-140.

16. Serra Braganc0a, F.M., Rhodin, M. and van Weeren, P.R. (2017) Clinical application of objective gait assessment in the horse: a review. Accepted.

17. Stallkamp, J., Schlipsing, M., Salmen, J. and Igel, C. (2012) Man vs. computer: benchmarking machine learning algorithms for traffic sign recognition. Neural Netw. 32, 323-332.

18. Keegan, K.G., Kramer, J., Yonezawa, Y., Maki, H., Pai, P.F., Dent, E.V., Kellerman, T.E., Wilson, D.A. and Reed, S.K. (2011) Assessment of repeatability of a wireless inertial sensor-based lameness evaluation system for horses. Am. J. Vet. Res. 72, 1156-1163.

19. Rhodin, M., Roepstorff, L.K., French, A., Keegan, K.G., Pfau, T. and Egenvall, A. (2016) Head and pelvic movement asymmetry during lungeing in horses with symmetrical movement on the straight. Equine Vet. J. 48, 315-320.

20. Rhodin, M., Egenvall, A., Haubro Andersen, P. and Pfau, T. (2017) Head and pelvic movement asymmetries at trot in riding horses in training and perceived as free from lameness by the owner. PLoS One 12, e0176253.

21. Crofford, L.J. (2015) Chronic pain: where the body meets the brain. Trans. Am. Clin. Climatol. Ass. $126,167-183$. 
4 Anex 2

What is lameness and what (or who) is the gold standard to detect it?
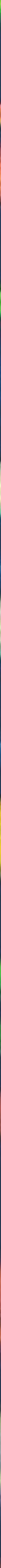
The editorial 'Do we have to redefine lameness in the era of quantitative gait analysis?' [1] has unleashed an interesting scientific discussion. In a first reaction, Drs Bathe, Judy and Dyson agreed that modern quantitative gait analysis techniques outperform the human eye regarding spatial and temporal resolution, but stated that lameness evaluation is more complex than the measurement of asymmetries only [2]. Their main argument is that accurate lameness evaluation in horses should remain exclusively in the hands of experienced clinicians, as only these can make the correct synthesis of the huge number of variables they consider. They do not shy from quoting the acronym VOMIT, created by the medical community, which stands for 'Victim of Modern Investigational Technology' and to end with the Latin phrase caveat utilitor, meant for the user of modern gait analysis technology. Adair and 38 other equine vets, all working in the area of lameness assessment responded [3]. They strongly disagreed with Bathe and colleagues' assertions, which they interpreted as fear for what objective measurements may do and how it might affect current methods for lameness evaluation and with that the position of the equine clinician. Their main argument is that the new quantitative techniques will not, nor should, replace the clinician, but should be seen as a valuable complementary tool for the clinician helping her/him in clinical decision making, and indeed, also serving as a test to keep the own objectivity and clinical skills sharp. Adair and colleagues see the use of quantitative gait analysis techniques as evidence-based veterinary medicine.

It is interesting to see that the original core subject of the editorial ('how should we define lameness') has been given little attention in both letters. Bathe and co-authors agree that 'lameness is a continuum rather than a binary concept' and Adair et al. state that 'lameness is a simple concept that is sometimes difficult to detect', with which they implicitly state that lameness is identical to asymmetry. The rest of the debate mainly focuses on the role of the technology versus that of the clinician. In fact, we now have two issues: what is lameness and what (or who) is the gold standard to detect it? As authors of the original editorial, we would like to address both issues and to start with the second one, which seems to be most polemic in nature.

At submission of their letter, Dr Bathe was so kind to send a copy to the current authors. He signed that email with 'The Luddite clinicians'. The Luddites were a group of English textile workers in the early 19th century, who destroyed the then newly introduced weaving machinery out of fear that the time spent learning the skills of their craft would go to waste, as machines would replace their role in the industry. Although not originally meant as such, the term has come to mean one opposed to industrialisation, automation, computerisation or new technologies in general albeit nowadays often in a light-hearted manner [4]. However, the Luddites should not 
only be remembered as a reactionary movement that, evidently in vain, tried to halt progress. They also laid the foundation for the recognition of the value and position of the working class that would later in the 19th century result in the rise of the trade unions and their socio-economic power. We, therefore, think the self-chosen name of 'Luddite clinicians' to be an excellent one. On the one hand there is the undeniable and unstoppable progress of technology that neither can nor should be ignored; on the other hand, there is a continuous need for good clinical judgement. Emeritus Professor Derek Knottenbelt has summarised the issue very well in his statement that 'Technology won't replace vets.. .but vets who use technology logically and carefully will replace those who don't' [5].

In this context, it may be good to draw the attention to a well-known phenomenon in the psychology of learning, which is the so-called Dunning- Kruger effect that describes the relationship of confidence and experience as a hyperbole (Fig 1). It shows that the self-confidence of inexperienced professionals rises very sharply after beginning exercising some professional skills and quickly reaches a level that is unjustified by their real skills, that is a clear situation of overconfidence [6]. After that, there comes a much longer period of gradually decreasing confidence that almost hits bottom before starting to increase gradually again. One of the biggest

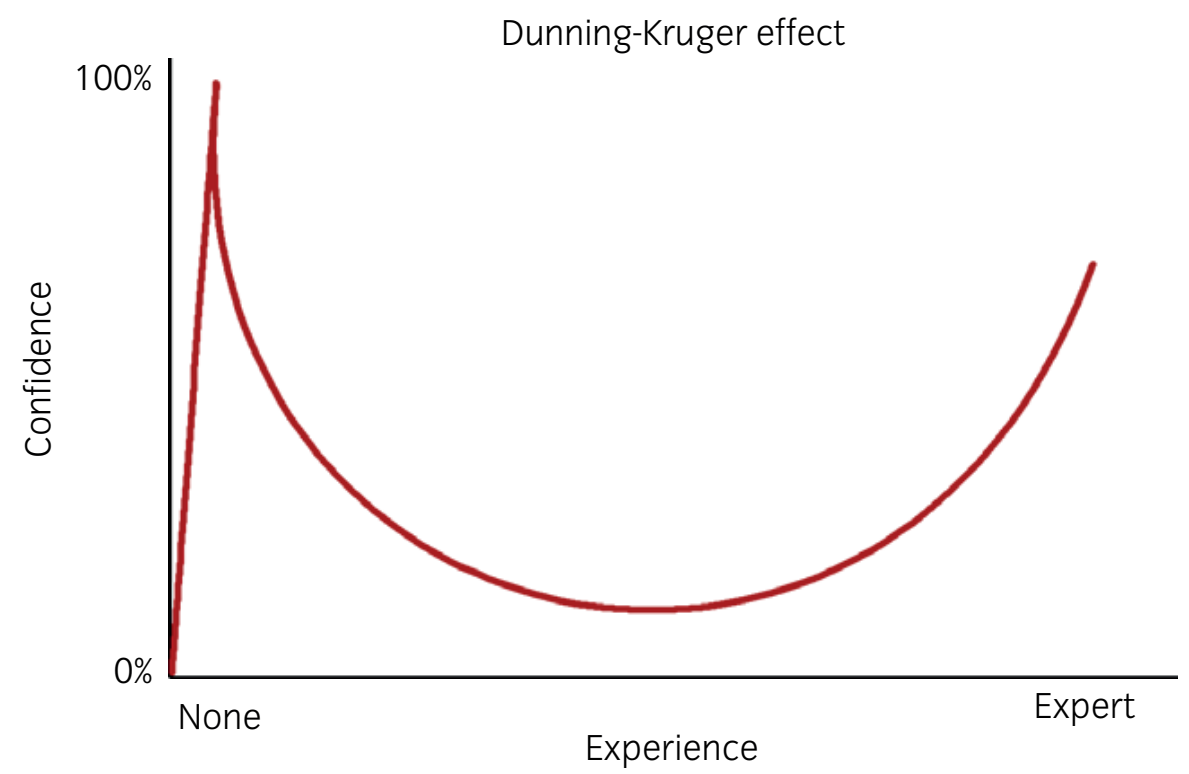

Fig 1: The level of self-confidence of professionals is highest when starting to carry out a certain professional skill, then falls dramatically with increasing experience to almost regain the initial high level when reaching the expert status. 
advantages of objective lameness assessment is that this strong fluctuation of selfconfidence may be dampened and remains closer to what is justified given the real level of expertise of the professional. Quantitative gait data gives us the tool to better confront young clinicians with their limitations, especially in hindlimb lameness cases where it has been shown that the ability to recognise lameness is quite poor. To move forward, we need to accept our own limitations, learn with the cases where we might be wrong, and only then we can become more competent. This does not only apply to beginning clinicians, but also to the very experienced ones where the curve creeps very close to the initial high level. Peak confidence sells well to horse owners, but we should remain honest and be prepared to self-criticism. If not, the warning caveat utilitor has a counterpart that is certainly as relevant, which is caveat clinicus.

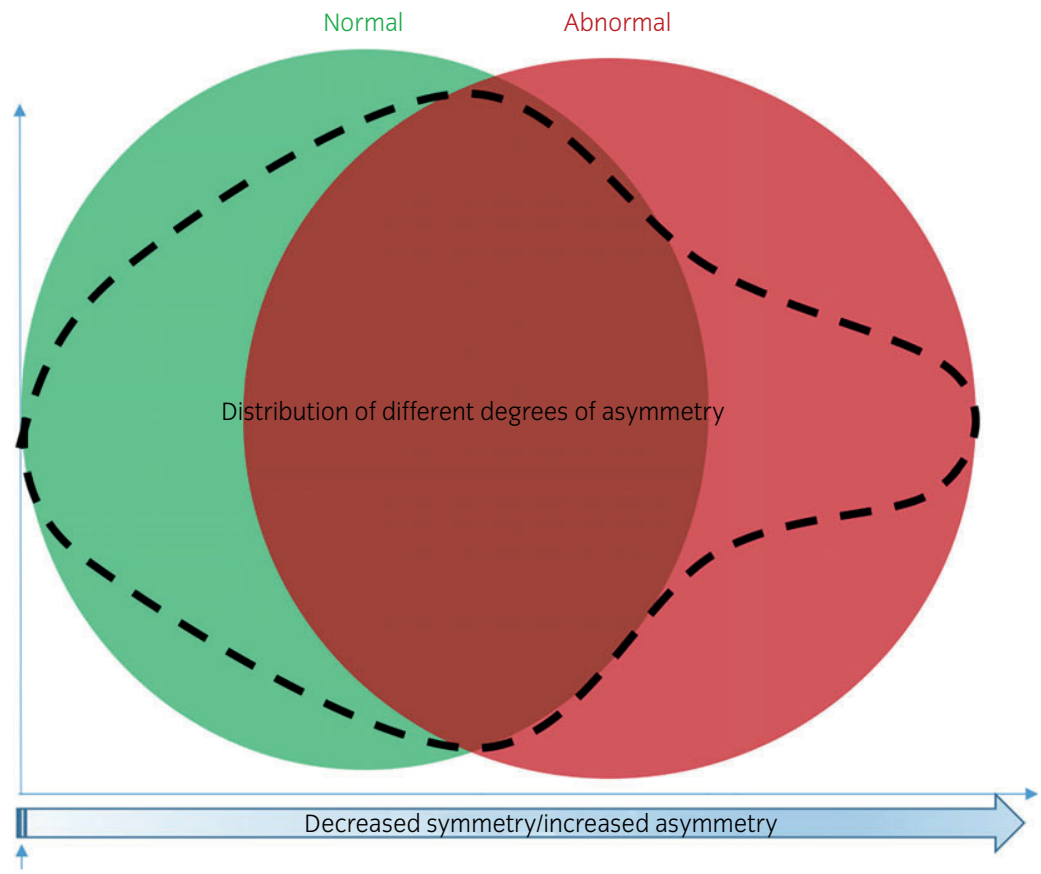

Fig 2: Conceptual visualisation of distribution of asymmetries and lameness (abnormal function) in the equine population. Technically, asymmetries can be both negative and positive (i.e. occur to the left and to the right of the 'perfect symmetry' line), but for reasons of clarity, the X-axis represents absolute values.

Whereas the issue of whom or which should be considered the supreme authority in lameness detection raises most emotion, the discussion of what we should consider lameness is more critical in our perspective. This discussion may seem technical, but is primarily a linguistic one. In the original editorial, we stated that the word 'lameness', 
both in the professional and in the lay world, has a negative emotional value. For millennia already lameness in horses has a negative meaning and is associated with unfitness to perform, loss of value, and impaired welfare. It is never used in a positive sense and even never has a neutral value. Unless we are arrogant enough to assume that we, as equine orthopaedists in the era of quantitative gait analysis, are so powerful that we can change this societal appreciation of the word lameness, we cannot and should not equal 'lameness' to asymmetry. This because in that case we implicitly say that perfect symmetry should be considered normal and all asymmetries, aberrations of that. Do we expect all horses to move perfectly symmetrical? What about young, immature horses - if they are asymmetrical, do we then assume that they are lame? Also, if we assume that perfect symmetry is desirable, we place ourselves in a position where any small deviations of perfect symmetry should be considered lameness.

Of course, we then can immediately mitigate that statement by saying that mild asymmetries are not clinically relevant, but that is not the point. We touch something very fundamental here, as apart from the points discussed above, the statement in itself is inherently wrong and scientifically unsound. This statement denies one of the fundamental principles of biology, which is a hallmark of every living being and even lies close to the definition of life, that is the existence of biological variation. There is absolutely no biological variable that has one single discrete value (such as perfect symmetry, which is equal to zero asymmetries) as the definition of a healthy status. All biological processes can be seen as equilibria within a given area in the middle of a linear scale that we use to call 'physiological' and that gradually changes into some state of pathology when moving too far to either the left or the right. The variation in these balances regarding bandwidth, type and way of occurrence of pathology et cetera, is virtually endless, but the basic pattern is immutable. In medical terminology, these biological variables themselves should be designated by neutral terms, such as blood pressure, heart rate or $\mathrm{pH}$. Clinically relevant imbalances can be indicated by terminology having a negative association, such as hypertension, arrhythmia and acidosis. (Degree of) asymmetry is a neutral term, lameness not.

Based on the reasoning given above, it will be clear that we fiercely oppose the interchangeable use of the terms 'lameness' and 'asymmetry'. Instead, we propose that 'asymmetry' is just a biological variable like any other that obeys basic biological laws. Figure 2 is an attempt to demonstrate this visually. In that case, we should do the same what both the medical and veterinary profession has done already for ages, that is establishing reference values for a respective variable just like we have for any clinical chemistry parameter, heart rate, body temperature, et cetera. A first attempt in this direction has been proposed for the weightbearing (a)symmetry of contralateral 
limbs using vertical ground reaction forces [7]. It is more than likely that, as in other biological variables, also in the case of locomotion asymmetry these reference values may vary a little with characteristics of the population studied, like breed, equestrian use, age and perhaps other factors. In fact, we already have scientific data pointing in this direction [8]. It can, therefore, be expected that in the coming years with ongoing data collection we will be able to tailor and refine these reference values. In the end it is up to the clinician, Luddite by conviction or not, to interpret the outcome of the measurements. This should be done within the bigger picture as described by Bathe et al. and it is the clinician who should decide whether the measurement, which may fall outside or even inside the reference range, should be deemed clinically relevant or not. It is the outcome of this clinical evaluation process that does or does not justify the use of the term 'lameness' by the professional, not the measurement in itself.

\section{Authorship}

P. R. van Weeren ${ }^{\dagger *}$, T. Pfau ${ }^{\ddagger}$, M. Rhodin ${ }^{\S}$, L. Roepstorff ${ }^{\S}$, F. Serra Braganca ${ }^{\ddagger}$ and M. A. Weishaupt ${ }^{\natural}$

${ }^{\dagger}$ Department of Equine Sciences, Utrecht University, Utrecht, the Netherlands; ${ }^{\ddagger}$ Department of Clinical Science and Services, The Royal Veterinary College, University of London, Hatfield, UK; ${ }^{\S}$ Department of Clinical Sciences, Swedish University of Agricultural Sciences, Uppsala, Sweden and "Equine Department, University of Zurich, Zurich, Switzerland

*E-mail: prvw@evj.co.uk 


\section{References}

1. Van Weeren, P.R., Pfau, T., Rhodin, M., Roepstorff, L., Serra Braganc_a, F. and Weishaupt, M.A. (2017) Do we have to redefine lameness in the era of quantitative gait analysis? Equine Vet. J. 49, 567569.

2. Bathe, A.P., Judy, C.E. and Dyson, S. (2018) Letter to the Editor: do we have to redefine lameness in the era of quantitative gait analysis? Equine Vet. J. 50, 273.

3. Adair, S., Baus, M., Belknap, J., Bell, R., Boero, M., Bussy, C., Cardenas, F., Casey, T., Castro, J., Davis, W., Erskine, M., Farr, R., Fischer, T., Forbes, B., Ford, T., Genovese, R., Gottschalk, R., Hoge, M., Honnas, C., Hunter, G., Joyce, J., Kaneps, A., Keegan, K., Kramer, J., Lischer, C., Marshall, J., Oosterlinck, M., Radue, P., Redding, R., Reed, S.K., Rick, M., Santschi, E., Schoonover, M., Schramme, M., Schumacher, J., Stephenson, R., Thaler, R., Vedding Neilsen, J. and Wilson, D.A. (2018) Response to Letter to the Editor: do we have to redefine lameness in the era of quantitative gait analysis. Equine Vet. J. 50, 415-417.

4. Luddite. Available at: https://en.wikipedia.org/wiki/Luddite (Accessed April 112018 ).

5. Knottenbelt, D.C. (2017) Using the past to make the future better: the long and winding road. Plenary opening lecture, 56th Annual Congress British Equine Veterinary Association, Liverpool, UK. pp 30-31.

6. Dunning-Kruger effect. Available at: https://en.wikipedia.org/wiki/Dunning- Kruger_effect (Accessed April 12 2018).

7. Weishaupt, M.A., Wiestner, T., Hogg, H.P., Jordan, P. and Auer, J.A. (2004) Vertical ground reaction force-time histories of sound Warmblood horses trotting on a treadmill. Vet. J. 168, 304-311.

8. Pfau, T., Sepulveda Caviedes, M.F., McCarthy, R., Cheetham, L., Forbes, B. and Rhodin, M. (2018) Comparison of visual lameness scores to gait asymmetry in racing Thoroughbreds during trot in-hand. Equine Vet. Educ. Epub ahead of print; https://doi.org/10.1111/eve.12914. 